INSTITUTIONS, STRATEGIC POSTURE AND PERFORMANCE OF MICRO, SMALL AND MEDIUM ENTERPRISES

By

Hernan "Banjo" G. Roxas

A thesis

submitted to Victoria University of Wellington

in fulfilment of the requirements for the degree of

Doctor of Philosophy

in International Business

Victoria University of Wellington

2009 


\begin{abstract}
The thesis of this study is that perceptions of formal and informal institutions permeating the business environment in a city in an emerging economy have significant influence on the strategic posture of micro, small and medium enterprises (MSMEs); and that strategic posture is viewed to have significant influence on the firms' overall organisational performance. The study emphasises the mediating role of strategic posture, being the conduit through which perceptions of sub-national institutions exert their influence on organisational performance. Institutional theory, which considers institutions as 'the rules of the game' that govern human interaction, serves as the study's theoretical foundation. An extensive review of the literature was undertaken in the areas of institutional theory, strategic management, organisational performance, investment or business climates, MSME/entrepreneurial development, decentralisation and local economic development at the city level.
\end{abstract}

The study adopts an empirical-deductive research design through which a survey generated a total sample of 900 MSMEs located in two cities in the south-eastern region of the Philippines. Hierarchical multiple regression modelling, using ordinary least squares method with confirmatory robust technique, was applied to test the hypotheses. Results suggest that all of the five formal institutions and two of the five informal institutions had positive relationships with an entrepreneurial strategic posture, which in turn, was shown to be positively associated with higher levels of product/service, strategic and financial performance. Moreover, strategic posture was shown to partially mediate the relationships between three formal institutions and two facets of organisational performance.

However, when the five formal institutions and five informal institutions were aggregated into two sets of indices, mediation analysis revealed that the index of formal institutions - product/service performance relationship was partially mediated by strategic posture. The index of formal institutions - strategic performance relationship was shown to be fully mediated by strategic posture. On the other hand, the index of informal institutions - product/service performance relationship was shown to be fully mediated by strategic posture. Overall, the empirical results offer acceptable level of support to the main thesis of the study. 


\section{ACKNOWLEDGEMENTS}

The journey is the reward. This Taoist proverb profoundly describes the previous three years of my life presumably pursuing, at the onset, a PhD degree but ultimately earned more than a degree could offer. This page is my humble way of thanking all who travelled with me in my journey.

The journey never fell short of immeasurable support from my dearest wife Niña, the only person in the world who understands me, and my three-year old daughter Yana, who occasionally acts as my research assistant by 'editing' the print-outs of my manuscripts with her colourful scribbles. My gratitude to Mama Ludz as well, for always being around when needed most. These ladies never cease to make life worth loving for which I am truly grateful.

My gratitude to my mentors, Drs. Val Lindsay, Nicholas Ashill, and Antong Victorio, who showed me the meaning of academic scholarship. I may have stumbled and fallen countless times in my journey, yet my mentors refused to give up on me. I could always get up from a fall, knowing that I could stand on the shoulders of three giants. Thank you, Val, Nick and Antong for instilling in me the discipline in doing academic research.

Heartfelt thanks to Education New Zealand, the Ministry of Education, and the New Zealand government in general, for giving me the New Zealand International Postgraduate Research Scholarship. Thank you so much, Ms. Camilla Swan of Education New Zealand.

The journey has been enriched by the support of my superiors and colleagues at the Ateneo de Davao University and the University of South-eastern Philippines. My gratitude to Dean Jonie, Dean Christine, Dean Rose, A/Dean Emi, Dean Braveheart, Dr. Antipolo, and 'frendster' Mely for believing in me.

I owe the School of Marketing and International Business of Victoria University of Wellington, and all its faculty, staff, and fellow PhD students (Aaron, Mao, Nick, Janine, and Stephan) for all the support they extended to me in various ways. Indeed it is an SMIB: school of magnanimous intellectual beings.

Special thanks to all the people involved in the field work including my survey enumerators, the officers and staff of the city governments of Tagum and Panabo, and of course, all the survey participants.

My gratitude to the three anonymous reviewers of this manuscript who gave very insightful and helpful suggestions to improve the overall quality of the thesis.

The journey has been truly meaningful with the grace and wisdom of God, the ultimate source of infinite knowledge and truth.

With all the support, both divine and human, indeed the journey is, in itself, the reward. In this journey, I learned to see the greatness in small things and the smallness in great things.

$$
\text { Ad Majorem Dei Gloriam }
$$




\title{
LIST OF PUBLICATIONS
}

\author{
required by VUW Statute $4.5(b)$ and $(c)$
}

Roxas H., Lindsay V., Ashill N., Victorio, A. (2008) Institutional Analysis of Strategic Choice of Micro, Small and Medium Enterprises: Development of a Conceptual Framework. Singapore Management Review. 30 (2), p. 47-72. (ISSN: 0129-5977)

Banjo Roxas is the lead author of the article with guidance, critique, additional insights and references from the co-authors who are Banjo's PhD dissertation supervisors. The article presents a portion of the final conceptual framework that was used in this dissertation.

Roxas H. (2008). An Institutional Analysis of Strategic Posture. Journal of Business and Governance. 10 (2), pp. 1-28. (ISSN: 0119-9161).

Preliminary results of the dissertation were presented in this article upon the invitation of the journal's editor, Dr. Antong Victorio of SOG-VUW, Banjo's tertiary supervisor.

Roxas H., Lindsay V., Ashill N., Victorio, A. (2007). An Institutional View of Local Entrepreneurial Climate. Asia Pacific Social Science Review. 7 (1), pp. 27-44. (ISSN: 0119-8386)

Banjo is the lead author of the article with guidance, critique, additional insights and references from the co-authors who are Banjo's dissertation supervisors. The article presents a portion of the preliminary conceptual framework that was developed during the early versions of the research proposal relative to this dissertation.

Roxas H., Lindsay V., Ashill N., Victorio, A. (2007) Institutional Analysis of Strategic Choice of Micro, Small and Medium Enterprises. Philippine Review of Economics (December 2007 issue - still in press as of July 12, 2007). (ISSN 16551516)(a publication of the School of Economics, University of the Philippines).

Banjo is the lead author of the article with guidance, critique, additional insights and references from the co-authors who are Banjo's dissertation supervisors. The article presents a portion of the pre-final conceptual framework that was ultimately used in this dissertation.

Roxas B. (2007). Clarifying the Link between Social Capital and MSME Innovation Performance: The Role of Absorptive Capacity. Asia Pacific Social Science Review. 7(2), pp. 31-51. (ISSN: 0119-8386)

The article is an offshoot (by-product) of the review of literature conducted by Banjo with regards to the theoretical, conceptual and empirical nature of 'informal institutions' as well as 'MSME performance' - two constructs that formed a major part of the framework of this dissertation. 
$\begin{array}{ll}\text { Abstract } & \text { ii }\end{array}$

Acknowledgements

List of Publications

Table of Contents $\quad$ V

List of Tables viii

List of Figures $\quad$ xi

\section{CHAPTER 1. INTRODUCTION}

1.1 Background of the Study 1

$\begin{array}{ll}1.2 \text { Research Questions } & 10\end{array}$

1.3 Research Objectives 11

1.4 Research Contribution \& Significance of the Study 12

1.5 Outline of the Thesis 14

\section{CHAPTER 2. REVIEW OF LITERATURE}

2.1 Institutional Theory 16

2.2 Local Economic Development 24

2.3 Business Climate 26

2.4 Micro, Small and Medium Enterprises (MSMEs) 30

2.5 Decentralisation of Governance 35

2.6 Strategic Posture of Organisations 39

2.7 MSME Organisational Performance 41

2.8 Summary of Research Gaps 48

CHAPTER 3. CONCEPTUAL FRAMEWORK \& HYPOTHESIS DEVELOPMENT

3.1 Levels of Conceptual Schemes $\quad 54$

3.2 The Research Framework 54

3.3 The Conceptual Model 60

3.3.1 Institutions 62

3.3.2 Perceived Local Institutional Environment 63 
3.3.4 MSME Organisational Performance 67

3.3.5 Institutions - Strategic Posture Link 69

3.4 Formal Institutions $\quad 76$

3.5 Informal Institutions $\quad 90$

3.6 Strategic Posture and MSME Organisational Performance 110

$\begin{array}{ll}\text { 3.7 Mediation in Research Design } & 121\end{array}$

3.8 Industry, Firm and Owner/Manager Characteristics 133

3.9 Summary of Hypotheses 144

CHAPTER 4. RESEARCH DESIGN \& METHODOLOGY

$\begin{array}{ll}4.1 \text { Research Design } & 148\end{array}$

4.2 The Research Instrument 152

4.3 Validity and Reliability of the Survey Questionnaire 172

4.4 Locale and Respondents of the Study 175

4.5 Data Gathering Techniques 183

4.6 Data Analytical Tools 186

$\begin{array}{ll}4.7 \text { Ethical Implications } & 187\end{array}$

\section{CHAPTER 5. DATA ANALYSIS}

5.1 Data Preparation 189

5.2 Analysis of Non-Response Bias 190

5.3 Analysis of Response Bias: 'Field Enumerator Effects' 192

5.4 Analysis of Common Method (Bias) Variance 194

$\begin{array}{ll}\text { 5.5 Missing Values Analysis } & 198\end{array}$

5.6 Assessment of Normality of Distribution 201

5.7 Descriptive Statistics on the Profile of the Sample Firms 204

5.8 Reliability and Dimensionality 210

5.9 Summary and Inter-correlation of Variables 232

5.10 Descriptive Comparison of the Two Cities on the Key Constructs 235

5.11 Descriptive Analysis of Organisational Performance and Strategic Posture regardless of City Location 238

5.12 Statistical Testing of Hypotheses 241

$\begin{array}{ll}4.13 \text { Summary } & 280\end{array}$ 
CHAPTER 6. DISCUSSION

6.1 The Refined Conceptual Model 283

6.2 The Effects of Formal Institutions 285

6.3 The Effects of Informal Institutions 291

6.4 The Effects of Industry Characteristics 294

6.5 The Effects of Firm Characteristics 295

6.6 The Effects of MSME Owner/Manager Characteristics 295

6.7 Variations on the Level of Strategic Posture 296

6.8 The Effects of Strategic Posture on Organisational Performance 297

6.9 The Mediating Role of Strategic Posture 299

6.10 The Prevalence of Micro-Enterprises 301

6.11 Measurement of Organisational Performance 302

6.12 Alternative Views of the Empirical Results 302

CHAPTER 7. CONCLUSIONS

7.1 Theoretical Contributions of the Study 306

7.2 Contribution to the Extant Literature 307

7.3 Methodological Contributions of the Study 312

7.4 Policy Contributions of the Study 313

7.5 Contributions to Managerial Practices 314

7.6 Limitations and Directions for Future Research 315

$\begin{array}{ll}7.7 \text { Summary } & 320\end{array}$

APPENDICES

A.The Research Instrument - Survey Questionnaire 322

B. Determination of Sample Size 335

$\begin{array}{ll}\text { REFERENCES } & 336\end{array}$ 


\section{LIST OF TABLES}

2.1 Various Definitions of Institutions 20

$\begin{array}{lll}2.2 & \text { Institutional Matrix } & 22\end{array}$

2.3 Categories of Philippine Business Establishments 32

2.4 Approaches to Organisational Effectiveness Measurement 42

2.5 Approaches to Performance Measurement 44

2.6 Measures of Organisational Performance 47

3.1 Selected Empirical Studies on Institutions 58

3.2 Various Empirical Studies on Strategic Posture 114

3.3 Direct Relationships Between Institutions and

$\begin{array}{ll}\text { Organisational Performance } & 128\end{array}$

3.4 Summary of Hypotheses 146

4.1. Definition, Operationalisation and Sources

of Measures: Rule of Law and Property Rights Protection 158

4.2. Definition, Operationalisation and Sources

of Measures: Government Policies and Regulatory Quality 159

4.3. Definition, Operationalisation and Sources

of Measures: Government Assistance 160

4.4. Definition, Operationalisation and Sources of

Measures: Informal Institutions

4.5. Definition, Operationalisation and Sources of

Measures: Strategic Posture, Managerial, Firm and

Industry Characteristics

4.6. Definition, Operationalisation and Sources of

Measures: Organisational Performance (Operational Performance) 165

4.7. Definition, Operationalisation and Sources of

Measures: Organisational Performance (Financial Performance) 166

4.8. Potential Errors in Survey Research and their Remedies 176

5.1 Rates of Retrieval and Usable Responses 190

5.2 Testing for Non-Response Bias: $t$-test 191

5.3 Testing for Non-Response Bias: $\chi^{2}$ Test 192

5.4 Testing for Enumerator Effects: One-way ANOVA 193 
5.5 Testing for Enumerator Effects: Pearson $\chi^{2}$

5.6 Zero Order Correlation Matrix Examining the

Effects of the Marker Variable

5.7 Partial Correlation Matrix Examining the Effect

of the Marker Variable

5.8 Missing Value Analysis - Part 1 199

5.9 Missing Value Analysis - Part 2 200

5.10 Skewness and Kurtosis Indices of Items - Part 1

5.11 Skewness and Kurtosis Indices of Items - Part 2

5.12 Distribution of Firms in terms of Size and Sector 205

5.13 Distribution of Firms in terms of the Nature of the Industry 206

5.14 Distribution of Firms in terms of Age and Type of Ownership 207

5.15 Distribution of Firms in terms of Age, Sector and City Location 207

5.16 Distribution of Firms in terms of Age, Ownership and City Location 208

5.17 Distribution of Respondents in terms of Age and Gender 208

5.18 Distribution of Respondents in terms of Educational Qualifications 209

5.19 Distribution of Respondents in terms of Age, Gender and Ownership 209

5.20 Factor Analysis of the Formal Institutions Variables 215

5.21 Weighted Performance Scores 217

5.22 Factor Analysis of the Organisational Performance Variables 218

5.23 Goodness of Fit Indices used in Confirmatory Factor Analysis 223

5.24 Confirmatory Factor Analysis of the Informal Institutions Variables 225

5.25 Summary of Goodness-of-Fit Indices for the Informal Institutions Variables using Maximum Likelihood Method

5.26 Summary of the Goodness-of-Fit Indices for the Informal Institutions Variables using the Robust Method

5.27 Inter-Item Consistency of the Informal Institution Variables from the GLOBE Study

5.28 Unidimensionality and Inter-Item Consistency of the Strategic Posture Variable 
5.29 Goodness of Fit Indices of the CFA of the

Strategic Posture Variable - Maximum Likelihood Method

5.30 Goodness of Fit Indices of the CFA of the Strategic

Posture Variable - Robust Method

5.31 Unidimensionality and Internal Consistency of the

Industry-related Constructs

5.32 Summary of the Variables used in this Study

5.33 Correlation Matrix of the Major Independent Variables

5.34 Comparison of Tagum and Panabo Cities in terms of Mean Values Across the Major Variables

5.35 Comparison of Organisational Performance of Sample Firms in Both Cities

5.36 Skewness and Kurtosis Indices of the Variables in the Study

5.37 Multiple Regression Models of Strategic Posture using OLS Method on Institutions, Industry-, Respondent-, and Firm- Characteristics with City as Control Variable

5.38 Multiple Regression using ROBUST Method

5.39 Summary of Hypothesis Testing - 1

5.40 Regression Model on Strategic Posture and Org'l. Performance

5.41 Regression Model on Strategic Posture and Orgnisational Performance using the ROBUST Method

5.42 Regression Model on Strategic Posture and Individual Indicators of Organisational Performance

5.43 Summary of Hypothesis Testing - 2

5.44 OLS Regression on Formal and Informal Institutions and the Three Sub-dimensions of Organisational Performance

5.45 OLS Regression Model on Institutions and Strategic Posture 266

5.46 Mediation Analysis and Post-Hoc Tests - Part 1

5.47 Summary of Hypothesis Testing on InstitutionsOrganisational Performance Linkages

5.48 Summary of Hypothesis Testing - 3

5.49 Regression with Formal and Informal Institution Indices-Part 1275

5.50 Regression with Formal and Informal Institution Indices-Part 2277

5.51 Mediation Analysis and Post-Hoc Tests - Part 2 


\section{LIST OF FIGURES}

1.1 Road Map of the Chapter 1

$\begin{array}{lll}1.2 & \text { Outline of the Study } & 14\end{array}$

2.1 Road Map of the Chapter 15

3.1 Road Map of the Chapter 53

3.2 Schematic Diagram of the Research Framework 54

3.3 The Conceptual Model and Hypothesised Relationships 61

4.1 Road Map of the Chapter 147

$\begin{array}{lll}\text { 4.2 Map of the Philippines } & 178\end{array}$

4.3 Regional Map of the Davao del Norte Province 179

5.1 Outline of Data Analysis 188

5.2 Importance Attached to and Performance of MSMEs

on the 13 Indicators of Organisational Performance 239

5.3 Distribution of Respondents on the Seven Points of the Strategic Posture Scale 240

5.4 Examples of Scatterplots of Selected Independent (x-axis) and Dependent Variables (y-axis) 243

5.5 Examples of Q-Q Plots of Selected Variables 244

5.6 Regression Equations for All Independent Variables and Strategic Posture 248

5.7 Regression Equations for Strategic Posture and Three Facets of Organisational Performance

5.8 Regression Equations on Indices of Institutions and Strategic Posture 274

5.9 Regression Equations on Indices of Institutions and Strategic Posture 276

6.1 Road Map of the Chapter 282

6.2 Refined Conceptual Model 284

7.1 Road Map of the Chapter 305 


\section{CHAPTER 1. INTRODUCTION}

This chapter presents the background of the study by describing the overall context of the research issues which prompted the current investigation. This is followed by the presentation of the research questions and the articulation of the research objectives. The chapter ends with a discussion of the significance of this research in light of the theoretical, conceptual, empirical and methodological research gaps which this study aims to address. Figure 1.1. shows the outline of this chapter.

Figure 1.1. Road Map of the Chapter

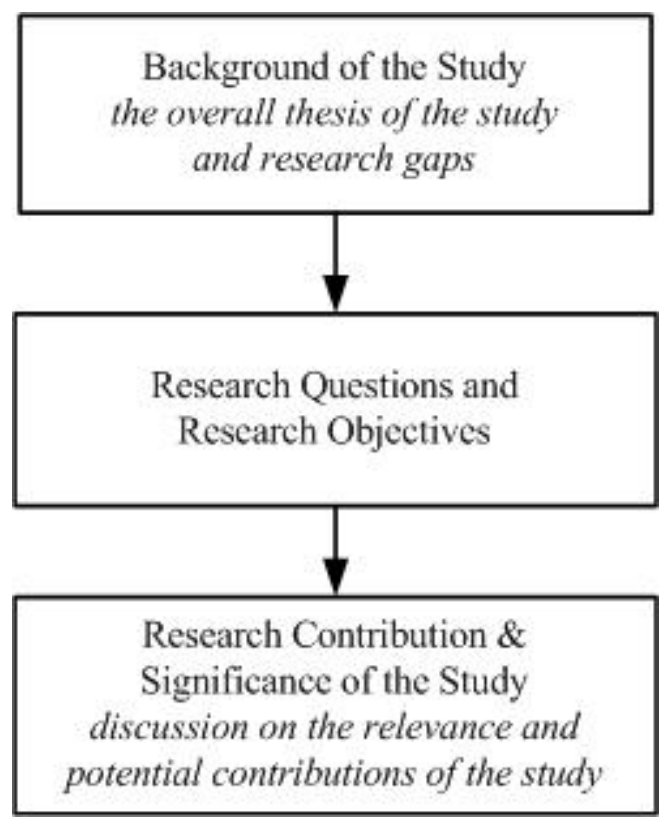

\subsection{Background of the Study}

If the micro, small and medium enterprise (MSME) sector is an engine of economic growth in emerging economies, then the local institutional framework is the steering wheel. This is the underlying theme of this study. Its main thesis is that perceptions of the formal and informal institutions emanating from the economic, political, and socio-cultural environments at sub-national level, such as a city, significantly influence the strategic posture of MSMEs located in that city. Consequently, strategic posture shapes MSMEs' perceptions of their organisational performance. In effect, the study posits that strategic posture is the conduit through which perceptions of the 
city-level formal and informal institutions exert their influence on the firms' overall organisational performance.

Triggered by institutional theory in its contemporary form, the focal point of the current investigation is on the relationships between institutions, strategic posture, and organisational performance of MSMEs. North (1990 p.3), defines institutions as those formal and informal 'rules of the game' of a society which are humanly devised constraints and incentives that structure human interaction and exchanges whether political, social or economic. The core arguments in this strand of institutional theory are that the economic performance of countries is a function of institutions and that overall economic development is best achieved within an institutional framework that is supportive of productive activities (Hodgson, 2006; North, 1990; Rodrik, Subramanian \& Trebbi, 2004).

Whilst the proposition that 'institutions matter' is hardly controversial nowadays, the questions worth of scholarly investigation are on how institutions matter and in what context do various forms of institutions matter? (Bowen \& De Clercq, 2008; Manolova, Eunni \& Gyoshev, 2008; Peng, Wang \& Jiang, 2008; Rodrik, 2006). The current investigation derives inspiration from these two critical questions. Guided by these questions, the study attempts to offer answers to the eight research gaps that serve as the driving forces behind the current investigation. These eight research gaps emanate from the extant literature and are considered specifically important in the analysis of the research model subsuming the institutions-strategic postureorganisational performance nexus. These gaps represent the missing linkages essential in understanding how the wider institutional environment relates to firmlevel level phenomena such as strategic posture and organisational performance.

The first research gap is the lack of emphasis on institutions in strategy research. The application of institutional theory in the fields of business strategy management, and organisational performance has gained increasing prominence in the academic literature. However, current empirical explanations on the role institutions play in the development of organisational strategy, for instance, leave much to be desired (Greenwood, Oliver, Sahlin \& Suddaby, 2008). Relative to the popularity of the industrial organisational (I/O) theory represented by Porter (1980) as well as the 
resource-based view (RBV) of the firm represented by Barney (1991), institutions have not been well regarded as principal antecedents of organisational strategy and organisational performance (Peng et al., 2008). Instead, institutions are often relegated to the background as merely appendages to the more popular variables found in the immediate "task environment" of firms (Parboteeah, Hoegl \& Cullen, 2008).

Hence, the need to bring institutions to the forefront of the debate on the role of the much wider external institutional environment in shaping the strategic configurations as well as the overall performance of firms (Henisz \& Swaminathan, 2008). Bruton and Lau (2008) declared that given the drastic changes in regions like Asia, the interaction of institutions and strategic posture appears to be a particularly rich area of potential theory development.

As a consequence of the first research gap, this study uncovers the second research gap: lack of understanding how institutions directly relate to organisations like MSMEs (Bruton et al., 2008). Closely associated with it is the third research gap which is the lack of explanations on how institutions relate to the strategic posture of firms. Previous studies focused on how institutions relate to macro-economic indicators of a country's growth and development (Fergusson, 2006; Hasan et al., 2007; Pajunen 2008; Rodrik, 2006). There is paucity of empirical studies linking institutions to firm-level variables. The formidable task of constructing convincing tests of hypothesis that institutions are important determinants of MSME strategic behaviour and entrepreneurial activity explains these two gaps in research (Rodrik, 2006; Davidsson and Henrekson, 2002). Whilst previous studies have noted that organisations such as business firms are naturally embedded in an institutional environment (Hollingsworth, 2002), the extant literature remains unclear as to the nature and magnitude of impact the institutional environment exerts upon organisations (Dollar et al., 2005; Fogel et al., 2006; Vatn, 2005).

Hence, this study recognises the need to establish the link between the institutional environment and MSMEs' strategic posture and overall performance to fill in the first three research gaps. The deterministic role of the environment under institutional theory and the rational decision-making under the strategic choice 
perspective of organisations imply contradictions when the two are put side by side (Beckert, 1999; Oliver, 1991; Whittington, 1988). A study, that adds further understanding on how strategic choice - operationalised by the firms' strategic posture - may be exercised by organisations under the deterministic constraints of the institutional environment, is a vital step to address the first three research gaps.

Moreover, this study considers it worthwhile to investigate if the 'effects' of the institutional environment on the organisational performance of firms are indirect through the mediating role of the firm's strategic posture. By doing so, deeper understanding is gained concerning the dictum that institutions shape economic performance' through an investigation of the institutions - strategic posture organisational performance nexus within the context of MSMEs which are assumed to be key economic players in the two cities considered in the study. Due to their large number, MSMEs and their overall organisational performance can have considerable impact on the general economic performance of cities in emerging economies like the Philippines.

The fourth research gap in the extant literature is the lack of an integrated institutional framework that can explain firm behaviour and performance. This research gap emanates from a major theoretical issue in the study of North's (1990) institutional theory: the interpretation of what constitutes formal and informal institutions and the operational definition of these two broad concepts. Whilst there are numerous studies dealing with formal institutions, albeit with divergent results, the operationalisation of informal institutions remains under-researched as shown by the scarce literature on this topic (Helmke \& Levitsky, 2004; Hodgson, 2006). Previous studies often take the form of conceptual discussions, case studies and very few empirical investigations (Boliari, 2007; Hodgson, 2006; Vatn, 2005).

There is a need therefore to enrich current understanding of formal and informal institutions by developing a set of variables which capture the definition of these two types of institutions as they relate to MSMEs. The current study recognises that there remains a need to integrate several facets of institutions to come up with more comprehensive theorising not only as a matter of intense scholarly interest in institutionalism but also of value to public policy (Meyer \& Peng, 2005). In addition, 
the current study considers it theoretically and empirically useful to establish the link between formal/informal institutions and the strategic posture of MSMEs. Understanding that link requires empirical determination of the overall strategic responses of firms vis-à-vis the pressures exerted by these institutions (Verheul, 2002; Carlsson, 2002; Lee \& Peterson, 2000).

The fifth research gap stems from the over-emphasis on the legalistic and political approach of institutional measurement and analysis in the extant literature. Previous empirical studies tend to reduce the concept of institutions into legal and political elements such as laws, policies, and government programs and examined in terms of their influence on small firms (Co, 2004; Siu, Lin, Fang \& Liu, 2006; Sui, Lin, Fang \& Liu, 2006; Wan, 2005). This treatment of institutions is rather deficient as will be shown in the following review of literature on the rich traditions of institutionalism. Informal institutions should not be treated as mere appendages to formal institutions because both offer plausible explanations on firm behaviour and performance (North 1990; 2005).

Hence, the study acknowledges the need to examine various institutional influences on small businesses such as MSMEs beyond what the legally- and politicallyorientated studies have done in the past. This study advances the view that culture captures well the conceptual substance of informal institutions consistent with North's (1990) typology of institutions. Developing an integrated (i.e. formal and informal) institutional framework as it relates to MSME strategic posture and organisational performance is a research goal which this study considers worth pursuing.

The sixth research gap is the lack of emphasis on sub-national institutional frameworks. Previous studies tend to take country-wide institutional view of business climate, business development, and economic growth or development (Bowen $\&$ de Clerq 2008; Wan, 2005; Bevan et al., 2004). Little systematic knowledge exists about the determinants of MSME strategic behaviour and performance at subnational level such as state or city level (Goetz \& Freshwater, 2001). The viability of studying institutions at sub-national level (i.e. city-level) rests on the view that there 
are wide institutional disparities between and amongst regions and cities within a country (Ando, 2007; Meyer \& Nguyen, 2005; Narayanan \& Fahey, 2005).

Hence, aggregate measures of the overall national socio-economic condition do not necessarily reflect the real economic landscapes at sub-national levels. It is logical to argue that MSMEs in one city operate in an entirely different business and institutional landscape compared to those in other cities. The immediate concern therefore is to understand the influence of sub-national institutional factors on MSMEs operating in that local business environment. The sub-national focus is one of the novel features of the current investigation as typical studies tend to take on a country-wide look at institutions, disregarding the potential institutional variations within the same national boundary, especially in geographically-dispersed and ethically-diverse countries like the Philippines and Indonesia (Ando, 2007; Gambarotto \& Solari, 2005; Henisz \& Swaminathan, 2008; Narayanan \& Fahey, 2005; Peng \& Heath, 1996).

The advent of decentralisation of governance systems of many developing or emerging countries like the Philippines provides further support for a sub-national focus in investigating institutions as they relate to MSMEs. Governance reforms that are sweeping the world all over highlight the importance of decentralisation of government systems (Work, 2001). Government units at sub-national level such as a region, state or city, are entrusted more powers, authority and responsibility including the gruesome task of intensifying the locality's efforts for economic development under their newly found fiscal, political, and administrative autonomy (Brillantes Jr., 2004; Legaspi, 2000; Thornton, 2007).

As a consequence, local economic development has become a major preoccupation amongst local government units especially in the developing countries in the Asia Pacific region (ADB, 2008; Beer, 2002; Helmsing, 2000). Since many of these local government units seek to develop locally-based businesses as a growth strategy, questions of how the entrepreneurial strategic configurations and overall organisational performance of MSMEs can be improved and sustained are at the core of policy making framework (Blakely \& Bradshaw, 2002). 
In previous studies, various local economic development frameworks and models were proposed (e.g. Wong, 2002; Magdaluyo et al., 2001). Lacking in these studies is determining how these set of factors directly influence organisational-level variables in a small business or MSME context. Of prime importance is the identification of the formal and informal institutions comprising the external business environment that influences the firms' entrepreneurial strategic efforts which will eventually dictate the nature and pace of economic development of a geo-political area (Goodwin, Jones \& Jones, 2005; Hodgson, 1993; Ma \& Delios, 2007; Raco, 1999).

This mandate of local economic development affirms the role of cities as being the "growth machines" that drive national growth and productivity (Logan \& Molotch, 1996). The process of economic growth of a country may be better understood by focusing on the cities comprising the national socio-political and economic landscape (Glaeser, Kallal, Scheinkman \& Shleifer, 1992; Naudee \& Krugell, 2003). Hence, the study's focus on MSMEs in relation to city-level institutions is in line with the 'city as growth machine' school of thought.

On the other hand, there is on-going debate as to what specific factors support local economic development through MSME development. Several models of 'local investment climate' have been proposed, debated on, modified, improved, and debunked (Bartik, 1992; Beer, 2002; Begg, 2002; Dewees, Lobao \& Swanson, 2003; Harding, Wilks-Heeg \& Hutchins, 2000; Helmsing, 2003; Hughes, 1991; Krumholz, 1999; Wilkinson, 2006; Wong, 2002). Some of these studies focus on developing a "traditional" business climate conducive for potential investors such as multinational companies whilst others ventured into the development of business climate models that will promote endogenous growth through local business development. The current study addresses this issue in part by looking at which aspects of the institutional environment (i.e. what institutions) are likely to relate to an entrepreneurial kind of strategic posture which ultimately leads to better organisational performance.

In effect, the study fills in the seventh research gap identified in the literature, the lack of a model of MSME institutional development in an emerging or developing country setting. The popularity of institutional frameworks developed in Western 
contexts inspires the current study to explore the possibility of developing an institutional model to explain MSME strategic posture and organisational performance that is most applicable to a developing country setting (Fogel et al., 2006; Okamuro \& Kobayashi, 2006; Goetz \& Freshwater 2001).

The eighth research gap is the lack of emphasis on micro-enterprises in the mainstream SME-oriented research (e.g. Co, 2004; Harvie \& Lee 2002). The need to focus on MSMEs stems from the crucial role these firms play in the economic development of many developing or emerging countries like the Philippines (OECD, 2005; Wilkinson \& Brouthers, 2006). In the Asia-Pacific region, MSMEs comprise over $98 \%$ of the total enterprises (APEC 2002). It is important to emphasise the role of micro-enterprises as extant literature tends to focus on small and medium enterprises (SMEs) although the difference could be accounted for by studies subsuming the micro-enterprises under the small enterprise category. In the Philippines, for instance, $99.6 \%$ of the total 810,362 business establishments as of 2003 are micro (91.75\%), small (7.5\%) and medium (0.35\%) firms generating 67.9\% of the country's total employment (DTI, 2005). However, there are studies which proclaim the dominance in number and importance of SMEs in the Philippines but did not include the micro-enterprises (Co, 2004; Co \& Mitchell, 2005; Lallana, Pascual \& Andam, 2002; Tambunan, 2005).

MSME-related studies often deal with any of the three major areas of research: the individual entrepreneur; the enterprise or firm; and the firm's environment (Harvie \& Lee, 2002; Kuratko \& Hodgetts, 2004). Of particular research interest to date is determining the environmental factors that influence the strategic behaviour and success of small businesses (at the enterprise level), especially MSMEs in emerging economies (Bruton, Ahlstrom \& Obloj, 2008; Manolova et al., 2008). Furthermore, some authors argue that studies on entrepreneurial environment (i.e. the kind of environment that fosters entrepreneurship) remain fragmented and do not focus on the needs of entrepreneurs themselves (Bruton et al., 2008; Cassis \& Minoglou, 2005; Fogel, Hawk, Morck \& Yeung, 2006; Manolova et al., 2008). In previous studies, no explicit link is made between the needs of entrepreneurs and how the environment can fulfil those needs. This could be attributed to the fact that there are 
few guidelines available to conduct empirical research on entrepreneurial environments (Fogel et al., 2006; Gnyawali \& Fogel, 1994).

Some studies look at the business environments of various countries and produce a general report card of each country's business climate. Studies that have been conducted are likely to have focused on evaluation of environmental support systems for small businesses (Brown, 2005; Taylor, 2004). However, these studies are mostly inconclusive and anecdotal in nature (Co, 2004). Hence, the current study acknowledges the need to conceptualise institutional frameworks that facilitate the recognition and description of formal and informal institutions and then to develop and empirically test a set of hypotheses that could offer explanations why firms are more entrepreneurial in their strategic posture than others. In effect, the study attempts to gather support for the view that the institutional environment offers MSMEs the opportunity to engage in an entrepreneurial strategic posture in order to improve overall organisational performance.

Moreover, the focus on MSMEs in the Philippines is consistent with the current research interest on emerging economies - referring to countries which are undergoing rapid pace of economic development aided by government policies that favour economic liberalisation and adoption of a free-market system (Hoskisson, Eden, Lau \& Wright, 2000; Wright, Filatotchev, Hoskisson \& Peng, 2005). Understanding how domestic firms behave and manage performance is one of the key research imperatives to understand the business environment of emerging economies (Peng et al., 2008; Wan, 2005; Wright et al., 2005).

Lastly, the extant literature is replete with entrepreneurship-oriented studies with the basic assumption that MSMEs equates to entrepreneurship (Co, 2004). This is rather flawed because studies have shown that not all MSMEs are entrepreneurial in their strategic posture (Covin \& Slevin, 1989; Covin \& Slevin, 1990; Lumpkin \& Dess, 1996). Hence, this study hopes to gather empirical evidence to reinforce the argument that not all MSMEs are necessarily entrepreneurial in their strategic posture. 


\subsection{Research Questions}

Against this background, the two main research questions that this study seeks to answer are:

\section{Is there a significant relationship between the perceived local institutional environment and the strategic posture of micro, small and medium enterprises in a city in a developing country setting?}

\section{Does strategic posture mediate the institutional environment - MSME organisational performance relationship?}

The current study proposes the development and subsequent examination of a model of formal and informal institutions comprising the local institutional environment as perceived by owners and/or managers of MSMEs. These institutions may be wellentrenched in a given locality or city and very "efficient" at either supporting or inhibiting the entrepreneurial strategic posture and performance of MSMEs. These institutions are studied in the context of a sub-national economy, in this case, two cities in an emerging country like the Philippines whereby MSMEs comprise the significant majority of all registered or legally-operating businesses.

The two cities were selected such that both cities are "under" the same provincial government thereby ensuring that institutional variations (especially formal institutional variations) could not be attributed to different provincial governments. In the Philippines, a number of cities (except those classified as independent) are under a provincial (or regional) government, which in turn, is under the national government. Moreover, one city is classified as a first class or 'high-income' city whilst the other is a fourth class or 'low-income' city (NSCB, 2007a). It is assumed in this study that the nature and level of resources held by the city's local government unit may influence the formal institutional frameworks operating within each city. Furthermore, studying two cities takes into account the possibility of within-country variations in informal institutions (Ma \& Delios, 2007; Meyer, 2005). 
In describing the external institutional environment, this study adopts the cognitive perspective on enacted environments (Bourgeois III, 1980; Daft, Sormunen \& Parks, 1988; Duncan, 1972; Weick, 1988). A cognitive perspective emphasises that the firm's external environment comprises objectives facts and figures but the significance of these objects depends on how MSME managers and/or owners perceived them to be relevant to the firm's strategy-making activities (Lefebvre, Mason \& Lefebvre, 1997). Hence, what matters are the perceptions of the owners/managers of MSMEs of these formal and informal institutions and their relationships with the firms' strategic posture and organisational performance.

This local institutional environment is then examined in terms of its relationships with the strategic posture of MSMEs. Building on previous research on institutional determinism and strategic choice, this study will attempt to shed more light on how these two apparently contradictory theories can be used in a complementary fashion to understand the environment - MSME behaviour nexus. Extant literature suggests that small firms (relative to large firms) inherently suffer organisational disabilities making them more vulnerable to the vagaries of a complex and competitive environment (Arinaitwe, 2006; Cooke \& Wills, 1999; Ruane, 2007). If formal and informal institutions constrain as well as provide incentives in MSME strategic choices, it can be argued that these institutions could also explain the state of MSMEs in terms of their strategic posture (as manifestation of the firms' strategic choices) and organisational performance.

\subsection{Research Objectives}

This research aims to investigate:

a. the perceived formal and informal institutional factors at the city-level that influence the strategic posture of micro, small and medium enterprises (MSMEs) in two cities in an emerging or developing country such as the Philippines;

b. the influence of strategic posture on the organisational performance of MSMEs; 
c. the mediating role of strategic posture within the institutions - organisational performance relationship; and

d. the influence of other factors - both external and internal to the firms - on the strategic posture of MSMEs, such as managerial, firm and industry characteristics.

\subsection{Research Contribution and Significance of the Study}

The value of this study is established in terms of its potential to have theoretical or conceptual, conceptual and methodological contributions in the study of institutions, local economic development, as well as organisational studies and strategic management.

On the empirical side, the study contributes to the current debate on the role of institutions in shaping (leading actors in) local economies - a deviation or an offshoot from the strand of previous research with national or country-wide focus. Meyer and Nguyen (2005) noted that there are wide institutional disparities between and amongst cities within a national boundary, especially those countries with diverse multicultural identifications situated in dispersed geographic locations. This has strong relevance in the case of the archipelagic geography of the Philippines comprising 7,107 islands under a decentralised system of government. It can be expected that in such a geographically-dispersed economy and decentralised political landscape, within-in country variations in (sub-national) institutions can have significant impact on the local firms' (such as MSMEs) tendency to pursue an entrepreneurial strategic posture, and ultimately on the firms' overall organisational performance.

Knowing if there is a direct link between perceptions of local institutions and existing MSMEs' strategic posture forms another empirical contribution worth pursuing. The inclusion of the micro enterprises in the investigation, distinguishes this study from the mainstream entrepreneurship-oriented literature with heavy SME focus. Furthermore, the emerging economy or developing country-context of the study is another empirical value inspiring this study. 
The potential of this study to generate conceptual and theoretical contributions rests on the goals of determining the elements or dimensions of perceived formal and informal institutions as they relate to MSMEs. The study's attempt to go beyond the traditional legal-political domains of institutional research by incorporating the informal (e.g. cultural) variables is another potential contribution to the understanding on the nature of institutions and how they shape organisations. It was emphasised in the current literature that institutional analysis should take into consideration both the formal and informal (cultural) constraints in decision-making given that national culture is manifested in the very fabric of institutions. (Matten $\&$ Geppert, 2004; Vandenberg, 1999). This study advances the view that the 'culture' of a given society captures North's $(1990,2005)$ concept of informal institutions. This view is based on the synthesis of previous studies (on informal institutions) that converged on the conclusion that the cultural characteristics of a group of people, society or community represent the 'unwritten rules' governing human interaction.

The study considers it imperative to look at both types of institutions to better explain organisational level-phenomena. Furthermore, a one-sided focus on either formal or informal constraints may constitute a myopic view of economic behaviour in transition, emerging or developing economies which limit the potentials of institutional analysis to offer plausible explanations and directions for economic development (Nee 1998).

Likewise, the study has the potential to enrich further understanding of the complementary rather than opposing interaction between the concepts of environmental determinism and strategic choice. By understanding how strategic posture of MSMEs is exercised in the context of external institutional embeddedness, the study argues that strategic choice, as manifested by the firms' strategic posture is still possible despite the external environmental pressures and constraints. Furthermore, the study will generate empirical evidence supporting the tenability of the institutional view of organisational strategy (Peng et al., 2008).

The methodological value of the study rests on the effort of identifying specific formal and informal institutional factors perceived to be relevant to MSMEs in a city. Whilst there are existing measures of formal institutions at the country/national level, 
studies that propose and empirically test some measures applicable at the city-level are scarce and fragmented. Likewise, the process of "validating" or confirming the relevance of these perceived institutions by linking them to organisational level variables as opposed to national aggregate economic indicators is an effort that adds rigour to determining what constitutes a perceived local institutional environment.

\subsection{Outline of the Thesis}

This thesis is organised as shown in Figure 1.2.

Figure 1.2 Outline of the Study

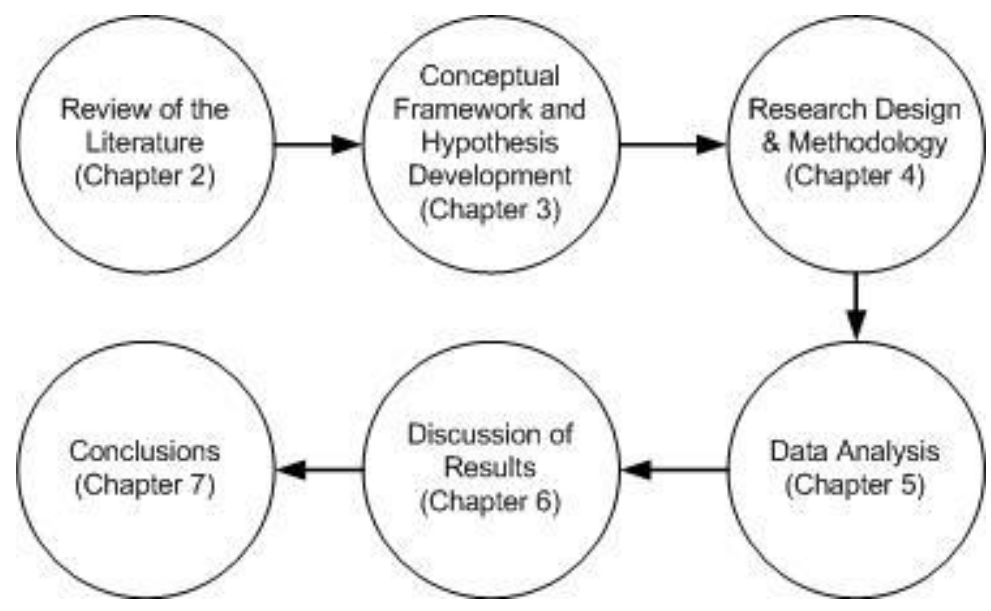


Understanding the theoretical background of a research topic is the seedbed from which a sound research framework may emerge. Reviewing the theoretical background situates the current study's arguments in the context of the traditions of the scientific disciplines that relate to it. Furthermore, a review of the empirical work undertaken in relevant fields establishes the relevance and significance of the questions raised in the current study. The following review of the literature seeks to provide the theoretical background necessary to establish an appropriate research framework. Figure 2.1 shows the outline of the chapter.

Figure 2.1. Road Map of the Chapter

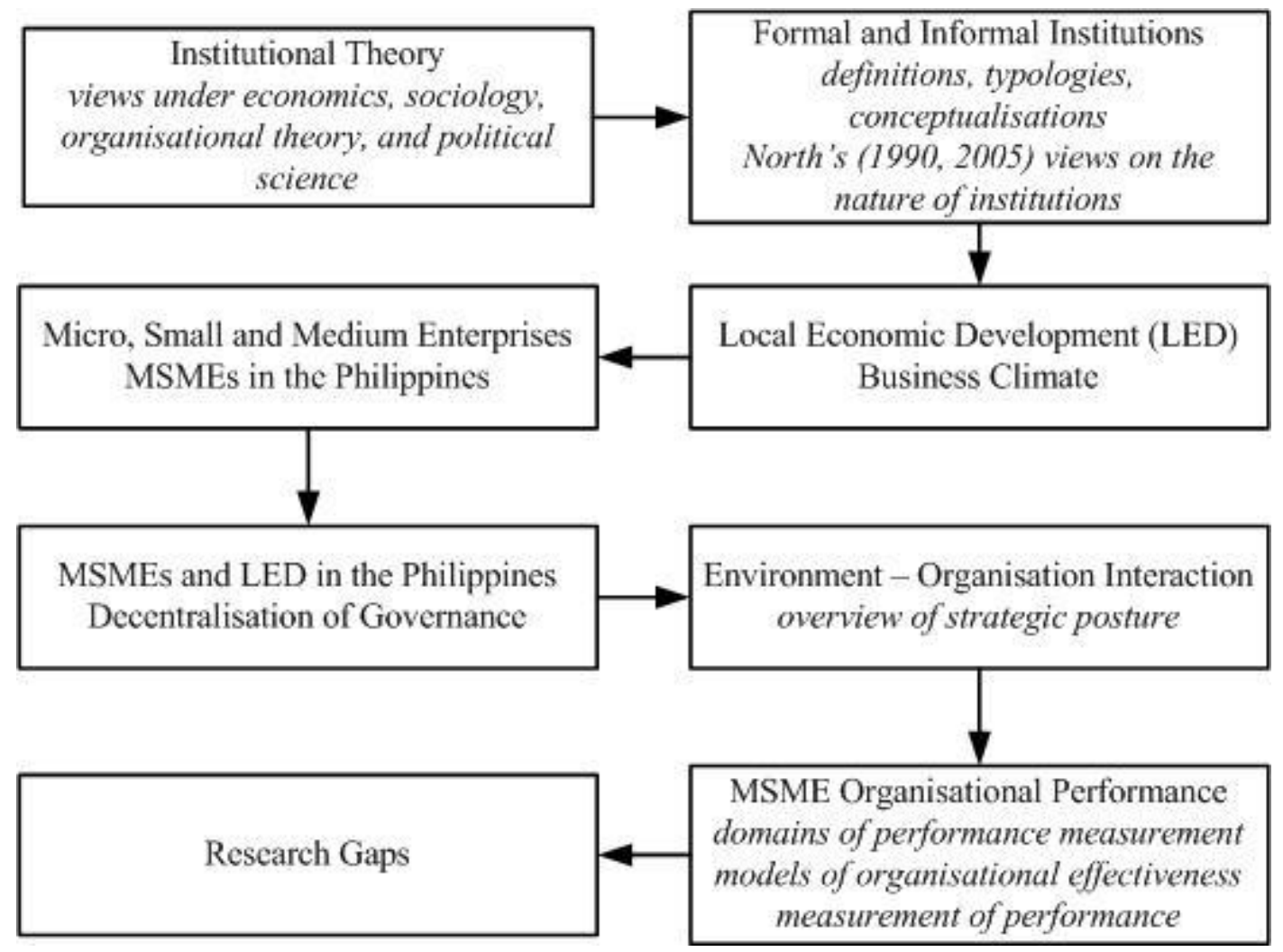

The review starts with a multidisciplinary analysis of institutional theory. The review traces the roots of this theory from the fields of economic, sociology, organisational theory and political science. A distinction is made between the old and new 
institutional theory to highlight the nature and impact of the evolutionary path by institutional theory.

The review includes a synthesis of the diverse definitions and conceptualisations of the nature of institutions. It then proceeds with a discussion of the Northian dichotomy of formal and informal institutions. Likewise, the review establishes the relevance of these institutions by looking at the institutional frameworks which illustrate how institutions relate to other social phenomena.

The second part of the review is a synthesis of scholarly work done in the area of local economic development (LED) by looking at the theories and empirical work done in this field. Closely related to LED is the concept of business climate viewed in terms of the various frameworks used to measure how conducive an external environment is to business creation and growth.

The third part looks at the emergence of micro, small and medium enterprises (MSME) as the leading players in economic development. This is followed by a situation analysis of MSMEs in the Philippines.

The fourth part reviews the role of local government in local economic development in the context of decentralisation as it was implemented in the Philippines. The fifth part, examines briefly the strategic choice perspective of organisational interaction with the external environment. The last part of the review examines the concept of MSME performance and its measurement.

\subsection{Institutional Theory}

The study of institutions traverses the disciplines of economics, sociology, political science and organisational theory. An underlying theme in studying institutions is the concept of 'embeddedness' (Baum \& Oliver, 1992; Hollingsworth, 2002). This concept suggests that social phenomena such as MSME strategic posture and performance are embedded in an external institutional environment. This institutional environment is the source of legitimisation, rewards or incentives and constraints on the activities of MSMEs. 
However, disagreements remain on how exactly institutions influence human activities (Ahmadi, 2003). Despite widespread use, there is still no consensus in the social sciences on the meaning of institutions and institutional analysis (Hollingsworth, 2002). Parto (2005) concludes that this lack of unanimity of views has triggered the increasing prevalence of studies treating institutions as a mere addon factor or a filter to be accounted for in schematics representing causal flows in a given situation. It is important therefore to briefly outline the salient characteristics of institutional theory to support the context of this study.

\subsubsection{The Roots of Institutional Theory}

Institutionalism has deep theoretical foundations in the fields of economics, sociology and political science. A number of theorists across these scientific disciplines offered diverse explanation on how institutional forces shape human activities as well as how these institutional arrangements come into being.

\subsubsection{1. "Old" Institutional Theory}

The 'old' institutional theory emanates from institutional economics (Rutherford, 2001). This theory challenged the concept of the 'rational economic man' suggesting that economic activities are not necessarily outcomes of rational decision-making but are products of the social environment (Hodgson, 1998; Parto, 2005; Vatn, 2005). By extending the 'rational economic man theory', it can be argued that MSME activities emerged from specific historical and social settings (Parto, 2005). The theory suggests that institutions are ways to support the interests of and handle conflicts amongst various individuals, organisations or groups and the wider environmental forces and actors (Vatn, 2005). Paradoxically, the same institutions serve as remedy or mechanism to achieve harmony amongst these economic entities (Hodgson, 1998). The works of Commons, Veblen, Mitchel and Ayres, amongst others (please see Scott, 2001 for detailed review) heavily influenced this early phase of institutional theory. 
In political science, the underlying themes of debates on the role of institutions in shaping political activities include: issues with law and the central role of law in governing; the importance of structures such as political systems; holistic analysis of systems; historical development of political institutions; and a strong normative element in institutional analysis (Peters, 1999).

The "natural systems model" of Selznick (in Scott 2001) succinctly explains the role of institutions in shaping organisational behaviour, which heavily influenced the sociological view of institutions. Selznick' theory (in Scott 2001) situates MSMES in a complex social system which implies that organisational structures of MSMEs could be understood well by understanding the environmental social structures in tandem with its non-rational dimensions such as the complex informal systems that link social participants (e.g. MSMEs) with one another and with others beyond its boundaries.

Equally prominent in the field of sociology is Talcott Parsons (1960 in Scott 2001) whose seminal work on cultural-institutional theory explored the relationship between organisations and their environment, the ways through which the value system of an organisation is legitimated by its connections to the "main institutional patterns" of its outside environment. Parson's theory implies that an MSME as an organisation acts as a subsystem of a wider social system which is a source of meaning, legitimation, or higher level support. This further implies that success of an organisation depends on whether it has the necessary support from the wider system.

\subsubsection{2. "New" Institutional Theory}

New institutional economics emerged from the writings of Coase (1960), Williamson (1979, 1981), and more recently, by North whose contribution in the field of economics was honoured with a Nobel Prize in 1993. The focus of analysis of this strand of institutional theory is on the origins, incidence, and ramifications of transaction costs (Coase, 1960; Rao, 2003; Williamson, 1979). The theme of this strand of institutional theory dwells on the role of institutions in reducing transaction costs or 'those costs associated to initiate, manage, and complete various types of economic exchanges' (Rao, 2003). 
The work of North (1992) significantly influenced this new institutional theory. North's main argument suggests that the presence of economic uncertainty increases transaction costs such as the costs of gaining access to information as well as the cost of enforcing proprietary rights. Institutions are formed to reduce this uncertainty by setting the "rules of the game" in the form of formal rules, informal norms, and their enforcement characteristics (North, 1992, 2005). Likewise, the same "rules of the game" can constrain and provide incentives that encourage entrepreneurs to switch from unproductive to productive activity, and ultimately improve the general economic well-being of a society (North, 1990). North (2005) repeatedly refers to the non-ergodic economic world and postulated that the key to improved performance is a mixture of formal rules and informal constraints and an understanding of exactly what combination will produce the desired results both at a moment of time and over time.

Parallel to the advances in the field of economics, institutional theory became an important macro-analytical framework in understanding organisations. Scholars like DiMaggio, Powell, Scott, Meyer, Boli, and Thomas, amongst others, have done substantive work on the institutions-organisations nexus in the context of organisational theory. The new institutional theory in this field focuses more on the cognitive aspects of institutions, on culture as carriers of institutions, as well as legitimacy and embeddedness of organisational fields (McKinley \& Mone, 2003).

\subsubsection{The Nature of Institutions}

This section deals with a brief discussion of the various definitions of institutions; the treatment of institutions as rules, collection action, structures and rules of the game; and the formal and informal institutions. This study builds on North's (1992) view of institutions as described previously. However, the literature is rich with various definitions and typology of institutions as shown in Table 2.1. As there is no common definition, institutions can be defined in the context in which they are being studied (Vatn, 2005). 
Table 2.1. Various Definitions of Institutions

\begin{tabular}{|c|c|}
\hline \multicolumn{2}{|r|}{ Different Definitions of Institutions } \\
\hline Author/Proponent & Definition \\
\hline Veblen $1919^{*}$ & settled habits of thought common to the generality of men \\
\hline Commons $1924^{*}$ & $\begin{array}{l}\text { collective action exercised by different types of organisations in control of } \\
\text { individual action }\end{array}$ \\
\hline Parsons 1940 & $\begin{array}{l}\text { normative pattems which define what are felt to be, in the given society, } \\
\text { proper, legitimate, or expected modes of action or of social relationship }\end{array}$ \\
\hline Mitchell $1950^{*}$ & $\begin{array}{l}\text { convenient term for the more important among the widely prevalent, highly } \\
\text { standardised social habits }\end{array}$ \\
\hline $\begin{array}{l}\text { Berger \& Luckman } \\
1966^{*}\end{array}$ & reciprocal typification of habitual actions \\
\hline Bush 1986* & set of socially prescribed pattems of correlated behaviour \\
\hline $\begin{array}{l}\text { Gohler \& Schmalz- } \\
\text { Bruns } 1988^{* *}\end{array}$ & $\begin{array}{l}\text { pattems of recurrent acts structured in a manner conditioning the behaviour } \\
\text { within the institution, shaping a particular value or set of values and projecting } \\
\text { values in the social system in tems of attitudes or acts }\end{array}$ \\
\hline $\begin{array}{l}\text { Hodgson 1988, } \\
1998\end{array}$ & $\begin{array}{l}\text { social organisation which through the operation of tradition, custom, or legal } \\
\text { constraint, tends to create durable and routinised patterns of behaviour }\end{array}$ \\
\hline $\begin{array}{l}\text { March \& Olsen } \\
1989^{* *}\end{array}$ & $\begin{array}{l}\text { collections of interrelated rules and routines that define appropriate action in } \\
\text { terms of a relation between a role and situation }\end{array}$ \\
\hline Jepperson $1991^{*}$ & $\begin{array}{l}\text { multifaceted, durable social structures with symbolic elements, social activities, } \\
\text { and material resources }\end{array}$ \\
\hline $\begin{array}{l}\text { North 1991, 1992, } \\
2005\end{array}$ & $\begin{array}{l}\text { humanly devised constraints that structure political, economic, and social } \\
\text { interactions }\end{array}$ \\
\hline $\begin{array}{l}\text { Thelen \& Steinmo } \\
1992^{*}\end{array}$ & formal structures and informal rules and procedures that structure conduct \\
\hline Neale $1994^{*}$ & $\begin{array}{l}\text { the regularities of people's actions and their responses to questions about } \\
\text { what they are doing }\end{array}$ \\
\hline Conat \& Dosi 1998 & $\begin{array}{l}\text { formal organisations, patterns of behaviour, and negative norms and } \\
\text { constraints }\end{array}$ \\
\hline Kratke 1999* & $\begin{array}{l}\text { set of conventions and rules that prevail in the economy and are embedded in } \\
\text { the local structure and show a marked regional differentiation }\end{array}$ \\
\hline Scott 2001 & $\begin{array}{l}\text { resilient social structures composed of cultured-cognitive, normative, and } \\
\text { regulative elements and structures to bring order and stability to social life; } \\
\text { provide guidance and resources for acting as well as prohibitions and } \\
\text { constraints on action }\end{array}$ \\
\hline Carlsson 2002 & $\begin{array}{l}\text { normative structures which promote pattems of social } \\
\text { interaction/transactions necessary for the performance of vital societal } \\
\text { functions }\end{array}$ \\
\hline Elsbach, 2002 & $\begin{array}{l}\text { taken-for-granted beliefs that anise within and across organisational groups } \\
\text { and delimit acoeptable and normative behaviour for members of those } \\
\text { groups" }\end{array}$ \\
\hline $\begin{array}{l}\text { Gambarotto \& } \\
\text { Solari } 2005\end{array}$ & social mechanisms such as trust as well as collective actors \\
\hline Ostrom 2005 & $\begin{array}{l}\text { prescriptions humans use to organise all forms of repetitive and structured } \\
\text { interactions }\end{array}$ \\
\hline *ated in Parto 2005 & \\
\hline $\begin{array}{l}\text { *xited in Bogason } \\
2000\end{array}$ & \\
\hline
\end{tabular}




\subsubsection{Institutions as Rules of the Game}

As previously noted, North's $(1990 ; 1992 ; 2005)$ work on institutionalism provides one of the prominent models explaining the nature of institutions and how they influence human activities, particularly economic development. North (1990) argues that institutions are rules or humanly devised constraints that shape human interaction which consequently structure incentives in human exchange, whether political, social, or economic. North (1990) categorically distinguishes institutions (i.e. the rules of the game) from organisations (i.e. the players of the game). This distinction makes institutional analysis clearer than common institutions-analyses which tend to interchange the two concepts.

In developing his theory, North (1990) highlights the presence of uncertainty in economic activities. His theory suggests that to reduce uncertainty experienced by MSMEs, an environment that increases information flow amongst the actors is of prime importance. This environment, according to him, is a construct of rules, norms, conventions, and ways of doing things that define the framework of human interaction. North further elaborated by saying that institutions could take the form of formal rules as well as informal norms and their enforcement characteristics (North, 1990). Consequently, North's theory points out that the quality of these institutions can reduce transaction costs making economic activities more predictable.

North's theory further explains that the viability, profitability and indeed survival of MSMEs typically depend on the existing institutional matrix. This concept of institutional matrix is a kind of institutional web that governs socio-economic activities and determines the opportunities available for MSMEs.

\subsubsection{Formal and Informal Institutions}

North (1990) develops a typology of institutions, namely formal and informal institutions. He defines formal institutions as written policies, laws, and regulations. They also include political rules, economic rules and contracts (North, 2005). North (1992) intentionally included political rules because he believes that these rules oftentimes lead to economic rules although the causality could run both ways. By 
this he means that rights and contracts are specified by political decision-making but the structure of economic interests will also influence the political structure. Moreover, North (1990) argues that these formal institutions exhibit a hierarchy: "from constitutions, to statute and common laws, to specific bylaws, and finally to individual contracts".

On the other hand, informal institutions are defined by North (1990) as codes of conduct, norms of behaviour, and conventions - all these generally emanate from a society's culture (North, 2005). These are mechanisms which run in tandem with formal institutions serving as tools for solving coordination problems. These informal institutions exist to coordinate "repeated human interaction" and more specifically consist of: extensions, elaborations, and modifications of formal rules; socially sanctioned norms of behaviour; and internally enforced standards of conduct (Fiori, 2002).

In general, formal and informal institutions display a dichotomy: the former are created, written and intentional; the latter "evolve over time" and are "unwritten" norms. It is important to note, however, that in North's model, these two sets of institutions are mutually dependent. Informal institutions oftentimes result from formal institutions which in turn, they modify. In this regard, informal institutions evolve as a culture-specific interpretation of formal rules (Welter \& Smallbone, 2005). Table 2.2 presents North's concept of an institutional matrix.

Table 2.2. Institutional Matrix

\section{Characteristics of North's Institutional Matrix}

A. produces a set of organisations

B. establishes a set of rights and privileges

C. provides a stable structure of exchange relationships in both economic and political markets

D. develops an underlying structure that credibly commits the state to a set of political rules and enforcement mechanisms that protect organisations and exchange relationships

E. promotes conformity as a result of some mixture of norm internalisation and coercive enforcement 
The foregoing discussion of the nature of institutions reveals the following significant themes:

a. that institutions could be formal or informal;

b. that the study of institutions traverse the boundaries across social sciences;

c. that institutions provide the structure of socio-economic systems;

d. that institutions constrain and provide incentives to economic activities;

e. that institutions sustain and are sustained by shared conceptions and expectations; and

f. that institutions could be tangible or intangible;

\subsubsection{Institutional Frameworks and Institutional Analysis}

In studying institutions, the terms institutional framework and institutional analysis are commonly used in the literature. An institutional framework is the matrix which defines the ends and shapes the means by which interests are determined and pursued (Scott , 2001). This definition is consistent with North's (1992) concept of an institutional matrix which outlines the rules and players of the game. Formal (informal) institutional frameworks may also be viewed as concrete (consensus) institutional environment (Boland, 1992). Institutional analysis, on the other hand refers to the analytical technique used to examine institutions in various units or levels of analysis.

\subsubsection{Section Summary}

Institutional theory takes a variety of forms in the field of economics, sociology, organisational theory, and political science. Despite the variations, themes converge on the fundamental assumption that organisations are embedded in an institutional framework that exerts constraints and incentives thereby shaping the behaviour or activities of organisations. Institutions may take the form of rules, collective action or structures. In the context of new institutional theory of North (1990), institutions may be formal or informal and separate or distinct from the concept of organisations. To account for the behaviour of firms, institutional analysis in various levels must take into consideration these two types of institutions. Only then can the institutional matrix be understood fully in terms of how this matrix shapes the behaviour of the 
players (e.g. organisations) embedded within in. The relevance of the formal and informal institutional framework as used in study may be made clearer if it is discussed in the context of local economic development. The following section discusses the role of institutions in local economic development in many emerging economies in the Asia Pacific region.

\subsection{Local Economic Development}

Local economic development refers to the process in which sub-national governments (i.e. below that of a country's national government) and/or communitybased organisations are engaged to stimulate or maintain business activity and employment (Blakely, 2002). Underlying this definition is a proactive attempt to manage and shape economic change at the sub-national level. The principal goal of which, as Blakely (2002) argues, is to stimulate "endogenous development" through employment opportunities in sectors that improve the community, using existing human, natural and institutional resources (Krumholz, 1999).

The stimulants of local economic development include: the economic disparities between and amongst regions and cities across a given country (Eberts, 2005); rediscovering place identities and enhancing the competitiveness of the locality in the national and global economy (Wong, 2002); allowing communities to take increased responsibility for determining their own economic and community destinies (Blakely \& Bradshaw, 2002); and the responsibility of local government units for economic development policy-making and implementation as an offshoot of decentralisation of government powers from the national government down to the lower levels of governance in many developing countries (Dewees et al., 2003).

Furthermore, economists note the increasing role of sub-national economies such as that of cities in a country's development. Rather than looking at cities as "sources of decay" as a result of massive urbanization, cities are now viewed as economic assets and fundamental building blocks for national economic competitiveness. However, capitalising on the potentials of sub-national economies such as cities requires a radical approach in economic development planning (Porter, 1995). One approach is 
to develop/nurture an institutional matrix that supports entrepreneurship (Beer, 2002; Brorstrom, 2002; Lam, 2003).

The importance of local economic development is consistent with the idea of pursuing sustainable economic development at the local level. In a review of literature on sustainable economic development, Lindsay (2003) underscores the importance of entrepreneurship, motivation, and community support for entrepreneurial development. Networks within and outside communities are important in the establishment and activities of entrepreneurs, facilitating access to information and knowledge transfer (Lindsay, 2003). Lindsay concludes that in pursuit of "indigenous" economic development, the provision of supportive institutional and policy structures must be addressed both at national and local level with a strong bias towards the holistic needs of the community taking into account the social, cultural, economic, and environmental dimensions. As Beer (2002) points out, local economic development embraces strategies and actions designed to advance the economy or well-being of a locality with aspirations to decrease unemployment, increase competitiveness and profitability of businesses, stimulate business start-ups, improve infrastructure, attract inward investment and increase the quality of life.

Closely related and oftentimes used interchangeably is the term regional economic development. The difference is simply a matter of hierarchy of administrative arrangements that varies in every country, if not a matter of emphasis. The extant literature refers to regional economic development when dealing with any issues pertaining to sub-national economies such as at state or provincial level (Blakely, 2002; Eberts, 2005; Dewar, 1998). Other scholars may refer to local economic development when discussing issues at city or municipal level (Blakely, 2002; Robinson, 1989). Local economic development, in this research, refers to city-level economic development.

A common strand in local economic development implementation is the creation or enhancement of a business-enabling environment in the locality. The focus is on economic revitalization through entrepreneurship. McIntyre (2002) argues there are major flaws and false hopes on the assumption that entrepreneurs often represented 
by small and medium enterprises (SME) will prosper once market economy conditions are laid down. While small businesses are a potentially dynamic force in local economic revitalization and poverty reduction, they seldom are cumulatively successful (at more than subsistence levels) without active institution-building and "support" from outside the small business or SME sector (McIntyre, 2002). Hence, nurturing the business environment is a strategic move to attain the goals of local economic development.

\subsubsection{Section Summary:}

Local economic development has become a preoccupation of government units at sub-national level because of the search for alternatives to economic development given the apparent disparities of economic performance across regions and cities within the same national boundary. Central to local economic development efforts is the role of the local business sector, often times represented by MSMEs. The main theme of the discussion in this section is that the creation of an enabling-business environment is prerequisite to support the growth of MSMEs who are the major players in the local economic development of a city. In this context, the extent of local economic development is oftentimes measured by business climate indices to gauge the attractiveness or investment-worthiness of a locality. Hence the following section presents a discussion of the nature and measurement of business climates.

\subsection{Business Climate}

The use of indices or a set of indicators to determine the degree of risk, uncertainty, and attractiveness of a given place or locality for business investment has become popular since the 1980's (Fisher 2005). These indices or indicators are viewed as proxy of the business climate of a place describing various aspects such as its overall economic development given the place's geo-physical, social, political, and economic conditions (Fisher, 2005). Typical business climate indices gauge a country's overall attractiveness for investment (Fisher, 2005).

Business climate is “the sum total of a place's human and capital resources including infrastructure, public policies, and attitudes that affect the formation and operation of 
business enterprises" (Erickson, 1987). Fisher (2005) defines a business climate as the "capacity or potential of a place (such as a city) for economic growth". Closely related to the concept of business climate and oftentimes used interchangeably is investment climate which refers to the "institutional, policy, and regulatory environment in which firms operate - factors that influence the link from sowing to reaping" (Dollar et al., 2005). It can be observed that investment climate is normally used to describe the business potentials of a locality from the point of view of potential external investors whilst business climate is a term used more by the existing actors in the present business environment - hence a matter of perspective.

Business climate indices have various uses. Potential investors (both local and foreign) may look at the business climate for long-term and short-term investment decisions. The local business sector uses business climate information as a basis for business contraction or expansion. Policy-makers may use the same information to improve the country's overall political and policy infrastructure and develop programs to attract foreign investors.

The underlying factor in these business climate studies is the concept of transaction cost. A business climate study should reveal which place demands the least amount of running a business. This would explain why many business climate studies investigate those quantifiable and easily obtainable measures to describe the attractiveness of a certain locality (Erickson, 1987).

The use of business climate indices is not without its critics, however. Criticisms relate to the nature, operational definition and scope of use of business climate (Blakely \& Bradshaw, 2002; Erickson, 1987), the components of the indices used to measure business climate, and the methodology of data-gathering and timelines of data (Erickson, 1987). Some studies found business climate indices as less useful in explaining economic development (Bierman 1984 in Erickson 1987; Fisher 2005).

By contrast and although scarce, studies examining the usefulness of business climate indices reported results encouraging the use of these scorecards. Business climate indices have been shown to positively correlate with economic growth (Plaut and Pluta 1983 in Erickson 1987). Another study found significant correlations 
between investment climate indices and a country's total factor productivity, wages, and profit rates of the manufacturing industry (Dollar et al., 2005).

Despite these contradictory or ambiguous results on the utility of business climate indices or scorecards, scholars tend to affirm the fact that business climate surveys are useful in sending signals to various sectors of a given place as well as potential external investors (Erickson, 1987; Blakely \& Bradshaw 2002). Erickson (1987) concludes that the usefulness of business climates studies depends on future research examining the concept more empirically, use of better measures as well as sources of data, and to establishing more definitively the causal relationships between business climate and economic growth (or its various aspects/dimensions) over the long run.

\subsubsection{Frameworks of "Business Climate"}

A number of studies have been conducted offering various models and methodologies in explaining those conditions that facilitate or promote business activity in a locality. The common goal is to find out the appropriate mixture of environmental factors that are considered conducive to business.

Bartik (1991) developed the new wave local economic development framework which highlights the role of the government in promoting local businesses. The entrepreneurial environment framework provides an integrated framework of economic, socio-cultural and political factors that influence people's willingness and ability to undertake entrepreneurial activities (Gnyawali \& Fogel, 1994). The British model of local economic development highlights the geo-physical factors and intangible elements such as business culture as essential to economic growth (Wong, 2002). The model of investability of cities considers locational attributes such as availability of public capital, factors of production, socio-cultural factors, and governance factors (Begg, 2002). The entrepreneurial climate model on the other hand, views entrepreneurial development of a place or region as a function of ideas and innovation, human capital and financial capital (Goetz \& Freshwater, 2001). Germany's systemic competitiveness framework emphasises an economy's competitiveness as resting on purposive and intermeshed measures at four system levels (the meta-, macro-, meso-, and micro levels) and a multidimensional guidance 
concept consisting of competition, dialogue, and shared decision-making and integrating the most important groups of actors (Esser, Hillebrand, Messner \& Meyer-Stamer, 1995).

In the Philippines, the framework for city competitiveness identified a number of factors that are crucial for city competitiveness (Magdaluyo et al., 2001). This framework has been applied in the Philippines through the Asian Institute of Management patterned from Switzerland's International Institute for Management Development (IMD) research on competitiveness of countries.

There are, however, major issues associated with these frameworks to date. One is the lack of studies examining the impact of these frameworks in real terms. The validity of the research instruments used in determining the scorecards is another issue. For instance, the work of Magdaluyo et al (2001) on the competitiveness of Philippine cities did not report whether the instrument has been subjected to robust validation process.

Furthermore, these scorecards tend to have an "external investor" orientation such that the information about the local business climate are designed for 'external investors' and lack the emphasis on knowing what the local firms think of the local business climate. Whilst it is important to attract foreign investors, giving due consideration to the local or domestic firms is also crucial to local economic development. Another issue is on the use of aggregate, proxy measures of economic development such as total exports of the state or city as an indicator of a vibrant economy. This may hide the fact that the aggregate export value may have been dominated only by a few large firms. Moreover, the national or country-wide in scope may hide the significant variations amongst the regions, states or cities within a country.

In terms of the validity of these approaches to measure business climate, there appears to be a desperate need to validate these approaches against that of the performance of local firms. Cities that have been rated as "best" across a spectrum of criteria according to the above mentioned approaches need to be examined whether the local businesses in that city feel that the city is indeed "best" for business as 
shown by the performance of their firms. A good business climate should equal good business activities.

Likewise, many business climates may have a strong bias towards readily available data sources, which have public sector tax and regulatory orientation (Erickson, 1987). This makes many appopraches to business climate measurement relatively inadequate to provide strong signal as to the viability of businesses in a certain city.

\subsubsection{Section Summary}

Several models have been developed to describe and explain a business environment or business climate that is conducive for business development. This section presents a number of approaches to characterise the business climate of a country, region or city. Whilst the utility of these approaches remain debatable, the fact remains that measuring the degree to which the external business environment supports the business sector is of paramount concern. The next section presents a discussion of micro, small and medium enterprises (MSMEs). This study argues that an institutional environment should foster a business climate that is supportive of these MSMEs at subnational setting because of their importance to local economic development.

\subsection{Micro, Small and Medium Enterprises (MSMEs)}

Micro, small and medium enterprises (MSMEs) are considered to be one of the principal driving forces in economic development. Szabo (2003) offers the following reasons:

1. MSMES stimulate ownership and entrepreneurial skills;

2. they form the backbone of the market economy;

3. they are flexible and can adapt quickly to changing market demands and supply situations, thus a competitive SME sector is a precondition for sustainable development and respond the demand of globalization;

4. they generate massive employment 
5. they help diversify economic activity and make significant contribution to exports and trade; and

6. they contribute significantly to local development.

In the Asia Pacific region, MSMEs make up over 98\% of all enterprises, provide over $60 \%$ of the private sector jobs and over $30 \%$ of total employment; generate about $50 \%$ of sales or value added and $30 \%$ of direct exports, and account for about $10 \%$ of FDI (APEC, 2002). Hence, MSMEs are hailed as the new engine of economic growth and development amongst emerging economies (Gibb, 2006; Harvie \& Lee, 2002).

Numerous studies have shown the positive contribution of MSMEs in generating employment, increasing aggregate income and the country's overall gross domestic product, as well as enhancing the overall competitiveness of nations (Ayyagari, Beck \& Demirguc-Kunt, 2003; Lundstrom and Stevenson 2005). Hence, the perceived need to develop the MSMEs sector especially in developing countries in the Asia Pacific in order to boost economic development (Hall, 2002).

In addition, the 1999 Global Entrepreneurship Monitor reports that a country's high levels of MSME entrepreneurial activity are positively associated with: the degree to which members of its population perceive opportunity and have the capacity to pursue it both in the areas of motivation and capacity (skill and education); infrastructure suitability (e.g. capital, professional services, R \& D transfer, and flexible labour markets); population growth; high educational levels; and a positive cultural attitude towards entrepreneurship (Reynolds, Hay \& Camp, 1999). The 2006 report showed findings consistent with those of previous years with the conclusion that entrepreneurial behaviour especially amongst MSMEs continues to propel innovation and growth amongst many countries (Bosma \& Harding, 2006), hence, the need to investigate the external institutional factors which are supportive of MSMEs especially at the sub-national level to account for variations in the external institutional environment (Harvie \& Lee, 2002). 


\subsubsection{Philippine Micro, Small and Medium Enterprises (MSMEs)}

Micro, small and medium enterprises (MSME) play a prominent role in the economic landscape of the Philippines. The MSME sector consists of "any business activity or enterprise in industry, agribusiness and or/services, whether single proprietorship, partnership or corporation whose total assets fall within the bounds set by the Small and Medium Enterprise Development Council (SMED) - a multi-sectoral group which is mandated by law to oversee the promotion, growth and development of MSMEs in the country. Table 2.3 shows the different categories of businesses in the country.

Table 2.3. Categories of Philippine Business Establishments

\begin{tabular}{|c|c|c|}
\hline Categories & By Asset Size* & By Employment** \\
\hline Micro Enterprises & up to PhP 3 Million & 1 - 9 employees \\
\hline Small Enterprises & > PhP 3 to PhP 15 Million & 10-99 employees \\
\hline Medium Enterprises & > PhP 15 to PhP 100 Million & 100-199 employees \\
\hline Large Enterprises & > PhP 100 Million & 200 or more employees \\
\hline \multicolumn{3}{|c|}{$\begin{array}{l}\text { source: Philippine Department of Trade and Industry, } 2008 \\
\text { "preferred basis of classification by the MSME Development Council, Phils. }\end{array}$} \\
\hline${ }^{* *}$ preferred basis of classi & by National Sta & \\
\hline
\end{tabular}

The 2003 census of business establishments in the Philippines reports that of the 810,362 total business enterprises in the country, micro, small and medium enterprises (MSME) account for 91.75\%, 7.5\%, and 0.35\% respectively (DTI, 2005). The same report reveals that the MSME sector generated $67.9 \%$ of the total employment, contributed around $30 \%$ of the total sales and value added in the manufacturing industry, and was responsible for $25 \%$ of the country's total exports revenue. These MSME are largely found in sectors such as wholesale and retail, manufacturing, hotels and restaurants, community, social and personal services, and real estate. 


\subsubsection{Current Framework of MSME Development in the Philippines}

The Philippine government has long been recognizant of the importance of the MSME sector in the country's overall industrial growth framework. Hence, Republic Act 6977 or the Magna Carta for Small Enterprises was passed into law in 1991 and amended in 1997 and in 2008 through Republic Acts 8289 and 9501 respectively. This landmark legislation aims to foster a dynamic MSME sector in the country by: (a) setting minimal rules and simplification of procedures and requirements; (b) participation of the private sector in implementation of government policies and programs; and (c) coordination of government efforts on MSME-related issues. This national legislation mandated the formation of Small and Medium Enterprise Development Council (an agency to coordinate all national SME programs), the Small Business Guarantee and Finance Corporation (providing alternative modes of financing to small enterprises), and setting of mandatory loan facility for MSME from government and private financial institutions. Republic Act 7882 was also enacted by Congress in 1995 to recognise and nurture the role of women entrepreneurs in the country.

The Philippine Development Strategy was drafted in 1998 to support further the needs of MSME in the country. This national policy gives emphasis on identifying and investing on priority sectors, developing linkages amongst small and large firms, strengthening technology and R \& D initiatives, and improving access to finance.

The Philippine Export Development Plan (1999-2001) is another policy instrument which aimed to boost the export activities of local firms. In 2000, the national SMEDC finalized its SME development strategy and highlighted the strategies needed to support the MSME sector in terms of finance, information, data banking, marketing, human resources, and technology.

The Philippine Medium Term Development Plan as well as the SME Development Plan for 2003-2004 is put in place to support the aim of having a vibrant MSME sector that provides strong domestic supply base for globally competitive industries. Given the number of micro enterprises, the government enacted the first Countryside and Barangay Business Enterprise Law in 1989 and another similar law in 1998. The 
aim of this law is to support micro enterprises through exemption from the normal business requirements as well as the provision of certain incentives. Barangay is the smallest political unit in the Philippines. In 2002, Republic Act 9178 known as the Barangay Micro Business Enterprise Law was enacted to intensify grassroots entrepreneurship.

The above review on the state of MSME in the country reveals that the national framework for MSME development is well established. Plans and programs seem to point at the right directions. However, questions remain as to how well these plans and programs are put into practice all throughout the archipelago in the context of a decentralised bureaucracy whereby local government units are given an autonomous role in local economic development.

\subsubsection{Challenges faced by MSMEs}

In a review of the macro economic policies and programs on small and medium enterprises in the developing countries in Asia, it was revealed that despite tremendous efforts to help the small business sector, an institutional environment conducive for entrepreneurship leaves much to be desired. There is a need to strengthen the idea of small business competitiveness as a long-term strategy, more private-public sector dialogue, supportive financial system, more focused and streamlined government institutions focused on MSME sector development, presence of strong support network as well as better capacity of government agencies to help the plight of small businesses other than the extension of subsidies (Lallana et al., 2002; Narain, 2003; Skuras et al., 2000). Furthermore, success of these small businesses in the global market place depends heavily on policies and regulatory environments conducive to small business needs in terms of information technology, communication development, transportation, customs, and delivery service regimes (Lall, 2000). Institutional rigidities (such as lack of relevant policies and efficient regulatory framework) are still considered as major obstacles faced by MSMEs in many developing countries in the Asia Pacific region (ADB, 2008; Bosma \& Harding, 2006). 


\subsubsection{Section Summary:}

The preceding discussion shows that MSMEs are key players in economic development especially in developing countries. This is true particularly in the Philippines whereby MSMEs dominate in number the business sector. Hence, MSMEs have been given due recognition in terms of the policy agenda of the country. Several policies and programs have been put in place to support the needs of this sector. Despite the existing policy framework, empirical evidence shows that MSMEs continue to face institutional obstacles that stifle entrepreneurial development.

Decentralisation of governance is one of propellants of local economic development approach that is focused on MSME development. The next section highlights the decentralisation of governance in countries like the Philippines which challenges sub-national government levels to address the institutional obstacles faced by MSMEs as part of the locality's overall local economic development program.

\subsection{Decentralisation of Governance}

One of the underlying reasons why this study focuses on institutional environment at the city level is the wave of political decentralisation taking place in many countries, including the Philippines. Decentralisation, along with local governance, has been found to be a key mechanism that can be and is being used by a number of countries to broaden public sector legitimacy, transparency, and accountability (Brillantes Jr., 2004; Work, 2001). In this context, decentralisation is defined as the restructuring or reorganisation of political, fiscal, and administrative authority by giving sub-national government units more authority and responsibility in governance (Brillantes Jr., 2004; Work, 2001). Decentralisation may take the form of devolution, delegation, deconcentration, and divestment (please see Brillantes Jr., 2004 and Cheema \& Rondinelli, 1983 for more details).

Decentralisation of governance is one of the structural changes that many emerging economies adopt as part of a country's overall socio-economic development strategy (Thornton, 2007). Countries classified as emerging economies are those that are 
undergoing rapid pace of economic development whilst implementing government policies favouring economic liberalisation and the adoption of a free-market system (Hoskisson et al., 2000). In 2000, 51 developing countries and 13 countries in transition (those that underwent reforms from being a centrally-planned economy to a free-market system) were classified as emerging economies (Hoskisson et al., 2000). National governments of many (if not all) of these emerging economies have followed the trend of decentralisation in a variety of approaches to ensure that all parts of the country enjoy a fair share of economic development (Brillantes Jr., 2004).

\subsubsection{The Case of the Philippines}

In the Philippines, there is evidence showing that decentralisation was attempted by the national government as early as in the 1970s (Antipolo, 2001). However, it was the enactment of the Local Government Code in 1991 that sent a strong signal throughout the country that decentralisation was the order of the day. Antipolo (2001) argues that the 1991 Local Government Code is a detailed legal instrument for local autonomy the impact of which was the creation of an enabling environment through self-governance. By unleashing energies and initiatives at the front lines, local autonomy is expected to bring about greater productivity and broaden access to resources and opportunities (Antipolo, 2001; Brillantes, 2004).

The Code decentralises governance by devolving powers and functions to local government units (LGUs) and by strengthening the mechanisms for people's participation in governance. This is based on the judgement that local leaders and residents know their own problems best and can decide on the best way of using resources to meet their needs. However, the implementation of the decentralisation program continues to meet challenges to date, given the increasing number of localities that aim to become municipalities or cities because of the perceived benefits of increases in the localities' revenues and population. 


\subsubsection{Decentralised Local Administrative System}

The Philippine local governance system runs through the country's sub-national level government units composed of 80 provinces, 114 cities, 1496 municipalities and 41,945 barangays. Each local government unit (LGU) is headed by an elected local chief executive (LCE) and governed by an elected legislative body (Sanggunian). Each level of government exercises autonomy over its prescribed functions. Superior jurisdictions (e.g. provinces) exercise some degree of supervision over lower-tier jurisdictions (e.g. municipalities and component cities). Cities and municipalities are established by the Philippine Congress, but must be ratified by local plebiscite. Barangays are established by the elected councils of cities (Sangguniang Panglalawigan) or municipalities (Sangguniang Panglungsod). Highly urbanized cities (those having a minimum population of 200,000 and a minimum annual income of PhP50 million) are, however, independent of provinces, and barangays are subordinate to cities and municipalities (DOF, 2005; RA7160, 1991). A 'barangay' is similar to the New Zealand 'ward' being the smallest electoral district or unit.

The Local Government Code of 1991 is a bold move that empowers local government units. Prior to the enactment of the code, LGU functions were limited to levying and collecting of local taxes, regulation of business activities; and administration of garbage collection, public cemeteries, public markets and slaughterhouses (DOF, 2005). The 1991 code devolved to LGUs the principal responsibility for the delivery of basic services and the operation of facilities in agricultural extension and research, social forestry, environmental management and pollution control, primary health and hospital care, social welfare services, repair and maintenance of infrastructure, water supply and communal irrigation, and land use planning (Brillantes, 2004; RA7160, 1991).

Amongst the sections relevant to the role of local governments in local economic development include the mandate to promote full employment in the locality (sec. 16), operation of business enterprises (sec. 17), tourism development (sec. 17), developing investment support services (sec. 17), partnerships with other nongovernment entities for local enterprise development (sec.35), and formation of multi-stakeholder local development councils (sec 109). 
Despite the enactment of the local government code 15 years ago, questions remain regarding the extent to which the fundamental values of the legislation are in place in the actual running of a local government unit endowed with more power and added responsibilities. Questions on how well the objectives of the code have been achieved in terms of making governance work at the local level continue to receive equivocal replies, hence making it an interesting area of research. Furthermore, the number of cities in the country continues to increase as growing municipalities strive for "city hood" in the hope of increasing government revenues as well as catapulting the locality for industrial and commercial development.

This wave of decentralisation is one of the fundamental bases of this thesis that local institutional building is a prerequisite of local economic development. Setting an institutional matrix that supports the MSME sector as a viable means to achieve economic growth should be at the forefront of the discussion of issues pertaining to decentralisation.

\subsubsection{Section Summary:}

This section presents the underlying reason why the current study focuses on MSMEs at city level. The phenomenon of decentralisation of governance systems across many countries including the Philippines has altered the imperatives of economic development. Regional and city-level government units in the Philippines have gained substantial political, administrative and economic autonomy. However, along with the autonomy come the responsibilities to propel local economic development machinery.

To support the argument that the institutional environment at the sub-national level has immense impacts on MSMEs, the following section presents a discussion of MSME strategic posture being the key organisational variable in the institutions organisation interface. 


\subsection{Strategic Posture of Organisations}

The proposed study recognises the bounded rationality of MSMEs because they are embedded in an institutional framework. Bounded rationality bestows upon MSMEs the capability to exercise strategic choices through the firms' competitive stance such as strategic posture (Simon, 1997; Vandenberg, 1999). The concept of strategic posture as used in this study, is best understood in the context of the theory of strategic choice (Child, 1997).

Strategic choice involves the determination of courses of strategic action an organisation should take (Child, 1997). Strategic choice, in this context is considered as an organisational variable although it is normally exercised by the top management of organisations. The choice is strategic as it involves matters of critical importance to an organisation as a whole. Child (1997) argues that strategic choice enables an organisation to relate to its external environment, set standards of operating performance, and determine the design of the organisation. In Child's (1997) model of strategic choice, the environmental conditions (i.e. liberality, variability, and complexity) shape the strategic choice (i.e. situational analysis, choice of goals, and strategy) of organisations. Strategic choices consequently influence the organisation's scale of operation, technology, structure, and human resources. Ultimately, strategic choices determine the organisation's operating effectiveness and environmental receptivity.

In essence, Child (1990) is suggesting that strategic or organisational choice is still limited in the midst of external institutional constraints. However, organisational responses to the external environment will vary from conforming to resistant, from passive to active, from preconscious to controlling, and from habitual to opportunistic depending on the nature of external pressures (Oliver, 1991). This is consistent with the theory of adaptation positing that despite the perceived highly deterministic nature of the environment of an open system which controls fully and precisely the ends or outcomes that are tolerated, organisational choice is still possible due to the control over and selection of the means (i.e. equifinality) by which the prescribed outcomes may be achieved (Hrebiniak \& Joyce, 1985). 
The preceding arguments imply that strategic choice is the primary link between organisations and their environment, that it focuses on management's ability to create, learn about, and manage the organisation's environment, and that it encompasses the multiple ways that organisations respond to environmental conditions (Judge \& Zeithaml, 1992).

More prominent scholars who have done extensive work in this field include Miles and Snow (1978) who developed a typology of firms based on their organisational responses to the external environment, Hrebiniak and Joyce (1985) who proposed a quadratic approach in analysing strategic choice vis-à-vis environmental determinism, Miller and Friesen (1982) who developed the two models of strategic momentum, Covin and Slevin (1989) who developed the concept of strategic posture, and Lumpkin and Dess (1996) who developed further the entrepreneurial orientation construct which was part of the strategic posture construct of Covin and Slevin (1989).

This study adopts Covin's and Slevin's (1989) strategic posture as a manifestation of the strategic choice of MSMEs. Extensive discussion of this concept is presented in the next chapter on conceptual framework and hypothesis development.

It must be noted that strategic posture has been used in a number of studies but took different names although the conceptual meaning and dimensions remain essentially the same. A number of studies have termed it as: entrepreneurial orientation (i.e. shortcut to entrepreneurial strategic posture) (Madsen, 2007; Marino, Strandholm, Steensma \& Weaver, 2002; Lumpkin \& Dess,1996); corporate entrepreneurship (as applied to corporate entities and multinational firms) (Barret, Balloun \& Weinsten, 2000; Luo, Sivakumar \& Liu, 2005a; Morris, Davis \& Allen, 1994; Wincent, 2005); and entrepreneurial proclivity (Griffith, Noble \& Chen, 2006; Matsuno, Mentzer \& Ozsomer, 2002). Despite its widespread use, there appears to be no published study on various forms of institutions that influence strategic posture and its alternative terms. 


\subsubsection{Section Summary}

Strategic posture is one way of operationalising strategic choice. The contention is that strategic posture is the link between the organisation and its external environment. A number of empirical studies were presented describing the way strategic choice is exercised as well as the various forms and dimensions of strategic posture.

The following section extends the institutional environment - strategic posture linkage by discussing the concept of organisational performance. In effect, the study investigates whether the institutional environment affects the firms' strategic posture, which then shapes the firms' overall business performance.

\subsection{MSME Organisational Performance}

This section presents a brief discussion of the domains of performance measurement, models of organisational effectiveness, organisational performance, and measures of performance.

\subsubsection{The Domains of Performance Measurement}

Organisational effectiveness is the broader domain of organisational performance that is reflected in many conceptual and theoretical discussions in the strategic management and organisation theory literature (Venkatraman \& Ramanujam, 1986). Organisational effectiveness has been defined in a variety of ways including: the attainment of goals; goal attainment without imposing strains on the organisational system; exploitation of the organisation's environment for resources; and in terms of meeting criteria set by the multiple constituencies of an organisation. (Zammuto 1982). This variety of definitions stems from the different approaches in the characterisation of an effective organisation. 
2.7.2. Models of Organisational Effectiveness

The literature on organisation effectiveness shows the five popular models or approaches to measuring organisational effectiveness. Whilst there are other (perhaps equally popular) models, it is argued that these five models capture well the current themes on the topic (Cameron, 2005). Table 2.4 shows these models along with their brief descriptions.

Table 2.4. Approaches to Organisational Effectiveness Measurement

\begin{tabular}{c|l}
\hline Approach & \multicolumn{1}{c}{ Theme } \\
\hline Goal Model & $\begin{array}{l}\text { attainment of goals (official and } \\
\text { operative goals) (Campbell, 1977; } \\
\text { Price, 1968) }\end{array}$ \\
\hline $\begin{array}{c}\text { Resource Dependence/ } \\
\text { Internal Congruence Model }\end{array}$ & $\begin{array}{l}\text { extent to which the firm acquires } \\
\text { needed resources from the wider system } \\
\text { or environment (Pfeffer \& Salancik, } \\
\text { 1978; Yuchtman \& Seashore, 1967) }\end{array}$ \\
\hline Multiple Constituency Model & $\begin{array}{l}\text { consistent, efficient \& strain-free } \\
\text { (Lewin \& Minton, 1986) }\end{array}$ \\
\hline the interests of various stakeholders of \\
thuman Relations Model & $\begin{array}{l}\text { engagement of organisational } \\
\text { members/collaborative organisational } \\
\text { climate (Argyris 1960 as cited in } \\
\text { Cameron 2005) }\end{array}$ \\
\hline
\end{tabular}

Cameron (2005) summarised that these models have different emphases: goal model stresses productivity, aggressiveness and achievement; systems-view stresses adaptation to external environment as well as innovation; internal congruence stresses efficiency and control; multiple constituency stresses boundary spanning activities as well as customer focus; and human relations model stresses collaboration and harmonious relations amongst organisational members. 
Cameron (2005) concludes that because no conceptualisation of an organisation is comprehensive, no conceptualisation of an effective organisation is comprehensive enough. Hence, organisational effectiveness is mainly a problem-driven construct rather than a theory-driven one. This implies that measuring effectiveness depends on a wide array of factors including the nature of organisation, purpose of evaluation, timeframe, level of analysis, and reference of judgement.

\subsubsection{Organisational Performance}

Organisational performance, as used in this study is considered a subset of the organisational effectiveness construct consistent with the argument of Venkatraman \& Ramanujam (1986). Another subset of this framework are the two more measurable layers of performance measurement domains: business performance comprising operational and financial performance; and the financial performance domain.

According to Venkatraman \& Ramanujam (1986), the business performance domain places emphasis on indicators of operational performance along with the well-known financial performance indicators. Measures of functional effectiveness, technological efficiency and other input or process-related measures of effectiveness and efficiency are subsumed under this domain (Venkatraman \& Ramanujam, 1986).

Finally, organisational performance can be measured by outcome-based indicators of financial activities being the ultimate manifestations of the achievement of the goals of an economic entity: the business firm (Venkatraman \& Ramanujam, 1986). These goals commonly assume the form of sales, profit, and returns on investment as well as other financial rations articulating the financial returns to the business venture.

\subsubsection{Measures of Performance}

Despite the fact that there is no consensus on the development of specific measures that accurately represent the complexity and multi-faceted nature of organisational 
performance, several studies may prove useful in developing measures of performance appropriate for MSMEs.

White (1996) succinctly summarised the approach to performance measurement of firms by coming up with four factors through which a firm's performance could be assessed. Table 2.5 shows this approach. The data to be used in assessing performance may come from sources external to the firm. Records maintained by government, research organisations, trade associations, award-giving bodies or certifying agencies could provide a variety of information about industries and/or firms within those industries. Obviously, the organisation is itself the ultimate source of information about how it performs by looking at operational (e.g. plans, programs, audit reports, etc.) or financial documents (i.e. financial statements).

Whilst there are data that can be culled straight from documents which are considered objective in nature or based on observable facts and figures, the difficulty and historical limitations of using objective data may warrant the use of data based on the best judgements, perceptions or opinions of individuals or groups who have the knowledge and expertise to give them. In the absence of observable facts, the judgement of an industry expert or the owner or manager of a firm could be an alternative source of information.

Table 2.5. Approaches to Performance Measurement

\begin{tabular}{cc}
\hline Classification & Foci of Measurement \\
\hline Data Source & $\begin{array}{c}\text { internal to firm } \\
\text { external to firm }\end{array}$ \\
\hline Data Type & $\begin{array}{c}\text { subjective (perception/opinion) } \\
\text { objective (observable facts) }\end{array}$ \\
\hline Reference & benchmark (comparison with others) \\
& self-referenced \\
\hline Orientation & inputs \\
& process \\
& outcome \\
\hline adapted from: White (1996)
\end{tabular}


Likewise, reporting the performance-related information may be presented as standalone or self-referenced information. Alternatively, the information could be presented by comparing it to competitors, the industry average, or to some other standards that may well serve as benchmarks of performance.

Furthermore, assessment of performance may be done by looking at the quality of inputs, process, or outputs of the firm. Input-oriented measures may look at the quality of its human resource as an indicator of performance. Process-oriented measures look at how well the organisation transforms its resources into products or services. Ultimately, the firm's performance could be measured in terms of its output: the achievement of the goals of the firm such as generating above-average returns for the business and satisfying its customers. Variations in the use of performance measures could be accounted for by several factors such as the nature and purpose of investigation, type and size of the firm/s, nature of industry, amongst others (White, 1996).

The ultimate measures of performance are the output of business operations. A classic typology of business performance measurement is the dichotomy of the financial domain and operational (non-financial) domain (Venkatraman \& Ramanujam, 1986). Results of business performance can be measured in terms of financial indicators which reflect the fulfilment of economic goals of the firm. These indicators include sales growth, profitability, return on investment and earnings per share. On the other hand, performance can be measured using operational indicators such as market share, new product introductions, and marketing effectiveness, amongst others. Venkatraman and Ramanujam (1986) likewise explain that these two types of measurement may vary depending on whether primary or secondary sources are used.

Another classification is to categorise measures as either accounting based, marketbased, or subjective measures of performance (Rowe \& Morrow, 1999). Accountingbased measures rely on the traditional facts and figures culled from financial statements. Typical measures include volume of sales, profit, and the wide array of financial ratios such as return on investment (ROI), return on sales (ROS), return on 
equity (ROE), plus measures used to gauge the liquidity and financial leverage of a business. Market-based measures gauge the value of future streams on income. These include Tobin's q, Jensen's, Sharpe's, and Treynor's market-return measures (Dubofsky \& Varadajan, 1987). Rowe and Morrow (1999) completed their typology by adding the subjective measures of performance which are often used in lieu or in tandem with objectives measures. Table 2.6 shows a number of SME- oriented studies using different measures of organisational performance.

In addition to the measures described in Table 2.6, a number of other studies made use of measures that fall within the domain of operational performance such as: customer retention (Pelham, 2000); process and efficiency improvements (Gomes, Yasin \& Lisboa, 2006); product or service quality (Aragon-Sanchez \& SanchezMarin, 2005; Delaney \& Huselid, 1996; Lopez, Peon \& Ordas, 2005; Mabey \& Gooderham, 2005; Venkatraman \& Ramanujam, 1986); and customer satisfaction (Delaney \& Huselid, 1996; Mabey \& Gooderham, 2005). It is also important to note that many of these studies utilised sources of self-reported data and/or subjective data bsed on perceptions relative to one's goals or other firms in the same business, competitors or the industry as a whole.

\subsubsection{Section Summary}

Organisational performance is a multi-layered and multi-dimensional concept. It is best understood using the concept of organisational effectiveness which could be viewed under a variety of approaches. Measures of performance can be financial or non-financial and methods of assessment can be objective and subjective means. Likewise, the problem-driven nature of organisational performance as a construct suggests that the purposes and context of the investigation shall primarily determine the selection of measures of organisational performance. 
Table 2.6 Measures of Organisational Performance

\begin{tabular}{|c|c|c|c|}
\hline Measures & Data Types & Reference & Authors \\
\hline \multirow[t]{2}{*}{$\begin{array}{l}\text { Sales } \\
\text { Revenue }\end{array}$} & subjective & self-referenced & $\begin{array}{l}\text { (Bhaskaran, 2006; Chaston \& Mangles, 1997; } \\
\text { Hsueh \& Tu, 2002; Lerner \& Almor, 2002; } \\
\text { Meijaard, Brand \& Mosselman, 2005; Pelham, } \\
\text { 2000; Spillan \& Parnell, 2006; Wang \& Ang, } \\
\text { 2004; Westhead \& Howorth, 2006; Wijewardena, } \\
\text { De Zoysa, Fonseka \& Perera, 2004) }\end{array}$ \\
\hline & objective & self-referenced & (Mazzola \& Bruni, 2000) \\
\hline \multirow[b]{2}{*}{$\begin{array}{l}\text { Gross/Net } \\
\text { Profit }\end{array}$} & \multirow[b]{2}{*}{ subjective } & benchmarked & $\begin{array}{l}\text { (Caloghirou, Protogerou, Spanos \& } \\
\text { Papagiannakis, 2004; Hadjimanolis, 2000; Keh et } \\
\text { al., 2006; Keskin, 2005) }\end{array}$ \\
\hline & & self-referenced & $\begin{array}{l}\text { (Bhaskaran, 2006; Bracker \& Pearson, 1986; } \\
\text { Hsueh \& Tu, 2002; Lerner \& Almor, 2002; } \\
\text { Meijaard et al., 2005; Pelham, 2000; Wang \& } \\
\text { Ang, 2004; Westhead \& Howorth, 2006; } \\
\text { Wijewardena et al., 2004) }\end{array}$ \\
\hline \multirow{3}{*}{ Market Share } & \multirow{2}{*}{ subjective } & self-referenced & $\begin{array}{l}\text { (Liao, 2006; Pelham, 2000; Spillan \& Parnell, } \\
\text { 2006; Wang \& Ang, 2004; Yan \& Zhang, 2003) }\end{array}$ \\
\hline & & benchmarked & $\begin{array}{l}\text { (Craig \& Dibrell, 2006; Hadjimanolis, 2000; Keh et } \\
\text { al., 2006; Keskin, 2005) }\end{array}$ \\
\hline & objective & self-referenced & (Smith \& Cooper, 1988) \\
\hline \multirow[b]{2}{*}{$\begin{array}{l}\text { New Products } \\
\text { or Services }\end{array}$} & \multirow[b]{2}{*}{ subjective } & self-referenced & (Pelham, 2000) \\
\hline & & benchmarked & $\begin{array}{l}\text { (Aragon-Sanchez \& Sanchez-Marin, 2005; } \\
\text { Keskin, 2005; Sarkar, Echambadi \& Harrison, } \\
\text { 2001; Wolff \& Pett, 2006; Zehir, Acar \& } \\
\text { Tanriverdi, 2006) }\end{array}$ \\
\hline \multirow[t]{3}{*}{$\begin{array}{l}\text { Growth in } \\
\text { Sales }\end{array}$} & \multirow[t]{2}{*}{ subjective } & self-referenced & $\begin{array}{l}\text { (Bhaskaran, 2006; Hsueh \& Tu, 2002; Lee \& } \\
\text { Tsang, 2001; Liao, 2006; Sadler-Smith, } \\
\text { Hampson, Chaston \& Badger, 2003; Spillan \& } \\
\text { Parnell, 2006; Wang \& Ang, 2004; Watson, 2006; } \\
\text { Westhead \& Howorth, 2006; Wijewardena et al. } \\
\text { 2004; Yusuf \& Saffu, 2005) }\end{array}$ \\
\hline & & benchmarked & $\begin{array}{l}\text { (Craig \& Dibrell, 2006; Hadjimanolis, 2000; Keh et } \\
\text { al., 2006; Wolff \& Pett, 2006; Zehir et al., 2006) }\end{array}$ \\
\hline & objective & self-referenced & (Carlsson 2002) \\
\hline $\begin{array}{l}\text { Growth in } \\
\text { Profit }\end{array}$ & subjective & self-referenced & $\begin{array}{l}\text { (Bhaskaran, 2006; Lee \& Tsang, 2001; Liao, } \\
\text { 2006; Nguyen \& Bryant, 2004) }\end{array}$ \\
\hline \multirow{2}{*}{$\begin{array}{l}\text { Growth in } \\
\text { Market Share }\end{array}$} & \multirow{2}{*}{ subjective } & self-referenced & (Wang \& Ang, 2004; Yusuf \& Saffu, 2005) \\
\hline & & benchmarked & (Zehir et al., 2006) \\
\hline \multirow{3}{*}{$\begin{array}{l}\text { Returns on } \\
\text { Investment, } \\
\text { Assets, Equity }\end{array}$} & \multirow{2}{*}{ subjective } & self-referenced & $\begin{array}{l}\text { (Liao, 2006; Pelham, 2000; Spillan \& Parnell, } \\
\text { 2006; Westhead \& Howorth, 2006) }\end{array}$ \\
\hline & & benchmarked & (Craig \& Dibrell, 2006; Wolff \& Pett, 2006) \\
\hline & objective & self-referenced & $\begin{array}{l}\text { (Bharadwaj 2000; Aragon-Sanchez and Sanchez- } \\
\text { Marin 2005)Bharadwaj 2000; Aragon-Sanchez } \\
\text { and Sanchez-Marin 2005) }\end{array}$ \\
\hline
\end{tabular}




\subsection{Summary of Research Gaps}

The study aims to address the research gaps listed below. These research gaps emanate from the extant literature and are considered specifically relevant to the relationships of the three major variables of the study: institutions, strategic posture, and organisational performance of MSMEs. It was previously noted that there remains sizeable research gap in understanding how institutions matter, this study explores this research gap further by reviewing the literature on the institutionsstrategic posture-organisational performance nexus in an MSME, emerging economy, and sub-national setting. In effect, these research gaps are considered important in understanding why and how the three major variables relate to one another in a specific context.

\section{Lack of Emphasis on Institutions in Strategy Research}

Institutions are often treated as mere background in the study of organisational strategy. Industry factors and firm resources and capabilities are normally given major emphasis to explain the strategic configurations of firms as popularised by the industrial organisation (I/O) theory (Porter, 1980) and the resource-based view (RBV) of the firm (Barney, 1991). Peng et al (2008 p. 922)) noted that 'scholars rarely looked beyond the task environment to explore the interaction among institutions, organisations and strategic choices'. Those that did study institutions focused on market-based institutions and relegated in the background the wider institutional environment which may have significant bearing on the firms' strategic choices that are articulated in the firms' strategic posture (Peng et al., 2008).

This partial treatment of institutions results in an inadequate understanding of the strategic posture and performance of firms which is even more evident when probing into emerging or developing economies characterised by intense institutional heterogeneity and variability (Peng et al., 2008). Hence, the current research agendum is to use the frameworks of institutional theory to examine the strategic behaviour and performance of firms located in developing or emerging economies like the Philippines (Bruton \& Lau, 2008; Wan, 2005; Wright et al., 2005). Efforts 
supporting this research agendum can complement the $\mathrm{I} / \mathrm{O}$ theory and $\mathrm{RBV}$ in putting the strategy tripod in a firmer ground (Peng et al., 2008)

\section{Lack of Understanding on How Institutions Directly Relates to MSMEs}

At the most fundamental level, the current study attempts to bridge the research gap on the direct link between institutions and MSMEs. Little systematic knowledge exists about the environmental determinants of MSMEs' strategic behaviour at subnational levels, such as state or city level. Previous studies are deemed fragmented and lacking in focus as they fail to establish any link between the needs of MSMEs and on how the external environment can help in fulfilling those needs (Bruton et al., 2008). This fragmented and macro-economic approach can be manifested by studies dealing with how well the external environment at the national level shape economic productivity and growth (as surrogate and aggregate measure of productivity of business firms) (Davidsson and Henrekson 2002; Ahmadi 2003; Dollar et al. 2005; Wan 2005; Welter and Smallbone 2005). A plausible explanation of this research gap could be the "formidable task of constructing convincing tests of hypothesis that the institutional set-up is an important determinant of firm growth and entrepreneurial activity" (Davidsson and Henrekson 2002, p. 82).

\section{Lack of Explanations on How Institutions Relate to Strategic Posture}

This study attempts to expand current understanding of the external institutional factors as they relate to strategic posture. Whilst strategic posture, as a construct that operationalises the firms' strategic choices, has been studied in various contexts (e.g. Covin \& Slevin, 1989; Jantunen, Puumalainen, Saarenketo \& Kylaheiko, 2005; Jogaratnam, Tse \& Olsen, 1999), a review of the literature did not reveal any study linking an integrated set of formal and informal institutional factors to the strategic posture of MSMEs. If institutions are the rules of the "game" of an economy, it is important to determine how these rules shape the strategic posture of MSMEs being major players in that game. Furthermore, this study hopes to enrich the debate on the two opposing views of environmental determinism which suggests that external environmental factors such as institutions determine the actions of firms and strategic choice as manifested in strategic posture which suggests that despite 
external environmental constraints, firms remain capable of exercising bounded rationality to pursue risk-taking, innovative, and proactive endeavours. The review of the literature reveals that no study has ever been published on the link between institutions (formal and informal) and strategic posture.

\section{Lack of an Integrated Institutional Framework of Analysis}

Studies on the link between institutions and small businesses tend to be fragmented such that these studies examine only one or few institutional factors as well as the corresponding impact on just one or a few aspects of small firm performance (Veciana et al. 2002; Wattanapruttipaisan 2002; Wijewardena et al 2004; Wilkinson 2006). Typical studies include: the impact of finance on the growth of firms (Cook 2001; Becchetti and Trovato 2002); impact of social capital on firm innovation (Cooke and Wills 1999; Davidsson and Honig 2003); impact of external business advice on performance of firms (Bennett and Robson 1999; Berry and Sweeting 2006); impact of technical assistance on the growth of firms (Brown et al. 2005); and impact of government programmes on the new product development function of SMEs (Siu, Lin, Fang and Liu 2006).

This study attempts to overcome this fragmentation of empirical research by identifying an integrated set of both formal and informal institutions and how these institutions relate to firm-level phenomena.

5. Over-emphasis on the Legalistic-Political (or Formal) Approach of Institutional Analysis

Another research gap is founded on the tendency of empirical studies to reduce the concept of institutions into legal and political elements such as laws, policies, and government programs and examined in terms of their influence on small firms (Henrekson and Johansson 1999; Co 2004; Siu 2005; Wan 2005). This treatment of institutions is rather flawed as shown in the review of literature on the rich traditions of institutionalism. Hence, this study shall examine institutional influences on small businesses beyond what legal-political orientated research has covered in the past. 
This is achieved by considering the set of informal institutions in addition to the formal institutions.

\section{Lack of Emphasis on Sub-national Institutional Analysis}

The advent of decentralisation and increasing importance of local economic development planning in many developing or emerging countries has bestowed upon the sub-national localities (such as cities) and their corresponding local government units immense fiscal, economic, and political autonomy (Harding, 2005; Legaspi, 2000; Work, 2001). These trends that are taking place in a geographically-dispersed and ethnically-diverse countries like the Philippines or Indonesia may explain the possible variations in the formal and informal institutional characteristics of regions and cities within the same national boundary (Begg, 1999; Meyer \& Nguyen, 2005). Hence, typical country-wide institutional analyses often expressed in the form of business or investment climate scorecards and competitiveness indices may prove inadequate to capture the institutional heterogeneity within a single country (Ando, 2007). Current research agenda should focus more on sub national-entities such as cities being considered strategic players in national socio-economic development of developing countries (Begg, 2002; Ma \& Delios, 2007; Porter, 1995). It is logical to argue that it is important to study MSMEs at the city level taking into account how the city's institutional profile influence MSME strategic posture.

7. Lack of a Model of MSME Institutional Development in a Developing Country Setting

Most previous studies on the study of regional or city factors affecting the growth of small firms tend to focus on Western economies particularly in the US and UK (Okamuro and Kobayashi 2006; Goetz and Freshwater 2001; Begg 2002; Kirby and Watson 2003; Audretsch and Thurik 2004). Whilst these studies serve as reliable references, the current study could begin a trajectory of research on MSME development amongst cities and regions in the 'developing or emerging world' with a focus on institutions. 


\section{Lack of Emphasis on Micro-enterprises}

This study also addresses a significant issue on the use of the term SMEs in various studies. A number of studies consistently argued that SMEs comprise the biggest number of business entities in many economies (Dhaliwal 2000; Cook 2001; Hill 2001; Harvie and Lee 2002; Co 2004). However, in the Philippines for instance, a review of statistics on trade and investment reveals that small and medium firms comprise roughly 8 percent only of the total number of registered firms. The largest number (more than 90\%) of registered businesses is actually "micro" in nature. Whilst this may be a matter of definition, there are studies which have clearly proclaimed the dominance in number of SMEs when in fact, micro-businesses were not part of their study (Wattanapruttipaisan 2002; Co 2004; DTI 2005; Tambunan 2005). This makes previous studies on Philippine SMEs misleading as the micro enterprises were not taken into account whilst making proclamations on the dominance (in number) of SMEs in the national economy. 


\section{CHAPTER 3. CONCEPTUAL FRAMEWORK}

\section{AND HYPOTHESIS DEVELOPMENT}

This chapter presents the conceptual framework of the study and the associated hypotheses on the relationships of the constructs under investigation. Figure 3.1 shows the road map of this chapter.

Figure 3.1. Road Map of the Chapter

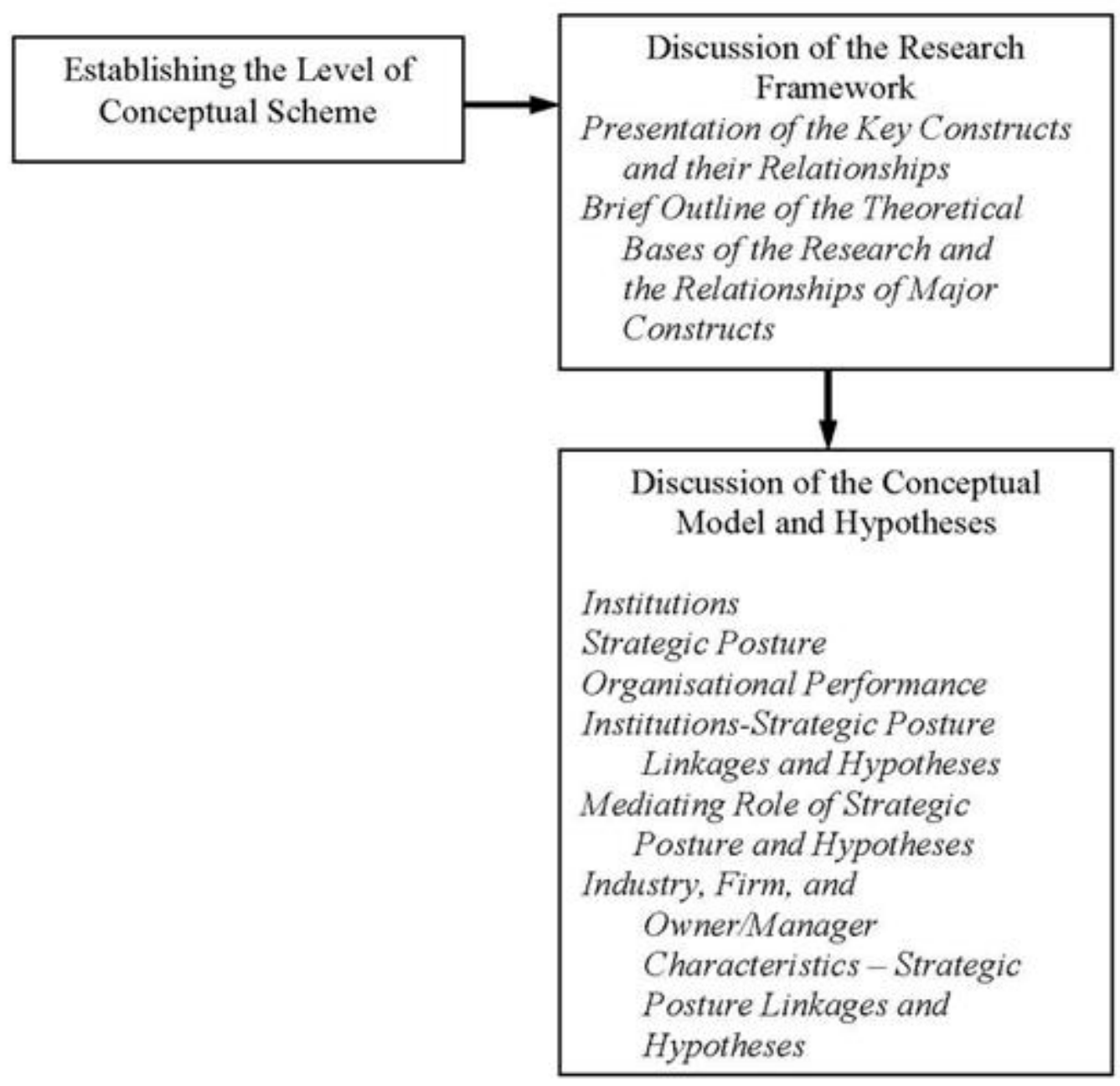




\subsection{Levels of Conceptual Schemes}

The development of the conceptual framework of the study follows the standards recommended by Parsons and Shils (1951) and Ostrom (2005) on the levels of systematisation of conceptual schemes and the use of models, theories and frameworks. A good conceptual framework presents propositions or hypotheses to summarise explanations and predictions regarding the relationships or interactions of variables. For the sake of brevity, it is sufficient to state that the development of the conceptual framework and ultimately, the conceptual model and its related hypotheses adheres with these standards.

\subsection{The Research Framework}

The basic research framework of this study is anchored on North's (1990, 1991, 1992, 2005) new institutional theory in its contemporary form to describe and explain the perceived institutional environmental dimensions of MSMEs' strategic posture. As shown at the left hand side of Figure 3.2, the perceived environment of

Figure 3.2. Schematic Diagram of the Research Framework

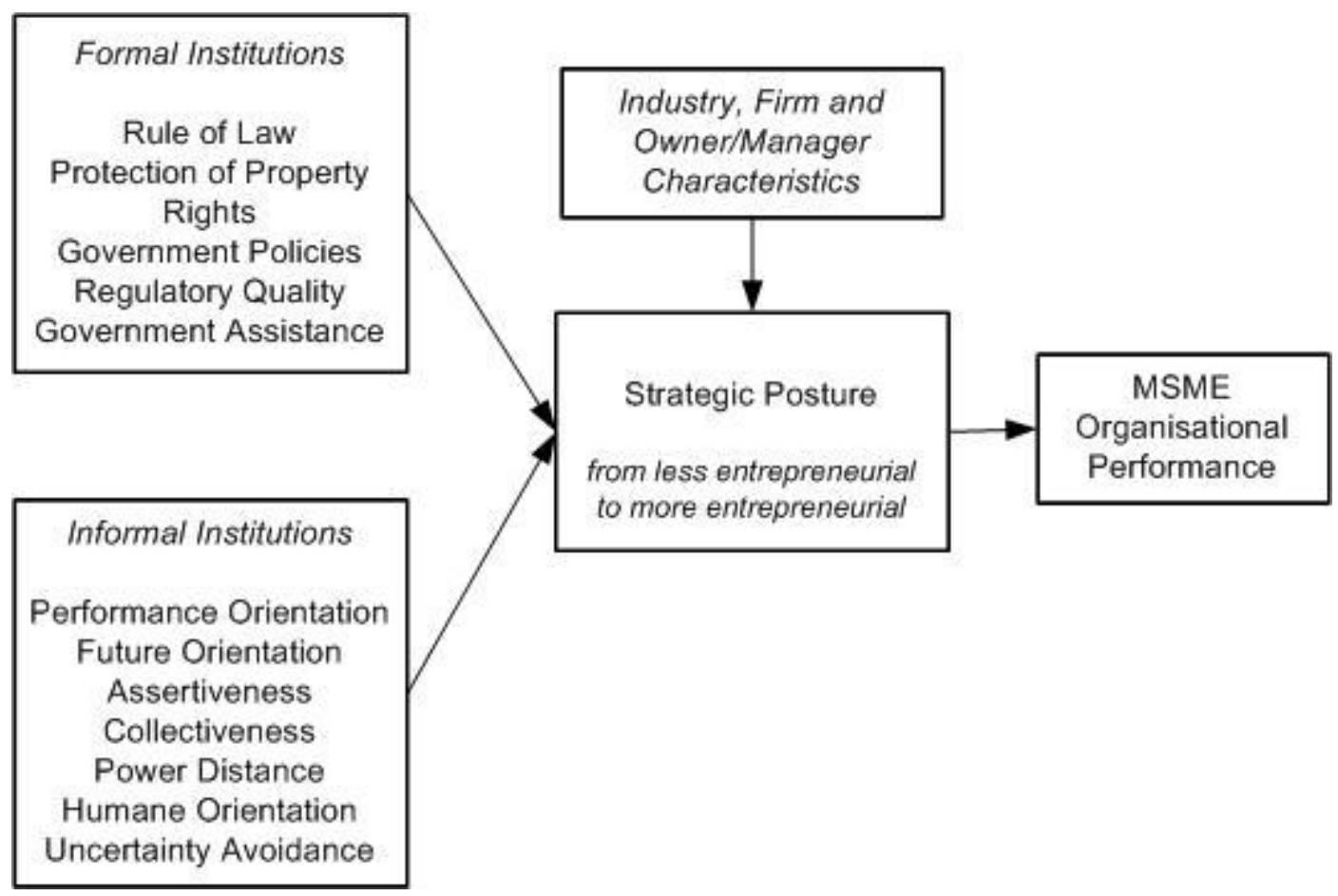


MSMEs, referred to as the perceived local institutional environment is composed of two sets of forces: formal and informal institutions. These two sets of institutions provide the structure of business activities by determining the incentives and constraints faced by MSMEs. In general terms, these perceived institutional forces constitute the 'rules of the game' that shape the playing field of economic activities.

The research framework also illustrates the strategic posture and performance of MSMEs. A major objective of this study is to determine if MSME owners'/managers' perceptions of the formal and informal institutions shape their strategic posture. It is expected that a positive local institutional environment of the city as perceived by MSME owners/managers will have positive influence on the firms' proactive, innovative and risk-taking activities, which will subsequently increase their level of organisational performance. Likewise, strategic posture is also examined in terms of how it is influenced by a set of managerial, firm and industry characteristics.

The framework focuses on perceived institutional environment based on the theory of enacted environment (Weick, 1988), the cognitive perspective of external environment (Lenz \& Engledow, 1986), the proximal model of environment (Jessor $\&$ Jessor, 1973), and the model of managerial perception-strategic behaviour linkage (Anderson \& Paine, 1975). The main concern is MSME managers' or owners/managers' perception of the environment as opposed to the "actual" characteristics of the environment - a distinction that must be made clear in any study concerning environment-organisation nexus (Bourgeois III, 1980).

The investigation of the link between institutions and strategic posture is guided by institutional theory (North, 1990), strategic choice theory (Child, 1997), theory of organisational adaptation (Hrebiniak \& Joyce, 1985), environmental management theory (Zeithaml \& Zeithaml, 1984), resource dependency theory (Pfeffer \& Salancik, 1978), theory of environmental munificence (Castrogiovanni, 1991), transaction costs theory (Rao, 2003; Williamson, 1979), theory of enabling authority (Leach, Stewart \& Walsh, 1994), the theory of planned behaviour (Ajzen, 1991), cultural theory (van Heffen \& Klok, 2003), organisational legitimacy theory (Deephouse \& Carter, 2005; Suchman 1995), and the resource-based view of the 
firm (Barney, 1991). The fundamental argument is that resource-constrained MSMEs exercise their strategic posture as a form of responding or adapting to, and managing their dependence on the munificence of the external institutional environment.

The link between strategic posture and organisational performance is examined in the light of the resource based view of the firm (Barney, 1991), strategic orientation theory (Miles \& Snow, 1978), contingency theory of business strategy (Hofer, 1975), and the industrial organisation view (Porter, 1980). The main argument is that the strategic posture of MSMEs is an antecedent of the firms' overall organisational performance.

The link between a set of managerial, firm and industry characteristics and strategic posture is also explored as suggested by the upper echelon theory (Hambrick \& Mason, 1984), model of manager-strategy linkage (Gonvindarajan, 1989), explanations on the organisational context of strategies (Falbe, Dandridge \& Kumar, 1998), and the industrial organisation (i.e. industry-conduct-performance link) view (Hawanini, Subramanian \& Verdin, 2003; Porter, 1980). The argument is that the demographic profile of the MSME owners/managers, organisational features and industry factors are likely to influence the level of entrepreneurial strategic posture these MSMEs may take on.

In this study, strategic posture acts as a mediating variable between institutions and MSME organisational performance. This mediating role is proposed and shall be analysed based on the conditions required to perform mediation analysis (see Baron \& Kenny, 1986; MacKinnon, Lockwood, Hoffman, West \& Sheets, 2002). The population ecology model (Hannan \& Freeman, 1977) and theory of environmental munificence (Castrogiovanni, 1991) provide the theoretical bases of the mediating role of strategic posture in the institutions-organisational performance link. Details of this proposed mediating role of strategic posture are discussed later in the chapter.

\subsubsection{The Local Institutional Environment}

The review of the literature on formal and informal institutions as well as the wide variety of conceptual models and frameworks previously published form the 
foundation in the development of the conceptual framework proposed in this study. Table 3.1 shows a number of studies which investigated formal and informal institutions in their various manifestations. Some of these studies empirically examined institutions as they relate to concepts such as entrepreneurship in general (Adams, 1993; Busenitz, Gomez \& Spencer, 2000), economic growth and development (Fergusson, 2006; Rodrik et al., 2004), innovation and small business start up (Carlsson, 2002; Siu et al., 2006), growth and success (Aidis, 2005; Fogel et al., 2006; Nkya, 2003) whilst other studies provide theoretical or conceptual discussion (Leaptrott, 2005; Rutherford, 2001).

Studies of formal institutions tend to show similarities in terms of operationalising the specific constructs. Many studies on informal institutions examined social capital as well as various aspects of national culture as manifestations of the informal institutional framework (e.g. Hill, 1995; Pejovich, 1999). Social capital is referred to in many studies as essentially synonymous with informal institutions which provides social structure - regulating the actions of those within the structure (Coleman, 1988). Likewise, social or informal networks have attracted much attention in the literature particularly as they relate to the emergence, activities and success of entrepreneurs.

Noticeable in these studies are the operationalisations of these institutions that tend to overlap with one another. Typical studies of national culture subsumed family ties and support, social networks, and risk aversion (Hill, 1995; Nkya, 2003; Tabellini, 2005). Studies of business culture tend to include social networks, and business community norms and values (Assaad, 1993; Peng \& Heath, 1996).

\subsubsection{The Use of Multidimensional Constructs}

A classification system is a set of specified rules for describing the structure of and relations among a set of objects drawn from some domain that permits similar units to be assigned to a smaller number of categories (Law, Wong \& Mobley, 1998). Fleishman and Quaintaince (1984) in Law et al., (2002) declare that the most powerful determinant of a classification system is its intended purpose. 
Table 3.1. Selected Empirical Studies on Institutions

\begin{tabular}{|c|c|c|}
\hline Authors & Formal Institutions & Informal Institutions \\
\hline (Aidis, 2005) & tax policies, legislation & $\begin{array}{l}\text { corruption, bureaucratic processes, } \\
\text { business-government relations }\end{array}$ \\
\hline (Assaad, 1993) & $\begin{array}{c}\text { contracts, training programs, trade } \\
\text { unions }\end{array}$ & $\begin{array}{l}\text { labour relations, apprenticeships, } \\
\text { informal groups }\end{array}$ \\
\hline (Basu, 1998) & formal sources of finance & informal sources of finance \\
\hline (Busenitz et al., 2000) & \multicolumn{2}{|c|}{ regulatory, cognitive, normative } \\
\hline (Carlsson, 2002) & $\begin{array}{l}\text { science base/technology transfer, } \\
\text { networks/business support, policy }\end{array}$ & \\
\hline$(\mathrm{Co}, 2004)$ & policies, business laws \& regulations & \\
\hline $\begin{array}{l}\text { (Colding \& Folke, } \\
2000)\end{array}$ & & taboo system \\
\hline (Davis, 2006) & & social ties \\
\hline (Demirbas, 2006) & $\begin{array}{c}\text { policies on R\&D, taxation, business } \\
\text { legislations, property rights, } \\
\text { regulations }\end{array}$ & $\begin{array}{l}\text { corruption, cultural attitudes to } \\
\text { bribery, transparency, informal } \\
\text { economy }\end{array}$ \\
\hline $\begin{array}{l}\text { (Dollar \& Kraay, } \\
\text { 2003) }\end{array}$ & institutional quality (rule of law) & \\
\hline (Fogel et al., 2006) & \multicolumn{2}{|c|}{$\begin{array}{c}\text { rules, property rights, legal regime, government quality and actions, } \\
\text { distribution of control of corporations, culture, education, market diversity, } \\
\text { openness }\end{array}$} \\
\hline $\begin{array}{l}\text { (Glaeser, La Porta, } \\
\text { Silanes \& Shleifer, } \\
\text { 2004) }\end{array}$ & $\begin{array}{l}\text { judicial independence, constitutional } \\
\text { review, plurality, representation, } \\
\text { mortality, years of schooling }\end{array}$ & \\
\hline (Hill, 1995) & & Japanese norms, value system \\
\hline $\begin{array}{c}\text { (Keefer \& Knack, } \\
1997)\end{array}$ & $\begin{array}{l}\text { rule of law, property rights, } \\
\text { bureaucratic quality }\end{array}$ & \\
\hline (Luo, 2005) & $\begin{array}{l}\text { legal system, government } \\
\text { intervention, environmental volatility }\end{array}$ & \\
\hline $\begin{array}{l}\text { (Meyer \& Nguyen, } \\
2005)\end{array}$ & $\begin{array}{l}\text { accessibility of scarce resources, } \\
\text { private land ownership }\end{array}$ & \\
\hline (Nkya, 2003) & $\begin{array}{l}\text { tax laws/process, access to credit, } \\
\text { competition, regulations, } \\
\text { administrative practices, bureaucracy }\end{array}$ & societal norms, practices, trust \\
\hline $\begin{array}{l}\text { (Pejovich, 1999; } \\
\text { Tabellini, 2005) }\end{array}$ & & culture \\
\hline (Peng \& Heath, 1996) & $\begin{array}{l}\text { central government planning, } \\
\text { bureaucratic control, lack of property } \\
\text { rights, political structure }\end{array}$ & $\begin{array}{l}\text { socialist values, collectivism, } \\
\text { networks, personal exchange }\end{array}$ \\
\hline (Peng, 2004) & & kinship networks \\
\hline (Robson, 2004) & state policy & Individualism/collectivism \\
\hline (Rodrik et al., 2004) & rule of law and trade openness & \\
\hline (Scully, 1988) & political openness & \\
\hline $\begin{array}{l}\text { (Siegel, Licht \& } \\
\text { Scwartz, 2006) }\end{array}$ & & egalitarianism \\
\hline
\end{tabular}


Hence, this study proposes a classification system based on institutional theory. This system is composed of empirically-based and theoretically-grounded variables and constructs which are multi-dimensional in nature. The multidimensionality means that no construct can be measured with a single indicator. Several aspects or dimensions must be taken altogether to provide a clear understanding of what the constructs truly represent.

Furthermore, this study adheres to the three requirements for a good classification system: development of mutually exclusive and exhaustive categories; capturing meaningful differences of the objects being classified in a parsimonious manner; and the operationability of the classification scheme (Law et al., 1998). The present classification system of the factors or constructs comprising the local institutional environment, strategic posture and organisational performance is based on a thorough review of the extant literature. Existing models and frameworks were closely examined to determine what has been previously investigated and what else remains unexamined. Hence, the first requirement has been satisfied.

Likewise, clear cut distinctions are made between and amongst the variables and constructs. The formal and informal variables are clearly delineated from each other. The constructs (e.g. rule of law, government assistance) under each variable (e.g. formal institution) are likewise well-differentiated. Parsimony is observed by making sure that only those constructs that are supported by empirical studies are included in the model. Prudence was exercised in identifying the factors within the confines of the extant literature on the disciplines from which the current study is drawn.

In addition, the operationability requirement is also satisfied such that any identified factor can be easily classified into any of the classes of constructs by looking at the definitions for each class. In this case, two major classes of institutions were identified: the formal and informal institutions. Likewise, two classes of organisational performance measures were initially identified. The definitions of each class of variables and constructs set the limits or the rules for classifying any idea or factor deemed relevant to the model being developed. 
Whetten (1989), in his widely cited paper "What constitutes a theoretical contribution?" echoes Dubin (1978) in stating that a complete theory has four essential components: identifying factors to include (taking account of both comprehensiveness and parsimony); explaining how the factors operate together (their causal relationships); describing a plausible mechanism for relationships between the factors (the why); and setting the temporal and contextual boundaries of the model (Dubin, 1978; Fry \& Smith, 1987; Whetten, 1989).

The four components were considered in the development of the model used in this study. The factors shaping the local institutional environment, strategic posture, organisational performance and managerial, firm and industry characteristics have been identified based on the review of the literature. The factors have been categorised based on the theories of institutionalism, strategic posture and organisational performance. Using the same theories, the classified factors have been examined in terms of how they interact with one another in the context of MSMEs. Hence, the requirements set by Whetten (1989) were adequately considered in this study.

\subsection{The Conceptual Model}

The model shown in Figure 3.3 presents the six fundamental domains of the study: (1) institutions; (2) strategic posture; (3) managerial characteristics; (4) firm characteristics; (5) industry characteristics; and (6) organisational performance. These domains are discussed in the following sections. 
Figure 3.3. The Conceptual Model and Hypothesised Relationships

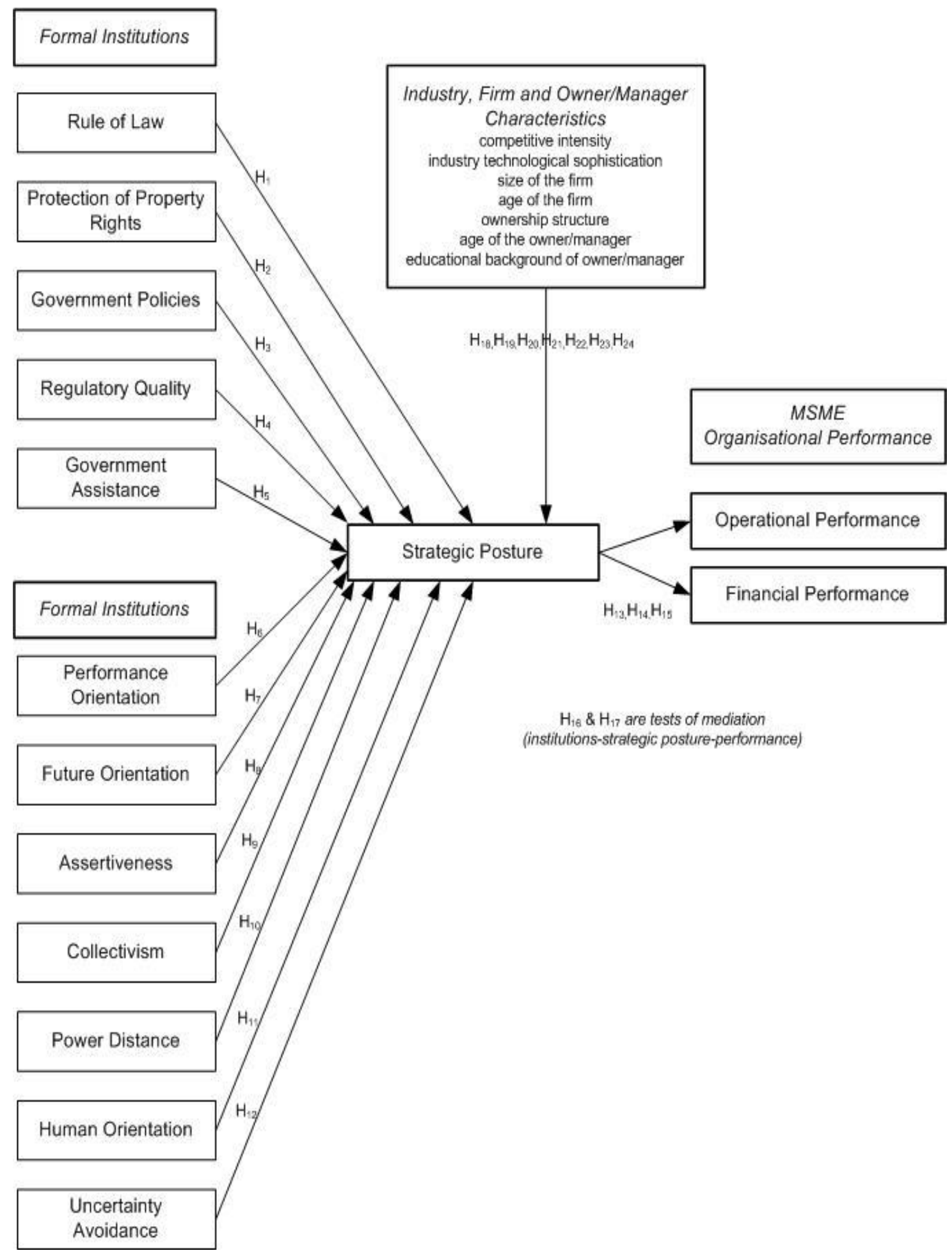




\subsubsection{Institutions}

Institutions are generally defined as the rules of the game in a society (North, 1990; 1992; 1991). These rules take the form of humanly devised constraints that shape human interaction by reducing uncertainty through the provision of formal and informal structures to everyday life (North, 1991). Within these structures, human interactions of all sorts take place such as production, consumption and exchange or business transactions (Parto, 2005; Slangen, van Kooten \& Suchanek, 2004).

These institutions are generically classified as either formal or informal institutions. The degree of formality lies in the articulation of these institutions and their corresponding enforcement mechanisms (Hodgson, 2006; North, 1990). As used in this study, formal institutions refer to the legal and political structures and processes in the city that explicitly specify and enforce the rights, duties, responsibilities and privileges of its local populace including MSMEs and govern the interrelationships amongst them (Aidis, 2005; Busenitz et al., 2000; Fogel et al., 2006; Nkya, 2003; Peters, 1999; Prasad, 2003). This definition stems from previous studies arguing that formal institutions refer to laws, constitutions, contracts, and property rights which are considered the official rules of a society with high degree of legitimacy and purposefully created by the state, by private enterprises, or by other alliances or individuals in civil society (Hodgson, 2006; North, 1990; Olsson, 1999; Redmond, 2005). These formal institutions are articulated in written forms, administered by a central authority, and violations of these "rules" entail legal sanctions (Redmond, 2005).

Identification of these formal institutions is mainly based on the seminal work of Kaufmann et al (1999) on governance and institutional quality which inspired more studies on the role of formal institutions in economic development. Furthermore, Busenitz et al (2000) argue that firms are able to leverage resources that are available through government-sponsored programs and enjoy privileges stemming from government systems and policies favourable to small businesses such as MSMEs.

On the other hand, informal institutions refer to the cultural factors shared by members of a society in a given locality or city that serve as constraints and/or 
standards of conduct or behaviour and the violation of which entails social rather than legal penalties (North, 1990; Olsson, 1999; Redmond, 2005). This operational definition stems from the characterisation of informal institutions by North as codes of conduct, norms of behaviour, unwritten rules, conventions, and generally accepted ways of thinking that come from socially transmitted information and are part of the heritage that we call culture (North, 1990, 2005; 1991). These norms, ethics, customs, taboos, and ideologies form the unofficial rules of a society, learned through socialization and are largely the inherited view of the world from older generations (Olsson, 1999; Redmond, 2005). These institutions are created, communicated and enforced outside officially sanctioned channels (Helmke \& Levitsky, 2004; North, 1990). These are referred to by Busenitz et al (2000) as the normative institutional profile of a given society synonymous to a country's culture, values, beliefs and norms that affect the entrepreneurial orientations of its people.

Given these theoretical bases, the conceptual model shown in Figure 3.3 presents the two generic categories of institutions. These two categories reflect the "institutional framework" as characterised by Hodgson (2006) that shows the "institutional thickness" of a city, a concept developed by Amin and Thrift in 1995 (1995; Raco, 1999). Consistent with Hollingsworth (2002), this study examines the formal and informal institutions in terms of their influence on micro, small, and medium enterprises (MSMEs) in the manufacturing and service sectors in two cities in the Philippines.

\subsubsection{Perceived Local Institutional Environment}

The current study aims to describe the institutional environment using the perceptions of MSME owners/managers rather than relying on objective facts and figures available from archived data. This decision rests on a number of theoretical underpinnings.

Foremost is the argument presented by Weick (1988) in his theory of enacted environment suggesting that the firm's external environment comprises "real" objects but the significance, meaning and content of these objects vary. These objects gain significance only when they are acted upon and incorporated into events, 
situations and explanations (Oswald, Mossholder \& Harris, 1997; Weick, 1988). Bourgeois III (1980) concludes that what matters therefore, is what manager's perceive from the environment and on how they act on it.

Theoretical support is also provided by the cognitive perspective of external environment which posits that managerial perceptions have strong influence on organisational responses to the environment (Frishammar, 2006; Lenz \& Engledow, 1986). In fact, managerial perceptions of the environment have been shown to be more critical to organisational strategy, structure and process than objective or archival measures of the environment (Anderson \& Paine, 1975; Frishammar 2006; Lefebvre et al., 1997; Oswald et al., 1997). Miller (1988, p.291) argues that "perceived measures of the environment are expected to have the strongest associations with business strategy since it is perceptions that strategists act on". To understand the environment in an objective sense is virtually impossible due to the complexity and the limited information-processing capabilities of organisations. Several empirical studies support the cognitive perspective of a firm's environment (Anderson \& Paine, 1975; Daft et al., 1988; Duncan, 1972).

Moreover, Jessor and Jessor's (1973) theory on the proximal environment supports the use of managerial perceptions on environment. The institutional environment can be classified as a proximal (i.e. perceived) environment such that it is an environment of perception, experience, or functional stimulation, usually described in psychological language and referring to variables which are directly experienced or responded to (Jessor \& Jessor, 1973). Expectations of others, negative evaluations, models of action, social approval and support are examples of variables that make up proximal or perceived environments such that they are environment of meanings (Lenz \& Engledow, 1986). The use of concepts, variables and labels are simply viewed as tools in describing and making sense of the external world (Frishammar, 2006). The environment is constituted by the firm through the definition of situations which become real in their consequences in the form of firm choices or actions (Jessor and Jessor 1973).

Finally the application of perceived institutional environment in this study is warranted based on the work of Anderson and Paine (1975) which asserts that the 
link between managerial perception and strategic behaviour makes sense only if a single individual formulates the strategies for the entire firm or that one individual dominates a coalition of strategy formulators within the firm. In as much as this study considers MSMES, this requirement is satisfied since many (if not all) of these small businesses are owned and/or operated by one or few individuals. Typical micro-enterprises for instance, are a one-person business operation or at least managed by the owners themselves with very few employees.

Likewise, the current study builds on the argument of Bourgeois III (1980) positing that there is nothing wrong with the use of managerial perceptions as long as there is an explicit distinction between the characteristics of the environment itself and the perception of that environment by MSME owners/managers. In this study, the emphasis is on determining how perceptions of the formal and informal institutional environment influence the strategic posture of MSMEs rather than objectively characterising the institutional environment itself. The main concern is on determining the value, interpretations or meanings derived by the owner/manager of MSMEs from a given set of institutions and their influence on strategic posture.

\subsubsection{Strategic Posture}

Strategic posture, as defined in the literature, reflects the top management's risk taking behaviour with regard to investment decisions and strategic actions in the face of uncertainty, the extensiveness and frequency of product innovations and the related tendency toward technological leadership, and the pioneering nature of the firm as evident in the firm's propensity to compete with industry rivals aggressively and proactively (Covin \& Slevin, 1990; Covin, Slevin \& Schultz, 1994; Gibbons \& O'Connor, 2005). It places a firm along a continuum ranging from conservative (i.e. less entrepreneurial) to entrepreneurial (Covin, 1991).

Strategic posture, whilst exercised by the owner/manager or top managers of an MSME, is considered an organisational variable as organisations are reflections of the values and cognitive bases of powerful actors (Carpenter \& Fredrickson, 2001). MSMEs, compared to large firms may have flatter structures (e.g. one owner/manager and a few employees). Micro or very small enterprises may even be 
a one-person business operation. Hence, the strategic posture of the principal decision-maker has the greatest impact on the overall strategic posture of the firm.

Strategic posture hinges on three fundamental constructs: innovativeness, proactiveness, and risk-taking. Innovativeness reflects a tendency to support new ideas, novelty, experimentation, and creative processes, thereby departing from established practices and technologies (Lumpkin \& Dess, 1996). Proactiveness refers to a posture of anticipating and acting on future wants and needs in the marketplace, thereby creating a first-mover advantage vis-à-vis the competitors (Lumpkin \& Dess, 1996). Risk-taking is associated with a willingness to commit large amounts of resources to projects where the cost of failure may be high (Miller \& Friesen, 1982). It also implies committing resources to projects where the outcomes are unknown. It largely reflects the organisation's willingness to break away from the tried-and-tested and venture into the unknown (Wiklund \& Shepherd, 2003).

Covin et al (1994) argue that firms with conservative (i.e. less entrepreneurial) strategic posture are risk averse, non-innovative and reactive firms whilst those with an entrepreneurial strategic posture are risk taking, innovative, and proactive. These three components comprise a basic, uni-dimensional strategic orientation (Covin et al., 1994; Gibbons \& O'Connor, 2005; Naldi, Nordqvist, Sjoberg \& Wiklund, 2007). Essentially, strategic posture reflects the firm's strategic orientation, that is, the firm's overall competitive orientation (Covin \& Slevin, 1989).

\subsubsection{Importance of Strategic Posture}

The importance of studying strategic posture or its synonymous term, strategic orientation rests on previous research that generated the following results amongst others:

a. strategic posture is the organisation's response or adaptation to the vagaries of the external environment (i.e. hostility, turbulence, complexity, etc.) (Strandholm, Kumar \& Subramanian, 2004);

b. strategic posture is the exploitation of the firms' resources to generate competitive advantage (Ordaz, Alcazar \& Cabrera, 2003); 
c. strategic posture/orientation shapes the level of innovation within the firm (O'Regan \& Ghobadian, 2005; Salavou, Baltas \& Lioukas, 2004); and

d. strategic posture shapes the performance outcomes of firms (Aragon-Sanchez \& Sanchez-Marin, 2005; Durand \& Coeurderoy, 2001; Morgan \& Strong, 2003; Noble, Sinha \& Kumar, 2002; Pelham, 1999; Rajagopalan, 1996; Ramaswamy, Thomas \& Litschert, 1994).

\subsubsection{MSME Organisational Performance}

MSME organisational performance in this context refers to the operational and financial results of the firm's value-creating processes and activities guided by goals, constrained by resources, complicated by diverse interests, and measured by various means (Adams \& Sykes, 2003; Cameron, 2005; Venkatraman \& Ramanujam, 1986; Zammuto, 1982).

A fundamental concept in performance measurement is that an MSME produces a certain amount and quality of output in relation to a pre-determined aim or target. The ultimate goal of this process is to generate outcomes that will satisfy the needs of the business owner or owners and other stakeholders of the business. Hence, measuring performance allows the generation of information on how well the goals and targets of the firm have been achieved (Lewin \& Minton, 1986). The information will not only determine causal connections between and amongst organisational variables leading to a certain level of output or outcome, it could also direct future performance of the firm.

The current study examines the two major dimensions of organisational performance of MSMEs: operational performance and financial performance. Operational performance indicators refer to those key operational success factors that might lead to financial performance and do not lend themselves to immediate financial quantification whilst financial performance indicators reflect the fulfilment of the economic goals of the firm of which profitability is at the core (Venkatraman \& Ramanujam, 1986). 
The current study builds on various approaches to measure performance. It is consistent with the goal approach (Campbell, 1977; Price, 1968) whereby performance shall be measured in terms of how well MSMEs attain their financial and operational objectives such as sales, profitability, and customer satisfaction. Likewise, the study is consistent with the resource dependence or systems view approach (Yuchtman \& Seashore, 1967) by incorporating measures such as attraction of essential labour or talents or skills. This approach manifests how well MSMEs acquire needed resources from the external environment. Furthermore, the current study conforms to the prescription of the internal congruence model of organisational effectiveness (Lewin \& Minton, 1986) by incorporating measures such as the development of new products/services and improvement in business and/or production processes. The use of these measures along with other measures reveals the synergistic congruence of internal activities that is able to generate positive outcomes for the business enterprise.

As will be shown in Chapter 4, measures of performance of MSMEs are based on data source internal to the firm which takes the form of perceptual and objective (self-report) measures. Likewise, performance is perceptually compared with the firms' competitors or other firms in the same industry consistent with previous studies described in Chapters 2 and 4. Comparing one's business results against competitors or other firms in the same industry reflects the competitiveness of the firm (Wan, Lau \& Chan, 2002). Looking at competitors or other firms in the same industry as benchmarks of business results is a control mechanism for performance differences amongst industries and markets (e.g. differences in capital structure or depreciation accounting conventions) (Brah, Wong \& Madhu-Rao, 2000). Detailed discussion of the measurement of organisational performance is discussed in Chapter 4.

It is important to note at this stage that the study ensures that performance measures used in this study are relevant or applicable for MSMEs. The review of the literature identified a number of SME-related studies which made use of various performance measures in different contexts. The study builds on these previous empirical investigations. 


\subsubsection{Institutions-Strategic Posture Link}

In the current literature, institutions are often relegated to the background when seeking explanations on the strategic choices and behaviour of firms. Task environmental factors like industry characteristics as well as firm resources often take precedence in organisational strategy research (Peng et al., 2008). In the extant literature, the industrial organisation (I/O) theory (Porter, 1980) and the resourcebased view of the firm (Barney, 1991) appear to be the popular frameworks to analyse the strategic configurations of firms (Peng et al., 2008). Studies that used an institutional approach often looked at market-based institutions whilst treating the much wider institutional environment as mere background conditions (Bowen \& De Clercq, 2008; Manolova et al., 2008; Narayanan \& Fahey, 2005; Peng et al., 2008).

Hence, it has been argued that understanding organisational strategic behaviour visà-vis the formal and informal institutions outside of the immediate task environment of firms should be at the forefront of future research in strategic management. Fior example, Peng et al (2008) argue that the institutional view of strategy should constitute the third leg in the strategy tripod along with the I/O theory and the RBV. This research agendum is especially applicable in emerging economies (as many Asian countries like the Philippines are currently categorised as such) characterised by institutional heterogeneity even at sub-national levels (Bruton et al., 2008; Bruton \& Lau, 2008). Whilst this research agendum may have strong relevance to international firms (e.g. multi-national firms) which intend to invest in emerging economies, it is also important to the quest of understanding the strategic configurations of domestic firms as they operate their businesses within an heterogeneous institutional environment within the same national boundary (Wright et al., 2005).

The study uses the 'theory of strategic choice' (Beckert, 1999; Child, 1997) to develop/offer an explanation of the institutions - strategic posture relationships. This is the current study's response to the current research agendum in order to clarify further how institutions relate to organisational strategic behaviour (Beckert, 1999; Child, 1997; Clark, Varadarajan \& Pride, 1994; Pfeffer \& Salancik, 1978). 
The 'strategic choice theory' of the growth of the firm builds on the assumption that the firm operates in a market economy in which it is relatively free to pursue its own strategic choices (Peng \& Heath, 1996). Strategic choice refers to the process whereby power holders within organisations decide upon courses of strategic action (Child, 1997). If institutions provide the framework of rules and informal constraints within which organisations perform their economic functions, is there any room for an organisation to exercise strategic posture to advance its perceived interests?

Beckert's (1999) view suggests that organisations are capable of exercising strategic posture as a response to a complex and incoherent institutional framework. Furthermore, institutions and strategic posture may be viewed as interdependent in the context of uncertainty. Uncertainty in this case refers to the degree to which future states of the world cannot be anticipated and accurately predicted (Pfeffer \& Salancik, 1978). It has been noted in this study that North's (1990) view of institutions rely heavily on the concept of transaction costs - which are the costs of specifying what is being exchanged (i.e. attributes) and enforcing the subsequent agreement (Vandenberg, 1999). It is argued that strategic posture can be exercised to reduce the uncertainties faced by firms due to institutional constraints (Beckert, 1999).

The theory of transaction costs (Rao, 2003) explains that the presence of these institutions enable the firm to reduce the costs of engaging in various forms of exchanges with its customers and other economic players. Consequently, reduced transaction costs enable the firm to have access to valued resources, exploit existing resources, be more productive, be more innovative, hence, able to sustain and grow the business.

Oliver (1991) further argues that firms are not passive entities floating in the ocean of institutions. Institutional theory can accommodate interest-seeking, active organisational behaviour when organisations' responses to institutional pressures and expectations are not assumed to be invariably passive and conforming across all institutional conditions (Oliver, 1991). By combining institutional and resource dependency theories, Oliver (1991) suggests that organisations take on different strategic configurations to protect their interests vis-à-vis the pressures of the 
external institutional environment. Organisations adapt to the changes in their environmental although their choice of strategic actions may be severely limited by the environmental constraint and opportunities (Strandholm et al., 2004).

Likewise, Shane (2003) asserts that opportunity exploitation is one of the basic tenets of strategy formulation and development. The economic, political and socio-cultural environment provides the institutional framework through which MSMEs gain access to information about entrepreneurial opportunities (Shane, 2003). For instance, political freedom characterised by the rule of law encourages free exchange of information as well as development of internal locus of control which facilitates the exploitation of entrepreneurial opportunity (Shane, 2003).

The relationship between institutions and strategic posture can also be explained by the theory of organisational adaptation (Hrebiniak \& Joyce, 1985). In the context of the open systems view, the deterministic nature of the environment is balanced by the ability of the organisation to affect the process of exchange and transformation with the external environment. The principle of equifinality implies that whilst the environment is the ultimate source of resources as well as prescriptions of the means and ends, the organisation retains control over and selection of the means by which the prescribed outcomes may be achieved (Hrebiniak \& Joyce, 1985). This approach resists the temptation of treating environmental determinism and strategic posture as opposite ends of a spectrum but to emphasise that the two can be placed in axes ranging from low to high with each axis denoting variance on levels of assertiveness and potential to influence the other (Eisenhardt \& Schoolhoven, 1990; Geiger \& Hoffman, 1998; Hrebiniak \& Joyce, 1985).

In the marketing arena, the seminal work of Zeithaml \& Zeithaml in 1984 challenged the prevailing notion that marketing theory adopts a reactive stance with respect to the external environment, the factors of which are well-established and therefore must be accepted as they are. The authors introduced the concept of environmental management denoting the proactive perspective on organisation-environment relations (Zeithaml \& Zeithaml, 1984). Rather than looking at organisations as passive recipients of environmental endowments, environmental management 
challenges organisations to adopt strategies that circumvent environmental constraints or boldly alter the state of environmental factors.

If the business environment is viewed in terms of inputs to the organisation which are under the control of other organisations or interest groups, environmental management may be defined as deliberate actions aimed at controlling, changing, influencing, or adapting to those inputs (Clark et al., 1994). However, Clark et al (1994) warns that success in environmental management will vary in as much as decision-makers within the organisation will perceive environments differently despite their rationality; hence responses to enacted environment will generate a variety of results.

The institutions - strategic posture interface is also consistent with the work of Pfeffer and Salancik (1978) on resource dependency theory which suggests that organisations assume a certain type of strategic posture and pursue various forms of strategies to manage its dependence with the external organisation for valued resources. Firms may adapt their strategic posture to reduce their dependence on some scarce or hostile aspects of the external institutional environment.

Likewise, the theory of environmental munificence which posits that the scarcity or abundance of critical resources needed by a firm operating within an environment influences the survival and growth of firms sharing that environment (Castrogiovanni, 1991). Environmental munificence refers to the environment's ability to support sustained growth of firms (Anderson, Drakopoulou-Dodd \& Scott, 2000; Anderson \& Tushman, 2001; Goll \& Rasheed, 2005). It is reflected in the capacity of the firm's external environment to provide the necessary resources to a firm. Goll and Rasheed (2005) reveal that environmental munificence has pervasive effects on organisational processes as shown by the literature on the subject published over the last two decades.

The presence of supportive institutions reflects environmental munificence which has been shown to be positively associated with a range of strategy and organisational response options (Castrogiovanni, 1991). If resources are abundant, it is easy for firms to survive and more able to pursue goals other than survival. Environments 
perceived to be munificent have been empirically-linked to greater structural complexity indicated by increased functional specialisation and decentralisation of operating decisions (Yasai-Ardekani, 1989). Under conditions of scarcity, there tends to be greater formalisation of procedures and centralisation of strategic decision-making, indicative of the interaction between the external environment and the firm's overall strategic configurations.

All these point to one argument - the institutional environment is a source of resources for the firm which in turn shapes the kind of strategies the firm will pursue. However, not all organisations have equal access to these resources. Only those that enjoy what Parsons (1951) in (Scot 2001;) called legitimacy will have the support of the wider system, in which an organisation, as a system is subsumed (Deephouse \& Carter, 2005). A number of inter-organisation theorists (Adamek \& Lavin, 1975; Lorch, 1975; Phillips, Lawrence \& Hardy, 2000) place great emphasis on the interdependence and interlink of the external environment on the internal functioning of organisations based on the basic tenets of the open systems perspective.

The theory of planned behaviour (TPB henceforth) (Ajzen, 1987; Ajzen, 1991b), which is an extension of the theory of reasoned action (Ajzen \& Fishbein, 1980) may well explain the link between informal institutions and strategic posture of MSMEs. TPB assumes that social behaviour is reasoned, controlled or planned such that the likely consequences of the behaviour are taken into consideration (Ajzen \& Fishbein, 2000). At the core of TPB is the principle that intentions which refer to the degree of commitment toward some future target behaviour robustly predict and explain a plannable social behaviour (Krueger, Reilly \& Carsrud, 2000). TPB explains that attitudes are precursors to intentions which are antecedents to behaviours (Ajzen, 1991). Furthermore, intentions are accurate predictors of planned behaviour especially in cases where the behaviour is difficult to observe, rare or involves unpredictable time lags (Ajzen 2000).

The concept of intentions, and consequently behaviour, are formed over time as a result of three principal factors: perceived desirability of performing the behaviour; perceived social norms; and perceived behavioural control (Ajzen \& Fishbein, 2000). Perceived desirability of the behaviour and perceived behavioural control are 
attitudinal factors whilst perceived social norms take into account the social context surrounding these attitudes as well as the planned or intended behaviour.

Perceived desirability of performing the behaviour is considered as the attitude towards the act which subsumes perceptions of likely intrinsic and extrinsic personal outcomes of the behaviour valued by an individual (Krueger et al., 2000). Perceived social norms as a concept refers to one's awareness of the social standards and pressures resulting from a perception of what other people (of importance) think should be done and the reasons for submitting to their expectations (Krueger et al., 2000). Perceived behavioural control refers to an individual's perception of the feasibility of performing the behaviour and is thus related to perceptions of situational competence (Krueger et al., 2000). Perceived behavioural control is a construct that overlaps with Bandura's $(1977$; 1986) construct of perceived selfefficacy or the perception that one can execute the target behaviour (Krueger et al., 2000). These three factors are argued to shape an individual's overall intention to pursue certain behaviours.

Given the current study's questioning of whether the strategic intentions, decisions and behaviour of the individual owners/managers of MSMEs have the greatest impact on the firm's overall strategic posture, it is argued that the three drivers of intentions and behaviour described in the TPB will explain well the strategic posture of MSMEs. The TPB suggests that MSMEs' (or their owners'/managers') strategic intentions, and consequently behaviour, are the result of three factors: the attitudinal influences based on perceived desirability of engaging in a certain level of entrepreneurial strategic posture, and perceived self-efficacy of doing so; and the perceived social norms that are considered psychologically supportive or deterrent to performing such kind of strategic posture.

When perceived desirability and self-efficacy are high and social norms are perceived as favouring an entrepreneurial strategic posture, the owner/manager (i.e. MSMEs) is likely to engage in an entrepreneurial strategic posture. This is where informal institutions are argued to have significant effects upon MSMEs and/or their owners/managers. The informal institutions (of the city where the MSMEs are 
located) are likely to significantly shape the MSMEs' owners'/managers' perceptions on the desirability of, and social norms related to an entrepreneurial strategic posture.

The TPB proposition is well supported by cultural theory (van Heffen \& Klok, 2003) which explains that one's beliefs and norms untimately influence one's decisions and actions even in organisational contexts. Hence, MSME owners/managers may make strategic decisions (in line with a certain type of strategic posture) heavily influenced by their own beliefs and norms. Studies have noted that one's beliefs and norms are largely shaped by one's socio-cultural environment (Hofstede, 1980; 1983; House et al, 2004). Likewise, the theory on organisational legitimacy (Deephouse \& Carter, 2005; Suchman, 1995) offers a similar view on the tendency of organisations like MSMEs to conform to social and cultural standards or expectations to gain legitimacy - the perception that an entity's actions are consistent with the greater social system.

All these theoretical underpinnings are predicated on the resource-based view (RBV) of the firm (Barney, 1991). RBV holds that firms can earn sustainable returns (and hence, become competitive) if they have superior resources and those resources are protected by some form of isolating mechanisms preventing their diffusion throughout the industry (Barney, 1991). The work of Edith Penrose dating back in 1959 became a solid foundation of this school of thought with the main argument that a firm is more than an administrative unit - it is also a collection of productive resources, the disposal of which between different users and over time is determined by administrative decisions (Penrose, 1959; Wernerfelt, 1984). RBV's argument that the firm is a bundle of resources in a variety of forms implies the importance of the external environment being the source of these resources. A firm with access and which consequently obtains possession of firm-specific, valuable, non-substitutable, and difficult to imitate resources are likely to gain above-average returns (Barney, 2001). A combination of these physical and human resources explain well the growth of firms. In effect, RBV suggests that the institutional environment is a source of resources that are valued by the firm and are critical to the firm's entrepreneurial and productive activities to generate favourable returns. 
Summing up the determinism-strategic posture debate, Whittington (1988) suggests that environmental structures (i.e. institutions) are not necessarily antagonistic to strategic posture, rather they both form its precondition and inform its content. The subjective perceptions (mental models) of MSME owners/managers - correct or incorrect - determine the posture and choices they make which are the ultimate sources of action (North, 2005).

\subsection{Formal Institutions}

In this study, formal institutions refer to the legal and political structures and processes in the city that explicitly specify the rights, duties, responsibilities and privileges of its local populace including MSMEs and govern the interrelationships amongst them (Aidis, 2005; Busenitz et al., 2000; Fogel et al., 2006; Nkya, 2003; Peters, 1999; Prasad, 2003). The identification of formal institutions used in this study is primarily guided by the original theoretical and conceptual discussions found in the seminal work of North (1990). Subsequent studies (conceptual/theoretical and empirical) were also searched out and examined to determine the extent of previous attempts to operationalise North's concepts of formal institutions (e.g. Hodgson, 2006; Vatn, 2005; Verhuel et al., 2003).

Consequently, this study adopts the measures of formal institutions developed by Kaufmann et al (1999; 2006) and repeatedly used in other studies (Dollar \& Kraay, 2003; Robson, 2004) by looking at the institutional quality of governance. This study adopts a number of variables from Kaufmann et al (2006) with some modifications because the latter's study takes a country-level of analysis and relates institutional quality with macro-economic indicators like GDP. "Government policies" and "government assistance" are not part of Kaufmann et al.'s framework, yet are included in this study as supported by previous theoretical and empirical evidence (Bevan, Estrin \& Meyer, 2004; Busenitz et al., 2000).

The aim of specifically relating institutions to organisational variables (strategic posture and firm performance) requires the selection of theoretically and empirically grounded constructs to establish focus and brevity without sacrificing consistency with previous studies. Given the wide array of possibilities in identifying which 
formal institutions to include in this study, the formal institution variables in the study's model include only those theoretically-compelling variables most relevant to the research questions (Hollingsworth, 2002; Parboteeah et al., 2005). Consistency with North's (1990) original concept of formal institutions is the basic criterion in the selection of the variables. Hence, the proposed study considers the following formal institutions: rule of law, protection of property rights, government policies, regulatory quality and government assistance. The following sections present the discussions on the five formal institutions as they relate to MSME strategic posture.

\subsubsection{Rule of Law}

Rule of law refers to the supremacy of law whereby decisions are made by the application of known principles or laws without the intervention of discretion in their application (Kahn, 2006). Rule of law assumes that law is what should govern society and not the arbitrary will of particular persons (Pejovich, 1995; Wang, 2004). Laws, being the primary conscious ordering force in modern nations (Reed, 2001), serve as a necessary foundation for the promotion of business because the rule of the state creates the private market by establishing private property in the limited resources that are voluntarily exchanged through this system (Reed, 2001). A place with a strong rule of law is defined as one having sound political institutions, a strong court system, and provisions for orderly succession of power as well as citizens who are willing to accept the established institutions and to make and implement laws and adjudicates disputes (Oxley \& Yeung, 2001).

Rule of law rests on the principles that there can be no offence without the law, all laws apply to all citizens, and that there must be an independent and politically neutral judiciary that is broadly accessible to aggrieved individuals. It requires a system in which the laws are public knowledge, are clear in meaning, and apply equally to everyone (Carothers, 1998). Furthermore, all laws should be prospective, open, clear, and relatively stable.

The making of particular laws must be guided by open, stable, clear and general rules; the independence of the judiciary must be guaranteed; courts should be easily 
accessible, and the discretion of crime preventing agencies should not be allowed to pervert the law (O'Donnell, 2004).

\subsubsection{Rule of Law and Strategic Posture}

Rule of law has been noted to have a direct impact on firm activities, including the exercise of certain types of strategic behaviour (Pajunen, 2008). The rule of law has the capability to influence transactional trust. Fogel et al (2006) highlight the importance of transactional trust in entrepreneurial activities. Referring to the degree of trust that parties to a business transaction place on each other, transactional trust is enhanced if there is strong adherence to the rule of law characterised by effective legal and judicial systems. Through adherence to rule of law, parties to a transaction have the confidence that they are protected from opportunistic behaviour such as cheating and illegal deviations from agreed terms as they enter into economic exchanges. Rule of law generates greater transparency and stability regarding the boundaries of acceptable behaviour (Oxley \& Yeung, 2001).

This in turn reduces transaction uncertainty about what legal protection MSMEs can expect and enhances their ability to successfully litigate at the least, serious cases of fraudulent dealings (Oxley \& Yeung, 2001). A strong enforcement regime lowers the cost of transacting because it screens out those who might have no intention of fulfilling the terms of a contract and it encourages those who have entered into a contract to follow through and fulfil their obligations (Vandenberg, 1999). Increased transactional trust therefore allows MSMEs to be more aggressive in seeking for opportunities, building alliances, bearing risks, raising capital and entering markets (Fogel et al., 2006).

The reverse situation, lack of rule of law, increases transaction costs (Scully, 1988). Absence of legal protection and/or inefficient legal means to settle disputes increases the level of uncertainty faced by MSMEs as they enter into exchanges with other economic agents (e.g. suppliers, distributors, the government, customers, etc.). Likewise, Oxley \& Yeung (2001) further opined that a weak rule of law influences people's general attitudes, decreasing the level of trust in markets and in the process of contracting. This severely affects MSMEs as they attract and interact with 
potential and existing customers as well as potential investors and business partners. The fear of opportunistic behaviour and discretionary actions between/amongst contracting parties could stifle genuine and productive business intentions such as innovation-related activities (Fogel et al., 2006; Kaufmann, Kraay \& Mastruzzi, 2006; Scully, 1988). Economies grow and expand because transactional trust is high as economic exchanges take place under transparent, stable and efficient legal and judicial systems. Rule of law enhances confidence through protection from arbitrary actions and guarantee of an efficient judicial process should the other party to an exchange deviates from the legally-prescribed rules of engagement.

Furthermore, rule of law is a prerequisite to maintain public safety or the degree of safety and security of people and their property (Begg, 1999; Hopkins, 2002). Begg (2002) suggested that crime or a threat of it is a deterrent to business in so far as it increases the costs of security and insurance and has adverse impact on staff and potential customers. Previous research has shown how crime can have serious effect on the viability of small businesses, business sales, recruitment of talents, and costs of securing the business (Hopkins, 2002; Taylor \& Matthew, 2002).

The "investability" of a city requires that people and property are safe and secured as safety and security are essential elements to achieve "economic freedom" (Kreft \& Sobel, 2005). Furthermore, a number of studies support the argument that public safety is significant in economic development (Fisher, 2005). For instance, graffiti and other forms of vandalism tend to motivate fear of crime in the community and may be taken as signals or symptoms of instability and deterioration of a place or community (Gibbons, 2004). This perception of instability reduces the potential of a place for business investment.

The study of Peng \& Heath (1996) of firms in economies in transition shows that firms were unable to take advantage of strategic factor markets (such as finance) nor grow through generic expansion and acquisition because of the unstable legal system and political structures. The results suggest that strategic decisions and choices were significantly constrained by the institutional inadequacies which make transactions highly uncertain and agreements or contracts costly to enforce. 
The foregoing discussion highlights the importance of rule of law in reducing transaction costs associated with uncertainty, opportunistic behaviour of exchange partners, monitoring and enforcement of contracts, as well as dispute resolution. The presence of rule of law increases transactional trust which reinforces the confidence of MSMEs to engage in innovative, proactive and even risky undertakings knowing that their assets are well protected and secured from the threat of discretionary actions from the government and other economic players. Hence, it is hypothesised in this study that:

\section{$H_{1}$ - Rule of law is positively associated with entrepreneurial strategic posture.}

\subsubsection{Protection of Property Rights}

Possession of significant assets cannot be efficiently used to increase output and promote economic growth if such assets lack the legal status of property. Protection of property rights include the protection and enforcement of right to use, exclude others from using, modify, obtain income from, and sell assets (Landau, 2003; Reed, 2001). These rights allow the owner to enjoy a benefit stream that is only as secure as the duty of all others to respect the conditions that protect that stream (Prasad, 2003). Property rights identify and protect the set of tangible and intangible resources that can be transferred in the market place and provides necessary incentives to owners to risk improvement to resources by ensuring that they will benefit from the improvement and that others will not deprive them of the benefit (Reed, 2001). Consequently, protection of property rights allows the creation of security for capital borrowing and investment (Reed, 2001).

\subsubsection{Protection of Property Rights and Strategic Posture}

Property rights are essential in economic growth as they allow economic agents to enter into contracts with minimal transaction costs (Norton, 1998). The ability of entrepreneurs to contract creatively and effectively - facilitating market exchange and creating firms or hybrid organisational forms - is largely dependent on the property rights configurations of a given place or society (Norton, 1998). Lack of protection would mean erosion of confidence as a result of one's precious asset being 
appropriated by another without due compensation. This in turn inhibits firms or individuals from investing in research and commercialization for fear of not recovering the costs incurred (Norton, 1998). The establishment of secure and stable property rights has been a key element in the onset of modern economic growth as it not only protects ownership and control of property but provides the incentives to put the property or resource into productive use (Heitger, 2004; Rodrik, 2006). These incentives increase the confidence of MSMEs to innovate and become economically active without the fear of being cheated out of the fruits of their efforts (Heitger, 2004).

Protection of property rights has been shown to be related to higher gross domestic product amongst countries as it leads to more (better) efficient allocation of resources (Scully, 1988). Other advantages include the promotion of investment in knowledge creation and business innovation by establishing exclusive rights to use and sell newly developed technologies, goods and services (Maskus, 2000). Consequently it promotes widespread dissemination of new knowledge by encouraging rights holders to put their inventions and ideas in the market (Maskus, 2000). As information is viewed as a resource, it will open up opportunities for further research and development by the rights holder and other firms. Fogel et al (2006) cited a study showing how weak property rights discourage firms from reinvesting their profits even if potentially profitable reinvestment opportunities exist. It stands to reason that protection of property rights is essential for firms to engage in an entrepreneurial strategic posture because of the greater security of the fruits of innovativeness and proactiveness and reduction of risks (e.g. violation of property rights) associated with business opportunity exploration and exploitation (Rodrik, 2006). Hence, it is hypothesised in this study that:

\section{$\mathrm{H}_{2}$ - Protection of property rights is positively associated with entrepreneurial strategic posture.}

\subsubsection{Government Policies}

The development and maintenance of a policy framework conducive for private enterprise in general and for MSME development in particular cannot be over emphasised. In this context, government policies refer to the locally enacted and 
implemented laws, ordinances, regulations and any other forms of legislations and/or government decisions especially those that affect the business sector (Fogel, 2001). The concern in this study is to determine if these local government policies are perceived as conducive for MSME business operation. These policies can be subsumed under the term public policy towards entrepreneurship (Kuratko \& Hodgetts, 2004).

The relevance of government policies is well supported by the argument of Rodrik (2006) that strategic government intervention may often be required to get out of the low-level traps and elicit private investment brought about by coordination failures and capital market imperfections. Wong (2002) likewise noted that government policies play a pivotal road for local economic development such that it provides the roadmap for what future investments are necessary to support the goals of development. It is argued that policies consistent with expanding the economic freedom of individuals are the cornerstone of successful economic development policy (Kreft \& Sobel, 2005). Moreover, government policies form part of the overall regulatory component of the institutional framework of a country, region or city which promote certain types of business behaviours and restrict others (Parboteeah et al., 2008).

\subsubsection{Government Policies and Strategic Posture}

If institutions are the rules of the game, according to North $(1990,1992,200)$, then policies are clear-cut manifestations of institutions - the shared and explicit "understandings by participants about enforced prescriptions, concerning what actions or outcomes are required, prohibited, or permitted" (Ostrom, 2005). These policies make market activities more predictable and lower the cost of searching for information as well as enforcement of rights and contracts.

Moreover, the policies supportive of entrepreneurship are manifestations of what Talcott Parsons $(1949$; 1951) calls as 'legitimation' of organisations (i.e. the organisation has gained the support of its wider system - the external environment) (Scott, 2001). Clarity and coherence of policies are crucial in setting the tone for small business development (OECD, 2004). The policies in place which could be 
reinforcement of the national policies as well as policies indigenous to the city are important ingredients of an entrepreneurial climate. These are the clear-cut examples of North's (1990) concept of formal institutions as "rules of the game" designed to shape the behaviour of economic players.

In the current study, government policies may be viewed as conduits through which MSMEs can engage in business activities consistent with external rules and regulations, hence, reducing the level of uncertainty (e.g. fear from government intervention). Likewise, government policies open up opportunities for MSMEs such as resource acquisition, mobilisation, alliance/network formation (e.g. subcontracting), establishment of industry clusters, and market development or expansion (e.g. export) (Audretsch, 2004; Jackson, 2002; Skuras, Dimara \& Vakrou, 2000; Tambunan, 2005). Another non-pecuniary advantage includes better strategic planning on the part of MSMEs brought about by consistency and hence, increased predictability in government plans and economic programs. This study argues that a policy environment conducive to business should encourage entrepreneurship development by supporting MSMEs' pursuit for innovation and proactive exploration and exploitation of business opportunities. Hence, it is hypothesised in this study that:

\section{$\mathrm{H}_{3}$ - Government policies perceived as conducive for MSME business are positively associated with entrepreneurial strategic posture.}

\subsubsection{Regulatory Quality}

The presence of a sound regulatory system is an effective mechanism to increase the level of transactional trust between two or more economic agents (Fogel et al., 2006). The presence of rules and regulations facilitates smooth transaction between and amongst businesses as well as their customers. Rodrik (2006) noted that every successful market economy is overseen by a panoply of regulatory institutions governing conduct in goods, services, labour, assets, and financial markets. In fact, one of the fundamental considerations in assessing the investability of a place is the regulatory framework of businesses (Begg, 1999, 2002). Regulating businesses can be justified where there are market failures of some sort or another, for example, 
monopoly, imperfect information or significant externalities. Regulation be it social (i.e. regulation of non-economic activities across industries) or economic (i.e. regulation aimed at specific industries), is an environmental force affecting a firm's choice and performance (Dollar et al., 2005; Geiger \& Hoffman, 1998).

In this study, regulatory quality refers to the degree to which compliance of the existing laws, rules, and other government regulatory procedures does not impose unreasonable burden on MSMEs (Fogel \& Zapalska, 2001; Geiger \& Hoffman, 1998; Gnyawali \& Fogel, 1994). Closely associated with it is bureaucratic efficiency measured in terms of the burdens and delays associated with compliance of laws and regulations in the areas of starting a business, hiring and firing employees, property registration, getting credit, protecting investors, enforcing contracts, and closing a business (Djankov, McLiesh \& Ramalho, 2006; Dollar et al., 2005; Frye \& Zhuravskaya, 2000). Regulatory quality forms part of the regulatory component of the institutional framework of a country, region or city (Coeurderoy \& Murray, 2008; Parboteeah et al., 2008).

\subsubsection{Regulatory Quality and Strategic Posture}

Burdensome regulatory requirements impose significant costs on the firm. In their eclectic theory of entrepreneurship, Verheul et al (2002) argue that small businesses are relatively sensitive to the administrative costs of compliance with government regulation; the time and energy entrepreneurs spend on administrative commitments distract them from their basic activities. Hence, administrative burdens are considered as barriers to entry as well as to firm growth (Verheul et al., 2002). Likewise, higher level of perceived regulatory uncertainty has been shown to be negatively related to risk taking and innovation (Tan, 2001). Risk-aversion and low level of innovation drive the firm to be more conservative rather than entrepreneurial in its strategic posture (Covin \& Slevin, 1990).

Government regulations may affect MSMEs through the following ways:

a. increased prices to absorb the cost of regulatory compliance;

b. pressure of cost inequities as small companies feel the brunt of regulatory burdens more than large firms; 
c. competitive restrictions may significantly discourage small firms;

d. managerial restrictions resulting from MSMEs sacrificing managerial time to comply with government regulations; and

e. and mental burden arising from postponed projects, wasted time, managerial failure due to lack of time and energy (Gnyawali \& Fogel, 1994; Hellman, Jones, Kaufmann \& Schankerman, 2000; Kuratko \& Hodgetts, 2004).

In addition, regulation may also reduce the flow of innovation and the production of new and better products because so many government regulatory agencies have the power to decide whether or not a new product will go in the market at all (Frye \& Zhuravskaya, 2000). Bureaucratic rigidities also open up potent opportunities for unofficial fees thereby increasing the costs of regulatory compliance by MSMEs (Frye \& Zhuravskaya, 2000; Levy, 1991).

Organisational theorists argue that high regulatory stringency (referring to the extensive or severe regulatory pressures imposed on organisations) impede organisational efficiency and autonomy (Oliver, 1997). This is evident amongst firms in the manufacturing sector where innovation is a crucial component of business. Stringent and long-winding regulatory systems governing licensing applications for inventions as well as lack of protection of intellectual property rights may stifle these innovative activities of small firms which in turn pose a threat to the sustainability of the business. MSMEs may find it costly and cumbersome to apply for legal protection of newly developed technology or invention. Consequently, MSMEs may avoid commercialization of such innovation for fear of opportunistic behaviour of other firms which ultimately stifles the whole innovation process.

Djankov et al.'s (2006) study shows the predictive power of their newly developed business regulations index vis-à-vis GDP growth rate of 135 countries. The study shows that countries with burdensome regulatory requirements are those that are not performing-well in terms of national output. National economic output heavily depends on the local firms' aggregate output which hinges on innovation, production, business expansion, and creation of more business opportunities. Furthermore, efficient regulatory systems have been shown to be positively related to increase in intra-foreign direct investment flows (Rammal \& Zurbruegg, 2006) in as much as 
investment climate depends on a sound and developmental regulatory system (Dollar et al., 2005; Hallward-Driemer, Wallsten \& Xu, 2006). Governments can influence market mechanisms and make them function efficiently by removing conditions that create market imperfections and administrative rigidities (Gnyawali \& Fogel, 1994).

Turner (2003) uncovers the problems with bureaucracy including corruption experienced by Indonesian small businesses as hindering their growth. In a World Bank study of 76 countries, it was revealed that regulatory efficiency and efforts for institutional development to fight red tape and corruption are significant factors influencing the growth of SMEs (Ayyagari et al., 2003). Conversely, greater regulatory costs disproportionately force smaller firms out of business (Ollinger \& Fernandez-Cornejo, 1998). Likewise, long drawn-out processes for obtaining government approval of new products hinder innovative activities of small firms (Audretsch, 2004). The general consensus is that the quality of bureaucracies is one of the most critical factors that determine long-term growth performance across regions and economies (Bowen \& De Clercq, 2008; Levy, 1991; Park, 2006).

The link between bureaucratic processes and MSME strategic posture could be further explained by the economic theory of transaction costs (Blakely \& Bradshaw, 2002; Clingermayer \& Feiock, 2001; Dewees et al., 2003; Rao, 2003) Bureaucratic inefficiencies increase the unnecessary costs incurred by businesses in governmentbusiness exchanges as illustrated above. These costs include direct financial costs as well as the time and effort spent for the completion of these transactions. The tedious and long-winding bureaucratic processes could take away precious time from the productive activities of small businesses. Audrestch (2004) argues that prohibitive regulatory costs encourage non-compliance of legal requirements which, as a matter of consequence, forces small business to go underground with their business activities. Consequently, this lack of legal personality stifles the growth of these small businesses such that any innovation (e.g. patents/licenses) is not accorded any legal protection. The lack of legal personality also limits the ability of small businesses to conduct commercial activities in the mainstream of a city's commercial system (Capelleras, Mole, Greene \& Storey, 2008). 
Likewise, the theory of enabling of authority (Leach et al., 1994; Legaspi, 2000) posits that the market enhancing role of the local government is crucial in the promotion and development of entrepreneurs. This market-oriented enabling role of the local government is manifested in the government's efficient delivery of services as well as proactive stand on local economic development. By doing so, efficient quality services, access to legal protection, and quality information, are well extended to those who may need them - including the MSME sector. This in turn, should enhance the capability of MSMEs to concentrate on the productive activities of their business. Regulatory quality becomes an enabling system for MSMEs as they exploit new opportunities through innovative activities.

In short, MSME's entrepreneurial strategic posture can be supported well by the local government through the quality of its regulatory system that does not impose burdensome financial (e.g. excessive fees) and non-financial (e.g. time and effort) costs on MSME as they try to satisfy the legal requirements for business operation. Hence, this study proposes that:

\section{$\mathrm{H}_{4}-$ Regulatory quality is positively associated with entrepreneurial strategic posture.}

\subsubsection{Government Assistance}

Government assistance has been noted as a key component in small business or MSME development (Helmsing, 2000; Hill, 1995; Jackson, 1999). Assistance may take the form of specific policies and programs designed to improve the financial conditions and/or the efficiency of a firm (Verheul et al., 2002). The government may design specific programs that provide small businesses access to needed resources or reduce the risks for starting or expanding the business (Busenitz et al., 2000). In this study, government assistance is expressed as the extent to which the local government extends various forms of assistance or incentives supportive of the MSME sector (Busenitz et al., 2000). The concern is more on determining the extent to which the local government provides help to MSMEs rather than knowing the specific assistance programs/packages which would be naturally voluminous and beyond the scope of the current study. 
Several studies noted that governments have a significant role to play in nurturing the small business sector by being involved in the provision of non-traditional functions such as coordinating and monitoring economic agents, market development, financing, supporting producers, enabling community self-provision, supporting customers through provision of information, and direct provision of services not undertaken by the market (Arinaitwe, 2006; Co, 2004; Jackson, 1999).

Whilst government assistance programs and other forms of market intervention could be viewed by others as harmful to the free market economy, it has been shown that selective interventions seem to generate positive results (Cameron \& Massey, 1999). The importance of MSMEs in economic development cannot be overemphasised despite the possible liability of smallness. The perceived high risks in investing in such a "fragile" business sector make it difficult for MSMEs to gain access to providers of resources such as the mainstream financial markets. This situation warrants the provision of government assistance being the bastion of institutional support for the survival and/or growth of MSMEs.

\subsubsection{Government Assistance and Strategic Posture}

Government assistance as a formal institution provides direct incentives to, and remains a major force for development of MSMEs (Kotabe \& Czinkota, 1991; Ramsden \& Bennet, 2005; Yung-Ching \& Tsui-Hsu, 2006). McIntyre (2002) argues that little can be expected from the small business sector without the active support at the local level.

This type of assistance enriches the munificence of the external environment of MSMEs. It can be recalled that the scarcity or abundance of critical resources needed by a firm operating within an environment influence the survival and growth of firms sharing that environment (Castrogiovanni, 1991). The actions (or inaction) of the state (i.e. local government unit) has formal institutional weight as it forms part of the formal administrative-bureaucratic framework through which the functions of the state are disposed. The local government's role in providing assistance to MSMEs 
could be viewed as a "stock" from which firms draw services without necessarily making direct payments (Kotabe \& Czinkota, 1991).

Munificence has been shown to be positively associated with a range of strategy and organisational options. In an abundant (i.e. highly munificent) environment, firms may it easy to survive and be more able to pursue goals other than survival (Castrogiovanni, 1996). A munificent environment has been shown to shape the level of innovation of established firms as it opens up access to critical resources (Zahra, 1993).

Furthermore, institutional support in the form of subsidies and training programs can be enabling mechanisms through which small businesses are able to pursue a range of strategic orientations such as survival-oriented or more aggressive-type of strategies (Skuras, Caldas, Meccheri, Psaltopoulos \& Viladomiu, 2003). However, these studies were conducted in the rural context so it would be interesting to determine whether government assistance shapes the strategic posture of MSMEs in an urban setting.

Government assistance is also considered as providing incentives in the truest sense of the word. Incentives, in the Northian institutional context, refer to a set of institutional factors that encourages or supports specific behaviours or activities (in this case, entrepreneurial activities). As North (1990) puts it, formal institutions have two fundamental functions: to discourage unproductive behaviour through the use of rules; and to promote productive behaviour through the use of incentives.

The theory of enabling authority (Leach et al., 1994) could well explain the role of government assistance in promoting more proactive and innovative MSMEs. This theory poses a challenge of whether a local government unit can rise above the traditional regulatory functions and play a more pro-active role in broadening the range of choices available for MSMEs. The notion of enabling authority entails the exercise of the three fundamental economic roles of a modern local government provider of formal institutions, income distributor, and promoter of economic growth. The local government may exercise its powers to provide MSMEs with access to critical resources should the private market fails to do so (Leach et al., 
1994). Consequently, MSMEs are given the opportunity to expand their business activities by discovering new opportunities, developing new products and services, or improving their production operations given their access to a wide range of assistance from the local government being the government authority closest to the residents of a city.

Hence, it is advanced in this study that:

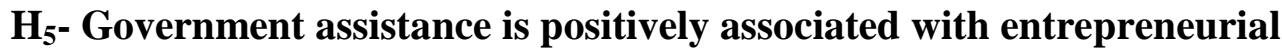 strategic posture.}

\subsection{Informal Institutions}

The development of an institutional environment conducive to MSMEs does not depend solely on the installation and upkeep of formal institutions. It also requires nurturing the informal institutions that may be as influential as that of the formal institutional (or legal-political) framework. The concept of informal institutions as used in this study refers to the cultural factors shared by members of a society in a given locality or city that serve as constraints and/or standards and the violation of which entails social rather than legal penalties (North, 1990; Olsson, 1999; Redmond, 2005). Despite the lack of legal enforcement mechanisms, informal institutions and their enforcement characteristics including traditions, customs, moral values, religious beliefs, social conventions, and generally accepted ways of thinking and doing are able to impose restrictions on the behaviour of individuals belonging to such social group.

These informal institutions or unwritten rules are created, communicated, and enforced outside officially sanctioned channels (Helmke \& Levitsky, 2004). Their enforcement takes place by way of sanctions such as expulsion from the community, ostracism by friends and neighbours, or loss of reputation (Pejovich, 1999). Whilst informal institutions can be considered as constituting norms which specify rules of conduct and appropriate behaviour in a given range of social settings or prescribe/forbid a given type of behaviour (Bilton et al., 1996; Giddens, 1997), the 
difference lies in the understanding that informal institutions as used in this study may not have legal enforcement mechanisms.

The scarcity of published studies specifically describing and examining the role of informal institutions especially in the context of entrepreneurship and/or small business development posed the greatest challenge in this study. Whilst there are a number of studies discussing the theoretical and conceptual bases of informal institutions (Aidis, 2005; Davis, 2006; Pejovich, 1999), only a handful of empirical studies attempted to measure specific constructs categorically classified as informal institutions (Nkya, 2003; Peng \& Heath, 1996; Peng, 2004; Robson, 2004; Tabellini, 2005). Even so, informal institutions are oftentimes treated ex post facto or as residuals after exhaustively discussing formal institutional mechanisms. This is anathema to North's (1990) original concept of informal institutions for which he argues that "informal constraints should not be treated as mere appendages of formal rules" (North, 1990).

Whilst North provides a comprehensive theoretical framework for the discussion of information institutions, he has not operationalised the concept in a manner that is sufficiently clear to engender consistency or rigour in empirical work. Subsequent studies (as discussed in Chapter 2) exploring informal institutions took either a more exploratory and qualitative approach to describe informal institutions or a very focused, context-specific, and problem oriented approach to quantify specific types of informal institutions. Moreover, the review of the literature reveals that there is no universal typology of informal institutions. The relevance of a set of institutions is founded on the specific context in which they are being studied (Hollingsworth, 2002).

The scarce published empirical studies on informal institutions examined socio cultural factors such as kinship, community networks, religion, norms, and values as manifestations of informal institutions having varying degrees of influence on human or organisational behaviour (Hill, 1995; Nkya, 2003; Pejovich, 1999; Tabellini, 2005). Obviously, there is a plethora of studies examining culture using the popular framework of Hofstede $(1983$; 1980) whereby cultural dimensions such as 
collectivism and uncertainty avoidance were shown to be related to entrepreneurship in various respects (Robson, 2004).

\subsubsection{Culture as Informal Institutions}

By building on previous studies directly categorising culture as informal institutions as well as the theoretical/conceptual explanations of North, it is advanced in this study that culture captures well the essence of the 'informality' of informal institutions. This argument is founded on the fundamental operationalisation of informal institutions by North $(1990 ; 1991 ; 1992)$ saying that informal institutions such as codes of conduct, norms of behaviours and conventions are socially transmitted information and are part of the heritage that is called culture. North $(1990 ; 1991 ; 1992)$ further emphasises the transmission of this culture from one generation to the next via teaching and imitation of knowledge, values, and other factors that influence behaviour. Hence, the formality/informality of institutions lies in a continuum: taboos, customs, and traditions at one end representing informal institutions, and written constitutions, and contracts at the other end, representing formal institutions (North, 1990).

North's (1990) operationalisation of informal institutions is open to wide interpretations giving the researcher a significant amount of uncertainty whether to call one variable informal institution or not. More often than not, studies are likely to define informal institutions but then focus the discussion on formal institutions and leave informal institutions in the background.

The review of the literature reveals a paucity of studies that address the clear categories or types of informal institutions in the forms of world values (Tabellini, 2005), individualism-collectivism (Robson, 2004), culture in general (Pejovich, 1999), socialist values (Peng \& Heath, 1996) and kinship networks (Ahlstrom \& Bruton, 2002; Peng, 2004). The works of Pejovich (1999), Peng and Heath (1996; 2004), Ahlstrom \& Bruton (2002) and Li, Lam and Qian (2001) are amongst the very few studies that explicitly categorised culture and its various levels of dimensions as manifestations of informal institutions. In a more recent study, culture was viewed as a set of normative institutions which consists of norms, values, beliefs, and assumptions that are socially shared by individuals (Parboteeah et al., 2008). In 
effect, institutional theory implies that culture is subsumed under the overall institutional environment of firms (Wu, Lawler \& Yi, 2008)

Given that informal institutional analysis may look at specific norms, beliefs or conventions, the use of a widely accepted typology of cultural dimensions as in the case of the present research is warranted. This approach remains true to North's concept of informal institutions and consistent with previous, albeit few studies on the subject. Studies have shown that culture greatly shapes the normative and cognitive dimensions of a nation's institutional profile (Ahlstrom \& Bruton, 2002; Kostova, 1997; Parboteeah et al., 2008). Wan and Hoskisson (2003) suggest looking at cultural factors as institutions shaping the strategies and performance of firms.

In this study, culture is broadly referred to as the collective programming of the mind that makes a group of people distinct from others (Hosfstede, 1980). These 'mental programme' in turn, allows sharing of a certain set of values, beliefs, norms, conventions, ideologies and taken for granted assumptions and lifestyles by members of that particular group or society (Hosfstede, 1980). According to Malach-Pines et al (2005), culture is learned and is manifested through heroes, symbols, rituals, and values and that it consists of the abstract values, beliefs, and perceptions of the world that underlie and are reflected in people's behaviour.

Similar to formal institutions, culture places boundaries on human behaviour by defining acceptable and unacceptable behaviour and/or actions (McGrath, MacMillan, Yang \& Tsai, 1992; Parboteeah, Bronson \& Cullen, 2005). A national culture for instance, is a fairly consistent set of value orientations developed in response to two universal facts: that there are a limited number of common societal problems and that there are a limited number of known responses (McGrath et al., 1992). In effect, culture exerts some degree of control on how people of a given society view the world and generates meaning from and for it which subsequently shape their responses in cognitive, affective and behavioural forms. Likewise, culture helps human communities find solution to problems of external adaptation (i.e. how to survive) and internal integration (i.e. how to stay together) (Javidan, 2004). 
The literature on culture is replete with assertions that this mental program sets limits to economic rationality and shapes intra- and inter-firm practices. National culture has been shown to have greater impact on employees than organisational culture ( $\mathrm{Li}$ et al., 2001). It influences managerial decision-making, leadership style and human resource management practices ( $\mathrm{Li}$ et al., 2001). Societal culture may also be seen as part of the firm's resources leading to competitive advantage (Li et al., 2001). Moreover, culture may be instrumental in shaping the nature and impact of management practices of firms (Wu et al., 2008).

Furthermore, economic rationality may be restricted due to the ability of culture to shape one's perception of risk and decision-making - influencing how one sizes up the situation, perceives the problem, generates possible solutions, and measures the probable consequences (Martinsons \& Davison, 2007; Weber \& Hsee, 2000). Culture shapes an individual's schema and sense making, which subsequently act as powerful filters that shape interpretation of reality (Chrisman, Chua \& Steier, 2002). Because culture is a shared attribute, individuals with common cultural backgrounds will tend to have more similar views (interpretations and perceptions) of their environments than those with different cultural backgrounds (Chrisman et al., 2002). Therefore, it stands to reason that these culturally-based perceptions and interpretations significantly shape behaviours and outcomes such as the strategic posture and performance of owners/managers of MSMEs.

Several theories support this culture-strategic posture link. Cultural theory, for instance, posits that the beliefs, actions, and norms of an individual mesh with the organisation of social relations making individual rationality and choice processes biased to a certain extent (van Heffen \& Klok, 2003). This theory also contends that whilst human decisions and actions are determined by culture, the same decisions and actions may slightly adjust or completely change the social structure often termed as cultural shift (van Heffen \& Klok, 2003). It implies that there is an interdependent relationship between individual rationality and culture.

In addition to cultural theory, it was previously noted that the theory of planned behaviour (TPB) (Ajzen, 1991) seeks to explain how informal institutions relate to the strategic behaviour of owners/managers of MSMEs. TPB suggests that informal 
institutions could shape the MSME owner's/manager's perceptions on the desirability of engaging in entrepreneurial strategic posture as well as the social norms on the acceptability of such kind of strategic posture. Consequently, these perceived desirability and social norms shape the owner's/manager's intentions and actual behaviour to pursue an entrepreneurial strategic posture (Ajzen, 2002).

The theory of organisational legitimacy offers further explanation of the informal institutions - strategic posture link (Suchman, 1995). Legitimacy is referred to as the generalised perception or assumption that the actions of an entity are desirable, proper, or appropriate within a social system or that it conforms to the society's system of norms, values, beliefs and definitions (Deephouse \& Carter, 2005; Suchman, 1995). A legitimated organisation meets and adheres to the expectations of the institutional forces in the wider social system in which an organisation is embedded. In a firm's efforts to gain legitimacy, it alters its form, structure and processes to be more consistent with its external environment being the source of legitimation - a process popularly known in organisational theory as isomorphism (Deephouse \& Carter, 2005). Legitimacy is sought after to reap the benefits of continuity, credibility, and/or support (Suchman, 1995).

Hence, these informal institutions (i.e. socio-cultural factors) significantly "control" the internal functions of an organisation that is in pursuit of legitimacy. More specifically, organisations exercise their strategic posture to gain and maintain legitimacy. Efforts to gain legitimacy include conforming to existing environmental demands, selecting an environment that is likely to support the organisation, or manipulate the existing environment (Suchman, 1995). Maintaining legitimacy may entail proactive efforts to perceive future changes and emerging challenges and protect past accomplishments so as to convert episodic legitimacy into continuous forms within the organisation (Suchman, 1995).

Therefore, in this study, informal institutions are operationalised by cultural dimensions through the use of an existing "cultural framework". It is important to note that they are other ways of operationalising informal institutions and/or culture and the approach used in this study is one method that suits the purpose of the study. 


\subsubsection{Use of the GLOBE Cultural Framework}

It is important to note that there is a plethora of ways to "measure" culture and no single way is better than the other. This study adopts the Global Leadership and Organisational Behaviour Effectiveness (GLOBE) cultural framework developed by House et al (2004) for a number of reasons. The study of Parboteeah et al (2005) claims that the GLOBE cultural study is the most up-to-date national culture study providing helpful updates to the cultural dimensions identified by Hofstede (1980) whose work has been criticised for many of its conceptual and methodological issues. As such, using the GLOBE framework tends to avoid Hofstede's (1980) problematic issues and incorporates other cultural dimensions not included in Hofstede's work nor in other cultural schemes (Parboteeah et al., 2005).

The GLOBE cultural framework fits the purposes of the current investigation. Apart from being the most current framework to measure cultural practices, GLOBE's survey of 17,300 middle managers in 951 organisations in 62 societies is an approach that fits the purposes of the current study. The methodology of asking middle managers about cultural practices in the societies where they live fits the objective of the current study to measure the perceptions of owners/managers of MSMEs of the cultural practices of the cities where they live. The GLOBE framework also assumes cultural heterogeneity within the same national boundary, hence the focus on societies rather than countries. It acknowledges the possibility of cultural variations within countries - an approach that suits the focus of the current study: sub-national institutional environments. Moreover, the GLOBE framework relates the cultural practices to leadership behaviour of the middle managers who were surveyed. This approach is relevant to the current study such that the informal institutional environment as manifested by cultural practices is examined in terms of its relationship with the strategic posture of the top management of MSMEs.

The focus on city-context (i.e. sub-national) measurement of culture is based on the view that there is possibility of cultural variations even within the same national boundary (Ma \& Delios, 2007; Meyer, 2005). There is reason to believe that in ethnically-diverse and geographically-dispersed countries like the Philippines, such institutional (cultural) heterogeneity would be highly noticeable. Whilst the GLOBE 
cultural framework has a country-wide focus, Professor Peter W. Dorfman of the GLOBE team acknowledges, in a seminar held at Victoria University of Wellington in 1997 (attended by this study's author), the need to examine within-country cultural variations as a step forward to understand the role of culture in organisational and leadership behaviour.

The next section presents the different cultural dimensions that can be viewed as informal institutions relevant to understanding MSME strategic posture and performance. The specific informal institutions include performance orientation, future orientation, assertiveness, collectivism, power distance, humane orientation, and uncertainty avoidance. The focus of this study is on describing the cultural practices of a given locality (i.e. city) across these cultural dimensions identified by the GLOBE study (House et al., 2004). Whilst these dimensions are derived from the same GLOBE study, it must be noted that collectivism as used in this study refers to "institutional collectivism" as opposed to "in-group" collectivism (which refers to pride, loyalty, and interdependence in families) - both of which are part of the GLOBE study. Likewise, gender egalitarianism - another GLOBE cultural variable, was excluded in this study as there appears to be no theoretical or empirical basis to relate this construct to strategic posture of MSMEs.

The study followed the recommendation of Kostova (1997) and Parboteeah et al (2008 p. 798) to "use only those elements that theory suggests are most relevant to the issue under investigation". Hence, the study included only those theoretically compelling GLOBE cultural dimensions that are considered to be related to the strategic posture of MSMEs (Parboteeah et al., 2008). This problem- and contextdriven approach to inclusion of variables allows the development of a meaningful and substantial research model that will allow empirical testing and/or validation.

The GLOBE cultural framework measures culture using the Direct Values Inference method whereby cultural characteristics are inferred from the aggregated values of respondents in a survey (Lenartowicz \& Roth, 1999). One of the strengths of the framework is its predictive validity whereby cultural dimensions are studied not just in the context of the general society but also in the context of leadership and organisational behaviour (House, Hanges, Javidan, Dorfman \& Gupta, 2004). The 
application of this framework in this study includes asking MSMEs their perception on the degree of presence of the different dimensions of culture (i.e. informal institutions) of their society in a city-context.

\subsubsection{Performance Orientation}

Performance orientation reflects the extent to which a community encourages and rewards innovation, high standards, and performance improvement (Javidan, 2004). Performance-orientated cultures also value results, assertiveness, competition, and materialism (Javidan, 2004). Performance-orientated societies tend to value those individuals who can perform and achieve and who can produce results which becomes the basis of social judgement (Parboteeah et al., 2005).

Performance orientation shows strong resemblance to McClelland's Need for Achievement as well as the Protestant Ethics of individual responsibility, hard work, knowledge and challenge (Javidan, 2004). It is considered as an important dimension of a community's culture as the underlying practices and values have an impact on the way the community defines success in adaptation to external challenges (Javidan, 2004). It promotes the values of seeking betterment, setting high standards of performance, ambitious expectations and a thirst for learning (Javidan, 2004).

According to Javidan (2004), societies with high level of performance orientation tend to display high levels of competitiveness, self-confidence, and ambition. Likewise, Javidan further argues that in these societies, time is considered nonrenewable and subject to high depletion thereby promoting a strong sense of urgency in meeting challenges and making decisions.

Amongst the scarce studies on performance orientation as it relates to entrepreneurship and/or MSMEs are those that include the work of Javidan (2004), Hansemark (1998), and Lee and Peterson (2000). Javidan (2004) correlated performance orientation with economic prosperity and productivity as well as competitiveness. Results revealed that countries having high level of performance orientation are likely to have higher levels of economic development and are more 
competitive than others. One study supports the link between high need for achievement of founders of businesses and that of growth and success in business (Hansemark, 1998). A study further supports the link between society's emphasis on achievement and that of high levels of risk-taking and innovation (Lee \& Peterson, 2000).

In as much as performance orientation values competitiveness, assertiveness, initiative, results-driven, innovativeness, and ambition, it can be argued that in a society with high level of performance orientation, MSMEs with entrepreneurial strategic posture are likely to flourish. Stated differently, MSME owners/managers who are risk-takers, innovative, and proactive are likely to flourish in a performanceoriented city where these characteristics are valued and in fact rewarded. Hence it is proposed in this study that:

\section{$\mathrm{H}_{6}$ - High levels of performance orientation are positively associated with entrepreneurial strategic posture.}

\subsubsection{Future Orientation}

Future orientation broadly refers to the extent to which individuals engage in futureorientated behaviours such as delaying gratification, planning and investing in the future (Corral-Verdugo \& Pinheiro, 2006). It is a dimension of the more general construct - time orientation - that relates to the subjective experience of time (Ashkanasy, Gupta, Mayfield \& Trevor-Roberts, 2004). Based on the above definitions, future orientation is used in this study to mean the tendency to conscientiously think and plan for the future and consider the long-term consequences of one's actions in the present.

Cultures with high future orientation display strong capability and willingness to imagine future contingencies, formulate future goals states, and seek to achieve goals and develop strategies for meeting their future aspirations (Ashkanasy et al., 2004). Despite their tendency to lack a solid appreciation of situational realities because of neglect of their present personal and social relationships and interactions, people in societies with strong future orientation tend to have capacity to enrich their lives and 
maintain self-control (Ashkanasy et al., 2004). They are likely to be good in establishing and achieving goals and in planning strategies for meeting long-term obligations (Corral-Verdugo \& Pinheiro, 2006). Furthermore, individuals in future oriented societies tend to visualise and formulate future objectives, which in turn influence present decisions and judgements (Corral-Verdugo \& Pinheiro, 2006). Low future orientation reflects the capability to enjoy the moment and be spontaneous, free of past worries or future anxieties but at the same time, seek hedonistic pleasures (Ashkanasy et al., 2004).

Future orientation shows strong resemblance to the newly added cultural dimension of Hofstede (1980) called long-term orientation (Gong, Li \& Stump, 2007). It was uncovered that long term orientation tends to reinforce the adoption of new technologies (innovation) with the strong belief that innovations are mechanism through which goals are attained (Gong et al., 2007). Likewise, future orientation tend to have a facilitative role for achievement orientation as it was shown that future oriented individuals tend to have high need of achievement as well (Ashkanasy et al., 2004).

Individuals in a future oriented society transform future time into discrete sub-goals thereby bring the future into the present (Ashkanasy et al., 2004). They are more likely to emphasise education and training, and practice persistence, thriftiness and the delay of immediate gratification for the sake of attaining more rewarding goals (Li et al., 2001).

Fatalism and determinism are two constructs that appear to be the opposite of future orientation. Fatalism is being described in the literature as the belief that whatever happens must happen and that it is not possible to fully control the outcomes of one's actions (Aycan et al., 2000). Aycan et al (2000) concludes that fatalistic people tend to view trying too hard to achieve something, making long-term plans, and taking preventative action as worthless exercises. Similarly, determinism, which has been shown to be a strong characteristic of the Philippine society, is expressed in the local saying "bahala na" (i.e. "Come what may) implying that one need not worry about the future because nothing can be done about it anyway (Church \& Katigbak, 2000; Kirkman \& Shapiro, 2001; Pe-Pua \& Protacio-Marcelino, 2000). This is a fatalistic 
resignation or withdrawal from an engagement or crisis or shrinking from personal responsibility (Pe-Pua \& Protacio-Marcelino, 2000).

It was subsequently found out that high determinism makes it difficult for organisations to implement self-managing work team programs (Kirkman \& Shapiro, 2001). A society with a fatalistic attitude feels subject to many rules and obligations, that it is a plaything of forces that are difficult to fathom, and feels that there is little choice about the way of living and therefore little individual autonomy (van Heffen \& Klok, 2003).

The foregoing discussion suggests that MSMEs are likely to seek out and exploit new opportunities for business by taking more risks, becoming more innovative and be proactive vis-à-vis other players in the industry. These activities are wellsupported in a place where the culture values capabilities and willingness to imagine future contingencies, formulating future goals states, and seeking to achieve goals and developing strategies for meeting future aspirations. Hence, the following hypothesis:

\section{$\mathrm{H}_{7}$ - High levels of future orientation are positively associated with entrepreneurial strategic posture.}

\subsubsection{Assertiveness}

Assertiveness reflects the beliefs as to whether people are encouraged to be assertive, aggressive, and tough or non-assertive, non-aggressive, and tender in social relationships (Den Hartog, 2004; Parboteeah et al., 2005). Assertiveness in behaviour includes making it clear to others what one wants, refusing what one does not want and generally expressing one's intentions in clear and unambiguous terms (Parboteeah et al., 2005). Assertiveness also entails willingness to confront opposing views and to express one's ideas and feelings in social encounters (Niikura, 1999). It is reported that assertive societies tend to be competitive, value success and to think of others as necessarily opportunistic (Den Hartog, 2004). 
The concept of assertiveness as a cultural dimension originates from Hofstede's (1980) cultural dimension of masculinity versus femininity although the GLOBE study is the only cultural framework that treats assertiveness as a cultural dimension (Den Hartog, 2004). Hence, it can be argued that assertiveness is a construct that falls under the wider concept of masculinity-femininity of Hofstede (1980). Treating aggressiveness as a cultural dimension implies that the nature of the relationships of individuals, groups, and societies with the outside world tend to be of dominance rather than subjugation or harmony (Den Hartog, 2004). Assertive societies tend to look at nature as something to be controlled and manipulated, take a pragmatic stance towards reality, and have a belief in human perfectibility (Den Hartog, 2004). A highly aggressive culture places high value on achievement, independence, heroism, monetary rewards, and decisiveness (Gleason, Mathur \& Mathur, 2000; McGrath et al., 1992; Su, 2006)

The relationship between assertiveness and MSME strategic posture may be explained in terms of the dimensions of strategy-making. It is argued that assertiveness is an inherent dimension of strategy-making which concerns the levels of risk-taking and reactiveness or proactiveness of decisions (Koberg, Tegarden \& Wilsted, 1993; Miller, 1987). Since entrepreneurial firms are viewed as risk-takers and act on rather than react to their environment, then an assertive culture is likely to support entrepreneurial strategic posture as strategy-making and implementation are considered as an exercise of assertiveness (Koberg et al., 1993; Miller, 1987). Previous studies linking assertiveness to various aspects of business organisations uncover diverse results. One study shows that high masculinity/assertiveness results to lesser tendency of firms to engage in alliances (Steensma, Marino, Weaver \& Dickson, 2000). McGrath et al (1992) argue that managers in masculine or highly assertive culture are likely to "show off" compared to those coming from feminine/unassertive culture. Specifically, managers in feminine cultures will be more likely to talk themselves out of an action that they perceive as containing unnecessarily high levels of risk (McGrath et al., 1992). This study lends credence to the argument that assertiveness is associated with risk-taking.

Likewise, it has been shown that a culture with low level of assertiveness tends to have modes of self-expression characterised by circumlocution, deference for one's 
superiors, diffidence, and a preference for harmony rather than confrontation (Niikura, 1999). These attributes are seemingly in contradiction to the proactive dimension of entrepreneurial strategic posture which implies continuous search for market opportunities and experimentation. Opportunity seeking requires foresight to act as well as decisiveness to pursue strategic moves - attributes that are not supported by diffidence (i.e. hesitation to act due to lack of confidence). Experimentation may require challenging the status quo (as opposed to maintaining harmony), and even questioning what superiors or higher authorities believe as opposed to deference and submission. Hence it is proposed in this study that:

\section{$\mathrm{H}_{8}$ - High levels of assertiveness are positively associated with entrepreneurial strategic posture.}

\subsubsection{Collectivism}

Collectivism involves the subordination of personal interests to the goals of the larger group, an emphasis on sharing, cooperation, interpersonal connectedness, group harmony and solidarity, and joint responsibility, a concern for group welfare, and hostility toward out-group members (Gelfand, Bhawuk, Nishii \& Bechtold, 2004; Hosfstede, 1980; Hostede, 1983; Morris, Avila \& Allen, 1993; Parboteeah et al., 2005; Su, 2006; Yilmaz, Alpkan \& Ergun, 2005). As a concept, collectivism refers to the interdependence between self and one's group or community implying that collectivists place more value on collective goals and are guided more by group norms and traditional authority figures (Oyserman, Coon \& Kemmerlmeier, 2002; Triandis \& Gelfand, 1998) The opposite construct is individualism which refers to self-orientation, an emphasis on self-sufficiency and control, the pursuit of individual goals that may or may not be consistent with in-group goals, willingness to confront members of the in-group to which they belong, and a culture where people derive pride from their own accomplishments (Morris et al., 1993; Yan \& Hunt, 2005). Personal freedom is valued and individual decision-making is encouraged in societies with high individualism culture (Gong et al., 2007).

The link between the bipolar factor - collectivism/individualism - and strategic posture is muddled with controversy. One study, often cited in the literature, found a 
curvilinear relationship between the two implying that firms tend to be entrepreneurial in their strategic posture under balanced conditions of individualism/collectivism and less so in highly individualistic or collectivist cultures (Morris et al., 1993). However, the relatively small sample size (i.e. 180 firms) situated in the same state in the United States has major implications on the generalisability of the result - a limitation of the study which the researchers duly recognised.

However, studies have shown that cultures that are low in collectivism (i.e. high in individualism scores) tend to support entrepreneurial strategic posture. McGrath et al (1992) argue that entrepreneurs must have high individualism score since under individualist culture, individual initiative, achievement, right to privacy as well as formation of one's own opinion are highly valued. This is consistent with the findings of Parboteeah et al (2005) and Yan \& Hunt (2005).

Furthermore, members from individualist cultures tend to exhibit more favourable attitudes toward differentiation and uniqueness whilst members from collectivist cultures tend to show more favourable attitudes toward building and maintaining relationships with people within their social structure (Gong et al., 2007). Another study shows that there is positive relationship between innovation and high level of individualism (Shane, 1993; Yaveroglu \& Donthu, 2002). This could be explained by the fact that managers in individualistic countries tend to be more autonomous and independent than managers in collectivist cultures and they are more likely to be willing to violate group norms (Morris et al., 1994). It is argued that McClelland's high need for achievement nurtures entrepreneurial efforts whilst the need for affiliation which is similar to collectivism, inhibits such activities because it distracts people from productive, and achievement-oriented activity (Tiessen, 1997).

In the study of Philippine society, a high level of collectivism manifests itself in the cultural value of social acceptance which is considered as a major value that takes precedence over economic security and advancement (Espiritu \& Hunt, 1964). Social acceptance is gained by positive or "smooth" inter-personal relations and the desirability of any action may be governed more by its effect on inter-personal relationships than by other concerns (Espiritu \& Hunt, 1964). The values of 
pakikisama (i.e. accompany or getting along with others), amor propio (i.e. selfesteem), hiya (i.e. shame) all stem from and point to the basic desire to maintain harmonious social relationships. As a result, behaviours that do not conform to group norms and actions that upset the collective are viewed as kahiya-hiya (i.e. shameful), may reduce one's self-esteem as a result of community or group ostracism for walang pakisama (i.e. not going along with the common norms) (Pe-Pua \& ProtacioMarcelino, 2000). Such values characterise a highly collective Philippine society.

A highly collective society such as the Philippines may result in having members who are very conscious of the social consequences of their actions. Efforts are made to avoid upsetting the social norms or engaging in behaviours which may result in social embarrassment (Espiritu \& Hunt, 1964). In a study of small firms in Pakistan, it was revealed that women tended to limit their financial risk to their own funds, mainly because they are afraid of the social consequence of business failure such as social embarrassment (Shabbir \& Di Gregorio, 1996). Fielden \& Dawe (2004) concur that social stigma toward entrepreneurial failure is a critical barrier to business creation. Consequently, conservative use of limited funds constrict the productive capacity of a firm.

An entrepreneurial strategic posture can be perceived as a direct challenge to the major attributes of collectivism: conformity to social norms and avoidance of actions that upset the balance of social relations. These attributes may inhibit MSMEs within that collectivist culture in being proactive vis-à-vis their competitors. They may stifle innovation as novel and untested ideas are never shared nor tried out for fear of violating social norms. Putting immense value on avoiding social embarrassment may prevent MSMEs to take risks in seeking out business opportunities. Hence it is proposed in this study that:

\section{$\mathrm{H}_{9}$ - High levels of collectivism are negatively associated with entrepreneurial strategic posture.}




\subsubsection{Power Distance}

Power distance reflects the extent to which a community accepts and endorses authority, power differences, and status privileges (Carl, Gupta \& Javidan, 2004). Acceptance of asymmetry in power relationships explains the psychological distance separating the power-holders and those who are under or subject to them (Yilmaz et al., 2005). High degree of power distance leads to a less participative stance in decision making, greater reliance on rules and procedures, and higher levels of subordinate submissiveness (Yilmaz et al., 2005). Likewise, preservation of current status tend to be highly noticeable in societies with high power distance (Hosfstede, 1980).

Shane (1992) explains that high power distance is anathema to innovation because it promotes hierarchical social structure and inequality, inhibits informal communication between people in different hierarchical levels, encourages centralisation of power, endorses elaborate control systems especially in organisations, and upholds unwillingness to accept change in the distribution of power. All these, according to Shane (1992) inhibit innovation such that: dispersed power structures create coalitions that support innovation; frequent informal communication as well as decentralisation permit free flowing of ideas which facilitates knowledge acquisition and diffusion; control systems based on trust rather than rigid rules and procedures encourage active participation and creative thinking amongst employees; and social mobility increases occupational mobility, technical change and innovation.

McGrath et al (1992) express a different argument that high power distance may create particular incentives for entrepreneurial activity by blocking other routes to attain success. If entrepreneurship is perceived as a way out of poverty, the more extreme the difference in wealth, the greater the incentive to start a business (McGrath et al., 1992).

Despite McGrath et al's (1992) argument, other studies lend support to Shane's (1992) findings. Innovation tends to be significantly lower in countries with high power distance (Yaveroglu \& Donthu, 2002). Cultures that exhibit large power 
distance will be less innovative because people in such cultures are encouraged to respect authority, follow directions and avoid standing out through original thinking (Gong et al., 2007). People may take less initiative to consider and discuss the introduction of new products and technologies and will generally wait for signals from authority figures or opinion leaders (Gong et al., 2007). Likewise, people will have little inclination to take responsibility outside the immediate scope of their jobs, to act on urgent marketplace information, and to provide individual input into strategy and planning (Yilmaz et al., 2005). Shane (1993 ) further suggests that managers with low power distance will be more willing to engage in risky behaviours aimed at improving their current industry standing. This would partly explain the higher rates of innovation in countries with low power distance. Hence, it is advanced in this study that:

\section{$\mathrm{H}_{10}$ - High levels of power distance are negatively associated with entrepreneurial strategic posture.}

\subsubsection{Humane Orientation}

Humane orientation characterises those societies where people's behaviours are guided by values of altruism, benevolence, kindness, love, and generosity (Kabasakal \& Bodur, 2004). The need for belongingness and affiliation rather than selffulfilment, pleasure, material possession and power are likely to be the dominant bases (Kabasakal \& Bodur, 2004). Societies that have high humane orientation tend to place greater importance on others (i.e. family, friends, or community), have high need for belonging and affiliation, values obedience and promotes close monitoring of children by children rather than promoting independence (Kabasakal \& Bodur, 2004).

There appears to be a paucity of literature examining in detail the nature of humane orientation, more so as it relates to business. What is known is that this cultural dimension has been shown to be positively associated with GLOBE's institutional collectivism and in-group collectivism (House et al., 2004). The same study shows that it is negatively associated to assertiveness. This implies that a society with friendly members who care for others has a tendency to be collective and non- 
assertive (Kabasakal \& Bodur, 2004). Likewise, humane orientation is associated by Kabasakal and Bodur (2004) to humane-oriented leadership characterised by more consideration and maintenance-oriented leadership, less task-orientation, and building informal and personal relationships with subordinates.

As a cultural dimension, humane orientation is a recently developed concept which explains the very limited theoretical and empirical literature on the subject. Nonetheless, this study relies primarily on the findings of the GLOBE study in its attempt to operationalise humane orientation.

The GLOBE study characterisation of a humane oriented culture tends to contradict the elements of an entrepreneurial strategic posture: risk-taking, proactiveness, and innovation. Greater emphasis on affiliation rather than achievement, less emphasis on self-fulfilment, material possession and power, less emphasis on independence, strong tendency towards collectivism, and lesser value placed on assertiveness: all these do not fit nor support the conceptual scope of entrepreneurial strategic posture. To achieve something is an underlying purpose of entrepreneurial risk-taking. Likewise, independence is an essential element of innovation and proactiveness based on the assumption that one can only be innovative and proactive if one is willing to take a firm stand on what they think and feel (independent) and pursue ideas contrary to popular beliefs. Hence it is advanced in this study that:

\section{$\mathrm{H}_{11}$ - High levels of humane orientation are negatively associated with entrepreneurial strategic posture.}

\subsubsection{Uncertainty Avoidance}

Uncertainty avoidance refers to the extent to which ambiguous situations are threatening to individuals, to which rules and order are preferred and to which uncertainty is tolerated in society (De Luque \& Javidan, 2004; Gleason et al., 2000). It refers to the extent to which members of a society seek orderliness, consistency, structure, formalised procedures, and laws to cover situations in their daily lives (De Luque \& Javidan, 2004). In short, uncertainty avoidance reflects the level of tolerance for ambiguity within a given culture (Parboteeah et al., 2005). 
A society with low uncertainty avoidance implies that its members have greater willingness to take risks (Hosfstede, 1980). The notion of ambiguity and risk are easily accepted (McGrath et al., 1992). Likewise low uncertainty avoidance comes with it values for risk-taking, strong motivations for individual achievement and more optimism- a very good climate for entrepreneurial endeavours to thrive (Gong et al., 2007; McGrath et al., 1992).

The intention to become an entrepreneur and start up a business is characterised as a risky behaviour compared to establishing an employment career with predictable and steady flow of income. There is a significant amount of ambiguity and anxiety in one's intention to engage in a business venture regardless of the size. The fear of failure (usually operationalised by one's risk aversion) is a particularly critical issue for entrepreneurs due to the little separation between business and personal risk in an entrepreneurial venture (Watson and Robinson 2003). In this case, an entrepreneurial strategic posture can be characterised as requiring fair tolerance of ambiguity, locus of control that is more internal than external as well as willingness to take risks that are relatively well calculated (Pitt \& Kannemeyer, 2000). This implies that low uncertainty avoidance may be a contributory factor in shaping the risk-taking behaviour of MSMEs.

De Luque and Javidan (2004) cited studies showing how uncertainty avoidance can serve as human barrier to successful adoption of technologies and new projects with uncertain outcomes. Uncertainty avoidance turns out to be anathema to innovation as the latter tends to introduce unanticipated changes and cause uncertainty which in turn leads to resistance to innovation (De Luque \& Javidan, 2004; Erumban \& de Jong, 2006). Hofstede (1980) noted that in high uncertainty avoidance societies, there is greater fear of failure, lower willingness to take risks, lower levels of ambition, and lower tolerance for ambiguity. These values tend to contradict the entrepreneurial values of proactiveness, innovation, and risk-taking. Hence it is proposed in this study that:

\section{$H_{12}$ - High levels of uncertainty avoidance are negatively associated with entrepreneurial strategic posture.}




\subsection{Strategic Posture and MSME Organisational Performance}

A major argument advanced in this study is that strategic posture shapes the organisational performance of MSMEs. At the core of this argument is the view that strategic posture is the embodiment of the managerial choices in the form of strategies which ultimately determine the performance outcomes of firms (Priem, 1994; Venkatraman \& Prescott, 1990b). The argument emanating from the industrial organisation (I/O) literature highlights the structure-conduct-performance link suggesting that conduct (i.e. strategic posture) is an antecedent of firm performance (Porter 1980; Andrews, Bower, Christensen, Hamermesh and Porter 1986; Swamidaas and Newell 1987; Kotha and Nair 1995; Hitt, Ireland and Hoskisson 2007). Similarly, the strategy-coalignment principle (Venkatraman \& Prescott, $1990 \mathrm{~b}$ ) posits that the firm's strategies, if properly suited to the firm's external environmental and organisational context, have significant positive implications for firm performance (Bayo-Moriones \& Merino-Diaz de Cerio, 2002; Cavusgil \& Zou, 1994). Strategies are the mechanisms through which the firm manages its relationships with the external environment and serve as the basic driving force in the value-creating processes of the firm in all functional areas of the business (Swamidaas \& Newell, 1987). This creation of value is manifested in the firm's organisational performance.

Likewise, the resource dependency theory (Pfeffer and Salancik 1978) and contingency theory of business strategy (Hofer, 1975) offer explanations that converged on the theme that the exercise of strategic posture is the firm's way of responding to the pressures of the external environment in order to preserve the interests of the organisation including the achievement of organisational goals (i.e. performance outcomes). These two theories suggest that firm performance is a function of how well a firm gains access to valued resource and/or mobilises its internal capabilities to deal with resource scarcity (Shane \& Kolvereid, 1995). It is imperative, therefore that strategy be studied in the context of the sequential relationships amongst the variables - external environment, strategic posture, and performance (Bourgeois III \& Astley, 1979; Swamidaas \& Newell, 1987). The major implication of these theories is that strategic posture is a valid antecedent of firm performance. 
The resource-based view (RBV) of the firm (Barney, 1991; Barney, 2001; Penrose, 1959) provides another explanation for the link between strategic posture and performance. As previously discussed, RBV regards the firm as a bundle of resources and suggests that the attributes of these resources significantly affect the firm's competitive advantage and, by logic, their performance (Barney, 2001). A firm gains competitive advantage if it possesses resources that are valuable, scarce, imperfectly tradable and hard to imitate (Barney, 1991). Competitive advantage is necessary to generate above-average returns in business performance (Eriksen \& Mikkelsen, 1996; Porter, 1980).

Applying RBV in their study of new technology-based ventures, Lee, Lee and Pennings (2001) argue that an entrepreneurial strategic posture is considered as part of the firm's critical resources for performance as has been implied in previous studies establishing the link of strategic posture with firm performance (e.g.Covin \& Slevin, 1990; Lumpkin \& Dess, 1996). Hence, an entrepreneurial strategic posture can be regarded as an organisational resource that provides sustainable competitive advantage since it is embedded in organisational routines (Knight, 1997), is intangible and is dispersed within the organisation (Lee et al., 2001). Lee et al (2001) argue that entrepreneurial strategic posture is an internal capability of the firm and if properly executed, is a source of superior competitive advantage because firms cannot buy it from the market and should invest a great deal of time to cultivate such capability.

Furthermore, according to the strategic orientation literature, a firm can achieve its competitive advantage through organisational adaptability or rigidity (Miles and Snow 1978). Organisational adaptability corresponds to an innovative, risk-taking, and proactive strategic posture (i.e. entrepreneurial strategic posture) (Miller and Friesen 1983). Firms using this strategy concentrate on scanning, identifying, and capitalising on emerging market opportunities, and maintain and bear the costs and risks inherent in extensive capabilities for responding to market and contextual changes (Luo, 1999). 
Wiklund and Shepherd (2003) argue that firms with high levels of risk-taking, innovativeness and proactiveness tend to focus more on external opportunities such as creating and introducing new products and technologies ahead of the competition hence creating first-mover advantages and being able to target premium market segments, dominate distribution channels, and establish brand recognition. Supportive of this assertion are a number of studies noting the direct positive relationship between entrepreneurial strategic posture and that of organisational innovation (O'Regan \& Ghobadian, 2005; Salavou et al., 2004).

The opposite of organisational adaptability is organisational rigidity which corresponds to a non-adaptive, defensive, and risk-aversive strategy (Miller and Friesen 1983). Firms adopting this orientation are rigid, non-innovative, and shortsighted organisations that deliberately reduce innovative and adaptive costs and risks by selecting a stable and narrowly defined product or market domain (Luo, 1999; Wright, Kroll, Bevalee \& Lado, 1995). A study showed the major differences in the performance outcomes of firms characterised as having high level of organisational adaptation or rigidity (Tan \& Litschert, 1994).

Likewise, strategic posture heavily influences whether the firm should pursue long or short term goals given the myriad of pressures internal and external to the organisation (Doyle \& Hooley, 1992). It was also revealed that market orientation (with customer satisfaction and competitive orientation as components showing strong resemblance to proactiveness and product innovation content of entrepreneurial strategic posture) has been shown to be positively related to business performance (Pelham, 1999; Voss \& Voss, 2000). A plausible explanation is that the firm with entrepreneurial strategic posture is able to offer customers the choice of product or service and their associated attributes better than competitors.

The thrust of the argument for a positive influence of entrepreneurial strategic posture on organisational performance is related to the first-mover advantages and the tendency to take advantage of emerging opportunities implied by being proactive, innovative and risk-taker. Zahra and Covin (1995) hold that firms with entrepreneurial strategic posture can target premium market segments, charge high prices and "skim" the market ahead of their competitors. These firms monitor market 
changes and respond quickly, thus capitalising on emerging opportunities. Innovation keeps them ahead of their competitors, gaining a competitive advantage that leads to improved financial results. Proactiveness gives firms the ability to present new products/services to the market ahead of competitors, which also gives them a competitive advantage (Wiklund, 1999). All these have been confirmed by a metaanalysis of studies on strategic posture concluding that that the dimensions of strategic posture influence both financial and non-financial dimensions of organisational performance (Zahra, Jennings \& Kuratko, 1999)

Table 3.2 shows a number of studies which examined the relationships between strategic posture (or its various components) and various facets of firm performance. The Cronbach alpha $(\alpha)$ values suggests that the items comprised a unidimensional construct of strategic posture (i.e. that the items measure only one construct). Almost all of the studies reported positive relationships between strategic posture and firm performance.

The conceptual definition of strategic posture indicates three components that gauge the extent to which MSMEs are entrepreneurial in their business operation. The following sections discuss the importance of these components. The discussion aims to establish the link between the different components of strategic posture and that of organisational performance as well as its two components namely: operational and financial performance. It can be recalled that operational performance indicators refer to those key operational success factors that might lead to financial performance and do not lend themselves to immediate financial quantification whilst financial performance indicators reflect the fulfilment of the economic goals of the firm of which profitability is at the core (Venkatraman \& Ramanujam, 1986). The main proposition underlying the foregoing discussion is that MSME strategic posture influences both the operational and financial performance of firms (Hsueh \& Tu, 2002; Wiklund, 1999). 
Table 3.2. Various Empirical Studies on Strategic Posture

\begin{tabular}{|c|c|c|c|}
\hline Independent Variable & Dependent Variables & $\begin{array}{l}\text { Significant } \\
\text { Relationship }\end{array}$ & Author/s \\
\hline $\begin{array}{l}\text { proactiveness, } \\
\text { innovativeness, and } \\
\text { risk taking } \\
(\alpha=75)\end{array}$ & $\begin{array}{l}\text { sales growth, revenue growth, growth } \\
\text { in the number of employees, net profit } \\
\text { margin, product/service innovation, } \\
\text { process innovation, adoption of new } \\
\text { technology, product/service quality \& } \\
\text { variety, and customer satisfaction } \\
(\alpha=.82)\end{array}$ & + & $\begin{array}{l}\text { (Wiklund \& } \\
\text { Shepherd, 2003) }\end{array}$ \\
\hline $\begin{array}{l}\text { proactiveness and risk } \\
\text { taking }\end{array}$ & $\begin{array}{l}\text { sales volume, growth in revenues, } \\
\text { gross profit margin, net income, market } \\
\text { share, change in market share, entry to } \\
\text { new markets }\end{array}$ & + & $\begin{array}{l}\text { (Avionitis \& } \\
\text { Salavou, 2007) }\end{array}$ \\
\hline $\begin{array}{l}\text { proactiveness, } \\
\text { innovativeness, and } \\
\text { risk taking } \\
(\alpha=84)\end{array}$ & $\begin{array}{l}\text { company growth, sales volume, market } \\
\text { share, profit }(\alpha=86)\end{array}$ & + & $\begin{array}{l}\text { (Poon, Ainuddin \& } \\
\text { Junit, 2006) }\end{array}$ \\
\hline $\begin{array}{l}\text { proactiveness, } \\
\text { innovativeness, and } \\
\text { risk taking } \\
(\alpha=.78)\end{array}$ & sales profit & + & (Chow, 2006) \\
\hline $\begin{array}{l}\text { proactiveness, } \\
\text { innovativeness, and } \\
\text { risk taking } \\
(\alpha=82)\end{array}$ & export sales growth & + & $\begin{array}{l}\text { (Mostafa, Wheder } \\
\text { \& Jones, 2006) }\end{array}$ \\
\hline $\begin{array}{l}\text { proactiveness, } \\
\text { innovativeness, and } \\
\text { risk taking } \\
(\alpha=83)\end{array}$ & $\begin{array}{l}\text { profitability, sales growth, market } \\
\text { share, overall performance, start-up } \\
\text { goals achievement, job security for } \\
\text { employees, satisfaction with company } \\
\text { performance }(\alpha=89)\end{array}$ & + & (Keh et al., 2006) \\
\hline $\begin{array}{l}\text { proactiveness, } \\
\text { innovativeness, } \\
\text { assertiveness and risk } \\
\text { taking ( } \alpha=84 \text { ) }\end{array}$ & $\begin{array}{l}\text { growth in sales and sales per } \\
\text { employee }\end{array}$ & $\begin{array}{l}\text { + but not } \\
\text { significant }\end{array}$ & $\begin{array}{l}\text { (Walter, Auer \& } \\
\text { Ritter, 2006) }\end{array}$ \\
\hline $\begin{array}{l}\text { proactiveness, } \\
\text { innovativeness, and } \\
\text { risk taking } \\
(\alpha=83)\end{array}$ & $\begin{array}{l}\text { market share, } \\
\text { \% of new product sales to total sales, } \\
\text { and } \\
\text { ROI }\end{array}$ & $\begin{array}{l}\text { - (ROI) and } \\
+ \text { but not } \\
\text { significant for } \\
\text { other DV }\end{array}$ & $\begin{array}{l}\text { (Matsuno et al., } \\
\text { 2002) }\end{array}$ \\
\hline $\begin{array}{l}\text { proactiveness, } \\
\text { innovativeness, and } \\
\text { risk taking } \\
(\alpha=89)\end{array}$ & sales growth and market share & + & $\begin{array}{l}\text { (Luo, Zhuo \& Liu, } \\
\text { 2005b) }\end{array}$ \\
\hline
\end{tabular}




\subsubsection{Value of Innovativeness}

Innovativeness is one of the distinctive marks of firms with entrepreneurial strategic posture relative to those with conservative strategic posture (Covin et al., 1994). Innovativeness is considered as a strategic decision that is critical to many organisations as it provides one important way to adapt to changes in markets, technology, and competition. The firm's proclivity, receptivity, and inclination to adopt ideas that depart from the usual way of approaching business and to try untested methods, allow the firm to developed resources and capabilities that are firm specific which can then be turned into sustainable competitive advantage (Menguc \& Auh, 2006).An previously noted, sustainable competitive advantage is an antecedent of superior organisational returns.

Innovativeness reflects the firm's propensity to engage in new idea generation, experimentation, and $\mathrm{R} \& \mathrm{D}$ activities resulting in new products and processes (Lumpkin \& Dess, 1996). An entrepreneurial strategic posture, stressing product/process innovativeness and a generally proactive approach to the external environment, is associated with the development of a quality leadership, in which firms emphasise product and product-service quality (Knight, 2000). Without this, small firms such as MSMEs would have to rely on traditional ways of doing business, and traditional products/services which place them in a disadvantage position in a competitive situation, thereby reducing their potential to reap better performance outcomes (Lee et al., 2001).

Increasingly, scholars have linked innovativeness to organisational performance, suggesting that a firm needs to be innovative to gain a competitive edge in order to survive and grow (Damanpour, 1991; Deshpande, Farley \& Webster, 1993; Hult, Hurley \& Knight, 2004; Knight \& Cavusgil, 2004). Firm innovativeness has been shown to have positive impact on performance and contributes to competitive advantage by facilitating creative thinking within a firm's learning activities, improving the application of market intelligence acquired through market research and informing the generation of intelligent solutions (Hughes \& Morgan, 2007). Furthermore, a strong emphasis on innovativeness mobilises entry into new arenas, renews the firm's presence in existing ones and embodies a capability to explore new 
possibilities thereby creating differentiation and developing solutions to undermine those of the competitors (Hughes \& Morgan, 2007). A study shows that innovativeness is an effective buffer against the vagaries of the external environment as evidenced by the positive contributions it makes to business performance regardless of market turbulence (Hult et al., 2004).

For instance, innovative manufacturing firms tend to enjoy better new product performance compared to those that are slow in their innovation efforts (Avlonitis \& Salavou, 2007). Likewise, innovation orientation has been found to be correlated positively with higher levels of employee satisfaction, organisational commitment, and confidence in future firm performance (Zhou, Gao, Yang \& Zhou, 2005). Innovativeness, referred to as product and service innovation with an emphasis on development and innovation in technology, has been shown to be positively associated with firm performance (Zehir \& Eren, 2007). After finding a significant relationship between firm innovativeness and performance, Deshpande et al (1993) concluded that innovation along with customer focus form the raison d' etre (i.e. reason for being) of every business. Sustained competitive advantage arising from innovation raises the bar of organisational performance by generating above-average returns (Hitt, Ireland \& Hoskisson, 2007; Thomson, 2001).

\subsubsection{Value of Risk-Taking}

Gilley et al (2002) explain that risk-taking is regarded as inevitable for firms wanting to prosper in competitive business environments. In the context of strategic posture, risk-taking is illustrated by large resource commitments to high-risk and high-return business (Lumpkin \& Dess, 1996). Risk-taking has been associated with strategic decision speed and both have been subsequently linked to improved business performance (Eisenhardt, 1989). Without risk-taking, firms delay or refrain from introducing innovations, from undertaking exploitative activities, and react conservatively to changing market conditions which subsequently result to weaker performance as the firm would do little to seize customer and market opportunities (Hughes \& Morgan, 2007). Whilst risk taking also entails the possibility of failure, risk taker-managers usually seize opportunities and make commitments of resources after careful analysis of the situation (Covin \& Slevin, 1990b). 
It has been noted that firms with risk-averse top management team are not likely to become involved in groundbreaking new ventures to enhance organisational success (Gilley, Walters \& Olson, 2002). Risk-averse firms will choose strategies that maintain the status quo, thereby decreasing the firm's level of innovation and reducing the firm's commitment to cutting edge-products and technologies whereas risk-seeking firms will be more likely to engage in behaviours that lead to identification of opportunities, process enhancements, highly competitive new products or services and innovative marketing techniques, and consequently gain rapid returns (Avlonitis \& Salavou, 2007; Gilley et al., 2002; Tan, 2001).

\subsubsection{Value of Proactiveness}

Proactiveness reflects the firm's proactive or anticipatory behaviour in relation to participation in emerging industries, continuous search for market opportunities and experimentation with potential responses to changing environmental trends (Venkatraman, 1989). It is a characteristic of a marketplace leader that has the foresight to act in anticipation of future demands (Lee et al., 2001; Lumpkin \& Dess, 2001). Proactiveness allows firms to engage in continuous market research and first mover actions such as the introduction of new products or services ahead of the competition (Lumpkin \& Dess, 1996). Proactiveness has strong positive effects on growth and profitability measures of performance (Venkatraman, 1989). The rationale is that the creation of sustainable competitive advantage is the key to gain above-average returns. First mover actions may generate high returns for proactive firms as they pave the way to forge new market segments or replace existing yet outdated or obsolete products or services offered by other firms (Lee et al., 2001).

Fundamental to the creation of sustainable competitive advantage is the acquisition of resources and development of capabilities (Barney, 1991). Lumpkin and Dess (2001) extend this idea by saying that the generation and creation of resources and capabilities represent the proactiveness of the firm. A proactive firm is able to "shape" the environment to its own advantage and ultimately influence the firm's performance of generating favourable outcomes (Lumpkin \& Dess, 2001). Proactiveness increases the firm's receptivity to market signals and awareness of 
customers' needs thereby allowing firms to understand customers, ascertain and exploit their needs whilst the at the same time, actively deconstructing the value package of competitors to generate superior offerings (Hughes \& Morgan, 2007).

\subsubsection{Strategic Posture and Operational Performance}

The discussion above presents theoretical and empirical evidence on the contribution of entrepreneurial strategic posture on business performance. It is also worthwhile to examine the evidence supporting the view that entrepreneurial strategic posture shapes the operational performance of MSMEs. The focus of the next section is to look at evidence of entrepreneurial strategic posture or its components and its influence on performance in a non-financial way such as influences on the development of new products or services, product or service quality, customer satisfaction, improvement in business or production processes, attraction and retention of essential employees, market share and growth of market share (being the indicators of operational performance used in this study).

A number of studies support the view that strategic posture shapes the operational performance of firms. Entrepreneurial strategic posture has been shown to be positively associated with the development of new products or services, product or service quality, as well as improvements in business or production processes including efficiency of these processes (Damanpour \& Evans, 1984; Li \& AtuaheneGima, 2001; Wiklund \& Shepherd, 2003). Likewise, it has been shown to be positively related to both the number of patents secured by the firm and total number of innovations (i.e. new products and process improvements) conducted by the firm (Kemelgor, 2002). In a study of 745 Greek SMEs, proactiveness and risk taking have been shown to be positively related to product innovations measured by the number of new products introduced in the market (Helen \& Lioukas, 2003). It is not surprising to know that entrepreneurial strategic posture is also positively related to customer satisfaction and customer loyalty (Madsen, 2004; Wiklund \& Shepherd, 2003)

Entrepreneurial strategic posture, especially its major component, innovativeness, has been shown to be positively related to better product/service quality and variety 
(Damanpour \& Evans, 1984; Wiklund \& Shepherd, 2003). Studies showing the positive effects of entrepreneurial strategic posture on the increase number of employees (i.e. as an indicator of firm growth) (Madsen, 2004; Swierczek \& Ha, 2003a; Wiklund, 1999; Wiklund \& Shepherd, 2003) implies that firms are able to attract and retain employees as a consequence of their being proactive, innovative and risk-taker. The longitudinal study of Wiklund (1999) involving small firms further supports this view. A study looking at proactiveness concludes that it is an explanatory factor for the increase in the number of employees of firms, perhaps as a consequence of business growth and expansion (Krauss, Frese, Friedrich \& Unger, 2005).

Likewise, firms with entrepreneurial strategic posture are likely to have greater market share compared to those who are not entrepreneurial (Avlonitis \& Salavou, 2007; Jogaratnam, 2002; Lumpkin \& Dess, 1996; Madsen, 2004; Zahra, 1993). The positive link between entrepreneurial strategic posture and growth in market share is also well supported by empirical evidence (Avlonitis \& Salavou, 2007; Li \& Atuahene-Gima, 2001). Other studies concluded that entrepreneurial strategic posture is positively associated with market value compared to competitors (Chaney, Devinney \& Winer, 1991; Wiklund, 1999), external success evaluation (Krauss et al., 2005), stakeholder satisfaction (Lumpkin \& Dess, 1996), and firm reputation (Li \& Atuahene-Gima, 2001).

\subsubsection{Strategic Posture and Financial Performance}

The positive contributions of entrepreneurial strategic posture on the financial performance of firms are also established in the literature (Covin \& Slevin, 1990; Lumpkin \& Dess, 1996; Wiklund, 1999; Zahra et al., 1999). As discussed previously, financial performance reflects the economic goals of the firm which are measured numerically in the form of sales, sales growth, net income, net income growth, and return on investment.

A number of studies support the positive association between entrepreneurial strategic posture and the sales performance (Avlonitis \& Salavou, 2007; Jogaratnam, 2002; Poon et al., 2006) as well as net income (also known as profit) of firms 
(Lumpkin \& Dess, 1996; Swierczek \& Ha, 2003a; Wiklund, 1999). A study of proactiveness of firms concludes that it has strong contribution in the sales performance of firms (Becherer \& Maurer, 1999). Return on investment (ROI) is also found to be higher amongst firms with entrepreneurial strategic posture (Li \& Atuahene-Gima, 2001). Other studies looked at return on assets (ROA) which is closely related to ROI and reveal similar conclusions (Han, Kim \& Srivastava, 1998; Tan, 2001; Zahra \& Covin, 1995).

There is a plethora of studies supporting the positive association between entrepreneurial strategic posture and growth indicators like sales growth ( $\mathrm{Li} \&$ Atuahene-Gima, 2001; Lumpkin \& Dess, 1996; Wiklund, 1999), and net income growth (Krauss et al., 2005; Madsen, 2004; Zahra \& Covin, 1995). Studies have likewise established a positive association between entrepreneurial strategic posture and financial indicators such as cash flow (Jogaratnam, 2002; Li \& Atuahene-Gima, 2001), return on sales (Kemelgor, 2002; Zahra \& Covin, 1995), price earnings ratio of publicly traded firms (Chaney et al., 1991), and gross profit (Wiklund, 1999).

All of the empirical evidence presented above converge on the fundamental view that entrepreneurial strategic posture enables MSMEs to proactively respond to the demands of the external environment, uncover and meet the needs of customers better than competition, expand to new markets, and invest in innovative products, services or process in the pursuit of achieving superior organisational performance outcomes in monetary and non-monetary terms.

The multidimensional nature of organisational performance and the diverse association of entrepreneurial strategic posture with a wide range of performance indicators demand that entrepreneurial strategic posture be examined in terms of how it relates not only to the overall measure of organisational performance but also to the different indicators/dimensions of operational and financial performance. That is, in as much as previous studies have established the significant relationship of entrepreneurial strategic posture and composite measures of performance, it will be interesting to find out if the same conclusion can be drawn when performance measures are broken down into their specific components. Accordingly, the following hypotheses are proposed: 
$\mathrm{H}_{13 \mathrm{a}}$ - There is a positive relationship between MSMEs' entrepreneurial strategic posture and operational performance.

$\mathbf{H}_{13 \mathrm{~b}}$ - There is a positive relationship between MSMEs' entrepreneurial strategic posture and financial performance.

$\mathrm{H}_{14}$ - An entrepreneurial strategic posture is positively related to the operational performance measures namely:

$H_{14 a}$ development of new products or services;

$\mathrm{H}_{14 \mathrm{~b}}$ product or service quality;

$\mathrm{H}_{14 \mathrm{c}}$ customer satisfaction;

$\mathrm{H}_{14 \mathrm{~d}}$ improvements in business or production processes;

$\mathrm{H}_{14 \mathrm{e}}$ attraction of essential employees;

$H_{14 f}$ retention of essential employees;

$\mathrm{H}_{14 \mathrm{~g}}$ market share; and

$\mathrm{H}_{14 \mathrm{~h}}$ growth of market share.

$H_{15}$ - Entrepreneurial strategic posture is positively related to the financial performance measures namely:

$\mathrm{H}_{15 a}$ sales;

$\mathrm{H}_{15 \mathrm{~b}} \quad$ sales growth;

$\mathrm{H}_{15 \mathrm{c}} \quad$ net income;

$\mathrm{H}_{15 d} \quad$ net income growth; and

$\mathrm{H}_{15 \mathrm{e}}$ return on investment.

\subsection{Mediation in Research Design}

There are two major schools of thought in establishing mediational designs in research. The most current view explains that mediation involves a chain reaction whereby an independent variable causes a change in the mediator which then causes the change in the dependent variable (Collins, Graham \& Flaherty, 1998). This is, in effect, a stage-sequential mediation process suggesting that it must be established that institutions relate to strategic posture and that strategic posture must be 
established to be related to organisational performance. Under this school of thought, it is sufficient to establish theoretically and empirically the sequence of relationships of the variables under study in order to propose the presence of mediation, which shall then be subjected to statistical testing. It does not require an overall independent variable-ultimate dependent variable effect to establish the mediated process (Collins et al., 1998).

It is argued that the conditions to establish mediation under this school of thought have been met. Previous sections presented a thorough discussion of the theoretical and empirical justifications on the link between institutions and strategic posture, as well as the link between strategic posture and organisational performance. This study will seek to provide the statistical evidence to examine such mediated relationships in the institutions-strategic posture-organisational performance link.

An alternative school of thought argues that mediation analysis is a four step process (Baron \& Kenny, 1986; Hair, Black, Babin, Anderson \& Tatham, 2006). Baron and Kenny (1986) assert that mediation analysis is performed through the following steps: (1) the theoretical basis of the relationship between the independent variable(s) and the ultimate dependent variable(s) must first be established; (2) the relationship between the independent variable and the mediating variable must be established; (3) the relationship between the mediating variable and the ultimate dependent variable must also be established; and (4) partial or full mediation must be established by controlling the mediating variable in the statistical analysis of the relationship between the independent variable and the ultimate dependent variable. Full (or partial) mediation is established if the effect of the independent variable on the ultimate dependent variable is zero (non-zero) (Baron \& Kenny, 1986). In other words, if the independent variable accounts for variance in the ultimate variable that is not accounted for by the mediating variable, then the mediation is deemed partial in nature (Shrout \& Bolger, 2002). Baron and Kenny (1986) pointed out that partial models are more realistic in most social science research because a single mediator cannot be expected to explain completely the relationship between an independent variable and an ultimate dependent variable. 
In order to satisfy the four-step process set forth by Baron and Kenny (1986), it is important to establish first, the theoretical justification(s) for the overall link between institutions and organisational performance (i.e. step one). The next section presents these justifications. Steps 2 and 3 have been partly satisfied by the discussions presented in Sections 3.3.5 and 3.6. They shall be completed when statistical analysis is performed on the data that would be gathered at the later stage of the study. Step four comprises statistical analysis to determine whether the relationship between the independent variable and the ultimate dependent is subject to mediation and if so, whether it is partial or full mediation (MacKinnon et al., 2002).

\subsubsection{Institutions-Organisational Performance Link}

The population ecology model offers a theoretical argument for the the direct link between institutions (as comprising the firm's environment) and MSME organisational performance. The population ecology model posits that the performance and ultimately survival of firms are determined or selected by the characteristics of the environment in which they are found (Aldrich, 1979; Betton \& Dess, 1985; Hannan \& Freeman, 1977; Shane \& Kolvereid, 1995). This model explains that the strategies of managers are not needed to explain the performance of firms (Gharavi \& Sor, 2006; Shane \& Kolvereid, 1995). The main argument is determined by environmental selection in such as way that the managerial exercise of strategy cannot directly determine success because a strategy is just one of the many sources of random variation that will be selected for or against, by the environment (Shane \& Kolvereid, 1995; Tsai, MacMillan \& Low, 1991). This implies that strategy has minimal impact on adaptation. Instead, environments can be conceptualised as "selecting" organisations through resource scarcity and competition (Lewin \& Volberda, 1999). An institutional environment with inherently scarce resources allows for stiff competition amongst MSMEs hence determining their ultimate performance outcomes.

Ketchen, Thomas and Snow (1993) state that the population ecology model considers the firm's external environment to be composed of "niches" such as sectors, industries or clusters which can provide both resources and constraints to a population of organisations such as MSMEs (Ketchen et al., 1993). Within each 
niche, certain organisational forms are "selected" to be successful and others simply fail (Ketchen et al., 1993). Organisations cannot easily change their forms because of inertia (e.g. due to the size of the organisation), hence there will be differences in performance between these forms brought about by external environmental requirements.

Whilst the model was developed to examine firm survival, the argument applies to firm performance as well because survival of firms can also be measured in terms of how well a firm performs in its given industry (Shane \& Kolvereid, 1995). It has been shown that in the long run, well-performing organisations survive whilst poorly performing ones suffer demise (Gimeno, Folta, Cooper \& Woo, 1997).

Shane and Kolvereid (1995) found empirical support for the population ecology argument or model when they examined 500,1,146, and 1,000 entrepreneurs from New Zealand, Norway, and the UK respectively in 1986. The study shows that the variations in the performance of firms (i.e. growth in number of employees, growth in sales revenue, growth in profits, and profitability relative to competitors) were explained well by the differences in national environments (i.e. munificence, hostility, and complexity). On the other hand, an examination of fit between strategies and environment did not reveal any influence on firm performance. Their findings are consistent with the assumption(s) of the population ecology model that environmental factors have direct impact on firm performance (Lewin \& Volberda, 1999).

The theory of environmental munificence (Castrogiovanni, 1991) provides another explanation for the direct link between institutions and MSME organisational performance. As discussed previously, munificence describes the richness of opportunities for venturing and renewal (Boyd, 1990; Wang \& Ang, 2004). It reflects the scarcity or abundance of critical resources needed by firms operating within that environment (Castrogiovanni, 1991). Lumpkin and Dess (1996) argued that environmental factors may have direct influence on performance and suggested that environmental munificence and entrepreneurial strategic posture may have independent effects on organisational performance. 
In the context of environmental munificence, formal and informal institutions may be considered indicators of how munificent the MSME external environment is. Munificence is manifested by two factors, namely the tangible forms of support for firms such as physical infrastructure and intangible institutions including political (i.e. credibility and effectiveness of the bureaucratic infrastructure being the foundation for business transactions), legal (i.e. formal rules whereby business transactions takes place), and societal institutions (i.e. general level of trust, cooperative norms and associational level of trust ) (Wan \& Hoskisson, 2003). It was argued that environmental munificence is the underlying factor that describes these tangible and intangible dimensions of the external environment (Wan \& Hoskisson, 2003).

This is consistent with what Castrogiovanni (1991) calls as "macro environment" which refers to the general environmental context of a specified area and contains those forces recognised to have important influences on organisational characteristics and outputs. In this study, the use of the formal and informal typology of North's institutional theory to characterise this macro-environment avoids the pitfalls of over abstraction by assessing the level of munificence of a particular level of environment most relevant to a specific purpose (which in this case is to relate these institutions to MSME's behaviour).

The direct influence of munificence in firm performance has been established in previous studies. In a study of the Japanese machine tool industry, Kotha and Nair (1995) showed that munificence is positively associated with growth and profitability. Furthermore, the effects of environmental variables such as munificence are stronger relative to those of organisational strategies in predicting profitability (Kotha \& Nair, 1995). Likewise, firm growth (i.e. change in sales) was shown to be strongly influenced by environmental factors but minimally (or non at all) affected by strategies (Kotha \& Nair, 1995). Their findings are consistent with other studies concluding that munificence is: (a) one of the most important aspects for explaining organisational outcomes (Castrogiovanni, 1996; Wan \& Hoskisson, 2003); (b) positively related to firm performance (measured by a subjective evaluation of growth in market share, growth in cash and sales) (Wang \& Ang, 2004)); (c) a strong predictor of sales growth as revealed in a study of 193 firms in 48 industries over a 
20 year period (Weinzimmer, Nystrom \& Freeman, 1998); and (d) munificence is positively related to firm growth (Fitsimmons, Douglas, Antoncik \& Hisrich, 2004)

Furthermore, munificence may be defined in terms of the investment climate of the environment. An investment climate that is favourable for MSMEs to conduct business may be characterised as a munificent environment. Consequently, where there is a positive climate, returns, measured as profit, should be high (Dollar et al., 2005).

In terms of the direct link between the specific formal and informal institutions and firm performance, a number of studies are worth mentioning. For instance, it has been argued previously in this study that the role of property rights and contracts enforcements paves the way for more predictable markets so that firms can effectively trade their goods and services hence increasing the returns on their business (Clague, Keefer, Knack \& Mancur, 1999). This partially explains the economic growth of countries with more stable and efficient institutions (Clague et al., 1999).

Empirical evidence is provided by a study on Indian firms whereby performance (i.e. returns on assets and on sales) of foreign owned firms is heavily shaped by the security of property rights of foreign owners (Chhibber \& Majumdar, 1999). By extension, the same rights should also produce the same effect on locally based firms such as MSMEs. Investment risk, being an indicator of a stable and reliable regulatory and political system has been shown to be inversely related to the nonfinancial performance (i.e. market share) of firms (Brouthers, 2002). Likewise, in a study of 1,632 firms in Bangladesh, small firms receiving support from the government have been shown to perform significantly better (in terms of growth in sales, employment and productivity) than those which were not receiving support (Sarder, Ghosh \& Rosa, 1997).

The role of government policies designed to support MSMEs has also been studied extensively. The major conclusion from these studies is that a well-crafted government policy has been shown to increase the performance and survival of small firms like MSMEs (Eberts, 2005; Nkya, 2003; OECD, 2004; Smallbone, 2004) 
In terms of the informal institutions, cultural dimensions such as long-term orientation have been shown to shape the performance of firms ( $\mathrm{Li}$ et al., 2001). In an experimental study, individualism has been shown to have an independent effect on manufacturing performance (Chow, Shields \& Chan, 1991). It must be noted that there is very scarce empirical literature linking national culture and that of firm-level performance. A meta-analytic review on national culture as it relates to entrepreneurship and small business did not report any study on cultural dimensions as they directly relate to firm performance (Hayton, George \& Zahra, 2002).

A more recent study shows that the performance of firms (in this case, sales volume to average inventory ratio) significantly varies across groups with different cultural motivational values such as achievement, pro-social and self-direction (Lenartowicz $\&$ Roth, 2001). Achievement or the "motivation to pursue personal success through demonstrated competence" (Lenartowicz \& Roth, 2001) shows strong resemblance to performance orientation. Self-direction or "the motivation to be independent in thought and action" and pro-social or "the motivation to engage in active protection or enhancement of the welfare of others" (Lenartowicz \& Roth, 2001) show strong resemblance to individualism and collectivism respectively. The study's results are even more relevant as they pertain to business performance at sub-national levels. This implies that variations in cultural values even within the same country do influence the performance of firms.

As a summary, the foregoing discussion presents the theoretical argument supporting the direct link between institutions and organisational performance. Hence, the primary requirement of testing for mediation as set forth by Baron and Kenny (1986) has been met. Likewise, as presented in Section 7.2, strategic posture is considered as a mediating variable whereby institutions are able to influence MSME performance because MSMEs respond or react to these institutional factors. These responses or reactions are manifested through strategic posture. The munificence of these institutions influences MSMEs' level of entrepreneurial strategic posture, which then determines the ultimate performance outcomes of these firms. It is proposed in this study that: 


\section{$H_{16}$ - There are direct relationships between institutions and MSME organisational performance.}

This hypothesis subsumes twenty-four specific hypotheses as shown in Table 3.3. For instance, $\mathrm{H}_{16 \mathrm{a}}$ and $\mathrm{H}_{16 \mathrm{~b}}$ refer to rule of law being hypothesised to be positively related to operational and financial performance respectively as shown by the plus sign under the last two columns. $\mathrm{H}_{16 \mathrm{q}}$ and $\mathrm{H}_{16 \mathrm{r}}$ refer to collectivism being hypothesised to be negatively related (as sown by the minus sign) to operational and financial performance respectively.

\subsubsection{The Mediating Role of Strategic Posture}

The framework of the study rests on the fundamental thesis that institutions influence the strategic posture of MSMEs, which subsequently determine the firms' organisational performance. In effect, strategic posture serves as a mediating variable between institutions and organisational performance. Several theoretical arguments support this view.

Table 3.3. Direct Relationships between Institutions and Organisational Performance

\begin{tabular}{|c|c|c|c|}
\hline $\begin{array}{l}\text { Hypothesis } \\
\text { Number }\end{array}$ & Institutions & $\begin{array}{l}\text { operational } \\
\text { performance }\end{array}$ & $\begin{array}{c}\text { financial } \\
\text { performance }\end{array}$ \\
\hline $\mathrm{H}_{16 \mathrm{a}} \& \mathrm{H}_{16 \mathrm{~b}}$ & rule of law & + & + \\
\hline $\mathrm{H}_{16 c} \& \mathrm{H}_{16 \mathrm{~d}}$ & property rights protection & + & + \\
\hline $\mathrm{H}_{16 \mathrm{e}} \& \mathrm{H}_{16 \mathrm{f}}$ & government policies & + & + \\
\hline $\mathrm{H}_{169} \& \mathrm{H}_{16 n}$ & regulatory quality & + & + \\
\hline $\mathrm{H}_{161} \& \mathrm{H}_{16}$ & government assistance & + & + \\
\hline $\mathrm{H}_{16 \%} \& \mathrm{H}_{16}$ & performance orientation & + & + \\
\hline $\mathrm{H}_{16 m} \& \mathrm{H}_{16 n}$ & future orientation & + & + \\
\hline $\mathrm{H}_{16_{0}} \& \mathrm{H}_{16 \mathrm{p}}$ & assertiveness & + & + \\
\hline$H_{16 q} \& H_{16 r}$ & collectivism & - & - \\
\hline $\mathrm{H}_{16 \mathrm{~s}} \& \mathrm{H}_{16 \mathrm{t}}$ & power distance & - & - \\
\hline $\mathrm{H}_{16 u} \& \mathrm{H}_{16 \mathrm{v}}$ & humane orientation & - & - \\
\hline $\mathrm{H}_{16 w} \& \mathrm{H}_{10 \mathrm{x}}$ & uncertainty avoidance & - & - \\
\hline
\end{tabular}


North's (1991) institutional theory posits that institutions are necessary to establish the "rules of the game" thereby reducing transaction costs associated with uncertainty. Lower transaction costs open up a wide range of opportunities available to MSMEs such as: gaining access to valued resources from the external environment (e.g. information about markets, about new technology and sources of finance, and government assistance); developing proprietary assets under the condition that property rights are well-protected; and full concentration on the productive activities of the business including growth and expansion without the fear of negative social normative sanctions brought about by informal institutions, as well as discretionary or opportunistic behaviour from other economic players like competitors and government authorities. All these are necessary for a firm to engage in entrepreneurial (i.e. risk-taking, innovative, and proactive) activities. A small firm is likely to avoid R \& $\mathrm{D}$ without access to critical resources or reliable legal protection on the proprietary outcomes of such expensive endeavour.

Consequently, MSMEs may assume a specific strategic posture in order to achieve a set of organisational goals or outcomes which are subsumed under the theory of organisational effectiveness (Venkatraman \& Ramanujam, 1986). A firm's strategic posture can be viewed as the firm's adaptive response to the environment for threat attenuation and as proactive actions to extend its influence over the environment for opportunity exploration ( $\mathrm{Li}, 2001)$. The exercise of strategic posture is a manifestation of managerial choices which determine the outcomes of firms (Priem, 1994). Furthermore, the theory on bounded rationality supports the view that managers are able to pursue strategies in a nearly optimal fashion with respect to some goals as the resources will allow (Simon, 1997).

In summary, it considered that institutions set the rules of the game for which MSMEs respond through the exercise of strategic posture in order to achieve a desired set of performance outcomes. Tan and Litschert (1994) tested these relationships and found that the strategic adaptation of firms in a highly-regulated business environment such as the case of the Chinese economy tends to generate distinctive strategies and are significantly related to the firms' overall performance and profitability. 
Another justification emanates from the industrial organisation (I/O) literature which converge on the view that strategy is a major determinant of a business's performance and the external environment, be it the firm's immediate industry or the wider general environment, in turn, is a major determinant of strategy (Andrews, Bower, Christensen, Hamermesh \& Porter, 1986; Hitt et al., 2007; Kotha \& Nair, 1995; Porter, 1980; Swamidaas \& Newell, 1987). The dominant view in industrial organisational research looks at the structure-conduct-performance (SCP) proposition, suggesting that the external environment such as the firm's industry structure affects the firm's competitive behaviour (or conduct) and subsequently, the firm's performance (Li, 2001; Scherer, 1980; Thomson, 2001). The SCP framework suggests that organisations are dependent on their environments for resources (Pfeffer \& Salancik, 1978) and organisations can manage this dependency by developing and maintaining strategies (Hofer, 1975). The fit between environmental conditions and strategy will then determine the performance levels of firms (Jogaratnam et al., 1999; Venkatraman \& Prescott, 1990).

This is consistent with the contingency theory of business strategy (Hofer, 1975). Hofer's (1975) theory is considered as one of the most articulate expositions of the environment-strategy-performance link (Bourgeois III \& Astley, 1979). This theory holds that the interaction between strategy and environment determines firm performance (Miles \& Snow, 1978; Shane \& Kolvereid, 1995). Central to this theory is the assertion that managers consciously select strategies which reflect their perceptions of the external environment and the view of appropriate or optimal strategy in a given environmental condition in order to maximise performance outcomes (Shane \& Kolvereid, 1995). Similar to the I/O view as discussed above, it is suggested that performance will be contingent on the fit between strategy and the environment in which a firm operates (Shane \& Kolvereid, 1995). The study of Carpano et al (1994) offers empirical evidence supportive of this theory. Thus we state there is evidence to suggest that there exists a sequential relationship among the variables: environment (e.g. institutions), strategy (e.g. strategic posture), and organisational performance (Swamidaas \& Newell, 1987) 
The third explanation is based on the resource dependency theory which posits that the environment is a source of scarce resources which are sought after by competing organisations (Pfeffer \& Salancik, 1978). As the environment becomes less munificent or more hostile, firms are subjected to greater uncertainty. The top management of firms attempt to manage this uncertainty by utilising a range of strategy options in order to reduce the firm's dependence on or increase its control over these resources. It is argued that several dimensions of the external environment affect top management's perception of uncertainty which in turn influence strategic decision characteristics such as propensity for risk-taking, futurity, proactiveness and defensiveness (Miles \& Snow, 1978; Miller \& Friesen, 1982; Tan \& Litschert, 1994; Venkatraman \& Prescott, 1990).

In short, strategy can be considered to be the firm's response to uncertainty (Dutton \& Jackson, 1987; Parnell, Lester \& Menefee, 2000). The top managers may view environmental issues as either a threat or an opportunity which consequently shapes the kind of organisational responses that are utilised in order to preserve and/or advance the firms' interests, including the attainment of the firm's goals (Dutton \& Jackson, 1987). To sum up, the exercise of various strategic options in response to environmental uncertainty will ultimately determine the firm's organisational effectiveness (Tan \& Litschert, 1994; Venkatraman \& Prescott, 1990).

The mediating role of strategic posture may also be explained by previous studies on cognitive or decision processes. The work of Anderson and Paine (1975) as well as Priem (1994) highlighted the role of managerial perceptions or executive judgements, which subsequently shape strategic behaviour within the firm. It can be understood in the context of the perceived environment-strategy-performance link using Fazio's (1986) attitude-behaviour model. This model suggests that perceptions of the external environment are likely to shape managerial attitude which is defined as the "evaluation of an object associated in memory with the representation of that object" (Berger \& Mitchell, 1989, p. 270). In this case, MSMEs' top managers' exposure or experience with external institutional factors will shape their attitude. In a study of cultural effects on attitude involving managers from three countries, it was revealed that each group showed distinct attitudes which the authors attribute to national cultural characteristics (Kelley, Whatley \& Worthley, 1987). 
Attitudes will form part of a manager's belief structure that represents organised knowledge about a given concept or stimulus (Walsh, 1988). This belief structure reduces information-processing demands and renders information load more manageable by structuring experience, facilitating information acquisition and retrieval, and by providing a basis for inference (Walsh, 1988). Research has shown that an attitude, being a specific mental process subsumed by a broader term called "affect" (Bagozzi, Gopinath \& Nyer, 1999), may spur, inhibit or constrain one into action (Bagozzi, 1992; Bagozzi et al., 1999; Berger \& Mitchell, 1989). This suggests that top managers' attitudes will define their belief structure, which subsequently influences their likelihood to engage in or refrain from actions related to risk-taking, innovativeness or proactiveness. These attitudes and belief structure will determine the kind of strategies MSMEs utilise in pursuit of organisational adaptation to its external environment (Miles \& Snow, 1978). These managerial choices ultimately determine the outcomes of firms (Priem, 1994). Whilst it has been argued beforehand that there are direct relationships between institutions and MSME organisational performance as suggested by the population ecology model and the environmental munificence theory, such relationships may well be explained by the exercise of strategic posture. Hence, it is proposed in this study that:

$H_{17}$ - The relationships between institutions and organisational performance are mediated by the level of entrepreneurial strategic posture exercised by MSMEs.

$H_{17 a}-$ The relationships between institutions and operational performance are mediated by the level of entrepreneurial strategic posture exercised by MSMEs.

$H_{17 b}-$ The relationships between institutions and financial performance are mediated by the level of entrepreneurial strategic posture exercised by MSMEs. 


\subsection{Industry, Firm and Owner/Manager Characteristics}

Whilst the major theme of the current study is on the institutions-strategic postureperformance link, it is important to ascertain a number of managerial, organisational and industry factors which may have considerable bearing on strategic posture considering that this study involves MSMEs in varying sectors/industries. The importance of industry factors otherwise known as "industry effect" is at the core of the industrial organisation $(\mathrm{I} / \mathrm{O})$ theory which explains that industry factors place intense demands on organisations to actively interpret opportunities and threats when making key strategic decisions (Dess, Lumpkin \& Covin, 1997b; Porter, 1980).

This theory argues that ultimately, firm performance is determined by how well an organisation adopts or responds to the competitive pressures exerted by the industry forces (Hawanini et al., 2003). The study looks at two aspects of a firm's industry: the level of technological sophistication and the intensity of competition within the industry. Pelham (1999) argues that technological sophistication can increase barriers to entry in an industry thereby defining the intensity of competition amongst existing and potential players in the industry. Competitive intensity, on the other hand, shapes the extent of hostility of the firms' external environment (Brush \& Chaganti, 1999).

MSMEs may also differ in their strategic posture given the differences in organisational context. The structural variations amongst organisations are likely to affect strategic processes within these organisations (Falbe et al., 1998; Kauser \& Shaw, 2004). Firm characteristics such as age, size and ownership structure are the commonly used variables to define the internal environment or organisational context which influence managerial choice of strategy (Freel, 2005; Helen \& Lioukas, 2003; Sharma, 2000). As will be shown in the following sections, the environmental context shapes the degree of formalisation, centralisation and managerial control systems which in turn will determine the internal "structural inertia" affecting the exercise of strategic posture (Falbe et al., 1998; Freel, 2005).

The resource-based theory of the firm explains that a firm's strategic decisions hinge on ways to use existing resources and means to acquire or internally develop additional unique resources (Brush \& Chaganti, 1999; Wernerfelt, 1984). The 
number of employees within the firm (a common proxy for organisational size) and age since founding of the business (associated with accumulation of knowledge) form part of the firm's bundle of intangible resources (Dess et al., 1997; Grant, 2002; Mosakowski, 1993). The age of the owner/manager also forms part of the firm's overall human capital endowment (Preisendorfer \& Voss, 1990). Likewise, the education background of the owner/manager is a major component of the firm's stock of knowledge and skills (Borch, Huse \& Senneseth, 1999). In the context of the $\mathrm{RBV}$, the nature and amount of organisational resources will dictate the kind of strategies the firm will pursue in order to achieve its performance objectives.

Furthermore, the strategy-manager alignment perspective (also known as the upper echelon perspective) suggests that variations in strategies manifested by the exercise of strategic posture may be accounted for by the characteristics of top managers (Entrialgo, 2002; Gupta, 1984; Hambrick \& Mason, 1984; Kathuria \& Porth, 2003). These managerial characteristics, as discussed in sections 3.8.6 to 3.8.8 below, include the managers' age, gender and educational background.

Hambrick's and Mason's (1984) work implies that managerial choices such as the different decisions to take on risky projects or to invest in innovation reflect the personal and professional attributes of these managers. When faced with the same objective environment, different managers will make different decision based on their individual characteristics (Hambrick \& Mason, 1984). Research has shown that managerial characteristics such as age and educational background make a difference in strategy formulation and implementation (Entrialgo, 2002; Hitt \& Tyler, 1991; Karami, Analoui \& Kakabadse, 2006). Managerial decisions and actions depend on prior processes of human perception and evaluation (Child, 1997; Hitt \& Tyler, 1991). These processes are shaped by managerial orientation created by needs, values, experiences, expectations, and cognitions of the manager (Child, 1997; Hitt \& Tyler, 1991). These needs, values, experiences, and cognitions are partly shaped by factors such as age and formal training (Kathuria \& Porth, 2003; Kitchell, 1997).

The manager-strategy linkage is explained very well by Govindarajan (1989) who argued that different strategies have different job requirements with the use of tasks, behaviours, knowledge, skills, and values. Managers differ in their behaviour, 
knowledge, skills and performance of tasks due to differences in their biographical background which consequently shapes their ability to function effectively in all types of strategic contexts (Gonvindarajan, 1989). The implication of this argument is that the execution of a particular type of strategic posture is also contingent upon certain managerial skills, knowledge, and behaviour (as formed by their biographical background such as age and formal educational training).

The succeeding sections will examine the link between strategic posture and that of the MSME owner/manager characteristics (i.e. age, gender, and educational background of the owner/manager), firm characteristics (i.e. firm size, age, and ownership structure), and the industry characteristics (degree of technological sophistication of the industry and competitive intensity).

\subsubsection{Competitive Intensity in the Industry}

An MSME's strategic posture could be viewed as a function of internal organisational and external environmental influences in as much as it involves harnessing resources in a creative and proactive way to meet the demands and/or challenges of the external environment. The nature of the industry is that any one of the many external challenges that may have a bearing on the type of strategic posture a firm may assume. The importance of the industry in which a firm competes being a significant predictor of the firm's selection of strategies is well established especially in the literature on modern industrial organisation (Davidsson, Kirchhoff, Hatemi-J \& Gustavsson, 2002; Dess, Ireland \& Hitt, 1990; Geiger \& Hoffman, 1998; Mauri \& Michaels, 1998). One of these industry factors is competitive intensity.

Competitive intensity refers to the extent of rivalry or level of competition amongst firms in an industry (Appiah-Adu \& Singh, 1998; Grewal \& Tansuhaj, 2001). The strategy-conduct-performance argument ingrained in the industrial organisation (I/O) view of strategic management explains that an industry characterised by high levels of competitive conduct has negative consequences for firm performance (Gatignon \& Xuereb, 1997; Porter, 1980; Young, Smith \& Grimm, 1996). As a response to a competitive environment, a firm may engage in entrepreneurial undertakings such as proactive and innovative activities to differentiate itself from others or to serve niche 
markets (Grewal \& Tansuhaj, 2001; Porter, 1980). In effect, an entrepreneurial strategic posture is the firm's unique way of responding to such a competitive and hostile industry environment in order to realise and/or enhance it performance objectives. Hence it is hypothesised that:

\section{$\mathbf{H}_{18}-$ Competitive intensity is positively associated with entrepreneurial strategic posture.}

\subsubsection{Industry Technological Sophistication}

Industry technological sophistication refers to the extent to which products and processes produced or utilised in this industry involve the use of very sophisticated and complex operations technologies with a lot of research and development involved (Covin et al., 1990b; Khandwalla, 1977). Research show that industry technological sophistication can have a major impact on the individual firm's strategic decisions, business strategy patterns, and overall strategic posture of firms (Covin et al., 1990b; Yusuf, 2002).

The industry life cycle model suggests that innovation such as technological advances fuelled by research and development is the main force of industry evolution (Covin, Prescott \& Slevin, 1990a; Covin \& Slevin, 1990; Nelson, 1995). The more intensive the $\mathrm{R} \& \mathrm{D}$ efforts practiced in an industry, the more technologically sophisticated that industry becomes as it evolves over time. In such situation, every firm must consistently engage in innovation to retain its industry presence (Singh, 1997). The level of technological sophistication in the industry may influence whether firms should engage in entrepreneurial strategic posture in order to keep pace with and possibly define technological changes in the industry (Covin et al., 1990b; Eisenhardt, 1990). The more technologically sophisticated an industry is, the more likely it is that firms will proactively engage in innovative activities to continuously adapt to the changes in that industry (Eisenhardt, 1990).

Hence, it is advanced in this study that: 


\section{$H_{19}$ - High levels of industry technological sophistication are positively associated with entrepreneurial strategic posture.}

\subsubsection{Firm Size}

Firm size is considered a major part of the organisational context that shapes the strategic posture of firms (Chen \& Hambrick, 1995; Covin et al., 1990b). It has been shown to affect variables such as change in core features of an organisation, $\mathrm{R}$ \& D expenditures, and innovation (Chen \& Hambrick, 1995). Firms of different sizes would have different combinations of human and organisational resources which shape strategic practices to achieve success (Penrose, 1959; Young et al., 1996).

The literature dealing with firm size in relation to innovation, proactiveness and risktaking presents diverse findings. Some studies argue that small ventures, although facing relatively severe resource constraints, may exhibit more speed and flexibility in the exercise of entrepreneurial strategic posture (Yusuf, 2002). Smaller firms enjoy flexible adaptation and quick response time because they do not have to contend with multiple layers of decision-makers and formal channels for approval compared to larger firms (Entrialgo, Fernandez \& Vazquez, 2001). Large size is associated with greater formalisation, standardisation, structural complexity, bureaucracy, and unwieldy information-processing systems which are generally inversely related to innovation and creativity in organisations (Chen \& Hambrick, 1995; Entrialgo et al., 2001; Helen \& Lioukas, 2003).

Furthermore, small firms are more likely to consider growth strategies, adopt a more innovative and entrepreneurial approach to avoid sales decline and loss of business (Luo et al., 2005b). Lou et al's (2005) study of Chinese study of firms supports this claim. Chen and Hambrick's (1995) study lends further support to this argument by empirically showing that small firms tend to have greater propensity for action and faster action execution. Perhaps it may even be argued that the liability of smallness confers upon the smaller firms some sense of insecurity which they must then compensate with a more aggressive or competitive posture to make their presence known in the market vis-à-vis the larger firms. 
Moreover, one study shows that managers in most large, established organisations have a good deal to lose financially and psychologically from entrepreneurial strategic posture-related activities (Falbe et al., 1998). On the other hand, founders and members of small firms are viewed as having less to lose and therefore more to gain by operating with the ambiguity of innovation and entrepreneurial activities (Entrialgo et al., 2001).

On the other hand are studies revealing that firm size, measured in terms of number of employees (Chow, 2006; Mohan-Neill, 1995; Yasuda, 2005; Yusuf, 2002) and/or sales (Jantunen et al., 2005; Mohan-Neill, 1995) tend to have a negative relationship with entrepreneurial strategic posture (Chow, 2006; Luo et al., 2005b). Smaller firms tend to be less innovative because of the financial resource involved in innovation activities (Huergo \& Jaumandreu, 2004; Kam, Kiese, Singh \& Wong, 2003). In one longitudinal study of Irish firms, it was revealed that small firms tend to suffer from shortage of financial capital to support innovation (Hewitt-Dundas, 2006). The same study revealed that smaller firms tend to have more difficulty attracting the necessary skills or expertise relative to larger firms. These financial and human resource constraints will curtail innovation activity and success to a greater extent amongst small firms (Hewitt-Dundas, 2006). The same conclusion that larger firms outperform smaller firms in product, process and business systems innovations was reached by another study focusing on a single industry (Wagner \& Hansen, 2005). Likewise, smaller firms use less marketplace information when making decisions and rely more on informal and immediately-available information which may consequently limit their capacity to engage in entrepreneurial strategic posturerelated activities (Mohan-Neill, 1995).

It may be hypothesised that smaller firms are less likely to pursue an entrepreneurial strategic posture. Small firms' typical attributes of speed in action, agility, flexibility and perhaps informality will only be meaningful if the necessary resources are in place and available to be acted upon (Rogers, 2004). Hence, if firm size was the only basis of comparison, indeed larger firms with more resources are likely to outperform smaller firms in innovation, proclivity for high risk projects and boldness in opportunity exploitation. Therefore, it is advanced in this study that: 


\section{$\mathrm{H}_{20}$ - There is a positive relationship between firm size and entrepreneurial strategic posture.}

\subsubsection{Firm Age}

A firm's strategic posture may also be shaped by its longevity. Firms of varying ages will have different amount and combinations of resources which influence choices and flexibility of strategic actions (Brush \& Chaganti, 1999). Empirical studies, however, offer divergent views. Younger firms may exhibit more innovation, risk-taking and proactiveness in their desire to achieve full capacity (Yusuf, 2002). The "entrepreneurial" activity that characterises new organisations tends to disappear as organisations grow older because of maturity-related factors such as: a. the choice of leadership to recreate or protect adaptive processes to ensure systemic innovation; b. the learned capacity to focus on routine problems; c. the use of ritualized programs to monitor problems; d. ignoring critical external information; and e. the increasing detachment of upper management from those personally/closely connected to the environment (Entrialgo et al., 2001).

This is consistent with Chow's (2006) findings of negative correlation between age and entrepreneurial orientation arguing that younger firms tend to be more innovative and daring than the more mature and established ones. In his study of small British firms, Freel (2005) argues that firm age or enterprise maturity is a proxy for structural development. This theory of structural development posits that firms tend to stop or slow down their creative activities as the firm grows bigger and bigger (Freel, 2005). This "structural inertia" increases monotonically with firm age thereby having a negative effect upon innovation (Freel, 2005). When organisations grow older, there are pressures to increase formalisation and standardisation to maintain internal consistency (Falbe et al., 1998). These contribute to structural inertia. As the degree of inertia builds up through the development of systems and procedures, firm innovativeness is likely to be lower compared to firms at a younger age ceteris paribus (Freel, 2005).

On the other hand, other studies have generated contradictory results. According to Zhou et al (2005), firms with longer history seem to have higher motivation to adopt 
an innovation orientation. The argument is that new firms tend to use informal and immediately available market place information because limited human and financial resources make acquisition of much needed market-related information a difficult task (Mohan-Neill, 1995). As a result, younger firms tend to incur higher likelihood of making wrong decisions (Rodriquez, Molina, Perez \& Hernandez, 2003).

This study will examine the notion that younger firms tend to compensate their liability of newness by taking a more proactive stance in developing new products or services to break the market which may be dominated by more established, and larger firms. Intuitively, new firms enter the industry and start the business because they proactively took the risks in the first place. It may be inferred that the older the organisation, the more bureaucratic and the less receptive it is to entrepreneurial activities whilst young organisations without established routines and managerial ties may need to be more proactive and take more risks to compensate their weakness of social capital (Luo et al., 2005b). Lou et al's (2005) study of Chinese firms supports this assertion. Hence it is proposed in the study that:

\section{$\mathrm{H}_{21}$-There will be a negative relationship between MSME age and entrepreneurial strategic posture.}

\subsubsection{Ownership Structure}

The legal structure of firm ownership may also influence strategic posture. An MSME's ownership structure refers to its legal form which determines the type of ownership and management of the business as well as the extent of sharing and absorption of liability arising from the business operation. Ownership structure may take the legal form of sole proprietorship (i.e. single ownership and management of the business), a partnership (i.e. two or more partners forming a business entity which takes a legal personality separate from the partners), or a corporation (i.e. at least five persons form a business entity which takes a legal personality separate from the incorporators) (GBCCPA, 2007). In a partnership, partners are either general (i.e. with unlimited liability for business losses) or limited (i.e. with liability only up to the extent of one's capital contribution to the business). A corporation assumes a legal personality of its own as if it is a person endowed with its own rights and obligations. 
Ownership structure determines the nature of management and control systems within the business. For instance, amongst small firms, the owner probably has a significant share of control over most or all decisions (Kazem \& van der Heijden, 2006). The conventional notion is that for the small business, the objectives of the firm are synonymous with those of the owner (Bhaskaran, 2006; Birley \& Westhead, 1990). The owner's value system will influence whether a firm pursues growth as opposed to a mere survival policy (Bhaskaran, 2006; Birley \& Westhead, 1990). Hence, the structure of ownership determines the particular strategic orientation, decision-making style and a set of operational strategies occurring within the firm.

The situation may be different when the ownership becomes diluted such as in the case of partnerships or corporations (Birley \& Westhead, 1990). In terms of management and control, the manager may be someone who is professionally hired by the owners, someone who is also a partner or incorporator/stockholder of the business. In any case, the manager has the added burden of considering the interests of multiple owners before making strategic decisions. The degree to which the manager takes risks is also dependent on the support (or lack of it) given by business partners or incorporators.

On a positive note, partnerships and corporations open up the firm to pluralistic ownership which allows for capital infusion into the business. Capital infusion may come from other individuals or other organisations. This implies that partnerships and corporations may be endowed with more resources compared to a sole proprietorship opening up more investment opportunities for growth.

Furthermore, the presence of institutional investor ownership has been shown to be positively related to R \& D spending (Kor \& Mahoney, 2005). Because of the financial interests, owners and other investors maintain varying amounts of control and perform close monitoring of the activities of the business. As a result, managers may be less likely to use resources to pursue non-profit maximizing goals such as aggressive sales growth at the expense of future (i.e. long term) profitability (Kor \& Mahoney, 2005). Likewise, as the firm takes a formal structure as opposed to a oneman show, there is also a tendency to adopt more formal strategic planning 
approaches. Firms with entrepreneurial strategic posture tend to have more formalised strategic planning approaches (Gibbons \& O'Connor, 2005).

The liabilities inherent in each ownership structure may also limit investment into research and development as well as the risks owners/investors are willing to assume. In the Philippines, the owner of a sole proprietorship business assumes all the risks and liabilities risking even one's personal assets whereas in corporations, incorporators of the business assume liabilities only up to their capital contribution. In a partnership, "limited partners" assume liabilities only up to the extent of their contribution whilst general partners assume unlimited liabilities (GBCCPA, 2007). A corporation-type MSME that is managed by a professional management team may have better proclivity to engage in entrepreneurial undertakings. This proclilvity to entrepreneurial activities is partly driven by the fact that, in case of major failures and/or losses, the owners (called incorporators and shareholders) may only be held liable up to their financial contribution to the business.

These views concur with those of Davidsson et al (2002) who found out that firms tend to realise higher growth rates when owners have limited liability and are therefore willing to take risks since their personal wealth is protected from excess losses of the firm. Under-investment is common amongst small firms with highlyconcentrated ownership structures (Danielson \& Scott, 2007). Hence it is advanced in this study that:

\section{$\mathbf{H}_{22}$ - MSMEs under sole proprietorship are less entrepreneurial in their strategic posture compared to those under partnership and corporate ownership.}

\subsubsection{Age of the Manager}

Research has shown that the age of the executives of an organisation affects strategic decisions (Hitt \& Tyler, 1991; Karami et al., 2006). Age has been shown to influence one's ability to evaluate risk (Hitt \& Tyler, 1991). More specifically, it has been noted that younger managers are associated with innovativeness and risk-taking whilst older managers are associated with risk aversion and strong tendency to take a 
more conservative stand on organisational matters (Karami et al., 2006; Kitchell, 1997; Thomas, Litschert \& Ramaswamy, 1991). Cognitive theories suggest that certain learning abilities such as memory decline with age (Kitchell, 1997). Older managers are less able to evaluate new ideas quickly and integrate them effectively in decision-making. They may also lack the stamina to endure the constant stresses and strains associated with risks and innovation (Kitchell, 1997).

Furthermore, younger managers are associated with more willingness to be more innovative and open to change and to challenge the status quo (Kathuria \& Porth, 2003). Thomas et al study (1991) shows that when there is a strategic alignment between age and the prospector (i.e. aggressive) type of strategy, firm performance tends to be higher. It can be recalled that the profile of a prospector type of firm (Miles \& Snow, 1978) shows strong resemblance to that of firms with strong entrepreneurial strategic posture. Hence, it is hypothesised in this study that:

\section{$\mathrm{H}_{23}$ - There is a negative relationship between MSME owner/manager' age and entrepreneurial strategic posture.}

\subsubsection{Gender of Manager}

It is enticing to advance the idea that the strategic posture of MSMEs depends on whether the owner/manager is male or female. Some studies have shown the apparent differences between female- and male-managed firms (Machado et al., 2002). One study found mixed results in terms of how gender influences managerial choices (Barnett \& Karson, 1989).

However, close scrutiny of these studies reveals that differences among male and female business owners may be attributed to business exposure, training, educational qualification, and the nature of the business activities rather than by the biological status of business owners/managers (Machado et al., 2002; Verheul \& Thurik, 2001). Likewise, studies have shown that: gender is an insignificant factor in the productivity of small firms (Noboyuki, 2004); gender is not a primary determinant of export behaviour (Grondin \& Schaefer, 1995); gender has marginal effect on entrepreneurial orientation (Chow, 2006); men and women do not differ in their 
decision-making styles (Spicer \& Sadler-Smith, 2005); gender is not a determining factor in investigating problems associated with strategies of small businesses (Chaganti \& Parasuraman, 1996; Perry, 2002); and that male and female business owners arrive at growth decisions using a similar process (Orser \& Hogarth-Scott, 2002).

Finally, one study showed that men and women were found to have no difference at all in terms of how they pursue innovation and the level of risk they take (Sonfield, Lussier, Corman \& McKinney, 2001). Therefore, gender, as a managerial characteristic, will not be included in the process of hypothesis testing as previous studies have unequivocally established that strategies of firms are not influenced by gender.

\subsubsection{Educational Background}

The educational background of the owner/manager of an MSME provides an indication of managerial knowledge and skills-base (Bantel \& Jackson, 1989; Hitt \& Tyler, 1991; Karami et al., 2006). Drawing on cognitive theory, it is argued that better educated managers are more able to generate a wider range of creative solutions when faced with complex problems and are therefore more receptive to innovation (Bantel \& Jackson, 1989; Karami et al., 2006; Kitchell, 1997).

Previous studies have noted the positive relationship between the level of a manager's formal education and a firm's entrepreneurial strategic posture, particularly in the aspect of innovation (Chow, 2006; Hitt \& Tyler, 1991; Thomas et al., 1991). As the level of education increases, training and perspectives about social phenomena become more specialised and focused which consequently shape the cognitive models and the ultimate strategic choices made by these managers (Hitt \& Tyler, 1991). The rationale is that educational training enhances intellectual ability, increases knowledge, and widens social contacts that allow managers to engage in complex activities involving higher level of risks such as R \& D (Chow, 2006). Another study shows that the level of education is positively correlated with innovation and with greater speed in implementing innovation (Kathuria \& Porth, 2003). 
These studies converge on the view that high level of formal educational training endows managers with skills or mental capabilities that are essential to take on the challenges associated with risky situations, innovation and proactive responses to the demands of the firm's external environment. Hence, it is proposed in the study that:

\section{$\mathrm{H}_{24}$ High levels of education of the MSME owner/manager are positively associated with entrepreneurial strategic posture.}

\subsection{Summary of Hypotheses}

The hypotheses developed/proposed above deal with four fundamental arguments advanced in this study: that formal and informal institutions shape the strategic posture of MSMEs; that strategic posture shapes MSME organisational performance; that certain managerial, firm and industry related factors shape strategic posture; and that the relationships between institutions and organisational performance are mediated by strategic posture. Presented in Table 3.4 is the summary of the hypotheses that will be tested in this study. 
Table 3.4. Summary of Hypotheses

\begin{tabular}{|c|c|c|}
\hline $\begin{array}{l}\text { Hypothesis } \\
\text { Number }\end{array}$ & Variables & $\begin{array}{c}\text { Expected } \\
\text { Outcomes } \\
\text { (relationships } \\
\text { or differences) }\end{array}$ \\
\hline $\mathrm{H}_{1}$ & Rule of Law $\rightarrow$ Entrepreneurial Strategic Posture & + relationship \\
\hline $\mathrm{H}_{2}$ & Protection of Property Rights $\rightarrow$ Entrepreneurial Strategic Posture & + relationship \\
\hline $\mathrm{H}_{3}$ & Government Policies $\rightarrow$ Entrepreneurial Strategic Posture & + relationship \\
\hline $\mathrm{H}_{4}$ & Regulatory Quality $\rightarrow$ Entrepreneurial Strategic Posture & + relationship \\
\hline $\mathrm{H}_{5}$ & Government Assistance $\rightarrow$ Entrepreneurial Strategic Posture & + relationship \\
\hline $\mathrm{H}_{6}$ & Performance Orientation $\rightarrow$ Entrepreneurial Strategic Posture & + relationship \\
\hline $\mathrm{H}_{7}$ & Future Orientation $\rightarrow$ Entrepreneurial Strategic Posture & + relationship \\
\hline $\mathrm{H}_{8}$ & Assertiveness $\rightarrow$ Entrepreneurial Strategic Posture & + relationship \\
\hline $\mathrm{H}_{9}$ & Collectivism $\rightarrow$ Entrepreneurial Strategic Posture & - relationship \\
\hline $\mathrm{H}_{10}$ & Power Distance $\rightarrow$ Entrepreneurial Strategic Posture & - relationship \\
\hline $\mathrm{H}_{11}$ & Humane Orientation $\rightarrow$ Entrepreneurial Strategic Posture & - relationship \\
\hline $\mathrm{H}_{12}$ & Uncertainty Avoidance $\rightarrow$ Entrepreneurial Strategic Posture & - relationship \\
\hline $\mathrm{H}_{13 \mathrm{a}} \& \mathrm{H}_{136}$ & $\begin{array}{l}\text { Entrepreneurial Strategic Posture } \rightarrow \text { Operational and Financial } \\
\text { Performance }\end{array}$ & + relationship \\
\hline $\mathrm{H}_{14 \mathrm{a}}-\mathrm{H}_{14 \mathrm{~h}}$ & $\begin{array}{l}\text { Entrepreneurial Strategic Posture } \rightarrow \text { Eight Measures of Operational } \\
\text { Performance }\end{array}$ & + relationship \\
\hline $\mathrm{H}_{15 \mathrm{a}}-\mathrm{H}_{15 \mathrm{a}}$ & $\begin{array}{l}\text { Entrepreneurial Strategic Posture } \rightarrow \text { Five Measures of Financial } \\
\text { Performance }\end{array}$ & + relationship \\
\hline $\mathrm{H}_{160}-\mathrm{H}_{16 \times}$ & $\begin{array}{l}\text { Formal and Informal Institutions } \rightarrow \text { Operational and Financial } \\
\text { Performance }\end{array}$ & $\begin{array}{l}\text { direct } \\
\text { relationships }\end{array}$ \\
\hline $\mathrm{H}_{17 \mathrm{a}}-\mathrm{H}_{17 \mathrm{~b}}$ & $\begin{array}{l}\text { Formal and Informal Institutions } \rightarrow \text { Operational and Financial } \\
\text { Performance but Mediated by Strategic Posture }\end{array}$ & $\begin{array}{l}\text { mediated } \\
\text { relationship }\end{array}$ \\
\hline $\mathrm{H}_{18}$ & Competitive Intensity $\rightarrow$ Entrepreneurial Strategic Posture & + relationship \\
\hline $\mathrm{H}_{19}$ & Industry Techno. Sophistication $\rightarrow$ Entrepreneurial Strategic Posture & + relationship \\
\hline $\mathrm{H}_{20}$ & Firm Size $\rightarrow$ Entrepreneurial Strategic Posture & + relationship \\
\hline $\mathrm{H}_{21}$ & Firm Age $\rightarrow$ Entrepreneurial Strategic Posture & - relationship \\
\hline $\mathrm{H}_{2}$ & $\begin{array}{l}\text { Sole Proprietorships < Partnerships \& Corporations in terms of } \\
\text { Entrepreneurial Strategic Posture }\end{array}$ & $\begin{array}{c}\text { less } \\
\text { entrepreneurial }\end{array}$ \\
\hline $\mathrm{H}_{23}$ & Age of Manager $\rightarrow$ Entrepreneurial Strategic Posture & - relationship \\
\hline $\mathrm{H}_{24}$ & Educational Level $\rightarrow$ Entrepreneurial Strategic Posture & + relationship \\
\hline
\end{tabular}


Scientific empirical investigation to generate the answers to the research questions identified above, demands a systematic lay-out of the design, methods, tools, and procedures to gather, organise, analyse and interpret the required information. That lay-out is presented in this chapter. The major sections of the chapter are shown in Figure 4.1.

Figure 4.1. Road Map of the Chapter

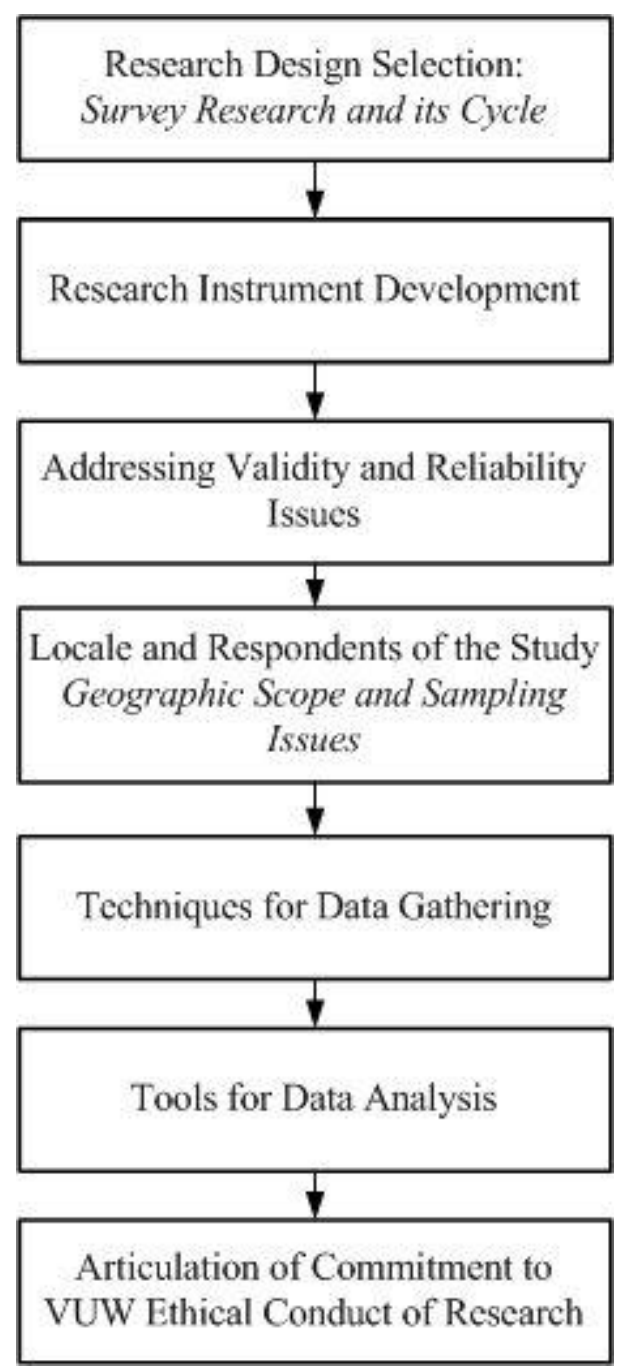




\subsection{Research Design}

To achieve the four research objectives, the study adopted the empirical-deductive route to scientific investigation whereby testing the application of existing theories through hypotheses is an essential component. The study adopted a quantitative orientation such that deductive logic was combined with precise empirical observations of the phenomena at hand to discover general patterns of human activity (Cavana, Delahaye \& Sekaran, 2001).

More specifically, it adopted the survey research design as the primary framework of the investigation. A survey is a systematic method for gathering information from entities for the purpose of constructing quantitative descriptors of the attributes of the larger population of which the entities are members (Czaja \& Blair, 2005; Groves et al., 2004).

Survey research design involves research in which (a) data are collected from members of a sample that represents a known population; (b) systematic technique of data gathering is observed by obtaining estimates of the population parameters in a rigorous fashion; (c) the researcher manipulates no independent variables; (d) data are sought directly from respondents; (e) respondents provide data in natural settings; (f) the purpose of the research may range from exploration of phenomena to hypothesis testing; and ( $\mathrm{g}$ ) the resulting data are often put to both descriptive and analytic uses (Czaja \& Blair, 2005). Specifically, the survey design took the form of one time cross-sectional study which entailed data collection at one-point in time (Zikmund, 2003).

The basic purpose of the current investigation entailed hypothesis testing to examine the thesis that institutions significantly shape the strategic posture of MSMEs. The study delved into the "environment-conduct-performance" view by testing hypotheses on the relationships between MSME strategic posture and organisational performance. Furthermore, it examined the manager-strategy alignment perspective, the organisational context-strategy link, and the I/O theory of strategy, by testing the hypotheses on the relationships between managerial characteristics and strategic 
posture, firm characteristics and strategic posture, and industry characteristics and strategic posture.

The extent of researcher interference was minimal as the study required looking at MSME as they normally exist in their business setting. The unit of analysis in this research was the firm. The entire firm or organisation was taken as a collective whole composed of resources and skills presumed to be heavily influenced by the institutional forces of the external environment. It is important to note, however, that in this study of MSMEs, there was an overlapping of domains: the firm-level domain and entrepreneur/individual-level domain. This was especially true when the microenterprise is a one-man business or a business that is managed by its owner with very few employees. In this case, the actions of the owner/manager may be interpreted as the action of the whole enterprise (Bhaskaran, 2006).

Prior to the selection of the final research design, alternative methods were explored. For instance, the use of the case study using a variety of data gathering techniques was viewed as an alternative method (Cavana et al., 2001). However, its dependence on a single case rendered it incapable of providing a generalisable conclusion (Yin, 1994). Since the current study aimed to identify the perceived factors constituting the institutional environment of MSMEs in a city using owners/managers as respondents, generalisability of the model across all MSMEs in a city was of paramount concern. Doing a case study of one or a few enterprises would impact adversely on the generalisability of the subsequent findings.

Longitudinal design was another alternative research design for this study. This research design would allow studying people or phenomena at more than one point in time (Cavana et al., 2001). However, time and other resource constraints made this research design too prohibitive for the current research. However, the adoption of cross-sectional design relative to longitudinal design did not diminish the scientific value of the current study. The descriptive nature of the study warranted the use of cross sectional survey to generate information. The main objective was to measure variations between/amongst members of the same group (i.e. MSMEs) rather than variations across time on a range of issues or factors (Groves et al., 2004). The study did not intend to measure trends or pattern of events which is a core feature of 
longitudinal studies. However, the information from cross sectional studies could well be used to do further longitudinal studies in the future if the objective is to determine directions of causal relationships between variables and to uncover the temporal order of changes of people or phenomena under study.

Likewise, the possibility of doing document, archival or content analysis was also explored. However, the apparent lack of reliable and up to date public documents relevant to the study precluded the use of these alternative methods. For instance, determining the presence of institutions in a city requires data on formal institutions found in a city. Data depicting or describing these institutions were not readily reflected in the annually-updated public documents, if at all. Moreover, elements of the informal institutions (i.e. culture) are not normally kept in public records, hence prohibiting the use of this type of research design.

The alternative of conducting field experiments is a powerful way of establishing causal relationships. Gaining popularity in the field of policy analysis, field experiments allow for the study of a person, groups, or phenomenon in natural setting but treatments are given to one or more groups (Cavana et al., 2001). The nature and objectives of the proposed research discounted the possibility of using field experiments. If a field experiment was used in this study, then a set of programs, projects, events, or activities must be developed and implemented to cover every aspect of the institutional framework and test its impact on one set of MSMEs (the experimental group) relative to other MSMEs (control group). Temporal and financial limitations prohibited the use of this type of design. Likewise, technical limitations included the problem of isolating the experimental group against the control group which would be an extremely difficult, if not an impossible task. Extraneous variables were also difficult to isolate from the independent and dependent variables under study.

Finally, the use of the survey research design was viewed as consistent with previous studies which provided the conceptual and theoretical inspirations for the current research (e.g. Wong 2002; Zapalska et al. 2003; Co 2004; Dollar et al. 2005; amongst others). 


\subsubsection{Survey Life Cycle: Design Perspective}

The adoption of survey design as the method of inquiry in this study followed the prescription recommended by Groves et al (2004). The process of doing the survey went through four distinct stages with the ultimate aim of generating survey statistics from which inferences were made. Groves et al (2004) suggested the development of clear and well-defined variables and their corresponding constructs that were used in the study. Constructs were the elements of information that were sought by the researcher (Groves et al., 2004).

In this study, the variables describing the institutional environment and MSME strategic posture and organisational performance were latent variables. Hence, construct measures were used/adopted/developed with multiple item indicators or scales. Multi-item scales increase the reliability of the research instrument and decreases measurement error (Churchill, 1979).

Generating the definitions of the variables and constructs required a systematic review of relevant literature. This was similar to the prescription of Churchill (1979) in developing new variables and measures. The purpose of the review was to establish the domain of the constructs that were used in this study. By this, Churchill (1979) referred to exactly delineating what was included and excluded in the definition of constructs.

Chapters two and three of the current study presented the theoretical bases of the study and the wide array of previous empirical studies on the subject. From there, specific constructs were generated. The institutional environmental dimensions were identified guided by institutional approach of understanding the external environment. Likewise, MSME strategic posture and organisational performance were examined under various theoretical approaches such as RBV, strategic choice, and organisational effectiveness, amongst others. Furthermore, empirical studies were analysed to identify specific variables that were eventually classified as formal or informal institutions, strategic posture, and indicators of performance. 
Measurement was the second stage in the survey process whereby specific ways to gather information about the constructs were determined. Survey measurements could be diverse - gathering qualitative or quantitative information in a variety of ways from various sources (Groves et al., 2004). Nonetheless, Groves et al (2004) argue that the critical task for measurement is to design questions that produce answers reflecting perfectly the constructs to be measured. This is similar to Churchill's (1979) process of developing measures to generate sample items to capture the domain of each variable used in this study. To do this, previous studies were examined to identify specific measures that the researcher considered to be relevant under each variable. Attention was given to the way a specific variable was used in a study as well as its dimensions or components.

The next step was ascertaining the reliability as well as the validity of the set of measures which ultimately comprised the research instrument. This step is thoroughly discussed in the succeeding sections below. The next stage dealt with the responses to be generated from the survey. The nature of the responses is determined by the nature of the measurements (Groves et al., 2004). The current study made use of a mixture of measures generating objective information such as the demographic profile of the respondents as well as subjective measures to gauge perception on a range of factors.

The last stage prescribed by Groves et al (2004) refers to editing of response which was done once all data were turned in to check for various errors as well as outlier detection. The edited responses formed the basis for analyses and inferences that were subsequently done in the course of the study.

\subsection{The Research Instrument}

A self-administered, self-reporting (i.e. self-rating) questionnaire was developed to gather data required to generate answers to the research problem. Using this type of data gathering is well-established in the social sciences including management, marketing and organisational studies (Avolio, Yammarino \& Bass, 1991; O'Regan \& Ghobadian, 2004b). Whilst this can be viewed as subjective in nature, previous studies pointed out that even those "objective measures" contain elements of 
subjectivity (Boyd et al., 1993). This is especially true amongst traditional secondary data sources - the creation of which requires judgements and involves several potential sources of error. Furthermore, the use of archival data requires the judgement of the researcher thereby introducing some element of subjectivity as well (Boyd et al., 1993).

The constructs and their corresponding indicators/items were judged as reflective (rather than formative) based on the following criteria set by Jarvis, Mackenzie and Podsakoff (2003) and Diamantopolous and Siguaw (2006): direction of causality is from construct to items; the indicators are manifestations of the construct; changes in the construct do cause changes in the indicators; indicators of a construct have the same or common theme; dropping an indicator does not alter the conceptual domain of the construct; and indicators of a construct co vary with each other. Reflective indicators were created under the perspective that they all measured the same underlying phenomenon based on the theoretical and conceptual domains of the construct capturing that specific phenomenon (Diamantopolous \& Siguaw, 2006).

\subsubsection{Use of Self-Ratings}

The use of self-ratings have been shown to be useful when the following conditions are met: (1) there is a structured rating instrument; (2) they are used as a selfdevelopment tool; (3) individuals working in isolation or possess rare skills; and (4) they are used in discriminating across performance/skill dimensions (Chandler \& Hanks, 1993). The research instrument used in this study was a well-structured instrument which consisted mostly of close-ended questions. MSMEs responding to the survey were likely to have answered this questionnaire in isolation as the questionnaire was delivered to their office or business site. The items specifically referred to constructs relevant to institutional factors and MSME strategic posture and organisational performance, hence, possessed the ability to classify respondents based on the scales of these constructs. The thorough process of identifying the indicators of the constructs formed one argument for reliance on its content validity and accuracy (Hanson, 2001). Likewise, results of the study could be used for developmental purposes as it could point out specific areas for improvement such as 
knowing which institutional factor influences strategic posture and the kind of strategic posture that generates positive performance in a given industry.

\subsubsection{Use of Likert Scales}

The research design of this study aimed to gather perceptions about the variables under investigation and the use of Likert type of scale was argued to elicit these perceptions best. A seven-point and five-point Likert type of scale were used in this study which the researcher considered to be sufficient enough to capture the best judgement of the respondents befitting the purposes of the study. There were variables used in the study for which existing (i.e. standard) questionnaires were adopted such as the formal and informal institutions, strategic posture, industry technological sophistication and competitive intensity. These pre-existing constructs had measures with seven-point Likert type of scale. The use of five-point Likert type of scale was used for measuring organisational performance which was consistent with previous studies (Aragon-Sanchez \& Sanchez-Marin, 2005; Spillan \& Parnell, 2006; Yusuf \& Saffu, 2005).

Having numerous response positions in a scale increased the sensitivity of the scale to the variability of the responses to a question (Zikmund, 2003). It allowed aggregation of a set of indicators, was easy to administer, and gave respondents convenience (e.g. quick understanding on how to respond) in answering the survey questionnaire (Boyd et al., 1993; Devlin, Dong \& Brown, 2003; Lundstrom \& Lamont, 1976).

Likewise, the use of the Likert scale allowed the generation of interval-type of data that permitted advanced data analytical tools (Cavana et al., 2001). Each position or category in the scale was given a corresponding verbal label or description to help respondents in understanding the response positions better (Zikmund, 2003). A fullydefined scale was considered appropriate in this study as a check on 'leniency errors' (i.e. responses concentrating on the higher part of the scale), hence avoiding the tendency of the questionnaire to yield higher (more positive) or lower (more negative) ratings (Frisbie \& Brandenburg, 1979). A point by point label enhanced the discriminant function of the scale. This helped the respondent in making a better 
and more informed judgement in choosing the answer to each item knowing the equivalent qualitative meaning of the 'numbers' in the scale. Labelling the rating scale points has been shown to increase the reliability and validity of the instrument because it clarifies the meaning of each point (Krosnick, 1999). This is because the labels further enhance the discriminatory function of each of the points in the scale as it attempts to "standardise" across respondents the semantic properties of the points, hence establishing the scales' "psychological interval" (Myers \& Warner, 1968). Since Likert type of scales are inherently ordinal, attempts to establish the psychological interval supports the use of Likert type scales (as if they possess interval scale properties). The use of a Likert type of scale in the present context was consistent with previous related studies (Caloghirou et al., 2004; Chung-Ming \& Ngo, 2001; Covin \& Slevin, 1989; Dess, Lumpkin \& Covin, 1997; Slater \& Narver, 2000; Wolff \& Pett, 2006).

Furthermore, the use of the Likert type of scale had the ability to measure the intensity of how MSMEs think and feel about the statements described in the questionnaire. It was assumed that thoughts and feelings lie in a broad spectrum and dichotomous scaling methodology would hide this variability of the population being studied. The use of Likert type of scale allowed the inclusion of a large number of diverse statements which were believed to be necessary to scale comprehensively a relatively unknown or latent construct.

Another evident feature of the questionnaire was the use of multiple items to measure the different constructs describing the variables. Because of the multidimensional nature of many of the constructs used in the study, the use of these composite measures was a method of increasing precision and accuracy of the research instrument (Zikmund, 2003).

\subsubsection{Parts of the Questionnaire}

The survey questionnaire has seven major parts as follows:

$\begin{array}{llll}\text { Part A - } & \text { Formal Institutions } & - & 28 \text { items } \\ \text { Part B - } & \text { Informal Institutions } & - & 29\end{array}$


Marker Variable

- Attitude Towards Information Seeking - 4

Part C - $\quad$ Strategic Posture $\quad$ - 9

Part D - $\quad$ MSME Organisational Performance

Section I - Importance of Measures $\quad$ - 13

Section II - Perceived Performance $\quad-\quad 13$

$\begin{array}{llll}\text { Part E - } & \text { MSME Details } & - & 18\end{array}$

Part F - $\quad$ Industry Technological Sophistication $\quad$ - 2

Part G - Competitive Intensity $\quad-\quad 3$

Total Items $\quad$ - $\quad 119$ items

A copy of the final version of the questionnaire is presented in the appendix.

\subsubsection{Part A - Formal Institutions}

Part A consisted of 28 items dealing with the formal institutional environment whereby respondents evaluated the statement/factor described in each item using a scale ranging from 1 - strongly disagree 2 - disagree, 3 - moderately disagree, 4 neutral (or neither agree nor disagree), 5 - moderately agree, 6 - agree, 7 - strongly agree. The use of this type of scaling has been viewed favourably as it has minimal response bias, ease of administration, and ease of interpretation and understanding by respondents (Devlin et al., 2003; Frisbie \& Brandenburg, 1979; Myers \& Warner, 1968).

The use of perceptual measurement of the institutional environment could be justified on certain grounds including the opportunity for aggregation of a set of indicators to reflect the current state of the firm's institutional environment (Boyd et al., 1993). More so, the cognitive perspective of the firm's external environment as discussed previously lends credence to this approach of measuring institutions.

Furthermore, a substantial number of previous studies that attempted to measure the external environment and its various dimensions such as complexity, munificence, uncertainty and turbulence used perception-based measures by using scales of different types (Ashill \& Jobber, 2001; Boulton, Lindsay, Franklin \& Rue, 1982; 
Bstieler \& Gross, 2003; Duncan, 1972; Jogaratnam et al., 1999; Tung, 1979; Ward \& Lewandowska, 2005). Scales used previously include an importance scale, a satisfaction scale, an uncertainty scale, a predictability scale, an agree-disagree scale, amongst others. Tables 4.1, 4.2, and 4.3 show the different formal institutions and the specific sets of items that appeared in the questionnaire.

Part A of the questionnaire reflected these items consistent with the numbers as shown in these tables. It must be noted however, that this part was subjected to rigorous validation process. Whilst the specific items were culled from existing measures, it was imperative that content and construct validation procedures be conducted to ensure that the objectives of the study were achieved well. As defined in chapter 3, formal institutions referred to the legal and political structures and processes in the city that explicitly specify and enforce the rights, duties, responsibilities and privileges of its local populace including MSMEs and governing the interrelationships amongst them (Aidis, 2005; Busenitz et al., 2000; Fogel et al., 2006; Nkya, 2003; Peters, 1999; Prasad, 2003). As a multi-dimensional construct, formal institutions were manifested by the city's rule of law, protection of property rights, government policies, regulatory quality, and government assistance to MSMEs.

\subsubsection{Part B - Informal Institutions}

Part B asked 29 questions on informal institutions. As argued in the previous chapter, informal institutions referred to the cultural factors shared by members of a society in a given locality or city that serve as constraints and/or standards of conduct or behaviour and the violation of which entails social rather then legal penalties. The GLOBE questionnaire on culture was adopted in this study specifically section 1 of that instrument measuring the societal cultural practices (i.e. the way things are) (House et al., 2004). This was important to note since the GLOBE questionnaire also measured values, leadership, and organisational culture. Hence, what was being measured in this section was the perception of MSME owners/managers "on the way things are" in the city along the seven dimensions of informal institutions. Written permission from the GLOBE authors was sought for this purpose. 
Table 4.1. Definition, Operationalisation and Sources of Measures:

Rule of Law and Property Rights Protection

\begin{tabular}{|c|c|}
\hline $\begin{array}{l}\text { Rule of Law } \\
\text { supremacy of law whereby decisions are made by the } \\
\text { application of known principles or laws without the intervention of } \\
\text { discretion in their application }\end{array}$ & Sources \\
\hline \multicolumn{2}{|l|}{ In this city: } \\
\hline $\begin{array}{l}\text { 1. the occurrence of crime does not impose costs on my } \\
\text { business. }\end{array}$ & $\begin{array}{l}\text { (Lopez-Claros, } \\
\text { Altinger, Blanke, } \\
\text { Drzeniek \& Mia, } \\
\text { 2007) }\end{array}$ \\
\hline 2. the judicial system is fair and impartial. & (WorldBank, 2002) \\
\hline $\begin{array}{l}\text { 3. the legal system is effective in enforcing commercial } \\
\text { contracts. }\end{array}$ & (WorldBank, 2002) \\
\hline $\begin{array}{l}\text { 4. people are willing to accept legal means to adjudicate } \\
\text { disputes rather than depend on physical force or illegal } \\
\text { means. }\end{array}$ & $\begin{array}{l}\text { (Lopez-Claros et al., } \\
\text { 2007) }\end{array}$ \\
\hline 5. court rulings and/or arbitration awards are complied with. & $\begin{array}{l}\text { (Lopez-Claros et al., } \\
\text { 2007) }\end{array}$ \\
\hline $\begin{array}{l}\text { 6. the legal framework to challenge the legality of government } \\
\text { actions is efficient. }\end{array}$ & $\begin{array}{l}\text { (Lopez-Claros et al., } \\
\text { 2007) }\end{array}$ \\
\hline \multicolumn{2}{|l|}{$\begin{array}{l}\text { Property Rights Protection } \\
\text { protection and enforcement of the right to use, exclude others } \\
\text { from using, modify, obtain income from, and sell assets }\end{array}$} \\
\hline \multicolumn{2}{|l|}{ In this city, } \\
\hline 7. private property is adequately protected by law. & $\begin{array}{l}\text { (La Porta, Lopez-de- } \\
\text { Silanes, Shleifer \& } \\
\text { Vishny, 1999) }\end{array}$ \\
\hline 8. intellectual property rights are adequately protected & $\begin{array}{l}\text { (La Porta et al., } \\
\text { 1999) }\end{array}$ \\
\hline 9. the government enforces laws that protect private property & $\begin{array}{l}\text { (La Porta et al., } \\
\text { 1999) }\end{array}$ \\
\hline 10. violations of property rights are prosecuted accordingly & $\begin{array}{l}\text { (La Porta et al., } \\
\text { 1999) }\end{array}$ \\
\hline
\end{tabular}


Table 4.2. Definition, Operationalisation and Sources of Measures: Government Policies and Regulatory Quality

\begin{tabular}{|c|c|}
\hline $\begin{array}{l}\text { Government Policies } \\
\text { refer to the locally enacted and implemented laws, ordinances, } \\
\text { regulations any other forms of legislations and/or government } \\
\text { decisions especially those that affect the business sector }\end{array}$ & Sources \\
\hline \multicolumn{2}{|l|}{ In this city: } \\
\hline $\begin{array}{l}\text { 7. laws and regulations imposed by the local government are } \\
\text { conducive for business. }\end{array}$ & (Fogel, 2001) \\
\hline $\begin{array}{l}\text { 8. taxation laws and policies including incentives and } \\
\text { exemptions are good enough for my business }\end{array}$ & (Fogel, 2001) \\
\hline $\begin{array}{l}\text { 9. local government economic policies adapt quickly to } \\
\text { changes in the economy }\end{array}$ & (IMD, 2006) \\
\hline 10. local government decisions are effectively implemented. & (IMD, 2006) \\
\hline 11. the policy direction of the local government is consistent & Original \\
\hline $\begin{array}{l}\text { Regulatory Quality } \\
\text { the degree to which compliance of the existing laws, rules, and } \\
\text { other government regulatory procedures does not impose } \\
\text { unreasonable burden on MSMEs }\end{array}$ & \\
\hline \multicolumn{2}{|l|}{ In this city, } \\
\hline 12. information about laws and regulations is easy to obtain & (WorldBank, 2002) \\
\hline $\begin{array}{l}\text { 13. interpretations of the laws and regulations are consistent } \\
\text { and predictable }\end{array}$ & $\begin{array}{l}\text { (IFC, 2007; WorldBank, } \\
\text { 2002) }\end{array}$ \\
\hline 14. business regulations are less of a burden for business. & $\begin{array}{l}\text { (La Porta et al., 1999; } \\
\text { WorldBank, 2002) }\end{array}$ \\
\hline $\begin{array}{l}\text { 15. procedures in government transactions are consistently } \\
\text { enforced }\end{array}$ & (La Porta et al., 1999) \\
\hline 16. the time required to register a business is reasonable. & (Frye \& Zhuravskaya, 2000) \\
\hline 17. the number of permits required is manageable. & (Frye \& Zhuravskaya, 2000) \\
\hline $\begin{array}{l}\text { 18. the number of government agencies to deal with is } \\
\text { reasonable. }\end{array}$ & (Frye \& Zhuravskaya, 2000) \\
\hline $\begin{array}{l}\text { 19. The number of government inspection required before } \\
\text { opening a business is reasonable. }\end{array}$ & (Frye \& Zhuravskaya, 2000) \\
\hline
\end{tabular}


Table 4.3. Definition, Operationalisation and Sources of Measures:

Government Assistance

\begin{tabular}{l|l}
\hline \multicolumn{1}{c|}{$\begin{array}{l}\text { Government Assistance } \\
\text { extent to which the local government provides various forms of } \\
\text { assistance and incentives to the MSME sector }\end{array}$} & Sources \\
\hline In this city, & (Busenitz et al., 2000) \\
\hline $24 . \quad \begin{array}{l}\text { local government agencies assist individuals in } \\
\text { starting their own business. }\end{array}$ & (Busenitz et al., 2000) \\
\hline $25 . \quad \begin{array}{l}\text { the local government sets aside government contracts } \\
\text { for new and small businesses. }\end{array}$ & (Busenitz et al., 2000) \\
\hline $26 . \quad \begin{array}{l}\text { the local government has special support available for } \\
\text { individuals who want to start a new business }\end{array}$ & (Busenitz et al., 2000) \\
\hline $27 . \quad \begin{array}{l}\text { the local government sponsors organisations that help } \\
\text { new businesses develop. }\end{array}$ & (Busenitz et al., 2000) \\
\hline 28. & $\begin{array}{l}\text { even after failing in an earlier business, the local } \\
\text { government assists entrepreneurs in starting again. }\end{array}$
\end{tabular}

In this part of the questionnaire, respondents were asked to rate the items on a 7point Likert-type scale. For some scales, the response indicators ranged from 1, indicating high agreement to 7 , indicating high disagreement. For other scales, the verbal anchors in the 7-point scale reflected the end points on a continuum (e.g. $1=$ dominant, $7=$ non-dominant) (House et al., 2004).

Table 4.4 shows the cultural dimensions used as measures of informal institutions. It must be noted that collectivism referred to institutional collectivism and did not include "in-group" collectivism described in the original work of House et al (2004). Institutional collectivism reflected the degree to which practices at the societal level encourage and reward collective action whilst in-group collectivism refers to the 
degree to which individuals express pride, loyalty and interdependence in their families (Gelfand et al., 2004).

Table 4.4. Definition, Operationalisation and Sources of Measures: Informal Institutions

\begin{tabular}{|c|c|c|c|}
\hline \multicolumn{4}{|c|}{ Informal Institutions } \\
\hline \multicolumn{4}{|c|}{$\begin{array}{l}\text { cultural factors shared by members of a society in a given locality or city that serve as constraints } \\
\text { and/or standards and the violation of which entails social rather than legal penalties }\end{array}$} \\
\hline Construct & Definition & Measurement & Remarks \\
\hline $\begin{array}{l}\text { Performance } \\
\text { Orientation }\end{array}$ & $\begin{array}{l}\text { the extent to which a community } \\
\text { encourages and rewards innovation, high } \\
\text { standards, and performance improvement }\end{array}$ & $\begin{array}{l}3 \text { items } 7 \text { pt likert } \\
\text { type scale } \\
\text { (items } 13,15,17 \text { ) }\end{array}$ & $\begin{array}{l}\text { Adapted from } \\
\text { (House et al. } \\
\text { 2004) }\end{array}$ \\
\hline $\begin{array}{l}\text { Future } \\
\text { Orientation }\end{array}$ & $\begin{array}{l}\text { tendency to conscientiously think and plan } \\
\text { for the future and consider the long-term } \\
\text { consequences of one's actions in the } \\
\text { present }\end{array}$ & $\begin{array}{l}5 \text { items - } 7 \text { pt - likert } \\
\text { type scale } \\
\text { (part B, items } 2,3 \\
, 7,24,25 \text { ) }\end{array}$ & $\begin{array}{l}\text { Adapted from } \\
\text { (House et al. } \\
\text { 2004) }\end{array}$ \\
\hline Assertiveness & $\begin{array}{l}\text { the beliefs as to whether people are } \\
\text { encouraged to be assertive, aggressive, } \\
\text { and tough or non-assertive, } \\
\text { nonaggressive, and tender in social } \\
\text { relationships }\end{array}$ & $\begin{array}{l}3 \text { items likert type } \\
\text { scale (part B, items } \\
5,9,12)\end{array}$ & $\begin{array}{l}\text { Adapted from } \\
\text { (House et al. } \\
\text { 2004) }\end{array}$ \\
\hline Collectivism & $\begin{array}{l}\text { the subordination of personal interests to } \\
\text { the goals of the larger work, an emphasis } \\
\text { on sharing, cooperation, interpersonal } \\
\text { connectedness, group harmony and } \\
\text { solidarity, and joint responsibility, a } \\
\text { concern for group welfare, and hostility } \\
\text { toward out-group members }\end{array}$ & $\begin{array}{l}4 \text { items } 7 \text { pt likert } \\
\text { type scale } \\
\text { (part B, items 6, } \\
10,23,29 \text { ) }\end{array}$ & $\begin{array}{l}\text { referring to } \\
\text { institutional } \\
\text { collectivism; } \\
\text { Adapted from } \\
\text { (House et al. } \\
\text { 2004) }\end{array}$ \\
\hline Power Distance & $\begin{array}{l}\text { extent to which a community accepts and } \\
\text { endorses authority, power differences, } \\
\text { and status privileges }\end{array}$ & $\begin{array}{l}5 \text { items } 7 \text { pt likert } \\
\text { type scale } \\
\text { (part B, items 4, } \\
11,21,22,28 \text { ) }\end{array}$ & $\begin{array}{l}\text { Adapted from } \\
\text { (House et al. } \\
\text { 2004) }\end{array}$ \\
\hline $\begin{array}{l}\text { Humane } \\
\text { Orientation }\end{array}$ & $\begin{array}{l}\text { characterizes those societies where } \\
\text { people's behaviours are guided by values } \\
\text { of altruism, benevolence, kindness, love, } \\
\text { and generosity }\end{array}$ & $\begin{array}{l}5 \text { items } 7 \text { pt likert } \\
\text { type scale (part B, } \\
\text { items } 8,18,20,26,27 \text { ) }\end{array}$ & $\begin{array}{l}\text { Adapted from } \\
\text { (House et al. } \\
\text { 2004) }\end{array}$ \\
\hline $\begin{array}{l}\text { Uncertainty } \\
\text { Avoidance }\end{array}$ & $\begin{array}{l}\text { extent to which ambiguous situations are } \\
\text { threatening to individuals, to which rules } \\
\text { and order are preferred and to which } \\
\text { uncertainty is tolerated in society }\end{array}$ & $\begin{array}{l}4 \text { items - } 7 \text { pt - likert } \\
\text { type scale } \\
\text { (part B, items } 1 \text {, } \\
14,16,19 \text { ) }\end{array}$ & $\begin{array}{l}\text { Adapted from } \\
\text { (House et al. } \\
\text { 2004) }\end{array}$ \\
\hline
\end{tabular}




\subsubsection{Marker Variable}

Four items were inserted right after the 29 questions on informal institutions. These four items refer to "attitudes towards information-seeking" (Cronbach $\alpha=.95$ ) (Das, Echambadi, McCardle \& Luckett, 2003) which was used as a marker variable - a statistical technique to detect common method variance. Details of this technique are discussed in Section 4.3.2.

\subsubsection{Part C - Strategic Posture}

Part $\mathrm{C}$ of the questionnaire referred to nine (9) items describing the strategic posture of MSMEs. The items were measures of strategic posture adopted from previous studies (Covin \& Slevin, 1990; Covin et al., 1990b; Covin et al., 1994; Khandwalla, 1977). This standardised questionnaire developed by Covin and Slevin in 1990 with an alpha of .85 has been used and validated in more recent studies (Avlonitis \& Salavou, 2007; Matsuno et al., 2002; Poon et al., 2006; Swierczek \& Ha, 2003b; Wiklund \& Sheperd, 2005). The study of Covin \& Slevin (1994) reported an alpha of .77 whilst Covin et al (1994) reported an alpha of .84 similar to the one reported by Poon et al (2006). Swierczek \& Ha (2003) reported an alpha of .88 in their study of SMEs in Vietnam.

Respondents rated each item using a 7 point scale representing a continuum of low to high levels of entrepreneurial characteristics of strategic posture. Higher points in a scale manifested the higher level of entrepreneurial tendencies of MSMEs (Covin \& Slevin, 1989). Table 4.5 shows the description of strategic posture. 
Table 4.5. Definition, Operationalisation and Sources of Measures:

Strategic Posture, Managerial, Firm and Industry Characteristics

\begin{tabular}{|c|c|c|c|}
\hline Construct & Definition & Measurement & Remarks \\
\hline $\begin{array}{l}\text { Strategic } \\
\text { Posture }\end{array}$ & $\begin{array}{l}\text { top management's risk taking behaviour } \\
\text { with regard to investment decisions and } \\
\text { strategic actions in the face of } \\
\text { uncertainty, the extensiveness and } \\
\text { frequency of product innovations and the } \\
\text { related tendency toward technological } \\
\text { leadership, and the pioneering nature of } \\
\text { the firm as evident in the firm's } \\
\text { propensity to compete with industry rivas } \\
\text { aggressively and proactively }\end{array}$ & 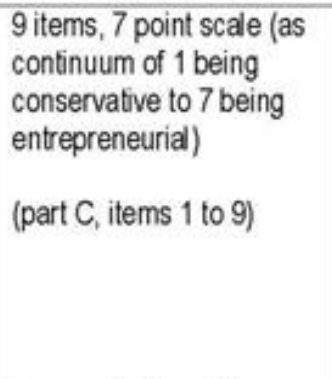 & $\begin{array}{l}\text { Adopted from Covin } \\
\text { and Slevin 1990; } \\
\text { Covin et al. } 1994\end{array}$ \\
\hline Age of Manager & number of years since birth of manager & $\begin{array}{l}\text { open ended question } \\
\text { (part E, item 2) }\end{array}$ & $\begin{array}{l}\text { References: Hitt and } \\
\text { Tyler 1991; Thomas } \\
\text { et al. 1991 }\end{array}$ \\
\hline Sex of Manager & biological sex of manager & $\begin{array}{l}\text { open ended question } \\
\text { (part E, item 3) }\end{array}$ & $\begin{array}{l}\text { References: Barnett } \\
\text { and Karson 1989; } \\
\text { Machado et al. } 2002\end{array}$ \\
\hline $\begin{array}{l}\text { Educational } \\
\text { Background of } \\
\text { Manager }\end{array}$ & highest level of educational attainment & $\begin{array}{l}\text { question with 1-7 choices } \\
\text { (part } E \text {, item 4) }\end{array}$ & $\begin{array}{l}\text { References: Hitt and } \\
\text { Tyler 1991; Chow } \\
2006\end{array}$ \\
\hline Size of the Firm & $\begin{array}{l}\text { referring to how big/small the firm is in } \\
\text { terms of capital and number of } \\
\text { employees }\end{array}$ & $\begin{array}{l}\text { Open ended questions } \\
\text { asking for amount of total } \\
\text { business capital in Pesos } \\
\text { and number of full-time } \\
\text { employees } \\
\text { (part E, item } 11 \text { and 13) }\end{array}$ & $\begin{array}{l}\text { References: Mohan- } \\
\text { Neill 1995; Entrialgo } \\
\text { et al. 2001; Yusuf } \\
\text { 2002; Luo et a. } 2005\end{array}$ \\
\hline Age of the Firm & $\begin{array}{l}\text { referring to the length of time the } \\
\text { business has been in continuous } \\
\text { operation since the business started. }\end{array}$ & $\begin{array}{l}\text { Open ended question } \\
\text { asking for the length of } \\
\text { time the business has } \\
\text { been in operation in years } \\
\text { and/or months } \\
\text { (part } E \text {, item 7) }\end{array}$ & $\begin{array}{l}\text { Reference: Mohan- } \\
\text { Neill } 1995\end{array}$ \\
\hline $\begin{array}{l}\text { Ownership } \\
\text { Structure }\end{array}$ & legal structure of ownership of the firm & $\begin{array}{l}\text { question with } 3 \text { choices } \\
\text { (part } E \text {, item 10) }\end{array}$ & $\begin{array}{l}\text { References: Bifley } \\
\text { and Westhead 1990; } \\
\text { Davidsson et al. } \\
\text { 2002; Kazem and } \\
\text { van der Heijden } \\
\text { 2006; Danielson and } \\
\text { Scott } 2007\end{array}$ \\
\hline $\begin{array}{l}\text { Industry } \\
\text { Technological } \\
\text { Sophistication }\end{array}$ & $\begin{array}{l}\text { the extent to which products and } \\
\text { processes produced or utilized in this } \\
\text { industry involve the use of very } \\
\text { sophisticated and complex operations } \\
\text { technologies with a lot of research and } \\
\text { development involved }\end{array}$ & $\begin{array}{l}2 \text { items, } 7 \text { point scale with } \\
1 \text { as the lowest score } \\
\text { representing low-tech as } \\
\text { opposed to } 7 \text { being the } \\
\text { highest score } \\
\text { representing high-tech } \\
\text { industry } \\
\text { (part F, items 1\&2) }\end{array}$ & $\begin{array}{l}\text { Adapted from } \\
\text { Khandwalla 1977; } \\
\text { Covin et al. } 1990\end{array}$ \\
\hline $\begin{array}{l}\text { Competitive } \\
\text { Intensity }\end{array}$ & $\begin{array}{l}\text { the extent of rivalry or level of } \\
\text { competition amongst firms in an industry }\end{array}$ & $\begin{array}{l}\text { 3 items, } 7 \text { point scale } \\
\text { (strongly agree to strongy } \\
\text { disagree) } \\
\text { (part G item } 1 \text { to } 3 \text { ) }\end{array}$ & $\begin{array}{l}\text { Reference: Appiah- } \\
\text { Adu \& Singh, } 1998\end{array}$ \\
\hline
\end{tabular}




\subsubsection{Part D - Organisational Performance}

Part D of the questionnaire measured the organisational performance of MSMEs. Subsection I measured the level of importance MSMEs attach to the thirteen (13) measures of organisational performance identified in the literature. The level of importance was measured in a 5-point Likert scale from very unimportant (1) to very important (5). Subsection II measured the level of performance as perceived by the MSMEs (i.e. owners/managers) themselves across the 13 measures. Tables 4.6 and 4.7 show the organisational performance variables.

\subsection{Operational and Financial Performance}

This study considered 13 dimensions of organisational performance. The basic premise in the selection of these dimensions was that performance was viewed as a multifaceted concept that characterised effectiveness, efficiency, adaptability and growth (Baker \& Sinkula, 2005). Furthermore, performance measures are normally used in studies to gauge the success of a firm relative to some standards or benchmarks (Adams \& Sykes, 2003). Likewise, multiple measures were used to capture the multidimensionality of business performance. The performance measures described in items 1 to 8 were considered as operational measures as defined in the framework of Venkatraman and Ramanujam (1986) whilst measures described in items 9 to 13 reflected the financial performance of firms. Operational performance indicators referred to those key operational success factors that might lead to financial performance and did not lend themselves to immediate financial quantification whilst financial performance indicators reflected the fulfilment of the economic goals of the firm of which profitability is at the core (Venkatraman \& Ramanujam, 1986). The use of composite measures of performance in this study was consistent with previous studies (Keh et al., 2006; Spillan \& Parnell, 2006; Tse, Sin, Yau, Lee \& Chow, 2003; Westhead \& Howorth, 2006; Wu \& Leung, 2005). The composite measures for operational and financial performance were used to account for the multidimensional nature of these performance constructs (Venkatraman \& Ramanujam, 1986). 
Table 4.6. Definition, Operationalisation and Sources of Measures:

Organisational Performance (Operational Performance)

\begin{tabular}{|c|c|c|c|}
\hline \multicolumn{4}{|c|}{ Organisational Performance } \\
\hline \multicolumn{4}{|c|}{$\begin{array}{c}\text { the operational and financial resuls of the firm's value-creating processes and activities guided by goals, constrained by } \\
\text { resources, compicated by diverse interests, and measured by various means }\end{array}$} \\
\hline \multicolumn{4}{|c|}{$\begin{array}{l}\text { subcomponent: operational performance - key operational success factors that might lead to financial performance and } \\
\text { do not lend themse ves to immediate financial quantification (Venkatraman and Ramanujam 1986) }\end{array}$} \\
\hline Operationalization & $\begin{array}{l}\text { Measurement } \\
\text { (part } D, / 1-8 \text {, and // 1-8) }\end{array}$ & Direct Source & Reference \\
\hline $\begin{array}{l}\text { 1. Development of } \\
\text { new products or } \\
\text { services }\end{array}$ & $\begin{array}{l}5 \text { point Likert-type scale on } \\
\text { importance and performance } \\
\text { relative to other firms over the } \\
\text { last } 3 \text { years }\end{array}$ & $\begin{array}{l}\text { (Gupta and Govindarajan 1984; } \\
\text { Delaney and Huselid 1996; } \\
\text { Pelham 2000; Sarkar et al. 2001; } \\
\text { Keskin 2005; Mabey and } \\
\text { Gooderham 2005; Gomes et al. } \\
\text { 2006; Wolff and Pett 2006; Zehir et } \\
\text { al. 2006) }\end{array}$ & $\begin{array}{l}\text { (Venkatraman and } \\
\text { Ramanujam 1986; } \\
\text { Stuart 2000) }\end{array}$ \\
\hline $\begin{array}{l}\text { 2. Product or service } \\
\text { quality }\end{array}$ & $\begin{array}{l}5 \text { point Likert-type scale on } \\
\text { importance and performance } \\
\text { relative to other firms over the } \\
\text { last } 3 \text { years }\end{array}$ & $\begin{array}{l}\text { (Delaney and Huselid 1996; } \\
\text { Aragon-Sanchez and Sanchez- } \\
\text { Marin 2005; Gonzalez-Benito and } \\
\text { Gonzales-Benito 2005; Kase and } \\
\text { Zupan 2005; Mabey and } \\
\text { Gooderham 2005; Gomes et al. } \\
\text { 2006) }\end{array}$ & $\begin{array}{l}\text { (Venkatraman and } \\
\text { Ramanujam 1986) }\end{array}$ \\
\hline $\begin{array}{l}\text { 3. Customer } \\
\text { satisfaction }\end{array}$ & $\begin{array}{l}5 \text { point Likert-type scale on } \\
\text { importance and performance } \\
\text { relative to other firms over the } \\
\text { last } 3 \text { years }\end{array}$ & $\begin{array}{l}\text { (Delaney and Huselid 1996; } \\
\text { Carmeli and Tishler 2004; Tsai and } \\
\text { Shih 2004; Gonzalez-Benito and } \\
\text { Gonzales-Benito 2005; Kase and } \\
\text { Zupan 2005; Mabey and } \\
\text { Gooderham 2005; Gomes et al. } \\
\text { 2006; Keh et al. 2006) }\end{array}$ & $\begin{array}{l}\text { (Tse, Sin, Yau, Lee } \\
\text { and Chow 2003) }\end{array}$ \\
\hline $\begin{array}{l}\text { 4. Improvements in } \\
\text { business and/or } \\
\text { production } \\
\text { processes }\end{array}$ & $\begin{array}{l}5 \text { point Likert-type scale on } \\
\text { importance and performance } \\
\text { relative to other firms over the } \\
\text { last } 3 \text { years }\end{array}$ & original & $\begin{array}{l}\text { (Venkatraman and } \\
\text { Ramanujam 1986; } \\
\text { Gomes et al. 2006; } \\
\text { Wolff and Pett 2006) }\end{array}$ \\
\hline $\begin{array}{l}\text { 5. Altraction of } \\
\text { essential } \\
\text { employees/skilled } \\
\text { labour } / \text { talents }\end{array}$ & $\begin{array}{l}5 \text { point Likert-type scale on } \\
\text { importance and performance } \\
\text { relative to other firms over the } \\
\text { last } 3 \text { years }\end{array}$ & $\begin{array}{l}\text { (Delaney and Huselid 1996; } \\
\text { Mabey and Gooderham 2005) }\end{array}$ & $\begin{array}{l}\text { (Mazzola and Bruni } \\
2000 ; \text { Lerner and } \\
\text { Almor 2002; Craig } \\
\text { and Dibrell 2006; } \\
\text { Spillan and Parnell } \\
\text { 2006) }\end{array}$ \\
\hline $\begin{array}{l}\text { 6. Retention of } \\
\text { essential } \\
\text { employees/skilled } \\
\text { labourftalents }\end{array}$ & $\begin{array}{l}5 \text { point Likert-type scale on } \\
\text { importance and performance } \\
\text { relative to other firms over the } \\
\text { last } 3 \text { years }\end{array}$ & $\begin{array}{l}\text { (Delaney and Huselid 1996; } \\
\text { Mabey and Gooderham 2005; } \\
\text { Spillan and Parnell 2006) }\end{array}$ & $\begin{array}{l}\text { (Mazzola and Bruni } \\
2000 ; \text { Lerner and } \\
\text { Almor 2002; Craig } \\
\text { and Dibrell 2006) }\end{array}$ \\
\hline 7. Market Share & $\begin{array}{l}5 \text { point Likert type scale on } \\
\text { importance and performance } \\
\text { relative to other firms over the } \\
\text { last } 3 \text { years }\end{array}$ & $\begin{array}{l}\text { (Gupta and Govindarajan 1984; } \\
\text { Murray, Kotabe and Wildt 1995; } \\
\text { Huselid et al. 1997; Richard 2000; } \\
\text { Yan and Zhang 2003; Keskin } \\
\text { 2005; Sanchez and Perez 2005; } \\
\text { Falshaw, Glaister and Tatoglu } \\
\text { 2006; Keh et al. 2006; Liao 2006; } \\
\text { Seggie, Kim and Cavusgil 2006; } \\
\text { Spillan and Parnell 2006) }\end{array}$ & $\begin{array}{l}\text { (Venkatraman and } \\
\text { Ramanujam 1986) }\end{array}$ \\
\hline $\begin{array}{l}\text { 8. Growth of Market } \\
\text { Share }\end{array}$ & $\begin{array}{l}5 \text { point Likert type scale on } \\
\text { importance and performance } \\
\text { relative to other firms over the } \\
\text { last } 3 \text { years }\end{array}$ & $\begin{array}{l}\text { (Chandler and Jansen 1992; } \\
\text { Carmeli and Tishler 2004; Yusuf } \\
\text { and Saffu 2005; Craig and Dibrell } \\
\text { 2006; Falshaw ot al. 2006) }\end{array}$ & $\begin{array}{l}\text { (Venkatraman and } \\
\text { Ramanujam 1986) }\end{array}$ \\
\hline
\end{tabular}


Table 4.7. Definition, Operationalisation and Sources of Measures: Organisational Performance (Financial Performance)

\begin{tabular}{|c|c|c|c|}
\hline \multicolumn{4}{|c|}{$\begin{array}{l}\text { the operational and financial results of the firm's value-creating processes and activities guided by goals, } \\
\text { constrained by resources, complicated by diverse interests, and measured by various means }\end{array}$} \\
\hline subcomponent: finan & $\begin{array}{l}\text { al performance - reflect the } \\
\text { core Nenka }\end{array}$ & $\begin{array}{l}\text { Ifiment of the economic goals of the firm of w/ } \\
\text { aman and Ramanujam 1986) }\end{array}$ & ich profitability is at the \\
\hline Operationalisation & $\begin{array}{l}\text { Measurement } \\
\text { (part D, /9-13, and //9-13) }\end{array}$ & Direct Source & Reference \\
\hline 9. Sales & $\begin{array}{l}5 \text { point Likert type scale } \\
\text { on importance and } \\
\text { performance relative to } \\
\text { other firms over the last } \\
3 \text { years }\end{array}$ & $\begin{array}{l}\text { (Chaston and Mangles 1997; Lerner } \\
\text { and Almor 2002; Wang and Ang 2004; } \\
\text { Wijewardena et al. 2004; Mejjaard et } \\
\text { al. 2005; Bhaskaran 2006; Falshaw et } \\
\text { al. 2006; Gomes et al. 2006; Spillan } \\
\text { and Parnell 2006; Westhead and } \\
\text { Howorth 2006) }\end{array}$ & $\begin{array}{l}\text { (Venkatraman and } \\
\text { Ramanujam 1986) }\end{array}$ \\
\hline 10. Sales Growth & $\begin{array}{l}5 \text { point Likert type scale } \\
\text { on importance and } \\
\text { performance relative to } \\
\text { other firms over the last } \\
3 \text { years }\end{array}$ & $\begin{array}{l}\text { (Gupta and Govindarajan 1984; Kotha } \\
\text { and Nair 1995; Murray et al. 1995; } \\
\text { Huselid et al. 1997; Maiga and Jacobs } \\
\text { 2004; Lopez et al. 2005) }\end{array}$ & $\begin{array}{l}\text { (Venkatraman and } \\
\text { Ramanujam 1986) }\end{array}$ \\
\hline 11. Net Income & $\begin{array}{l}5 \text { point Likert type scale } \\
\text { on importance and } \\
\text { performance relative to } \\
\text { other firms over the last } \\
3 \text { years }\end{array}$ & $\begin{array}{l}\text { (Gupta and Govindarajan 1984; } \\
\text { Lumpkin and Dess 1995; Huselid et al. } \\
\text { 1997; Lau and Ngo 2001; Lerner and } \\
\text { Almor 2002; Yan and Zhang 2003; } \\
\text { Caloghirou et al. 2004; Keskin 2005; } \\
\text { Bhaskaran 2006; Inma and Debowski } \\
\text { 2006; Wu, Yeniyurt, Kim and Cavusgil } \\
\text { 2006) }\end{array}$ & $\begin{array}{l}\text { (Venkatraman and } \\
\text { Ramanujam 1986; } \\
\text { Lumpkin and Dess } \\
\text { 1996) }\end{array}$ \\
\hline $\begin{array}{l}\text { 12. Net Income } \\
\text { Growth }\end{array}$ & $\begin{array}{l}5 \text { point Likert type scale } \\
\text { on importance and } \\
\text { performance relative to } \\
\text { other firms over the last } \\
3 \text { years }\end{array}$ & $\begin{array}{l}\text { (Lee and Tsang 2001; Maiga and } \\
\text { Jacobs 2004; Nguyen and Bryant } \\
\text { 2004; Lopez et al. 2005; Bhaskaran } \\
\text { 2006; Falshaw et al. 2006; Liao 2006) }\end{array}$ & \\
\hline $\begin{array}{l}\text { 13. Return on } \\
\text { Investment }\end{array}$ & $\begin{array}{l}5 \text { point Likert type scale } \\
\text { on importance and } \\
\text { performance relative to } \\
\text { other firms over the last } \\
3 \text { years }\end{array}$ & $\begin{array}{l}\text { (Gupta and Govindarajan 1984; } \\
\text { Conant, Mokwa and Varadarajan } \\
\text { 1990; Lumpkin and Dess 1995; Murray } \\
\text { et al. 1995; Dess, Lumpkin and Covin } \\
\text { 1997; Sanchez and Perez 2005; Wu } \\
\text { and Leung 2005; Inma and Debowski } \\
\text { 2006; Seggie et al. 2006; Spillan and } \\
\text { Parnell 2006) }\end{array}$ & $\begin{array}{l}\text { (Venkatraman and } \\
\text { Ramanujam 1986) }\end{array}$ \\
\hline
\end{tabular}

\subsection{Types of Financial Performance Measures}

Basic financial measures considered in this study included sales (in peso terms), net income, and return on investment. These are oftentimes called accounting-based measures of performance. Sales volume (in peso terms) reflects the effectiveness of the firm in attracting demand whilst net income (total sales minus production and 
operating expenses) reflects the profitability of the firm (Gonzalez-Benito \& Gonzales-Benito, 2005). Return on investment (ROI) measures the efficiency of the firm's use of past investment (Rockmore \& Jone, 1996). This will indicate if the business owner is earning out of the total investments he had made so far in the business. It is also a measure that cancels out the size effect inherent in sales and net income measures (Gonzalez-Benito \& Gonzales-Benito, 2005). ROI has been shown to be an important and valid measure of business performance (Chen \& Shimerda, 1981; Jacobson, 1987)

Growth is another indicator that is commonly used as a proxy for performance because it indicates the long term income-earning prospects of the business (Wolff \& Pett, 2006). In this study, growth in sales and income were included as manifestations of the financial performance of MSMEs

\subsection{Types of Operational Performance Measures}

Financial measures of performance tend to suffer from its inherent limitations such as being historical in nature and retrospective in temporal scope (Rowe \& Morrow, 1999). Therefore, operational (i.e. non-financial) measures were needed to provide a balanced view of the value-creating process of the firm (Jusoh, Ibrahim \& Zainuddin, 2006). This was consistent with the previous work on the use of multiple measures of performance (Huselid et al., 1997; O'Regan \& Ghobadian, 2004b; Venkatraman \& Ramanujam, 1986). Hence, the study incorporated the operational measures of performance described in the following paragraphs.

Development of new products and/or service is an indicator of the adaptability of the business as it reflects success in responding overtime to changing conditions and opportunities in the environment. (Baker \& Sinkula, 2005; Haber \& Reichel, 2005). Product or service quality can be considered as an indicator of effectiveness and efficiency of the production process or service delivery system (Wiklund \& Shepherd, 2003). Product and process related quality improvements have been shown to be significantly related to the future sales performance of firms (Nagar \& Rajan, 2001). Customer satisfaction is an indicator of adaptability of the firm to the demands of its customers (Wiklund \& Shepherd, 2003). Improvements in business 
and/or production processes are another reflection of the firm's innovation as well as flexibility (Gibson, Ivancevich \& Donnelly, 1994; Wolff \& Pett, 2006). The use of attraction and retention of essential employees or talents as measures of performance was consistent with the work of Huselid et al 1997. These non-financial measures of performance were proposed to capture the competitive objectives of cost, quality, flexibility, reliability and speed (Gonzalez-Benito \& Gonzales-Benito, 2005).

The firm's market share was also included as it describes the position of a firm within its industry (O'Regan, 2002). Market share was considered an important factor for successful business operation as it is a key indicator of how a firm performs in the market relative to competitors. It indicates a firm advantage over competitors because of the market power and efficiencies the firm can offer. It is even presumed that increases in market share lead to higher profitability in the long run, in part because market share dominance is almost equal to monopoly power (O'Regan, 2002). Several SME-related studies have included market share as an indicator of firm performance (Avlonitis \& Salavou, 2007; Hadjimanoulis, 2000; Keh et al., 2006; Liao, 2006; Yusuf \& Saffu, 2005).

\subsection{Perceptual Measures of Performance}

The use of self-reported perceptual measures of operational and financial performance was based on the argument that respondents may not be willing to provide exact figures but may be more comfortable with other surrogate measures (Chung-Ming \& Ngo, 2001). Furthermore, subjective measures of performance such as profitability are commonly used in management and marketing research (Caloghirou et al., 2004; Chaston \& Mangles, 1997). Table 2.6 in Chapter 2 shows a substantial number of previous studies using subjective measures of performance outcomes. Moreover, subjective measures have been shown to correlate highly with objective measures (Shortell \& Zajac, 1990).

Aragon-Sanchez and Sanchez-Marin (2005) used subjective measures of performance composed of knowledge and experience in the business, ability to provide quality products and services, capacity to develop new products and processes, ability to manage/work in a group, workforce productivity, and the firm's 
environmental responsibility. This instrument had a Cronbach alpha of .72. Likewise, the study of Delaney \& Huselid (1996) made use of various perceived organisational and market performance measures with Cronbach alpha of .85 and .86 respectively. Sarkar et al (2001) considered perceived market performance (market share, sales growth, market development, and product development) and generated Cronbach alpha of .75 whilst Seggie's et al (2006) study generated an alpha of .92. These studies, amongst others inspired the development of specific measures used in this study.

However, this research attempted to ask for objective (i.e. non-perceptual) data regarding sales, market share, net income, and ROI. Respondents were asked to provide figures on sales, market share and net income gained from 2004, 2005, and 2006. ROI would be for the past year only (i.e. 2006).

\subsection{Perceptual Benchmarking of Performance against Competitors}

The questionnaire asked respondents to evaluate their business's performance relative to competitors or other firms in the same business or industry (Brah et al., 2000; Delaney \& Huselid, 1996; Kaynak, 2003; Tse et al., 2003). Comparing one's business results against competitors or other firms in the same industry reflects the competitiveness of the firm (Hooley et al., 2005; Venkatraman \& Ramanujam, 1986; Wan et al., 2002). Looking at competitors or other firms in the same industry as benchmarks of business results is a control mechanism for performance differences amongst industries and markets (e.g. differences in capital structure or depreciation accounting conventions) (Brah et al., 2000). Furthermore, extant literature suggested that performance measures should highlight the relative competitive positioning of the organisation (Spillan \& Parnell, 2006; Zairi, 1994).

\subsection{Temporal Benchmarking of Perceived Performance}

The use of a three year period as the inclusive date of comparison was based on the view that performance of MSMEs may be subject to short-term (e.g. one year) fluctuations and not representative of their long-term results (Samie \& Roth, 1992). The approach of using the three year period as reference of evaluation was aimed at 
minimising the influence of short term variations or fluctuations on the reported performance outcomes compared to other firms (Appiah-Adu, 1997; Chang \& Huang, 2005; Delaney \& Huselid, 1996; Priem, 1994).

\subsection{Weighting of Performance Measures}

In evaluating the business performance, the questionnaire asked respondents to indicate the level of importance they attach to each of the measures of operational and financial performance. Likewise, the respondents were asked to indicate the level of their firms' performance in each of the measures compared to other firms of the same industry. This method was consistent with previous studies (Datta, 1991; Naman \& Slevin, 1993; Westhead \& Howorth, 2006). This method accounted for the possibility that MSMEs may attach varying degrees of importance on these measures as evidenced by the study of O'Regan and Ghobadian (2004) showing the diversity of goals reported by firms even in the same industry. A low score in one measure may be due to the firm giving stronger emphasis (i.e. importance) on other measures of performance. Hence, failure to account for variations of importance MSMEs attach to each measure may lead to erroneous conclusions on the overall performance of these firms.

The use of a scale ranging from 1 to 5 was used to enhance the discriminating power of the instrument allowing it to help distinguish MSME performance. (Devlin et al., 2003; Frisbie \& Brandenburg, 1979). Studies using Liker-type scales to measure sales and profit growth made use of either a $0-100$ or $1-5$ continuum, 3, 56 , or 7 point scales, or graphical rating scales. The study used a 5 point scale consistent with previous studies (Devlin et al., 2003; Keh et al., 2006; Spillan \& Parnell, 2006; Yusuf \& Saffu, 2005).

In order to establish the relative weight of the measures, the importance scores would be multiplied by the perceived performance scores to generate a weighted average performance scores for each of the 13 indicators (Naman \& Slevin, 1993; Westhead $\&$ Howorth, 2006). It must be noted however, that the 13 performance measures would be subjected to factor analysis as a method of construct validation. 
Part E - Managerial, Firm and Industry-related Information

Part E asked for the details of the respondents such as age, gender, and educational background of the manager or owner/manager, age and nature of business, ownership structure, asset size (exclusive of any land ownership), type of business organisation, and industry category. The use of open-ended questions for age of the manager, and size and age of the firm was predicated on the need to generate continuous (as opposed to nominal or categorical) type of data. Table 4.5 shows more details on these variables.

\subsubsection{Part F -Industry Technological Sophistication}

This section presented the two items measuring the level of industry technological sophistication as perceived by the MSMEs' owners/managers. These measures were adopted from previous studies of Khandwalla (1977) and Covin et al (1990). Respondents rated each item using a 7 point continuum with bipolar anchors describing a low level and a high level of industry technological sophistication. Table 4.5 describes further this part of the questionnaire.

\subsubsection{Part G. Competitive Intensity}

Part $\mathrm{G}$ of the questionnaire shows the three items measuring competitive intensity with a seven point Likert type of scale $(1=$ strongly disagree to $7=$ strongly agree $)$ (Appiah-Adu \& Singh, 1998; Pelham, 2000). Table 4.5 describes further this variable.

\subsubsection{Part H. Self-Reported Measures of Performance}

In part $\mathrm{H}$, four items were included as an attempt to extract "objective" self-reported information on sales, net income, market share, and return on investment. This information could be used to corroborate the data gathered from the perceptual measures of organisational performance. However, results of the pre-test showed 
that none of the respondents were willing to provide figures for the four items. Consequently, these items were excluded in the final version of the questionnaire.

\subsubsection{Part I. Export Activity}

This section of the questionnaire asked the respondents if they are engaged in exporting overseas as well as the extent of their export activity. In the final questionnaire, however, questions on export activity were placed under part $\mathrm{H}$ because the original part $\mathrm{H}$ (i.e. self-reported measures of performance) as discussed in the previous sub-section (i.e. section 4.2.3.9) was excluded.

\subsection{Validity and Reliability of the Survey Questionnaire}

The developed research instrument for the survey research was subjected to validation and reliability testing prior to the formal conduct of the survey. This was to ensure that only appropriate and quality data were collected to find plausible answers to the research questions. This was especially applicable to Part A (formal institutions), and Part E (organisational performance) which, despite their use and application in previous studies, were composed of items taken from various studies and were re-grouped or re-classified to suit the purposes of the study.

\subsubsection{Validity Issues: Pre-testing of the Questionnaire}

A fundamental requirement is to ensure that the questionnaire truly measures that which it is intended to measure (Cavana et al., 2001). Hence face and content validation were performed. The objective of this task was to check if the items in the questionnaire appeared to measure what they claimed and whether the items were adequate enough to attain the purposes of the study (Cavana et al., 2001). Whilst this was considered a weak form of validation, the researcher contended that this task was fundamental before other forms of validation could take place.

The review of the literature formed the fundamental basis in identifying the specific constructs used in the study. This was the initial step in developing the research 
instrument consistent with extant literature (Hinkin, 1995; Sin, Tse \& Yim, 2005). The next step involved presenting the questionnaire to a panel of subject matter and questionnaire design experts. Subject matter experts examined the substantive element of the questions to make sure that the information that would be generated met the analytic objectives of the study (Groves et al., 2004; Pons, Mourali \& Nyeck, 2006).

Questionnaire design experts examined the technical elements of the questionnaire by looking at issues like the wording and structure of questions, the response alternatives, the order of questions, instructions to interviewers/enumerators for administering the questionnaire, and the navigational rules of the questionnaire (Groves et al., 2004). These experts applied the generally accepted questionnaire design principles and knowledge based on their own pre-testing experiences. The task of the experts was to identify potential problems that may result in reporting errors or inconsistencies and to suggest solutions, often in a written report (Willimack, 2004).

The subject matter/questionnaire design experts include the researcher's supervisory committee composed of experts in international business, marketing, and public policy and econometrics, experts from the Davao City Business Bureau, Department of Trade and Industry, and from the Davao City Chamber of Commerce and Industry in the Philippines. This process followed the recommendation laid out in previous studies (Delamere, Wankel \& Hinch, 2001; Hinkin, 1995). The copy of the set of questions which were asked from the experts regarding the quality of the questionnaire is available from the author upon request.

It must be noted that only the sections of the questionnaire on formal institutions and organisational performance were offered for subject matter experts' review. Although the specific measures and items were adapted from previous studies, significant modifications and re-classifications were made to suit the purposes of the study. Hence, the need for review by subject matter experts. The specific measures for the other variables in the study were also adopted from previous studies but no major modifications were made requiring no substantive review. The entire questionnaire, however, was subjected to a technical review by the questionnaire 
design experts. The use of the expert method is regarded as the most cost effective and most productive methods of pre-testing (Presser \& Blair, 1994).

The next step of the pre-testing process requires that the expert-reviewed and newly revised questionnaire be tested with a small number of MSMES (e.g. 20 samples) using the debriefing method (Presser \& Blair, 1994). Debriefing method entails asking the MSME respondent to fill out the questionnaire completely whilst the interviewer/enumerator makes careful observations after which the interviewer probes the respondent for any potential problems associated with the filling out of the questionnaire (Presser \& Blair, 1994).

For instance, the debriefing may uncover items/questions that respondents tend to have difficulty in understanding their meaning or interpret differently than the researcher intended (Krosnick, 1999). Whilst there is no universal rule as to the number of respondents that should be used in this stage, twenty (20) MSMEs were deemed sufficient to generate the needed information (Sudman, 1983). Consequently, outputs of these pre-testing processes aided the development of a more substantive, and technically efficient and productive research instrument. A copy of the debriefing questions is available from the author upon request.

\subsubsection{Mechanisms to Reduce Measurement Errors in Survey}

The previous discussion of validity and reliability testing of the survey instrument dealt with specific ways to ensure that the research instrument will function consistent with the goals of the study. However, other specific measures were also applied to ensure that measurement errors were avoided, reduced or minimised. Table 4.8 presents major sources of measurement errors and the remedies that were considered in the development of the questionnaire used in this study.

Mono-method bias or common method variance was a particular concern because of the reliance of the study on single self-report method of data gathering. Podsakoff et al (2003) recommended a number of procedural and statistical remedies which were conscientiously applied in the current study. 
Of particular emphasis was the statistical remedy of using a marker variable in the questionnaire as a partial correlation technique. In using this technique, a special variable (i.e. one that is theoretically unrelated to at least one variable) is deliberately prepared and incorporated into a study along with the other research variables (Malhotra, Kim \& Patil, 2006).

Common method variance is assessed by looking at the correlation between the marker variable and the substantive variables. If the correlation coefficients between substantive variables remain significant despite partialling out the marker variable, it provides support that obtained statistically significant correlations are not due to common method variance (Lindell \& Whitney, 2001).

Following the prescription, this study uses "attitude towards information seeking" as a marker variable described above. As prescribed by Lindell and Whitney (2001), the marker variable should be considered as a theoretically unrelated variable in the context of the current study. The four items were inserted in Part B, page 6, of the questionnaire.

\subsection{Locale and Respondents of the Study}

Locale of the Study. The research was conducted in two cities in the south-eastern region of the Philippines: Tagum City and Panabo City. Whilst the primary unit of analysis was at firm level, delineation of MSMEs in terms of their city location offered a point of reference and added rigor to the analysis in as much as the concern of the study was the perception of MSMEs of the institutional environment at the city, rather than at the national, level. Whilst more cities would have been desirable, constraints in logistics prohibited a wider coverage. Two cities were deemed adequate to account for variations in institutional frameworks. 
Table 4.8. Potential Errors in Survey Research and their Remedies

\begin{tabular}{|c|c|c|}
\hline Sources of Error & Description & Remedies \\
\hline $\begin{array}{c}\text { Social Desirability } \\
\text { Bias }\end{array}$ & $\begin{array}{l}\text { over-reporting of admirable } \\
\text { attributes and behaviours and } \\
\text { underreporting those that are } \\
\text { not socially respected } \\
\text { (Krosnick, 1999) }\end{array}$ & $\begin{array}{l}\text { clear instructions to alert respondents to potential memory } \\
\text { confusion (Kline, Sulsky \& Rever-Moriyama, 2000; } \\
\text { Krosnick, 1999) } \\
\text { protecting respondent anonymity (Podsakoff, Mackenzie, } \\
\text { Lee \& Podsakoff, 2003) } \\
\text { assurance that there are no wrong answers (Podsakoff et } \\
\text { al., 2003) }\end{array}$ \\
\hline Satisficing & $\begin{array}{l}\text { tendency of respondents to } \\
\text { settle for merely satisfactory } \\
\text { answers because they are } \\
\text { not willing to expend more } \\
\text { effort in answering the } \\
\text { questionnaire (Krosnick, } \\
\text { 1999) }\end{array}$ & $\begin{array}{l}\text { varying the structures of items so that they look dfferent } \\
\text { (Tepper \& Tepper, 1993) } \\
\text { juxtaposition of constructually dissimilar items : placing } \\
\text { items that measure different constructs next to each other } \\
\text { rather than grouping items with similar content and format } \\
\text { (Tepper \& Tepper, 1993) } \\
\text { putting difficult questions (i.e. those requiring more } \\
\text { cognitive effort) first (Lindell \& Whitney, 2001) }\end{array}$ \\
\hline Acquiescence & $\begin{array}{l}\text { Tendency to endorse any } \\
\text { assertion made in a question } \\
\text { regardess of its content } \\
\text { (Krosnick, 1999; Spector, } \\
2006 \text { ) }\end{array}$ & $\begin{array}{l}\text { reverse scoring of some of the items (Kline et al., 2000; } \\
\text { Lindell \& Whitney, 2001) } \\
\text { provide verbal labels for the midpoint scales (Frisbie \& } \\
\text { Brandenburg, 1979; Podsakoff et al., 2003) } \\
\text { anonymity (Hall, 1995) }\end{array}$ \\
\hline Mono-method Bias & $\begin{array}{l}\text { Tendency of relationships } \\
\text { between variables measured } \\
\text { with the same method to be } \\
\text { inflated (Spector, 2006) }\end{array}$ & $\begin{array}{l}\text { provide dear instructions (Kline et al., 2000) } \\
\text { make all responses of equal effort (Kline et al., 2000) } \\
\text { avoid implying that one response is preferred over another } \\
\text { (Kline et al., 2000) } \\
\text { use of statistical controls to treat CMV such as inclusion of } \\
\text { a marker variable as well as Harman's single-factor test } \\
\text { (Podsakoff et al., 2003; Spector, 2006) } \\
\text { use of various scales within the same questionnaire } \\
\text { (Podsakoff et al., 2003) } \\
\text { separate administration of major sections of the } \\
\text { questionnaire } \\
\text { define unfamiliar terms, avoidance of vague concepts, } \\
\text { simplify questions, etc. (Podsakoff et al., 2003) }\end{array}$ \\
\hline $\begin{array}{c}\text { Response Order } \\
\text { Effects }\end{array}$ & $\begin{array}{l}\text { A design effect on selection } \\
\text { of responses emanating from } \\
\text { the order in which the } \\
\text { response alternatives are } \\
\text { presented (Krosnick, 1999) }\end{array}$ & $\begin{array}{l}\text { varying the structures of items so that they look dfferent } \\
\text { (Tepper \& Tepper, 1993) } \\
\text { juxtaposition of constructually dissimilar items : placing } \\
\text { items that measure different constructs next to each other } \\
\text { rather than grouping items with similar content and format } \\
\text { (Tepper \& Tepper, 1993) } \\
\text { putting difficult questions (i.e. those requiring more } \\
\text { cognitive effort) first (Lindell \& Whitney, 2001) }\end{array}$ \\
\hline
\end{tabular}


Two major criteria were used in deciding from which cities the respondents would be recruited for the study. One criterion was that the two cities must be under the same provincial government so that the variances in the results of the survey would be accounted for by city-level factors (e.g. formal institutions) rather than factors exerted by different provincial governments on the cities' formal institutions. In general, the hierarchy of the Philippine government (bureaucracy) suggests that the national government is the highest governing body of the country, followed by regional and provincial governments, city governments, municipal governments and barangay (NSCB, 2007b). With the exception of the three major independent cities (i.e. Manila, Cebu and Davao), almost all cities are under or affiliated with a regional or provincial government unit. The cities of Tagum and Panabo are under the provincial government of Davao del Norte. The selection of cities rather than municipalities rested on the argument that cities are considered relatively "independent political units" such that they manage their own political and economic affairs subject to the limitations set forth by law (DILG, 2005).

The second criterion was the annual income classification of the cities. Philippine cities are classified based on the annual income they internally generate such as from taxes, licenses, permits and revenues from local economic enterprises (DILG, 2005). It can be argued that the higher the income of the city, the more resources the city can procure and mobilise to deliver government services, build better infrastructure, and improve the overall administrative operations of the city government. Based on the latest database of the National Statistical Coordination Board, Tagum City is classified as a first class city with an annual income of at least 300 million pesos or more whilst Panabo City is classified as a $4^{\text {th }}$ class city with an annual income within the range of 120 to 180 million pesos (NSCB, 2007a). Whilst there are six classes in the classification system based on annual income, Panabo City is the only city with the least annual income amongst the three cities currently established under the provincial government of Davao del Norte.

The cities of Tagum and Panabo are located in the south-eastern region of the Philippines with Davao City as the landmark being the oldest city in that region which is located in the island of Mindanao. Tagum City is situated 55 kilometres north of Davao City with a land area of 19,580 hectares and a population of 205,993 
as of 2006 (OCM, 2008). Panabo City is situated 32 kilometres north of Davao City with a land area of 25,123 hectares and a population of 153,693 as of 2006 (OCM, 2007). Figure 4.2 shows the map of the Philippines stressing the location of the Davao region in relation to Manila whilst Figure 4.3 shows the regional map of Davao del Norte.

Figure 4.2. Map of the Philippines

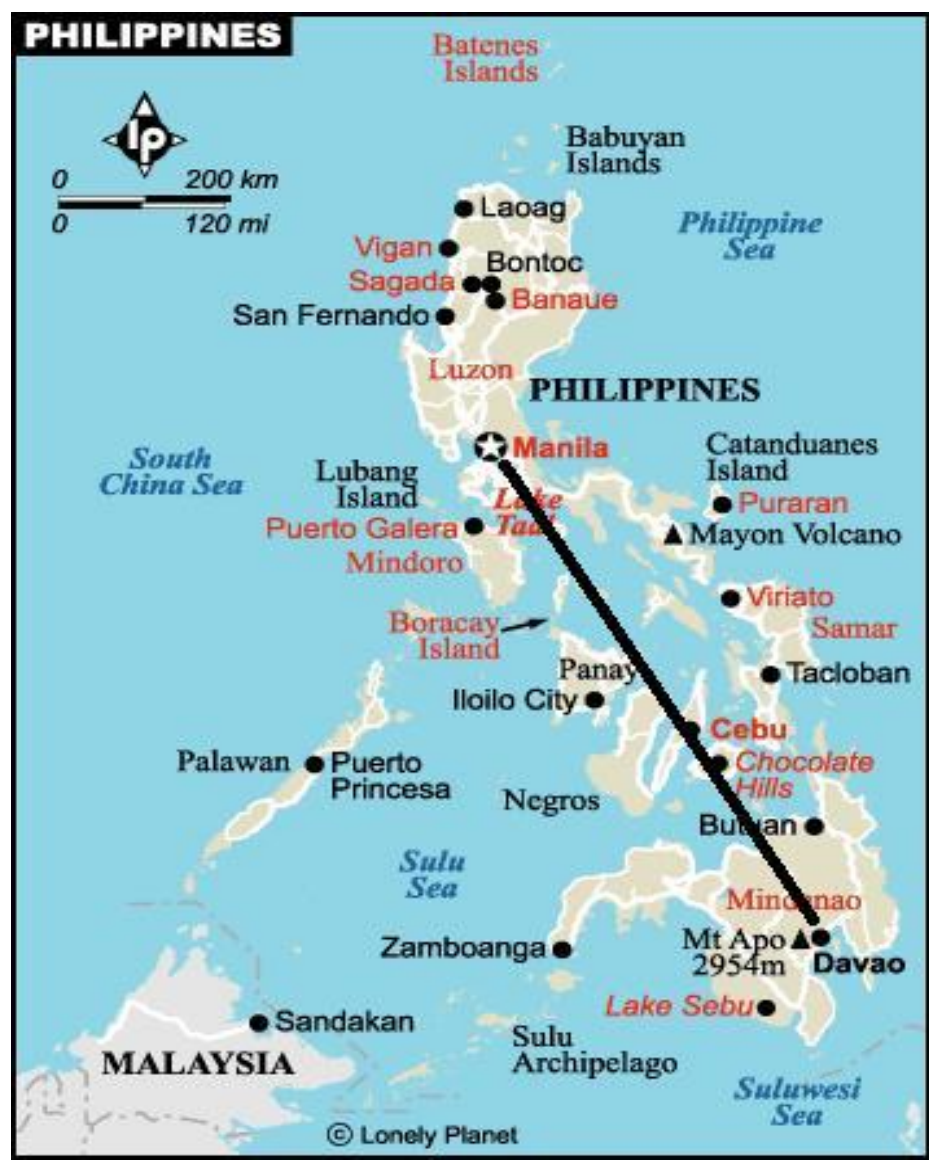


Figure 4.3. Regional Map of the Davao del Norte Province

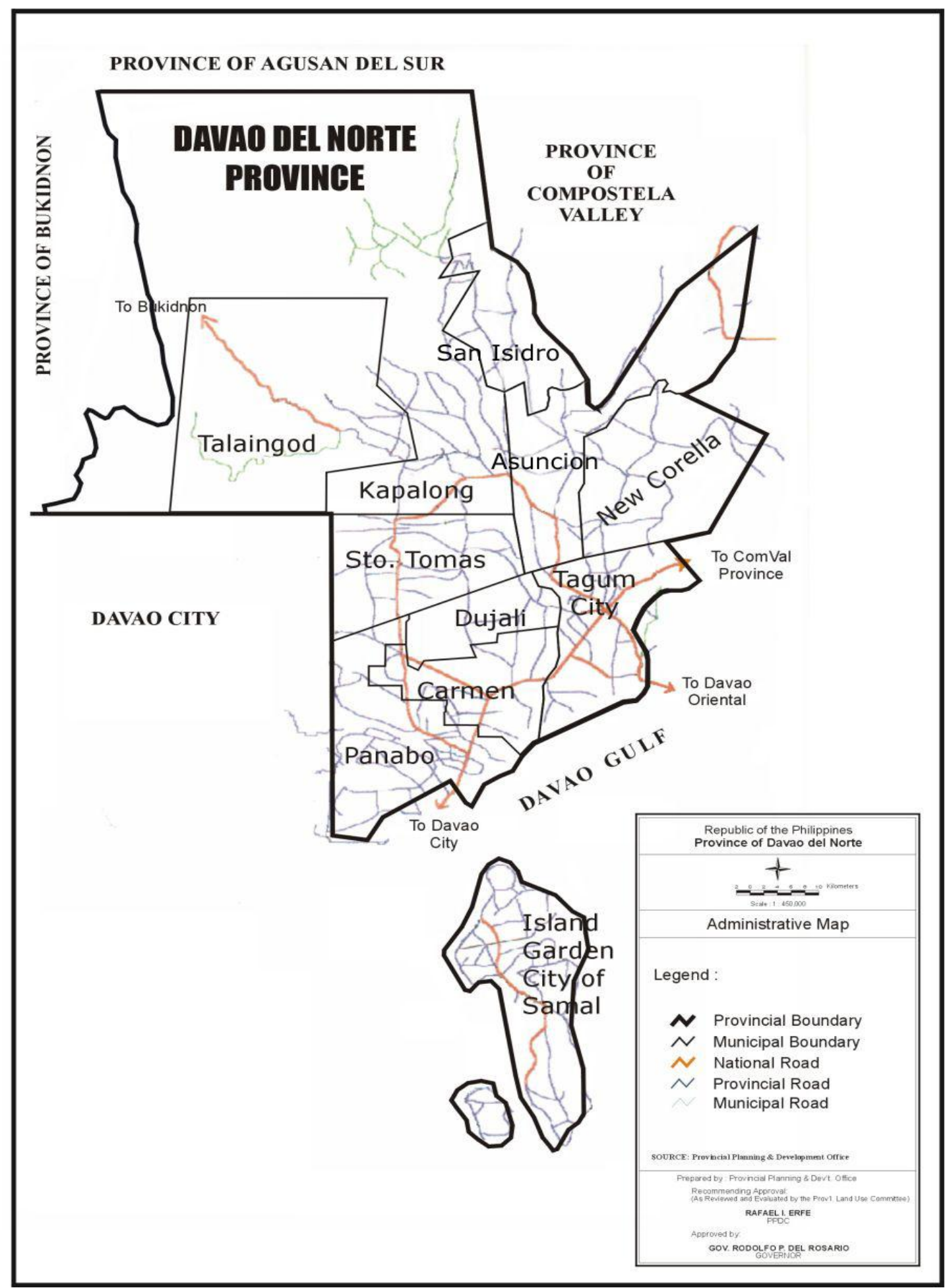


Respondents of the Study. The respondents of the study were owners, managers or owners/managers of MSMEs in both the manufacturing and service (excluding trading/retail and government services) sectors. For the purposes of this study, owners are those who own the business but may not be necessarily involved in the day-to-day operations of the business. Managers are those who are hired by the business owner to manage or run the day-to-day operations of the business. Owners/managers are those who own and manage/run the business at the same time.

Trading firms were excluded as the researcher viewed that the variables of interest (such as the innovativeness and risk-taking aspects of strategic posture) may not have strong relevance to this type of firms. Their huge number may also overshadow the relatively fewer manufacturing firms which could distort the overall results of the study. Government services were also excluded as providers of these services operate as not-for-profit entities.

In this study, the terms, organisations, enterprises, business firms, business enterprises or business entities were used interchangeably to refer to organisations classified as either micro, small or medium enterprises. Similarly, the term small business sector was used synonymously with the MSME sector based on previous studies done in the context of comparing small business firms against large ones (such as Fortune 500 or multinational firms) (Arinaitwe, 2006; Castrogiovanni, 1996; Cooke \& Wills, 1999; Gartner \& Bhat, 2000). An MSME is defined by the Philippine Department of Trade and Industry as any business activity or enterprise engaged in industry, agribusiness and/or services, whether single proprietorship, cooperative, partnership or corporation whose total assets, inclusive of those arising from loans but exclusive of the land on which the particular business entity's office, plant and equipment are situated, must have value falling under categories (i.e. based on number of employees or asset size) set forth by the government (DTI, 2005).

The classification of MSMEs was based primarily on the capital or asset size of the firm. However, the classification was cross-checked using the size of employment or number of employees being the method of classification adopted by the Philippine Small and Medium Enterprise Development Council. The database of registered 
businesses maintained by the City Business Bureau was the primary source of the list of the population of MSMEs. This list is the most up to date registry of businesses operating in the city as every business enterprises must register annually (i.e. every January) to be able to secure the necessary licenses for legal business operation.

As previously mentioned, only MSMEs in the manufacturing and service sectors (excluding trading and government services) in both cities were included in the study. The Philippine National Statistics Office defines the manufacturing sector as comprising of all establishments in the form of a shop, factory, bakery, millwork, distillery, refinery, cannery, abattoir, brewery, foundry, tannery or plant engaged in manufacturing, processing, fabricating of finishing products, mechanically or manually, including the assembly of component parts of manufactured products and the substantial alteration, reconstruction and repair of special types of goods (NSCB, 2007c). On the other hand, the service sector (excluding trading and government services) comprises all establishments engaged in the business of transport, communication and storage, finance, ownership of dwellings and real estate, and private services (NSCB, 2008).

A report on the economic performance of the Philippines highlighted the significant role played by the manufacturing and service sectors in the overall economic growth of the country. Statistics showed that as of 2006, the manufacturing and service sectors comprise $31.6 \%$ and $54.2 \%$ respectively of the country's gross domestic product (GDP) (ADB, 2008). The manufacturing sector has been noted for its crucial role in economic development whereby the fast rates of economic growth are almost invariably associated with the fast rate of growth in the manufacturing sector in many developed countries (Felipe, 1998). This is known in economics as Kaldor's First Law. Felipe (1998) analysed the economic development of five Southeast Asian nations using Kaldor's first law and conclude that the manufacturing sector is a major propellant of economic growth in the region.

Whilst the service sector may prove to be a lucrative sector as in the Philippines, a robust manufacturing sector will have positive impact on a trading nation's ability to generate sufficient exports to pay for necessary imports, and hence, also the growth of productivity, national income and living standards (Kitson \& Michie, 1997). 
Reliance on agriculture, Felipe (1998) argues, is unsustainable because this sector has been noted for its low productivity and surplus labour relative to the capitalintensive manufacturing sector characterised by rapid technical change and increasing returns.

The service sector on the other hand, has been noted for its significant contribution to the overall economic output of countries in the Asian region, including the Philippines (Cororaton, 2005; Pasadilla, 2005). In 2004, the service sector in the Philippines employed more than 15 million employees accounting for $46.96 \%$ share in the country's employment (Pasadilla, 2005).

Furthermore, the manufacturing and service sectors were deemed ideal for the study because it is in these sectors where innovation efforts such as research and development are more observable relative to other sectors such as trading (e.g. retail and wholesale). In these sectors, questions on the extent of risk-taking, proactiveness and most especially innovativeness would have strong relevance to the respondents.

Sample Size. The work of Bartlett, Kotrlik, and Higgins (2001) outlines that the sample size to be extracted from the population depends on three major factors: primary variables of measurement, error estimation and variance estimation. Following such prescription and using an alpha level (i.e. confidence level) of .05, margin of error of 3\%, and variance estimation of 1.67 (based on a 7 point Likert scale), the derived minimum sample size is 118 . However, the low response rates typical in social science surveys and the statistical analyses to be performed to answer the research question require a sample size significantly more than the identified minimum size. This step is also balanced with the financial and time constraints associated with the conduct of the study. In this case, over-sampling is recommended as a necessary step towards achieving the goals of the study (Bartlett, Kotrlik \& Higgins, 2001). Please refer to the appendix for the details of the computation of the sample size.

Based on the listing of registered business establishments, there were 452 and 564 manufacturing firms and 1,318 and 1,929 service firms in Tagum City and Panabo City respectively (CTO, 2007a, 2007b). The two lists, however, were unclear as to 
the size of the firms (micro, small, medium and large) and the specific nature of the business as there were overlapping labels/description (e.g. manufacturer of wood products vs. retailer of wood products). Likewise, the researcher raised doubts on the veracity of the lists in terms of whether the lists were cumulative over the last few years and on whether the businesses were still operating to date. Given the crude database technology and loose records management of many government offices at the local government level in the Philippines, it was virtually impossible to confirm the correctness of the database.

Other government offices were consulted such as the Philippines' Department of Trade and Industry to no avail. However, using the lists as baseline information, it was deemed reasonable (given the resources allocated for this research) to target 1400 firms (700 in each city). The researcher had strong reasons to believe that the manufacturing sector in both cities would only be around $20 \%$ to $30 \%$ of the total businesses operating in these cities based on the researcher's discussion with experts from the local chamber of commerce and that of the Department of Trade and Industry. Of the targeted number (1400), the plan was to recruit as many as $50 \%$ manufacturing firms and $50 \%$ service firms as possible.

\subsection{Data Gathering Techniques}

Previous studies involving SMEs in the Philippines have reported response rates from $11 \%$ up to $86 \%$. One study looking at SMEs in one city sampled 1000 SMEs of which 113 were returned (Munoz, Liao \& Welsch, 2005). Another study sampled 186 large exporting firms across the Philippines, of which 100 were returned. (Mintu-Winsatt \& Gassenheimer, 1995). In another study, 350 were returned out of the 400 firms surveyed (Co \& Mitchell, 2005). However, it was unclear as to which specific method of data gathering (e.g. mail survey or survey using enumerators) was used in these studies.

The previous experience of the researcher attested to the fact that the Philippine postal system is relatively costly, inefficient and unreliable making mail survey a less viable option. If this method was chosen, MSMEs would experience the burden of not only filling up the questionnaire but also taking the unnecessary trip to the 
Philippine Post office branch just to mail the completed survey forms as there are no mailboxes along strategic streets/locations are there are in developed countries. Likewise, ordinary mail takes about one week or more, to get to the destination in the same city assuming they it is handled properly by poorly-paid contractual labourers in the Philippine Postal Office.

Hence, the study recruited 10 field or survey enumerators (or field work assistants) (five in Tagum City and five in Panabo City). These survey enumerators were recently graduated students from a state university in Davao City, Philippines, with a major in Economics. Most of them had intensive experience in conducting field surveys sponsored by organisations like The World Bank and Asian Development Bank. Nonetheless, all enumerators underwent an orientation program/briefing conducted by the researcher on the specific context and purposes of the study as well as the nature and content of the questionnaire.

Enumerators were assigned to specific areas within which they personally visited the MSMEs and requested the owners/managers to fill out the questionnaire. As they were trained, they would be able to answer questions that the respondents may have regarding the questionnaire. The enumerators could also check on the spot if there were missing data in the questionnaire for which they could immediately ask the respondent to supply. If permitted by the respondent, the enumerators waited whilst the respondent was filling out the questionnaire. Alternatively, if the respondent so desired, the enumerator revisited the respondent at an agreed upon later date to collect the filled out survey form. The enumerators were also trained to mark questionnaires from early respondents to late respondents which became the basis for the response bias analysis. Early respondents were those that completed the questionnaire on the spot or were visited only twice - one for distribution and another for collection of the completed questionnaire. Respondents that required revisits more than twice in order to collect the questionnaire were classified as late respondents (Armstrong \& Overton, 1977; Lankford, Buxton, Hetzler \& Little, 1995).

Prior to the actual field work, all trained enumerators were asked to sign a confidentiality form as part of the ethical standards required to protect the anonymity 
of the survey participants and confidentiality of the information gathered from the survey. A copy of the confidentiality agreement is available from the author upon request.

In conducting the survey, enumerators were guided by the list of business establishments grouped according to sector (manufacturing or service) and business location given the map of the city. The map of each city were divided into four quadrants with the City Hall (i.e. government building housing the local government offices) as the central point of reference. Enumerators were instructed to survey at random business establishments in a given quadrant in a specific period of time. Specific areas within the quadrant were assigned to one enumerator. The researcher met all the enumerators at $7 \mathrm{pm}$ every day to collect the questionnaires, gather feedback from the enumerators, and provide instructions for the following day's survey activity.

As a matter of quality control, the researcher double checked the turned-over questionnaires by randomly calling/visiting the concerned business establishment (which the enumerators claimed to have surveyed) and confirmed/validated their participation in the survey. No irregularities were uncovered in the course of validation/confirmation.

Whilst a number of forces beyond the control of the researcher may influence the ultimate survey turn-out, there are strategies which research has shown to increase the quantity and quality of survey responses (Newby, Watson \& Woodliff, 2003). The following section outlines the strategies which were employed to increase the rate of quality responses to the survey.

Attention-Seeking. The presence of the enumerator in the respondents' vicinity gained the attention of the MSME. The logo of VUW as a New Zealand institution earned the interest and consideration of the respondents as shown during the pretesting as well as reported by the enumerators after their field work. 
Questionnaire Completion. Encouraging the respondent to answer the question thoroughly included steps such as assurances of anonymity, and using coloured print on coloured paper.

Questionnaire Return. To increase questionnaire return, the researcher/survey enumerator personally visited/revisited the respondents.

Incentives. To reinforce the strategies mentioned above, that some form of incentives was designed. Respondents who return their completed questionnaires were included in a raffle draw for various prizes (e.g. grocery vouchers and audio compact discs). A copy of the raffle coupon is available from the author upon request.

\subsection{Data Analytical Tools}

Preliminary analysis of the data required descriptive statistical tools like the determination of means, graphical display, and cross tabulations. This was especially applicable when presenting aggregate results with regards to the data that were generated by part IV of the survey instrument such as age, sex, educational attainment, industry category, amongst others. Descriptive statistics also aided data screening and cleaning to ensure fidelity and precision of data. Purification of data including the determination of dimensionality, reliability and validity of constructs was done using mainly factor analyses (both exploratory and confirmatory) as well as Cronbach $\alpha$ estimation, convergent and discriminant validity estimation (Hair et al., 2006).

The subsequent analyses utilised inferential statistical tools to answer the research questions. In as much as the current study aimed to test the hypotheses on the local institutional environment-MSME strategic posture-organisational performance nexus, with the ultimate goals of validating the proposed model, multivariate quantitative data analysis was deemed appropriate tool. This was consistent with the multidimensional nature of the concepts involved in the study. More specifically, hierarchical multiple regression analysis using ordinary least squares method (OLS) with confirmatory robust technique was used as the main tool to analyse the relationships between a single dependent variable and several independent variables 
(Hair et al., 2006). The next chapter provides further details supporting the view that multiple regression analysis was the best statistical tool to test the hypotheses.

Analysis of Variance (ANOVA) was used to examine the relationships between independent variables that were categorical in nature and dependent variables that were continuous in nature (Hair et al., 2006). To examine mediated relationships between variables, both multiple regression and supplementary tools like the Sobel and Goodman tests as well as bootstrapping method were performed (Preacher \& Hayes, 2004; Tabachnick \& Fidell, 2005). The Sobel (1982) test, Goodman (1960) tests were utilised using the SPSS syntax developed by Preacher and Hayes (2004) to test for mediation. Another SPSS syntax recently developed by Preacher and Hayes (2007) using the bootstrapping method was used to complement the weaknesses of the Sobel and Goodman tests.

Statistical software including SPSS v.14, Stata v. 9.1, and EQS v. 6.1 were used according to the statistical tests that were required by the nature of the hypotheses, purposes of the study, as well as the nature of the data at hand.

\subsection{Ethical Implications}

The voluntary nature of participation of MSME owners/managers as well as observance of confidentiality and anonymity in the conduct of the survey and in the production of subsequent reports ensured that the research that was conducted conformed to the ethical standards the Victoria University's Human Ethics Committee (HEC). Provisional HEC approval was granted on 4 October 2007 subject to minor revisions. Full HEC approval was granted on 21 February 2008. Every participant of the study was provided with sufficient information regarding the study through an information sheet that came with the questionnaire. Subsequently, informed consent was requested from the participants by asking them to sign the consent form which also came with the questionnaire. Copies of the information sheet and consent forms are available from the author upon request. 


\section{CHAPTER 5. DATA ANALYSIS}

This section presents the data management and analytical processes involved in generating empirical evidence by testing the proposed model and research hypotheses. The first section deals with the procedures and processes used in preparing and cleaning the data from the survey, assessing biases and missing values and examining the normality of the distribution of data. This section also presents the general description of the survey respondents. The second section presents the assessment of the scales measuring the key constructs used in the study. The third section presents the statistical analyses that were performed in order to test the research hypotheses. Whilst SPSS v 14 (SPSS, 2005) was the main software used in data processing, EQS 6.1 (Bentler, 1995) and Stata 9.1 (StataCorp, 2007) were also used when SPSS could not process the required statistical tests. The major sections of the chapter are summarised in Figure 5.1.

Figure 5.1 Outline of Data Analysis

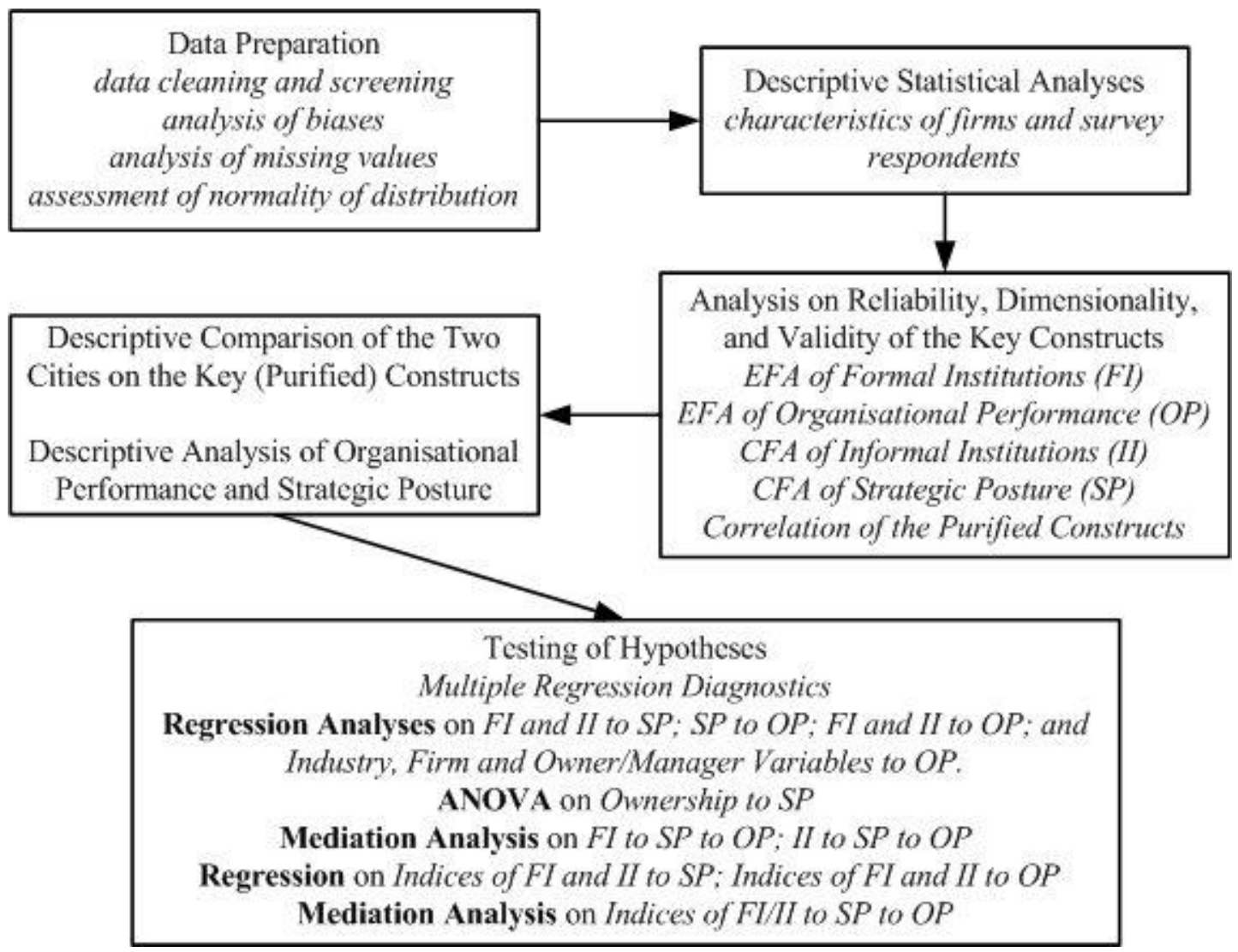




\subsection{Data Preparation}

Retrieval of Questionnaire. The enumerators scanned and double-checked each of the questionnaires upon retrieval from the respondents. If there were unanswered or blank items, the enumerators consulted/referred back to the respondents. Most of the time, the unanswered/blank items were attributed to respondents having unintentionally missed them. Subsequently, the respondents provided their answers when the enumerators referred back the blank items to them. This, however, did not apply to part E., no. 15 (an item that asked for the firm's total assets in peso terms) for which majority $(95 \%)$ of the respondents categorically refused to provide an answer for confidentiality reasons. The enumerators, however, were trained to be aware of this issue beforehand.

Data Encoding and Screening. The researcher coded and entered the raw data into a database using SPSS version 14 (SPSS, 2005). The entries were double-checked for errors by a different person to ensure the accuracy of the data entry. Corrections were made when necessary to rectify any discrepancy. Retrieved questionnaires with the following characteristics were excluded outright: randomly and sporadically filled out first few pages only (more than $50 \%$ to $90 \%$ of items were left unanswered), unfilled out pages on respondent- and firm-related details, hard-to-believe answers (e.g. a small bakery claimed that exporting overseas account for more than $50 \%$ of its sales), and unanswered section on strategic posture and firm performance (the dependent variables). Hair et al (2006 p. 56) recommended that "cases with missing data on the dependent variable/s should be excluded to avoid any artificial increase in relationships with the independent variables of the study".

Response Rates. Table 5.1 shows the rates of retrieval as well as usable responses. A total of 1400 questionnaires were distributed to MSMEs in the two cities from which 955 were retrieved. However, retrieved questionnaires deemed useless (as described above) were dropped from the data set. Hence, 900 questionnaires constituted the final set of data used in the succeeding analyses. 
Table 5.1 Rates of Retrieval and Usable Responses

\begin{tabular}{cccccc}
\hline City & Total Sample & \multicolumn{2}{c}{ Retrieved Questionnaires } & \multicolumn{2}{c}{ Usable Responses } \\
& $f$ & $f$ & Retrieval Rate & $f$ & Response Rate \\
\hline Tagum & 700 & 475 & $67.86 \%$ & 454 & $64.86 \%$ \\
Panabo & 700 & 480 & $68.57 \%$ & 446 & $63.71 \%$ \\
\hline Total & 1400 & 955 & $68.21 \%$ & 900 & $64.29 \%$ \\
\hline
\end{tabular}

\subsection{Analysis of Non-Response Bias.}

Despite generating a retrieval rate of $68 \%$ which was considered adequate (Babbie, 2007), non-response bias was examined to add rigour to the current study. Nonresponse bias occurs when respondents and non-respondents differ in the major variable(s), in which case the population parameters of these variables can be overor under-estimated (Armstrong \& Overton, 1977; Rogelberg \& Stanton, 2007; Ullman \& Newcomb, 1998). To determine if the data contained non-response bias, a comparison of demographic and firm characteristics between early and late respondents was performed as a matter of non-response bias impact assessment strategy (Rogelberg \& Stanton, 2007). It has been established in the literature that late respondents are more likely to be similar to the general population (including non-respondents) in the context of the present study (Armstrong \& Overton, 1977; Groves, 2006). This non-response bias impact assessment strategy is well known in the literature as wave analysis (Lankford et al., 1995).

Criteria. In the current study, early respondents were those from whom the enumerators collected the duly filled out questionnaire by visiting only twice - one time for distribution and another for collection. Late respondents were those which the enumerators had to visit more than twice - one time for distribution and twice or more times in order to collect the filled out questionnaire. These late respondents were likely to be non-respondents if the enumerators did not take the extra effort of visiting them repeatedly and "courting"/"enticing" them to fill out the questionnaire. This method of differentiating early and late respondents is consistent with previous studies treating early respondents as those who replied immediately without any 
delay, hesitation nor reluctance (Biemer, 2001; Filion, 1976; Lankford et al., 1995; O'Neil, 1979) and late respondents as those who showed reluctance but who later participated in the survey after one or more follow-up visits, telephone calls or reminder letters (Biemer, 2001; Filion, 1976; Lankford et al., 1995; O'Neil, 1979). There were $456(50.70 \%)$ early respondents and 444 (49.30\%) late respondents identified in the study by using the criteria discussed above.

An independent sample t-test (for continuous variables) (Field, 2005) and Pearson's chi-square test (for discreet variables) (Greenwood \& Nikulin, 1996) between these two groups using a set of managerial and firm characteristics revealed no significant differences. Tables 5.2 and 5.3 show this comparison. Table 5.2 shows that at a confidence level of .05 assuming equal variance, there were no significant differences between early and late respondents in terms of age, educational level, age of the business and number of full-time staff. The same results of no significant difference were generated when equal variances were not assumed.

Table 5.2 Testing for Non-Response Bias: $t$-test

\begin{tabular}{|c|c|c|c|c|c|c|c|}
\hline \multirow[t]{2}{*}{ Variables } & \multirow[t]{2}{*}{ Equal Variances: } & $\begin{array}{c}\text { Levene's Test } \\
\text { for Equality of } \\
\text { Variance }\end{array}$ & \multicolumn{5}{|c|}{ t-test for Equality of Means } \\
\hline & & Sig. & $\mathrm{t}$ & df & $\begin{array}{c}\text { Sig. } \\
\text { 2-tailed }\end{array}$ & $\begin{array}{c}\text { Mean } \\
\text { Difference }\end{array}$ & $\begin{array}{l}\text { Std. Error } \\
\text { Difference }\end{array}$ \\
\hline Age of Respondent & $\begin{array}{l}\text { assumed } \\
\text { not assumed }\end{array}$ & .916 & $\begin{array}{l}-1.669 \\
-1.670\end{array}$ & $\begin{array}{r}898 \\
897.97\end{array}$ & $\begin{array}{l}.095 \\
.095\end{array}$ & $\begin{array}{r}-1.053 \\
-1.053\end{array}$ & $\begin{array}{l}.631 \\
.631\end{array}$ \\
\hline Educational Level & $\begin{array}{l}\text { assumed } \\
\text { not assumed }\end{array}$ & .186 & $\begin{array}{l}-.662 \\
-.662 \\
\end{array}$ & $\begin{array}{r}898 \\
897.82 \\
\end{array}$ & $\begin{array}{l}.508 \\
.508 \\
\end{array}$ & $\begin{array}{l}-.043 \\
-.043 \\
\end{array}$ & $\begin{array}{l}.064 \\
.064 \\
\end{array}$ \\
\hline Age of the Business & $\begin{array}{l}\text { assumed } \\
\text { not assumed }\end{array}$ & .869 & $\begin{array}{l}-.038 \\
-.038\end{array}$ & $\begin{array}{r}898 \\
897.99\end{array}$ & $\begin{array}{l}.969 \\
.969\end{array}$ & $\begin{array}{l}-179 \\
-.179\end{array}$ & $\begin{array}{l}4.671 \\
4.670\end{array}$ \\
\hline Number of Full-time Staff & $\begin{array}{l}\text { assumed } \\
\text { not assumed }\end{array}$ & .183 & $\begin{array}{l}1.883 \\
1.901 \\
\end{array}$ & $\begin{array}{r}898 \\
589.31 \\
\end{array}$ & $\begin{array}{l}.060 \\
.058 \\
\end{array}$ & $\begin{array}{l}1.299 \\
1.299 \\
\end{array}$ & $\begin{array}{l}.690 \\
.690 \\
\end{array}$ \\
\hline
\end{tabular}

Table 5.3 shows consistent results whereby early and late respondents were not found to differ by their position in the business (i.e. manager or owner/manager), gender (i.e. male or female), ownership of the business (i.e. sole proprietorship, partnership or corporation), sector (i.e. manufacturing or service), and city or location of business (i.e. Tagum or Panabo City). The foregoing analyses showed 
that non-response bias did not appear to be a concern in this study and that the data were fair representation of the responses of the broader population (Groves, 2006).

Table 5.3 Testing for Non-Response Bias: $\chi^{2}$ Test

\begin{tabular}{lccc}
\hline \multicolumn{1}{c}{ Nominal Variables } & Pearson Chi-Square & degrees of freedom & $p$ value \\
\hline Respondent's Position in the Business & 0.068 & 1 & 0.967 \\
Respondents' Gender & 0.001 & 1 & 0.974 \\
Type of Ownership & 1.094 & 2 & 0.579 \\
Sector & 0.231 & 1 & 0.631 \\
City & 0.069 & 1 & 0.792 \\
\hline
\end{tabular}

NB: comparison of 2 waves of retrieval

\subsection{Analysis of Response Bias: 'Field Enumerator Effects'}

The use of survey enumerators or fieldwork assistants during the data gathering phase required the analysis of 'interviewer effects' or in this study, 'field enumerator effects'. 'Interviewer effects' refer to the total response variance which can be attributed to differences among interviewers or field enumerators (Groves \& Magilavy, 1986; Stokes, 1988). Although they were fully informed that their role was mainly distribution and collection of questionnaires only (rather than interviewing the respondents), the field enumerators reported that there were instances when the survey respondents asked some questions, clarifications, or explanations from them with regards to the survey as a whole or some specific questions within the survey questionnaire. Hence, it was deemed necessary to determine the variations on the participation in the survey and responses to the survey questions which could be attributed to differences amongst the survey enumerators.

Following the suggestions of Groves and Magilavy (1986) and Schwarz et al (1991), a one-way analysis of variance (ANOVA) (for continuous variables) and Pearson's chi-square test (for nominal variables) were performed to determine the differences amongst the enumerators with respect to the responses of firms that they individually 
surveyed. ANOVA was also performed to determine if there were response variances within the major variables of the current study with the concerned field enumerator as the basis of grouping. As previously noted, five field enumerators were assigned in each city.

As shown in Table 5.4, the field enumerators did not differ significantly with respect to the managerial (e.g. age of respondents) and firm characteristics (e.g. age of the business) of the respondents they surveyed. They did not also differ significantly with respect to the collected responses describing the major variables of the study such as the formal and informal institutions and strategic posture. The comparison of field enumerators in each city (i.e. Tagum and Panabo) and across-city (i.e. both cities) both revealed insignificant differences.

Table 5.4 Testing for Enumerator Effects: One-way ANOVA

\begin{tabular}{|c|c|c|c|c|c|c|}
\hline \multirow[t]{2}{*}{ Variables } & \multicolumn{3}{|c|}{$F$ values } & \multicolumn{3}{|c|}{ Significance } \\
\hline & Tagum* & Panabo** & Both*** & Tagum & Panabo & Both \\
\hline Age of Respondents & .74 & .11 & .46 & .57 & .98 & .91 \\
\hline Educational Level & .24 & .64 & 1.10 & .92 & .63 & .36 \\
\hline Age of the Business & .33 & 1.16 & 1.75 & .86 & .33 & .07 \\
\hline Number of Full Time Employees & .69 & .95 & .88 & .60 & .44 & .54 \\
\hline Rule of Law & 1.49 & .05 & .35 & .20 & .99 & .96 \\
\hline Protection of Property Rights & 1.56 & .50 & .27 & .18 & .74 & .98 \\
\hline Government Policies & 1.09 & .39 & .13 & .36 & .81 & .99 \\
\hline Regulatory Quality & 1.48 & .46 & .35 & .16 & .77 & .96 \\
\hline Government Assistance & 1.05 & .28 & 1.02 & .38 & .89 & .42 \\
\hline Performance Orientation & .832 & .79 & .66 & .51 & .54 & .74 \\
\hline Future Orientation & 1.04 & .28 & .99 & .39 & .89 & .44 \\
\hline Assertiveness & 1.61 & .81 & 1.13 & .17 & .52 & .34 \\
\hline Collectivism & .27 & .20 & .63 & .90 & .94 & .77 \\
\hline Power Distance & .43 & .82 & 1.89 & .79 & .52 & .50 \\
\hline Humane Orientation & .88 & .64 & .44 & .47 & .64 & .91 \\
\hline Uncertainty Avoidance & 1.38 & .69 & 1.27 & .24 & .60 & .25 \\
\hline Strategic Posture & 1.219 & .45 & .56 & .30 & .77 & .83 \\
\hline Product/Service Performance & .48 & .26 & .30 & .75 & .91 & .98 \\
\hline Strategic Performance & .43 & .84 & .21 & .79 & .50 & .99 \\
\hline Financial Performance & .62 & .48 & .21 & .65 & .75 & .99 \\
\hline
\end{tabular}


Table 5.5 shows consistent results whereby the field enumerators did not differ significantly with respect to the respondents' position in the business (i.e. manager or owner/manager), gender, ownership of the business (i.e. sole proprietorship, partnership, or corporation), and sector (manufacturing or service). Overall, the results suggested that 'field enumerator effects' per se, could not explain the variations in the respondent and firm characteristics and the responses to the specific questions describing the key constructs in the survey questionnaire.

Table 5.5 Testing for Enumerator Effects: Pearson $\chi^{2}$

\begin{tabular}{clccc}
\hline \multirow{2}{*}{ Nominal Variables } & & $\begin{array}{c}\text { Pearson } \\
\chi^{2}\end{array}$ & $\begin{array}{c}\text { degrees of } \\
\text { freedom }\end{array}$ & Significance \\
\hline Respondents' Position in the Business & - Tagum & 2.22 & 8 & .97 \\
& - Panabo & 3.36 & 8 & .91 \\
\multirow{3}{*}{ Respondents' Gender } & - Both Cities & 13.43 & 18 & .77 \\
& - Tagum & 9.18 & 4 & .16 \\
& - Panabo & .26 & 4 & .99 \\
Type of Ownership & - Both Cities & 8.91 & 9 & .45 \\
& - Tagum & 2.01 & 8 & .98 \\
\multirow{5}{*}{ Sector } & - Panabo & 4.24 & 8 & .84 \\
& - Both Cities & 10.96 & 18 & .90 \\
& - Tagum & .04 & 4 & .99 \\
& - Panabo & .03 & 4 & .99 \\
\hline
\end{tabular}

NB: comparison of 5 (10) enumerators in each (both) city/ies

\subsection{Analysis of Common Method (Bias) Variance}

Because of the mono-methodological nature of the study, two major tests were performed to determine the presence of common method bias: Harman's single factor test (Harman, 1976; Podsakoff et al., 2003) and partial correlation technique using a marker variable (Lindell \& Whitney, 2001). Harman's single factor test explains that common method bias is present when a single factor emerges or one factor accounts for more than fifty percent of the variance of the items in the factor analysis (i.e. unrotated matrix) whereby all items measuring all the variables in the study are allowed to load simultaneously (Harman, 1976). 
All of the items (i.e. describing formal institutions, informal institutions, strategic posture and organisational performance) were entered into a principal axis factor

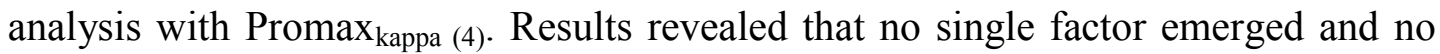
factor accounted for more than fifty-percent of the variance. More details are presented later in the chapter on exploratory factor analysis. Moreover, the confirmatory factor analysis presented later in the chapter also confirmed that the items describing the informal institutions formed seven distinct factors. These findings supported the assertion that under Harman's single factor rule, common method bias was not an issue in the current study.

Furthermore, using Lindell's and Whitney's (2001) partial correlation technique using a marker variable is another effective diagnostic tool to check for monomethod bias. Four items forming the construct called attitude towards information seeking (Das et al., 2003) served as the marker variable which was included in the questionnaire. This construct was established a priori to have no theoretical nor conceptual relationship with at least one of the major variables under study (Malhotra et al., 2006). Using this technique, a data set is said to be contaminated with common method bias if the correlation coefficients amongst the variables significantly change when the effects of the marker variable are controlled (Lindell \& Whitney, 2001).

The correlational analysis in Table 5.6 shows the zero-order correlation coefficients of the five formal institutions, seven informal institutions, and two industry characteristics. Results showed that the marker variable had correlation coefficients close to zero for nine variables. The correlation coefficient findings further suggested that common method bias was not an issue in the current study (Podsakoff et al., 2003).

As shown in Table 5.7, there were no significant changes in the relationships at $95 \%$ level of confidence amongst the variables when the marker variable was controlled. The results further suggested that common method bias, per se, could not explain the results of the current study. 
Table 5.6 Zero Order Correlation Matrix Examining the Effect of the Marker Variable

\begin{tabular}{|c|c|c|c|c|c|c|c|c|c|c|c|c|c|c|c|c|c|}
\hline Control Variable & Variables & & 1 & 2 & 3 & 4 & 5 & 6 & 7 & 8 & 9 & 10 & 11 & 12 & 13 & 14 & 15 \\
\hline \multirow[t]{15}{*}{-none- } & 1 Rule of Law & $\begin{array}{c}\text { Correlation } \\
\text { Sig. }(2 \text {-tailed })\end{array}$ & 1 & & & & & & & & & & & & & & \\
\hline & 2 Protection of Property Rights & $\begin{array}{l}\text { Correlation } \\
\text { Sig. (2-tailed) }\end{array}$ & $\begin{array}{l}.71 \\
.00\end{array}$ & 1 & & & & & & & & & & & & & \\
\hline & 3 Government Policies & $\begin{array}{c}\text { Correlation } \\
\text { Sig. }(2 \text {-tailed })\end{array}$ & $\begin{array}{l}.80 \\
.00\end{array}$ & $\begin{array}{l}.78 \\
.00\end{array}$ & 1 & & & & & & & & & & & & \\
\hline & 4 Regulatory Quality & $\begin{array}{c}\text { Correlation } \\
\text { Sig. }(2 \text {-tailed) }\end{array}$ & $\begin{array}{l}.79 \\
.00\end{array}$ & $\begin{array}{l}.75 \\
.00\end{array}$ & $\begin{array}{l}.80 \\
.00\end{array}$ & 1 & & & & & & & & & & & \\
\hline & 5 Government Assistance & $\begin{array}{c}\text { Correlation } \\
\text { Sig. }(2 \text {-tailed })\end{array}$ & $\begin{array}{l}.26 \\
.00\end{array}$ & $\begin{array}{l}.16 \\
.00\end{array}$ & $\begin{array}{l}.24 \\
.00\end{array}$ & $\begin{array}{l}.21 \\
.00\end{array}$ & 1 & & & & & & & & & & \\
\hline & 6 Performance Orientation & $\begin{array}{c}\text { Correlation } \\
\text { Sig. (2-tailed) }\end{array}$ & $\begin{array}{l}.07 \\
.05\end{array}$ & $\begin{array}{l}.03 \\
.31\end{array}$ & $\begin{array}{l}.04 \\
.20\end{array}$ & $\begin{array}{l}.05 \\
.16\end{array}$ & $\begin{array}{l}.05 \\
.12\end{array}$ & 1 & & & & & & & & & \\
\hline & 7 Future Orientation & $\begin{array}{c}\text { Correlation } \\
\text { Sig. }(2 \text {-tailed })\end{array}$ & $\begin{array}{l}.19 \\
.00 \\
\end{array}$ & $\begin{array}{l}.27 \\
.00 \\
\end{array}$ & $\begin{array}{l}.21 \\
.00 \\
\end{array}$ & $\begin{array}{l}.22 \\
.00 \\
\end{array}$ & $\begin{array}{l}.08 \\
.02 \\
\end{array}$ & $\begin{array}{l}.01 \\
.81 \\
\end{array}$ & 1 & & & & & & & & \\
\hline & 8 Assertiveness & $\begin{array}{c}\text { Correlation } \\
\text { Sig. }(2 \text {-tailed })\end{array}$ & $\begin{array}{r}-.02 \\
.46\end{array}$ & $\begin{array}{l}.01 \\
.67\end{array}$ & $\begin{array}{r}-.02 \\
.56\end{array}$ & $\begin{array}{r}-.03 \\
.37\end{array}$ & $\begin{array}{l}.05 \\
.11\end{array}$ & $\begin{array}{r}-.01 \\
.73\end{array}$ & $\begin{array}{l}.01 \\
.76\end{array}$ & 1 & & & & & & & \\
\hline & 9 Collectivism & $\begin{array}{c}\text { Correlation } \\
\text { Sig. }(2 \text {-tailed })\end{array}$ & $\begin{array}{r}-.04 \\
.19\end{array}$ & $\begin{array}{r}-.09 \\
.01\end{array}$ & $\begin{array}{r}-.05 \\
.14\end{array}$ & $\begin{array}{r}-.03 \\
.42\end{array}$ & $\begin{array}{r}-.06 \\
.10\end{array}$ & $\begin{array}{r}-.04 \\
.21\end{array}$ & $\begin{array}{r}-.03 \\
.38\end{array}$ & $\begin{array}{r}-.01 \\
.72\end{array}$ & 1 & & & & & & \\
\hline & 10 Power Distance & $\begin{array}{c}\text { Correlation } \\
\text { Sig. (2-tailed) }\end{array}$ & $\begin{array}{l}.01 \\
.68\end{array}$ & $\begin{array}{l}.01 \\
.77\end{array}$ & $\begin{array}{r}-.01 \\
.68\end{array}$ & $\begin{array}{l}.01 \\
.80\end{array}$ & $\begin{array}{l}.01 \\
.74\end{array}$ & $\begin{array}{l}.03 \\
.37\end{array}$ & $\begin{array}{r}-.01 \\
.82\end{array}$ & $\begin{array}{l}.04 \\
.20\end{array}$ & $\begin{array}{l}.03 \\
.41\end{array}$ & 1 & & & & & \\
\hline & 11 Humane Orientation & $\begin{array}{c}\text { Correlation } \\
\text { Sig. }(2 \text {-tailed })\end{array}$ & $\begin{array}{l}.27 \\
.00 \\
\end{array}$ & $\begin{array}{l}.28 \\
.00 \\
\end{array}$ & $\begin{array}{l}.29 \\
.00 \\
\end{array}$ & $\begin{array}{l}.28 \\
.00 \\
\end{array}$ & $\begin{array}{l}.07 \\
.05 \\
\end{array}$ & $\begin{array}{l}.04 \\
.30 \\
\end{array}$ & $\begin{array}{l}.08 \\
.02 \\
\end{array}$ & $\begin{array}{r}-.04 \\
.25 \\
\end{array}$ & $\begin{array}{l}.00 \\
.93 \\
\end{array}$ & $\begin{array}{r}-.02 \\
.54 \\
\end{array}$ & 1 & & & & \\
\hline & 12 Uncertainty Avoidance & $\begin{array}{c}\text { Correlation } \\
\text { Sig. }(2 \text {-tailed) }\end{array}$ & $\begin{array}{r}-.26 \\
.00\end{array}$ & $\begin{array}{r}-.19 \\
.00\end{array}$ & $\begin{array}{r}-.22 \\
.00\end{array}$ & $\begin{array}{r}-.24 \\
.00\end{array}$ & $\begin{array}{r}-.10 \\
.00\end{array}$ & $\begin{array}{r}-.00 \\
.92\end{array}$ & $\begin{array}{r}-.26 \\
.00\end{array}$ & $\begin{array}{l}.02 \\
.56\end{array}$ & $\begin{array}{r}-.07 \\
.04\end{array}$ & $\begin{array}{r}-.03 \\
.31\end{array}$ & $\begin{array}{r}-.09 \\
.01\end{array}$ & 1 & & & \\
\hline & 13 Competitive Intensity & $\begin{array}{c}\text { Correlation } \\
\text { Sig. }(2 \text {-tailed })\end{array}$ & $\begin{array}{l}.30 \\
.00\end{array}$ & $\begin{array}{l}.25 \\
.00\end{array}$ & $\begin{array}{l}.26 \\
.00\end{array}$ & $\begin{array}{l}.28 \\
.00\end{array}$ & $\begin{array}{l}.17 \\
.00\end{array}$ & $\begin{array}{l}.03 \\
.38\end{array}$ & $\begin{array}{l}.24 \\
.00\end{array}$ & $\begin{array}{l}.04 \\
.26\end{array}$ & $\begin{array}{r}-.06 \\
.09\end{array}$ & $\begin{array}{l}.04 \\
.25\end{array}$ & $\begin{array}{l}.04 \\
.18\end{array}$ & $\begin{array}{r}-.12 \\
.00\end{array}$ & 1 & & \\
\hline & 14 Technological Sophistication & $\begin{array}{c}\text { Correlation } \\
\text { Sig. }(2 \text {-tailed) }\end{array}$ & $\begin{array}{l}.41 \\
.00 \\
\end{array}$ & $\begin{array}{l}.41 \\
.00 \\
\end{array}$ & $\begin{array}{l}.45 \\
.00 \\
\end{array}$ & $\begin{array}{l}.41 \\
.00 \\
\end{array}$ & $\begin{array}{l}.22 \\
.00 \\
\end{array}$ & $\begin{array}{l}.08 \\
.02 \\
\end{array}$ & $\begin{array}{l}.08 \\
.02 \\
\end{array}$ & $\begin{array}{l}.00 \\
.89 \\
\end{array}$ & $\begin{array}{r}-.07 \\
.04 \\
\end{array}$ & $\begin{array}{l}.01 \\
.73 \\
\end{array}$ & $\begin{array}{l}.14 \\
.00 \\
\end{array}$ & $\begin{array}{r}-.14 \\
.00 \\
\end{array}$ & $\begin{array}{l}.09 \\
.01 \\
\end{array}$ & 1 & \\
\hline & 15 Marker Variable & $\begin{array}{l}\text { Correlation } \\
\text { Sig. }(2 \text {-tailed) }\end{array}$ & $\begin{array}{r}-.21 \\
.00\end{array}$ & $\begin{array}{r}-.11 \\
.00\end{array}$ & $\begin{array}{r}-.18 \\
.00\end{array}$ & $\begin{array}{r}-.16 \\
.00\end{array}$ & $\begin{array}{r}-.07 \\
.04\end{array}$ & $\begin{array}{l}.06 \\
.08\end{array}$ & $\begin{array}{r}-.03 \\
.36\end{array}$ & $\begin{array}{r}-.02 \\
.56\end{array}$ & $\begin{array}{l}-07 \\
.73\end{array}$ & $\begin{array}{r}-.05 \\
.12\end{array}$ & $\begin{array}{r}-.08 \\
.02\end{array}$ & $\begin{array}{l}.08 \\
.01\end{array}$ & $\begin{array}{r}-.11 \\
.00\end{array}$ & $\begin{array}{l}.02 \\
.66\end{array}$ & 1 \\
\hline
\end{tabular}


Table 5.7 Partial Correlation Matrix Examining the Effect of the Marker Variable

\begin{tabular}{|c|c|c|c|c|c|c|c|c|c|c|c|c|c|c|c|c|}
\hline Control Variable & Variables & & 1 & 2 & 3 & 4 & 5 & 6 & 7 & 8 & 9 & 10 & 11 & 12 & 13 & 14 \\
\hline \multirow[t]{14}{*}{ Marker Variable } & 1 Rule of Law & $\begin{array}{c}\text { Correlation } \\
\text { Sig. (2-tailed) }\end{array}$ & 1 & & & & & & & & & & & & & \\
\hline & 2 Protection of Property Rights & $\begin{array}{c}\text { Correlation } \\
\text { Sig. }(2 \text {-tailed })\end{array}$ & $\begin{array}{l}.71 \\
.00\end{array}$ & 1 & & & & & & & & & & & & \\
\hline & 3 Government Policies & $\begin{array}{c}\text { Correlation } \\
\text { Sig. (2-tailed) }\end{array}$ & $\begin{array}{l}.79 \\
.00\end{array}$ & $\begin{array}{l}.78 \\
.00\end{array}$ & 1 & & & & & & & & & & & \\
\hline & 4 Regulatory Quality & $\begin{array}{c}\text { Correlation } \\
\text { Sig. (2-tailed) }\end{array}$ & $\begin{array}{l}.78 \\
.00\end{array}$ & $\begin{array}{l}.75 \\
.00\end{array}$ & $\begin{array}{l}.80 \\
.00\end{array}$ & 1 & & & & & & & & & & \\
\hline & 5 Government Assistance & $\begin{array}{c}\text { Correlation } \\
\text { Sig. (2-tailed) }\end{array}$ & $\begin{array}{l}.25 \\
.00\end{array}$ & $\begin{array}{l}.15 \\
.00\end{array}$ & $\begin{array}{l}.23 \\
.00 \\
\end{array}$ & $\begin{array}{l}.20 \\
.00 \\
\end{array}$ & 1 & & & & & & & & & \\
\hline & 6 Performance Orientation & $\begin{array}{c}\text { Correlation } \\
\text { Sig. (2-tailed) }\end{array}$ & $\begin{array}{l}.08 \\
.02\end{array}$ & $\begin{array}{l}.04 \\
.22 \\
\end{array}$ & $\begin{array}{l}.05 \\
.10 \\
\end{array}$ & $\begin{array}{l}.06 \\
.08\end{array}$ & $\begin{array}{l}.06 \\
.10 \\
\end{array}$ & 1 & & & & & & & & \\
\hline & 7 Future Orientation & $\begin{array}{c}\text { Correlation } \\
\text { Sig. }(2 \text {-tailed })\end{array}$ & $\begin{array}{l}.19 \\
.00 \\
\end{array}$ & $\begin{array}{l}.21 \\
.00 \\
\end{array}$ & $\begin{array}{l}.21 \\
.00 \\
\end{array}$ & $\begin{array}{l}.22 \\
.00 \\
\end{array}$ & $\begin{array}{l}.08 \\
.02 \\
\end{array}$ & $\begin{array}{l}.01 \\
.77 \\
\end{array}$ & 1 & & & & & & & \\
\hline & 8 Assertiveness & $\begin{array}{c}\text { Correlation } \\
\text { Sig. }(2 \text {-tailed })\end{array}$ & $\begin{array}{r}-.03 \\
.38 \\
\end{array}$ & $\begin{array}{l}.01 \\
.72 \\
\end{array}$ & $\begin{array}{r}-.02 \\
.49 \\
\end{array}$ & $\begin{array}{r}-.03 \\
.31 \\
\end{array}$ & $\begin{array}{l}.05 \\
.12 \\
\end{array}$ & $\begin{array}{r}-.01 \\
.75 \\
\end{array}$ & $\begin{array}{l}.01 \\
.78 \\
\end{array}$ & 1 & & & & & & \\
\hline & 9 Collectivism & $\begin{array}{c}\text { Correlation } \\
\text { Sig. }(2 \text {-tailed })\end{array}$ & $\begin{array}{r}-.05 \\
.16 \\
\end{array}$ & $\begin{array}{r}-.09 \\
.01 \\
\end{array}$ & $\begin{array}{r}-.05 \\
.12 \\
\end{array}$ & $\begin{array}{r}-.03 \\
.38 \\
\end{array}$ & $\begin{array}{r}-.06 \\
.10 \\
\end{array}$ & $\begin{array}{r}-.04 \\
.22 \\
\end{array}$ & $\begin{array}{r}-.03 \\
.37 \\
\end{array}$ & $\begin{array}{r}-.01 \\
.71 \\
\end{array}$ & 1 & & & & & \\
\hline & 10 Power Distance & $\begin{array}{l}\text { Correlation } \\
\text { Sig. (2-tailed) }\end{array}$ & $\begin{array}{l}.00 \\
.93\end{array}$ & $\begin{array}{l}.00 \\
.90\end{array}$ & $\begin{array}{r}-.02 \\
.48\end{array}$ & $\begin{array}{l}.00 \\
.99\end{array}$ & $\begin{array}{l}.01 \\
.83\end{array}$ & $\begin{array}{l}.03 \\
.32\end{array}$ & $\begin{array}{r}-.01 \\
.79\end{array}$ & $\begin{array}{l}.04 \\
.21\end{array}$ & $\begin{array}{l}.03 \\
.42\end{array}$ & 1 & & & & \\
\hline & 11 Humane Orientation & $\begin{array}{c}\text { Correlation } \\
\text { Sig. (2-tailed) }\end{array}$ & $\begin{array}{l}.26 \\
.00\end{array}$ & $\begin{array}{l}.27 \\
.00\end{array}$ & $\begin{array}{l}.28 \\
.00\end{array}$ & $\begin{array}{l}.27 \\
.00\end{array}$ & $\begin{array}{l}.06 \\
.07\end{array}$ & $\begin{array}{l}.04 \\
.24\end{array}$ & $\begin{array}{l}.08 \\
.02\end{array}$ & $\begin{array}{r}-.04 \\
.23 \\
\end{array}$ & $\begin{array}{l}.00 \\
.95 \\
\end{array}$ & $\begin{array}{r}-.02 \\
.46 \\
\end{array}$ & $\overline{1}$ & & & \\
\hline & 12 Uncertainty Avoidance & $\begin{array}{c}\text { Correlation } \\
\text { Sig. }(2 \text {-tailed })\end{array}$ & $\begin{array}{r}-.25 \\
.00\end{array}$ & $\begin{array}{r}-.18 \\
.00\end{array}$ & $\begin{array}{r}-.21 \\
.00\end{array}$ & $\begin{array}{r}-.23 \\
.00\end{array}$ & $\begin{array}{r}-.09 \\
.01\end{array}$ & $\begin{array}{r}-.01 \\
.81\end{array}$ & $\begin{array}{r}-0.26 \\
.00\end{array}$ & $\begin{array}{l}.02 \\
.52\end{array}$ & $\begin{array}{r}-.07 \\
.04\end{array}$ & $\begin{array}{r}-.03 \\
.38\end{array}$ & $\begin{array}{r}-.08 \\
.02\end{array}$ & 1 & & \\
\hline & 13 Competitive Intensity & $\begin{array}{c}\text { Correlation } \\
\text { Sig. }(2 \text {-tailed })\end{array}$ & $\begin{array}{l}.28 \\
.00\end{array}$ & $\begin{array}{l}.24 \\
.00\end{array}$ & $\begin{array}{l}.24 \\
.00\end{array}$ & $\begin{array}{l}.27 \\
.00\end{array}$ & $\begin{array}{l}.17 \\
.00\end{array}$ & $\begin{array}{l}.04 \\
.28\end{array}$ & $\begin{array}{l}.24 \\
.00\end{array}$ & $\begin{array}{l}.04 \\
.29 \\
\end{array}$ & $\begin{array}{r}-.06 \\
.08\end{array}$ & $\begin{array}{l}.03 \\
.33\end{array}$ & $\begin{array}{l}.04 \\
.27\end{array}$ & $\begin{array}{r}-.11 \\
.00 \\
\end{array}$ & 1 & \\
\hline & 14 Technological Sophistication & $\begin{array}{c}\text { Correlation } \\
\text { Sig. }(2 \text {-tailed) }\end{array}$ & $\begin{array}{l}.42 \\
.00\end{array}$ & $\begin{array}{l}.41 \\
.00\end{array}$ & $\begin{array}{l}.46 \\
.00\end{array}$ & $\begin{array}{l}.42 \\
.00\end{array}$ & $\begin{array}{l}.22 \\
.00\end{array}$ & $\begin{array}{l}.08 \\
.02\end{array}$ & $\begin{array}{l}.08 \\
.02\end{array}$ & $\begin{array}{l}.01 \\
.89\end{array}$ & $\begin{array}{r}-.07 \\
.04\end{array}$ & $\begin{array}{l}.01 \\
.71\end{array}$ & $\begin{array}{l}.14 \\
.00\end{array}$ & $\begin{array}{r}-.14 \\
.00\end{array}$ & $\begin{array}{l}.09 \\
.01\end{array}$ & 1 \\
\hline
\end{tabular}




\subsection{Missing Values Analysis}

Missing values analysis using SPSS v. 14 was performed generating results presented in Tables 5.8 and 5.9. An examination of the items and cases with missing values revealed that the missing data were coming from known and unknown data processes and are not ignorable (Hair et al., 2006). Missing data from known processes included those that were missing due to errors in data entry as well as respondents who skipped some items. Missing data from unknown processes included those that were missing due to deliberate refusal to provide an answer to a specific item. Errors in data entry were corrected immediately by referring back to the hard-copy of questionnaires. Despite this, missing values remained.

According to Hair et al (2006), the remedy depends on the extent of missing data and the level of randomness of the missing data process. In the present study, the extent of missing data was considered negligible or minor as all items contained only missing values within the range of $1.7 \%$ to $.1 \%$ and were way below the acceptable threshold of $10 \%$ (Hair et al., 2006). Details of the missing values are shown in Tables 5.8 and 5.9. Further analysis revealed the absence of any specific pattern amongst the missing data.

Missing data amongst the independent variables did not show any pattern in relation to the dependent variables which further suggested that these values were missing completely at random (MCAR) (Hair et al., 2006). Rather than deleting these cases with data that were $M C A R$, the missing values were simply substituted with the mean of all the answered items comprising the construct in which that item belonged under each case or respondent. Mean substitution is warranted if there are relatively low levels of missing data and that there are relatively strong relationships among variables (Hair et al., 2006). These two conditions were met as far as preliminary data analysis was concerned. As a result, all cases $(N=900)$ that were included in subsequent statistical analyses contained complete information. 
Table 5.8 Missing Value Analysis - Part 1

Missing

The occurrence of crime does not impose costs on my business.

The judicial system is fair and impartial.

The legal system is effective in enforcing commercial contracts.

People are willing to accept legal means to settle disputes rather than depend on physical force or illegal means.

Court rulings and/or arbitration awards are complied with by the people involved.

The legal framework to challenge the legality of government actions is efficient.

Private property is adequately protected by law.

Intellectual property rights (like copyrights or trademarks) are adequately protected.

The city government enforces laws that protect private property.

Violations of property rights are prosecuted accordingly.

Laws and regulations imposed by the city government are conducive for business.

Taxation laws and policies including incentives and exemptions are good enough for my business.

City government economic policies adapt quickly to changes in the economy.

City government decisions are effectively implemented.

The policy direction of the city government is consistent.

Information about laws and regulations is easy to obtain.

Interpretations of the laws and regulations are consistent and predictable.

Business regulations are less of a burden for business.

Procedures in city government transactions are consistently enforced.

The time required to register a business with the city government is reasonable.

The number of permits required is manageable.

The number of city government offices to deal with is reasonable.

The number of city government inspections required before opening a business is reasonable.

City government offices assist individuals in starting their own business.

The city government sets aside government contracts for new and small businesses.

The city government has special support available for individuals who want to start a new business.

The city government sponsors organizations that help new businesses develop.

Even after failing in an earlier business, the city government assists businessmen/women in starting again.

In this city, orderliness and consistency are stressed, even at the expense of experimentation and innovation.

In this city, people lead highly structured lives with few unexpected events.

In this city, societal requirements and instructions are spelled out in detail so citizens know what they are expected to do.

This city has rules or laws to cover (almost all, some, very few) situations.

The way to be successful in this city is to (plan ahead - take events as they occur).

In this city, the accepted norm/usual practice/custom is to (plan for the future-accept the status quo).

In this city, social gatherings are usually (planned well in advanced - spontaneous).

In this city, more people (live for the present - live for the future).

In this city, people place more emphasis on (solving current problems-planning for the future).

In this city, a person's influence is based primarily on (one's ability and contribution in society - the authority of one's position).

In this city, followers are expected to (obey their leaders without question-question their leaders when in disagreement).

In this city, people in positions of power try to (increase-decrease) their social distance from less powerful individuals).

In this city, rank and position in the hierarchy (of society ) have special privileges.

In this city, power is (concentrated at the top - shared throughout the society).

In this city, people are generally (assertive-non assertive).

In this city, people are generally (dominant - non dominant).

In this city, people are generally (tough - tender).

In this city, leaders encourage group loyalty even if individual goals suffer.

The economic system in this city is designed to maximize (individual-collective) interests.

In this city, being accepted by the other members of a group is very important.

In this city, tight group membership is (more valued, equally valued, less valued) than individualism.

In this city, people are generally (very - not at all) concerned about others.

In this city, people are generally (very - not at all) sensitive toward others.

In this city, people are generally (very friendly-very unfriendly).

In this city, people are generally (very-not at all) tolerant of mistakes.

N Count Percent

$\begin{array}{lll}897 & 3 & 0.3 \\ 896 & 4 & 0.4\end{array}$

$\begin{array}{lll}898 & 2 & 0.2\end{array}$

$\begin{array}{lll}894 & 6 & 0.7\end{array}$

$\begin{array}{lll}895 & 5 & 0.6\end{array}$

$\begin{array}{lll}897 & 3 & 0.3\end{array}$

$\begin{array}{lll}897 & 3 & 0.3\end{array}$

$\begin{array}{lll}892 & 8 & 0.9\end{array}$

$\begin{array}{lll}891 & 9 & 1.0\end{array}$

$\begin{array}{lll}896 & 4 & 0.4\end{array}$

$\begin{array}{lll}898 & 2 & 0.2\end{array}$

$\begin{array}{lll}898 & 2 & 0.2\end{array}$

$\begin{array}{lll}893 & 7 & 0.8\end{array}$

$\begin{array}{lll}897 & 3 & 0.3\end{array}$

$\begin{array}{lll}898 & 2 & 0.2\end{array}$

$\begin{array}{lll}892 & 8 & 0.9\end{array}$

$\begin{array}{lll}897 & 3 & 0.3\end{array}$

$\begin{array}{lll}895 & 5 & 0.6\end{array}$

$\begin{array}{lll}888 & 12 & 1.3\end{array}$

$\begin{array}{lll}895 & 5 & 0.6\end{array}$

$\begin{array}{lll}889 & 11 & 1.2\end{array}$

$\begin{array}{lll}895 & 5 & 0.6\end{array}$

$\begin{array}{lll}892 & 8 & 0.9\end{array}$

$\begin{array}{lll}895 & 5 & 0.6\end{array}$

$\begin{array}{lll}899 & 1 & 0.1\end{array}$

$\begin{array}{lll}893 & 7 & 0.8\end{array}$

$\begin{array}{lll}891 & 9 & 1.0\end{array}$

$\begin{array}{lll}886 & 14 & 1.6\end{array}$

$\begin{array}{lll}897 & 3 & 0.3\end{array}$

$\begin{array}{lll}898 & 2 & 0.2\end{array}$

$\begin{array}{lll}889 & 11 & 1.2\end{array}$

$\begin{array}{lll}895 & 5 & 0.6\end{array}$

$\begin{array}{lll}895 & 5 & 0.6\end{array}$

$\begin{array}{lll}894 & 6 & 0.7\end{array}$

$\begin{array}{lll}896 & 4 & 0.4\end{array}$

$\begin{array}{lll}886 & 14 & 1.6\end{array}$

$\begin{array}{lll}894 & 6 & 0.7\end{array}$

$\begin{array}{lll}894 & 6 & 0.7\end{array}$

$\begin{array}{lll}897 & 3 & 0.3\end{array}$

$\begin{array}{lll}895 & 5 & 0.6\end{array}$

$\begin{array}{lll}895 & 5 & 0.6\end{array}$

$\begin{array}{lll}898 & 2 & 0.2\end{array}$

$\begin{array}{lll}892 & 8 & 0.9\end{array}$

$\begin{array}{lll}895 & 5 & 0.6\end{array}$

$\begin{array}{lll}898 & 2 & 0.2\end{array}$

$\begin{array}{lll}898 & 2 & 0.2\end{array}$

$\begin{array}{lll}897 & 3 & 0.3\end{array}$

$\begin{array}{lll}896 & 4 & 0.4\end{array}$

$\begin{array}{lll}885 & 15 & 1.7\end{array}$

$\begin{array}{lll}896 & 4 & 0.4\end{array}$

$\begin{array}{lll}898 & 2 & 0.2\end{array}$

$\begin{array}{lll}898 & 2 & 0.2\end{array}$

\begin{tabular}{lll}
898 & 2 & 0.2 \\
\hline
\end{tabular}


Table 5.9 Missing Value Analysis - Part 2

\begin{tabular}{|c|c|c|c|}
\hline \multirow[b]{2}{*}{ ITEMS } & \multicolumn{3}{|c|}{ Missing } \\
\hline & $\mathrm{N}$ & Count & Percent \\
\hline In this city, people are generally (very - not at all) generous. & 898 & 2 & 0.2 \\
\hline In this city, the internet is a very convenient source of information. & 894 & 6 & 0.7 \\
\hline In this city, the internet provides all kinds of useful information. & 895 & 5 & 0.6 \\
\hline In this city, the internet is a very useful tool to research for information. & 897 & 3 & 0.3 \\
\hline In this city, I would strongly recommend the internet as a research tool to find new information. & 897 & 3 & 0.3 \\
\hline In this city, teen-aged students are encouraged to strive for continuously improved performance. & 895 & 5 & 0.6 \\
\hline $\begin{array}{l}\text { In this city, major rewards are based on only performance effectiveness (pe), pe and other factors such as seniority (s) } \\
\text { or political connections }(\mathrm{pc}) \text {, or only factors other than pe such as s and pc). }\end{array}$ & 898 & 2 & 0.2 \\
\hline In this city, being innovative to improve performance is generally (substantially, somewhat, not) rewarded. & 896 & 4 & 0.4 \\
\hline $\begin{array}{l}\text { In general, my business favours a strong emphasis : on the marketing of tried and true products or services - } \\
\text { on research \& development, technological leadership, and innovation. }\end{array}$ & 897 & 3 & 0.3 \\
\hline How many new lines of products or services has your business marketed in the past few years? & 895 & 5 & 0.6 \\
\hline Changes in product or service lines have been mostly of a minor nature-have usually been quite dramatic. & 896 & 4 & 0.4 \\
\hline $\begin{array}{l}\text { In dealing with its competitors, my business....typically responds to actions which competitors initiate- } \\
\text { typically initiates actions to which competitors then respond. }\end{array}$ & 891 & 9 & 1.0 \\
\hline $\begin{array}{l}\text { In dealing with its competitors, my business is (very seldom-very often) the first business to - } \\
\text { introduce new products/services, administrative techniques, operating technologies, etc. }\end{array}$ & 895 & 5 & 0.6 \\
\hline $\begin{array}{l}\text { In dealing with its competitors, my business typically seeks to avoid competitive clashes, preferring a "live-and-let-live" } \\
\text { posture - typically adopts a very competitive, "undo-the competitors" attitude. }\end{array}$ & 895 & 5 & 0.6 \\
\hline $\begin{array}{l}\text { In general, my business has: a strong preference for low-risk projects (with normal and certain rates of return) - } \\
\text { A strong preference for high risk projects, (with chances of very high returns). }\end{array}$ & 899 & 1 & 0.1 \\
\hline $\begin{array}{l}\text { In general, my business believes that: owing to the nature of the environment, it is best to explore it gradually via cautious, } \\
\text { slowly increasing behaviour - bold, wide ranging acts are necessary to achieve the firm's objectives. }\end{array}$ & 895 & 5 & 0.6 \\
\hline $\begin{array}{l}\text { When confronted with decision-making situations involving uncertainty, my business: typically adopts a cautious, 'wait and se } \\
\text { posture in order to minimize the probability of making costly decisions -typically adopts a bold, aggressive posture in order to } \\
\text { maximize the probability of exploiting potential opportunities. }\end{array}$ & 896 & 4 & 0.4 \\
\hline Competition in our industry is very intense or tough. & 897 & 3 & 0.3 \\
\hline Anything that one competitor can offer, others can match. & 893 & 7 & 0.8 \\
\hline Our competitors are relatively weak. & 899 & 1 & 0.1 \\
\hline $\begin{array}{l}\text { How would you characterize the industry environment within which your business enterprise functions: An environment } \\
\text { demanding little in the way of technological sophistication-Technologically, a very sophisticated and complex environment }\end{array}$ & 891 & 9 & 1.0 \\
\hline $\begin{array}{l}\text { How much research and development }(R \& D) \text { activity takes place within your business enterprise's principal industry?: } \\
\text { Virtually no } R \& D \text { in industry (e.g. bakery, publishing, real estate, etc.)- } \\
\text { Extremely } R \text { \& D-oriented industry (e.g. telecommunications, space, pharmaceuticals, etc. }\end{array}$ & 895 & 5 & 0.6 \\
\hline age of the business & 899 & 1 & 0.1 \\
\hline educational level & 899 & 1 & 0.1 \\
\hline number of school years & 899 & 1 & 0.1 \\
\hline age of the respondent & 898 & 2 & 0.2 \\
\hline number of full-time staff & 898 & 2 & 0.2 \\
\hline ownership & 899 & 1 & 0.1 \\
\hline $\begin{array}{l}\text { Business enterprises have different ways to assess their performance. In your case, please let us know if the following factor } \\
\text { are important to you when you assess your business performance: }\end{array}$ & & & \\
\hline development of new products or services & 896 & 4 & 0.4 \\
\hline product or service quality & 894 & 6 & 0.7 \\
\hline customer satisfaction & 895 & 5 & 0.6 \\
\hline improvement in business and/or production processes & 896 & 4 & 0.4 \\
\hline attraction/recruitment of essential employees/skilled labour/talent & 897 & 3 & 0.3 \\
\hline retention of essential employees/skilled labour/talent & 898 & 2 & 0.2 \\
\hline market share & 897 & 3 & 0.3 \\
\hline growth of market share & 896 & 4 & 0.4 \\
\hline sales & 895 & 5 & 0.6 \\
\hline sales growth & 896 & 4 & 0.4 \\
\hline net income & 895 & 5 & 0.6 \\
\hline growth of net income & 894 & 6 & 0.7 \\
\hline return on investment & 893 & 7 & 0.8 \\
\hline $\begin{array}{l}\text { Now, please let us know your actual ENTERPRISE PERFORMANCE COMPARED TO COMPETITORS or similar firms } i \\
\text { industry over the last } 3 \text { years in terms of the following }\end{array}$ & & & \\
\hline development of new products or services & 892 & 8 & 0.9 \\
\hline product or service quality & 895 & 5 & 0.6 \\
\hline customer satisfaction & 896 & 4 & 0.4 \\
\hline improvement in business and/or production processes & 898 & 2 & 0.2 \\
\hline attraction/recruitment of essential employees/skilled labour/talent & 898 & 2 & 0.2 \\
\hline retention of essential employees/skilled labour/talent & 897 & 3 & 0.3 \\
\hline market share & 898 & 2 & 0.2 \\
\hline growth of market share & 897 & 3 & 0.3 \\
\hline sales & 898 & 2 & 0.2 \\
\hline sales growth & 899 & 1 & 0.1 \\
\hline net income & 899 & 1 & 0.1 \\
\hline growth of net income & 896 & 4 & 0.4 \\
\hline return on investment & 896 & 4 & 0.4 \\
\hline
\end{tabular}




\subsection{Assessment of Normality of Distribution}

Normal distribution of data is one of the assumptions that must be met in performing the parametric statistical tests of the hypotheses of the current study. Graphical analysis of the distribution of data (e.g. histograms) for all of the items comprising the dependent and independent variables including the residual plots was performed to assess normality (Chambers, Cleveland, Kleiner \& Tukey, 1983). Multiple opinions were sought by showing the graphs to a Master's (final year) student with a major in statistics, plus two other $\mathrm{PhD}$ students. The consensus was that despite the noticeable prevalence of slight negative skewness in many items, the distributions appeared to be normal as shown by the typical bell-shaped distribution with slightly elongated left-side tails.

A descriptive analysis of the skewness and kurtosis of each item as shown in Tables 5.10 and 5.11 revealed that skewness ranged from -1.41 to +1.06 whilst kurtosis ranged from -1.81 to +2.60 . Whilst normal distribution should have values of skewness and kurtosis close to zero (Field, 2005), the values presented in the two tables suggested that the distribution of data was relatively normal despite the presence of slight negative skewness. Conditions of mild skewness $(+1$ to -1$)$ or kurtosis (+2 to -2$)$ were judged to be within normal limits so that statistical analyses such as factor analysis that would be used in the current study could proceed (Heck, 1998, p. 189).

Furthermore, a number of authors suggest that absolute values of skewness indices greater than 3.00 seem to describe extremely skewed data sets (Chou \& Bentler, 1995; Hu, Bentler \& Kano, 1992; Kline, 2005; Schumacher \& Lomax, 1996). Likewise, absolute values of kurtosis indices greater than 10.00 may suggest a problem and values greater than 20.00 may indicate a more serious problem (Hoyle, 1995; Kline, 2005). All the skewness and kurtosis indices in the current data set were way below these maximum thresholds, which indicate that non-normality of distribution was not a major concern. Nonetheless, further tests on normality were performed (presented later in this chapter) in relation to multiple regression analysis. 
Table 5.10 Skewness and Kurtosis Indices of Items - Part 1

\begin{tabular}{|c|c|c|}
\hline ITEMS & $\begin{array}{l}\text { Skewness } \\
\text { Statistic }\end{array}$ & $\begin{array}{l}\text { Kurtosis } \\
\text { Statistic } \\
\end{array}$ \\
\hline The occurrence of crime does not impose costs on my business. & -0.065 & -1.580 \\
\hline The judicial system is fair and impartial. & -0.545 & -0.418 \\
\hline The legal system is effective in enforcing commercial contracts. & -0.160 & -1.267 \\
\hline $\begin{array}{l}\text { People are willing to accept legal means to settle disputes rather than depend on physical force } \\
\text { or illegal means }\end{array}$ & -0.470 & -0.489 \\
\hline Court rulings and/or arbitration awards are complied with by the people involved. & -0.569 & 0.991 \\
\hline The legal framework to challenge the legality of government actions is efficient. & -0.184 & -1.376 \\
\hline Private property is adequately protected by law. & -0.053 & -1.199 \\
\hline Intellectual property rights (like copyrights or trademarks) are adequately protected. & -0.021 & -0.761 \\
\hline The city government enforces laws that protect private property. & 0.092 & -0.656 \\
\hline Violations of property rights are prosecuted accordingly. & 0.004 & -1.635 \\
\hline Laws and regulations imposed by the city government are conducive for busines & -0.374 & -1.119 \\
\hline Taxation laws and policies including incentives and exemptions are good enough for my business. & -0.069 & -1.715 \\
\hline City government economic policies adapt quickly to changes in the economy. & -0.088 & -1.621 \\
\hline City government decisions are effectively implemented. & -0.056 & -1.623 \\
\hline stent. & -0.165 & -1.412 \\
\hline Inform & -0.007 & -1.693 \\
\hline Interpretations of the laws and regulations & -0.037 & -1.276 \\
\hline usiness regulations are less of a burden for business. & -0.083 & -1.634 \\
\hline nsisten & -0.126 & -1.513 \\
\hline ty government is reasonable. & -0.264 & -1.412 \\
\hline The number of permits required is manageable. & 0.022 & -1.351 \\
\hline The $n$ & -0.149 & -1.389 \\
\hline ing a business is reas & -0.428 & -0.661 \\
\hline City government offices assist individuals in starting their own business. & 0.928 & 0.320 \\
\hline The c & 0.770 & 0.485 \\
\hline The & 0.901 & 0.479 \\
\hline The city govern & 1.059 & 1.365 \\
\hline Even & 0.887 & 0.770 \\
\hline n this & 0.353 & -0.004 \\
\hline $\mathrm{n}$ this $\mathrm{c}$ & 0.452 & -0.111 \\
\hline In this city, societal requirements are spelled out in detail so citizens know what they are expected to do. & 0.137 & 0.189 \\
\hline & 0.246 & 0.342 \\
\hline & -0.099 & -0.263 \\
\hline pt the status quo). & -0.166 & -0.144 \\
\hline In this city, soci & -0.083 & -0.671 \\
\hline $\mathrm{ntl}$ & -0.224 & -0.201 \\
\hline anning for the future). & -0.217 & -0.312 \\
\hline ociety - the authorit & -0.812 & 0.798 \\
\hline & -0.416 & 0.409 \\
\hline from le & -0.816 & 1.179 \\
\hline In th & -0.964 & 1.786 \\
\hline 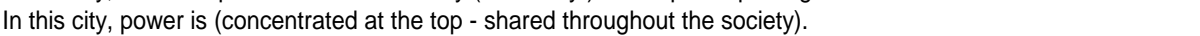 & -0.899 & 1.039 \\
\hline & -0.196 & -0.213 \\
\hline dominant). & -0.245 & -0.088 \\
\hline nder). & -0.640 & 0.317 \\
\hline & -0.141 & -0.188 \\
\hline ative intornctc & -0.236 & 0.285 \\
\hline In th & -0.272 & 0.342 \\
\hline In this city, tight group membership is (more valued, equally valued, less valued) than individualism. & -0.343 & 0.149 \\
\hline & -0.778 & 0.992 \\
\hline $\ln \mathrm{t}$ & -0.611 & 0.065 \\
\hline In this city, people are generally (very friendly-very unfriendly). & -0.682 & 0.814 \\
\hline In this city, people are generally (very-not at all) tolerant of mistakes. & -0.796 & 0.610 \\
\hline & -0.766 & 0.580 \\
\hline In th & -0.330 & -0.210 \\
\hline $\begin{array}{l}\text { In this city, major rewards are based on only performance effectiveness (pe), pe and other factors such } \\
\text { as seniority (s) or political connections (pc), or only factors other than pe such as s and pc). }\end{array}$ & -0.450 & 0.666 \\
\hline 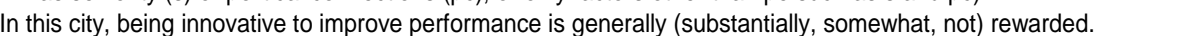 & & \\
\hline
\end{tabular}


Table 5.11 Skewness and Kurtosis Indices of Items - Part 2

\begin{tabular}{|c|c|c|}
\hline ITEMS & $\begin{array}{l}\text { Skewness } \\
\text { Statistic }\end{array}$ & $\begin{array}{l}\text { Kurtosis } \\
\text { Statistic }\end{array}$ \\
\hline $\begin{array}{l}\text { In general, my business favors a strong emphasis : on the marketing of tried and true products or services - } \\
\text { on research \& development, technological leadership, and innovation. }\end{array}$ & 0.046 & -0.865 \\
\hline How many new lines of products or services has your business marketed in the past few years? & -0.121 & -0.899 \\
\hline Changes in product or service lines have been mostly of a minor nature-have usually been quite dramatic. & 0.078 & -1.150 \\
\hline $\begin{array}{l}\text { In dealing with its competitors, my business....typically responds to actions which competitors initiate- } \\
\text { typically initiates actions to which competitors then respond. }\end{array}$ & 0.147 & -1.047 \\
\hline $\begin{array}{l}\text { In dealing with its competitors, my business is (very seldom-very often) the first business to - } \\
\text { introduce new products/services, administrative techniques, operating technologies, etc. }\end{array}$ & 0.200 & -1.007 \\
\hline $\begin{array}{l}\text { In dealing with its competitors, my business typically seeks to avoid competitive clashes, preferring a "live-and-let-I } \\
\text { typically adopts a very competitive, "undo-the competitors" attitude. }\end{array}$ & 0.115 & -0.582 \\
\hline $\begin{array}{l}\text { In general, my business has: a strong preference for low-risk projects (with normal and certain rates of return) - } \\
\text { A strong preference for high risk projects, (with chances of very high returns). }\end{array}$ & 0.099 & -0.996 \\
\hline $\begin{array}{l}\text { In general, my business believes that: owing to the nature of the environment, it is best to explore it gradually via c } \\
\text { slowly increasing behavior - bold, wide ranging acts are necessary to achieve the firm's objectives. }\end{array}$ & -0.057 & -0.812 \\
\hline $\begin{array}{l}\text { When confronted with decision-making situations involving uncertainty, my business...typically adopts a cautious, } \\
\text { 'wait and see' posture in order to minimize the probability of making costly decisions -typically adopts a bold, } \\
\text { aggressive posture in order to maximize the probability of exploiting potential opportunities. }\end{array}$ & -0.108 & -1.206 \\
\hline Competition in our industry is very intense or tough. & -1.238 & 1.572 \\
\hline Anything that one competitor can offer, others can match. & -1.207 & 1.529 \\
\hline Our competitors are relatively weak. & -1.201 & 1.211 \\
\hline $\begin{array}{l}\text { How would you characterize the industry environment within which your business enterprise functions: An environme } \\
\text { demanding little in the way of technological sophistication-Technologically, a very sophisticated and complex er } \\
\text { How much research and development (R \& D) activity takes place within your business enterprise's principal industr } \\
\text { Virtually no R \& D in industry (e.g. bakery, publishing, real estate, etc.)- }\end{array}$ & ry?: & 0.773 \\
\hline $\begin{array}{l}\text { Extremely R \& D-oriented industry (e.g. telecommunications, space, pharmaceuticals, etc. } \\
\text { Business enterprises have different ways to assess their performance. In your case, please let us know if the } \\
\text { following factors are important to you when you assess your business performance: }\end{array}$ & 0.539 & -0.176 \\
\hline development of new products or services & -0.320 & -0.657 \\
\hline product or service quality & -0.019 & -1.807 \\
\hline customer satisfaction & -1.025 & 0.362 \\
\hline improvement in business and/or production processes & -0.458 & -0.774 \\
\hline attraction/recruitment of essential employees/skilled labor/talent & -0.599 & -0.458 \\
\hline retention of essential employees/skilled labor/talent & -0.737 & 1.413 \\
\hline market share & -0.627 & 0.026 \\
\hline growth of market share & -0.522 & -0.275 \\
\hline sales & -1.411 & 2.602 \\
\hline sales growth & -1.012 & 0.659 \\
\hline net income & -0.976 & 0.638 \\
\hline growth of net income & -1.151 & 1.108 \\
\hline return on investment & -1.082 & 0.993 \\
\hline \multicolumn{3}{|l|}{$\begin{array}{l}\text { Now, please let us know your actual ENTERPRISE PERFORMANCE COMPARED TO COMPETITORS or } \\
\text { similar firms in your industry over the last } 3 \text { years in terms of the following }\end{array}$} \\
\hline development of new products or services & 0.198 & -0.548 \\
\hline product or service quality & -0.099 & -0.727 \\
\hline customer satisfaction & -0.212 & -0.961 \\
\hline improvement in business and/or production processes & 0.319 & -0.956 \\
\hline attraction/recruitment of essential employees/skilled labor/talent & 0.131 & -0.793 \\
\hline retention of essential employees/skilled labor/talent & 0.115 & -0.678 \\
\hline market share & 0.048 & -0.148 \\
\hline growth of market share & 0.966 & 0.716 \\
\hline sales & -0.264 & -0.730 \\
\hline sales growth & 0.461 & -0.814 \\
\hline net income & 0.311 & -0.966 \\
\hline growth of net income & 0.121 & -0.361 \\
\hline return on investment & 0.506 & -0.414 \\
\hline
\end{tabular}




\subsection{Descriptive Statistics on the Profile of the Sample Firms}

This section presents the characteristics of the respondents and their respective firms. It presents summaries of the number of MSMEs under the manufacturing and service sectors in each city, the number of firms under the different industries in each sector in each city, the age of MSMEs as business entities and types of business ownership. It also presents summaries of the profile of the owners/managers of these MSMEs in terms of age and educational background.

\subsubsection{Firm Characteristics}

The sample as a whole comprised of businesses that were fairly small in terms of size, measured by the number of full-time employees $(M=5.39, S D=10.360)$. Using the standard business size classification in the Philippines (DTI, 2005), the majority of the sample firms were micro-enterprises, as shown in Table 5.12. Likewise, micro-enterprises from the service sector comprised a greater proportion of the sample firms compared to those coming from the manufacturing sector. This pattern of sample distribution in terms of size and sector was understandable as the lists of registered businesses from the city governments of both cities showed that micro-enterprises comprised the majority of the total firms doing business in the respective city. The lists also showed that manufacturing firms comprised not more than $30 \%$ of the total firms registered to do business in the two cities as of 2007 (Business Bureau, 2007; City Treasurer, 2007).

The sample results showed that there were 107 firms (71 in Tagum and 36 in Panabo) with only one employee, 224 firms (110 in Tagum and 114 in Panabo) with two employees, and 160 firms (104 in Tagum and 56 in Panabo) with three employees. These firms with less than four employees accounted for $55 \%$ of the total sample. 
Table 5.12 Distribution of Firms in terms of Size and Sector

\begin{tabular}{|c|c|c|c|c|c|c|}
\hline \multirow{2}{*}{ Sector } & \multicolumn{2}{|c|}{ Manufacturing } & \multicolumn{2}{|c|}{ Service } & \multicolumn{2}{|c|}{ Total } \\
\hline Firm Size & $f$ & $\%$ & $f$ & $\%$ & $f$ & $\%$ \\
\hline Micro (1-9 employees) & 214 & 26 & 615 & 74 & 829 & 92 \\
\hline Small (10-99) & 53 & 82 & 12 & 18 & 65 & 7 \\
\hline Medium (100-199) & 4 & 67 & 2 & 33 & 6 & 7 \\
\hline Total & 271 & $30 \%$ & 629 & $70 \%$ & 900 & $100 \%$ \\
\hline
\end{tabular}

percentages may differ due to rounding off

Table 5.13 shows the distribution of the number of firms from both the manufacturing and service sectors. The manufacturing sector was dominated by the food processing industry whilst the service sector was dominated by the private services industry such as electrical/appliance repair shops, beauty salons, doctors' clinics, barber shops, accounting/auditing firms, laundry firms, janitorial (cleaning) service providers, and other professional and technical services.

Transportation services included those firms which provide land-based and water transportation services (e.g. jeepney, tricycle, bus, and mini-van (public transport) operators and owners of barge "lantsa" (i.e. small sea vessel) rented out for public transport or for commercial fishing. 
Table 5.13 Distribution of Firms in terms of the Nature of the Industry

\begin{tabular}{|c|c|c|c|}
\hline Sector & Tagum City & Panabo City & Total \\
\hline & $f$ & $f$ & \\
\hline \multicolumn{4}{|l|}{ Manufacturing } \\
\hline food processing (except beverage) & 32 & 58 & 90 \\
\hline beverage production & 12 & 4 & 16 \\
\hline footwear and wearing apparel & 19 & 14 & 33 \\
\hline wood and wood products & 15 & 11 & 26 \\
\hline furniture and fixtures & 25 & 13 & 38 \\
\hline paper and paper products & 1 & 0 & 1 \\
\hline chemical and chemical products & 0 & 1 & 1 \\
\hline electrical machinery & 0 & 1 & 1 \\
\hline basic metals processing & 30 & 6 & 36 \\
\hline non-metallic mineral products & 5 & 0 & 5 \\
\hline pottery & 9 & 1 & 10 \\
\hline candle wax making & 4 & 1 & 5 \\
\hline other manufacturing activities & 9 & 0 & 9 \\
\hline subtotal (\% in both cities) & $161(59 \%)$ & $110(41 \%)$ & $271(100 \%)$ \\
\hline$\%$ in each city/manufacturing sector & $35 \%$ & $25 \%$ & $30 \%$ \\
\hline \multicolumn{4}{|l|}{ Service } \\
\hline private services & 72 & 123 & 195 \\
\hline transportation services & 58 & 44 & 102 \\
\hline communication services & 41 & 47 & 88 \\
\hline storage services & 3 & 0 & 3 \\
\hline finance service & 52 & 18 & 70 \\
\hline ownership of dwellings and real estate & 31 & 21 & 52 \\
\hline other services & 36 & 83 & 119 \\
\hline subtotal (\% in both cities) & $293(47 \%)$ & $336(53 \%)$ & $629(100 \%)$ \\
\hline$\%$ in each city/service sector & $65 \%$ & $75 \%$ & $70 \%$ \\
\hline Grand Total (\% in both cities) & $454(50.4 \%)$ & $446(49.6 \%)$ & $900(100 \%)$ \\
\hline$\%$ in city & $100 \%$ & $100 \%$ & $100 \%$ \\
\hline
\end{tabular}

The average age of the sample firms was 6.33 years $(S D=5.83)$. The youngest and oldest businesses were 1 month (i.e. .08 years) and 40 years respectively. Table 5.14 shows further details on the longevity and nature of ownership of the firms. It could be noted that across the three types of ownership, the majority of the sample businesses were within the one to five years- and six to ten years-categories. 
Table 5.14 Distribution of Firms in terms of Age and Type of Ownership

\begin{tabular}{|c|c|c|c|c|c|c|c|c|c|c|c|c|c|c|}
\hline \multirow{3}{*}{ Age of the Firms } & \multicolumn{4}{|c|}{ Sole Proprietorship } & \multicolumn{4}{|c|}{ Partnership } & \multicolumn{4}{|c|}{ Corporation } & \multicolumn{2}{|c|}{$\begin{array}{l}\text { Grand } \\
\text { Total }\end{array}$} \\
\hline & $\mathrm{M}$ & $\mathrm{s}$ & subtota & & $M$ & $\mathrm{~S}$ & subto & & $M$ & $\mathrm{~s}$ & subtot & & & \\
\hline & $f$ & $f$ & $f$ & $\%$ & $f$ & $f$ & $f$ & $\%$ & $f$ & $f$ & $f$ & $\%$ & $f$ & $\%$ \\
\hline less than 1 year & 7 & 37 & 44 & 6.91 & 1 & 3 & 4 & 4.40 & 1 & 8 & 9 & 5.23 & 57 & 6.33 \\
\hline 1 to 5 years & 73 & 263 & 336 & 52.75 & 13 & 25 & 38 & 41.76 & 26 & 57 & 83 & 48.26 & 457 & 50.78 \\
\hline 6 to 10 years & 53 & 116 & 169 & 26.53 & 11 & 24 & 35 & 38.46 & 27 & 21 & 48 & 27.91 & 252 & 28.00 \\
\hline 11 to 15 years & 12 & 27 & 39 & 6.12 & 4 & 4 & 8 & 8.79 & 14 & 4 & 18 & 10.46 & 65 & 7.22 \\
\hline 16 to 20 years & 7 & 25 & 32 & 5.02 & 4 & 2 & 6 & 6.59 & 9 & 0 & 9 & 5.23 & 47 & 5.22 \\
\hline 21 to 30 years & 4 & 7 & 11 & 1.73 & 0 & 0 & 0 & 0 & 2 & 2 & 4 & 2.33 & 15 & 1.67 \\
\hline 31 years and above & 2 & 4 & 6 & .94 & 0 & 0 & 0 & 0 & 1 & 0 & 1 & .58 & 7 & .78 \\
\hline Grand Total & 158 & 479 & 637 & $100 \%$ & 33 & 58 & 91 & $100 \%$ & 80 & 92 & 172 & $100 \%$ & 900 & $100 \%$ \\
\hline
\end{tabular}

The results of the survey also showed that in both cities, the sample firms tend to have similar characteristics in terms of age of the business and sector classification. Table 5.15 shows the details.

Table 5.15 Distribution of Firms in terms of Age, Sector and City Location

\begin{tabular}{|c|c|c|c|c|c|c|c|c|c|c|}
\hline \multirow{3}{*}{ Age of Business } & \multicolumn{4}{|c|}{ Tagum City } & \multicolumn{4}{|c|}{ Panabo City } & \multirow{2}{*}{\multicolumn{2}{|c|}{$\begin{array}{c}\text { Grand } \\
\text { Total }\end{array}$}} \\
\hline & \multirow{2}{*}{$\begin{array}{c}M \\
f\end{array}$} & \multirow{2}{*}{$\begin{array}{l}S \\
f\end{array}$} & \multicolumn{2}{|c|}{ Total } & \multirow{2}{*}{$\begin{array}{c}M \\
f\end{array}$} & \multirow{2}{*}{$\begin{array}{l}\text { S } \\
f\end{array}$} & \multicolumn{2}{|c|}{ Total } & & \\
\hline & & & $f$ & $\%$ & & & $f$ & $\%$ & $f$ & $\%$ \\
\hline less than 1 year & 2 & 15 & 17 & 3.74 & 7 & 33 & 40 & 8.97 & 57 & 6.33 \\
\hline 1 to 5 years & 65 & 159 & 224 & 49.34 & 47 & 186 & 233 & 52.24 & 457 & 50.78 \\
\hline 6 to 10 years & 65 & 99 & 164 & 36.12 & 26 & 62 & 88 & 19.73 & 252 & .2800 \\
\hline 11 to 15 years & 16 & 8 & 24 & 5.29 & 14 & 27 & 41 & 9.19 & 65 & 7.22 \\
\hline 16 to 20 years & 9 & 11 & 20 & 4.41 & 11 & 16 & 27 & 6.05 & 47 & 5.22 \\
\hline 21 to 30 years & 2 & 1 & 3 & .66 & 4 & 8 & 12 & 2.69 & 15 & 1.67 \\
\hline 31 years and above & 2 & 0 & 2 & .44 & 1 & 4 & 5 & 1.12 & 7 & .78 \\
\hline Total & 161 & 293 & 454 & $100 \%$ & 110 & 336 & 446 & $100 \%$ & 900 & $100 \%$ \\
\hline & & & & & & & & & & \\
\hline
\end{tabular}

In both cities, the micro-enterprises comprised the majority of sample firms across the three types of ownership. The medium-sized firms in both cities turned out to be corporation-type of business as shown in Table 5.16. 
Table 5.16 Distribution of Firms in terms of Age, Ownership, and City Location

\begin{tabular}{|c|c|c|c|c|c|c|c|c|c|}
\hline \multirow{3}{*}{$\begin{array}{c}\text { Business } \\
\text { Size }\end{array}$} & \multicolumn{4}{|c|}{ Tagum City } & \multicolumn{4}{|c|}{ Panabo City } & \multirow{2}{*}{$\begin{array}{c}\text { Grand } \\
\text { Total }\end{array}$} \\
\hline & Sole & Partnership & \multirow[t]{2}{*}{ Corporation } & \multirow[t]{2}{*}{ Total } & Sole & \multicolumn{2}{|c|}{ Partnership Corporation } & \multirow[t]{2}{*}{ Total } & \\
\hline & \multicolumn{2}{|l|}{ Proprietorship } & & & Proprietorship & & & & \\
\hline Micro & 290 & 48 & 82 & 420 & 336 & 37 & 36 & 409 & 829 \\
\hline Small & 8 & 2 & 20 & 30 & 3 & 4 & 28 & 35 & 65 \\
\hline Medium & 0 & 0 & 4 & 4 & 0 & 0 & 2 & 2 & 6 \\
\hline$T_{0}$ & 298 & 50 & 106 & 454 & 339 & 41 & 66 & 446 & 900 \\
\hline I otal & $65.64 \%$ & $11.01 \%$ & $23.35 \%$ & $100 \%$ & $76.01 \%$ & $9.19 \%$ & $14.80 \%$ & $100 \%$ & \\
\hline
\end{tabular}

\subsubsection{Respondent Characteristics}

The respondents tended to be very diverse in terms of age $(M=40.39, S D=9.471)$ with reported ages in the range of 19 years to 74 years. There was relatively equal representation from both sexes $($ male $=489$, female $=411$ ) as shown in Table 5.17. The majority of the respondents fell within the 31 to 40 years and 41 to 50 years old categories. Male and female respondents tend to be more or less evenly distributed across the different age ranges.

Table 5.17 Distribution of Respondents in terms of Age and Gender

\begin{tabular}{|c|c|c|c|c|c|c|c|c|c|c|}
\hline & \multicolumn{4}{|c|}{ Tagum City } & \multicolumn{4}{|c|}{ Panabo City } & \multirow{2}{*}{\multicolumn{2}{|c|}{$\begin{array}{r}\text { Grand } \\
\text { Total }\end{array}$}} \\
\hline \multirow[t]{2}{*}{ Age of the Respondents } & Male & Female & \multicolumn{2}{|c|}{ Total } & Male & Female & \multicolumn{2}{|c|}{ Total } & & \\
\hline & $f$ & $f$ & $f$ & $\%$ & $f$ & $f$ & $f$ & $\%$ & $f$ & $\%$ \\
\hline $19-30$ years & 46 & 39 & 85 & 18.72 & 26 & 53 & 79 & 17.71 & 164 & 18.22 \\
\hline $31-40$ years & 109 & 75 & 184 & 40.53 & 62 & 65 & 127 & 28.48 & 311 & 34.56 \\
\hline $41-50$ years & 96 & 50 & 146 & 32.16 & 89 & 67 & 156 & 34.98 & 302 & 33.56 \\
\hline $51-60$ years & 22 & 13 & 35 & 7.71 & 29 & 44 & 73 & 16.37 & 108 & 12.00 \\
\hline 61 years and up & 4 & 0 & 4 & .88 & 6 & 5 & 11 & 2.47 & 15 & 1.67 \\
\hline Total & 277 & 177 & 454 & $100 \%$ & 212 & 234 & 446 & $100 \%$ & 900 & $100 \%$ \\
\hline
\end{tabular}

The results of the survey further showed that the majority of the respondents - both managers and owner-managers were relatively well-educated, having completed four-year college degrees as shown in Table 5.18. It was noted in the survey results that there were 91 respondents who ticked the box "owner" (from the triple choices 
of "owner", "manager", "owner-manager" in the questionnaire). It was logical to integrate this category to the other category called "owner-manager" for two reasons. First, those who ticked "owners" were surveyed on-site whilst they were on duty "managing" the day's business affairs. Second, considering that many of those who ticked "owners" were micro-enterprises, it was doubtful that they were not engaged in the actual management of the affairs of the enterprise. This could be considered as an unforeseen minor flaw (as the pilot test did not uncover it) in the questionnaire as the "owner" category was presented first amongst the choices in the questionnaire. Hence, for the purposes of the analysis, there were only two categories of respondents: manager and owner/manager.

Table 5.18 Distribution of Respondents in terms of Educational Qualifications

\begin{tabular}{|c|c|c|c|c|c|c|c|c|c|c|}
\hline \multirow{3}{*}{ Highest Educational Qualifications } & \multicolumn{4}{|c|}{ Tagum City } & \multicolumn{4}{|c|}{ Panabo City } & \multirow{2}{*}{\multicolumn{2}{|c|}{$\begin{array}{c}\text { Grand } \\
\text { Total }\end{array}$}} \\
\hline & \multirow[t]{2}{*}{ Manager } & \multirow{2}{*}{$\begin{array}{c}\text { Owner/ } \\
\text { Manager }\end{array}$} & \multicolumn{2}{|c|}{ subtotal } & \multicolumn{2}{|c|}{ Manager Owner/ } & \multicolumn{2}{|c|}{ subtotal } & & \\
\hline & & & $f$ & $\%$ & & Manager & $f$ & $\%$ & $f$ & $\%$ \\
\hline attended a few elementary years & 1 & 0 & 1 & .22 & 0 & 3 & 3 & .67 & 4 & .44 \\
\hline completed elementary years & 0 & 2 & 2 & .44 & 0 & 8 & 8 & 1.79 & 10 & 1.11 \\
\hline attended a few years in high school & 2 & 11 & 13 & 2.86 & 2 & 6 & 8 & 1.79 & 21 & 2.33 \\
\hline completed high school & 15 & 31 & 46 & 10.13 & 12 & 40 & 52 & 11.66 & 98 & 10.89 \\
\hline attended a few years in college & 27 & 59 & 86 & 18.94 & 19 & 57 & 76 & 17.04 & 162 & 18.00 \\
\hline completed college degree & 113 & 170 & 283 & 62.33 & 109 & 165 & 274 & 61.43 & 557 & 61.89 \\
\hline postgraduate degree (master's, $\mathrm{PhD}$ ) & 17 & 6 & 23 & 5.07 & 9 & 16 & 25 & 5.61 & 48 & 5.33 \\
\hline Total & 175 & 279 & 454 & $100 \%$ & 151 & 295 & 446 & $100 \%$ & 900 & $100 \%$ \\
\hline
\end{tabular}

The sample firms were being managed and/or owned/managed by individuals within the 31-50 years old range with a gender distribution being more or less evenly spread across the three types of ownership. Details are shown in Table 5.19.

Table 5.19 Distribution of Respondents in terms of Age, Gender, and Ownership

\begin{tabular}{|c|c|c|r|r|r|r|r|r|r|r|}
\hline & \multicolumn{4}{|c|}{ Tagum City } & \multicolumn{4}{c|}{ Panabo City } & \multicolumn{2}{c|}{ Grand } \\
\hline \multirow{2}{*}{ Age of the Respondents } & Male & Female & \multicolumn{2}{|c|}{ Total } & Male & Female & \multicolumn{2}{|c|}{ Total } & \multicolumn{2}{c|}{ Total } \\
\hline & $f$ & $f$ & $f$ & $\%$ & $f$ & $f$ & $f$ & $\%$ & \multicolumn{1}{c|}{$f$} & $\%$ \\
\hline $19-30$ years & 46 & 39 & 85 & 18.72 & 26 & 53 & 79 & 17.71 & 164 & 18.22 \\
\hline $31-40$ years & 109 & 75 & 184 & 40.53 & 62 & 65 & 127 & 28.48 & 311 & 34.56 \\
\hline $41-50$ years & 96 & 50 & 146 & 32.16 & 89 & 67 & 156 & 34.98 & 302 & 33.56 \\
\hline $51-60$ years & 22 & 13 & 35 & 7.71 & 29 & 44 & 73 & 16.37 & 108 & 12.00 \\
\hline 61 years and up & 4 & 0 & 4 & .88 & 6 & 5 & 11 & 2.47 & 15 & 1.67 \\
\hline Total & 277 & 177 & 454 & $100 \%$ & 212 & 234 & 446 & $100 \%$ & 900 & $100 \%$ \\
\hline
\end{tabular}




\subsection{Reliability and Dimensionality}

This section presents the statistical procedures used in determining the validity and uni- or multi-dimensionality of the constructs that were used in subsequent analysis to test the hypotheses. Major procedures were exploratory factor analysis and confirmatory factor analysis. Reliability testing was also performed with an emphasis on internal consistency of the responses on the items comprising each construct. The goal was to ensure construct validity as well as to establish the dimensionality of the variables used in the study.

\subsubsection{EFA on Formal Institution Variables}

Exploratory factor analysis (EFA) was performed in order to define the underlying structure and dimensionality of the constructs under investigation (Cavana et al., 2001; Hair et al., 2006). The five constructs that were categorised under formal institutions were composed of items culled form various previous studies. Items from different sources were combined to conceptualise a construct. Furthermore, these previous studies presented no evidence on the validity or reliability of the constructs they utilised. It was logical therefore to perform factor analysis in an exploratory manner in pursuit of data reduction and/or data summarisation such that the constructs to be used in subsequent analysis were composed of purified items or measures (Hair et al., 2006). Moreover, factor analysis is performed to understand the latent or unobserved variables (e.g. the five types of formal institutions) that account for relationships among the measured variables (e.g. the items measuring the five formal insitutions) (Costello and Osborne 2005).

A separate EFA was performed on each of the five constructs rather than loading all the items in one analysis. This approach was justified because the current goal of performing EFA was to check the uni-dimensionality of each of the five formal institutions. Unidimensionality refers to having a group of items measuring a single, underlying construct (Brown, 2006). Hair et al (2006) argue that the critical assumption of EFA is the conceptual character and composition of each construct and/or items entered into the analysis. Loading a set of obviously unrelated items of 
any sort will still create factors (representing a construct) sans theoretical nor conceptual substance (Field, 2005).

Furthermore, Kim and Mueller (1978) explained that knowing the factorial structure in advance helps select the items to be included and yields the best analysis of constructs. The previous chapters presented the conceptual and empirical background of the five constructs representing the formal institutions of a city. It was therefore logical to perform separate factor analysis for each of the five constructs to 'purify' each of them. This approach satisfied the goal of examining if the items under each construct really measure one factor (i.e. uni-dimensionality).

Subsequently, reliability analysis was performed on each of the 'purified' formal institution constructs. The goal was to determine the internal consistency (commonly expressed through Cronbach $\alpha$ ) of the scores on the items under each construct. Reliability of a measure indicates the stability and consistency with which a set of items measure a concept and helps to assess the goodness of the measure (Cavana et al., 2001). The major concern in the current study was to establish the internal consistency or the homogeneity of the scores on the items in the measure that tapped the construct such that the items "hang together", indicating that the respondents attached the same overall meaning to each of the items (Cavana et al., 2001). More specifically, an inter-item consistency reliability using Cronbach's alpha $(\alpha)$ was applied in this study.

Extraction. The method of extraction was principal axis factoring (PAF) - a method which seeks the least number of factors that account for the common variance (correlation) of a set of variables thereby making this method a preferred choice for detecting data structure or causal modelling (Brown, 2006; Widaman, 1993). PAF is highly recommended when the data are not ideally normally distributed in contrast to maximum likelihood factoring which is the preferred method of extraction assuming multivariate normality (Costello \& Osborne, 2005; Widaman, 1993). Both PAF and maximum likelihood factoring use the linear combination of variables to form common factors (Fabrigar et al, 1999; Widaman, 1993). 
The slightly negatively skewed distribution of the current data, (although considered as within normal limits) justified the use of principal axis factoring as opposed to the use of maximum likelihood method which is the method of choice for data with normal distribution (Brown, 2006; Thomson, 2004). Principal component analysis, despite its popularity (i.e. because it is the default method in programs like SPSS), was not used in the current study, as it is not a factor analytic method in the first place (Costello \& Osborne, 2005; Field, 2005; Hair et al., 2006).

Factor Selection. Two major criteria were used to determine the number of factors to be retained for subsequent analyses: the scree test (Cattell, 1966) and the Kaiser's criterion (Kaiser, 1960). The scree test requires that eigenvalues or the amount of variance accounted for by a factor be plotted in a graph (i.e. scree plot) with the eigenvalue in the $\mathrm{Y}$ axis and the associated factor in the $\mathrm{X}$ axis (Cattell, 1966). The cut off point for selecting factors should be at the point of inflexion of the curve (Field, 2005). Kaiser's criterion, on the other hand, recommends retaining all factors with eigenvalues greater than 1 (Hair et al., 2006). Both criteria have been found to be fairly reliable for factor selection given the current sample size of 900 (Field, 2005). Furthermore, the value of the total percent of variance explained was also checked given the criterion that the higher the total variance accounted for, the better the factor model would represent the data (Field, 2005).

Rotation. Rotation is a process in exploratory factor analysis that generates a simple and clear data structure (Thomson, 2004). Oblique rotation was used based on the argument that the items under each variable were shown to be conceptually/theoretically correlated as shown in the previous review of the literature. Costello and Osborne (2005, p. 3), Brown (2006, p. 32), and Netemeyer et al (2003, p. 125) argued that "oblique rotation should theoretically render a more accurate, more meaningful and perhaps more reproducible solution" in the case of correlated items and factors. Promax with the SPSS default kappa value of 4 was used as the specific method of oblique rotation although there is no widely preferred oblique rotation method (Costello \& Osborne, 2005). Thomson (2004), however, considers Promax to be 'almost always a good choice' (p.43) when oblique rotation is used. Promax has been found to be a faster procedure designed for large data sets such as the current study (Field, 2005). Costello and Osborne (2005) further 
conclude that they find no apparent reason to change the SPSS default value of Kappa which is 4.

Sample Size. The current sample size of 900 was considered sufficient to warrant the use of exploratory factor analysis (Hair et al., 2006; Tabachnick \& Fidell, 2005). Nonetheless, the Kaiser-Meyer-Olkin measure of sampling adequacy (KMO) was also examined in the EFA process (Kaiser, 1970). A KMO value greater than .50 is considered acceptable (Kaiser, 1974) and values above .80 are considered meritorious (Hair et al., 2006).

Intercorrelation. All the items comprising each variable were examined in terms of the significance of their correlations to one another. By visual inspection, the correlation coefficients must be greater than .30 but not more than .90 to warrant the use of EFA (Field, 2005; Hair et al., 2006). Moreover, the Bartlett's test of sphericity was used to detect significant correlations in order to justify the use of EFA.

Factor Loadings. Factor loadings indicate the substantive relevance of a given item to a factor (Brown, 2006). Only items with factor loadings of .40 and above were accepted to form part of a factor although factor loadings of .50 and above are generally considered necessary for practical significance (Field, 2005; Hair et al., 2006; Tabachnick \& Fidell, 2005).

Communalities. Communality is the estimate of an item's shared or common variance among the items that constitute a factor (Hair et al., 2006). It may be interpreted as the reliability of that specific item (Brown, 2006; Heck, 1998). An item with a communality value of at least .50 was retained as it demonstrated that at least half of the variance in the item has been taken into account in identifying the construct (Hair et al., 2006; Heck, 1998). Closely related to communalities is the percentage of variance explained by the extracted factor. Hair et al (2006) recommends that a satisfactory factor solution should account for at least $60 \%$ of the total variance.

Table 5.20 shows the result of EFA on each of the five formal institutions. For each of the five rounds of EFA, only one factor was extracted suggesting that each of the 
five formal institution variables was uni-dimensional. All of the items under each of the five variables loaded highly $(>.40)$ on each factor and were therefore retained to constitute the factors. The communalities were all above the threshold of .50 and the percentages of the variances were way above the threshold of $60 \%$ indicating that the factors explained more than $60 \%$ of the total variance of the items that constituted each factor.

The results further suggested that sampling adequacy as well as intercorrelation were not an issue as evidence by KMO values all above .60 and significant values on the Bartlett's test of sphericity. All the five factors had eigenvalues greater than one accounting for majority of the total variance. The values of the Cronbach alpha were all greater than the generally accepted lower limit of .70 (Hair et al., 2006; Tabachnick \& Fidell, 2005). Further analysis revealed that the values of the Cronbach alpha for the five factors would suffer reduction in value if an item under each factor was deleted. An examination of the inter-item correlations also revealed that the correlation coefficients met the threshold of greater than .30 but less than .90 .

To provide a contrasting view on the results, EFA was also conducted using maximum likelihood, which according to Brown (2006) is a commonly used estimation method in factor analysis. The results were relatively the same as that of the principal axis factoring.

Overall, the five formal institutional variables exhibited an acceptable degree of unidimensionality, internal consistency (i.e. reliability) and construct validity. 
Table 5.20 Factor Analysis of the Formal Institutions Variables

\begin{tabular}{|c|c|c|c|c|c|c|c|c|}
\hline Items & $\begin{array}{c}\text { Factor } \\
\text { Loadings }\end{array}$ & Communality & Iterations & KMO & $\begin{array}{l}\text { Bartlett's test } \\
\text { of sphericity }\end{array}$ & Eigenvalue & $\begin{array}{c}\% \text { of } \\
\text { variance }\end{array}$ & $\begin{array}{c}\text { Cronbach } \\
\alpha\end{array}$ \\
\hline Rule of Law & $1^{*}$ & & 5 & 0.886 & $\chi^{2} \quad 3631.26$ & 4.1600 & 69.335 & 0.902 \\
\hline The occurrence of crime does not impose costs on my business. & 0.9113 & 0.8270 & & & $d f$ & & & \\
\hline The legal framework to challenge the legality of government actions is efficient & 0.8975 & 0.8130 & & & .000 & & & \\
\hline The judicial system is fair and impartial. & 0.7620 & 0.6580 & & & & & & \\
\hline The legal system is effective in enforcing commercial contracts. & 0.7611 & 0.6570 & & & & & & \\
\hline People are willing to accept legal means to settle disputes rather than depend on physical force. & 0.7379 & 0.6300 & & & & & & \\
\hline Court rulings and/or arbitration awards are complied with by the people involved. & 0.6920 & 0.5750 & & & & & & \\
\hline $\begin{array}{l}\text { Protection of Property Rights } \\
\text { Violations of property rights are prosecuted accordingly. }\end{array}$ & $\begin{array}{c}1^{*} \\
09102\end{array}$ & 0.7990 & 8 & 0.690 & $\begin{array}{lr}\chi^{2} & 1703.36 \\
d f & 6\end{array}$ & 2.5600 & 63.989 & 0.798 \\
\hline Private property is adequately protected by law. & 0.8935 & 0.7880 & & & .000 & & & \\
\hline The city government enforces laws that protect private property. & 0.5561 & 0.5080 & & & & & & \\
\hline Intellectual property rights (like copyrights or trademarks) are adequately protected. & 0.5200 & 0.5010 & & & & & & \\
\hline Government Policies & $1^{*}$ & & 5 & 0.903 & $\chi^{2} \quad 5716.55$ & 4.3380 & 86.753 & 0.958 \\
\hline Taxation laws and policies including incentives and exemptions are good enough for my business. & 0.9685 & 0.9310 & & & $d f$ & & & \\
\hline City government decisions are effectively implemented. & 0.9684 & 0.9310 & & & .000 & & & \\
\hline City government economic policies adapt quickly to changes in the economy. & 0.9216 & 0.8790 & & & & & & \\
\hline The policy direction of the city government is consistent. & 0.8609 & 0.8080 & & & & & & \\
\hline Laws and regulations imposed by the city government are conducive for business. & 0.8463 & 0.7900 & & & & & & \\
\hline Regulatory Quality & $1^{*}$ & & 3 & 0.944 & $\begin{array}{ll}2 & 9563.83 \\
\end{array}$ & 6.6730 & 83.41 & 0.970 \\
\hline Information about laws and regulations is easy to obtain. & 0.9526 & 0.9080 & & & & & & \\
\hline Business regulations are less of a burden for business. & 0.9476 & 0.9010 & & & .000 & & & \\
\hline Procedures in city government transactions are consistently enforced. & 0.9256 & 0.8700 & & & & & & \\
\hline The number of city government offices to deal with is reasonable. & 0.9087 & 0.8470 & & & & & & \\
\hline The number of permits required is manageable. & 0.9017 & 0.8370 & & & & & & \\
\hline The time required to register a business with the city government is reasonable. & 0.8864 & 0.8160 & & & & & & \\
\hline Interpretations of the laws and regulations are consistent and predictable. & 0.8598 & 0.7790 & & & & & & \\
\hline The number of city government inspections required before opening a business is reasonable. & 0.8152 & 0.7170 & & & & & & \\
\hline Government Assistance & $1^{*}$ & & 6 & 0.865 & $\chi^{2} \quad 2192.17$ & 3.3530 & 67.065 & 0.876 \\
\hline The city government sponsors organisations that help new businesses develop. & 0.8441 & 0.7510 & & & $d f$ & & & \\
\hline The city government has special support available for individuals who want to start a new business. & 0.8081 & 0.7160 & & & sig & & & \\
\hline City government offices assist individuals in starting their own business. & 0.7537 & 0.6580 & & & & & & \\
\hline Even after failing in an earlier business, the city gov't. assists businessmen/women in starting again. & 0.7339 & 0.6360 & & & & & & \\
\hline The city government sets aside government contracts for new and small businesses. & 0.6933 & 0.6580 & & & & & & \\
\hline
\end{tabular}




\subsubsection{EFA on Organisational Performance}

The same process of EFA was performed on the 13 items of organisational performance but this time, all of the 13 items were loaded at the same time despite the two categories (i.e. operational and financial performance) that have been identified a priori. EFA was used because the 13 items were coming from various sources and no previous validity nor reliability estimates have been done consistent with the way the 13 items have been categorised into two. In effect, the two categories identified a priori were preliminary typology of organisational performance and their validity remained to be investigated using the empirical data at hand. The main concern here was to identify the underlying factors given the 13 items describing organisational performance.

The values of the 13 items used in this analysis were the weighted scores generated from the importance scores multiplied by the actual performance scores across the 13 performance. It was noted earlier that respondents were asked to rate the level of importance (in a scale of 1-5) they attached to each of the items. Subsequently, they were also asked to assess the firm's performance (in a scale of 1 to 5) on the same 13 items relative to competitors during the past 3 years. These two sets of values (i.e. importance and actual performance) were used to generate the overall weighted performance scores across the 13 performance indicators. Details of these scores are provided in Table 5.21. The use of weighted performance scores was consistent with previous studies (Covin \& Slevin, 1989; Datta, 1991; Naman \& Slevin, 1993; O'Regan \& Ghobadian, 2004a; Westhead \& Howorth, 2006; Yoo, 2001). These studies advocated the use of performance indices whereby a performance indicator is measured by the degree of importance attached to it and the degree of performance relative to some benchmarks (e.g. personal satisfaction, compared to competitors, or trend over the last three to five years).

The results of the EFA on the 13 indicators of organisational performance using the weighted performance scores are shown in Table 5.22. 
Table 5.21 Weighted Performance Scores

\begin{tabular}{|c|c|c|c|c|c|}
\hline Performance Indicators & $\begin{array}{l}\text { Perceived } \\
\text { Importance* }\end{array}$ & $x$ & $\begin{array}{c}\text { Perceived } \\
\text { Performance }^{\star \star}\end{array}$ & $=$ & $\begin{array}{c}\text { Weighted } \\
\text { Performance } \\
\text { Score }\end{array}$ \\
\hline development of new products or services & 4.34 & $\mathrm{x}$ & 3.54 & $=$ & 15.36 \\
\hline product or service quality & 4.49 & $x$ & 3.7 & $=$ & 16.61 \\
\hline customer satisfaction & 4.52 & $x$ & 3.86 & $=$ & 17.45 \\
\hline $\begin{array}{l}\text { improvement in business and/or } \\
\text { production processes }\end{array}$ & 3.96 & $x$ & 3.75 & $=$ & 14.85 \\
\hline $\begin{array}{l}\text { attraction/recruitment of essential } \\
\text { employees/skilled labour/talent }\end{array}$ & 4.14 & $x$ & 3.62 & $=$ & 14.99 \\
\hline $\begin{array}{l}\text { retention of essential employees/ } \\
\text { skilled labour/talent }\end{array}$ & 4.28 & $x$ & 3.6 & $=$ & 15.41 \\
\hline market share & 3.49 & $x$ & 3.33 & $=$ & 11.62 \\
\hline growth of market share & 3.48 & $x$ & 3.32 & $=$ & 11.55 \\
\hline sales & 4.52 & $x$ & 3.83 & $=$ & 17.31 \\
\hline sales growth & 4.46 & $x$ & 3.67 & $=$ & 16.37 \\
\hline net income & 4.17 & $x$ & 3.76 & $=$ & 15.68 \\
\hline growth of net income & 4.14 & $x$ & 3.54 & $=$ & 14.66 \\
\hline return on investment & 4.07 & $x$ & 3.59 & $=$ & 14.61 \\
\hline
\end{tabular}

*scale of 1 (very unimportant) to 5 (very important)

${ }^{* *}$ scale of 1 (much worse than competitors) to 5 (much better than competitors) 
Table 5.22 Factor Analysis of the Organisational Performance Variables

\begin{tabular}{|c|c|c|c|c|c|c|}
\hline \multirow{3}{*}{ ITEMS } & \multicolumn{6}{|c|}{ Factors } \\
\hline & \multicolumn{2}{|c|}{$\begin{array}{c}1 \\
\text { Financial Performance }\end{array}$} & \multicolumn{2}{|c|}{$\begin{array}{c}2 \\
\text { Strategic Performance }\end{array}$} & \multicolumn{2}{|c|}{$\begin{array}{c}3 \\
\text { Product/Service Performance }\end{array}$} \\
\hline & Loadings & Communality & Loadings & Communality & Loadings & Communality \\
\hline growth of net income & 0.9124 & 0.6860 & & & & \\
\hline ROI & 0.7641 & 0.6880 & & & & \\
\hline net income & 0.7512 & 0.6860 & & & & \\
\hline sales growth & 0.5980 & 0.6290 & & & & \\
\hline Cronbach $\alpha$ & 0.8960 & & & & & \\
\hline attraction of essential labour/employees & & & 0.9408 & 0.8610 & & \\
\hline retention of essential labour/employees & & & 0.7339 & 0.7350 & & \\
\hline improvement in business/production processes & & & 0.5715 & 0.6440 & & \\
\hline growth of market share & & & 0.8471 & 0.5510 & & \\
\hline market share & & & 0.4638 & 0.5100 & & \\
\hline Cronbach $\alpha$ & & & 0.8810 & & & \\
\hline product/service quality & & & & & 0.8124 & 0.7140 \\
\hline sales & & & & & 0.8123 & 0.7620 \\
\hline customer satisfaction & & & & & 0.7490 & 0.7000 \\
\hline development of new products/service & & & & & 0.5573 & 0.5910 \\
\hline Cronbach $\alpha$ & & & & & 0.8340 & \\
\hline Eigenvalue & 6.6030 & & 1.721 & & 1.1110 & \\
\hline$\%$ of Variance Explained & 50.7910 & & 13.238 & & 8.5480 & \\
\hline Cumulative \% & 50.7910 & & 64.029 & & 72.5760 & \\
\hline Iterations & & & 7 & & & \\
\hline $\mathrm{KMO}$ & & & 0.8710 & & & \\
\hline Bartlett's Test of Sphericity & & $\chi^{2}=$ & 8378.108 & & & \\
\hline & & $\begin{array}{r}d f= \\
\text { sig. }=\end{array}$ & $\begin{array}{c}78 \\
.000\end{array}$ & & & \\
\hline
\end{tabular}


Results of the exploratory factor analysis showed that there were three underlying factors amongst the 13 items instead of the two factors as identified a priori. All of the items were retained as each item loaded highly on a specific factor with the exception of growth of market share which cross-loaded on factor 1 with a value of .449 .

The first factor described the financial aspect of organisational performance. This factor was subsequently labelled 'Financial Performance'. The second factor consisted of items which did not lend themselves to immediate financial quantification. These items also tend to consider the long-term viability of the business, hence naming the factor as 'Strategic Performance'. The last factor consisted of items which tend to focus on how the firm's products or services perform in terms of the sales and customer satisfaction they generate given the quality of the products/services and the improvements/developments that took, or are taking, place, hence naming the factor 'Product/Service Performance'.

Previous studies tend to support this method of factorial nomenclature of organisational performance. The financial performance and product/service performance identified in the analysis were akin to short term performance (Haber \& Reichel, 2005), whilst strategic performance displayed similarities with long term performance identified in a previous study (Haber \& Reichel, 2005). The product/ service performance construct was also consistent with the work of Hughes and Morgan (2007). The labelling of the three factors also fitted in the strategic performance framework based on the work of Sureshchandar and Leisten (2005). Furthermore, based on the work of Demirbag et al (2006), financial performance fitted the description of this aspect of organisational performance whilst strategic and product/service performance fitted the description of non-financial performance.

The item that cross-loaded (i.e. growth of market share) into factor 1 and 2 was retained under factor 2 as the overall Cronbach alpha of factor 1 (with growth of market share) was only .888 but would increase to .896 without it. Inversely, the overall Cronbach alpha for factor 2 (with growth of market share) was .881 but would decrease to .864 without it. Moreover, this item enhanced the conceptual value of factor 2 having shown greater similarities in its characterisation with the rest of 
the items compared to those items under factor 1. Considering the exploratory approach of the factor analysis performed on this specific set of data, the potential contribution of this particular item to enrich the overall face/content validity of the factor or construct closely associated with the item prevented the outright exclusion of that item (Netemeyer et al., 2003 p. 125). This item suited well the long-term view of the factor 'strategic performance' whereby growth is a major element (Sureshchandar \& Lesiten, 2005).

The values of the KMO, Bartlett's test of sphericity, eigenvalues, percentage of variance explained by each factor, communality and inter-item consistency all supported the acceptability of the three factors for subsequent analysis. The three factors would suffer reduction in their Cronbach alphas if any one item is deleted from their respective factors. If three separate exploratory factor analyses were performed for each of the 3 factors, the percentages of variance would be $76.24 \%$, $68.04 \%$, and $67.28 \%$ for factors 1,2 , and 3 respectively. These values were above the minimum threshold of $60 \%$ (Hair et al., 2006).

Furthermore, visual examination of the correlation coefficient of the 13 items showed that most of the coefficients did not go below the threshold of .30 nor exceed 90. The data suggested that organisational performance was a multi-dimensional concept as discussed in the extant literature (Venkatraman \& Ramanujam, 1986; Wiklund \& Sheperd, 2005).

\subsubsection{Confirmatory Factor Analysis of Informal Institutions}

Confirmatory factor analysis (CFA) is a tool that seeks to determine if the number of factors and the loadings of measured indicators or variables on the factors conform to what is expected on the basis of pre-established theory (Mueller, 1996; Thomson, 2004). The indicators or items are pre-selected or assumed to load to a specific factor or construct based on prior strong theoretical, conceptual or empirical evidence (Brown, 2006; Hair et al., 2006).

The psychometric properties such as validity and reliability of the seven variables under informal institutions had been examined in previous studies (Gelfand et al., 
2004; House et al., 2004; Javidan, House, Dorfman, Hanges \& de Luque, 2006). However, the current context within which the seven variables were examined may differ from that of those previous studies. Hence, it was critical to perform factor analysis in a confirmatory fashion to ascertain that the data gathered along these seven variables were psychometrically comparable with the previous studies. In doing so, four specific stages of CFA were performed as outlined below.

Stage 1. Defining Individual Constructs. The seven variables of informal institutions were adopted from a previously-validated research instrument. The theoretical and conceptual definitions of the variables were well-established (Hair et al., 2006; House et al., 2004).

Stage 2. Developing the Overall Measurement Model. Items were assigned to specific variables (or factors) to form seven unidimensional constructs. Each variable or factor met the minimum criterion of having three items (Hair et al., 2006). It must also be noted that it was assumed that the factors or variables were reflective rather than formative functions of the items. Reflective measurement theory explains that latent (unobservable) constructs caused the measured items and that the error results in an inability to fully explain these measures (Hair et al., 2006).

Stage 3. Designing a Study to Produce Empirical Results. The seven factors were measured using Likert type of scale which is generally accepted as an interval type of measurement (Krosnick, 1999; Tabachnick \& Fidell, 2005). The sample size of 900 is considered adequate for CFA purposes (Thomson, 2004). In specifying the model, a value of 1 is assigned to each of the latent factors as well as to construct variances thereby allowing the generation of a correlation matrix or the relationships between factors or constructs (Hair et al., 2006). Likewise, errors in the specification of the measurement model were checked when identification problems were indicated (Hair et al., 2006).

The statistical program called EQS (Bentler, 1995) was used in this analysis. The researcher's prior familiarity with this program with its user-friendly graphical user interface (GUI) and the capability to deal with various types of data distributions (i.e. added ROBUST function for data with non-normal distribution) was the major 
reason for its use in this study. However, a review on software (used for CFA) available in the market revealed the no software had significant advantage over another (Kline, 1998).

Stage 4. Assessing Measurement Model Validity. This stage will examine the goodness-of-fit of the model to the data describing the seven variables. There are several areas of concern here. The path estimate (i.e. loading) linking a factor to an indicator should be at least .5, and low and insignificant loadings warrant the possibility of excluding such item/s (Brown, 2006). Standardised residuals also need to be examined such that values greater than 4.0 suggest a significant degree of error worthy of closer investigation (Hair et al., 2006).

There are a several goodness-of-fit indices that can be used to gauge whether there is an overall fit between the observed sample or data and that of the model. These indices serve as basis for accepting, rejecting or modifying the model (Byrne, 2006). The recommended technique is to use multiple indices of different types (Byrne, 2006). The commonly used indices are shown in Table 5.23 along with the acceptable values to indicate goodnesss-of-fit between the data and the model. Oftentimes, the model chi square $(\chi 2)$, CFI, SRMR and RMSEA should give adequate indications on the overall fit of the model (Hair et al., 2006). 
Table 5.23 Goodnes of Fit Indices used in Confirmatory Factor Analysis

\begin{tabular}{|c|c|c|}
\hline Goodness of Fit Indices & Description & Acceptable Values \\
\hline Model Chi-square $\left(x^{2}\right)$ statistic & $\begin{array}{l}\text { shows if there is a significant difference } \\
\text { between the actual data and the model }\end{array}$ & insignificant $p$-values \\
\hline Comparative Fit Index (CFI) & $\begin{array}{l}\text { compares the existing model fit (i.e. between } \\
\text { actual data and model) with a null model }\end{array}$ & at least .90 \\
\hline $\begin{array}{l}\text { Root Mean Square Error of } \\
\text { Approximation (RMSEA) }\end{array}$ & $\begin{array}{l}\text { used to counter check the } x 2 \text { result which } \\
\text { tends to reject models with large samples or } \\
\text { large number of observed variables }\end{array}$ & below .10 \\
\hline $\begin{array}{l}\text { Standardised Root Mean } \\
\text { Square Residual (SRMR) }\end{array}$ & $\begin{array}{l}\text { shows the average difference between the } \\
\text { predicted and observed variances and } \\
\text { covariances in the model, based on } \\
\text { standardised residuals }\end{array}$ & .08 or less \\
\hline Goodness of Fit Index (GFI) & $\begin{array}{l}\text { shows the percent of observed covariances } \\
\text { explained by the covariances implied in the } \\
\text { model }\end{array}$ & at least .90 \\
\hline $\begin{array}{l}\text { Adjusted Goodness of Fit } \\
\text { Index (AGFI) }\end{array}$ & $\begin{array}{l}\text { adjusts the GFI to account for model } \\
\text { complexity }\end{array}$ & at least .90 \\
\hline Normed Fit Index (NFI) & $\begin{array}{l}\text { reflects the proportion by which the } \\
\text { researcher's model improves fit compared to } \\
\text { the null model }\end{array}$ & at least .90 \\
\hline Non-Normed Fit Index (NNFI) & $\begin{array}{l}\text { compares the specified theoretical model and } \\
\text { the null model taking into account model } \\
\text { complexity }\end{array}$ & at least .90 \\
\hline Incremental Fit Index (IFI) & $\begin{array}{l}\text { used in assessing how well a specified model } \\
\text { fits relative to some alternative baseline } \\
\text { model }\end{array}$ & at least .90 \\
\hline McDonald Fit Index (MFI) & $\begin{array}{l}\text { a non-comparative index of model fit that } \\
\text { considers the model chi-square, degrees of } \\
\text { freedom and sample size }\end{array}$ & at least .90 \\
\hline
\end{tabular}

Table 5.24 shows the results of the CFA on the seven informal institution variables. All of the items loaded significantly on specific factors as expected based on previous studies. All the parameter estimates were significant at .05 level of confidence and greater than the minimum threshold of .50. An examination of the standardised residual matrix revealed that no residual value exceeded the threshold of 2.5. The average absolute standardised residual was .0222 with an average offdiagonal value of .0238. Furthermore, results of the Lagrange Multiplier (LM) Test as well as Wald Test suggested that respecification (e.g. freeing) of misfitting parameters would not significantly change the $\chi^{2}$ statistic (Kline, 2005). 
Five of the seven factors had internal consistency greater than .70 whilst two factors had coefficients greater than .60. Nunnaly (1978 p. 245) noted that for purposes of basic research, Cronbach alpha should be at least .70. Other authorities consider the values of .70 and above as very good (.70 being acceptable) levels of reliability (Cavana et al., 2001; Hair et al., 2006; Peterson, 1994; Tabachnick \& Fidell, 2005). Using this standard, two factors- power distance and assertiveness- were excluded from further analysis as the data on these factors displayed low and unacceptable level of internal consistency. The study upholds the view that reliability is an essential component of the validity of constructs that adds rigour to a scientific study (Hair et al., 2006).

The average variance extracted (AVE) values are also shown in Table 5.23. AVE is the variance in the indicator items captured by a construct as a proportion of captured plus error variance (Fornell \& Larcker, 1981). Ranging from 0 to 1, AVE is used as a measure of convergent validity such that adequately convergent valid measures should contain less than $50 \%$ error variance (i.e. AVE should be .50 and above) (Fornell \& Larcker, 1981). It was noted that all constructs (except power distance and assertiveness) had AVE values above the acceptable threshold, suggesting convergent validity. The result of AVE analysis further supported the view that power distance and assertiveness should be excluded in the succeeding analysis due to their psychometric weaknesses with respect to the data at hand. 
Table 5.24 Confirmatory Factor Analysis of the Informal Institutions Variables

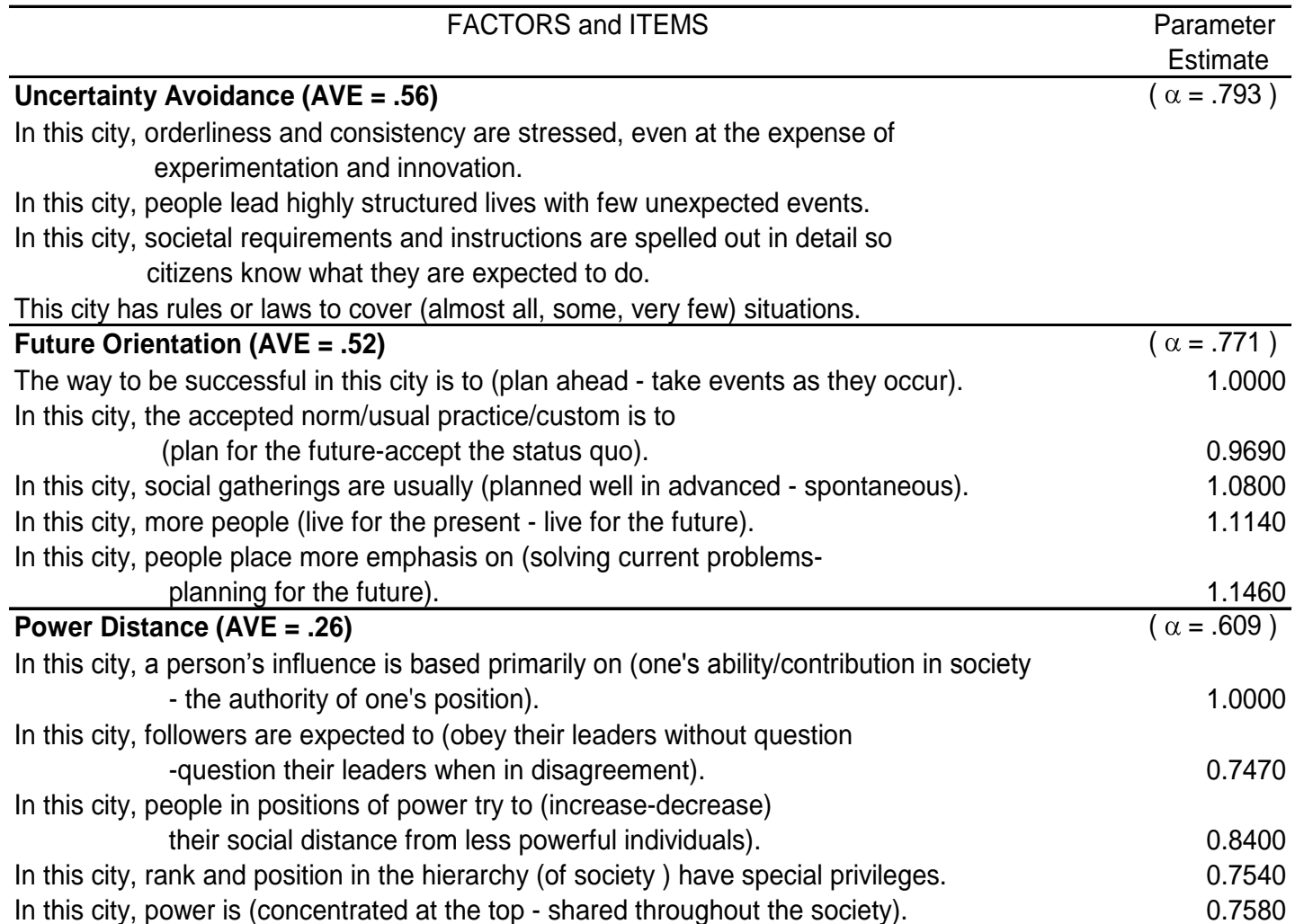

Assertiveness (AVE $=.38$ )

$(\alpha=.645)$

In this city, people are generally (assertive-non assertive).

1.0000

In this city, people are generally (dominant - non dominant).

0.9260

In this city, people are generally (tough - tender).

0.7950

Collectivism (AVE $=.52$ )

$(\alpha=.714)$

In this city, leaders encourage group loyalty even if individual goals suffer.

1.0000

The economic system in this city is designed to maximise (individual-collective) interests. $\quad 0.8340$

In this city, being accepted by the other members of a group is very important:

0.7960

In this city, tight group membership is (more valued, equally valued, less valued)

than individualism

0.7780

Humane Orientation (AVE $=.51$ )

$(\alpha=.738)$

$\begin{array}{lr}\text { In this city, people are generally (very - not at all) concerned about others. } & 1.0000 \\ \text { In this city, people are generally (very - not at all) sensitive toward others. } & 0.9360\end{array}$

$\begin{array}{ll}\text { In this city, people are generally (very friendly-very unfriendly). } & 0.9190\end{array}$

In this city, people are generally (very-not at all) tolerant of mistakes. $\quad 1.0620$

\begin{tabular}{lr} 
In this city, people are generally (very - not at all) generous. & 1.1010 \\
\hline Performance Orientation (AVE = .53) & $(\alpha=.736)$
\end{tabular}

In this city, teen-aged students are encouraged to strive for continuously improved performance.

In this city, major rewards are based on only performance effectiveness (pe), pe and other factors such as seniority (s) or political connections (pc), or only factors other than pe such as $s$ and $p c$ ).

In this city, being innovative to improve performance is generally (substantially, somewhat, not) rewarded.

*significant at .05 (i.e. test statistic $>+1.96$ )

$A V E=$ average variance extracted based on standardised solution

$\alpha=$ Cronbach alpha 
In Table 5.25, indices of the goodness-of-fit such as NFI, CFI, IFI, MFI, GFI and AGFI generated values far above the minimum threshold of .90. Likewise, SRMR and RMSEA values were well below the minimum threshold of .08 and .07 respectively. The $\chi^{2}$ statistic showed a significant value which contradicted the rest of the indices. However, previous studies have shown the problematic nature of using $\chi^{2}$ as a sole basis in judging the goodness-of-fit of the model (Byrne, 2006; Thomson, 2004).

An area of concern was the possibility that items coefficients or parameters may be significantly attenuated because of the slightly (negatively skewed) non-normal distribution of data. This was evident in Mardia's normalised estimate of 9.2331 which was above the acceptable maximum threshold of 5 thereby indicating that the data distribution was not normal due to multivariate kurtosis far from the ideal value of 0 (Byrne, 2006). In general, simulation studies (Kline, 2005) suggest that under conditions of severe non-normality of data, CFA parameter estimates are still fairly accurate but corresponding significance coefficients are too high.

Table 5.25 Summary of Goodness-of-Fit Indices for the Informal Institutions Variables using Maximum Likelihood Method

\begin{tabular}{|c|c|c|}
\hline \multicolumn{2}{|c|}{ Multivariate Kurtosis (Mardia's Normalized Estimate) } & 9.2231 \\
\hline \multicolumn{3}{|c|}{ Goodness of Fit Summary for Maximum Likelihood Method: } \\
\hline a. $\chi^{2}$ & $427.851 d f=356$ & $p=.00531$ \\
\hline b. Bentler-Bonnet NFI & 0.919 & \\
\hline c. Bentler-Bonnet Non-NFI & 0.983 & \\
\hline d. CFI & 0.985 & \\
\hline e. Bollen's IFI & 0.985 & \\
\hline f. McDonald's MFI & 0.961 & \\
\hline g. Joreskog-Sorbom's GFI & 0.968 & \\
\hline h. Joreskog-Sorbom's AGFI & 0.961 & \\
\hline i. $\mathrm{RMR}$ & 0.043 & \\
\hline j. Standardized RMR & 0.029 & \\
\hline k. RMSEA & 0.015 & \\
\hline
\end{tabular}

To investigate this issue, another round of CFA was performed using the ROBUST method. In EQS, the CFA - robust method is appropriate when the assumption of normality of data distribution is not adequately met (Byrne, 2006). However, the 
results of the goodness-of-fit indices as shown in Table 5.26 were relatively similar to that of the first CFA using maximum likelihood method. The parameter estimates remained significant across all items under the seven factors. Hence, the results suggested that multivariate normality was not an issue in the analysis. Overall, the results of the foregoing analysis supported the unidimensionality of the seven informal institutions. However, only five informal institutions (i.e. excluding power distance and assertiveness) were shown to possess acceptable qualities of internal consistency and convergent validity.

Table 5.26 Summary of Goodness-of-Fit Indices for the Informal Institution Variables using the Robust Method

\section{Goodness of Fit Summary for Robust Method:}

\begin{tabular}{|c|c|}
\hline \multicolumn{2}{|c|}{ a. Satorra-Bentler Scaled $\chi^{2} \quad 423.1736 d f=356 \quad p=.00822$} \\
\hline b. Yuan-Bentler Residual-B & atistic $\quad 395.195 p=.07452$ \\
\hline c. Bentler-Bonnet NFI & 0.915 \\
\hline d. Bentler-Bonnet Non-NFI & 0.983 \\
\hline e. CFI & 0.985 \\
\hline f. Bollen's IFI & 0.985 \\
\hline g. McDonald's MFI & 0.963 \\
\hline h. RMSEA & 0.014 \\
\hline
\end{tabular}

It was also important to note that the current values of the inter-item consistency of the five informal institutions (i.e. except power distance, assertiveness and humane orientation) were not far from the reported Cronbach alpha of the original authors of the GLOBE study (House et al., 2004) as shown in Table 5.27.

Table 5.27 Inter-item Consistency of the Informal Institution Variables from the GLOBE Study

\begin{tabular}{lc}
\hline \multicolumn{1}{c}{ Informal Institutions } & Cronbach $\alpha$ \\
\hline Uncertainty Avoidance & 0.88 \\
Future Orientation & 0.80 \\
Power Distance & 0.80 \\
Assertiveness & 0.75 \\
Collectivism & 0.67 \\
Humane Orientation & 0.88 \\
Performance Orientation & 0.72 \\
\hline source: House et al (2004) &
\end{tabular}




\subsubsection{Confirmatory Factor Analysis for Strategic Posture}

CFA using the same process (as above) was performed on the nine items which conceptually defined the construct - strategic posture - based on previous studies (Covin \& Miles, 1999; Covin \& Slevin, 1990; Jantunen et al., 2005). Table 5.28 shows the results of the analysis.

All of the items loaded significantly on one factor as expected based on previous studies (Covin \& Slevin, 1989; Gibbons, 2003). All the parameter estimates were significant at .05 level of confidence and greater than the minimum threshold of .50 . An examination of the standardised residual matrix revealed that no residual value exceeded the threshold of 2.5. The average absolute standardised residual was .0258 with an average off-diagonal value of .0323 .

Furthermore, results of the Lagrange Multiplier (LM) Test as well as Wald Test suggested that respecification (e.g. freeing) of misfitting parameters would not significantly change the $\chi^{2}$ statistic (Kline, 2005). Moreover, the reliability coefficient of .936 was considered superior which indicated the high level of internal consistency of the items comprising the construct (Cortina, 1993; Nunnaly, 1978; Tabachnick \& Fidell, 2005). Likewise, the average extracted variance (AVE) of .75 (i.e. $>$.50) suggested that construct had an acceptable level of convergent validity. 
Table 5.28 Unidimensionality and Inter-Item Consistency of the Strategic Posture Variable

\begin{tabular}{|c|c|c|c|}
\hline ITEMS & $\begin{array}{c}\text { Parameter } \\
\text { Estimate } \\
\end{array}$ & $\begin{array}{l}\text { Standard } \\
\text { Error }\end{array}$ & $\begin{array}{c}\text { test } \\
\text { statistic }^{*}\end{array}$ \\
\hline STRATEGIC POSTURE (AVE $=.75)$ & $(\alpha=.936)$ & & \\
\hline $\begin{array}{l}\text { In general, my business favours a strong emphasis : on the marketing of tried and true products } \\
\text { or services --- on research \& development, technological leadership, and innovation. }\end{array}$ & 1.0000 & & \\
\hline How many new lines of products or services has your business marketed in the past few years? & 1.2000 & 0.0370 & 32.4020 \\
\hline Changes in product or service lines have been mostly of a minor nature-have usually been quite dramatic. & 1.4050 & 0.0440 & 32.2050 \\
\hline $\begin{array}{l}\text { typically initiates actions to which competitors then respond. } \\
\text { dealing with its competitors. my business is (verv seldom-very often) th }\end{array}$ & 1.2940 & 0.0400 & 32.0590 \\
\hline $\begin{array}{l}\text { introduce new products/services, administrative techniques, operating technologies, etc. } \\
\text { In dealing with its competitors, my business typically seeks to avoid competitive clashes, preferring a }\end{array}$ & 1.2910 & 0.0420 & 30.9430 \\
\hline $\begin{array}{l}\text { "live-and-let-live" posture --- typically adopts a very competitive, "undo-the competitors" attitude. } \\
\text { In general, my business has: a strong preference for low-risk projects (with normal and certain rates of return) - }\end{array}$ & 0.9900 & 0.0350 & 28.6000 \\
\hline ---A strong preference for high risk projects, (with chances of very high returns). & 1.2480 & 0.0380 & 33.1180 \\
\hline $\begin{array}{l}\text { In general, my business believes that: owing to the nature of the environment, it is best to explore it gradually via } \\
\text { cautious,slowly increasing behaviour --- bold, wide ranging acts are necessary to achieve the firm's objectives. }\end{array}$ & 1.1370 & 0.0380 & 30.2800 \\
\hline $\begin{array}{l}\text { When confronted with decision-making situations involving uncertainty, my business... } \\
\text { typically adopts a cautious, 'wait and see' posture in order to minimize the probability of } \\
\text { making costly decisions ---typically adopts a bold, aggressive posture in order to }\end{array}$ & & & \\
\hline maximize the probability of exploiting potential opportunities & 470 & 0.0450 & 34.2600 \\
\hline
\end{tabular}

*significant at .05 (i.e. test statistic $> \pm 1.96$ )

$A V E=$ average variance extracted based on standardised solution 
A number of goodness-of-fit indices as shown in Table 5.29 also supported the unidimensionality of the strategic posture construct as shown by the values of CFI, NFI, IFI, and MFI having surpassed the minimum acceptable value of .90 . The value of SRMR was also well below the upper limit of .08. Despite having high value of $\chi^{2}$ as well as RMSEA, majority of the indices supported the overall goodness-of-fit of the model to the data at hand.

Table 5.29 Goodness of Fit Indices of the CFA of the Strategic Posture Variable - Maximum Likelihood Method

\begin{tabular}{lcc}
\hline \multicolumn{2}{l}{ Multivariate Kurtosis (Mardia's Normalised Estimate) } & 23.1628 \\
\hline \multicolumn{3}{l}{ Goodness of Fit Summary for Maximum Likelihood Method: } \\
\hline a. $\chi^{2}$ & $611.328 \mathrm{df}=27$ & $p=.0000$ \\
b. Bentler-Bonnet NFI & 0.928 & \\
c. Bentler-Bonnet Non-NFI & 0.907 & \\
d. CFI & 0.931 & \\
e. Bollen's IFI & 0.931 & \\
f. McDonald's MFI & 0.723 & \\
g. Joreskog-Sorbom's GFI & 0.848 & \\
h. Joreskog-Sorbom's AGFI & 0.746 & \\
i. RMR & 0.093 & \\
j. Standardized RMR & 0.037 & \\
k. RMSEA & 0.155 & \\
\hline
\end{tabular}

Because of the high value of Mardia's normalised estimate, another round of CFA was performed using the ROBUST method and the results remained relatively the same which suggested that normality of data distribution was not a major concern in the current data set on strategic posture. Details are provided in Table 5.30. 
Table 5.30 Goodness of Fit Indices of the CFA of the

Strategic Posture Variable - Robust Method

\section{Goodness of Fit Summary for Robust Method:}

\begin{tabular}{|c|c|}
\hline a. Satorra-Bentler Scaled $\chi^{2}$ & $483.2421 d f=27 \quad p=.0000$ \\
\hline b. Yuan-Bentler Residual-Based Test Statistic & $285.845 p=.0000$ \\
\hline c. Bentler-Bonnet NFI & 0.964 \\
\hline d. Bentler-Bonnet Non-NFI & 0.954 \\
\hline e. CFI & 0.966 \\
\hline f. Bollen's IFI & 0.966 \\
\hline g. McDonald's MFI & 0.776 \\
\hline h. RMSEA & 0.137 \\
\hline
\end{tabular}

5.8.5. Unidimensionality, Validity and Reliability of Other Variables

The two industry-related variables, competitive intensity and technological sophistication were also examined through CFA. As shown in Table 5.31, these two variables displayed acceptable levels of unidimensionality (i.e. high and significant factor loadings of items under each construct), internal consistency (i.e. Cronbach $\alpha$ above .70), and convergent validity (i.e. AVE above .50) (Hair et al., 2006). Confirmatory factor analysis revealed that the measurement model fit the data well (i.e. $\chi^{2}=47.192$ with $5 d f$ at $p=.000, \mathrm{NFI}=.98, \mathrm{CFI}=.98, \mathrm{RMSEA}=.07$ ) (Hair et al., 2006).

Table 5.31 Unidimensionality and Internal Consistency of the Industry-related Constructs

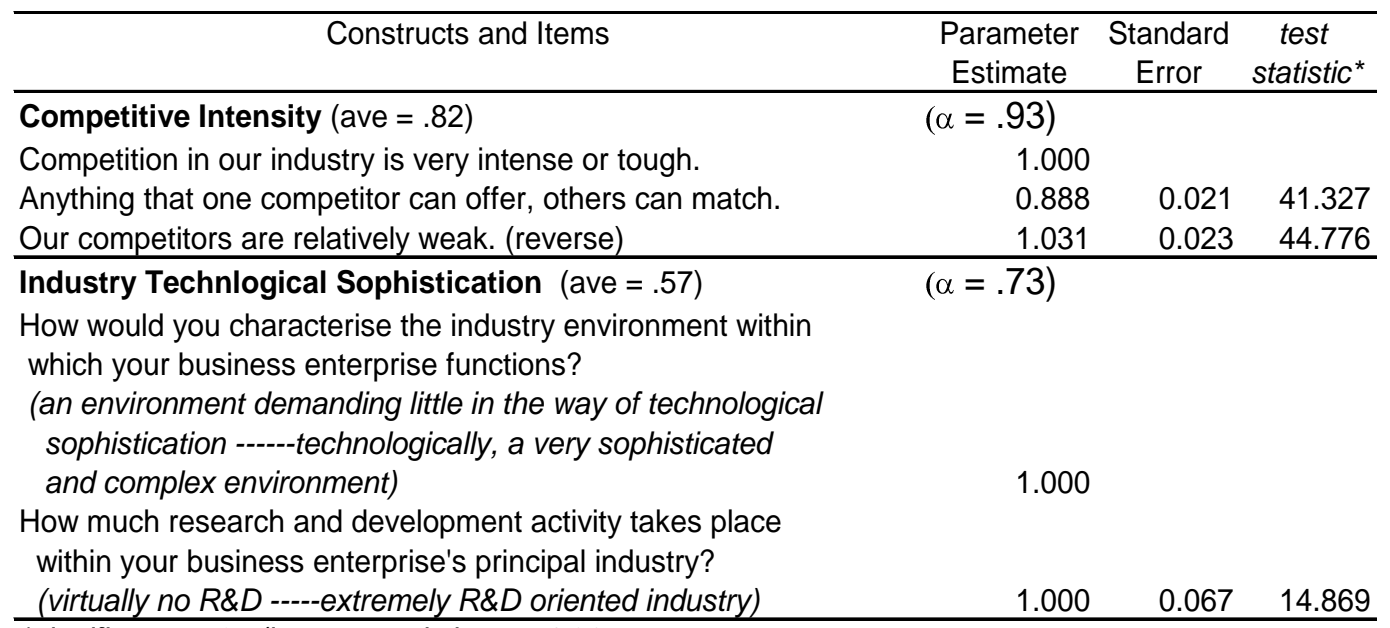

*significant at .05 (i.e. test statistic $> \pm 1.96$

ave $=$ average variance extracted based on standardised solution 


\subsection{Summary and Inter-correlation of Variables}

Table 5.32 shows the summary of the variables that were analysed in this study. Table 5.33 shows the correlation coefficients of all the major independent variables that had just been subjected to validation procedures. The table also shows evidence of discriminant validity and convergent validity which are essential to establish the construct validity. Shown in bold figures are the square root derivatives of the average variance extracted (AVE) values for each of the constructs.

Discriminant validity refers to the degree to which two or constructs are distinct from each other (Hair et al., 2006). This type of validity can be established by examining the correlation coefficients as well as the average variance extracted values of all the constructs. It was noted that the correlation coefficients were below the .85 maximum threshold recommended by Kline (2005) thereby suggesting acceptable level of discriminant validity. The discriminant validity of all the constructs was further established after knowing that the square root of each construct's AVE was found to be larger than its correlations with other constructs (Fornell \& Larcker, 1981; Hair et al., 2006).

Convergent validity is a measure of how well the items in a scale converge or 'load together' on a single latent construct (Fornell \& Larcker, 1981; Hair et al., 2006). All constructs had AVE values above the .50 minimum threshold (Fornell \& Larcker, 1981) suggesting acceptable level of convergent validity. Overall, it could be argued that the constructs used in subsequent analyses possessed acceptable levels of reliability and construct validity. 
Table 5.32 Summary of the Variables used in this Study

\begin{tabular}{|c|c|c|c|c|c|}
\hline Variables & Description & $\begin{array}{c}\text { Mean } \\
\text { (unless } \\
\text { otherwise } \\
\text { stated) }\end{array}$ & $\begin{array}{l}\text { Standard } \\
\text { deviation }\end{array}$ & $\begin{array}{l}\text { Min. } \\
\text { values }\end{array}$ & $\begin{array}{c}\text { Max. } \\
\text { values }\end{array}$ \\
\hline \multicolumn{6}{|l|}{ Formal Institutions } \\
\hline Rule of Law & $\begin{array}{l}\text { composite measure of } 6 \\
\text { items - } 7 \text { point Likert scale }\end{array}$ & 4.76 & 1.21 & 1.83 & 6.90 \\
\hline Protection of Property Rights & $\begin{array}{l}\text { composite measure of } 4 \\
\text { items }-7 \text { point Likert scale }\end{array}$ & 3.83 & 1.16 & 1.50 & 6.90 \\
\hline Government Policies & $\begin{array}{l}\text { composite measure of } 5 \\
\text { items - } 7 \text { point Likert scale }\end{array}$ & 4.30 & 1.77 & 1.60 & 7.00 \\
\hline Regulatory Quality & $\begin{array}{l}\text { composite measure of } 8 \\
\text { items - } 7 \text { point Likert scale }\end{array}$ & 4.30 & 1.53 & 1.62 & 7.00 \\
\hline Government Assistance & $\begin{array}{l}\text { composite measure of } 5 \\
\text { items }-7 \text { point Likert scale }\end{array}$ & 2.28 & 0.88 & 1.00 & 7.00 \\
\hline \multicolumn{6}{|l|}{ Informal Institutions } \\
\hline Performance Orientation & $\begin{array}{l}\text { composite measure of } 3 \\
\text { items - } 7 \text { point Likert scale }\end{array}$ & 4.39 & 0.99 & 1.33 & 6.67 \\
\hline Future Orientation & $\begin{array}{l}\text { composite measure of } 5 \\
\text { items }-7 \text { point Likert scale }\end{array}$ & 3.90 & 0.99 & 1.20 & 6.80 \\
\hline Collectivism & $\begin{array}{l}\text { composite measure of } 4 \\
\text { items - } 7 \text { point Likert scale }\end{array}$ & 4.38 & 0.86 & 1.25 & 6.75 \\
\hline Humane Orientation & $\begin{array}{l}\text { composite measure of } 5 \\
\text { items - } 7 \text { point Likert scale }\end{array}$ & 5.18 & 0.82 & 1.80 & 6.60 \\
\hline Uncertainty Avoidance & \begin{tabular}{|l} 
composite measure of 4 \\
items -7 point Likert scale
\end{tabular} & 3.93 & 0.98 & 1.75 & 7.00 \\
\hline \multicolumn{6}{|l|}{ Industry Factors } \\
\hline Competitive Intensity & $\begin{array}{l}\text { composite measure of } 3 \\
\text { items - } 7 \text { point Likert scale }\end{array}$ & 5.09 & 1.32 & 1.00 & 7.00 \\
\hline Technological Sophistication & $\begin{array}{l}\text { composite measure of } 3 \\
\text { items }-7 \text { point Likert scale }\end{array}$ & 2.49 & 0.95 & 1.00 & 5.50 \\
\hline Strategic Posture & $\begin{array}{l}\text { composite measure of } 9 \\
\text { items - } 7 \text { point Likert scale }\end{array}$ & 3.62 & 1.38 & 1.33 & 6.67 \\
\hline \multicolumn{6}{|l|}{ Organisational Performance } \\
\hline $\begin{array}{l}\text { a. Product/Service } \\
\text { Performance }\end{array}$ & $\begin{array}{l}\text { composite measure of } 4 \\
\text { items - } 5 \text { point Likert scale; } \\
\text { perceived importance (1-5) x } \\
\text { perceived performance (1-5) }\end{array}$ & 16.68 & 3.93 & 6.25 & 25.00 \\
\hline b. Strategic Performance & $\begin{array}{l}\text { composite measure of } 5 \\
\text { items - } 5 \text { point Likert scale - } \\
\text { perceived importance }(1-5) \mathrm{x} \\
\text { perceived performance }(1-5)\end{array}$ & 13.78 & 3.99 & 4.20 & 24.00 \\
\hline c. Financial Performance & $\begin{array}{l}\text { composite measure of } 4 \\
\text { items - } 5 \text { point Likert scale - } \\
\text { perceived importance }(1-5) \mathrm{x} \\
\text { perceived performance (1-5) }\end{array}$ & 15.41 & 4.14 & 1.50 & 25.00 \\
\hline \multicolumn{6}{|l|}{ Firm Characteristics } \\
\hline Age of the Business & number of years in business & 6.33 & 5.83 & 0.08 & 40.00 \\
\hline Number of Full-time Staff & $\begin{array}{l}\text { reported number of full-time } \\
\text { staff }\end{array}$ & 5.39 & 10.36 & 1.00 & 136.00 \\
\hline Legal Structure of Business & $\begin{array}{l}\text { sole proprietorship, } \\
\text { partnership or corporation }\end{array}$ & $\begin{array}{l}\text { median - } 1 \\
\text { (sole prop) } \\
\end{array}$ & 0.795 & 1.00 & 3.00 \\
\hline \multicolumn{6}{|l|}{$\begin{array}{l}\text { Owner/Manager } \\
\text { Characteristics }\end{array}$} \\
\hline Age of the Owner/Manager & age in years & 40.39 & 9.47 & 19.00 & 74.00 \\
\hline $\begin{array}{l}\text { Educational Qualifications of } \\
\text { Owner/Manager }\end{array}$ & no. of years of formal study & 13.56 & 2.62 & 2.00 & 25.00 \\
\hline
\end{tabular}


Table 5.33 Correlation Matrix of the Major Independent Variables

\begin{tabular}{|c|c|c|c|c|c|c|c|c|c|c|c|c|c|c|c|}
\hline Constructs & mean & $\mathrm{SD}$ & AVE & $\mathrm{PO}$ & FO & $\mathrm{C}$ & $\mathrm{HO}$ & UA & ROL & PPR & GP & $\mathrm{RQ}$ & GA & $\mathrm{CI}$ & $\mathrm{TS}$ \\
\hline performance orientation (PO) & 4.39 & 0.99 & .53 & .73 & & & & & & & & & & & \\
\hline future orientation (FO) & 3.90 & 0.99 & .52 & .01 & .72 & & & & & & & & & & \\
\hline collectivism $(\mathrm{C})$ & 4.38 & 0.86 & .52 & -.04 & -.03 & .72 & & & & & & & & & \\
\hline humane orientation (HO) & 5.18 & 0.82 & .51 & .04 & $.08 *$ & .00 & .71 & & & & & & & & \\
\hline uncertainty avoidance (UA) & 3.93 & 0.98 & .56 & -.00 & $-.26^{*}$ & $-.07 *$ & $-.09 *$ & .75 & & & & & & & \\
\hline rule of law (ROL) & 4.76 & 1.21 & .69 & $.07 *$ & $.19^{*}$ & $-.04 *$ & $.27^{*}$ & $-.26^{*}$ & .83 & & & & & & \\
\hline protection of property rights (PPR) & 3.83 & 1.16 & .64 & .03 & $.22 * *$ & $-.09 * *$ & $.28 * *$ & $-.19 * *$ & $.71 * *$ & .80 & & & & & \\
\hline government policies (GP) & 4.30 & 1.77 & .86 & .04 & $.21 * *$ & -.05 & $.29 * *$ & $-.22 * *$ & $.80 * *$ & $.78 * *$ & .93 & & & & \\
\hline regulatory quality (RQ) & 4.30 & 1.53 & .83 & .05 & $.22 * *$ & -.03 & $.28 * *$ & $-.24 * *$ & $.79 * *$ & $.75^{* *}$ & $.80^{* *}$ & .91 & & & \\
\hline government assistance (GA) & 2.28 & 0.88 & .67 & .05 & $.08^{*}$ & -.06 & $.07 *$ & $-.10 * *$ & $.26^{* *}$ & $.16^{* *}$ & $.24 * *$ & $.21 * *$ & .82 & & \\
\hline competitive intensity (CI) & 5.09 & 1.32 & .82 & .03 & $.24 * *$ & -.06 & .04 & $-.12 * *$ & $.30 * *$ & $.25 * *$ & $.26^{* *}$ & $.28 * *$ & $.17 * *$ & .91 & \\
\hline technological sophistication (TS) & 2.49 & 0.95 & .57 & $.08 *$ & $.08^{*}$ & -.07 & .14 & $-.14 *$ & $.41 * *$ & $.41 * *$ & $.45^{* *}$ & $.41 * *$ & $.22 * *$ & $.09 * *$ & .75 \\
\hline
\end{tabular}

Legend: $S D=$ standard deviation; $A V E=$ average variance extracted

square root of the average variance extracted (AVE) in bold numbers presented diagonally

*significant at .05 level (2-tailed)

**significant at .01 level (2-tailed) 
The sample firms in the two cities reported remarkably distinctive perceptions on their strategic posture, on all formal institutions and on almost all informal institutions in their city of business. Firms in Tagum City reported relatively higher mean values in almost all constructs compared to those in Panabo City as shown in Table 5.34. The respondents from Panabo City reported higher scores, relative to those from Tagum City, in two constructs only, namely collectivism and uncertainty avoidance.

Table 5.34 Comparison of Tagum and Panabo Cities in terms Of Mean Values Across the Major Variables

\begin{tabular}{|c|c|c|c|c|c|c|c|c|}
\hline \multirow[t]{2}{*}{ Variables } & \multicolumn{4}{|c|}{$\begin{array}{c}\text { Tagum City } \\
\text { Business Size }\end{array}$} & \multicolumn{4}{|c|}{$\begin{array}{c}\text { Panabo City } \\
\text { Business Size }\end{array}$} \\
\hline & Micro & Small & Medium & $\begin{array}{l}\text { Overall } \\
\text { Mean }\end{array}$ & Micro & Small & Medium & $\begin{array}{l}\text { Overall } \\
\text { Mean }\end{array}$ \\
\hline $\begin{array}{l}\text { Strategic Posture } \\
\quad \text { formal institutions }\end{array}$ & 4.74 & 5.04 & 4.31 & 4.76 & 2.47 & 2.49 & 3.17 & 2.47 \\
\hline Rule of Law & 5.75 & 5.99 & 6.08 & 5.77 & 3.75 & 3.42 & 4.33 & 3.73 \\
\hline Protection of Property Rights & 4.79 & 5.00 & 4.50 & 4.80 & 2.83 & 2.98 & 3.13 & 2.84 \\
\hline Government Policies & 5.90 & 5.95 & 6.25 & 5.90 & 2.69 & 2.40 & 2.40 & 2.66 \\
\hline Regulatory Quality & 5.61 & 5.75 & 5.81 & 5.62 & 2.96 & 2.89 & 2.63 & 2.95 \\
\hline $\begin{array}{l}\text { Government Assistance } \\
\text { informal institutions }\end{array}$ & 2.44 & 2.79 & 1.75 & 2.46 & 2.12 & 1.99 & 1.70 & 2.11 \\
\hline Performance Orientation & 4.42 & 4.61 & 4.08 & 4.43 & 4.35 & 4.30 & 5.67 & 4.36 \\
\hline Future Orientation & 4.13 & 4.02 & 3.40 & 4.12 & 3.68 & 3.58 & 3.80 & 3.67 \\
\hline Collectivism & 4.31 & 4.43 & 4.75 & 4.33 & 4.46 & 4.19 & 4.13 & 4.43 \\
\hline Humane Orientation & 5.43 & 5.47 & 5.45 & 5.43 & 4.90 & 5.12 & 5.20 & 4.91 \\
\hline $\begin{array}{l}\text { Uncertainty Avoidance } \\
\text { industry characteristics }\end{array}$ & 3.70 & 3.63 & 3.44 & 3.69 & 4.17 & 4.14 & 4.25 & 4.17 \\
\hline Competitive Intensity & 5.44 & 5.51 & 5.33 & 5.44 & 4.77 & 4.42 & 5.00 & 4.74 \\
\hline Technological Sophistication & 2.79 & 2.67 & 3.39 & 2.92 & 2.05 & 2.04 & 2.07 & 2.05 \\
\hline
\end{tabular}


Statistical test of differences (i.e. $t$-test with both equal and unequal variances assumed) between the two cities on the variables presented in Table 5.34 revealed significant differences in almost all of them except performance orientation and collectivism. This result suggested that respondents in Tagum City reported higher scores on strategic posture, rule of law, protection of property rights, government policy, regulatory quality, government assistance, future orientation, humane orientation, uncertainty avoidance, competitive intensity and technological sophistication relative to those reported by respondents from Panabo City. Likewise, respondents from Tagum City reported lower scores in uncertainty avoidance compared to those in Panabo City. The two groups of respondents did not differ significantly on their scores on performance orientation and collectivism.

In terms of organisational performance, the results of the survey showed distinctive differences in the mean values of the 13 performance indicators of sample firms between the two cities. Across the 13 performance indicators, firms in Tagum City reported better performance compared to firms in Panabo City as shown in Table 5.35. The pattern was consistent when looking at the reported importance of each indicator, the perceived performance on each indicator, as well as the weighted performance score, which was the product of importance scores multiplied by perceived importance.

Statistical test of differences (i.e. $t$-test with unequal variances assumed due to significant Levene's test result) between the two cities on the weighted performance scores revealed significant differences in all of the performance indicators. This result suggested that respondents in Tagum City reported higher weighted performance scores relative to those reported by respondents from Panabo City. 
Table 5.35 Comparison of Organisational Performance of Sample Firms in Both Cities

\begin{tabular}{|c|c|c|c|c|c|c|c|c|c|c|c|c|}
\hline \multirow{3}{*}{$\begin{array}{c}\text { Organisational } \\
\text { Performance Indicators }\end{array}$} & \multicolumn{6}{|c|}{ Tagum City } & \multicolumn{6}{|c|}{ Panabo City } \\
\hline & & Manufacturing & & & Service & & & lanufacturing & & & Service & \\
\hline & $\begin{array}{l}\text { Perceived } \\
\text { Importance }\end{array}$ & $\begin{array}{c}\text { Perceived } \\
\text { Performance } \\
\end{array}$ & $\begin{array}{l}\text { Weighted } \\
\text { Score }\end{array}$ & $\begin{array}{l}\text { Perceived } \\
\text { Importance }\end{array}$ & $\begin{array}{l}\text { Perceived } \\
\text { Performance }\end{array}$ & $\begin{array}{l}\text { Weighted } \\
\text { Score }\end{array}$ & $\begin{array}{l}\text { Perceived } \\
\text { Importance }\end{array}$ & $\begin{array}{l}\text { Perceived } \\
\text { Performance } \\
\end{array}$ & $\begin{array}{c}\text { Weighted } \\
\text { Score }\end{array}$ & $\begin{array}{l}\text { Perceived } \\
\text { Importance }\end{array}$ & $\begin{array}{l}\text { Perceived } \\
\text { Performance }\end{array}$ & $\begin{array}{c}\text { Weighted } \\
\text { Score }\end{array}$ \\
\hline development of new products/services & 4.40 & 3.84 & 16.99 & 4.27 & 3.89 & 16.63 & 4.50 & 2.90 & 13.06 & 4.31 & 3.30 & 14.19 \\
\hline product or service quality & 4.52 & 4.19 & 19.02 & 4.38 & 4.21 & 18.42 & 4.69 & 2.90 & 13.65 & 4.50 & 3.27 & 14.75 \\
\hline customer satisfaction & 4.72 & 4.42 & 21.01 & 4.66 & 4.43 & 20.58 & 4.61 & 2.97 & 13.69 & 4.27 & 3.38 & 14.45 \\
\hline $\begin{array}{l}\text { improvement in business and/or } \\
\text { production processes }\end{array}$ & 4.22 & 3.93 & 16.80 & 4.02 & 3.98 & 16.00 & 4.14 & 3.79 & 15.65 & 3.72 & 3.46 & 12.86 \\
\hline $\begin{array}{r}\text { attraction/recruitment of essential } \\
\text { employees/skilled labour/talent }\end{array}$ & 4.28 & 3.94 & 17.00 & 4.12 & 3.98 & 16.41 & 4.21 & 3.64 & 15.41 & 4.07 & 3.14 & 12.81 \\
\hline skilled labour/talent & 4.43 & 3.93 & 17.58 & 4.38 & 3.99 & 17.45 & 4.23 & 3.50 & 14.68 & 4.15 & 3.13 & 12.97 \\
\hline market share & 3.75 & 3.53 & 13.31 & 3.70 & 3.70 & 13.65 & 3.41 & 3.23 & 11.01 & 3.21 & 2.96 & 9.72 \\
\hline growth of market share & 3.75 & 3.38 & 12.73 & 3.70 & 3.37 & 12.44 & 3.40 & 3.65 & 12.60 & 3.20 & 3.15 & 10.05 \\
\hline sales & 4.43 & 4.37 & 19.43 & 4.48 & 4.38 & 19.63 & 4.54 & 2.95 & 13.26 & 4.58 & 3.37 & 15.45 \\
\hline sales growth & 4.44 & 3.93 & 17.63 & 4.48 & 3.99 & 17.87 & 4.45 & 3.55 & 15.84 & 4.45 & 3.31 & 14.74 \\
\hline net income & 4.30 & 3.93 & 17.00 & 4.30 & 3.99 & 17.15 & 4.12 & 3.82 & 15.81 & 4.00 & 3.47 & 13.89 \\
\hline growth of net income & 4.29 & 3.78 & 16.35 & 4.30 & 3.80 & 16.36 & 4.03 & 3.65 & 14.92 & 3.96 & 3.17 & 12.57 \\
\hline return on investment & 4.29 & 3.78 & 16.29 & 4.30 & 3.80 & 16.38 & 3.84 & 3.65 & 14.23 & 3.83 & 3.31 & 12.66 \\
\hline
\end{tabular}

*scale of 1 (very unimportant) to 5 (very important)

${ }^{* *}$ scale of 1 (much worse than competitors) to 5 (much better than competitors)

${ }^{* * *}$ derived by multipying the IMPORTANCE score (scale of 1 to 5) and PERCEIVED PERFORMANCE score (scale of 1 to 5) attributed to each performance indicator. 
5.11. Descriptive Analysis of Organisational Performance and Strategic Posture Regardless of City Location

Organisational Performance. A comparison of the two sets of performance scores (importance and perceived performance), as shown in Figure 5.2, indicated two lines with relatively similar patterns. This data-pattern suggested that when the respondents reported that they attributed high level of importance on one indicator (e.g. sales), their reported performance also tend to be higher relative to other indicators. On the hand, if they reported having attributed low level of importance (e.g. market share and growth of market share), they also reported having lower level of performance relative to other indicators. This comparison of importance scores and performance scores offered support to the use of weighted performance scores in gauging the overall organisational performance of the sample firms.

Strategic Posture. The respondents' overall strategic posture was reported to have a mean value of 3.68 with a standard deviation of 1.36. As shown in Figure 5.3, majority of the respondents $(58.10 \%)$ reported that their strategic posture ranged from 1 to 4 in the seven point scale whilst 343 respondents $(38.10 \%)$ of the respondents reported that their level of strategic posture was in the region of 5 in the same scale.

When the data was split into two by sector (manufacturing and service), the results revealed relatively similar pattern such that whilst many respondents reported that they were in the region of 5 in the scale, the concentration of the majority of the respondents was in the range of 2 to 4 in the 7 point scale. This could be interpreted such that majority of the respondents had relatively low to average level of entrepreneurial strategic posture. 
Figure 5.2 Importance Attached to and Performance of MSMEs on the 13 Indicators of Organisational Performance

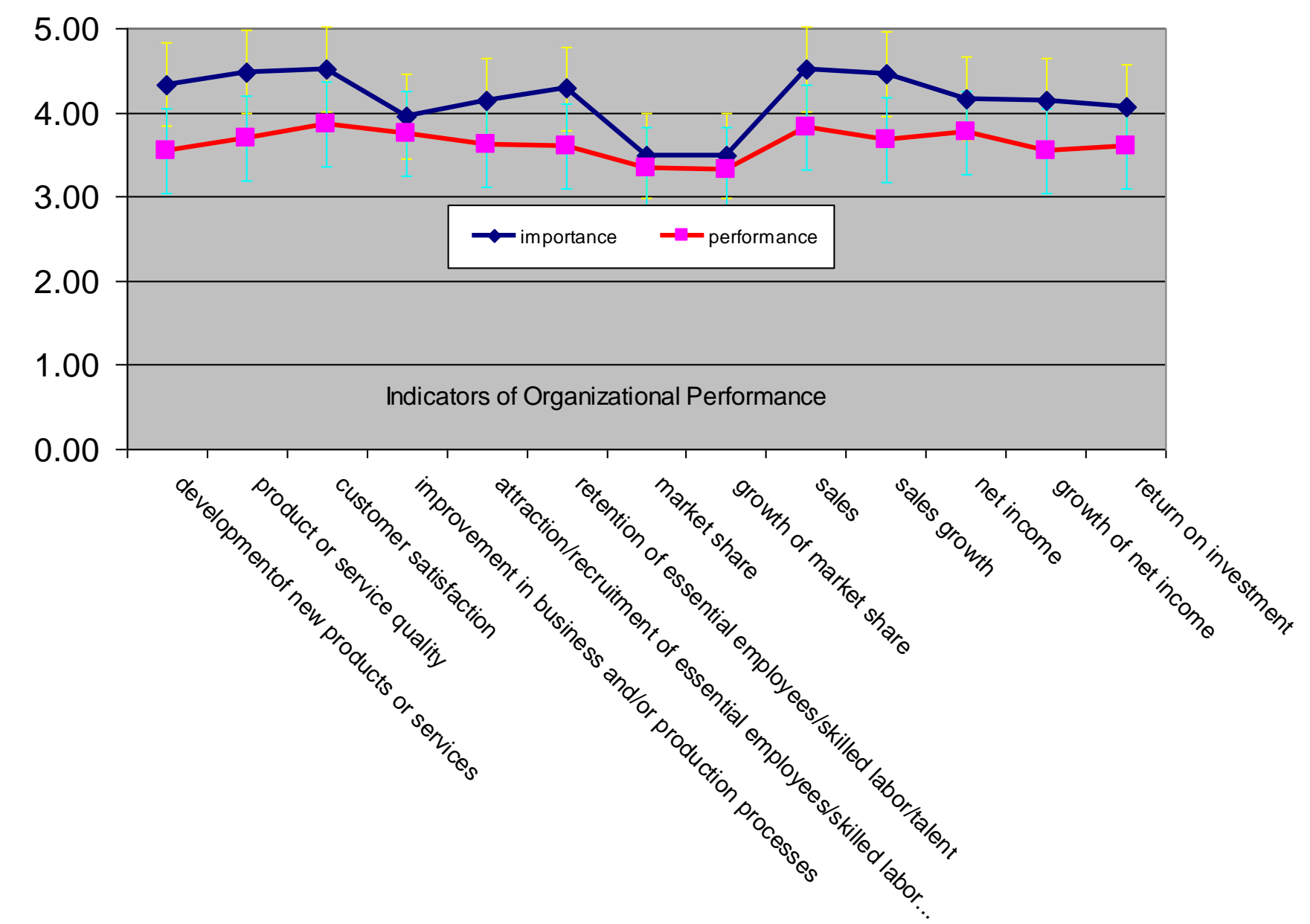


Figure 5.3 Distribution of Respondents on the Seven Points of the Strategic Posture Scale

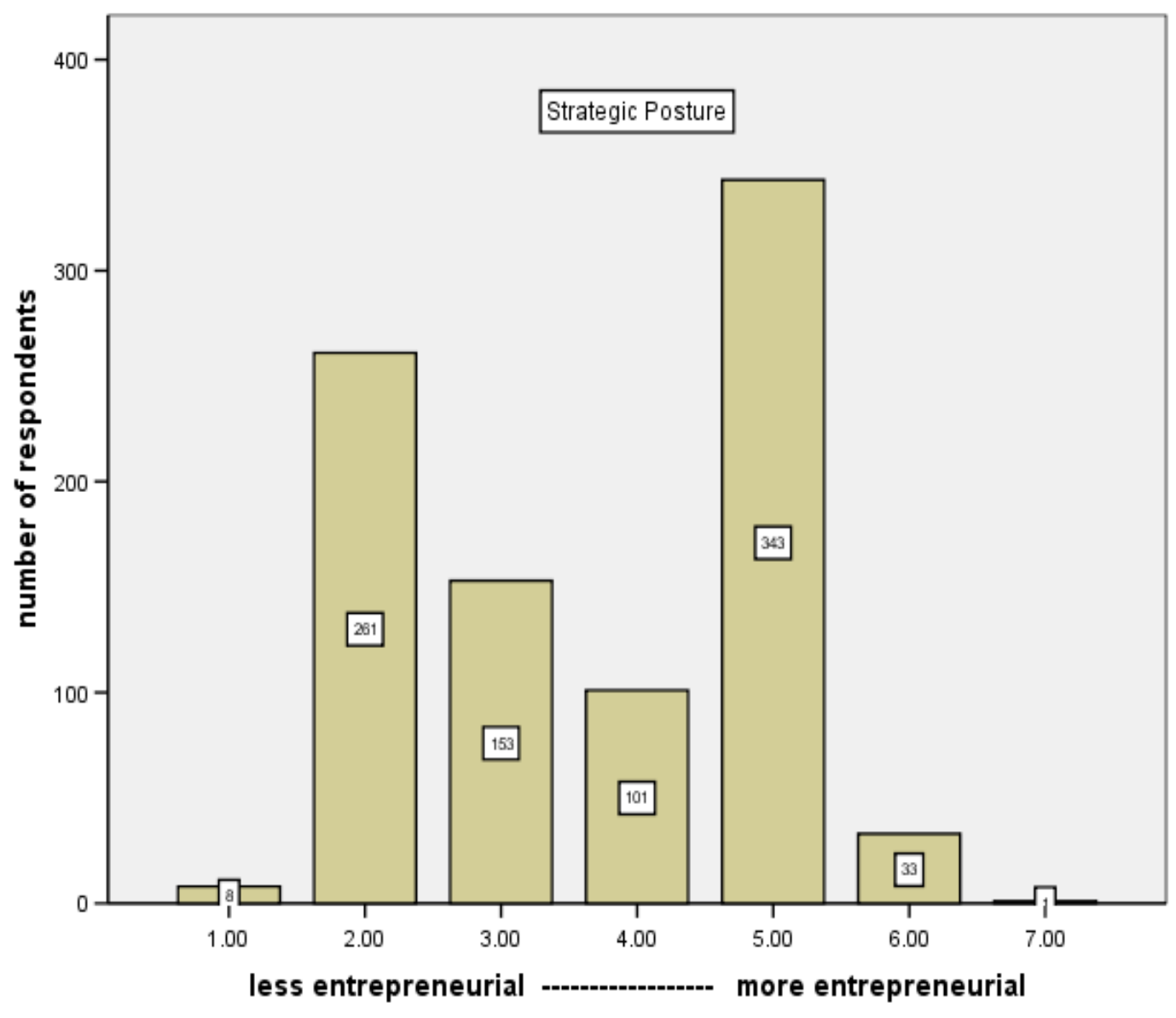




\subsection{Statistical Testing of Hypotheses}

Multiple regression analysis was the primary statistical technique used in testing the hypotheses in the study. Multiple regression provides 'the means of objectively assessing the degree and character of the relationship between the dependent and independent variables' (Hair et al., 2006, p. 190). This statistical tool suits the objectives of the study such that it allows for the examination of the magnitude, sign and statistical significance of the relationships between institutions (the independent variables) and strategic posture (the dependent variables) or of institutions as they relate to organisational performance. Analysis of Variance (ANOVA) and the appropriate post-hoc tests were also used as required by the nature of the data involved.

5.12.1. Formal/Informal Institutions/Industry Characteristics/Firm and Respondent Characteristics and their Relationships with Strategic Posture: Multiple Regression Analysis

The hypotheses that were put forward in this research were mainly analysed using multiple regression - ordinary least squares (OLS) method. This technique allows the examination of the relationships between independent and dependent variables (Hair et al., 2006). The OLS - linear regression method deals with the problem of finding a line that best fits a set of data points by using an equation which involves specification of parameters: an intercept and a slope of the (regression) (Cohen, Cohen, West \& Aiken, 2003). The least squares method defines the estimates of these parameters as the values which minimise the sum of squares (hence the name least squares) between the measurement and the model or the predicted values (Cohen et al., 2003). The stages that were followed in conducting the regression analysis are described below.

Stage 1. Appropriateness of the Tool. Multiple regression technique was considered appropriate in the current study. The immediate concern was to seek explanations on the degree and character of the relationships between formal/informal institutions and strategic posture and between strategic posture and organisational performance (Allison, 1999). 
Stage 2. Research Design. The sample size of 900 was considered adequate to perform multiple regression. The ratio of observations to variables was well above the minimum requirement of 20:1 thereby making the results more generalisable under the assumption that the sample size fairly represented the population (Field, 2005; Hair et al., 2006). Furthermore, the research design generated continuous type of data which were applicable for parametric tests like regression (Tabachnick \& Fidell, 2005).

Stage 3. Assumptions in Multiple Regression Analysis. The assumptions required by multiple regression such as linearity, normality, homoscedasticity, and multicollinearity were examined given the survey data at hand.

Linearity. The examination of the scatterplots as shown in Figure 5.4 (Chambers et al., 1983) between the independent variables and the dependent variables (e.g. formal/informal institutions in relation to strategic posture, and strategic posture in relation to organisational performance) suggested that graphically, there appeared to be a linear relationship between the independent and dependent variables. Furthermore, examination of the Q-Q plots of the variables as shown in Figure 5.5 suggested that the observed values representing the variables tended to follow the expected values in a straight line fashion. Consistent with Table 5.34, the Q-Q plots of a few variables displayed observed variables slightly deviating from the straight line in an s-like pattern with noticeable downward concavity indicating slight negative skewness (Chambers et al., 1983). Whilst this would be investigated further later in the multivariate modelling, preliminary analysis suggested that the assumption of linearity has been met.

Normality. It was also assumed that error terms in multiple regression were normally distributed as represented by the bell-shaped curve. Examination of the histograms and assessment of the values of kurtosis and skewness such as those presented in Table 5.36 revealed that the data (i.e. their associated error terms) on the major variables were relatively normally-distributed. There were variables which appeared to have cases suspected as outliers. However, following the prescription of 
Hair et al (2006), these outliers were retained as they were found to be valid values rather than errors of any kind.

Figure 5.4 Examples of Scatterplots of Selected Independent (x-axis) and Dependent Variables (y-axis)
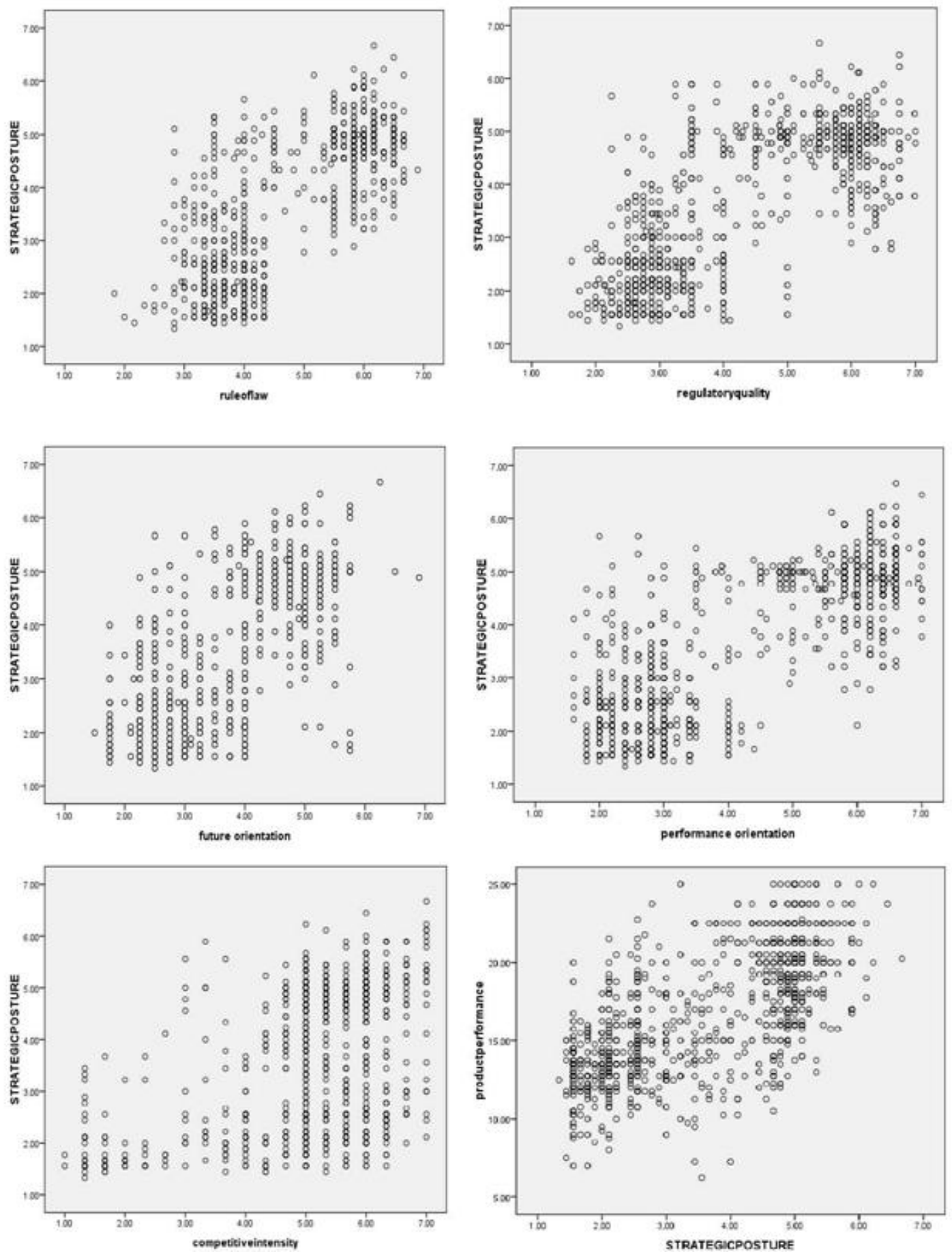
Figure 5.5 Examples of Q-Q plots of Selected

Variable
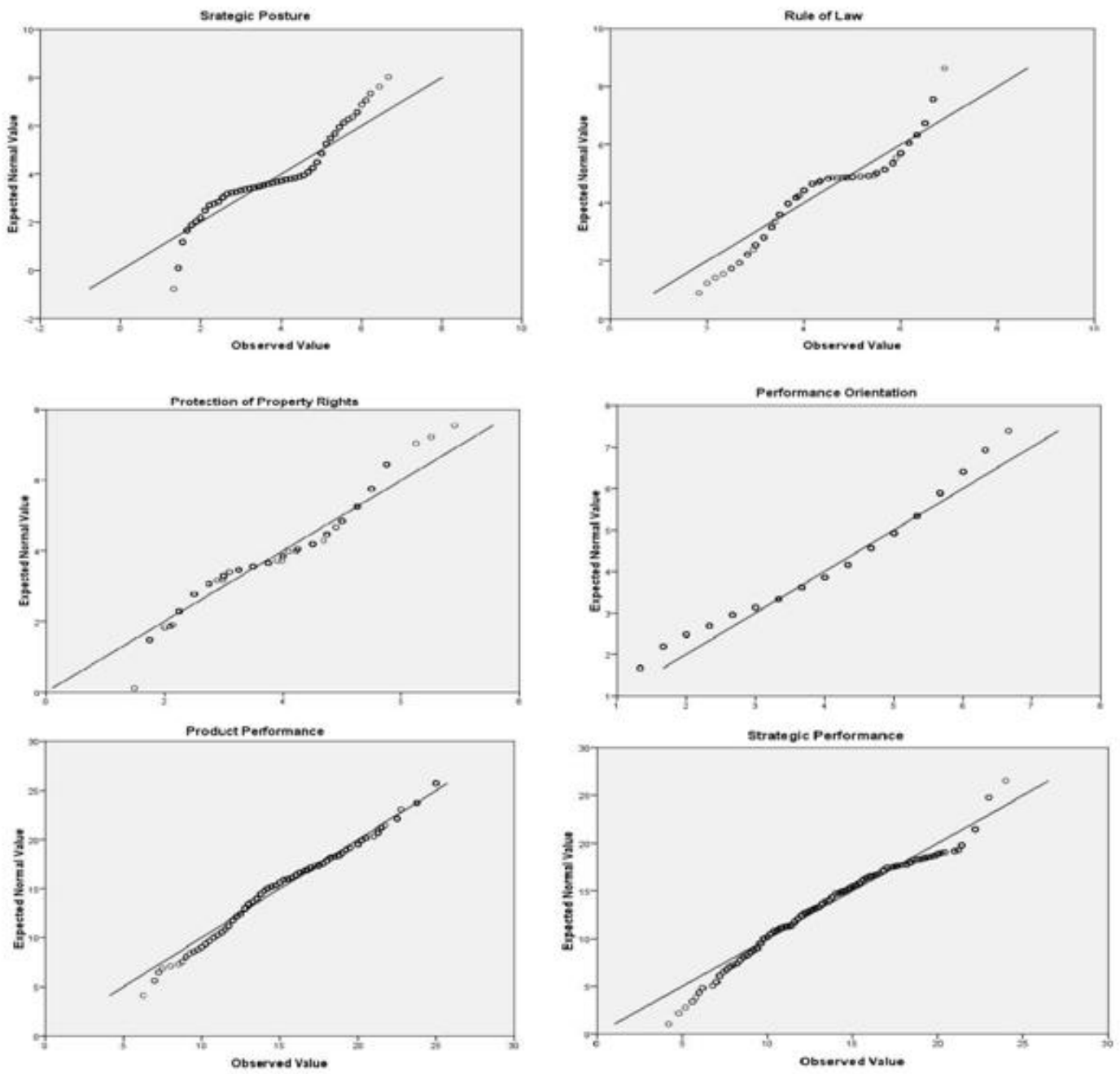

Homoscedasticity. Another assumption was that the variability in scores for one continuous variable should be roughly the same at all values of another continuous variable (Tabachnick \& Fidell, 2005). This assumption was explored by visual examination of the plots of the standardised residuals by the regression standardised predicted value (Osborne \& Waters, 2002). If the graphical method reveals heteroscedasticity, a formal statistical test shall be performed accordingly (Tabachnick \& Fidell, 2005). In this case, the Breusch-Pagan/Cook-Weisberg Test for heteroscedasticity was performed (Hamilton, 2006). 
Table 5.36 Skewness and Kurtosis Indices of the Variables in the Study

\begin{tabular}{|c|c|c|c|c|}
\hline \multirow[t]{2}{*}{ Variables } & \multicolumn{2}{|c|}{ Skewness } & \multicolumn{2}{|c|}{ Kurtosis } \\
\hline & Statistic & Std. Error & Statistic & Std. Error \\
\hline \multicolumn{5}{|l|}{ formal institutions } \\
\hline rule of law & 0.0602 & 0.0815 & -1.5163 & 0.1628 \\
\hline protection of property rights & -0.1263 & 0.0815 & -1.2426 & 0.1628 \\
\hline government policies & 0.0358 & 0.0815 & -1.6664 & 0.1628 \\
\hline regulatory quality & 0.1005 & 0.0815 & -1.5865 & 0.1628 \\
\hline government assistance & 1.5856 & 0.0815 & 2.0891 & 0.1628 \\
\hline \multicolumn{5}{|l|}{ informal institutions } \\
\hline performance orientation & -0.7320 & 0.0815 & 0.3323 & 0.1628 \\
\hline future orientation & -0.4300 & 0.0815 & 0.1091 & 0.1628 \\
\hline collectivism & -0.4859 & 0.0815 & 0.7890 & 0.1628 \\
\hline humane orientation & -1.6929 & 0.0815 & 3.2714 & 0.1628 \\
\hline uncertainty avoidance & 0.7230 & 0.0815 & 0.3538 & 0.1628 \\
\hline \multicolumn{5}{|l|}{ industry characteristics } \\
\hline competitive intensity & -1.4424 & 0.0815 & 1.7473 & 0.1628 \\
\hline technological sophistication & 0.9357 & 0.0815 & 0.4476 & 0.1628 \\
\hline strategic posture & -0.0913 & 0.0815 & -1.4965 & 0.1628 \\
\hline \multicolumn{5}{|l|}{ organisational performance } \\
\hline product/service performance & 0.1335 & 0.0815 & -0.7728 & 0.1628 \\
\hline strategic performance & 0.4485 & 0.0815 & -0.3363 & 0.1628 \\
\hline financial performance & 0.4244 & 0.0815 & -0.1699 & 0.1628 \\
\hline
\end{tabular}

Multicollinearity. This would be tested by examining the values of the correlation coefficients of all the independent variables with values greater than .80 or .90 as indicators of multicollinearity (Tabachnick \& Fidell, 2005). Examination of the variance inflation factor (VIF) as well as tolerance statistic was also helpful in this regard. VIF of 10 and above as well as average VIF values that are significantly greater than 1 should be a cause for concern whilst tolerance statistic below .20 requires a closer look at the data for multicollinearity. Details of the examination of this issue were presented later along with the regression analyses.

Stage 4. Estimating the Regression Model and Assessing Overall Model Fit. This stage required the selection of method for specifying the regression model to be estimated, assessing the statistical significance of the overall model in predicting the 
dependent variable and determining any undue influences on the results (Hair et al., 2006).

The estimation technique used in this study was sequential technique. Sequential technique (sometimes called hierarchical regression or block wise entry) allows the loading of the independent variables into the equation in an order specified by the researcher based on sound theoretical and conceptual justifications, including the purpose and logic of the research (Cohen et al., 2003; Hair et al., 2006; Tabachnick \& Fidell, 2005). This technique gives the researcher full control over variable selection and is the method of choice in developing regression models that have substantial meaning driven by sound theoretical and conceptual rationalisation rather than blind statistical manipulation (Allison, 1999; Field, 2005).

Furthermore, hierarchical regression technique permits understanding of the explanatory power of a specific variable in improving the explanation and prediction of the dependent variable/s after controlling the effects of other variables. As a result, it allows for the determination of the magnitude of the unique contribution of each independent variable in explaining the dependent variable/s. In effect, this technique affords a fuller exploration of the relative importance of each independent variable to the dependent variable/s.

In applying this technique, all formal institutions were entered as the first block. This was justified by the review of the literature showing the prevalence of studies looking at formal institutions and their impact on various phenomena such as innovation or national or regional performance (Adams, 1993; Aidis, 2005; Chelariu, Bello \& Gilliland, 2006). Field (2005) argued that predictors that are entered into the regression model must be guided by previous research as well as the substantive theoretical importance of these variables. The five formal institutions were also shown to have better internal consistency (as previously shown by Cronbach $\alpha$ values) and higher levels of discriminant and convergence validity relative to the informal institutions. Hence, the formal institutions were entered into the equation first because these have been extensively used as predictors in previous studies dealing with institutions as discussed in chapters 1, 2 and 3. Variables within this block were entered into the regression equation simultaneously to determine which 
formal institution would statistically explain better the dependent variable (i.e. strategic posture).

The second block that was entered into the equation comprised all of the informal institutions. It was logical to enter these variables second as they comprised the other major set of independent variables in the conceptual framework. As shown in the review of the literature, studies on informal institutions as they relate to firm-level phenomena were very scarce relative to those that dealt with formal institutions. Similarly, all of the informal institutions within the block were entered into the equation simultaneously.

The third block consisted of the industry-related factors - competitive intensity and technological sophistication. These variables were third in the hierarchy as they were not the major foci of the study even though they have been known in previous studies to have significant bearing on firm-level phenomena. All of the variables within the block were entered into the equation simultaneously.

The fourth block consisted of other variables which could explain well the firms' strategic posture: firm characteristics and profile of the respondents of the study. Similarly, all of these variables within the block were entered into the equation simultaneously. The fifth block consisted of a single variable - dummy for city (coded as 1 for Tagum City and 0 for Panabo City). This dummy variable was included because it was noted in the preliminary analyses that the two cities differed significantly in the reported scores in the majority of the variables under study. The inclusion of the dummy variable would generate regression results that could be considered relatively more accurate after controlling for the effects of city differences (Allison, 1999; Becker, 2005). Hence, the multiple regression equations for the above process are shown in Figure 5.6. 
Figure 5.6. Regression Equations for All Independent Variables and Strategic Posture

Model 1: Formal Institutions - Strategic Posture

$$
S P=\alpha_{1}+\beta_{1}(R L)+\beta_{2}(P P R)+\beta_{3}(G P)+\beta_{4}(R Q)+\beta_{5}(G A)+\ell_{1}
$$

Model 2: Formal and Informal Institutions -Strategic Posture

$$
\begin{gathered}
S P=\alpha_{2}+\beta_{1}(R L)+\beta_{2}(P P R)+\beta_{3}(G P)+\beta_{4}(R Q)+\beta_{5}(G A)+\beta_{6}(P O) \\
+\beta_{7}(F O)+\beta_{8}(C O)+\beta_{9}(H O)+\beta_{10}(U A)+\ell_{2}
\end{gathered}
$$

Model 3: Formal/Informal Institutions and Industry Characteristics - Strategic Posture

$$
\begin{aligned}
S P= & \alpha_{3}+\beta_{1}(R L)+\beta_{2}(P P R)+\beta_{3}(G P)+\beta_{4}(R Q)+\beta_{5}(G A)+\beta_{6}(P O) \\
& +\beta_{7}(F O)+\beta_{8}(C o)+\beta_{9}(H O)+\beta_{10}(U A)+\beta_{11}(C I)+\beta_{12}(T S)+\ell_{3}
\end{aligned}
$$

Model 4: Formal/Informal Institutions, Industry-, Respondents'- and Firm Characteristics - Strategic Posture

\begin{tabular}{|c|c|c|c|c|c|}
\hline \multicolumn{3}{|l|}{ where: } & \multirow[b]{2}{*}{$\mathrm{HO}$} & \multirow[b]{2}{*}{$=$} & \multirow[b]{2}{*}{ humane orientation } \\
\hline SP & $=$ & strategic posture & & & \\
\hline$\alpha_{1-5}$ & $=$ & intercept & UA & $=$ & uncertainty avoidance \\
\hline$\beta_{1-17}$ & $=$ & slope coefficients & CI & $=$ & competitive intensity \\
\hline RL & $=$ & rule of law & TS & $=$ & technological sophistication \\
\hline PPR & $=$ & protection of property rights & ar & $=$ & age of the respondent \\
\hline GP & $=$ & government policies & sy & $=$ & no. of school years \\
\hline RQ & $=$ & regulatory quality & fs & $=$ & number of fulltime staff \\
\hline GA & $=$ & government assistance & $a b$ & $=$ & age of the business \\
\hline $\mathrm{PO}$ & $=$ & performance orientation & dvc & $=$ & dummy variable for city \\
\hline $\mathrm{FO}$ & $=$ & future orientation & & & ( 1 for Tagum, 0 for Panabo) \\
\hline Co & $=$ & collectivism & $\ell_{1-5}$ & $=$ & error term \\
\hline
\end{tabular}

$$
\begin{aligned}
S P= & \alpha_{4}+\beta_{1}(R L)+\beta_{2}(P P R)+\beta_{3}(G P)+\beta_{4}(R Q)+\beta_{5}(G A)+\beta_{6}(P O) \\
& +\beta_{7}(F O)+\beta_{8}(C o)+\beta_{9}(H O)+\beta_{10}(U A)+\beta_{11}(C I)+\beta_{12}(T S) \\
& +\beta_{13}(a r)+\beta_{14}(s y)+\beta_{15}(f s)+\beta_{16}(a b)+\ell_{4}
\end{aligned}
$$

Model 5: Formal/Informal Institutions, Industry-, Respondents'-, FirmCharacteristics, and Dummy Variable for City - Strategic Posture

$$
\begin{aligned}
S P= & \alpha_{5}+\beta_{1}(R L)+\beta_{2}(P P R)+\beta_{3}(G P)+\beta_{4}(R Q)+\beta_{5}(G A)+\beta_{6}(P O) \\
& +\beta_{7}(F O)+\beta_{8}(C o)+\beta_{9}(H O)+\beta_{10}(U A)+\beta_{11}(C I)+\beta_{12}(T S) \\
& +\beta_{13}(a r)+\beta_{14}(s y)+\beta_{15}(f s)+\beta_{16}(a b)+\beta_{17}(d v c)+\ell_{5}
\end{aligned}
$$


Stage 5. Interpreting the Regression Variates. This stage requires evaluation of the regression coefficients for their explanation of the dependent variable/s.

Interpretation. Results of the multiple regression conducted to evaluate how well the five formal institutions, five informal institutions, two industry characteristics, two respondent characteristics, two firm characteristics and a dummy variable for city explained the strategic posture for firms are shown in Table 5.37. The sample multiple correlation coefficients were below .90 across the five models.

Table 5.37 Multiple Regression Models of Strategic Posture using OLS Method on Institutions, Industry-, Respondent-, and Firm- Characteristics with City as Control Variable

\begin{tabular}{|c|c|c|c|c|c|c|c|c|}
\hline & 1 & 2 & 3 & & 4 & & 5 & \\
\hline Independent Variables & $\beta$ & $\beta$ & $\beta$ & & $\beta$ & & $\beta$ & \\
\hline rule of law & .248 & .244 & .208 & & .209 & & .167 & * \\
\hline protection of property rights & .126 & .114 & .106 & & .103 & & $.056^{*}$ & ** \\
\hline government policies & .299 & .295 & .298 & & .302 & & .205 & * \\
\hline regulatory quality & .226 & .218 & .192 & & .184 & & .126 & * \\
\hline government assistance & .145 & .140 & .116 & & .111 & & .119 & * \\
\hline performance orientation & & .047 & .044 & & .043 & & .045 & * \\
\hline future orientation & & .103 & .065 & & .066 & & .064 & * \\
\hline collectivism & & -.021 & -.012 & & -.012 & & -.008 & \\
\hline humane orientation & & -.002 & .009 & & .010 & & .004 & \\
\hline uncertainty avoidance & & -.001 & .001 & & .002 & & .004 & \\
\hline competitive intensity & & & .215 & & .213 & & .216 & * \\
\hline technological sophistication & & & .020 & & .022 & & .015 & \\
\hline age of respondent & & & & & -.044 & & -.044 & * \\
\hline number of full time staff & & & & & .011 & & .014 & \\
\hline number of school years & & & & & .011 & & .009 & \\
\hline age of the business & & & & & .009 & & .006 & \\
\hline dummy variable for city & & & & & & & .238 & 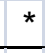 \\
\hline$r^{2}$ & .758 & .771 & .811 & & .813 & & .818 & \\
\hline F value & 561.176 & *299.497 & *'316.702 & & 239.589 & & 232.430 & - \\
\hline \multicolumn{9}{|c|}{ Dependent Variable: Strategic Posture } \\
\hline${ }^{*} p<.001$ & & & & & & & & \\
\hline${ }^{* *} p<.05$ & & & & & & & & \\
\hline
\end{tabular}


The results (in model five) indicated that after controlling for the effects of city (i.e. location of respondents which is either Tagum or Panabo), the linear relationship between the independent variables and dependent variable was significant at $F_{(17,882)}$ $=232.430, p=.000$. Approximately $82 \%$ percent of the variance in the firms' strategic posture could be accounted for by the five (out of five) formal institutions, two (out of five) informal institutions, competitive intensity, and age of the respondents.

It is also important to measure the magnitude or strength of the relationships that were found to be significant by examining 'effect size'. Field (2005) explains that an effect size represents an objective and standardised measure of the magnitude (or the degree of importance) of the observe "effect" of the independent variables to a dependant variable. Field (2005) argues that the value of the Pearson $r$ is an adequate measure of effect size. In the regression model shown above, the value of the Pearson $\mathrm{r}$ can be generated from the $r^{2}$ statistic. The large effect size (as indicated by the $r^{2}$ ) suggested that despite having small yet significant beta coefficients, the latter may be considered practically significant and meaningful from which conclusions can be drawn (Cohen, 1992; Field, 2005; Pedhazur, 1982).

Closer examination of the regression parameters revealed that government policies $(\beta=.205)$ accounted for the greatest explanatory power in relation to the strategic posture of firms. It could be interpreted such that an increase by one standard deviation (i.e. 1.77 as shown previously in Table 5.32) in the scale measuring government policies (i.e. extent of being conducive to business) generated a .205 standard deviations increase in the scale measuring the strategic posture of firms, holding other variables constant.

Competitive intensity, an industry characteristic, was the next variable with the highest explanatory power in relation to strategic posture. This result suggested that an increase by one standard deviation (1.32) in the competitive intensity scale was likely to generate a .216 standard deviations increase in the strategic posture of firms, holding other variables constant. 
Rule of law was the third in the rank of variables having significant predictive power in relation to the firms' strategic posture. The rest of the variables in the order of explanatory power were: regulatory quality, government assistance, protection of property rights, future orientation, age of the respondents (i.e. manager or owner/manager) and performance orientation. It was important to note that the beta coefficient for the age of the respondent was negative, suggesting an inverse relationship between age and strategic posture.

Furthermore, the significant coefficient of the dummy variable for city suggested that respondents from Tagum City tend to report higher levels of entrepreneurial strategic posture relative to those from Panabo City controlling for other independent variables used in the regression equation.

In general, results of the regression analysis suggested that firms are likely to have higher level of entrepreneurial strategic posture where:
a. there is rule of law;
b. property rights are well-protected;
c. there are government policies conducive for business;
d. there is high level of regulatory quality;
e. there is government assistance;
f. there is high level of future orientation;
g. there is high level of performance orientation;
h. the competition in the industry is very intense;
i. when the manager/owner of the firm is younger; and
j. when they are located in the city of Tagum.

Assessing for Multicollinearity. The values of the variance inflation factor (VIF) which indicated whether an independent variable had a strong linear relationship with the other independent variables were also examined. Most of the independent variables had values within the range of 1.01 to 1.34 whilst one independent variable had a value of 4.22 and two independent variables had values in the range of 3.50 to 3.71 . The average VIF was 1.59. Since there were no values greater than 10 and the average VIF was relatively not far from the acceptable value of 1.00, results suggested that multicollinearity was not a concern (Field, 2005). In 
the same way, the tolerance statistic values (which are the reciprocal of VIF (i.e. $1 / \mathrm{VIF}$ ) showed that no value was less than .2 which further confirmed the conclusion that multicollinearity was not an issue in the current data set (Field, 2005).

Assessing for Heteroscedasticity. The histograms and normal probability plots of the residuals were examined graphically to check for heteroscedastic distribution. The majority of the variables had residuals plotted in a random fashion indicating that homoscedasticity as an assumption was met. However, strategic posture, government assistance and competitive intensity tended to display heteroscedastic patterns. To investigate this further, the Breusch-Pagan/CookWeisberg test for heteroscedasticity was performed using Stata v. 9 to examine the null hypothesis of constant variance of the residuals (Hamilton, 2006). Results of the test revealed that for the fitted values of the residuals of strategic posture, the $\chi^{2}=$ $29.89, \mathrm{p}=.000$ which indicated that there was heteroscedasticity. For the fitted values of the residuals of all the IVs, $\chi^{2}=98.93, p=.000$. These values likewise indicated the presence of heteroscedasticity.

Remedy for Heteroscedasticity. The presence of heteroscedasticity can be explained by a combination of factors such as violations of the assumptions of linearity or normality (Allison, 1999). It was suspected that the slight negative skewness amongst the distribution of some of the variables as well as a number of outliers might be the major cause. Transformation of data was not undertaken because of the adverse effect it would have on the other variables which were relatively linear and normally-distributed. Authorities on the subject recommend transformation of data only if the benefits outweigh the costs of doing so (Cohen et al., 2003; Field, 2005; Hair et al., 2006; Tabachnick \& Fidell, 2005). Moreover, data transformation does not necessarily eliminate or attenuate the leverage of influential outliers and other issues pertaining to the assumptions of regression that bias the prediction and distort the significance of the parameters (Cohen et al., 2003; Yaffee, 2002)

To resolve this issue, another regression analysis was performed using the ROBUST FUNCTION under Stata version 9 program with the results presented in Table 5.37. This ROBUST method of regression performs better than the ordinary least square 
method (OLS) when there are outliers or the residuals have non-normal distribution with many extreme residuals in the tails (Cohen et al., 2003, p. 417). When the data meet the assumptions of multiple regression, results of the ROBUST approach should be relatively similar with the OLS method (Cohen et al., 2003). More technical details on Stata's ROBUST regression function are provided by Hamilton (1991).

Multiple regression using the ROBUST method is a form of weighted least squares regression that deals with data sets that have very high leverage, and cases that are outliers. Stata 9 Reference Manual (StataCorp, 2007 p 162) states that:

"the robust regression procedure runs the OLS regression, gets the Cook's D values, and then drops any observation if its Cook's D value is greater than 1 . The iteration process begins in which weights are calculated based on absolute residuals. The iteration stops when the maximum change between the weights from one iteration to the next is below tolerance. The method uses Huber weighting whereby observations with small residuals get a weight of 1 , consequently the larger the residual, the smaller the weight. Likewise, in using bi-weighting, all cases with a non-zero residual get down-weighted at least a little. The two kinds of weights are used because Huber weights can have difficulties with severe outliers, and bi-weights can have difficulties converging or may yield multiple solutions. Using the Huber weights first helps to minimize problems with the bi-weights. In short, robust regression method involves dropping the most influential points and then down-weighting cases with large absolute residuals".

The multiple regression analysis using ROBUST method as shown in Table 5.38 yielded similar results as that of the OLS method presented above in terms of the independent variables with significant relationships with the dependent variable (i.e. strategic posture). This confirmed the assertion that despite the presence of a few outliers and slight departures from the assumptions of multiple regression, the relationships between the independent variables and the dependent variable were not biased nor attenuated by these issues. The similarity of results between the OLS method and ROBUST method (in terms of significant relationships) suggested that further investigation of the effects of outliers and residuals were redundant and were 
therefore, deemed unnecessary (Cohen et al., 2003; Hamilton, 2006; Tabachnick \& Fidell, 2005).

Notable in the results of the ROBUST regression (model 5) relative to the OLS regression was the slight increase of beta coefficients for rule of law (.167 to .189), protection of property rights (.056 to .066), government assistance (.119 to .165), future orientation (.064 to .090), and age of respondent (-.044 to -.005).

Table 5.38 Multiple Regression using ROBUST Method

\begin{tabular}{|c|c|c|c|c|c|}
\hline & 1 & 2 & 3 & 4 & 5 \\
\hline Independent Variables & $\beta$ & $\beta$ & $\beta$ & $\beta$ & $\beta$ \\
\hline rule of law & .281 & .281 & $* .239 *$ & $* .243$ & *. .189 * \\
\hline protection of property rights & .164 & .154 & $* \quad .129 *$ & $*^{*} .126$ & ${ }^{*} .066$ * \\
\hline government policies & .263 & .261 & * .261 * & $\star^{*} .266$ & * .159 * \\
\hline regulatory quality & .206 & $*^{*} .200$ & * .179 * & $*^{*} .171$ & ${ }^{*} .113^{*}$ \\
\hline government assistance & .215 & $\star^{*} \quad .208$ & $*^{\top} .178$ * & $*^{*} .169$ & ${ }^{*} .165$ * \\
\hline performance orientation & & .048 & $*^{2} .046$ * & $\star^{*} .045$ & $\star^{\circ} .045$ * \\
\hline future orientation & & .150 & $* \quad .088$ * & $*^{*} .091$ & * . .090* \\
\hline collectivism & & -.021 & -.017 & -.017 & -.008 \\
\hline humane orientation & & -.013 & .008 & .008 & .006 \\
\hline uncertainty avoidance & & .014 & .015 & .016 & .006 \\
\hline competitive intensity & & & $.210^{*}$ & ${ }^{*} .208$ & $.194^{*}$ \\
\hline technologic & & & .034 & .038 & .032 \\
\hline age of resp & & & & -.005 & $\star-.005^{*}$ \\
\hline number of & & & & .001 & .014 \\
\hline number of school years & & & & .010 & .014 \\
\hline age of the busine & & & & .000 & .000 \\
\hline dummy variable for city & & & & & .238 * \\
\hline Fvalue & 725.28 & 400.36 & * 412.80 * & $* 311.70$ & *441.62 * \\
\hline \multicolumn{2}{|l|}{ Dependent Variable: Strat } & & & & \\
\hline${ }^{*}$ significant at $p<.01$ & & & & & \\
\hline
\end{tabular}

There was a slight decrease in the values of the coefficients in the case of government policy (.205 to .159), regulatory quality (.126 to .113), and competitive intensity (.216 to .194). Nonetheless, the significant relationships that were found under OLS regression were similar to those found under the ROBUST method. 
Stage 6. Validation of Results. Once the best regression model has been identified, the final step is to ensure that it represents the general population and is appropriate for the situations in which it will be used (Hair et al., 2006 p. 233). One approach to validation according to Hair et al (2006) is to gauge the model based on the theoretical model from which the analysis was based. This is done in the discussion and conclusion chapters wherein the results were analysed in the context of North's (1990) institutional theory.

The empirical approach to model validation suggested by Hair et al (2006) is to examine the adjusted $r^{2}$ relative to the $r^{2}$ to determine is there was overfitting in the regression model which reduces the latter's predictive or explanatory performance. Overfitting occurs when a statistical model describes random error or noise instead of the underlying relationship.

In the above regression model above, the adjusted $r^{2}$ value of .814 revealed little loss in predictive power when compared to the $r^{2}$ value of .818 . This trivial difference between the adjusted $r 2$ and $r$ values indicated that there was no overfitting in the model that would be shown by a more marked difference between the two values. Moreover, with 17 variables and 900 observations in the model, the model maintained ratio of observations to variables that was far beyond the minimum threshold recommended by Hair et al (2006) which is 20 observations for every predictor or independent variable.

\subsubsection{Ownership and Strategic Posture: Analysis of Variance (ANOVA)}

In determining the explanatory power of the nature of ownership on the strategic posture of firms, a one-way analysis of variance (ANOVA) was performed. Ownership, in this case, was measured in a nominal way such that there were three types of MSMEs: sole proprietorship, partnership, and corporation. This made ANOVA as the appropriate statistical tool to test the hypothesis (Cavana et al., 2001; Field, 2005).

The one-way ANOVA was performed by comparing the strategic posture of firms belonging to three ownership categories namely: sole proprietorship, partnership, and 
corporation. A significant difference was found among the firms $(F(2,897)=5.937, p$ $<.01$ ). Post-hoc test using Least Significant Difference (LSD) was used to determine the nature of the differences between the firms (Field, 2005; Hockberg \& Tamhane, 1987). The LST test result revealed that at .01 level of confidence, corporations tended to be significantly more entrepreneurial in their strategic posture ( $m=3.92, s d$ $=1.38)$ than firms under sole proprietorship $(m=3.53$, $s d=1.37)$. Firms under partnership ownership $(m=3.73, s d=1.35)$ did not differ significantly in their strategic posture from the other two. Furthermore, Games-Howell test (Field, 2005) was also performed considering the unequal sample size amongst the categories of ownership (Field, 2005). The results of the test confirmed the LSD findings. Overall, the results revealed that firms under corporation-ownership tended to be more entrepreneurial in their strategic posture compared to firms under any other types of ownership.

Summary. The summary of results of multiple regression and ANOVA is stated in Table 5.39. The hypotheses are presented according to their order of presentation in Chapter 3 (i.e. Conceptual Framework and Hypothesis Development). 
Table 5.39 Summary of Hypothesis Testing- 1

\begin{tabular}{|c|c|}
\hline Hypotheses & Result \\
\hline $\mathrm{H}_{1}$ - Rule of law is positively associated with entrepreneurial strategic posture. & Supported \\
\hline $\begin{array}{l}\mathrm{H}_{2} \text { - Protection of property rights is positively associated with entrepreneurial strategic } \\
\text { posture. }\end{array}$ & Supported \\
\hline $\begin{array}{l}\mathrm{H}_{3}-\text { Government policies perceived as conducive for MSME business are positively } \\
\text { associated with entrepreneurial strategic posture. }\end{array}$ & Supported \\
\hline $\mathrm{H}_{4}-$ Regulatory quality is positively associated with entrepreneurial strategic posture. & Supported \\
\hline $\mathrm{H}_{5}$ - Government assistance is positively associated with entrepreneurial strategic posture. & Supported \\
\hline $\begin{array}{l}\mathrm{H}_{6} \text { - High levels of performance orientation are positively associated with entrepreneurial } \\
\text { strategic posture. }\end{array}$ & Supported \\
\hline $\begin{array}{l}\mathrm{H}_{7}-\text { High levels of future orientation are positively associated with entrepreneurial } \\
\text { strategic posture. }\end{array}$ & Supported \\
\hline $\begin{array}{l}\mathrm{H}_{9}-\text { High levels of assertiveness are positively associated with entrepreneurial strategic } \\
\text { posture. NB: Hypothesis was not tested because assertiveness was excluded from analysis due to } \\
\text { construct validity issues }\end{array}$ & Not Supported \\
\hline $\begin{array}{l}\mathrm{H}_{9} \text { - High levels of collectivism are negatively associated with entrepreneurial strategic } \\
\text { posture. }\end{array}$ & Not Supported \\
\hline $\begin{array}{l}\mathrm{H}_{10} \text { - High levels of power distance are negatively associated with entrepreneurial strategic } \\
\text { posture. NB: Hypothesis was not tested because power distance was excluded from analysis due } \\
\text { to construct validity issues }\end{array}$ & Not Supported \\
\hline $\begin{array}{l}\mathrm{H}_{11} \text { - High levels of humane orientation are negatively associated with entrepreneurial } \\
\text { strategic posture. }\end{array}$ & Not Supported \\
\hline $\begin{array}{l}\mathrm{H}_{12} \text { - High levels of uncertainty avoidance are negatively associated with entrepreneurial } \\
\text { strategic posture. }\end{array}$ & Not Supported \\
\hline \multicolumn{2}{|l|}{$\begin{array}{l}H_{13} \text { to } H_{17} \text { were tested in subsequent sections and the summaries of results are shown in Tables } \\
5.40,5.44 \text {, and } 5.45\end{array}$} \\
\hline $\begin{array}{l}\mathrm{H}_{18} \text { - High levels of competitive intensity are positively associated with entrepreneurial } \\
\text { strategic posture. }\end{array}$ & Supported \\
\hline $\begin{array}{l}\mathrm{H}_{10} \text { - High levels of industry technological sophistication are positively associated with } \\
\text { entrepreneurial strategic posture. }\end{array}$ & Not supported \\
\hline $\begin{array}{l}\mathrm{H}_{20} \text { - There is a positive relationship between firm size and entrepreneurial strategic } \\
\text { posture. }\end{array}$ & Not supported \\
\hline $\begin{array}{l}\mathrm{H}_{21} \text {-There is a negative relationship between MSME age and entrepreneurial strategic } \\
\text { posture. }\end{array}$ & Not supported \\
\hline $\begin{array}{l}\mathrm{H}_{2} \text { MSMEs under sole proprietorship are less entrepreneurial in their strategic posture } \\
\text { compared to those under partnership and corporate ownership. Specific results: }\end{array}$ & $\begin{array}{l}\text { partially } \\
\text { supported }\end{array}$ \\
\hline \multicolumn{2}{|l|}{$\begin{array}{l}\text { Corporations are more entrepreneunial in their strategic posture compared to sole proprietorship } \\
\text { and partnerships. Sole proprietorships and partnerships did not differ significantly in their } \\
\text { strategic posture. }\end{array}$} \\
\hline $\begin{array}{l}\mathrm{H}_{23} \text { - There is a negative relationship between MSME owner/manager' age and } \\
\text { entrepreneurial strategic posture. }\end{array}$ & Supported \\
\hline $\begin{array}{l}\mathrm{H}_{24} \text { High levels of education of the MSME owner/manager are positively associated with } \\
\text { entrepreneurial strategic posture. }\end{array}$ & Not supported \\
\hline
\end{tabular}


5.12.3. Strategic Posture and Organisational Performance: Multiple Regression Analysis

Multiple regression equations were developed to test the relationship between strategic posture and MSME organisational performance which was represented by three constructs: financial performance, product/service performance and strategic performance. A dummy variable for city (coded as 1 for Tagum City and 0 for Panabo City) was likewise included similar to the regression analysis that was presented in the previous section. These equations are presented in Figure 5.7.

Results of the OLS regression for the three models are presented in Table 5.40. Results supported the hypotheses that an entrepreneurial strategic posture was significantly related to better organisational performance as measured by financial, product/service performance, and strategic performance indicators. The findings suggested that strategic posture had significant explanatory power in relation to product/service performance indicating that a standard deviation (1.38) increase in the scale evaluating strategic posture equalled a .580 standard deviation increase in financial performance after controlling for the effects of city-location of the firms. Moreover, results suggested that almost half of the variation in the level of product/service performance of firms could be accounted for by strategic posture. Strategic posture also predicted well the strategic and financial performance of the firms by .192 and .148 standard deviations respectively after controlling for the effects of city-location of the firms.

Moreover, the significant coefficient of the dummy variable for city suggested that respondents from Tagum City tend to report higher levels of financial, product/service, and strategic performance relative to those from Panabo City controlling for other independent variables used in the regression equation. 
Figure 5.7 Regression Equations for Strategic Posture and Three Facets of Organisational Performance

a. Strategic Posture and Financial Performance

Model 1. Strategic Posture - Financial Performance

$$
F P=\alpha_{6}+\beta_{18}(S P)+\ell_{6}
$$

Model 2. Strategic Posture - Financial Performance with City as Control Variable

$$
F P=\alpha_{7}+\beta_{18}(S P)+\beta_{19}(d v c)+\ell_{7}
$$

b. Strategic Posture and Product/Service Performance

Model 1. Strategic Posture - Product/Service Performance

$$
P S P=\alpha_{8}+\beta_{18}(S P)+\ell_{8}
$$

Model 2. Strategic Posture - Product/Service Performance with City as Control Variable

$$
P S P=\alpha_{9}+\beta_{18}(S P)+\beta_{19}(d v c)+\ell_{9}
$$

c. Strategic Posture and Strategic Performance

Model 1. Strategic Posture - Strategic Performance

$$
\operatorname{SratP}=\alpha_{10}+\beta_{18}(S P)+\ell_{10}
$$

Model 2. Strategic Posture - Strategic Performance with City as Control Variable

$$
\operatorname{SratP}=\alpha_{11}+\beta_{18}(S P)+\beta_{19}(d v c)+\ell_{11}
$$

where:

$\begin{array}{lll}\mathrm{FP} & = & \text { financial performance } \\ \mathrm{PSP} & = & \text { product/service performance } \\ \mathrm{SratP} & = & \text { strategic performance } \\ \mathrm{SP} & = & \text { strategic posture } \\ \alpha_{6-11}= & \text { intercepts } \\ \beta_{18-21}= & \text { slope coefficients } \\ \mathrm{dvc}= & \text { dummy variable for city (1 for Tagum and } 0 \text { for Panabo) } \\ \ell_{6-11}= & \text { error term }\end{array}$


Table 5.40 Regression Model on Strategic Posture and Organisational Performance

\begin{tabular}{lcccccc}
\hline \multicolumn{1}{c}{ Independent $\rightarrow$ Dependent Variables } & standardised & & \multicolumn{3}{c}{ Durbin- F-value } & sig. \\
& $\beta$ & p values & $r^{2}$ & Watson & & \\
\hline Strategic Posture $\rightarrow$ Financial Performance & .343 & .000 & .118 & 2.024 & 120.065 & .000 \\
Strategic Posture $\rightarrow$ Financial Performance & .148 & .008 & .135 & 2.024 & 69.902 & .000 \\
dummy variable for city & .234 & .000 & & & & \\
\hline Strategic Posture $\rightarrow$ Product/Service Performance & .656 & .000 & .430 & 1.549 & 678.312 & .000 \\
Strategic Posture $\rightarrow$ Product/Service Performance & .580 & .000 & .433 & 1.549 & 342.366 & .000 \\
dummy variable for city & .092 & .043 & & & & \\
\hline Strategic Posture $\rightarrow$ Strategic Performance & .376 & .000 & .141 & 1.290 & 147.543 & .000 \\
Strategic Posture $\rightarrow$ Strategic Performance & .192 & .001 & .156 & 1.290 & 83.011 & .000 \\
dummy variable for city & .221 & .000 & & & & \\
\hline
\end{tabular}

As suggested by the $r^{2}$, the effect sizes for the strategic posture $\rightarrow$ financial performance path and strategic posture $\rightarrow$ strategic performance path were considered medium effects whilst the effect size for the strategic posture $\rightarrow$ product/service performance path was deemed large effect (Field, 2005). These indicators of effect size suggested that despite having small yet significant beta coefficients, the latter may be considered practically significant and meaningful from which inferences could be drawn (Cohen, 1992; Field, 2005; Pedhazur, 1982).

Furthermore, diagnostics of the histogram and residual plots of the four variables did not suggest any issues at all. Nonetheless, regression using ROBUST method was performed and similar results were obtained in terms of the significant relationships between/amongst variables as shown in Table 5.41. Under ROBUST regression, however, the strategic posture $\rightarrow$ financial performance path coefficient increased (from .148 under OLS) to .502 . The strategic posture $\rightarrow$ product/service performance path coefficient increased (from .580 under OLS) to 1.716 . The strategic posture $\rightarrow$ strategic performance path coefficient increased (from .192 under OLS) to .570 . Similar to the OLS method, all these coefficients were derived after controlling for the effects of city location of the respondents. 
Table 5.41 Regression Model on Strategic Posture and Organisational Performance using ROBUST Method

\begin{tabular}{l|r|r|}
\hline \multicolumn{1}{|c|}{ Independent $\longrightarrow$ Dependent Variables } & \multicolumn{1}{c|}{$\beta$} & \multicolumn{1}{c|}{$F$ value } \\
\hline Strategic Posture $\longrightarrow$ Financial Performance & $1.022^{*}$ & $(1,898) 111.090^{*}$ \\
\hline Strategic Posture $\longrightarrow$ Financial Performance & $.502^{*}$ & \\
dummy variable for city & $1.723^{*}$ & $(2,897) 62.410^{*}$ \\
\hline Strategic Posture $\longrightarrow$ Product/Service Performance & $1.915^{*}$ & $(1,898) 677.890^{*}$ \\
\hline Strategic Posture $\longrightarrow$ Product/Service Performance & $1.716^{*}$ & $(2,897)$ \\
dummy variable for city & $.655^{*}$ & $(2,897) 341.700^{*}$ \\
\hline Strategic Posture $\longrightarrow$ Strategic Performance & $1.047^{*}$ & $(1,898) 122.380^{*}$ \\
\hline Strategic Posture $\longrightarrow$ Strategic Performance & $.570^{*}$ & \\
dummy variable for city & $1.577^{*}$ & $(2,897) 67.070^{*}$ \\
\hline${ }^{*}$ significant at $p<.01$ & & \\
\hline
\end{tabular}

As a form of model validation, the $r^{2}$ and adjusted $r^{2}$ were compared. In the regression model above, the adjusted $r^{2}$ values revealed little loss (i.e. lesser than the $r^{2}$ by .001 to .002$)$ in predictive power when compared to the $r^{2}$ values which suggested that there was no over fitting in the model that would otherwise be shown by a more marked difference between the two values (Hair et al., 2006).

Regression analysis was also performed on the 13 indicators of organisational performance with strategic posture as the predictor variable. As shown in Table 5.42, strategic posture significantly explained well the variations of all the indicators of organisational performance. It could be noted from the model that amongst the organisational performance indicators, customer satisfaction has the highest beta coefficient of 2.433 and $r^{2}$ of .41 suggesting that $41 \%$ of the variance in the performance of firms in terms of customer satisfaction could be explained well by an entrepreneurial strategic posture of these firms. Likewise, an entrepreneurial strategic posture is positively associated with higher levels of sales, product/quality, product/service development, and market share. 
Table 5.42 Regression Model on Strategic Posture as Independent Variable and Individual Indicators of Organisational Performance as Dependent Variables

\begin{tabular}{|c|c|c|c|c|c|}
\hline Organisational Performance & $\beta$ & sig. & $r^{2}$ & F value & $p$ \\
\hline \multicolumn{6}{|l|}{ Indicators as Dependent Variables } \\
\hline product/service development & 1.472 & .000 & .21 & 235.007 & .000 \\
\hline product/service quality & $1.679^{\circ}$ & .000 & .26 & 324.590 & .000 \\
\hline customer satisfaction & $2.433^{\prime}$ & .000 & .41 & $623.307^{\prime \prime}$ & .000 \\
\hline process improvement & $.9207^{\prime}$ & .000 & .06 & $59.771^{\prime \prime}$ & .000 \\
\hline attraction of skilled labour & 1.119 & .000 & .09 & $91.573^{\prime \prime}$ & .000 \\
\hline retention of skilled labour & 1.331 & .000 & .15 & 159.772 & .000 \\
\hline market share & 1.370 & .000 & .14 & 143.733 & .000 \\
\hline growth of market share & $.702^{\prime}$ & .000 & .05 & 49.103 & .000 \\
\hline sales & $1.905^{\prime}$ & .000 & .27 & 336.891 & .000 \\
\hline sales growth & $.918^{\prime}$ & .000 & .08 & 77.725 & .000 \\
\hline net income & $.954^{\prime \prime}$ & .000 & .07 & $72.498^{\prime \prime}$ & .000 \\
\hline growth of net income & $1.157^{\prime}$ & .000 & .11 & 104.953 & .000 \\
\hline return on investment & 1.103 & .000 & .10 & 101.727 & .000 \\
\hline independent variable: & & & & & \\
\hline
\end{tabular}

Summary. A summary of the results of the preceding hypothesis testing is shown in Table 5.43. 
Table 5.43 Summary of Hypothesis Testing - 2

\begin{tabular}{|c|c|}
\hline Hypotheses & Findings \\
\hline $\begin{array}{c}\mathrm{H}_{13 \mathrm{a}} \text { - There is a positive relationship between MSMEs' } \\
\text { entrepreneurial strategic posture and product/service } \\
\text { performance. }\end{array}$ & Supported \\
\hline $\begin{array}{c}\mathrm{H}_{13 \mathrm{~b}} \text { - There is a positive relationship between MSMEs' } \\
\text { entrepreneurial strategic posture and strategic performance. }\end{array}$ & Supported \\
\hline $\begin{array}{c}\mathrm{H}_{13 \mathrm{c}} \text { - There is a positive relationship between MSMEs' } \\
\text { entrepreneurial strategic posture and financial performance. }\end{array}$ & Supported \\
\hline $\begin{array}{l}\mathrm{H}_{14}-\text { An entrepreneurial strategic posture is positively related to } \\
\text { the product/service and strategic performance measures } \\
\text { namely: } \\
\mathrm{H}_{14 \mathrm{a}} \quad \text { development of new products or services; } \\
\mathrm{H}_{14 \mathrm{~b}} \quad \text { product or service quality; } \\
\mathrm{H}_{14 \mathrm{c}} \quad \text { customer satisfaction; } \\
\mathrm{H}_{14 \mathrm{~d}} \quad \text { improvements in business/production } \\
\text { processes; } \\
\mathrm{H}_{14 \mathrm{e}} \quad \text { attraction of essential employees; } \\
\mathrm{H}_{14 \mathrm{f}} \quad \text { retention of essential employees; } \\
\mathrm{H}_{14 \mathrm{~g}} \quad \text { market share; } \\
\mathrm{H}_{14 \mathrm{~h}} \quad \text { growth of market share; and } \\
\mathrm{H}_{14 \mathrm{i}} \quad \text { sales. }\end{array}$ & Supported \\
\hline $\begin{array}{l}\mathrm{H}_{15}-\text { An entrepreneurial strategic posture is positively related to the } \\
\text { financial performance measures namely: } \\
\qquad \begin{array}{ll}H_{15 a} \quad \text { sales growth; } \\
H_{15 b} \quad \text { net income; } \\
H_{15 c} \quad \text { net income growth; and } \\
H_{15 d} \quad \text { return on investment. }\end{array}\end{array}$ & Supported \\
\hline
\end{tabular}


5.12.4. Formal/Informal Institutions - Strategic Posture - Organisational Performance: A Mediation Analysis

In order to establish the direct or indirect relationships (i.e. to establish mediation) between the formal/institutions and organisational performance, the prescription of Baron and Kenny (1986) was followed in analysing mediation. Mediation is a hypothesised chain of variables in which one variable (the independent variable) relates to a second variable (the intervening variable) that, in turn, relates to a third variable (the dependent variable). The intervening variable is called 'mediating variable' as it "mediates" the relationship between a predictor (the independent variable), and an outcome (the dependent variable). The analysis requires the determination of the direct effects of the predictor on the outcome variable as well as the indirect effect accounted for by the presence of the mediating variable. The steps of mediation analysis are outlined below.

Step 1. Determine if there is/are significant relationship/s between the formal/informal institutions and organisational performance. Details are shown in Table 5.44.

Results of step 1 analysis showed that:

a. rule of law, government policies and government assistance were significantly and positively related with high levels of product/service performance;

b. uncertainty avoidance was significantly and negatively related with high levels of product/service performance;

c. government policies were significantly associated with high levels of strategic performance; and

d. uncertainty avoidance was positively associated with high levels of financial performance. 
Table 5.44 OLS Regression on Formal and Informal Institutions as Independent Variables and the Three Sub-dimensions of Organisational Performance as Dependent Variables

\begin{tabular}{|c|c|c|c|c|c|c|}
\hline Variables & $\beta$ & $p$ & $r^{2}$ & $\begin{array}{l}\text { Durbin- } \\
\text { Watson }\end{array}$ & F values & $p$ \\
\hline Product/Service Performance \& & & & .411 & 1.632 & 56.278 & .000 \\
\hline rule of law & .314 & $.000 *$ & & & & \\
\hline protection of property rights & .033 & .493 & & & & \\
\hline government policies & .172 & $.007 *$ & & & & \\
\hline regulatory quality & .096 & .074 & & & & \\
\hline government assistance & .131 & .000 * & & & & \\
\hline performance orientation & .048 & .063 & & & & \\
\hline future orientation & .021 & .437 & & & & \\
\hline collectivism & .008 & .759 & & & & \\
\hline humane orientation & -.012 & .668 & & & & \\
\hline uncertainty avoidance & -.059 & $.031 * *$ & & & & \\
\hline dummy variable for city & -.002 & .980 & & & & \\
\hline Strategic Performance * & & & .157 & 1.300 & 15.025 & .000 \\
\hline rule of law & .086 & .151 & & & & \\
\hline protection of property rights & .031 & .593 & & & & \\
\hline government policies & .157 & $.040 * *$ & & & & \\
\hline regulatory quality & .010 & .877 & & & & \\
\hline government assistance & -.010 & .764 & & & & \\
\hline performance orientation & -.015 & .634 & & & & \\
\hline future orientation & -.032 & .320 & & & & \\
\hline collectivism & -.015 & .626 & & & & \\
\hline humane orientation & .009 & .772 & & & & \\
\hline uncertainty avoidance & .057 & .085 & & & & \\
\hline dummy variable for city & .150 & .156 & & & & \\
\hline Financial Performance ^ & & & .142 & 2.063 & 13.340 & .000 \\
\hline rule of law & .056 & .355 & & & & \\
\hline protection of property rights & .040 & .493 & & & & \\
\hline government policies & .114 & .137 & & & & \\
\hline regulatory quality & .034 & .605 & & & & \\
\hline government assistance & -.015 & .645 & & & & \\
\hline performance orientation & .000 & .990 & & & & \\
\hline future orientation & -.018 & .587 & & & & \\
\hline collectivism & .013 & .679 & & & & \\
\hline humane orientation & .025 & .449 & & & & \\
\hline uncertainty avoidance & .093 & $.005 *$ & & & & \\
\hline dummy variable for city & .166 & .120 & & & & \\
\hline $\begin{array}{l}{ }^{*} \text { significant at } p<.01 \\
{ }^{* *} \text { significant at } p<.05 \\
* \text { dependent variable }\end{array}$ & & & & & & \\
\hline
\end{tabular}


Step 2. Using the variables having significant relationships with organisational performance, the analysis proceeded to determine if these variables had significant relationships with strategic posture. This had been determined using Table 5.36 presented above - a section of which is reproduced below (Table 5.45):

Table 5.45 OLS Regression Model on Institutions and Strategic Posture

\begin{tabular}{|c|c|c|}
\hline Independent Variables & $\beta$ & \\
\hline rule of law & .167 & * \\
\hline protection of property rights & .056 & ** \\
\hline government policy & .205 & * \\
\hline regulatory quality & .126 & * \\
\hline government assistance & .119 & * \\
\hline performance orientation & .045 & * \\
\hline future orientation & .064 & * \\
\hline collectivism & -.008 & \\
\hline humane orientation & .004 & \\
\hline uncertainty avoidance & .004 & \\
\hline$r^{2}$ & .818 & \\
\hline$F$ value & 232.430 & * \\
\hline \multicolumn{3}{|c|}{ Dependent Variable: Strategic Posture } \\
\hline${ }^{*} p<.001$ & & \\
\hline${ }^{* *} p<.05$ & & \\
\hline
\end{tabular}

The results indicated that:

a. rule of law, government policies, and government assistance were positively and significantly related to entrepreneurial strategic posture.

b. uncertainty avoidance was not significantly related with strategic posture.

After comparing the results in Tables 5.44 and 5.45, it was clear that there was mediation in the case of (a) and no mediation (i.e. only direct effect) in the case of (b). Therefore, only the variables rule of law, government policies, and government assistance were analysed to determine if their relationships with organisational 
performance were mediated by strategic posture and if they were, the extent of mediation.

Step 3. Determine if there is partial or full mediation in the case of (a) in step 2. This was done by examining the changes in the values of the beta coefficients and their corresponding significance of the variables involved. Hair et al (2007) offer the following general guidelines:

a. if the relationship (measured/represented by the $\beta$ coefficient) between the independent variable and dependent variable is reduced when the mediating variable is considered but remains significant, then there is partial mediation; and

b. if the relationship between the independent variable and the dependent variable is reduced when the mediating variable is considered such that it is no longer significant, then there is full or complete mediation.

However, it was also important to determine the significance of the difference between the total effect (i.e. effects of both independent and mediating variables on the dependent variable), and the direct effect (i.e. effect of the independent variable on the dependent variable) to sustain the argument that there was mediation (Tabachnick \& Fidell, 2005). Three related tests were applied in this research for that purpose as recommended by previous studies (Baron \& Kenny, 1986; Preacher $\&$ Hayes, 2004). The Sobel test (Sobel, 1982) will determine whether the indirect effect of the independent variable on the dependent variable through the mediating variable is significantly different from zero. Because of the inherent limitations of the Sobel test, two other tests were included for confirmatory purposes as recommended by authorities on the subject (Preacher \& Hayes, 2004). The Goodman test and its improved version, the Goodman II test were also applied. These three tests will produce the statistic, which when significant at .01 or .05 level of confidence, will confirm the presence and extent of mediation (Goodman, 1960; Preacher \& Hayes, 2004).

As can be shown in Table 5.46, analysis one examined the different independent variables in relation to a specific dependent variable. It was previously noted that 
only those independent variables which have direct and significant relationships with the mediating variable (i.e. strategic posture) and with the three organisational performance variables should be examined for mediation (Baron \& Kenny, 1986). All the beta coefficients were significant - implying that the relationships were significant. Analysis two examined the different independent variables in relation to the mediating variable (i.e. strategic posture). Similarly, the beta coefficients were significant implying that the relationships were likewise significant.

Analysis three examined both the independent variables and the mediating variable as they simultaneously related to the dependent variables. As expected, the beta coefficients were all significant implying that both had significant relationship with the dependent variables. However, in this stage of the analysis, the beta coefficients of the independent variable in relation to the dependent variable suffered reduction in value despite maintaining their level of significance. The difference is shown in the row: delta change $(\Delta \beta)$ of the beta coefficients. These changes in the values despite remaining significant suggested that the relationship between a specific independent variable and a specific dependent variable in the table was partially mediated by the mediating variable (strategic posture).

The presence of partial mediation was confirmed by the Sobel, Goodman and Goodman II tests indicating that the indirect effect of the specific independent variable on the specific dependent variable through the mediating variable was significantly different from zero. The $\mathrm{p}$ values $<.01$ indicated that there was partial mediation amongst the variables considered in the mediation analysis. 
Table 5.46 Mediation Analysis and Post-Hoc Tests

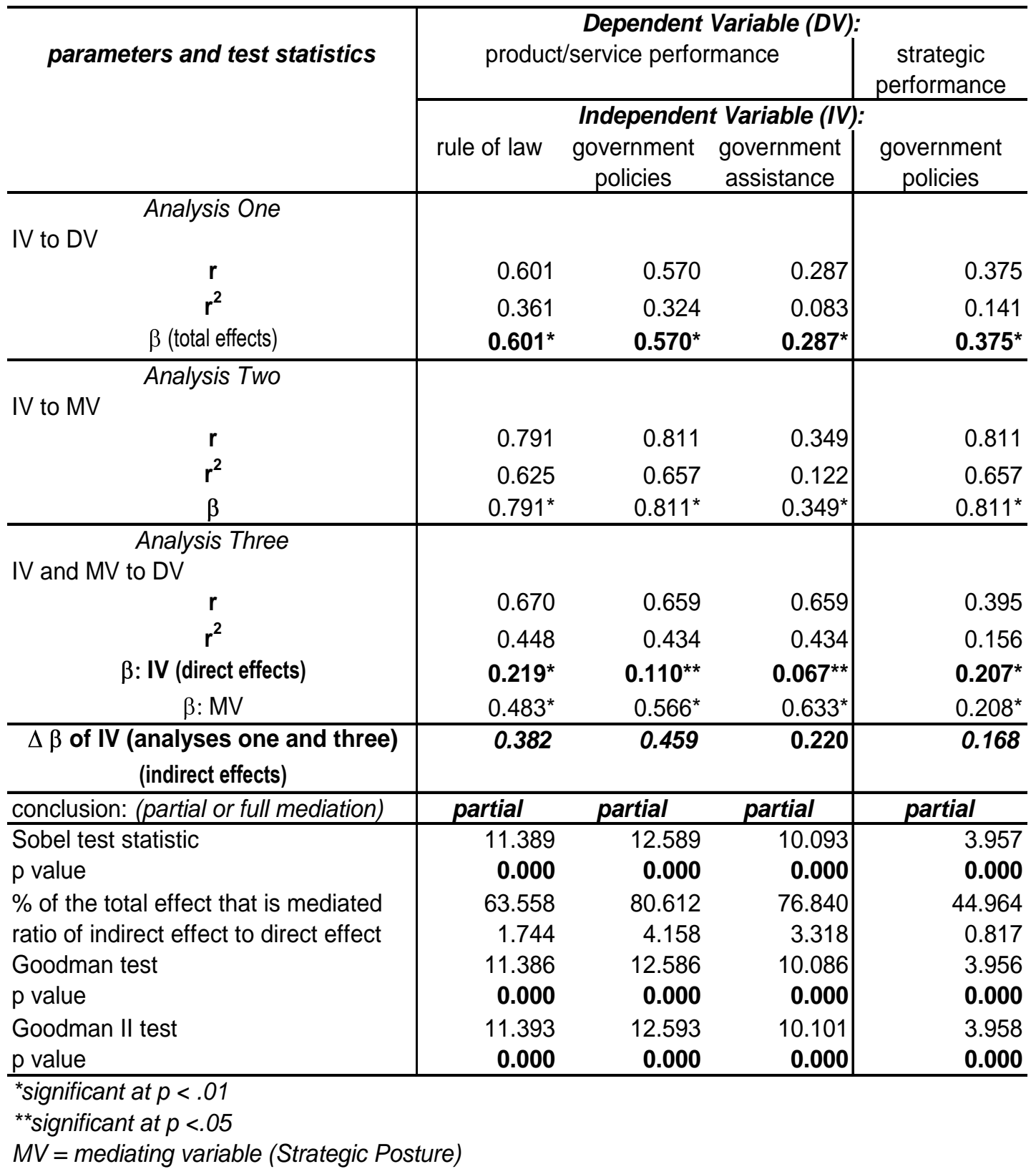

A closer examination of the results indicated that $80.61 \%$ of the "effect' of government policies on product/service performance was accounted for by strategic posture as the mediating variable. This suggests that a large part of the magnitude of the relationship between government policies and product/service performance was accounted for by the partial mediating role of strategic posture. 
Likewise, strategic posture accounted for $63.56 \%$ and $76.84 \%$ respectively, the rule of law $\rightarrow$ product/service performance and government assistance $\rightarrow$ product/service performance relationships. This result implies that the three formal institutions (i.e. rule of law, government policies, and government assistance) had direct and indirect effects on the level of product/service performance of firms with more than half of the total effects explained by strategic posture being the mediating variable. On the other hand, the results show that strategic posture accounted for $44.96 \%$ the government policies $\rightarrow$ strategic performance relationship.

These results of mediation analysis suggested that strategic posture partially mediated the relationships between these three types of institutions and two aspects of organisational performance.

Summary. The summaries of the results of mediation analysis with respect to the hypotheses are presented in Tables 5.47 and 5.48. 
Table 5.47 Summary of Hypothesis Testing on Institutions-Organisational Performance Linkages

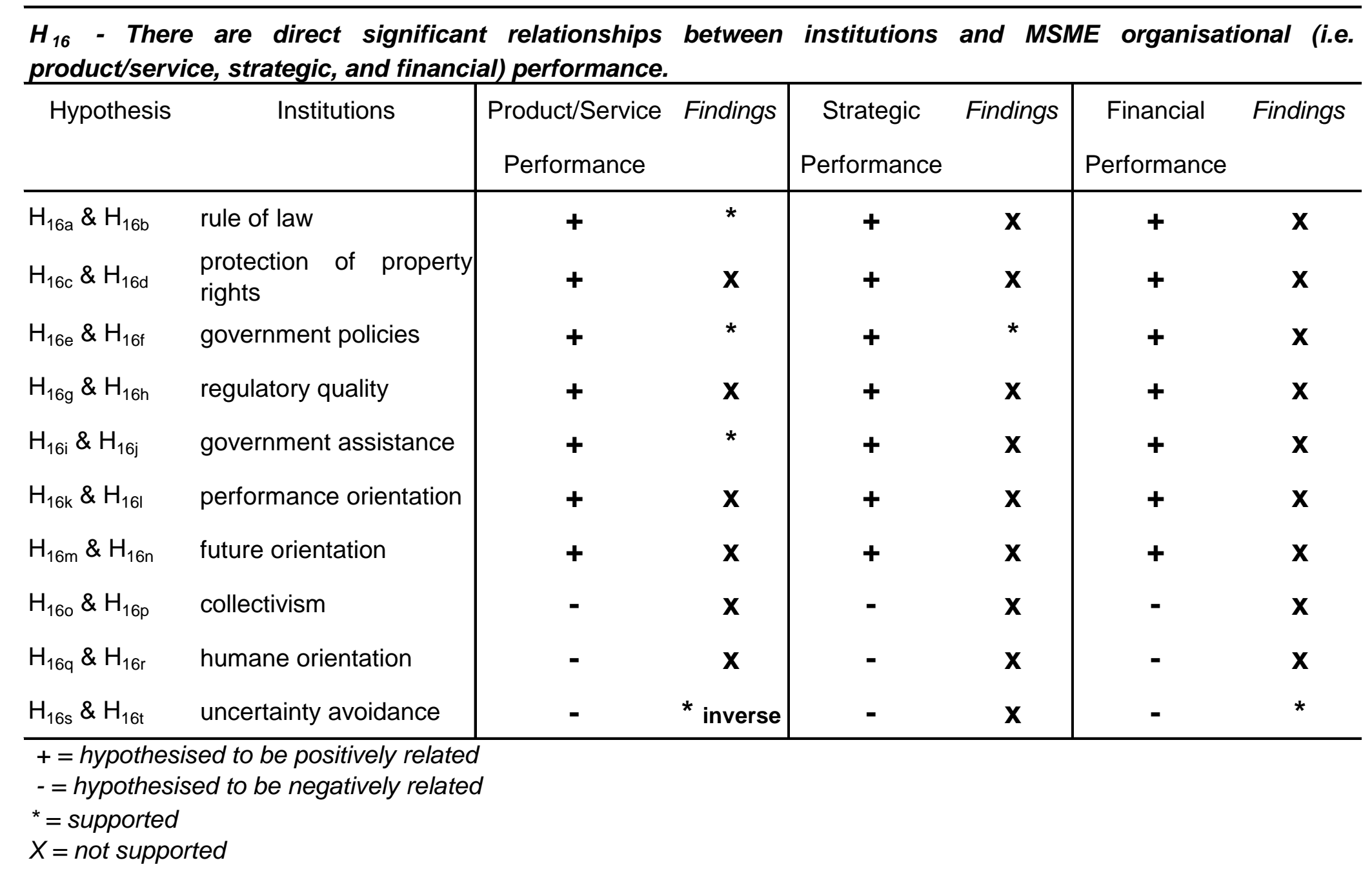


Table 5.48 Summary of Hypothesis Testing - 3

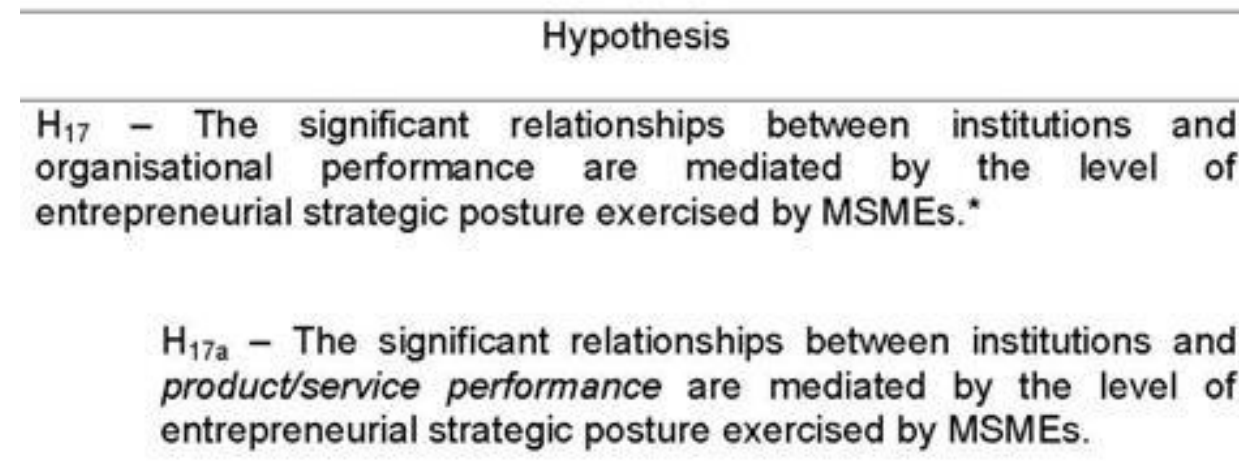

$\mathrm{H}_{17 a-1}$ - The significant relationship between rule of law and product/service performance is mediated by the level of entrepreneurial strategic posture exercised by MSMEs.

$\mathrm{H}_{17 \mathrm{a}-2}$ - The significant relationship between government policies and product/service performance is mediated by the level of entrepreneurial strategic posture exercised by MSMEs.

Supported; partial mediation only

Supported; partial mediation only

$\mathrm{H}_{17 \mathrm{a}-3}$ - The significant relationship between government assistance and product/service performance is mediated by the level of entrepreneurial strategic posture exercised by MSMEs.

$\mathrm{H}_{17 \mathrm{~b}}$ - The significant relationships between institutions and strategic performance are mediated by the level of entrepreneurial strategic posture exercised by MSMEs.

$\mathrm{H}_{17 b-1}$ - The significant relationship between government policies and strategic performance is mediated by the level of entrepreneurial strategic posture exercised by MSMEs

Supported;

partial mediation only

*original hypothesis as per research proposal 
5.12.5. Indices of Formal and Informal Institutions - Strategic Posture: Multiple Regression Analysis

The fundamental argument advanced in this study was that formal and informal institutions at the city level would have significant impact on firm-level phenomena, i.e. strategic posture and organisational performance. In order to facilitate anlaysis at an aggregate level, it was decided that a composite score or index should be developed for the formal and informal institutions by getting the average of the mean values of the variables (i.e. five formal and five informal) under each category of institutions. This process of index development is consistent with the approach called "total aggregation" of latent variables (Bagozzi \& Heatherton, 1994) whereby a single composite is formed by combining all of the measures of the variables subsumed under each category of institutions. Each component of the index was given equal weight consistent with the prescription of Babbie (2007 p. 159) stating that "all items be weighted equally unless there are compelling reasons for differential weighting”. Slotjje (1991 pp. 686-688) calls this an 'attributes-based' weighting system "whereby no explicit weighting is introduced other than that implicitly introduced during the scaling of the variables".

In developing the index for the informal institutions, the scales for the variables collectivism, humane orientation, and uncertainty avoidance were reversed to bring their polarity in line with the majority of other variables, and to ensure all scores were 'positive'. Booysen (2002) posits that the components of an index must be parallel with each other to come up with a meaningful and easily interpreted index.

Subsequently, strategic posture and organisational performance (product/service performance, strategic performance, and financial performance) were then regressed with the derived formal and informal institution indices. The multiple regression equations are shown in Figure 5.8. 
Figure 5.8 Regression Equations on Indices of Institutions and Strategic Posture

Model 1

$$
S P=\alpha_{12}+\beta_{20}(F I)+\ell_{12}
$$

Model 2

$$
S P=\alpha_{13}+\beta_{20}(F I)+\beta_{21}(I I)+\ell_{13}
$$

Model 3

$$
S P=\alpha_{14}+\beta_{20}(F I)+\beta_{21}(I I)+\beta_{22}(d v c)+\ell_{14}
$$

where:

$$
\begin{array}{lll}
\mathrm{SP} & = & \text { strategic posture } \\
\mathrm{FI} & = & \begin{array}{l}
\text { index of five formal institutions (i.e. overall average of the } \\
\text { means of the five formal institution variables) }
\end{array} \\
\mathrm{II} & = & \begin{array}{l}
\text { index of informal institutions (i.e. overall average of the means } \\
\text { of the five informal institution variables }
\end{array} \\
\mathrm{dvc}= & \text { dummy variable for city (1 for Tagum and } 0 \text { for Panabo) } \\
\alpha_{12-14}= & \text { intercepts } \\
\beta_{27-32}= & \text { slope coefficients } \\
\ell_{12-14}= & \text { error term }
\end{array}
$$

The results as shown in Table 5.49 indicated that both indices of the formal and informal institutions explained $76.6 \%$ of the variance in the strategic posture of firms. However, the index of formal institutions had greater explanatory power on the strategic posture of firms relative to the index of informal institutions.

Similar results in terms of the significant coefficients were generated when regression with ROBUST method was used. However, the formal institutions $\rightarrow$ strategic posture path coefficient decreased (from .724 under OLS) to .587 whilst the 
informal institutions $\rightarrow$ strategic posture path coefficient increased (from .088 under OLS) to .234 .

Table 5.49 Regression with Formal and Informal Institution Indices-Part 1

\begin{tabular}{|c|c|c|c|c|c|c|c|c|c|c|}
\hline Model & $\begin{array}{c}\text { Independent } \\
\text { Variables }\end{array}$ & & $\begin{array}{c}\text { Dependent } \\
\text { Variable }\end{array}$ & $\begin{array}{c}\text { standardised } \\
\beta\end{array}$ & $p$ values & $r^{2}$ & $\Delta r^{2}$ & $\begin{array}{l}\text { Durbin- } \\
\text { Watson }\end{array}$ & $F$-value & sig. \\
\hline 1 & Formal Institutions & $\rightarrow$ & Strategic Posture & .870 & .000 & .756 & - & 1.484 & 2787.171 & .000 \\
\hline \multirow[t]{2}{*}{2} & Formal Institutions & & Strategic Posture & .857 & .000 & .764 & .008 & 1.484 & 1449.285 & .000 \\
\hline & Informal Institutions & J & & .087 & .000 & & & & & \\
\hline \multirow[t]{3}{*}{3} & Formal Institutions & & & .724 & .000 & .766 & .002 & 1.484 & 978.053 & .000 \\
\hline & Informal Institutions & & Strategic Posture & .088 & .000 & & & & & \\
\hline & dummy variable for city & J & & .141 & .003 & & & & & \\
\hline
\end{tabular}

Furthermore, the significant coefficient of the dummy variable for city suggested that respondents from Tagum City tend to report higher levels of entrepreneurial strategic posture relative to those from Panabo City controlling for other independent variables used in the regression equation.

As a form of model validation, the $r^{2}$ and adjusted $r^{2}$ were compared. In the regression model above, the adjusted $r^{2}$ value (.765) revealed little loss in predictive power when compared to the $r^{2}$ value (.766) which indicated that there was no overfitting in the model that would have been shown by a more marked difference between the two values (Hair et al., 2006).

5.12.6. Indices of Formal and Informal Institutions - Organisational Performance: Multiple Regression Analysis

The three categories of organisational performance were also regressed with the two indices of institutions. The regression equations are shown in Figure 5.9. 
Figure 5.9 Regression Equations on Indices of Institutions and Strategic Posture

a. Product Service Performance

Model $1 \quad P S P=\alpha_{15}+\beta_{23}(F I)+\ell_{15}$

Model $2 \quad P S P=\alpha_{16}+\beta_{23}(F I)+\beta_{24}(I I)+\ell_{16}$

Model $3 \quad P S P=\alpha_{17}+\beta_{23}(F I)+\beta_{24}(I I)+\beta_{25}(d v c)+\ell_{17}$

b. Strategic Performance

Model $1 \quad$ StratP $=\alpha_{18}+\beta_{26}(F I)+\ell_{18}$

Model $2 \quad$ StratP $=\alpha_{19}+\beta_{26}(F I)+\beta_{27}(I I)+\ell_{19}$

Model $3 \quad$ StratP $=\alpha_{20}+\beta_{26}(F I)+\beta_{27}(I I)+\beta_{28}(d v c) \ell_{19}$

c. Financial Performance

Model $1 \quad F P=\alpha_{21}+\beta_{29}(F I)+\ell_{21}$

Model $2 \quad F P=\alpha_{22}+\beta_{29}(F I)+\beta_{30}(I I)+\ell_{22}$

Model $3 \quad F P=\alpha_{23}+\beta_{29}(F I)+\beta_{30}(I I)+\beta_{31}(d v c)+\ell_{23}$

where:

$\mathrm{PSP}=$ product/service performance

StratP $=\quad$ strategic performance

$\mathrm{FP}=$ financial performance

FI $=$ index of five formal institutions (i.e. overall average of the means of the five formal institution variables)

II $=$ index of informal institutions (i.e. overall average of the means of the

$\alpha_{15-23}=$ intercepts

$\beta_{23-31}=$ slope coefficients

$\ell_{15-23}=$ error term 
Results of the regression in Table 5.50 showed that the independent variables explained $39.4 \%, 15.1 \%$, and $13.5 \%$ of the variance in the firms' product/service performance, strategic performance, and financial performance respectively. The results did not support the link between the index of formal institutions and financial performance. Likewise, the results did not support the link between the index of informal institutions and strategic performance/financial performance.

Furthermore, the significant coefficients of the dummy variable for city suggested that respondents from Tagum City tend to report higher levels of strategic performance and financial performance respectively, relative to those from Panabo City controlling for other independent variables used in the regression equation.

As a form of model validation, the $r^{2}$ and adjusted $r^{2}$ were compared. In the regression model above, the adjusted $r^{2}$ values revealed little loss (i.e. lesser than the $r^{2}$ by .001 to .002$)$ in predictive power when compared to the $r^{2}$ values which indicated that there was no over-fitting in the model that would have been shown by a more marked difference between the two values (Hair et al., 2006).

Table 5.50 Regression with Formal and Informal Institution Indices-Part 2

\begin{tabular}{|c|c|c|c|c|c|c|c|c|}
\hline Models & $\begin{array}{c}\text { Independent } \\
\text { Variables }\end{array}$ & $\begin{array}{l}\text { Dependent } \\
\text { Variables }\end{array}$ & $\begin{array}{c}\text { standardised } \\
\beta\end{array}$ & $\begin{array}{c}p \\
\text { values }\end{array}$ & $r^{2}$ & $\Delta r^{2}$ & $F$-value & sig. \\
\hline 1 & Formal Institutions & Product/Service Performance & .623 & .000 & .389 & & 570.550 & .000 \\
\hline \multirow[t]{2}{*}{2} & Formal Institutions & Product/Service Performance & .613 & .000 & & & & \\
\hline & Informal Institutions & & .069 & .009 & .393 & .004 & 290.608 & .000 \\
\hline \multirow[t]{3}{*}{3} & Formal Institutions & Product/Service Performance & .692 & .000 & & & & \\
\hline & Informal Institutions & & .068 & .000 & & & & \\
\hline & dummy variable for city & & -.085 & .261 & .394 & .001 & 194.218 & .000 \\
\hline 1 & Formal Institutions & Strategic Performance & .377 & .000 & .142 & & 148.394 & .000 \\
\hline \multirow[t]{2}{*}{2} & Formal Institutions & Strategic Performance & .385 & .000 & & & & \\
\hline & Informal Institutions & & -.059 & .061 & .145 & .003 & 74.115 & .000 \\
\hline \multirow[t]{3}{*}{3} & Formal Institutions & Strategic Performance & .175 & .050 & & & & \\
\hline & Informal Institutions & & -.056 & .070 & & & & \\
\hline & dummy variable for city & & .224 & .012 & .151 & .006 & & \\
\hline 1 & Formal Institutions & Financial Performance & .351 & .000 & .123 & & 125.952 & .000 \\
\hline \multirow[t]{2}{*}{2} & Formal Institutions & Financial Performance & .346 & .000 & & & & \\
\hline & Informal Institutions & & .043 & .174 & .128 & .005 & 65.947 & .000 \\
\hline \multirow[t]{3}{*}{3} & Formal Institutions & Financial Performance & .141 & .118 & & & & \\
\hline & Informal Institutions & & -.071 & .052 & & & & \\
\hline & dummy variable for city & & .235 & .009 & .135 & .007 & 46.535 & .000 \\
\hline
\end{tabular}


5.12.7. Formal Institutions-Strategic Posture-Organisational Performance: $A$ Mediation Analysis

The conceptual framework of the study emphasised the mediating role of strategic posture between the various forms of institutions and organisation performance. Hence, it was necessary to determine the nature and magnitude of mediation present in these relationships of variables. The previous section had established that only the index of formal institution had significant relationships with product/service performance and strategic performance. The index of informal institutions, however, was shown to be significantly associated with product/service performance (see Table 5.49). Using the same process outlined in section 5.11.4. mediation analysis was performed with these variables.

The results of the mediation analysis are presented in Table 5.51. The relationships between the index of formal institutions and that of product/service performance and strategic performance were shown to be significant at .01 level of confidence as shown in analysis one. At the same level of confidence, the index of informal institutions showed significant relationship with product/service performance.

In the case of the index of formal institutions $\rightarrow$ strategic posture $\rightarrow$ product/service performance path, the coefficient decreased but remained significant when the effects of strategic posture was controlled for in the regression suggesting the presence of partial mediation.

The results further show that $49.10 \%$ of the effects of the index of formal institutions on product/service performance were accounted for by strategic posture. The Sobel (1982) and Goodman (1960) tests indicated that the indirect effects of the independent variables to the dependent variables were significantly greater than zero suggesting partial mediation. In the case of the index of formal institutions $\rightarrow$ strategic posture $\rightarrow$ strategic performance path, the coefficient of the index decreased (from .175 to .026 standard deviations) and became insignificant when the effects of strategic posture was controlled for in the regression suggesting the presence of full mediation based on Baron's and Kenny’s (1986) procedures . 
Table 5.51 Mediation Analysis and Post-Hoc Tests - Part 2

\begin{tabular}{|c|c|c|c|}
\hline \multirow{4}{*}{ parameters and test statistics } & \multicolumn{3}{|c|}{ Dependent Variables (DV): } \\
\hline & $\begin{array}{l}\text { product/service } \\
\text { performance }\end{array}$ & $\begin{array}{l}\text { strategic } \\
\text { performance }\end{array}$ & $\begin{array}{c}\text { product/service } \\
\text { performance }\end{array}$ \\
\hline & \multicolumn{3}{|c|}{ Independent Variable (IV): } \\
\hline & \multicolumn{2}{|c|}{ index of formal institutions } & index of informal institutions \\
\hline Analysis One & & & \\
\hline IV to DV & & & \\
\hline $\mathbf{r}$ & 0.628 & 0.389 & 0.628 \\
\hline$r^{2}$ & 0.394 & 0.151 & 0.394 \\
\hline$\beta$ (total effects) & $0.692^{*}$ & $0.175^{\star}$ & $0.068^{*}$ \\
\hline Analysis Two & & & \\
\hline IV to MV & & & \\
\hline$r$ & 0.875 & 0.875 & 0.875 \\
\hline$r^{2}$ & 0.766 & 0.766 & 0.766 \\
\hline$\beta$ & $0.724^{*}$ & $0.724^{\star}$ & $.088^{*}$ \\
\hline $\begin{array}{r}\text { Analysis Three } \\
\end{array}$ & & & \\
\hline$r$ & 0.667 & 0.395 & 0.658 \\
\hline$r^{2}$ & 0.445 & 0.156 & 0.434 \\
\hline$\beta:$ IV (direct effects) & $0.352^{*}$ & 0.026 & 0.026 \\
\hline$\beta: M V$ & $0.478^{*}$ & $.198^{\star}$ & $.571^{\star}$ \\
\hline $\begin{array}{c}\Delta \beta \text { of IV (analyses one and three) } \\
\text { (indirect effects) }\end{array}$ & 0.340 & 0.149 & 0.042 \\
\hline conclusion: (partial or full mediation) & partial & full & full \\
\hline Sobel test statistic & 9.112 & $\mathrm{n} / \mathrm{a}$ & $\mathrm{n} / \mathrm{a}$ \\
\hline$p$ value & 0.000 & & \\
\hline$\%$ of the total effect that is mediated & 49.10 & & \\
\hline ratio of the indirect effect to direct effect & 0.966 & & \\
\hline Goodman test & 9.110 & & \\
\hline$p$ value & 0.000 & & \\
\hline Goodman II test & 9.113 & & \\
\hline$p$ value & 0.000 & & \\
\hline
\end{tabular}

*significant at $p<.01$

$M V=$ mediating variable (Strategic Posture)

$n / a=$ not applicable

The Sobel (1982) and Goodman (1960) tests were not performed as these tests have been shown by Preacher and Hayes (2004) to produce erroneous results in situations where full mediation is detected as per Baron's and Kenny's (1986) procedures (refer to Preacher \& Hayes 2004 and Preacher et al 2007 for detailed discussion). For instance, applying the Sobel and Goodman tests in the current data would generate statistics suggesting that the indirect effect was not significantly different from zero, which contradicted the initial findings of full mediation for the variables shown in columns three and four of Table 5.51. Apparently, the SPSS syntax for Sobel and Goodman tests do not recognise the loss of significance of the effect of the independent variable on the dependent variable when the mediating variable is entered into the equation as shown in analysis three. 
Instead of the Sobel and Goodman tests, a statistical procedure recommended by Preacher and Hayes (2004) was carried out. This procedure involves "testing of the significance of indirect effects using both normal theory and bootstrap approach to obtain confidence intervals" (Preacher \& Hayes, 2004 p. 717). Preacher, Rucker and Hayes (2007) developed a syntax for use with SPSS to perform the bootstrapping procedure.

Results of the Preacher and Hayes (2004) procedure showed that the true indirect effect in the index of formal institutions $\rightarrow$ strategic posture $\rightarrow$ strategic performance path was estimated to lie between .1531 and 0.8760 with $95 \%$ confidence using 5000 bootstrap resamples. Because zero was not in the $95 \%$ confidence interval, it was concluded that the indirect effect was significantly different from zero at $p<.05$ (two tailed). Hence, the presence of full or complete mediation was confirmed.

In the case of the index of informal institutions $\rightarrow$ strategic posture $\rightarrow$ product/service performance path, the true indirect effect was estimated to lie between .3640 and 0.7862 with $95 \%$ confidence. Because zero was not in the $95 \%$ confidence interval, it was concluded that the indirect effect was significantly different from zero at $p<.05$ (two tailed) using 5000 bootstrap resamples. Hence, the presence of full or complete mediation was confirmed.

The foregoing mediation analysis revealed that strategic posture partially mediated the index of formal institutions - product/service performance path and completely mediated the index of formal institutions - strategic performance path as well as the index of informal institutions - product/service performance path.

\subsection{Summary}

The data from the survey were screened and cleaned to ensure accuracy. Wave analysis revealed that the data was not contaminated by non-response bias. Harman's single factor analysis and partial correlation technique using a marker variable showed that common method bias, per se could not explain the results of the study. 
Missing values were examined and mean substitution technique was applied accordingly. The data were also examined with respect to the normality of distribution.

The respondents were shown to be quite diverse with respect to firm characteristics, respondent characteristics, and manager and owner/manager profile. Factor analyses revealed the uni-dimensionality of the five formal institutions, seven informal institutions and strategic posture as well as the multi-dimensionality of the organisational performance construct. Construct validity and reliability analyses supported the use of the five formal and five informal institutions, strategic posture variable and three facets of organisational performance.

Hierarchical multiple regression - ordinary least squares technique was applied to test the hypotheses put forward in this study. The preliminary analysis gave careful consideration to the assumptions of this statistical technique that must be met given the purposes of the study as well as the nature of the data at hand. Post-hoc diagnostic tests were also performed to check if the model fit the data well. Mediation analysis was also performed to determine the direct and indirect effects of a set of independent variables on a set of dependent variables with strategic posture as the mediating variable. Overall, out of the 24 major hypotheses, 15 were supported by the empirical evidence generated by the current study. 


\section{CHAPTER 6. DISCUSSION}

This chapter presents the discussion of the results of data analysis by providing explanations, insights and reflections on the relevance and significance of the descriptive results as well as statistical testing of the hypotheses. More specifically, this chapter presents a discussion of the empirical evidence on the effects of formal and informal institutions, industry characteristics, firm characteristics, and manager or owner/manager characteristics on the strategic posture of MSMEs. This is followed by a discussion of the empirical evidence supporting the links between strategic posture and organisational performance as well as the mediating role of strategic posture in the institutions-organisational performance nexus. Figure 6.1 shows the outline of the chapter.

Figure 6.1. Road Map of the Chapter

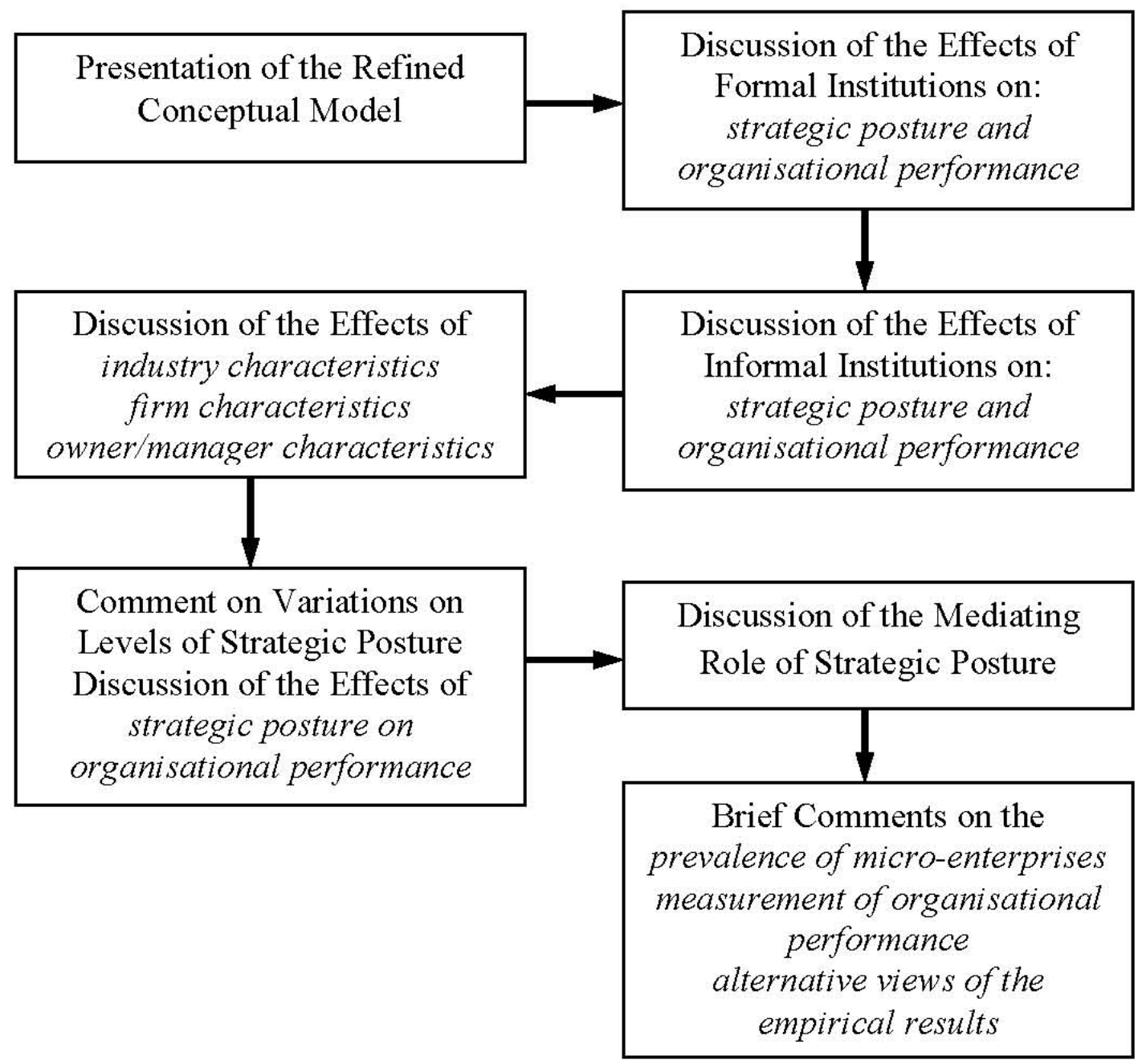




\subsection{The Refined Conceptual Model}

The factor analyses, which resulted in the refinement of the measures of the constructs under investigation, suggested a modification of the conceptual model of the study. The five formal institutions were retained and used for further analyses as suggested by the confirmatory factor analysis. Five of the seven informal institutions were retained and used for further analyses. The constructs, power distance and assertiveness were excluded in further analyses as the data measuring these two informal institutions displayed low degrees of internal consistency and low levels of convergent and discriminant validity.

The strategic posture construct was shown to be uni-dimensional, hence retaining it in the model as it was in the early chapters of this work. The managerial, firm and industry characteristics were likewise retained in the model. The data on MSME organisational performance suggested that the original categories of operational and financial performance were not adequate enough to capture the multi-dimensional nature of the organisational performance construct. The data indicated that there were three underlying factors: product/service performance, strategic performance, and financial performance. Consequently, the relationships between and amongst the constructs that were retained and/or added in the refined conceptual model were tested as presented in the previous chapter on data analysis - hypotheses testing. As expected, the hypotheses involving those constructs that were no longer part of the refined conceptual model were not subsequently tested. Figure 6.2 shows this refined conceptual model. 
Figure 6.2 Refined Conceptual Model

FORMAL INSTITUTIONS

RULE OF LAW

PROTECTION OF PROPERTY RIGHTS

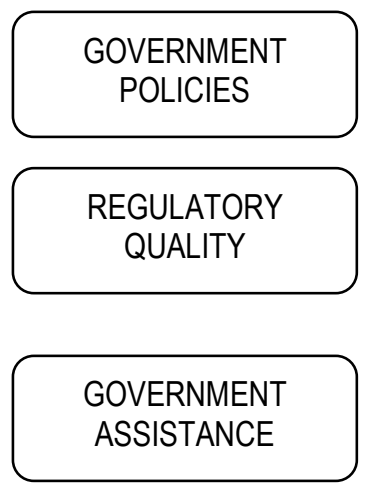

INFORMAL INSTITUTIONS

PERFORMANCE ORIENTATION

FUTURE ORIENTATION

COLLECTIVISM

HUMANE ORIENTATION

UNCERTAINTY AVOIDANCE

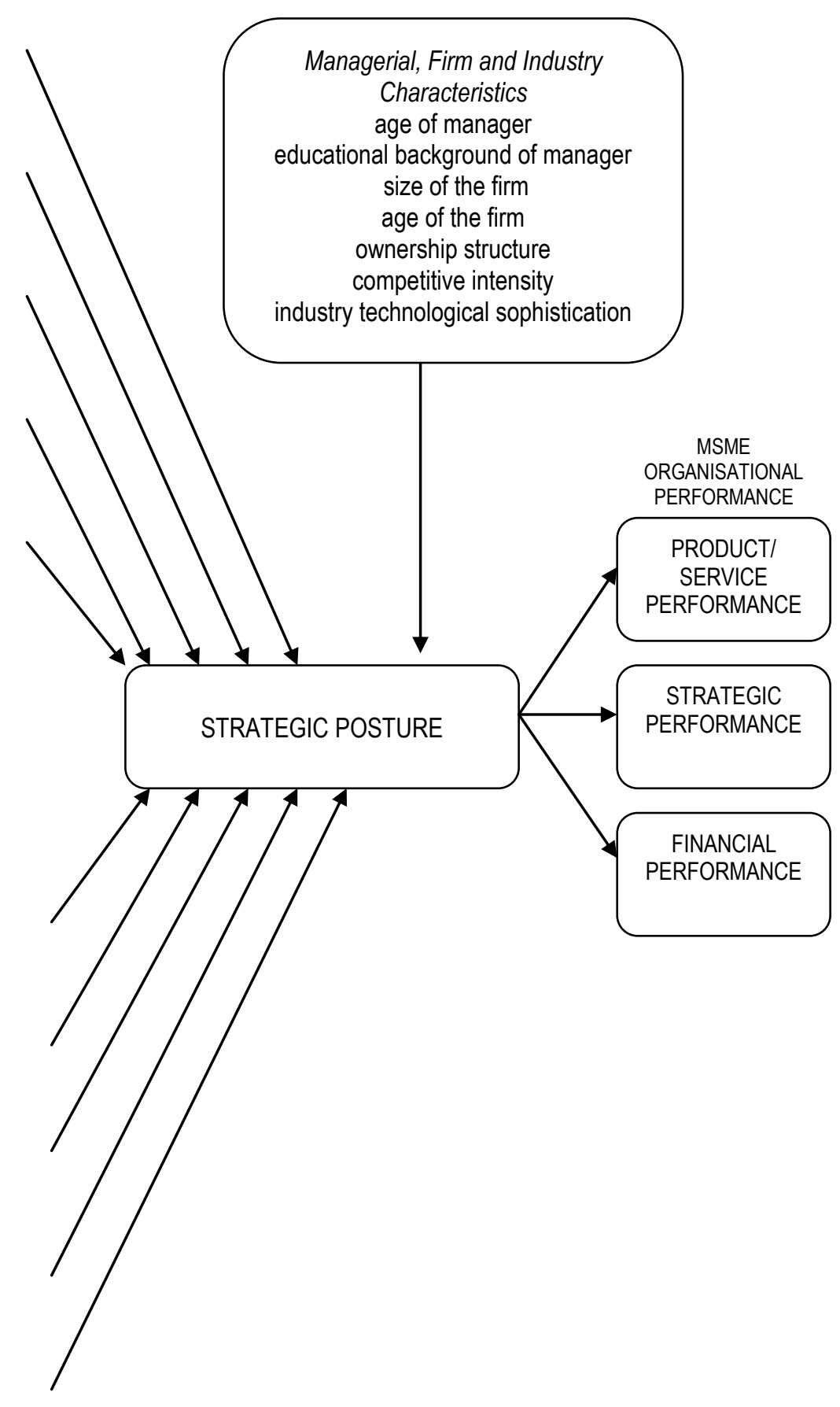




\subsection{The Effects of Formal Institutions}

Effects on Strategic Posture. The empirical evidence gathered in this study supports the fundamental assertion of this research that the five formal institutions at the citylevel bear substantial degrees of relationships with MSMEs' strategic posture - a firm-level phenomenon. This outcome may be considered a significant contribution of the study to existing literature as previous studies applying North's institutional theory (1990) were not clear as to why institutions matter in economic performance in general and to each MSME in particular. Moreover, the study represents an extension of prior work having national or countrywide focus, to consider the role of sub-national institutions on economic activities.

The empirical evidence generated by the study indicates strong support for the hypotheses that the five categories of formal institutions influence firm-level phenomenon- in this case, the strategic posture of firms, as represented by MSMEs. The current evidence at hand suggests that the rule of law in a particular city encourages firms doing business in that city to become more entrepreneurial in their strategic posture. Results of the ROBUST regression model indicate that rule of law has the most substantive explanatory power on strategic posture amongst all the forms of institutions included in the model. This suggests the importance of rule of law in the development of an institutional framework that is supportive of an entrepreneurial strategic posture amongst MSMEs.

It has been previously noted that the benefits gained in a situation where laws govern a city instead of the arbitrary will of particular persons could well explain the entrepreneurial strategic posture of the MSME business sector (Pejovich, 1999; Wang \& Ang, 2004). This particular result of the current study is consistent with the view that rule of law creates a private market in a level playing field (Reed, 2001). Rule of law suggests a fair legal and judicial system where economic or market players are equally protected by law which in turn, can reduce imitative behaviour. This system allows firm activities such as innovation and market exchanges to flourish without having firms enjoying undue advantage over others. 
Moreover, the effective enforcement of contracts that is inherent in a city under the rule of law may be encouraging and nurturing transactional trust (Fogel et al., 2006) and reducing transaction costs (Scully, 1988). Increased levels of transactional trust amongst MSMEs and their business partners (e.g. suppliers, distributors, buyers, etc.) and minimisation of transaction costs are necessary for firms to concentrate on the productive aspects of innovation and exploration of new business opportunities.

Furthermore, rule of law suggests that crimes are minimised as a matter of maintaining public safety (Hopkins, 2002). Public safety subsumes the safety of individuals and business entities like MSMEs in a locality. A safe city makes it easy for MSMEs to do business such that transactions with customers, suppliers, and distributors, amongst others could take place unimpeded by criminal elements. In effect, rule of law serves as a basic component of economic freedom (Kreft \& Sobel, 2005) under which MSMEs are able to pursue entrepreneurial undertakings with the belief that their rights are well-protected by the legal and judicial framework of the city.

Empirical evidence from this study also supports the view that protection of property rights encourages firms to engage more in innovative, proactive and risk-taking activities. In an environment where property rights are well-protected, unfair imitative behaviour can be greatly reduced. This is consistent with Norton's (1998) view that a regime of well-protected property rights not only protects ownership and control of property but also rewards those who put their property (such as their business or technology) into more productive use without the fear of being cheated out of the fruits of their labour (Heitger, 2004). Consequently, it nurtures amongst firms the confidence to pursue more entrepreneurial undertakings.

Whilst all formal institutions are positively associated with an entrepreneurial strategic posture, protection of property rights has the lowest beta coefficient. This may be explained by the fact that Philippines is one of the many developing countries where enforcement of property rights tends to be very loose (Gwartney, Lawson \& Clark, 2005; Kaufmann et al., 2006; Nerona, 2000). Specific laws on property rights are not persistently and consistently enforced. This may have created an "atmosphere of tolerance" for violations of property rights, which may have an 
influence on how people, including MSME owners/managers, think of property rights protection. It was only in recent years that government agencies started to prosecute violations of property rights often with the constant agitation of aggrieved individuals or corporate entities such as owners of intellectual property rights (e.g. copyrights or trademarks).

The positive impact of government policies perceived as conducive for business on the entrepreneurial strategic posture of firms is also well supported by the empirical evidence at hand. Government intervention in the form of public policies has been viewed as essential to correct for market imperfections where smaller firms are placed at a disadvantaged position (Rodrik, 2006). The absence of government policies designed to promote MSMEs vis-à-vis the presence of larger multinational firms, could undermine any firm-level entrepreneurial efforts such as innovation as evidenced by previous studies (Fogel et al., 2006; Verheul et al., 2002). Effective government policies chart the long-term directions for local economic development and the clear articulation of these opens up opportunities for MSMEs to take part in such development by engaging in more entrepreneurial activities.

The importance of government policies cannot be overemphasised as it is one of the institutions with high degree if relationship with the strategic posture of firms. This is logical since the instituted policies by the city government will serve as catalysts to implement and maintain regulatory quality, extend government assistance to MSMEs, and the legislation of specific laws and ordinances to protect property rights and promote/maintain rule of law within the city.

There is also evidence at hand supportive of the hypothesis that regulatory quality encourages firms to be entrepreneurial in their strategic posture. A sound regulatory system has been shown to increase transactional trust (Fogel et al., 2006), decrease transaction costs, including administrative burden (Verheul et al., 2002), decrease bureaucratic rigidities detrimental to business (Gnyawali \& Fogel, 1994), and serve as an enabling mechanism through the efficient delivery of basic services needed by the MSME sector (Leach et al., 1994). Results of the study suggest that these benefits are found to be essential for firms pursuing strong entrepreneurial strategic imperatives. 
Furthermore, the government's assistance to MSMEs has also been shown to shape the entrepreneurial nature of the firms' strategic posture - a result that confirms the view that it is a key component of MSME development (Helmsing, 2003). The evidence from this study suggests that the munificence of the MSME's external environment is enriched by government assistance which ultimately provides access to much needed resources for firms to engage in risk-taking, innovative and proactive ventures (Castrogiovanni, 1991). It is important to note, however, that the study did not identify specific programs as well as the magnitude of assistance offered to MSMEs. Identification of these programs points to an interesting area for further investigation.

In the interpretation of beta coefficients that represent the relative weights of the independent variables in explaining the dependent variable, both the statistical significance and meaningfulness of the size of coefficients should be given due consideration (Pedhazur, 1982). Meaningfulness, according to Pedhazur (1982), is specific to the context of research. In this study, the beta coefficients of the five formal institutions (in relation to the firms' strategic posture) are deemed significant and meaningful. The medium to large effect sizes provided evidence on the importance of the observed relationships between the formal institutions and strategic strategic posture (Chin, 1998; Field, 2005).

It is further argued in this study that these regression coefficients are meaningful and useful such that when MSME owners/managers reported favourable perception on the formal institutions (i.e. increase in the perception scales measuring the formal institutions), they also reported a more entrepreneurial strategic posture (i.e. an increase in the perception scale on strategic posture). This substantive interpretation derived from the beta coefficients of the formal institutions provides the overall justification to dismiss the impression that the effects of the formal institutions on strategic posture were statistically trivial or meaningless.

Moreover, when all of the five formal institutions were aggregated to derive an index, the formal institutions $\rightarrow$ strategic posture path (beta) coefficient as well as the $r^{2}$ were large enough to infer that this observed relationship is meaningful enough 
from which inferences could be drawn. This totally aggregated index of formal institutions subsumed the interaction of the five components with one another thereby producing the outcome 'effect' on strategic posture (Bagozzi \& Heatherton, 1994).

Effects on Organisational Performance. The results of this study also provide support on the linkage between three formal institutions and two facets of organisational performance. Rule of law, government policies and government assistance show positive relationships with product/service performance. Government policies on the other hand, shows a positive relationship with strategic performance. The empirical evidence, however, does not show any significant relationships between formal institutions and financial performance.

It can be inferred from the results that MSMEs (in their efforts to improve product/service performance such as the development of products/services and improving product or service quality) may perform well in an environment characterised by rule of law, having government policies perceived as conducive for business, and the presence of various forms of government assistance available for the MSME sector. The government policies - strategic performance relationship suggests that MSMEs tend to perform well in a strategic fashion when appropriate government policies covering business activities are in place. There is consistency in this result such that government policies may not necessarily have immediate impacts on the business sector. Oftentimes, long-term benefits are generated from these policies, which became evident through the firms' strategic performance indicators.

Finally, the empirical evidence suggests that the impact of formal institutions (either in their index form or as a specific component) may not be automatically equated with immediate financial gains. It is evident that formal institutions relate only to the non-financial aspects of the firms' performance. This offers a pragmatic approach in understanding the crucial role played by formal institutions in nurturing the MSMEs sector, in particular, and the overall business sector, in general. Whilst it is true that the development of a sound formal institutional framework may not necessarily relate to easily quantifiable financial gains for MSMEs, dismissing the ultimate 
utility of such framework reflects a myopic view of what these formal institutions can do. The current evidence suggests that the importance of the formal institutions is revealed by looking at the other critical dimensions of organisational performance, which were reported by MSME owners/managers to be just as valuable as financial returns.

The non-financial impact of formal institutions on MSME performance is a novel finding of the current study. Whilst previous studies have examined to what extent various forms of formal institutions relate to firm performance (Ramsden \& Bennet, 2005; Shane \& Kolvereid, 1995), to the best of the researchers' knowledge, no published study has made any substantive inferences on the nature (i.e. financial or non-financial) of the impact of a set of formal institutional on the performance of firms such as MSMEs.

The foregoing discussion emphasises the empirical evidence that addressed the research gaps discussed in the first two chapters of this study. The study's emphasis on institutions and how they relate to the strategic posture and performance of MSMEs in the Philippines is a contribution to understanding the importance of institutions in the strategic behaviour of small firms (i.e. referring to research gap number one - lack of emphasis on institutions in strategy research; research gap number two - lack of understanding how institutions directly relates to MSMEs; and research gap number three - lack of explanations on how institutions relate to strategic posture).

Variations Between Cities. The study revealed significant variations on the reported perceptions on formal institutions between the two cities. Respondents in the two cities differed in terms of their perceptions of the role and influence of institutions and institutional factors. Though the differences were statistically significant, additional ininsight may be gained from the following commentary on the nature of the two cities. For example, Tagum, construed as a first class city, with all its abundant resources, is able to put in place an institutional framework that is perceived as more supportive of MSMEs relative to cities of lower income classification. In effect, the study showed that "institutional thickness" (i.e. the presence of vibrant and supportive institutions) may vary depending on the 
availability of resources necessary for institutional development of a sub-national government unit (Amin \& Thrift, 1995). It has been previously noted that the resources of the local government unit may spell the difference in exercising its enabling role in MSME and economic development (Leach et al., 1994).

\subsection{The Effects of Informal Institutions}

Effects on Strategic Posture. Another contribution of the study was the generation of empirical evidence supporting the view that city-level informal institutions also matter in explaining firm-level phenomena such as the firm's strategic posture, albeit with equivocal results. Only performance orientation and future orientation were shown to have significant and positive relationships with higher levels of entrepreneurial strategic posture amongst firms. The empirical evidence in this study showed strong support for the notion that when the general populace of a city have attributes, values and practices consistent with performance orientation (such as strong level of competitiveness, proclivity for innovation, and setting high standards of performance), MSMEs in that city tend to report high levels of innovativeness, risk-taking and proactiveness in their business endeavours (Lee \& Peterson, 2000). Since the majority of the respondents were micro-enterprise owners/managers (i.e. with firms having less than ten employees), the cultural attributes of the owner/manager (being the firm's key strategic actor and at the same time a member of the wider society in a particular city) may have been manifested in the firm's overall strategic posture as measured in the study.

The current study's empirical evidence also supported the hypothesised positive link between future orientation and entrepreneurial strategic posture. The results of the study suggest that when the general populace tend to display a high tendency to conscientiously think and plan for the future and consider the long-term consequences of their actions, members of that populace, such as managers or owner/managers of MSMEs tend to value more risk-taking, innovativeness, and proactiveness as well (Ashkanasy et al., 2004; Gong et al., 2007). In this context, entrepreneurial strategic posture serves as the manifestation of the MSMEs' attempt to imagine and influence future contingencies as well as develop strategies to meet their future aspirations (Corral-Verdugo \& Pinheiro, 2006). These two major 
findings may be considered as significant contributions in understanding how informal institutions influence the activities of firms, such as MSMEs, in a subnational context as opposed to the wholesale nationwide focus on business or investment climates.

The findings on the substantial influence of performance orientation and future orientation on strategic posture were consistent with the view on proximal environment (Jessor \& Jessor, 1973) such that the external environment serves as a source of meaning composed of expectations of others, social approval, and negative evaluations which shape the behaviour of MSMEs operating within it. As the evidence showed, the majority of the firms were micro enterprises such that one individual (i.e. the owner/manager) is likely to dominate the strategic management of the business. Hence, the perception of these owners/managers on the proximal environment greatly shapes the firm's overall strategic posture - a view that is consistent with the work of Anderson and Paine (1975) on the link between managerial perception and strategic behaviour of firms.

However, when the informal institutions were formed into a single index, the results of this study suggest that informal institutions in general, have positive relationships with the firm's entrepreneurial strategic posture.

Effects on Organisational Performance. Only uncertainty avoidance as a form of informal institution showed significant relationships with product/service performance and financial performance. Uncertainty avoidance was negatively associated with product/service performance but was positively associated with financial performance.

The negative correlation implies that high levels of uncertainty avoidance are associated with low levels of product/service performance. It can be inferred that MSMEs tend to have lower performance in their product/service development, quality of products/services and customer satisfaction if the informal institutional environment is permeated by greater tendency to avoid uncertainty and the risks associated with it. 
This result is consistent with the view that product/service performance manifested by the development of new, (and improvement of the quality of) products or services requires more willingness for risk-taking amidst considerable amount of uncertainty (De Luque \& Javidan, 2004). Firm efforts like product/service development require considerable amount of ingenuity, risk-taking, and tenacity to tread on uncertain grounds - none of which would be well supported in an institutional environment where uncertainty is shunned rather than explored.

Interestingly, uncertainty avoidance was reported to have a positive relationship with financial performance. This result suggests a contradiction to the hypothesis drawn from previous studies and is inconsistent with the other results of this study (De Luque \& Javidan, 2004; Swierczek \& Ha, 2003a). It may be argued that uncertainty carries a significant amount of financial risk. Uncertainty therefore would have significant negative impact on the overall financial result of the business operation if that risk is not managed well. It can be further argued that based on this specific finding, MSMEs doing business whilst avoiding significant amount of risks in uncertain business situations (i.e. high uncertainty avoidance) may report that their financial performance is good enough for them. This argument on the other hand, contradicts the view that the risk-taking factor of an entrepreneurial strategic posture makes firms perform better relative to those that are less entrepreneurial.

This issue goes back to the previous discussion of substantive or meaningful value of the very low beta coefficient as well as the fact that only uncertainty avoidance showed a significant relationship with financial performance amongst all the formal and informal variables entered into the regression equation. It is possible that given the very low beta coefficient, the significant result could be attributed to the "crud factor" such that "everything correlates to some extent with everything else" (Meehl, 1990 p. 204).

Pedhazur (1982) recommended that a significant beta coefficient must also be evaluated in terms of its substantive meaning within the context of a specific research. Considering that the beta coefficient describing the uncertainty avoidance financial performance relationship is very low, is unique amongst all the variables regressed with the same dependent variable, is in contradiction with the rest of the 
results, and has no substantive meaning within the context of the current research, the possibility that the significant result could be explained by the "crud factor" carries substantial amount of weight for inferential consideration.

The foregoing discussion highlights the contribution of the study with respect to research gap number four (i.e. lack of an integrated approach to examine both types of formal and informal institutions) by examining various types of formal and informal institutionsd and their relationships with firm-level phenomena. Likewise, the attempt to examine the relationships between informal institutions and firm-level phenomena addresses research gap number 5 - the over-emphasis on the legalisticpolitical or formal institutions in the current literature of the study of institutions. Moreover, the focus on city-level formal/informal instituions address research gap number 6 - the lack of emphasis on subnational institutions in favour of countrywide institutional analysis in the current literature.

In effect, the study has the potential to contribute to the development of an institutional environment supportive of MSMEs in a developing or emerging economy context - a research gap (i.e. identified as research gap number 7 in this study) in the current literature.

\subsection{The Effects of Industry Characteristics}

MSMEs that face intense levels of competition in their respective industries are found to be high scoring on entrepreneurial strategic posture scales. This result is consistent with the literature explaining that strategic organisational configurations are influenced by the firms' immediate industry and market characteristics (Barnett, 1997; Borch \& Brastad, 2003; Ramaswamy, 2001). MSMEs engage in risk-taking, innovative and proactive actions to either assert or defend their presence in a competitive industry. This would explain the high explanatory power of competitive intensity on strategic posture relative to other variables in the regression models presented in the previous chapter.

The level of industry technological sophistication was not shown by the survey results to have any a significant influence on strategic posture. This is understandable 
as the industries operating in the two cities were generally not research and development intensive-industries. Likewise, the prevalence of micro-enterprises would indicate that these small firms may not have the resources necessary to engage in sophisticated technological developments. Hence, the lack of variations on the responses to questions describing this variable.

\subsection{The Effects of Firm Characteristics}

The findings suggest that strategic posture cannot be fully explained by firm characteristics such as size and age of the business. Only the nature of ownership has been shown to explain well the variations in the firms' strategic posture. The results indicate that the 'corporation type' of business tends to be more entrepreneurial in strategic posture compared to sole proprietorships and partnerships. The presence of professionally-hired managers, lesser personal financial liability of the owners (i.e. stockholders), and infusion of institutional capital into the business may explain the tendency of corporation-type of firms to engage in more entrepreneurial undertakings (Davidsson et al., 2002; Kor \& Mahoney, 2005).

The empirical evidence suggests that firms can have the capability to become entrepreneurial in their strategic posture regardless of age and size of the business. The lack of support for the hypothesis regarding the firm size - strategic posture link was consistent with the argument that size may not fully explain the adoption and implementation of organisational strategies such as those in pursuit of innovativeness (Acs \& Audretsch, 1988; Youndt, Snell, Dean \& Lepak, 1996). The circumstances surrounding the firm (such as the nature and extent of industry competition) regardless of it size, may be the more critical drivers of firm innovativeness, risktaking activities and proactiveness (Acs \& Audretsch, 1988). Others argue that perhaps size may have an indirect bearing on the strategic configurations of firms by its influence on other organisational variables such as the structure of the firm (Grinyer \& Yasai-Ardekani, 1981). This would explain the significant variations when strategic posture was analysed across the three types of ownership structure.

Likewise, the data indicated that firm age could not fully capture how firms mobilise their resources through strategies to achieve their objectives (Brush \& Chaganti, 
1999). In retrospect, firm age may be more relevant if studied in the context of the order of entry in the industry (e.g. pioneers, early followers, late entrants, etc.) as firms adopt different strategies based on timing of entry into the industry (Durand \& Coeurderoy, 2001). This, however, was beyond the scope of the current study.

\subsection{The Effects of MSME Owner/Manager Characteristics}

The result indicating the inverse relationship between the age of the respondents and entrepreneurial strategic posture is consistent with the extant literature on managerstrategy alignment (Gupta, 1984; Hambrick \& Mason, 1984) arguing that the characteristics of the manager of the firm will shape the nature of strategies that are implemented within the firm. In this study, the evidence suggests that the younger the manager, the more likely that the firm will pursue entrepreneurial undertakings. This empirical evidence support previous studies on the subject (Karami et al., 2006; Kathuria \& Porth, 2003; Kitchell, 1997). The basic argument is that younger managers tend to be positively associated with innovativeness and risk-taking (Thomas et al., 1991). Their drive for experimentation and their can-do attitude to compensate for lack of experience may explain this phenomenon. Others argue that older but more experienced managers may be more cautious and reluctant to alter strategies because of their narrower and more limited knowledge base from which to conduct a strategic search for new opportunities (Grimm \& Smith, 1991).

It was surprising to note that the data on the level of education failed to explain the variations in strategic posture. The a priori argument presented earlier on is that higher levels of education should equip an MSME owner/manager with more knowledge, better intellectual capability and wider business networks. A plausible explanation for the weak education-strategic posture linkage suggests that whilst knowledge and skills are necessary for a manager to effectively run a business, lack of these may be compensated by experience in the industry as well as learned skills and abilities from informal learning or modelling (Grimm \& Smith, 1991; Keeley \& Roure, 1990). Hence, one's level of formal education may not be considered as the appropriate measure of adequate knowledge and intellectual capability to engage in an entrepreneurial strategic posture. 
It was evident in the data that respondents differ in their level of entrepreneurial strategic posture. Whilst it was not subjected to hypothesis testing, descriptive data indicated that there were firms with relatively low, average, and high levels of entrepreneurial strategic posture - suggesting that some firms are more entrepreneurial than others. This challenges the popular notion that owners/managers of MSMEs are all entrepreneurs. In the researcher's review of the literature in relation to this study, SMEs and entrepreneurs were used interchangeably in a number of studies. If entrepreneurs are viewed as agents of "creative destruction" those that carry out new combinations as means of production (i.e. innovation and growth) (Carland, Hoy, Boulton \& Carland, 1984; Schumpeter, 1934; Stewart, Watson, Carland \& Carland, 1998) - then not all MSMEs are considered as entrepreneurs. The different levels of entrepreneurial strategic posture reported by the respondents lend support to this view. The distinction between entrepreneurial firms and MSMEs is helpful in understanding why some MSMEs are more entrepreneurial than others, casting light on an area of research that is crucial to the definition of economic policy issues.

\subsection{The Effects of Strategic Posture on Organisational Performance}

Consistent with the extant literature, the empirical evidence at hand offers support on the postive relationship between entrepreneurial strategic posture and organisational performance (Priem, 1994; Venkatraman \& Prescott, 1990). The data suggested that when MSME owners/managers reported higher levels of (i.e. entrepreneurial) strategic posture, they also reported higher levels of product/service, strategic, and financial performance. Entrepreneurial strategic posture was reported to have the highest degree of relationship with product/service performance, next to strategic performance, and with financial performance. This result lends support to the view on the sustainability of the entrepreneurial strategic posture - organisational performance relationship (Lumpkin \& Dess, 1996; Wiklund \& Sheperd, 2005; Wiklund \& Shepherd, 2003). 
The bias for innovativeness inherent in a highly entrepreneurial strategic posture could well explain the strong strategic posture - product/service performance linkage. Development of new products/services and finding ways to satisfy one's customers require persistent innovativeness and proactiveness on the part of the MSMEs. Whilst a proactive stance and the pursuit of innovation require resources and carry a significant amount of risk, the benefits - translated into organisational performance measures - that can be derived outweigh the costs of exercising an entrepreneurial strategic posture. The results of the study can be interpreted such that the exercise of entrepreneurial strategic posture is the firm's unique way of responding to the external environment to protect or enhance the organisation's interest and achieve better performance outcomes.

The explanatory power of entrepreneurial strategic posture on four of the performance indicators - customer satisfaction, sales, product/service quality, and product/service development is a remarkable result. The empirical evidence suggests that despite the resources and risks involved in becoming entrepreneurial, such strategic posture is likely to lead to satisfying customer demands as evidenced by increased sales. The pursuit of innovation is likely to result in developing more and more products/services and improving the quality of existing products or services.

Likewise, an entrepreneurial strategic posture is positively related with attraction and retention of skilled labour or essential talents. This link may be due to the fact that innovativeness requires the valuable input of essential skills. Despite the financial costs involved in assuming an entrepreneurial strategic posture, the noticeably high levels of reported net income, return on investment, and market share lend support to the view that an entrepreneurial stance in the firm's overall competitive posture is likely to generate short term (e.g. more sales) and long term (e.g. market share and ROI) gains. Furthermore, the positive relationships between entrepreneurial strategic posture and the 13 measures of performance suggested that such competitive posture have wide-ranging influence on the whole business organisation beyond that of the typical financial consequences. 


\subsection{The Mediating Role of Strategic Posture}

Another major contribution of the study is its ability to explain that institutions do explain a specific form of economic performance - entrepreneurial strategic posture and organisational performance of MSMEs. The current study did not only demonstrate that institutions help to explain economic performance (by shaping the MSMEs' performance, and assuming this to be a critical element in the economic performance of the two cities), it also showed that the influence on economic performance is through the institutions' relationships with the firms' strategic posture.

It has been noted in this study the paucity of published research dealing with how institutions (in the context of North's (1990) concept of institutions) shape firm-level phenomena. Whilst it has been established that institutions shape the economic performance in a macro-perspective (i.e. industry or country level) (North, 2005), studies dealing with institutions as they relate to firm-level activities are not common in the literature. The study yielded empirical evidence to add more understanding on the subject by uncovering the fact that city-level institutions affect firms by influencing the latter's strategic posture. The mediation analysis supported this view whereby institutions had the strongest influence on strategic posture, which in turn, had a strong influence on the three facets of organisational performance.

More specifically, the relationships between the formal institutions, namely, rule of law, government policies and government assistance, and that of product/service performance, were partially mediated by strategic posture. The relationships between government policies and that of strategic performance were all partially mediated by strategic posture.

When the direct relationships between indices of formal and informal institutions and that of the three categories of organisational performance were examined, the results were not unequivocal. The index of formal institutions $\rightarrow$ product/service performance path was shown to be partially mediated by strategic posture. The index of formal institutions $\rightarrow$ strategic performance path as well as the index of informal 
institutions $\rightarrow$ product/service performance path were shown to be fully or completely mediated by strategic posture.

The presence of partial mediation amongst the above-mentioned relationships suggests that formal institutions had both direct and indirect relationships with the firms' non-financial aspects of organisational performance. The presence of full or complete mediation indicates the importance of strategic posture as a conduit through which institutions exert their influence on the non-financial aspects of MSME's performance. It is logical to say that the firm's exercise of strategic posture is a response to the external institutional framework as a way of protecting its interests and goals (Simsek, Veiga \& Lubatkin, 2007). The evidence suggests that a particular MSME will pursue an entrepreneurial strategic posture to achieve its performance objectives only when the wider institutional framework is supportive enough of such undertaking.

However, despite the firms' response to the environment (through the exercise of entrepreneurial strategic posture) their organisation performance remains partly captive of the influences of the wider formal institutional forces. These findings supported the view that institutions shape economic performance in as much as the local economy may be considered as the aggregate indicator of the organisational performance of all of the MSMEs doing business in the locality. Furthermore, the results indicating the mediating role of strategic posture in the external environmentorganisational performance link were consistent with previous studies (Covin \& Slevin, 1989; Lee \& Peterson, 2000; Manev, Gyoshev \& Manolova, 2005; Zahra et al., 1999).

Analysis suggested that only three formal institutions (rule of law, government policies, and government assistance) and one informal institution were shown to be associated with product/service performance. Only the notion or construct of government policies was shown to be associated with strategic performance. Similarly, only uncertainty avoidance was shown to be associated with financial performance. Perceptions of the formal institutions were not shown to be associated with reported financial performance. These findings would have suggested sporadic associations between institutions and MSME performance. The mediation analysis 
provides a different perspective in interpreting the overall results of the study such that the majority of the institutional variables have been shown to be associated with strategic posture, which in turn, has been shown to be associated with the three facets of performance. In effect, the mediation analysis made clear that the institutional environment relates to MSMEs, through the former's influence with the latter's exercise of strategic posture. This view is even more evident when mediation analysis was performed using the indices of formal and informal institutions and that of product/service and strategic performance where both partially- and fully mediated relationships were found.

\subsection{The Prevalence of Micro-Enterprises}

The study also yielded empirical evidence supporting the argument that the term SME as used in the literature may be misleading. Previous MSME-related studies in the Philippine setting proclaimed the significance and dominance in number of SMEs in the local economy when in fact, micro-enterprises were not part of the study $(\mathrm{Co}$, 2004; Lallana et al., 2002). Even though it was not formally tested in this study, the researcher has reasons to believe that micro-enterprises should be given special emphasis in the mainstream SME-orientated literature.

The lists of registered businesses in the two cities revealed that more than $90 \%$ are actually micro-enterprises. Unless micro-enterprises are categorically excluded from the data set, the term MSME is a more inclusive term that is reflective of the reality of the Philippine business sector today. Moreover, micro-enterprises due to their large number, deserve the attention in terms of research and policy intervention. It is not unlikely that small and medium firms may arise from these micro-enterprises that will generate further local employment through entrepreneurial pursuits. Hence, an emphasis on micro-enterprises in addition to SMEs is a recognition of the contribution of these small firms to local economic development. This empirical evidence address research gap number eight which highlights the lack of emphasis on micro-enterprises in the mainstream SME-oriented literature. 


\subsection{Measurement of Organisational Performance}

The study's method of assessing organisational performance yielded a meaningful characterisation of the performance of MSMEs. MSME owners/managers reported low level of performance on some indicators, which they rated as less important relative to other indicators. Hence, the weighted performance method to measuring the firms' performance projected a more pragmatic research approach to assess MSME organisational performance. Furthermore, the method allowed a more parsimonious determination of the influence of strategic posture on organisational performance. Attributing factors that influence performance became rigorous by taking into account that a low performance in one indicator may be partly explained by the fact that it was considered by the owners/managers as less important in the business, hence the lack of emphasis on that indicator in the overall strategic imperatives of firms.

\subsection{Alternative Views of the Empirical Results}

This study recognises the possibility that there are other confounding variables which may provide alternative explanations on the significant relationships of variables discussed above. The level of sophistication of the formal institutions in Tagum City may be attributed to the more advanced economic development of the locality relative to Panabo City. In effect, MSMEs in Tagum City are also more advanced in their entrepreneurial undertaking as they can afford to do so given their higher level of economic prosperity. However, this view contradicts institutional theory which explains that functional institutions are antecedents of a prosperous economy.

Furthermore, whilst there are significant relationships between institutions and entrepreneurial strategic posture, it is important to recognise that despite operating in an institutionally-fragile locality, MSMEs may also exercise higher levels of entrepreneurial strategic posture in order to succeed ot at least survive. This, in effect may suggest the possibility that "strategic posture" as a concept does not necessarily capture all kinds of entrepreneurial behaviour. This study therefore, hinges on a very specific concept of strategic posture as a tool of understand the entrepreneurial behaviour of MSMEs. 
This study also examined the institutions - strategic posture - organisational performance linkage in a linear, uni-directional fashion. It is important to recognise the possibility of 'reverse-causality' such that the growing middle-class along with the increasing number of MSMEs may have served as push-factors for the development of the institutional environment of the city.

Moreover, the positive relationships between entrepreneurial strategic posture and the three types of organisational performance need to be interpreted in the context of survival bias. This study did not include firms that despite being entrepreneurial in their strategic posture, failed and ultimately closed their businesses. Obviously, this is one of the limitations of the research design of the study.

Finally, the higher scores in the specific measures of performance (e.g. better sales, higher levels of customer satisfaction, etc.) reported by MSMEs in Tagum City may also be accounted for by the general optimism and self-confidence of MSMEs operating in a 'prosperous' city rather than by the institutional environment. Tagum City may have a relatively 'well-off' local populace hence, MSMEs in the city may be facing more sophisticated and more demanding customers. In effect, MSMEs in Tagum City reported higher levels of customer satisfaction brought by the level of sophistication of the general customer base. 


\section{CHAPTER 7. CONCLUSIONS}

The current study generated empirical evidence, which offers a significant contribution in understanding how institutions matter in economic performance in the context of cities in a developing country where MSMEs play an important role. The results of the study may enrich current understanding of the role of institutions through the empirical evidence suggesting that sub-national (city-level) formal and informal institutions are related to the MSMEs' strategic posture, which in turn, is related to the firms' organisational performance. The formal institutions, namely rule of law, protection of property rights, government policies, regulatory quality and government assistance have been shown to positively relate with an entrepreneurial strategic posture. The informal institutions, namely performance orientation and future orientation have been shown to be positively related with an entrepreneurial strategic posture. The evidence suggests that an entrepreneurial strategic posture mediates the institutions - organisational performance linkage. However, the study uncovered that the positive effects of formal institutions on the overall organisational performance of firms may not be immediately quantifiable in financial terms.

The findings of the research provide evidence supporting the positive relationships between an entrepreneurial strategic posture and that of product/service performance, strategic performance, and financial performance - three facets of the reported organisational performance of firms. Furthermore, the study's contribution to existing literature is evident in the mediation analyses through which the institutions - organisational performance relationship was found to be well explained by the mediating role of strategic posture. In effect, the study highlighted the role of strategic posture as the conduit that reveals the nature and extent of the relationships between institutions and organisational performance of MSMEs. It was evident in the study that mediated relationships were present in the formal institutions organisational performance link. However, the results were equivocal when mediated relationships were examined in the informal institutions - organisational performance link.

This chapter presents the researcher's reflections on these major points by presenting the theoretical contributions of the study, contributions to the extant literature, 
methodological contribution, policy contribution, contributions to managerial practices, limitations of the study and directions for future research. Figure 7.1 shows the outline of the chapter.

Figure 7.1. Road Map of the Chapter

\begin{tabular}{|l|} 
Theoretical Contributions of the Study \\
institutions - strategy - organisational \\
performance interface \\
effects of sub-national institutional in an \\
emerging economy context on firm \\
strategy \\
operationalisation of North's informal \\
institutions \\
non-financial effects of formal \\
institutions on firm performance
\end{tabular}

\begin{tabular}{l} 
Methodological Contributions \\
psychometric properties of the measures \\
of formal institutions \\
measurement of informal institutions \\
\hline \multicolumn{2}{|c|}{ Policy Contributions } \\
formation of efficient institutional \\
framework as part of governance \\
reforms \\
enabling role of local government units \\
government - MSME sector \\
relationships \\
government programs to influence \\
informal institutions \\
institutions' - focused MSME \\
development
\end{tabular}

Contributions to the Extant Literature effects of various formal and informal institutions on MSME strategic posture indirect relationships bet. institutions and organisational performance added insights on the complementary roles of envinonmental determinism and strategic posture

empirical support on the theories of enabling authority, environmental munificence, and indigenous perspective of sustainable development insights on sub-national business climate' vs, nationwide scorecards empirical support to $I / O$ paradigm on strategic posture-performance relationship

emphasis on MSMEs in research

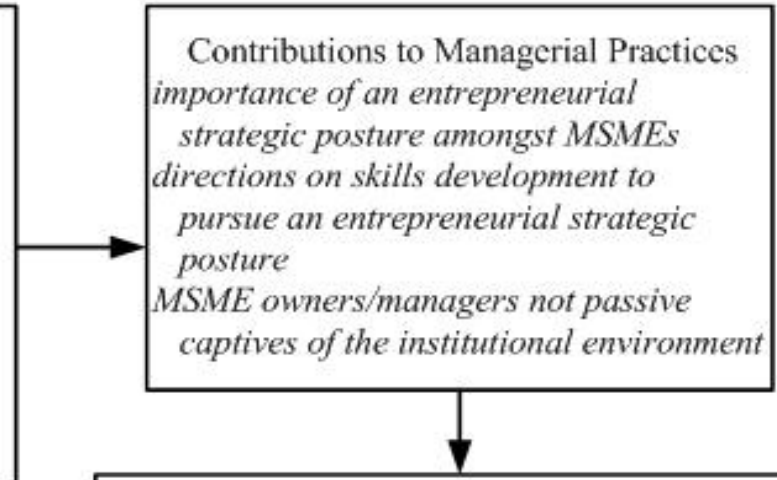

Limitations and Directions for Future Research city coverage

use of perceptual, subjective measures research design-longitudinal study validation of regression model exploratory formal institutional measures replication to validate informal institutions more 'business-specific context' informal institutions

interaction of formal and informal institutions consider other 'players of the game' in an institutional analysis

use of SEM in mediation analysis 


\subsection{Theoretical Contributions of the Study}

The attempt to enrich understanding of the institutional perspective of strategy and strategic behaviour of firms could be considered as the major theoretical contribution of the study. Instituional theory explains why institutions matter. The current study explains how they matter in a specific context - that is, for MSMEs in a sub-national, emerging economy setting. The current study yielded empirical evidence supportive of the study's overarching thesis that institutions have a strong influence on organisational activities as well as on overall organisational performance. These institutions, in their formal and informal manifestations, can be a source of constraints and benefits that substantively influence MSMEs' strategic posture and ultimately, organisational performance. The extent to which these institutions are perceived to be supportive of risk-taking initiatives, proactiveness, and innovativeness has been shown to be related to the entrepreneurial nature of the firm's overall strategic posture. Consequently, when firms take on a more entrepreneurial strategic posture, they may generate favourable gains in their product/service, strategic and financial performance.

On the other hand, the effects of formal institutions on the overall organisational performance of firms may not be necessarily financial in nature. The various forms of formal institutions may exert their influence on other aspects or dimensions of the firms' performance (through the mediating role of strategic posture) which may ultimately affect the firms' financial returns.

Moreover, the results provide a micro-perspective on the view that institutions shape economic performance such that specific categories of sub-national institutions were found to influence firm-level phenomena. The results mirror the view that institutions may constrain as well as provide incentives for MSMEs to be entrepreneurial in their strategic posture. Inefficient regulatory systems (as constraints) and government assistance (as incentives) have been implicitly and explicitly shown in the study to have strategic consequences on the part of MSMEs. The presence of informal institutions such as performance and/or future orientation was found to have a positive influence on MSMEs' efforts to become entrepreneurial. That there is empirical evidence supporting the sub-national 
institutions-strategic posture-organisational performance nexus is an added insight on current understanding of the institutional perspective of strategic behaviour of firms.

The focus on city-level institutions is a contribution to the current debate on how institutions shape economic performance, which is at the core of the study of new institutional economics. This challenges those conventional investment or business climate studies that present a wholesale barometer of a country's attractiveness or extent of being conducive for business. In the case of geographically diverse countries like the Philippines, a sub-national institutional analysis may offer a better way of explaining business activities and uncovering viable investment opportunities. The current study went beyond the simple thesis that institutions matter and sought to understand how institutions matter, to what extent and in what ways.

The attempt of the study to operationalise informal institutions and subsequently relating the latter to firm-level phenomena such as strategic posture forms part of the overall theoretical contribution of the study. Previous macroeconomic-orientated, conceptual as well as theoretical discussions of informal institutions did not offer conclusive empirical evidence on how informal institutions matter to firms such as MSMEs (Helmke \& Levitsky, 2004; Hodgson, 2006; North, 1990). Building on these previous studies, the current study concludes that the cultural environment is an acceptable representation of informal institutions. These informal institutions may offer plausible explanations on why owners/managers of MSMEs pursue an entrepreneurial strategic posture.

\subsection{Contributions to the Extant Literature}

The focus on formal and informal institutions adds further understanding that institutions are capable of providing resources, incentives, or opportunities that enable MSMEs to take on an entrepreneurial strategic posture. Entrepreneurial strategic posture is likely to flourish under certain supportive institutional contexts or in environments that provide flexibility, connectedness, and capacity for resource mobilisation. These two categories of institutions (formal and informal) may form part of the city's entrepreneurial climate within which entrepreneurial undertakings 
can take place. That informal institutions matter too in explaining the strategic configurations of MSMEs is a view duly supported by empirical evidence generated by this study.

Organisations are socially constituted and the informal institutional framework exerts pressures for conformity on the key organisational or strategic players. Consequently, conformity to these external pressures is manifested by the firms' strategic posture. This is particularly true amongst MSMEs where the majority are managed by the business owners themselves. The positive relationships of the two types of informal institutions and that of strategic posture enrich current understanding on the nature of institutions that goes beyond its typical political or legal treatment. That informal institutions matter, too is a message the empirical evidence at hand suggests.

The significant relationship between variables representing difference dimensions of formal institutions and strategic posture suggest that there is support for several theories explaining the relationship between the external environment and firm-level phenomena. The identification of these institutional dimensions is a contribution to the extant literature on institutional analysis whereby specific constructs were proposed and examined to adequately measure city-level formal institutions.

The study offers empirical evidence that the relationship between institutions and organisational performance is not necessarily direct. The study revealed that the relationship is partially mediated by the firm's strategic posture. This provides further understanding that institutions are significantly related to economic performance because they are associated with the strategic posture of the key players crucial in an economy. This is the case of MSMEs that dominate in number the economies of the two cities that were studied.

However, the study's results support the view that not all MSMEs are necessarily entrepreneurial in their strategic posture. Hence, MSME business operation may not be automatically referred to as entrepreneurship. It takes innovativeness, proactiveness and risk-taking for an MSME owner/manager to become an entrepreneur. 
Furthermore, MSMEs tend to differ in their organisational performance, which could be explained by both the degree of importance they attached to each performance indicator as well as by the strategic posture that they assumed. Paying closer attention to 'importance attribution', vis-à-vis the actual performance of firms, provides a holistic view on organisational performance. It is important to note, however, that this approach has its own inherent limitations just like any other methods of performance measurement. Moreover, it was beyond of the scope of the current study to compare the effectiveness of this method of performance measurement against other methods.

The results add further views to the environmental determinism and strategic choice debate (Child, 1997; Pfeffer \& Salancik, 1978; Whittington, 1988). The empirical evidence was clear concerning the positive relationships between formal/informal institutions and strategic posture, suggesting that the firm's strategic posture was largely related to the pressures exerted by the firm's environment (i.e. environmentally-determined). However, the positive relationship between strategic posture and organisational performance suggests that firms may exercise their strategic choice not merely as a matter of environmental acquiescence but also to maximise their ultimate performance goals as a way of protecting or advancing the firms' business interests.

Hence, the empirical evidence generated by this study, offers empirical support to both theories on environmental determinism and strategic choice in explaining the strategic motives and actions of MSMEs. This is consistent with the view advanced by the theory of organisational adaptation (Hrebiniak \& Joyce, 1985) explaining that environmental determinism and strategic choice should not be treated as opposite ends of a spectrum but as complementary perspectives, to yield greater understanding on how firms strategically respond to their external environment.

Likewise, the results enrich the theory of enabling authority (Leach et al., 1994) evidenced by the explanatory power of government assistance, rule of law, government policies, and regulatory quality at the city level on the strategic posture of firms. The presence of these efficient and effective institutions serves as the 
market-enhancing role of the local government (being the primary source of these institutions) in the promotion and development of MSMEs in the locality. In effect, the study provided tangible evidence on how the exercise of enabling authority by local authorities in the city (e.g. the city government) can have direct and measurable impacts on firm-level activities and performance.

The extent to which these formal and informal institutions encourage firms to be entrepreneurial represents the munificence of the firms' external environment. Environmental munificence has been shown to shape various organisational configurations depending on the extent to which firms gain access to critical resources (Castrogiovanni, 1991). The argument could be further extended to suggest that the resource-based view of the firms implies that MSMEs are likely to engage in risk-taking, innovative and proactive behaviour, if their current stock of resources (both tangible and intangible), as well as their perception of their possible access to resources which they do not currently have, allow them to do so (Barney, 2001). In effect, the results mirror the fundamental views of Pfeffer and Salancik (1978b) on resource dependency and Hofer's (1975) on contingency theory such that MSMEs' entrepreneurial activities partly depends on whether the institutional framework provides resources (or opens up access to resources) supportive of these kinds of activities.

Another major contribution of the study is its ability to clarify the misleading claims of popular investment or business climate indices that measure the "investability" of a country without due regard to variations in sub-national conditions, particularly the institutional frameworks governing each of the country's geopolitical subdivisions. The evidence supports the view that in many countries, especially those that have geographically-dispersed political subdivisions like the Philippines or Indonesia, it could be expected that there will be institutional variations that are likely to influence perceptions of business, investment and/or entrepreneurial climate (Chatman, Altman \& Johnson, 2008). Whilst the national scorecard of investment climate may give signals about whether it is viable to invest in the country, sub-national scorecards (which include sub-national institutional profile) may provide directions as to which specific place in the country to strategically locate one's investment (Wang, 2005). Whilst the current study has uncovered variations between the two cities, it cannot 
totally discredit the usefulness of country-level business climate indices until a thorough comparison is made between country-level and sub-national-level business climates.

The results of the study also offer empirical evidence supporting the indigenous perspective of sustainable economic development (Lindsay, 2003) which stresses the role of local businesses in the community's economic well-being. Supportive institutional structures as well as local culture that nurture entrepreneurship are paramount in local business development and regeneration, which are considered vital antecedents of overall economic development at both the national and local level.

The study yielded empirical evidence supporting the link between strategic posture and organisational performance. This is consistent with the views offered by the industrial organisation (IO) view suggesting that the conduct of firms is an antecedent of organisational performance (Hitt et al., 2007; Porter, 1980). The results on the strategic posture-organisational performance linkage were consistent with previous studies on the subject from most recent (Avlonitis \& Salavou, 2007) to the seminal work on the subject (Covin \& Slevin, 1989). That strategic posture is a basic driving force in the value creating processes of the firm, which ultimately impact performance outcomes, is a fundamental principle that the results clearly suggest and is consistent with current understanding of the subject.

The positive relationship between government policies/assistance and that of strategic posture lends credence to the view that the institutional environment may play a role in "legitimising" MSME activities and strategy such that these policies and various forms of assistance extended to the latter may suggest as an act of legitimisation of these firms as they pursue an entrepreneurial strategic posture (Scott, 2001).

Finally, the predominance in number of micro, small and medium enterprises in the business population of the two cities, supports the view that these firms form the engine of economic growth of cities in the Philippines. Their capacity to generate employment as well as to engage in entrepreneurial activities is critical in the socio- 
economic development of the cities where they operate their business. A clear understanding of the behaviour and performance of MSMEs may provide indicators of the overall business climate, 'investability' (i.e. investment-worthiness) and economic development of the city and/or country.

\subsection{Methodological Contributions of the Study}

On Formal Institutions. The results of the analysis of the psychometric properties of the five formal institution constructs as used in this study serve as significant contribution with respect to the measurement of formal institutions at the city-level. Whilst previous studies have used these constructs in a variety of ways, the current study's treatment of these constructs as "latent variables" with psychometric properties (i.e. reliability and validity) that required careful examination is a novel improvement that is useful in conducting institutional analyses. Even though the items measuring the constructs were adopted from previous studies, the psychometric credentials such as validity and reliability of these items and constructs remained unclear until this study.

On Informal Institutions. The distinctive characteristic of the current study relative to previous studies on informal institutions rests on the use of a set of constructs to empirically measure informal institutions. It was previously noted that whilst there is a plethora of studies done in the past that focused on the theoretical or conceptual meaning of informal institutions, empirical studies dealing with clear-cut typology of informal institutions were very scarce. The current study's argument that the cultural typology developed by the GLOBE study (House et al., 2004) fits the characterisation of informal institutions articulated in the seminal work of North $(1990 ; 2005)$ is an attempt at enriching the state of the art of the methodology of measuring informal institutions. Consequently, the current study's empirical analysis found some interesting relationships between a few of these informal institutions and organisational-level phenomena. 


\subsection{Policy Contributions of the Study}

In the context of governance reforms in many developing countries, formation and development of a supportive institutional framework should form part of the overall strategy of decentralisation and deregulation. The creation of sub-national government units such as cities should not simply be a matter of incomeclassification but also of institutional-building such that the major aim of decentralisation, which is local economic development, is achieved.

There was unequivocal evidence echoing the enabling role of the city government on the entrepreneurial endeavours of MSMEs doing business in the city. The exercise of leadership amongst the city government officials to ensure that good governance is practised in the city is an essential component of institutional-building for entrepreneurial development. Good governance requires rule of law, adequate protection of property rights, and sound government policies which are found to be associated with entrepreneurial undertakings.

Formal methods of consultation and collaboration between the city government and local business sector (i.e. MSMEs) remain a potent mechanism to identify unnecessary bureaucratic rigidities, explore investment opportunities and pursue multi-sectoral efforts that are mutually beneficial to all parties. Preferential treatment of MSMEs in the government procurement process has been shown by this study to be a significant element of government assistance that can augment the entrepreneurial endeavours of MSMEs. All these suggested programs and activities may form part of the overall strategy in governance designed to cultivate the city's institutional capacity for entrepreneurial development.

However, a local government unit with limited resources may not necessarily have the luxury to assist the MSME sector in general. Based on the descriptive analysis of the reported strategic posture of the firms in the survey, not all MSMEs may be considered "entrepreneurs" if the basis of that classification is the extent of risktaking, proactiveness and innovativeness - attributes of firms having high level of entrepreneurial strategic posture. The local government unit may want to focus their 
assistance on firms which have the potential and capacity to engage in entrepreneurial endeavours.

The city government may develop programs designed to influence the city's informal institutional environment. These programs, which may be best targeted to young people (i.e. potential entrepreneurs), may convey messages exalting entrepreneurial values and practices (such as future orientation and performance orientation). These programs should take a long-term perspective as changes in the normative institutional profile of a given place take time (Olsson, 1999; Redmond, 2005). These programs are suggested to foster an entrepreneurial culture amongst the local populace.

Finally, current thinking on MSME development in developing and emerging countries like the Philippines should go beyond the typical "lack of financial resources" mindset in understanding the performance of firms. Whilst financial capital is essential, thinking about the institutional framework of MSMEs may provide more holistic clues as to how to approach the challenge of supporting and developing the entrepreneurial capabilities of these key players of the economies of developing countries.

\subsection{Contributions to Managerial Practices}

The study highlighted the importance of strategic posture in the midst of institutional pressures. The results echoed the view that MSMEs are capable of pursuing strategic endeavours to protect their interests and achieve their goal/s. Managers and owners/managers of MSMEs should be made aware of the performance-enhancing benefits of entrepreneurial strategic posture. That being entrepreneurial despite various institutional pressures from the external environment will reap positive outcomes for the business. Hence, these key strategy makers within MSMEs should never abandon the pursuits of risk-taking, innovativeness and proactiveness in favour of strategic inertia as an implicit response to a hostile institutional environment. Whilst this may be a tall order for a micro-enterprise, entrepreneurial strategic posture may not necessarily demand radical business shifts. If coupled with other 
efforts like target or niche marketing, micro-enterprises may be better in placed to reap the benefits of entrepreneurial strategic posture.

MSMEs may consider structuring their business enterprise as a corporation. An incorporated business as opposed to a partnership or sole proprietorship may allow for more capital infused into the business, limits the personal liability of owners/stockholders, and attracts more professional managers. In effect, an incorporated business operation may allow the firm to be more entrepreneurial in its strategic posture as suggested by the study's results.

Furthermore, the specific indicators of strategic posture may provide directions for capability or skills development of MSME owners/managers. By examining how they rate across the measures of risk-taking, proactiveness and innovativeness, MSME owners/managers will have specific ideas as to which particular aspect they need to improve (e.g. through training) in order to promote the firm's overall entrepreneurial strategic posture.

It is noteworthy that MSMEs are not merely passive players who simply react to the demands of the institutional environment. North (1990) recognises the feasibility of economic players influencing the state of local institutions, especially the formal ones. MSMEs acting collectively as well as along with other players in the economy could effectively challenge the formal institutional framework to make the latter more responsive to the needs of economic development.

\subsection{Limitations and Directions for Future Research}

On City Coverage. The current study's focus on city-level institutional profiles yielded equivocal results in terms of the influence of informal institutions on firmlevel phenomena. Considering that only two cities were covered in the study, a much wider multi-city and multi-region study within the same national boundary is a desirable future research undertaking and will likely identify more variations in normative institutional profiles. Validation of the results of the current by taking another sample from the population and examining if the same propositions are tenable is a study that will yield more generalisable results. 
On The Use of Subjective Measures. A limitation of the research rests on the use of subjective measures of the variables. Although the use of perceptual measures was justified, using objective or archival measures or any other forms of triangulation approach could have further enriched an understanding of the variables and their interrelationships. This limitation is however inherent in many studies involving micro-enterprises from which archival data are difficult or impossible to obtain. Closely related to this limitation was the use of single informants in the survey. Multiple informants should provide better qualification of the results. For instance, customer satisfaction is best evaluated by the customers themselves rather than by monotonic views of the manufacturer or service provider. Future studies may be undertaken using triangulated data gathering methodology to supplement and enrich the results of current research. Studies may be designed using objective representations or proxy for institutions, strategic posture and organisational performance.

On Research Design. A longitudinal study is likely to generate a more comprehensive view of the impact of institutions on organisational phenomena by taking into account the dynamism inherent in these two sets of variables. Institutions change over time and a methodology to capture the corresponding effects of these changes on the dynamic strategic configurations of business firms will have better explanatory and predictive power concerning these phenomena.

The study did not take into account the stage (in their life cycle as well as industry life cycle) a particular firm was positioned or situated. The researcher is fully aware of the view that firms do change their strategic configurations consistent with industry dynamics (Porter, 1980). Examining the life cycle of the business and industry allows the identification of institutions that have the greatest impact on firms throughout the cycle. Doing so carries practical significance such that policy interventions could be targeted to small firms given their stage in their life cycle. For instance, exploring the varying influence of institutions on start-ups versus established firms as well as on those local firms operating in international markets is a potential research project. 
On Validation of the Regression Model. The use of multiple regression to test the conceptual model of the study requires the validation of the results (Hair et al., 2006). Authorities in the field of statistics recommend that "after identifying the best regression model, the final step is to ensure that it represents the general population and is appropriate for the situations in which it will be used" (Hair et al., 2006 p. 233). Validation is necessary to ensure transferability and generalisability of the model.

A recommended approach is studying additional samples thereby allowing the researcher to determine the validity of the original model by comparing to the regression models estimated with the new sample. Validation of results by obtaining another sample from the population and assessment of the correspondence of results from the two samples is necessary to ensure generalisability of results to the population of MSMEs.

Validation may also address the issue of "crud factor" which according to Chin (1998) and Meehl (1990) may explain low beta coefficients due to some complex unknown network of generic and environmental factors. This crud factor may render low beta coefficients to be theoretically meaningless. However, this task of adding more samples is considered beyond the scope and resources of the current study. Caution must be exercised therefore, in attributing the results to the overall characteristics of the population. The validation study may also include an investigation of the impact of possible confounding variables which may influence the nature and magnitude of relationships amongst the variables in the current study.

Further validation of the model that was developed in this study may entail comparison between micro-enterprises and SMEs (i.e. small and medium enterprises) to offer a deeper understanding on how the formal and informal institutions relate to these types of firms. Although the study's model took into account the number of full time employees (being the proxy indicator for the size of firms), the small number of SMEs relative to the micro-enterprises did not warrant a fair comparison of firms in terms of their sizes. Studies in the future may consider covering a larger sample size of firms coming from a larger number of cities across the Philippines. Covering more sub-national localities such as cities is necessary to increase the sample size of SMEs 
because it is reasonable to expect that there will be very few SMEs found in every Philippine city.

On Formal Institutions. The exploratory nature of the constructs and indicators used to measure the various forms of formal institutions requires further study to establish their validity in a robust manner. Examination of the concurrent validity of these constructs along with objective measures will further improve their psychometric properties, which will improve their utility in future institutional theory - oriented research.

On Informal Institutions. Future replication studies are suggested to validate further the components comprising the informal institutions. The study's results showing two informal institutions, namely assertiveness and power distance with low levels of reliability and validity, contradict the findings of the work of House et al (2004). Replication studies to examine the validity of the different variables categorised in this study as informal institutions will enhance the latter's psychometric properties and hence, utility for scholarly research.

Moreover, studies exploring those much more firm-specific informal institutions in the context of North's view of institutions (1990) would constitute interesting research worth conducting. This study examined sub-national culture to measure informal institutions. An investigation of firm or industry specific norms, practices, values, traditions, and other unwritten codes of conduct or modes of behaviour will shed more light on the role of institutions in entrepreneurial development in particular, and economic performance in general.

On The Interaction of Formal and Informal Institutions. The interaction of formal and informal institutions is another research opportunity worth pursuing in future research. Determination of the possible complementary, conflicting, additive or multiplicative effects of these two categories of institutions will generate better understanding of the role, dynamics, and effects of institutions on organisational or social phenomena. 
On Formal Institutions and Resources. The role of the resources of the (city) local government unit may offer explanations on the significant differences on the reported perceptions of formal institutions between the two cities. Future research may be directed towards the analysis of the type and amount of local government resources that can explain the institutional thickness in cities, which in turn, can explain MSME behaviour and performance.

On The Other 'Players of the Game'. It may also be interesting to know how the presence of other players (i.e. organisations) affects MSMEs within the same institutional framework. The influence of organisations like banks, business associations, and specific national and local government agencies may be worth investigating to provide a more comprehensive view on MSMEs development in the context of institutional theory. Markets are also shaped by institutions (Herrschel \& Newman, 2000). Examining how formal and informal institutions affect MSME's markets and industries may be worth pursuing in the future.

On Mediation Analysis. The previous analysis on the mediating role of strategic posture was an application of a method of mediation analysis (Baron \& Kenny, 1986; Podsakoff et al., 2003) which has been a focal subject of intellectual discussion in establishing causal relationships amongst a given set of variables. The use of OLS regression in the study showed the extent of direct and indirect relationships of the independent variables (e.g. institutions), the mediating variable (i.e. strategic posture) and the dependent variable (i.e. organisational performance) to determine the presence of mediated relationships. However, the analysis further examined the magnitude of the mediated relationships by using two other post-hoc tests (i.e. Sobel test and Goodman tests) to ascertain full or partial mediation. By doing so, the empirical evidence offered meaningful insights from interesting associations (of variables) that were decomposed into components which in turn, reveal possible causal relationships (Shrout \& Bolger, 2002). The study contributes to the on-going effort of bringing mediation analysis at the forefront of research methods in explaining the significance of relationships (including causal relationships) in a nexus of variables under investigation. 
However, the weaknesses of currently available tools to assess mediation using the Sobel and Goodman tests support the view that more methodology-oriented research is needed to perform mediation analysis. Therefore, further development of statistical tests of mediation to complement multiple regression remains an area of future research interest (Preacher et al., 2007). Alternatively, the use of structural equation modelling (SEM) is highly recommended as a straightforward approach to mediation analysis. Future studies should consider using SEM provided the nature of the study and the measures used in the study match the confirmatory approach of this powerful technique.

\subsection{Summary}

The overall results of the study offer support of the view that the local institutional environment of a city is significantly related to the tendency of MSMEs to adopt an entrepreneurial strategic posture. The formal and informal institutions comprising this business environment may encourage or discourage MSMEs with respect to their perceptions of the feasibility, desirability, and sustainability of an entrepreneurial strategic posture. The results of the study revealed, that MSMEs with an entrepreneurial strategic posture, are likely to report better organisational performance outcomes. In effect, the empirical evidence generated by the study supports the view that formal and informal institutions influence the firms' overall organisational performance through the mediating role of the firms' strategic posture.

The potential for MSMEs to perform better as business organisations and consequently, to fulfil the role of being the engine of sub-national (such as city) economic growth depend on factors such as their ability to exercise entrepreneurial strategic posture. The formal and informal manifestations of this institutional environment form the seedbed on which MSMEs pursue and nurture their risk-taking efforts, innovativeness and pro-activeness in a fashion that maximises organisational returns. 
Appendix A.

The Research Instrument - Survey Questionnaire 
VICTORIA

UNIVERSITY OF

WELLINGTON

5. Whase Wenang

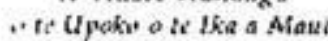

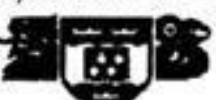

A Survey of Micro, Small and Medium Enterprises (MSMEs) in the Cities of Tagum and Panabo

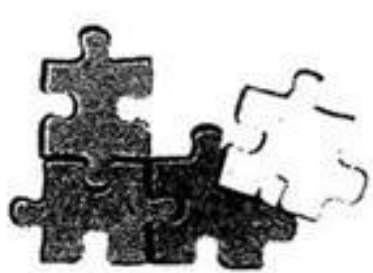

Banjo G. Roxas

Researcfier

SCHOOL OF MARKETING AND INTERMATIONAL BUSINESS

$$
\text { Te Kura Hokoboko, Pakini ki te Ao }
$$

PO Bax 600 , Wellingtoa, New Zealand
Plone $+64-4-463 \quad 5330$ Fax $+64-4-463 \quad 523$

October 2007

\section{Dear Sir/Madame:}

Please let us know what you think of the business and cultural environment of your city. We also wish to know the performance of your business within this environment. This survey is administered by the School of Marketing and International Business of Victoria University of Wellington in New Zealand as part of the PhD research of the undersigned. Your participation in this survey is STRICTLY CONFIDENTIAL and COMPLETELY VOLUNTARY.

If you do participate, you have a chance of winning exciting prizes as tokens of our appreciation for your concern and cooperation. Moreover, your participation will help in finding ways to make your city a better place for business.

The questionnaire will take around 30 minutes only to complete. The undersigned or an enumerator will collect the questionnaire.

We thank you for sharing your precious time with us.

Very truly yours,

Banjo G. Roxas

PhD Researcher

School of Marketing and International Business

Victoria University of Wellington

Rm. 101 Rutherford House, 23 Lambton Quay

Wellington New Zealand

Tel. Nos. +64043845350

victoriauniversitynz@yahoo.co.nz
Dr. Val Lindsay, PhD

Research Supervisor

SMIB

Victoria University of Wellington

Rm. 1101, Rutherford House, 23

Wellington New Zealand

Tel. Nos. +64 044636915

val.lindsay@vuw.ac.nz 


\section{Part A. Formal Institutions}

Overview: We are interested to know what micro, small and medium enterprises (MSMEs) like YOU think/feel about your city.

\section{Instructions:}

a. Please evaluate your city in terms of the items described below. To do this, please think of what is happening within YOUR CITY only. If you are asked about government issues or policies, think of your city government and no other.

b. Please state whether you agree or disagree to each statement about your city.

c. Please encircle the number that corresponds to your choice.

d. Remember there are NO WRONG answers.

e. Answers DO NOT indicate goodness or badness of the city.

For Example:

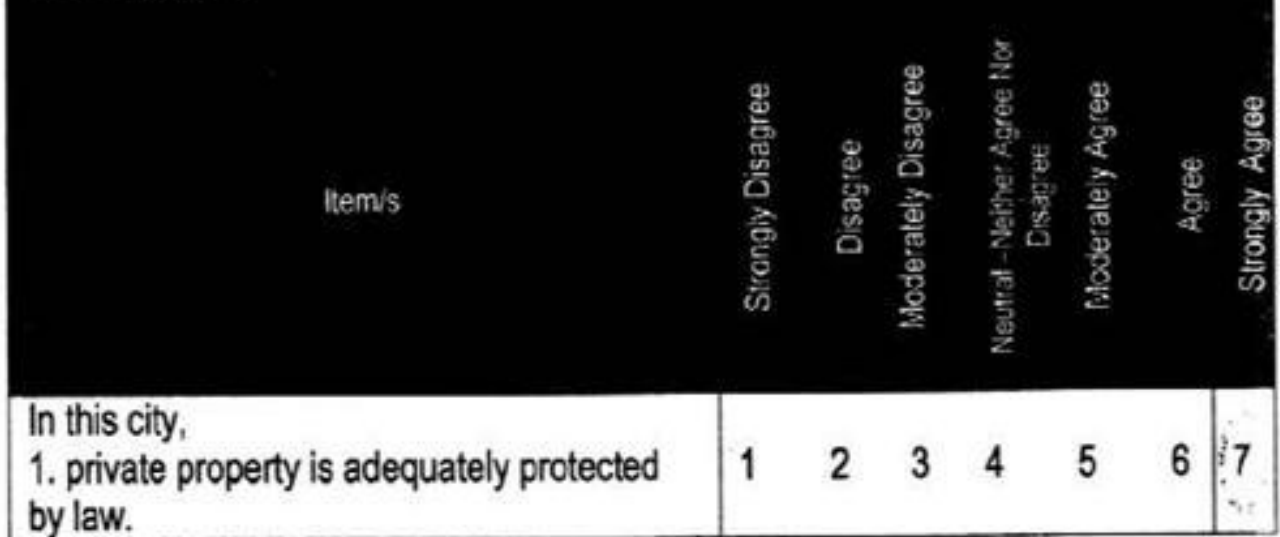

Encircle 7only if you strongly agree or if you strongly think/feel that in your city, private property that is owned by your business is wellprotected by the law.

Remember it is what you personally think/feel that matters in this survey. You may base your answer/judgment on past experiences, knowledge, opinion, perception, etc.

Note: MSME refers to micro, small and medium enterprises 


\begin{tabular}{|c|c|c|c|c|c|c|c|c|}
\hline & In this city: & 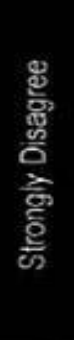 & $\begin{array}{l}\stackrel{\mathscr{W}}{\mathrm{W}} \\
\text { 总 }\end{array}$ & 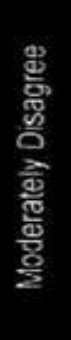 & 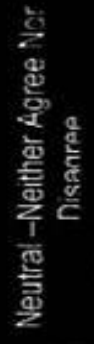 & 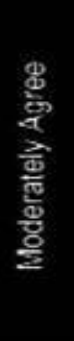 & 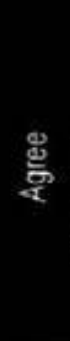 & 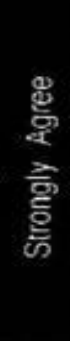 \\
\hline 1. & $\begin{array}{l}\text { the occurrence of crime does not impose } \\
\text { costs on my business. }\end{array}$ & 1 & 2 & 3 & 4 & 5 & 6 & 7 \\
\hline 2. & the judicial system is fair and impartial. & 1 & 2 & 3 & 4 & 5 & 6 & 7 \\
\hline 3. & $\begin{array}{l}\text { the legal system is effective in enforcing } \\
\text { commercial contracts. }\end{array}$ & 1 & 2 & 3 & 4 & 5 & 6 & 7 \\
\hline 4. & $\begin{array}{l}\text { people are willing to accept legal means } \\
\text { to settle disputes rather than depend on } \\
\text { physical force or illegal means }\end{array}$ & 1 & 2 & 3 & 4 & 5 & 6 & 7 \\
\hline 5. & $\begin{array}{l}\text { court rulings and/or arbitration awards } \\
\text { are complied with by the people involved }\end{array}$ & 1 & 2 & 3 & 4 & 5 & 6 & 7 \\
\hline 6. & $\begin{array}{l}\text { the legal framework to challenge the } \\
\text { legality of government actions is efficient. }\end{array}$ & 1 & 2 & 3 & 4 & 5 & 6 & 7 \\
\hline 7. & $\begin{array}{l}\text { private property is adequately protected } \\
\text { by law. }\end{array}$ & 1 & 2 & 3 & 4 & 5 & 6 & 7 \\
\hline 8. & $\begin{array}{l}\text { intellectual property rights (like copyrights } \\
\text { or trademarks) are adequately protected }\end{array}$ & 1 & 2 & 3 & 4 & 5 & 6 & 7 \\
\hline 9. & $\begin{array}{l}\text { the city government enforces laws that } \\
\text { protect private property }\end{array}$ & 1 & 2 & 3 & 4 & 5 & 6 & 7 \\
\hline 10. & $\begin{array}{l}\text { violations of property rights are } \\
\text { prosecuted accordingly }\end{array}$ & 1 & 2 & 3 & 4 & 5 & 6 & 7 \\
\hline
\end{tabular}

(.)
In this city:

\begin{tabular}{|c|c|c|c|c|c|c|c|c|}
\hline & In this city: & 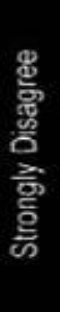 & 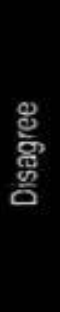 & 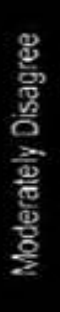 & 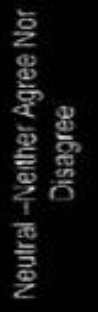 & 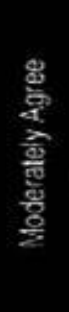 & $\frac{\Phi}{\Phi^{2}}$ & 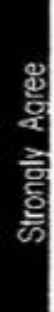 \\
\hline 11. & $\begin{array}{l}\text { laws and regulations imposed by the } \\
\text { city government are conducive for } \\
\text { business. }\end{array}$ & 1 & 2 & 3 & 4 & 5 & 6 & 7 \\
\hline 12. & $\begin{array}{l}\text { taxation laws and policies including } \\
\text { incentives and exemptions are good } \\
\text { enough for my business }\end{array}$ & 1 & 2 & 3 & 4 & 5 & 6 & 7 \\
\hline 13. & $\begin{array}{l}\text { city government economic policies } \\
\text { adapt quickly to changes in the } \\
\text { economy }\end{array}$ & 1 & 2 & 3 & 4 & 5 & 6 & 7 \\
\hline 14. & $\begin{array}{l}\text { city government decisions are } \\
\text { effectively implemented. }\end{array}$ & 1 & 2 & 3 & 4 & 5 & 6 & 7 \\
\hline 15. & $\begin{array}{l}\text { the policy direction of the city } \\
\text { government is consistent }\end{array}$ & 1 & 2 & 3 & 4 & 5 & 6 & 7 \\
\hline 16. & $\begin{array}{l}\text { information about laws and } \\
\text { regulations is easy to obtain }\end{array}$ & 1 & 2 & 3 & 4 & 5 & 6 & 7 \\
\hline 17. & $\begin{array}{l}\text { interpretations of the laws and } \\
\text { regulations are consistent and } \\
\text { predictable }\end{array}$ & 1 & 2 & 3 & 4 & 5 & 6 & 7 \\
\hline 18. & $\begin{array}{l}\text { business regulations are less of a } \\
\text { burden for business. }\end{array}$ & 1 & 2 & 3 & 4 & 5 & 6 & 7 \\
\hline 19. & $\begin{array}{l}\text { procedures in city government } \\
\text { transactions are consistently } \\
\text { enforced }\end{array}$ & 1 & 2 & 3 & 4 & 5 & 6 & 7 \\
\hline
\end{tabular}


In this city:

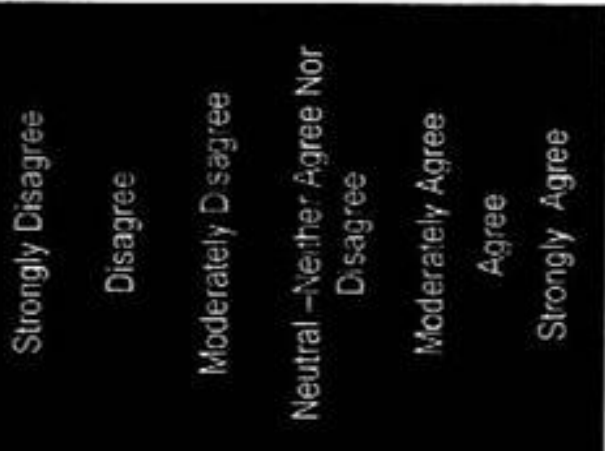

\begin{tabular}{|l|lllllllll|}
\hline 20. & $\begin{array}{l}\text { the time required to register a } \\
\text { business with the city government } \\
\text { is reasonable. }\end{array}$ & 1 & 2 & 3 & 4 & 5 & 6 & 7 \\
\hline 21. & $\begin{array}{l}\text { the number of permits required is } \\
\text { manageable. }\end{array}$ & 1 & 2 & 3 & 4 & 5 & 6 & 7 \\
\hline 22. & $\begin{array}{l}\text { the number of city govemment } \\
\text { offices to deal with is reasonable. }\end{array}$ & 1 & 2 & 3 & 4 & 5 & 6 & 7 \\
\hline 23. & $\begin{array}{l}\text { the number of city govemment } \\
\text { inspections required before } \\
\text { opening a business is reasonable. }\end{array}$ & 1 & 2 & 3 & 4 & 5 & 6 & 7 \\
\hline 24. & $\begin{array}{l}\text { city govemment offices assist } \\
\text { individuals in starting their own } \\
\text { business. }\end{array}$ & 1 & 2 & 3 & 4 & 5 & 6 & 7 \\
\hline 25. & $\begin{array}{l}\text { the city government sets aside } \\
\text { government contracts for new and } \\
\text { small businesses. }\end{array}$ & 1 & 2 & 3 & 4 & 5 & 6 & 7 \\
\hline 26. & $\begin{array}{l}\text { the city government has special } \\
\text { support available for individuals } \\
\text { who want to start a new business }\end{array}$ & 1 & 2 & 3 & 4 & 5 & 6 & 7 \\
\hline 27. & $\begin{array}{l}\text { the city government sponsors } \\
\text { organizations that help new } \\
\text { businesses develop. }\end{array}$ & 1 & 2 & 3 & 4 & 5 & 6 & 7 \\
\hline 28. & $\begin{array}{l}\text { even after failing in an earlier } \\
\text { business, the city government } \\
\text { assists businessmen/women in } \\
\text { starting again. }\end{array}$ & 1 & 2 & 3 & 4 & 5 & 6 & 7 \\
\hline
\end{tabular}

Part B. Informal Institutions

Overview: We are interested to know what micro, small and medium enterprises (MSME) like YOU thinkffeel about the way things are in your city - general bellefs about norms, values, and practices in the city as a society where you live. In other words, we are interested in the way your city is - not the way you think it should be.

Instructions:

a. Please evaluate your city in terms of the items described below.

b. Please indicate whether you agree or disagree to each statement that the item describes about your city.

c. Please encircle the number that corresponds to your choice.

d. Remember there are NO WRONG answers.

\begin{tabular}{|c|c|c|c|c|c|c|c|}
\hline 1. & \multicolumn{7}{|c|}{$\begin{array}{l}\text { In this city, orderliness and consistency are stressed, even at the expense of } \\
\text { experimentation and innovation }\end{array}$} \\
\hline & $\begin{array}{l}\text { strongly } \\
\text { agree }\end{array}$ & & & $\begin{array}{l}\text { neither } \\
\text { agree/ } \\
\text { disagree }\end{array}$ & & & $\begin{array}{l}\text { strongly } \\
\text { disagree }\end{array}$ \\
\hline & 1 & 2 & 3 & 4 & 5 & 6 & 7 \\
\hline 2. & \multicolumn{7}{|c|}{ The way to be successful in this city is to: } \\
\hline & $\begin{array}{l}\text { plan } \\
\text { ahead }\end{array}$ & & & & & & $\begin{array}{c}\text { take } \\
\text { events as } \\
\text { they occur }\end{array}$ \\
\hline & 1 & 2 & 3 & 4 & 5 & 6 & 7 \\
\hline 3. & \multicolumn{7}{|c|}{ In this city, the accepted norm/usual practice/custom is to: } \\
\hline & $\begin{array}{l}\text { plan for } \\
\text { the } \\
\text { future }\end{array}$ & & & & & & $\begin{array}{l}\text { accept the } \\
\text { status quo }\end{array}$ \\
\hline & 1 & 2 & 3 & 4 & 5 & 6 & 7 \\
\hline
\end{tabular}




\begin{tabular}{|c|c|c|c|c|c|c|c|}
\hline 4. & \multicolumn{7}{|c|}{ In this city, a person's influence is based primarily on: } \\
\hline \multicolumn{7}{|c|}{$\begin{array}{l}\text { one's ability and } \\
\text { contribution in } \\
\text { society }\end{array}$} & \multirow{2}{*}{$\begin{array}{c}\text { the authority } \\
\text { of one's } \\
\text { position } \\
7\end{array}$} \\
\hline & 1 & 2 & 3 & 4 & 5 & 6 & \\
\hline 5. & \multicolumn{7}{|c|}{ In this city, people are generally: } \\
\hline & assertive & & & & & & \multirow{2}{*}{$\begin{array}{c}\text { non- } \\
\text { assertive } \\
7\end{array}$} \\
\hline & 1 & 2 & 3 & 4 & 5 & 6 & \\
\hline 6. & \multicolumn{7}{|c|}{ In this city, leaders encourage group loyalty even if individual goals suffer. } \\
\hline & $\begin{array}{c}\text { strongly } \\
\text { agree }\end{array}$ & & & $\begin{array}{l}\text { neither } \\
\text { agree/ } \\
\text { Jisagre }\end{array}$ & & & $\begin{array}{l}\text { strongly } \\
\text { disagree }\end{array}$ \\
\hline & 1 & 2 & 3 & $\begin{array}{l}e \\
4\end{array}$ & 5 & 6 & 7 \\
\hline 7. & \multicolumn{7}{|c|}{ In this city, social gatherings are usually. } \\
\hline & $\begin{array}{l}\text { lanned well in } \\
\text { advanced } \\
\text { ir more weeks in } \\
\text { advance }\end{array}$ & & & & & & $\begin{array}{l}\text { Spontaneous } \\
\text { (planned less } \\
\text { than an hour in } \\
\text { advance) }\end{array}$ \\
\hline & 1 & 2 & 3 & 4 & 5 & 6 & 7 \\
\hline
\end{tabular}

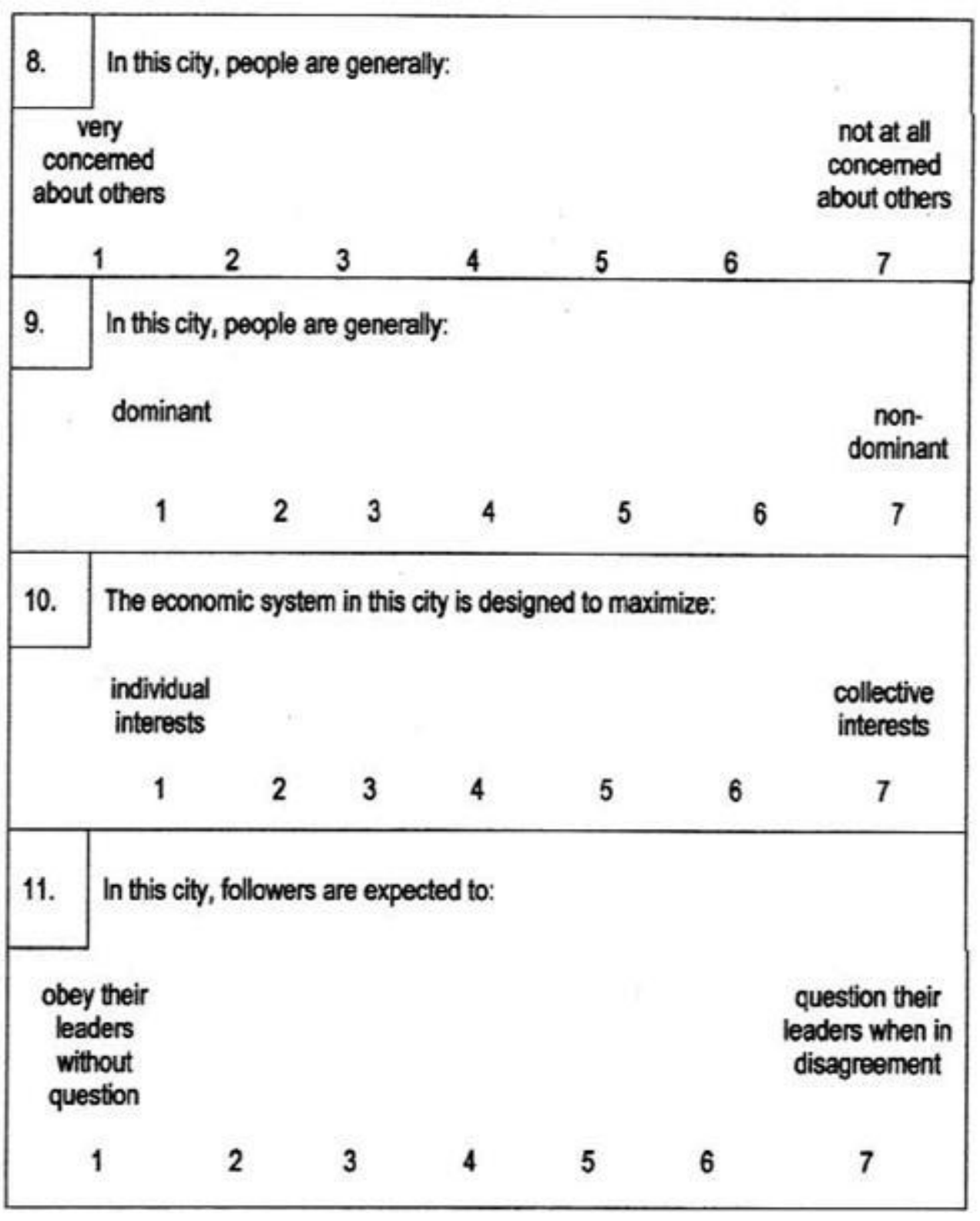




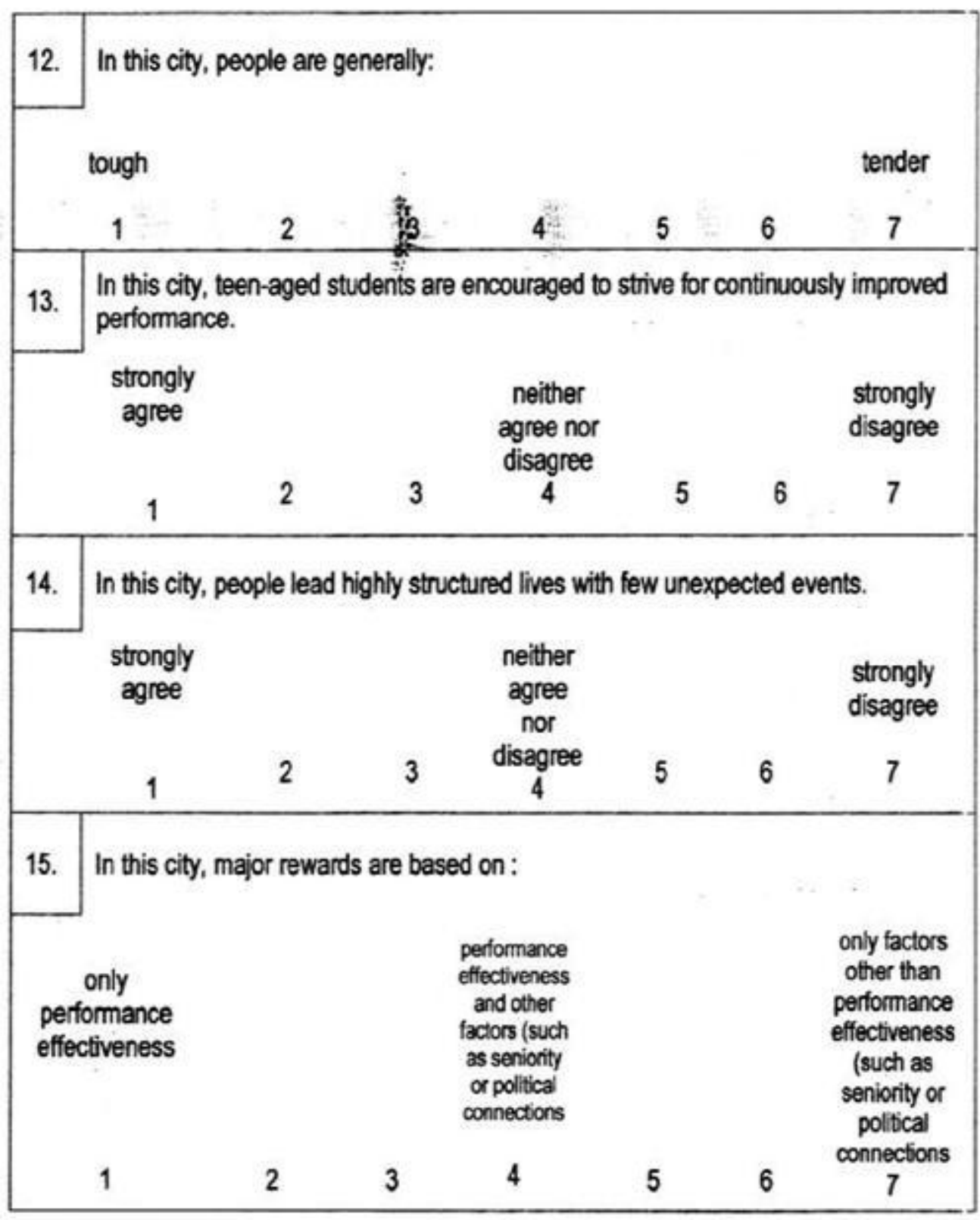

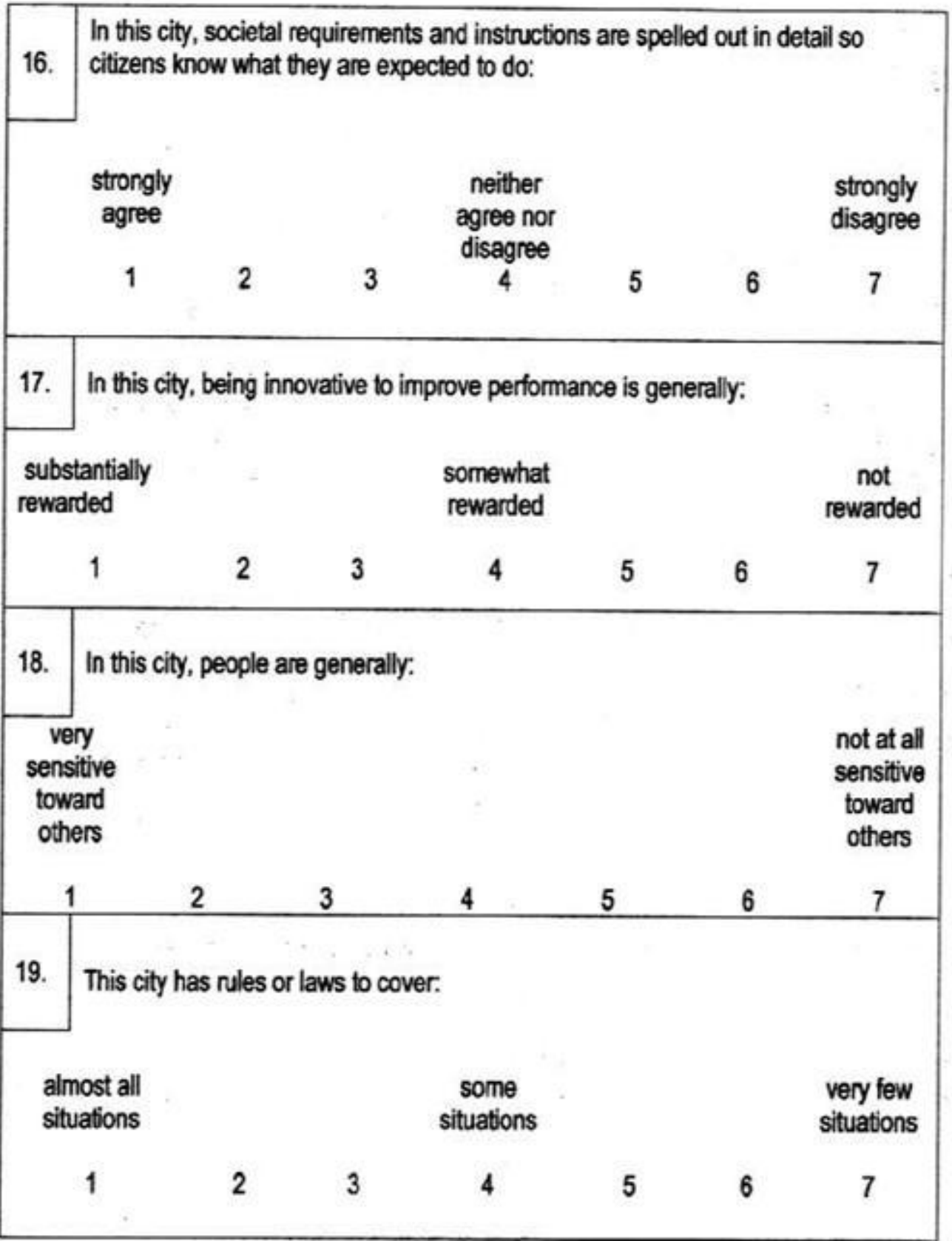




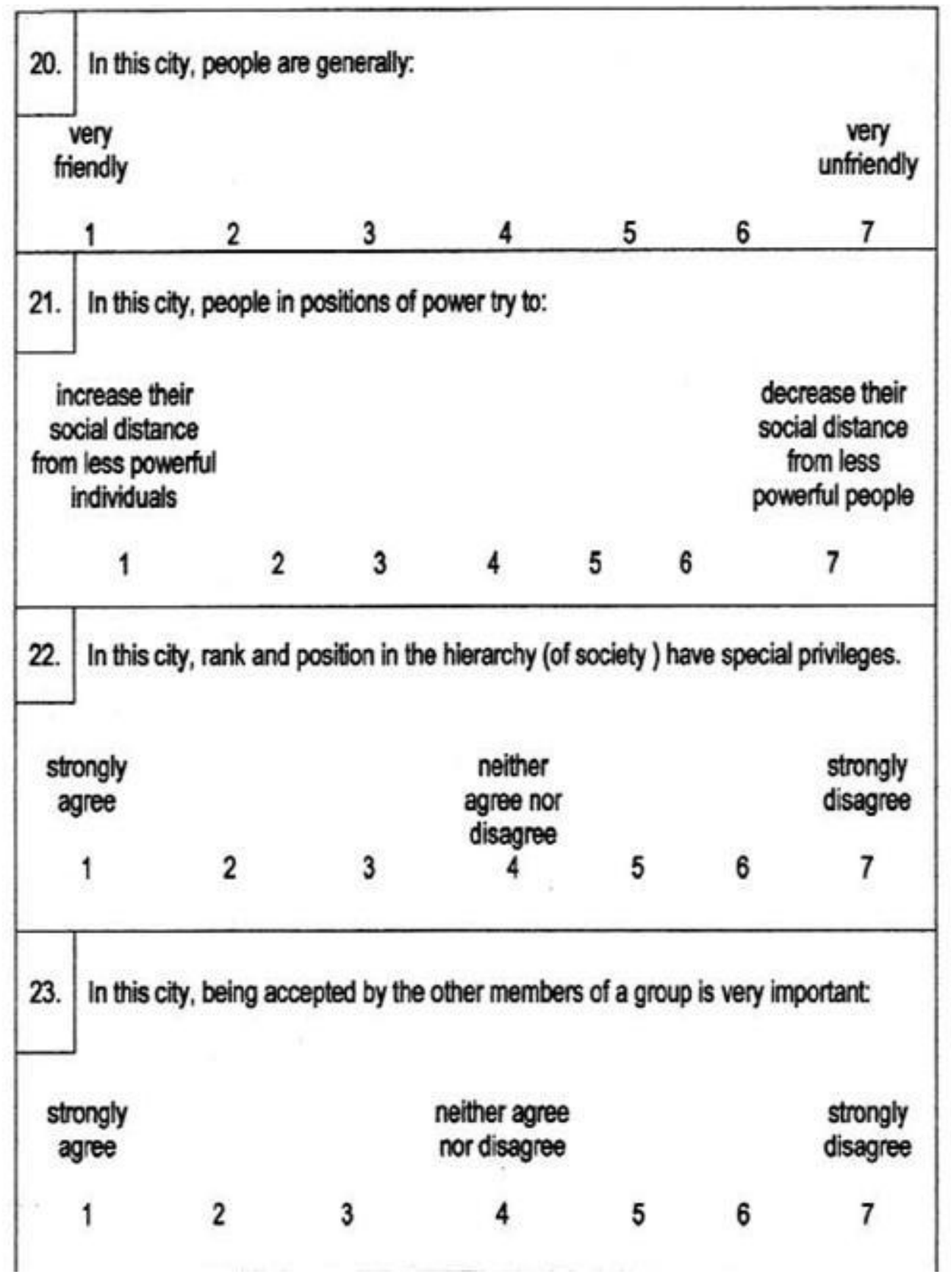

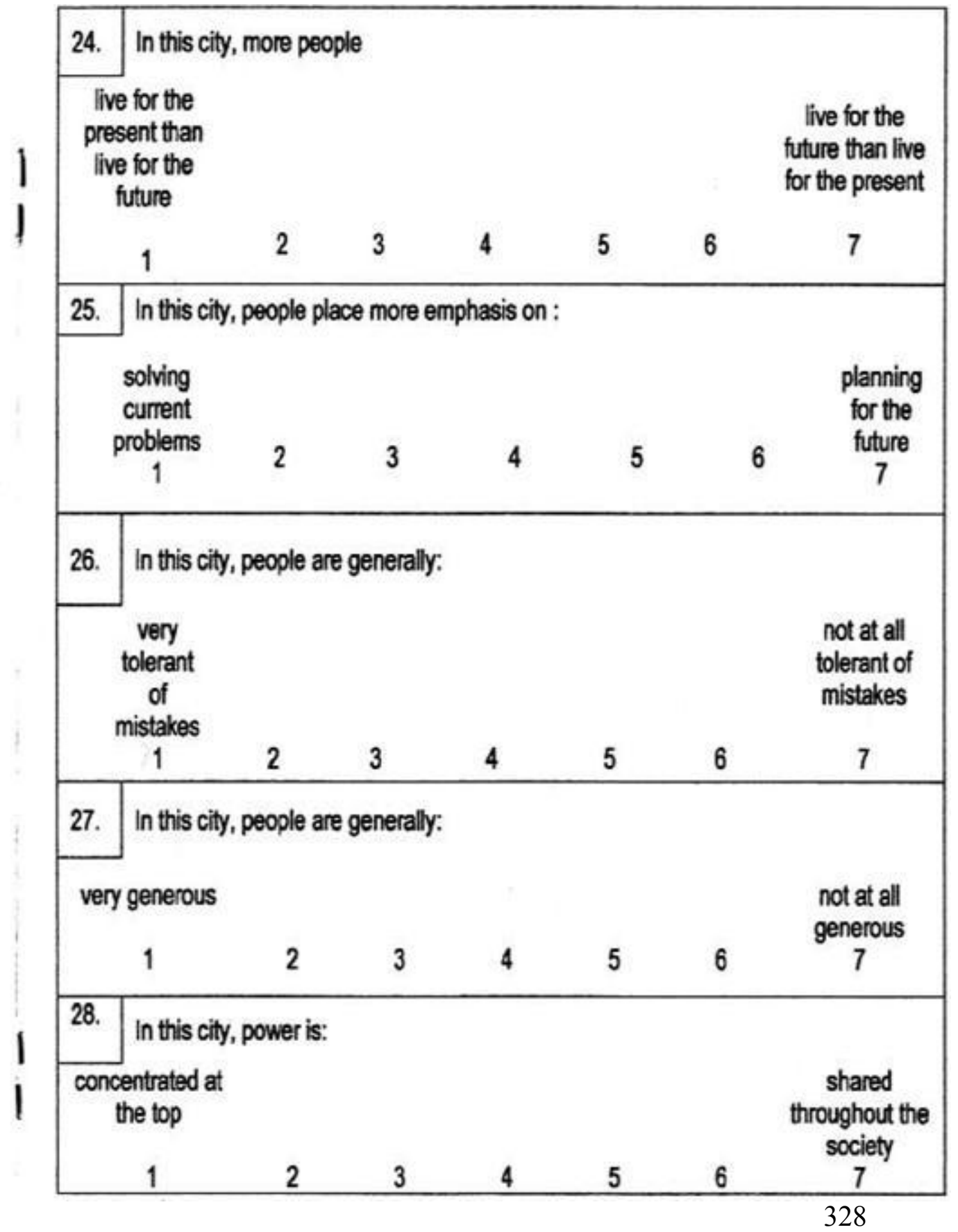




\begin{tabular}{|c|c|c|c|c|c|c|c|c|}
\hline 29. & \multicolumn{8}{|c|}{ In this city, } \\
\hline \multicolumn{3}{|c|}{$\begin{array}{l}\text { tight group } \\
\text { membership } \\
\text { is more } \\
\text { valued than } \\
\text { individualism }\end{array}$} & & $\begin{array}{l}\text { tight group } \\
\text { membership } \\
\text { and } \\
\text { individualism } \\
\text { are equally } \\
\text { valued }\end{array}$ & & & & $\begin{array}{l}\text { dividualism } \\
\text { is more } \\
\text { alued than } \\
\text { ght group } \\
\text { embership }\end{array}$ \\
\hline \multicolumn{2}{|c|}{1} & 2 & 3 & 4 & 5 & 6 & & 7 \\
\hline 30. & \multicolumn{8}{|c|}{ In this city, the intemet is a very convenient source of information. } \\
\hline \multicolumn{2}{|c|}{$\begin{array}{c}\text { Strongly } \\
\text { Disagree } \\
1\end{array}$} & 2 & 3 & 4 & 5 & & 6 & $\begin{array}{c}\text { Strongly } \\
\text { Agree } \\
7\end{array}$ \\
\hline 31. & \multicolumn{7}{|c|}{ In this city, the internet provides all kinds of useful information. } & \\
\hline \multicolumn{3}{|c|}{$\begin{array}{l}\text { Strongly } \\
\text { Disagree } \\
1\end{array}$} & 3 & 4 & 5 & & 3 & $\begin{array}{c}\text { Strongly } \\
\text { Agree } \\
7 \\
\end{array}$ \\
\hline 32. & \multicolumn{8}{|c|}{ In this city, the intemet is a very useful tool to research for information. } \\
\hline \multicolumn{2}{|c|}{$\begin{array}{c}\text { Strongly } \\
\text { Disagree } \\
1\end{array}$} & 2 & 3 & 4 & 5 & & & $\begin{array}{c}\text { Strongly } \\
\text { Agree } \\
7\end{array}$ \\
\hline 33. & \multicolumn{8}{|c|}{$\begin{array}{l}\text { In this city, I would strongly recommend the internet as a research tool to } \\
\text { find new information. }\end{array}$} \\
\hline $\begin{array}{r}\text { Stror } \\
\text { Disar } \\
1\end{array}$ & & 2 & 3 & 4 & 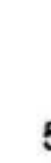 & & 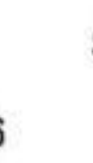 & $\begin{array}{l}\text { Strongly } \\
\text { Agree } \\
7\end{array}$ \\
\hline
\end{tabular}

\section{Part C. Strategic Posture}

Overview: As this stage, we would like to know the strategic posture of micro, Instructions: small and medium enterprises (MSMEs).

a. Please think of your business enterprise in terms of the items described below.

b. Please indicate in a scale of 1-7 at which point you would categorize your business ênterprise.

c. Please encircle the number that corresponds to your choice.

d. Remember there are NO WRONG answers.

e. Answers DO NOT indicate goodness or badness of the enterprise/business.

In general, my business favors:

1. A strong emphasis

on the marketing of

tried and true products

or services

A strong emphasis on research \& development, technological leadership,

How many new lines of products or services has your business marketed in the past few years?

\section{2. no new line of}

products or services

$\begin{array}{lllllll}1 & 2 & 3 & 4 & 5 & 6 & 7\end{array}$ very many new lines of

products or services 


\begin{tabular}{|c|c|c|c|c|c|c|c|c|}
\hline $\begin{array}{l}\text { 3. changes in product or } \\
\text { service lines have been } \\
\text { mostly of a minor nature }\end{array}$ & 1 & 2 & 3 & 4 & 5 & 6 & 7 & $\begin{array}{l}\text { changes in product or } \\
\text { service lines have } \\
\text { usually been quite } \\
\text { dramatic }\end{array}$ \\
\hline \multicolumn{9}{|c|}{ In dealing with its competitors, my business.... } \\
\hline $\begin{array}{l}\text { 4. typically responds to } \\
\text { actions which } \\
\text { competitors initiate }\end{array}$ & 1 & 2 & 3 & 4 & 5 & 6 & 7 & $\begin{array}{l}\text { typically initiates actions } \\
\text { to which competitors } \\
\text { then respond }\end{array}$ \\
\hline $\begin{array}{l}5 \text {. is very seldom the first } \\
\text { business to introduce } \\
\text { new products/services, } \\
\text { administrative } \\
\text { techniques, operating } \\
\text { technologies, etc. }\end{array}$ & 1 & 2 & 3 & 4 & 5 & 6 & 7 & $\begin{array}{l}\text { Is very often the first } \\
\text { business to introduce } \\
\text { new products/services, } \\
\text { administrative } \\
\text { techniques, operating } \\
\text { technologies, etc. }\end{array}$ \\
\hline $\begin{array}{l}\text { 6. typically seeks to avoid } \\
\text { competitive clashes, } \\
\text { preferring a 'live-and-let- } \\
\text { live' posture }\end{array}$ & 1 & 2 & 3 & 4 & 5 & 6 & 7 & $\begin{array}{l}\text { typically adopts a very } \\
\text { competitive, "undo-the } \\
\text { competitors' attitude }\end{array}$ \\
\hline
\end{tabular}

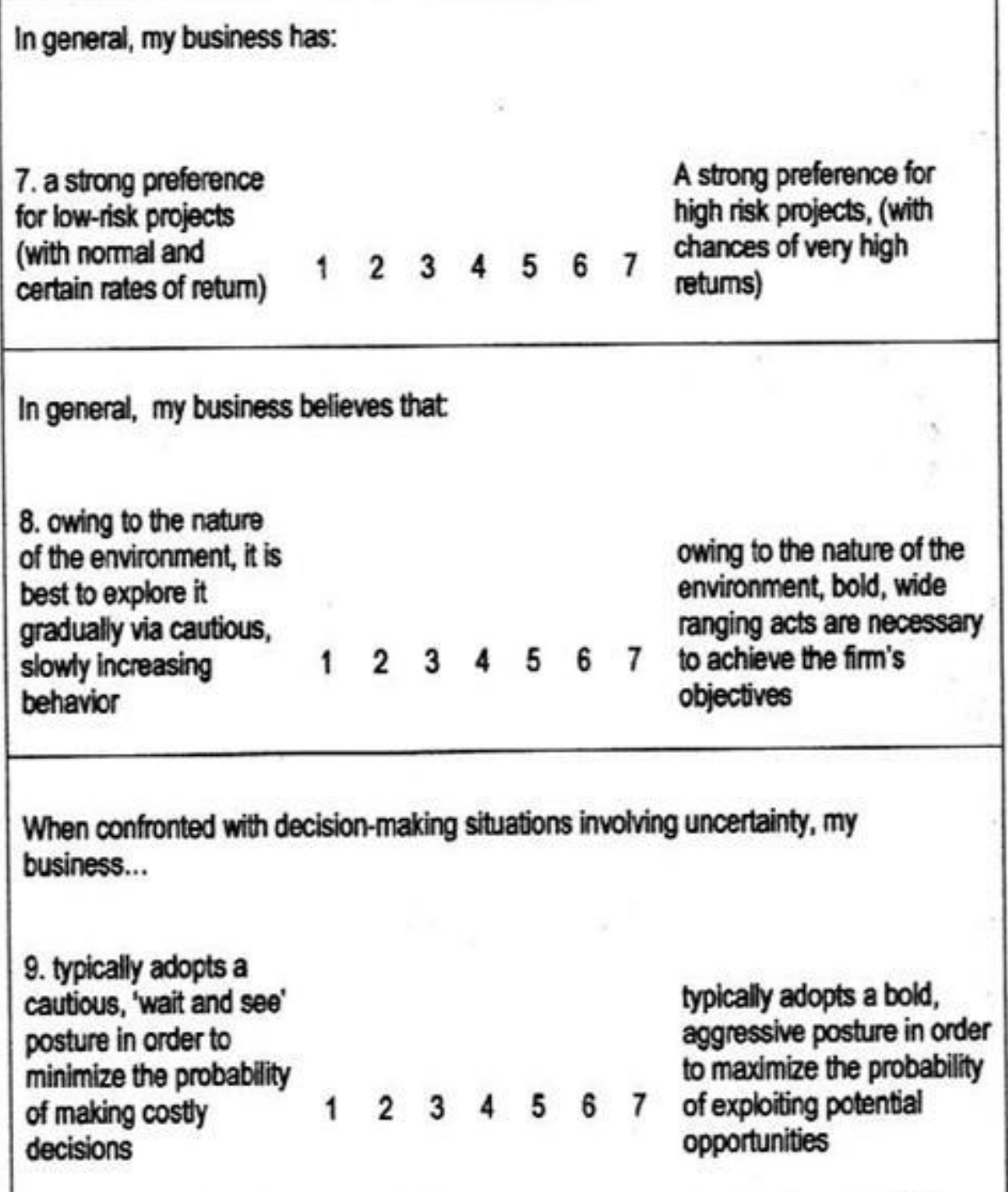


Part D. MSME Organizational Performance

Overview: As this stage, we would like to know the organizational performance of micro, small and medium enterprises (MSMEs). Instructions:

a. Please evaluate the performance of your enterprise.

b. For each item, please indicate:

i. level of importance you attach to the item described.

ii. level of enterprise performance in this item over the last 3 years compared to competitors

c. If your business enterprise is less than 3 years old, then you may compare your enterprise's performance against competitors since you started your business.

d. Please encircle the number that corresponds to your choice.

e. Remember there are NO WRONG answers. Encircling a small number does not mean your business performance is poor. Likewise, choosing a high number does not necessarily mean your business is excellent.

Business enterprises have different ways to assess their performance. In your case. please let us know if the following factors are important to you when you assess your business performance:

An important factor is one that you nomally use/check in order to say that your business is successful or not

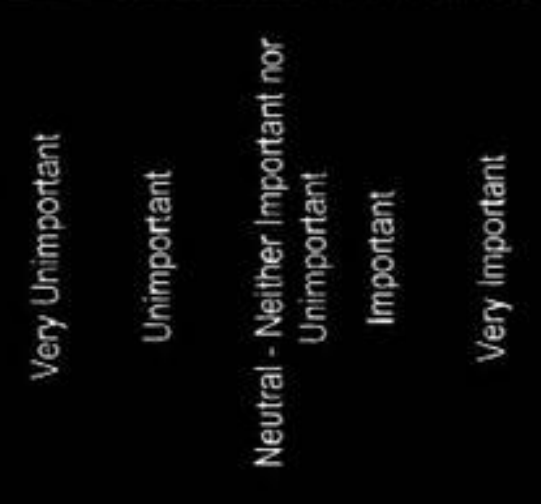

\begin{tabular}{|l|llllll|} 
1. & development of new products or services & 1 & 2 & 3 & 4 & 5 \\
\hline 2. & product or service quality & 1 & 2 & 3 & 4 & 5 \\
\hline 3. & customer satisfaction & 1 & 2 & 3 & 4 & 5 \\
\hline
\end{tabular}

Importance of the following factors as indicators of your business enterprise performance

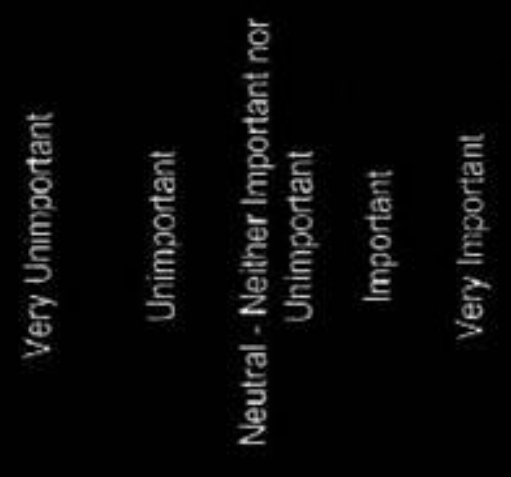

\begin{tabular}{|l|lrrrrr|}
\hline 4. & $\begin{array}{l}\text { improvement in business and/or } \\
\text { production processes }\end{array}$ & 1 & 2 & 3 & 4 & 5 \\
\hline 5. & $\begin{array}{l}\text { attraction/recruitment of essential } \\
\text { employees/skilled labor/talent }\end{array}$ & 1 & 2 & 3 & 4 & 5 \\
\hline 6. & $\begin{array}{l}\text { retention of essential employees/skilled } \\
\text { laboritalent }\end{array}$ & 1 & 2 & 3 & 4 & 5 \\
\hline 7. & market share & 1 & 2 & 3 & 4 & 5 \\
\hline 8. & growth of market share & 1 & 2 & 3 & 4 & 5 \\
\hline 9. & sales & 1 & 2 & 3 & 4 & 5 \\
\hline 10. & sales growth & 1 & 2 & 3 & 4 & 5 \\
\hline 11. & net income & 1 & 2 & 3 & 4 & 5 \\
\hline 12. & growth of net income & 1 & 2 & 3 & 4 & 5 \\
\hline 13. & retum on investment & 1 & 3 & 4 & 5 \\
\hline
\end{tabular}




\begin{tabular}{|c|c|c|c|c|c|c|}
\hline II. & $\begin{array}{l}\text { Now, please let us know your actual } \\
\text { ENTERPRISE PERFORMANCE } \\
\text { COMPARED TO COMPETITORS or } \\
\text { similar firms in your industry over the } \\
\text { - last } 3 \text { years in terms of the following; }\end{array}$ & 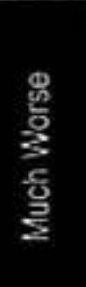 & $\begin{array}{l}\stackrel{8}{2} \\
\stackrel{0}{0}\end{array}$ & 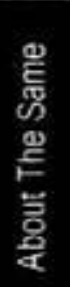 & 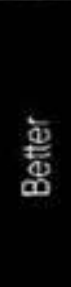 & 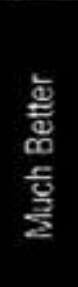 \\
\hline 1. & $\begin{array}{l}\text { development of new products or } \\
\text { services }\end{array}$ & 1 & 2 & 3 & 4 & 5 \\
\hline 2. & product or service quality & 1 & 2 & 3 & 4 & 5 \\
\hline 3. & customer satisfaction & 1 & 2 & 3 & 4 & 5 \\
\hline 4, & $\begin{array}{l}\text { improvement in business and/or } \\
\text { production processes }\end{array}$ & 1 & 2 & 3 & 4 & 5 \\
\hline 5. & $\begin{array}{l}\text { attraction/recruitment of essential } \\
\text { employees/skilled labor/talent }\end{array}$ & 1 & 2 & 3 & 4 & 5 \\
\hline 6. & $\begin{array}{l}\text { retention of essential employees/skilled } \\
\text { labor/talent }\end{array}$ & 1 & 2 & 3 & 4 & 5 \\
\hline 7. & market share & 1 & 2 & 3 & 4 & 5 \\
\hline 8. & growth of market share & 1 & 2 & 3 & 4 & 5 \\
\hline 9. & sales & 1 & 2 & 3 & 4 & 5 \\
\hline 10. & sales growth & 1 & 2 & 3 & 4 & 5 \\
\hline 11. & net income & 1 & 2 & 3 & 4 & 5 \\
\hline 12. & growth of net income & 1 & 2 & 3 & 4 & 5 \\
\hline 13. & return on investment & 1 & 2 & 3 & 4 & 5 \\
\hline
\end{tabular}

\section{Part E. MSME Details}

Please tell us some details about you and your business enterprise.

1. I am the owner manager $\begin{gathered}\text { owner \& } \\ \text { manager }\end{gathered} \begin{gathered}\text { (otse encirch } \\ \text { one thet } \\ \text { apclies) }\end{gathered}$

\begin{tabular}{|c|c|c|c|}
\hline 2. I am & & years of age & \\
\hline 3. I am & Male & Female & $\begin{array}{l}\text { (ols. encircle one } \\
\text { that applies) }\end{array}$ \\
\hline
\end{tabular}

4. I have:

1 studied a few elementary years

2 completed elementary school

please oncircle the $\quad 3$ studied a few years in high school

number that applies 4 completed high school

to you

5 studied a few years in college

6 completed college degree

7 postgraduate degree (masters, doctorate)

5. I have a total number of (pls. count sterting from grade 1 onwerds) years of formal schooling/study:

6. The main product/service of my business is:

7. As of today, this business is already years \&/or months old

8. My business operates mainly in the city of 
9. BEFORE managing or putting up this business, I already have years of business management experience (from other businesses \&/or previous employment).

\begin{tabular}{cll}
\hline 10. This business is a & 1 & sole proprietorship \\
& 2 & partnership \\
encircie one that applies & 3 & corporation \\
\hline
\end{tabular}

11. Number of FULL time employees as of now. (excluding you)

12. Number of PART time employees as of now. 13. My business's TOTAL ASSETS (excluding the land that you own AND use for the business) amount to

pesos.

$$
\text { (rough estimate is OK) }
$$

14. My business is under the sector called: manufacturing service pts encircle one

15. My business belongs under the industry called: (pls. encircle the number of your choice)

\begin{tabular}{ll|ll}
1 & food processing (except & 11 & basic metals processing \\
2 & beverage) & 12 & non-metallic mineral products \\
3 & footwear \& wearing & 13 & private services \\
4 & apparel manufacturing & 14 & transportation services \\
5 & furniture \& fixtures & 15 & communication services \\
6 & paper \& paper products & 16 & storage services \\
7 & chemical \& chemical & 17 & finance services \\
8 & products & 18 & ownership of dwellings and real estate \\
9 & electrical machinery & 19 & others (please specify): \\
10 & $\begin{array}{l}\text { transport equipment } \\
\text { manufacturing }\end{array}$ & & \\
\hline
\end{tabular}

Part F. Industry Technological Sophistication

Please think of the industry where you belong and answer the following questions.

1. How would you characterize the industry environment within which your business enterprise functions? (pls. encircle the number of your choice)

An environment

demanding little in the

way of technological

sophistication.

Technologically, a very sophisticated and complex $\begin{array}{llllllll}1 & 2 & 3 & 4 & 5 & 6 & 7 & \text { environment }\end{array}$

2. How much research and development (R \& D) activity takes place within your business enterprise's principal industry?

Virtually no $R$ \& $D$ in

industry (e.g. bakery, publishing, real estate, etc.)

Extremely R \& D-oriented industry (e.g.

nications, space, phamaceuticals, etc.

\section{Part G. Competitive Intensity}

Please think carefully and cvaluate how

competitive your industry is. An industry

comprises your firm and others

offering/selling similar products including

close substitutes)

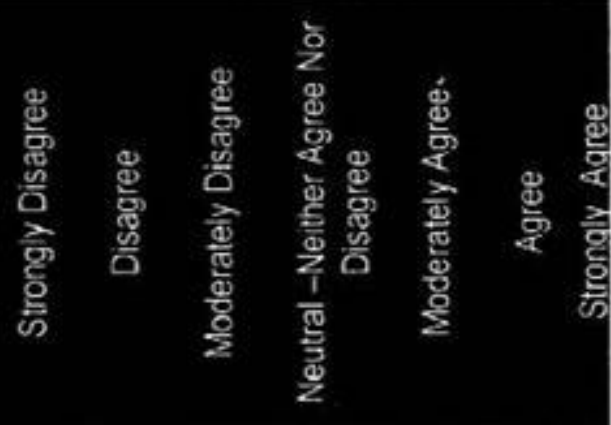

\begin{tabular}{|l|lllllllll}
\hline 1. & $\begin{array}{l}\text { Competition in our industry is very } \\
\text { intense or tough. }\end{array}$ & 1 & 2 & 3 & 4 & 5 & 6 & 7 \\
\hline 2. & $\begin{array}{l}\text { Anything that one competitor can } \\
\text { offer, others can match. }\end{array}$ & 1 & 2 & 3 & 4 & 5 & 6 & 7 \\
\hline 3. & $\begin{array}{l}\text { Our compettors are relatively } \\
\text { weak. }\end{array}$ & 1 & 2 & 3 & 4 & 5 & 6 & 7 \\
\hline
\end{tabular}




\section{Part H. Export Activity (pls, encircle your choice or answer)}

\section{Are you exporting your products overseas? Yes No}

2. If Yes, what percent of your total annual sales represents export sales?

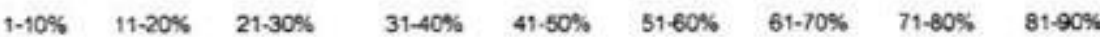

-END OF QUESTIONNAIRE -

\section{THANK YOU VERY MUCH FOR YOUR PARTICIPATION.}

Please return this questionnaire to the researcher or to the survey enumerator

(i.e. the person who gave this questionnaire to you).

Don't forget to fill in the raffle coupon that was given to you along with this booklet

if you wish to join the raffle draw and have the chance to win exciting prizes. 
Appendix B

Determination of Sample Size

Formula:

$\mathrm{n}=\frac{(\mathrm{t})^{2} *(\mathrm{~s})^{2}}{(\mathrm{~d})^{2}}=\frac{(1.96)^{2}(1.167)^{2}}{(7 * .03)^{2}}=118$

where:

$\mathrm{n} \quad=\quad$ sample size

$\mathrm{t}=\quad$ value for selected alpha level of .025 in each tail $=1.96$

(the alpha level of .05 indicates the level of risk the researcher is willing to take that true margin of error may exceed the acceptable margin of error.)

$\mathrm{s}=\quad$ estimate of standard deviation in the population $=1.167$

(estimate of variance deviation for 7 point scale calculated by using 7 [inclusive range of scale] divided by 6 [number of standard deviations that include almost all (approximately 98\%) of the possible values in the range])

The response scales in the majority of questions/items used to measure the major variables of the study are in a seven-point Likert type of scale.

$\mathrm{d}=\quad$ acceptable margin of error for mean being estimated $=.21$ (number of points on primary scale * acceptable margin of error; points on primary scale $=7$; acceptable margin of error $=.03$ [error researcher is willing to except])

source: Bartlett, Kortlik and Higgins (2001) 


\section{REFERENCES}

Acs, Z., \& Audretsch, D. (1988). Innovation in Large and Small Firms: An Empirical Analysis. The American Economic Review, 78(4), 678-690.

Adamek, R., \& Lavin, B. (1975). Interorganisational Exchange: A Note on the Scarcity Hypothesis. In A. Negandhi (Ed.), Interorganisation Theory. Kent: Kent State University.

Adams, B., \& Sykes, V. (2003). Performance Measures and Profitability Factors of Successful African-American Entrepreneurs: An Exploratory Study. Journal of American Academy of Business, Cambridge, 2(2), 418-424.

Adams, J. (1993). Institutions and Economic Development: Structure, Process, and Incentives. In M. Tool (Ed.), Institutional Economics: Theory, Method, Policy. Boston: Kluwer Academic Publishers.

ADB. (2008). Development Outlook for 2008: Philippines. Manila: Asian Development Bank.

Ahlstrom, D., \& Bruton, G. (2002). An Institutional Perspective on the Role of Culture in Shaping Strategic Actions by Technology-Focused Entrepreneurial Firms in China. Entrepreneurship Theory and Practice, 26(1), 53-69.

Ahmadi, A. (2003). The Entrepreneurial Process: An Institutional Perspective. Göteborg University. School of Business, Economics and Law, Department of Business Administration: Foretagsekonomiska Institutionen.

Aidis, R. (2005). Institutional Barriers to Small-and Medium-Sized Enterprise Operations in Transition Countries. Small Business Economics, 25(4), 305317.

Ajzen, I. (1987). Attitudes, Traits, and Actions: Dispositional Prediction of Behaviour in Social Psychology Advances in Experimental Social Psychology, 20(1), 1-63.

Ajzen, I. (1991). The Theory of Planned Behaviour. Organisational Behaviour and Human Decision Processes, 50(1), 179-211.

Ajzen, I. (2002). Perceived Behavioural Control, Self-Efficacy, Locus of Control, and the Theory of Planned Behaviour. Journal of Applied Social Psychology, $32(1-20)$.

Ajzen, I., \& Fishbein, M. (1980). Understanding Attitudes and Predicting Social Behaviour. Englewood Cliffs, NJ: Prentice Hall.

Ajzen, I., \& Fishbein, M. (2000). Attitudes, and the Attitude-Behaviour Relation: Reasoned and Automatic Processes. In W. Stroebe \& M. Hewstone (Eds.), European Review of Social Psychology (pp. 1-33). New York: Wiley.

Akinova, I. (1999). Development of Market Orientation and Competitiveness of Ukrainian Firms. European Journal of Marketing, 34(9/10), 1128-1148.

Aldrich, H. (1979). Organisations and Environments. Englewood Cliffs, N. J.: Prentice Hall.

Allison, P. (1999). Multiple Regression: A Primer. Thousand Oaks, CA: Sage Publications.

Amin, A., \& Thrift, N. (1995). Institutional Issues for the European Regions: From Markets and Plans to Socioeconomics and Powers of Association. Economy and Society, 24(1), 41-66.

Anderson, A., Drakopoulou-Dodd, S., \& Scott, M. (2000). Religion as an Environmental Influence on Enterprise Culture - The Case of Britain in the 
1990s. International Journal of Entrepreneurial Behaviour \& Research, 6(1), $5-25$.

Anderson, C. R., \& Paine, F. (1975). Managerial Perceptions and Strategic Behaviour. Academy of Management Journal, 18(4), 811-823.

Anderson, P., \& Tushman, M. (2001). Organisational Environments and Industry Exit: The Effects of Uncertainty, Munificence and Complexity Industrial and Corporate Change, 10(3), 675-711.

Ando, N. (2007). Effects of Regional Differences on the Choice of Entry Modes. International Journal of Business and Management, 2(3), 3-11.

Andrews, K. J., Bower, C. R., Christensen, R., Hamermesh, R., \& Porter, M. (1986). Business Policy: Text and Cases (6th ed.). Homewood, Ill.: Richard Irwin Inc.

Antipolo, S. (2001). Rhetoric and Reality: Decentralisation, Planning, and Development in the Southern Mindanao Region, Philippines. In W. Stohr, J. Edralin \& D. Mani (Eds.), New Regional Paradigms: Decentralisation, Governance, and the New Planning for Local Level Development (Vol. 3). Westport: Greenwood Press.

APEC. (2002). Profile of SMEs and SME Issues in APEC. Singapore: APEC Small and Medium Enterprises Working Group - Asia Pacific Economic Cooperation.

Appiah-Adu, K. (1997). Market Orientation and Performance: Do the Findings Established in Large Firms Hold in the Small Business Sector. Journal of Euro Marketing, 6(3), 1-26.

Appiah-Adu, K., \& Singh, S. (1998). Customer Orientation and Performance: A Study of SMEs. Management Decision, 36(6), 385-394.

Aragon-Sanchez, A., \& Sanchez-Marin, G. (2005). Strategic Orientation, Management Characteristics, and Performance: A Study of Spanish SMEs. Journal of Small Business Management, 43(3), 287-308.

Argy, F. (2002). Economic Governance and National Institutional Dynamics. In S. Bell (Ed.), Economic Governance and Institutional Dynamics: The Market, The State, and Networks. Oxford: Oxford University Press.

Arinaitwe, S. (2006). Factors Constraining the Growth and Survival of Small Scale Businesses: A Developing Countries Analysis. Journal of American Academy of Business, Cambridge, 8(2), 167-178.

Armstrong, J., \& Overton, T. (1977). Estimating Nonresponse Bias in Mail Surveys. Journal of Marketing Research, 14(3), 396-402.

Ashill, N., \& Jobber, D. (2001). Defining the Domain of Perceived Environmental Uncertainty: An Exploratory Study of Senior Marketing Executives. Journal of Marketing Management, 17(1), 543-558.

Ashkanasy, N., Gupta, V., Mayfield, M., \& Trevor-Roberts, E. (2004). Future Orientation. In R. House, P. Hanges, M. Javidan, P. Dorfman \& V. Gupta (Eds.), Culture, Leadership and Organisations: The GLOBE Study of 62 Societies. Thousand Oaks: Sage Publications.

Assaad, R. (1993). Formal and Informal Institutions in the Labour Market, with Applications to the Construction Sector in Egypt. World Development, 21(2), 925-939.

Audretsch, D. B. (2004). Sustaining Innovation and Growth: Public Policy Support for Entrepreneurship. Industry and Innovation, 11(2), 167-191. 
Avlonitis, G., \& Salavou, H. (2007). Entrepreneurial Orientation of SMEs, Product Innovativeness and Performance. Journal of Business Research, 60(5), 566575.

Avolio, B., Yammarino, F. J., \& Bass, B. M. (1991). Identifying Common Methods Variance with Data Collected from a Single Source: An Unresolved Sticky Issue. Journal of Management, 17(3), 571-587.

Aycan, Z., Kanungo, R., Mendonca, M., Yu, K., Deller, J., Stahl, G., et al. (2000). Impact of Culture on Human Resource Management Practices: A 10-Country Comparison. Applied Psychology: An International Review, 49(1), 192-221.

Ayyagari, M., Beck, T., \& Demirguc-Kunt, A. (2003). Small and Medium Enterprise Across the Globe. New York: The World Bank.

Babbie, E. (2007). The Practice of Social Research (11th ed.). Belmont, CA Wadsworth.

Bagozzi, R. (1992). The Self-Regulation of Attitudes, Intentions, and Behaviour. Social Psychology Quarterly, 55(2), 178-204.

Bagozzi, R., Gopinath, M., \& Nyer, P. (1999). The Role of Emotions in Marketing. Journal of the Academy of Marketing Science, 27(2), 184-206.

Bagozzi, R. P., \& Heatherton, T. F. (1994). A General Approach to Representing Multifaceted Personality Constructs: Application to State Self-Esteem. Structural Equation Modelling, 1(1), 35-67.

Baker, W., \& Sinkula, J. (2005). Environmental Marketing Strategy and Firm Performance: Effects on New Product Performance and Market Share. Academy of Marketing Science Journal, 33(4), 461-475.

Bandura, A. (1977). Self-Efficacy: Toward a Unifying Theory of Behavioural Change. Psychological Review, 84, 191-215.

Bandura, A. (1986). The Social Foundations of Thought and Action. Englewood Cliffs, NJ: Prentice Hall.

Bantel, H. G., \& Jackson, S. (1989). Top Management and Innovations in Banking: Does the Composition of the Top Team Make a Difference? Strategic Management Journal, 10(1), 107-104.

Barnett, J., \& Karson, M. (1989). Managers, Values, and Executive Decisions: An Exploration of the Role of Gender, Career Stage, Organisational Level, Function, and the Importance of Ethics, Relationships and Results in Managerial Decision-Making Journal of Business Ethics, 8(10), 747-771.

Barnett, W. (1997). The Dynamics of Competitive Intensity. Administrative Science Quarterly 42(1), 128-160.

Barney, J. B. (1991). Firm Resources and Sustained Competitive Advantage. Journal of Management, 17(1), 99-120.

Barney, J. B. (2001). Gaining and Sustaining Competitive Advantage (2nd ed.). New York: Prentice Hall.

Baron, R. M., \& Kenny, D. A. (1986). The Moderator-Mediator Variable Distinction in Social Psychological Research: Conceptual, Strategic and Statistical Considerations. Journal of Personality and Social Psychology, 51(6), 11731182.

Barret, H., Balloun, J., \& Weinsten, A. (2000). Marketing Mix Factors as Moderators of the Corporate Entrepreneurship-Business Performance Relationship - A Multistage, Multivariate Analysis. Journal of Marketing Theory and Practice, $8(2), 50-65$. 
Barrow, C. (1998). State Theory and the Dependency Principle: An Institutionalist Critique of the Business Climate Concept. Journal of Economic Issues, 32(1), 107-144.

Bartik, T. (1991). Who Benefits from State and Local Economic Development Policies? Kalamazoo, Michigan: W.E. Upjohn Institute for Employment Research.

Bartik, T. (1992). The Effects of State and Local Taxes on Economic Development: A Review of Recent Research. Economic Development Quarterly, 6(1), 102110 .

Bartlett, J., Kotrlik, J., \& Higgins, C. (2001). Organisational Research: Determining Appropriate Sample Size in Survey Research. Information Technology, Learning and Performance Journal, 19(1), 43-50.

Basu, A. (1998). The Role of Institutional Support in Asian Entrepreneurial Expansion. Journal of Small Business and Enterprise Development, 5(4), 319-326.

Baum, J. A. C., \& Oliver, C. (1992). Institutional Embeddedness and the Dynamics of Organisational Populations. American Sociological Review, 57(540-559).

Beauregard, R. A. (1994). Constituting Economic Development. In R. Bingham \& R. Miers (Eds.), Theories of Local Economic Development. Thousand Oaks: Sage.

Becchetti, L., \& Trovato, G. (2002). The Determinants of Growth for Small and Medium Sized Firms - The Role of the Availability of External Finance. Small Business Economics, 19(4), 291-306.

Becherer, R., \& Maurer, J. (1999). The Proactive Personality Disposition and Entrepreneurial Behaviour among Small Company Presidents. Journal of Small Business Management, 37(1), 28-37.

Becker, T. (2005). Potential Problems in the Statistical Control of Variables in Organisational Research: A Qualitative Analysis with Recommendations. Organisational Research Methods, 8(3), 274-289.

Beckert, J. (1999). Agency, Entrepreneurs, and Institutional Change. The Role of Strategic Choice and Institutionalised Practices in Organisations Organisation Studies, 20(5), 777-799.

Beer, A. (2002). Local Economic Development and Community Economic Development in International Context: Background to a Study and Preliminary Findings. Adelaide: School of Geography, Population and Environmental Management, Flinders University.

Begg, I. (1999). Cities and Competitiveness. Urban Studies, 36(5/6), 795-809.

Begg, I. (2002). 'Investability': The Key to Competitive Regions and Cities. Regional Studies, 36(2), 187-200.

Bell, S. (2002). Economic Governance \& Institutional Dynamics. Melbourne: Oxford University Press.

Bentler, P. M. (1995). EQS Program Manual. Encino, CA: Multivariate Software, Inc. .

Berger, I., \& Mitchell, A. (1989). The Effect of advertising on Attitude Accessibility, Attitude Confidence, and the Attitude-Behaviour Relationship. Journal of Consumer Research, 16(3), 269-279.

Berger, P. L., \& Luckman, T. (1966). The Social Construction of Reality: A Treatise in the Sociology of Knowledge. New York: Doubleday.

Betton, J., \& Dess, G. G. (1985). The Application of Population Ecology Models to the Study of Organisations. Academy of Management Review 10(4), 750-757. 
Bevan, A., Estrin, S., \& Meyer, K. (2004). Foreign Investment Location and Institutional Development in Transition Economies. International Business Review, 13(1), 43-64.

Bhaskaran, S. (2006). Incremental Innovation and Business Performance: Small and Medium-Size Food Enterprises in a Concentrated Industry Environment. Journal of Small Business Management, 44(1), 64-80.

Biemer, P. (2001). Nonresponse Bias and Measurement Bias in a Comparison of Face to Face and Telephone Interviewing. Journal of Official Statistics, 17(2), 295-320.

Bilton, T., Bonnet, K., Jones, P., Skinner, D., Stanworth, M., \& Webster, A. (1996). Introductory Sociology. London: Macmillan.

Birley, S., \& Westhead, P. (1990). Growth and Performance Contrasts Between "Types" of Small Firms. Strategic Management Journal, 11(7), 535-557.

Blakely, E., \& Bradshaw, T. (2002). Planning Local Economic Development: Theory and Practice (3rd ed.). Thousand Oaks: Sage Publications.

Bogason, P. (2000). Public Policy and Local Governance. Cheltenham: Edward Elgar.

Boland, L. (1992). The Principles of Economics: Some Lies My Teachers Told Me. New York: Routledge.

Boliari, N. (2007). Conceptualising Institutions and Organisations: A Critical Approach. Journal of Business and Economics Research, 5(1), 1-10.

Booysen, F. (2002). An Overview and Evaluation of Composite Indices of Development. Social Indicators Research, 59(2), 115-151.

Borch, O. J., \& Brastad, B. (2003). Strategic Turnaround in a Fragmented Industry. Journal of Small Business and Enterprise Development, 10(4), 393-407.

Borch, O. J., Huse, M., \& Senneseth, K. (1999). Resource Configuration, Competitive Strategies, and Corporate Entrepreneurship: An Empirical Examination of Small Firms. Entrepreneurship Theory and Practice, 24(1), 49-71.

Bosma, N., \& Harding, R. (2006). Global Entrepreneurship Monitor 2006 London: London Business School.

Boulton, W., Lindsay, W., Franklin, S., \& Rue, L. (1982). Strategic Planning: Determining the Impact of Environmental Characteristics and Uncertainty. Academy of Management Journal, 25(3), 500-509.

Bourgeois III, L. J., \& Astley, W. G. (1979a). A Strategic Model of Organisational Conduct and Performance. International Studies of Management and Organisation, 9(3), 40-66.

Bourgeois III, L. J. I. (1980). Strategy and Environment: A Conceptual Integration. The Academy of Management Review, 5(1), 25-39.

Bowen, H., \& De Clercq, D. (2008). Institutional Context and the Allocation of Entrepreneurial Effort. Journal of International Business Studies, 39(4), 747767.

Boyd, B. (1990). Corporate Linkages and Organisational Environment: A Test of the Resource Dependence Model. Strategic Management Journal, 11(6), 419430.

Boyd, B., Dess, G., \& Rasheed, A. (1993). Divergence between Archival and Perceptual Measures of the Environment: Causes and Consequences. The Academy of Management Review, 18(2), 204-226. 
Bracker, J., Keats, B., \& Pearson, J. (1988). Planning and Financial Performance Among Small Firms in a Growth Industry. Strategic Management Journal, 9(6), 591-603.

Bracker, J., \& Pearson, J. (1986). Planning and Financial Performance of Small, Mature Firms. Strategic Management Journal, 7(6), 503-522.

Brah, S., Wong, J. L., \& Madhu-Rao, B. (2000). TQM and Business Performance in the Service Sector: A Singapore Study. International Journal of Operations and Production Management, 20(11), 1293-1312.

Brillantes Jr., A. (2004). Decentralisation Imperatives: Lessons from Some Asian Countries. Journal of International Cooperation Studies, 12(1), 33-55.

Brouthers, K. (2002). Institutional, Cultural and Transaction Cost Influence on Entry Mode Choice and Performance. Journal of International Business Studies, 33(2), 203-221.

Brown, T. (2006). Confirmatory Factor Analysis for Applied Research. London: Guilford Press.

Brush, C., \& Chaganti, R. (1999a). Business without Glamour? An Analysis of Resources on Performance by Size and Age in Small Service and Retail Firms. Journal of Business Venturing, 14(3), 233-257.

Bruton, G., Ahlstrom, D., \& Obloj, K. (2008). Entrepreneurship in Emerging Economies: Where Are We Today and Where Should the Research Go in the Future. Entrepreneurship Theory and Practice, 32(1), 1-14.

Bruton, G., \& Lau, C. M. (2008). Asian Management Research: Status Today and Future Look. Journal of Management Studies, 45(3), 636-659.

Bstieler, L., \& Gross, C. (2003). Measuring the Effect of Environmental Uncertainty on Process Activities, Project Team Characteristics, and New Product Success. Journal of Business and Industrial Marketing, 18(2), 146-161.

Busenitz, L., Gomez, C., \& Spencer, J. (2000). Country Institutional Profiles: Unlocking Entrepreneurial Phenomena. Academy of Management Journal, 43(5), 994-1003.

Business Bureau (2007). List of Registered Business in Panabo City. Office of the City Treasurer. Panabo City Government. Philippines.

Byrne, B. M. (2006). Structural Equation Modelling with EQS: Basic Concepts, Applications and Programming (2nd ed.). London: Lawrence Erlbaum Associates.

Caloghirou, Y., Protogerou, A., Spanos, Y., \& Papagiannakis, L. (2004). Industryversus Firm-specific Effects on Performance: Contrasting SMEs and LargeSized Firms. European Management Journal, 22(2), 23-243.

Cameron, A., \& Massey, C. (1999). Small and Medium-sized Enterprise: A New Zealand Perspective: Pearson Education.

Cameron, K. (2005). Organisational Effectiveness: Its Demise and Re-emergence Through Positive Organisational Scholarship. In K. G. Smith \& M. Hitt (Eds.), Great Minds in Management: The Process of Theory Development. Oxford: Oxford University Press.

Campbell, J. P. (1977). On the Nature of Organisational Effectiveness. In P. S. Goodman \& J. M. Pennings (Eds.), New Perspectives on Organisational Effectiveness. San Francisco: Jossey-Bass Inc.

Capelleras, J. L., Mole, K., Greene, F., \& Storey, D. (2008). Do More Heavily Regulated Economies Have Poorer Performing New Ventures? Evidence from Britain and Spain. Journal of International Business Studies, 39(4), 688704. 
Carl, D., Gupta, V., \& Javidan, M. (2004). Power Distance. In R. House, P. Hanges, M. Javidan, P. Dorfman \& V. Gupta (Eds.), Culture, Leadership, and Organisations: The GLOBE Study of 62 Societies. Thousand Oaks: Sage Publications.

Carland, J., Hoy, F., Boulton, W., \& Carland, J. A. (1984). Differentiating Entrepreneurs from Small Business Owners: A Conceptualisation. Academy of Management Review, 9(2), 354-359.

Carlsson, B. (2002). Institutions, Entrepreneurship, and Growth: Biomedicine and Polymers in Sweden and Ohio. Small Business Economics, 19(2), 105-121.

Carmeli, A., \& Tishler, A. (2004). Resources, Capabilities, and the Performance of Industrial Firms: A Multivariate Analysis. Managerial and Decision Economics, 25(1), 299-315.

Carothers, T. (1998). The Rule of Law Revival. Foreign Affairs, 77(2), 95-107.

Carpano, C., Chrisman, J., \& Roth, K. (1994). International Strategy and Environment: An Assessment of the Performance Relationship. Journal of International Business Studies, 25(3), 639-656.

Carpenter, M., \& Fredrickson, J. (2001). Top Management Teams, Global Strategic Posture, and the Moderating Role of Uncertainty. Academy of Management Journal, 44(3), 533-546.

Cassis, Y., \& Minoglou, I. P. (2005). Entrepreneurship in Theory and History: State of the Art and New Perspectives. In Y. Cassis \& I. P. Minoglou (Eds.), Entrepreneurship in Theory and History. New York: Palgrave Macmillan.

Castrogiovanni, G. (1991). Environmental Munificence: A Theoretical Assessment. Academy of Management Review, 16(3), 542-565.

Castrogiovanni, G. (1996). Pre-start up Planning and the Survival of New Small Businesses: Theoretical Linkages. Journal of Management, 22(6), 801-822.

Cattell, R. B. (1966). The Scree Test for the Number of Factors. Multivariate Behavioural Research, 1, 245-276.

Cavana, R., Delahaye, B., \& Sekaran, U. (2001). Applied Business Research: Qualitative and Quantitative Methods. Queensland, Australia: John Wiley \& Sons.

Cavusgil, S., \& Zou, S. (1994). Marketing Strategy-Performance Relationship: An Investigation of the Empirical Link in Export Market Ventures. Journal of Marketing, 58(1), 1-21.

Chaganti, R., \& Parasuraman, S. (1996). A Study of the Impact of Gender on Business Performance and Management Patterns in Small Business. Entrepreneurship Theory and Practice, 21(2), 73-75.

Chambers, J., Cleveland, W., Kleiner, B., \& Tukey, P. (1983). Graphical Methods for Data Analysis. Belmont, CA: Wadsworth and Boston: Duxbury.

Chandler, G., \& Hanks, S. (1993). Measuring the Performance of Emerging Businesses: A Validation Study. Journal of Business Venturing, 7(3), 223236.

Chandler, G., \& Jansen, E. (1992). The Founder's Self-Assessed Competence and Venture Performance. Journal of Business Venturing, 7(1), 223-236.

Chaney, P. K., Devinney, T., \& Winer, R. S. (1991). The Impact of New Product Introductions on the Market Value of Firms. Journal of Business 64(4), 573610.

Chang, W., \& Huang, T. (2005). Relationship between Strategic Human Resource Management and Firm Performance: A Contingency Perspective. International Journal of Manpower, 26(5), 434-449. 
Chaston, I., \& Mangles, T. (1997). Core Capabilities as Predictors of Growth Potential in Small Manufacturing Firms. Journal of Small Business Management, 35(1), 47-57.

Chatman, D., Altman, I., \& Johnson, T. (2008). Community Entrepreneurial Climate: An Analysis of Small Business Owners' Perspective in 12 Small Towns in Missouri, USA. Journal of Rural and Community Development, 3(1), 60-77.

Cheema, G. S., \& Rondinelli, D. S. (1983). Decentralisation and Development: Policy Implementation in Developing Countries. Beverly Hills: Sage Publications.

Chelariu, C., Bello, D., \& Gilliland, D. (2006). Institutional Antecedents and Performance Consequences of Influence Strategies in Export Channels to Eastern European Transitional Economies. Journal of Business Research, 59(5), 525-534.

Chen, K., \& Shimerda, T. (1981). An Empirical Analysis of Useful Financial Ratios. Financial Management, 10(1), 51-60.

Chen, M.-J., \& Hambrick, D. (1995). Speed, Stealth, and Selective Attack: How Small Firms Differ from Large Firms in Competitive Behaviour. Academy of Management Journal, 38(2), 453-482.

Chhibber, P., \& Majumdar, S. (1999). Foreign Ownership and Profitability: Property Rights, Control, and the Performance of Firms in Indian Industry. Journal of Law and Economics, XLII, 209-238.

Child, J. (1997). Strategic Choice in the Analysis of Action, Structure, Organisations and Environment: Retrospect and Prospect. Organisation Studies, 18(1), 4376.

Chin, W. (1998). Issues and Opinion on Structural Equation Modelling. Management Information Systems Quarterly, 22(1), 7-16.

Chou, C. P., \& Bentler, P. M. (1995). Estimates and Tests in Structural Equation Modelling. In R. H. Hoyle (Ed.), Structural Equation Modelling: Concepts, Issues, and Applications Thousand Oaks: Sage Publications.

Chow, C., Shields, M., \& Chan, Y. (1991). The Effects of Management Controls and National Culture on Manufacturing Performance: An Experimental Investigation. Accounting, Organisations and Society, 16(3), 209-226.

Chow, I. (2006). The Relationship Between Entrepreneurial Orientation and Firm Performance in China. SAM Advanced Management Journal, 71(3), 11-20.

Chrisman, J., Chua, J., \& Steier, L. (2002). The Influence of National Culture and Family Involvement on Entrepreneurial Perceptions and Performance at the State Level. Entrepreneurship Theory and Practice, 26(4), 113-130.

Chung-Ming, L., \& Ngo, H. Y. (2001). Organisation Development and Firm Performance: A Comparison of Multinational and Local Firms. Journal of International Business Studies, 32(1), 95-114.

Church, A. T., \& Katigbak, M. S. (2000). Trait Psychology in the Philippines. The American Behavioural Scientist, 44(1), 73-94.

Churchill, G. (1979). A Paradigm for Developing Better Measures of Marketing Constructs. Journal of Marketing Research, 16(1), 64-73.

City Treasurer. (2007). List of Registered Business Establishments in Tagum City. Retrieved. from.

Clague, C., Keefer, P., Knack, S., \& Mancur, O. (1999). Contract-Intensive Money: Contract Enforcement, Property Rights, and Economic Performance. Journal of Economic Growth, 4(2), 185-211. 
Clark, T., Varadarajan, P. R., \& Pride, W. (1994). Environmental Management: The Construct and Research Propositions. Journal of Business Research, 29(2338), 23-38.

Clingermayer, J., \& Feiock, R. (2001). Institutional Constraints and Policy Choice: An Exploration of Local Governance. Albany: State University of New York Press.

Co, M. J. (2004). The Formal Institutional Framework of Entrepreneurship in the Philippines: Lessons for Developing Countries. The Journal of Entrepreneurship, 13(2), 185-203.

Co, M. J., \& Mitchell, B. (2005, June). An Analysis of Cultural Factors Affecting Entrepreneurship in the Philippines Paper presented at the International Council of Small Business World Conference 2005 World Conference, Washington DC.

Coase, R. (1960). The Problem of Social Cost. Journal of Law and Economics, 3(October), 1-44.

Coeurderoy, R., \& Murray, G. (2008). Regulatory Environments and the Location Decision: Evidence from the Early Foreign Market Entries of NewTechnology-based Firms. Journal of International Business Studies, 39(4), 670-687.

Cohen, J. (1992). A Power Primer. Psychological Bulletin, 112(1), 155-159.

Cohen, J., Cohen, P., West, S., \& Aiken, L. (2003). Applied Multiple Regression/Correlation Analysis for the Behavioural Sciences. New Jersey: Lawrence Erlbaum Associates.

Colding, J., \& Folke, C. (2000). The Taboo System: Lessons About Informal Institutions for Nature Management. Georgetown International Environmental Law Review, 12(2), 413-445.

Coleman, J. (1988). Social Capital in the Creation of Human Capital. American Journal of Sociology, 94(1), 95-120.

Collins, L., Graham, J., \& Flaherty, B. (1998). An Alternative Framework for Defining Mediation. Multivariate Behavioural Research, 33(2), 295-312.

Conant, J., Mokwa, M., \& Varadarajan, P. R. (1990). Strategic Types, Distinctive Competencies and Organisational Performance: A Multiple Measures-Based Study. Strategic Management Journal, 11(5), 365-383.

Cooke, P., \& Wills, D. (1999). Small Firms, Social Capital and the Enhancement of Business Performance through Innovation Programmes. Small Business Economics, 13(3), 219-234.

Coriat, B., \& Dosi, G. (1998). The Institutional Embeddedness of Economic Change: An Appraisal of the 'Evolutionary' and 'Regulationist' Research Programmes. In K. Nielsen \& B. Johnson (Eds.), Institutions and Economic Change: New Perspectives on Markets, Firms, and Technology. Cheltenham: Edward Elgar.

Cororaton, C. (2005). Total Factor Productivity Growth in the Philippines: 19602000. Asian Development Review, 22(1), 97-113.

Corral-Verdugo, V., \& Pinheiro, J. Q. (2006). Sustainability, Future Orientation and Water Conservation. European Review of Applied Psychology, 56(3), 191198.

Cortina, J. (1993). What is Coefficient Alpha? An Examination of Theory and Applications Journal of Applied Psychology, 78(1), 98-104. 
Costello, A. B., \& Osborne, J. W. (2005). Best Practices in Exploratory Factor Analysis: Four Recommendation for Getting the Most From Your Analysis. Practical Assessment, Research and Evaluation 10(7).

Covin, J., \& Slevin, D. (1989). Strategic Management of Small Firms in Hostile and Benign Environments. Strategic Management Journal, 10(January), 75-87.

Covin, J. G. (1991). Entrepreneurial versus Conservative Firms: A Comparison of Strategies and Performance. Journal of Management Studies, 28(5), 439-462.

Covin, J. G., \& Miles, M. (1999). Corporate Entrepreneurship and the Pursuit of Competitive Advantage. Entrepreneurship Theory and Practice, 23(3), 4763.

Covin, J. G., Prescott, J. E., \& Slevin, D. P. (1990a). The Effects of Technological Sophistication on Strategic Profiles, Structure and Firm Performance. Journal of Management Studies, 27(5), 485-509.

Covin, J. G., \& Slevin, D. P. (1990). New Venture Strategic Posture, Structure, and Performance: An Industry Life Cycle Analysis. Journal of Business Venturing, 5(2), 123-135.

Covin, J. G., Slevin, D. P., \& Covin, T. J. (1990b). Content and Performance of Growth-Seeking Strategies: A Comparison of Small Firms in High- and LowTechnology Industries. Journal of Business Venturing, 5(6), 391-412.

Covin, J. G., Slevin, D. P., \& Schultz, R. (1994). Implementing Strategic Missions: Effective Strategic, Structural, and Tactical Choices. Journal of management Studies, 31(4), 481-505.

CTO. (2007a). List of Business Establishment Registration for 2007. Panabo City: City Treasurer's Office, Office of the City Mayor, Panabo City Government, Philippines.

CTO. (2007b). List of Registered Business Establishments for 2007. Tagum City: City Treasurer's Office, Office of the City Mayor, Tagum City Government, Philippines.

Currie, M., \& Messori, M. (1998). New Institutional and New Keynesian Economics. In R. Arena \& C. Longhi (Eds.), Markets and Organisations. New York Springer.

Czaja, R., \& Blair, J. (2005). Designing Surveys: A Guide to Decisions and Procedures (2nd ed.). Thousand Oaks: Pine Forge Press.

Daft, R., Sormunen, J., \& Parks, D. (1988). Chief Executive Scanning, Environmental Characteristics, and Company Performance: An Empirical Study. Strategic Management Journal, 9(2), 123-139.

Damanpour, F. (1991). Organisational Innovation: A Meta-Analysis of Effects of Determinants and Moderators. Academy of Management Journal, 34(3), 555590.

Damanpour, F., \& Evans, W. M. (1984). Organisational Innovation and Performance: The Problem of Organisational Lag. Administrative Science Quarterly, 29(3), 392-409.

Danielson, M., \& Scott, J. (2007). A Note on Agency Conflicts and the Small Firm Investment Decision. Journal of Small Business Management, 45(1), 157175.

Das, S., Echambadi, R., McCardle, M., \& Luckett, M. (2003). The Effect of Interpersonal Trust, Need for Cognition, and Social Loneliness on Shopping, Information Seeking and Surfing on the Web. Marketing Letters, 14(3), 185202. 
Datta, D. (1991). Organisational Fit and Acquisition Performance: Effects of PostAcquisition Integration. Strategic Management Journal, 12(4), 281-297.

Davidsson, P., Kirchhoff, B., Hatemi-J, A., \& Gustavsson, H. (2002). Empirical Analysis of Business Growth Factors Using Swedish Data. Journal of Small Business Management, 40(4), 332.

Davis, L. (2006). Growing Apart: The Division of Labour and the Breakdown of Informal Institutions. Journal of Comparative Economics, 34(1), 75-91.

De Luque, M. S., \& Javidan, M. (2004). Uncertainty Avoidance. In R. House, P. Hanges, M. Javidan, P. Dorfman \& V. Gupta (Eds.), Culture, Leadership, and Organisations: The GLOBE Study of 62 Societies. Thousand Oaks Sage Publications.

Deephouse, D., \& Carter, S. (2005). An Examination of Differences Between Organisational Legitimacy and Organisational Reputation. Journal of Management Studies, 42(2), 329-360.

Delamere, T., Wankel, L., \& Hinch, T. (2001). Development of a Scale to Measure Resident Attitudes Toward the Social Impacts of Community Festivals, Part I: Item Generation and Purification of the Measure. Event Management, 7(1), 11-24.

Delaney, J., \& Huselid, M. (1996). The Impact of Human Resource Management Practices on Perceptions of Organisational Performance. Academy of Management Journal, 39(4), 949-969.

Demirbag, M., Tatoglu, E., Tekinkus, M., \& Zaim, S. (2006). An Analysis of the Relationship between TQM Implementation and Organisational Performance. Journal of Manufacturing Technology Management, 17(6), 829-847.

Demirbas, D. (2006). New Institutional Economy and Innovation Barriers: A Microeconometric Evidence. The Business Review, 5(2), 82-88.

Den Hartog, D. (2004). Assertiveness. In R. House, P. Hanges, M. Javidan, P. Dorfman \& V. Gupta (Eds.), Culture, Leadership, and Organisations: The GLOBE Study of 62 Societies Thousand Oaks: Sage Publications.

Deshpande, R., Farley, J., \& Webster, F. J. (1993). Corporate Culture, Customer Orientation, and Innovativeness. Journal of Marketing, 57(1), 23-38.

Dess, G., Ireland, R., \& Hitt, M. (1990). Industry Effects and Strategic Management Research. Journal of Management, 16(1), 7-27.

Dess, G., Lumpkin, G. T., \& Covin, J. G. (1997). Entrepreneurial Strategy Making and Firm Performance: Tests of Contingency and Configuration Models. Strategic Management Journal, 18(9), 677-695.

Devlin, S., Dong, H., \& Brown, M. (2003). Selecting a Scale for Measuring Quality. Marketing Research, 5(3), 12-17.

Dewees, S., Lobao, L., \& Swanson, L. (2003). Local Economic Development in an Age of Devolution: The Question of Rural Localities. Rural Sociology, 68(2), 182-206.

Diamantopolous, A., \& Siguaw, J. (2006). Formative vs. Reflective Indicators in Organisational Measure Development: A Comparison and Empirical Illustration. British Journal of Management, 17(4), 263-282.

DILG. (2005). The 1991 Local Government Code. Retrieved 4 June, 2008, from http://www.dilg.gov.ph/LocalGovernmentCode.aspx

Djankov, S., McLiesh, C., \& Ramalho, R. M. (2006). Regulation and Growth. Economics Letters, 92, 395-401.

DOF. (2005). Department of Finance Revenue Data. Manila: Bureau of Local Government Finance, Department of Finance, Republic of the Philippines. 
Dollar, D., Hallward-Driemer, M., \& Mengistae, T. (2005). Investment Climate and Firm Performance in Developing Countries. Economic Development and Cultural Change, 54(1), 1-31.

Dollar, D., \& Kraay, A. (2003). Institutions, Trade and Growth. Journal of Monetary Economics, 50, 133-162.

Doyle, P., \& Hooley, G. (1992). Strategic Orientation and Corporate Performance. International Journal of Research in Marketing, 9(1), 59-73.

DTI. (2005). Small and Medium Enterprises Statistical Report. Manila: Bureau of Small and Medium Enterprise Development, Department of Trade and Industry, Republic of the Philippines.

Dubin, R. (1978). Theory Development. New York: Free Press.

Dubofsky, P., \& Varadajan, R. (1987). Diversification and Measures of Performance: Additional Empirical Evidence. Academy of Management Journal, 30(3), 597-608.

Duncan, R. (1972). Characteristics of Organisational Environments and Perceived Environmental Uncertainty. Administrative Science Quarterly, 17(3), 313327.

Durand, R., \& Coeurderoy, R. (2001a). Age, Order of Entry, Strategic Orientation and Organisational Performance. Journal of Business Venturing, 16(5), 471494.

Dutton, J., \& Jackson, S. (1987). Categorising Strategic Issues: Links to Organisational Action. Academy of Management Review, 12(1), 76-90.

Eberts, R. (2005). Financing Local Economic Development: Experiences in Europe and the United States. In S. Giguere (Ed.), Local Governance and the Drivers of Economic Growth. Paris: Organisation for Economic Co-operation and Development.

Eisenhardt, K. (1990). Speed and Strategic Choice: How Managers Accelerate Decision Making. California Management Review, 32(3), 39-54.

Eisenhardt, K., \& Schoolhoven, C. B. (1990). Organisational Growth: Linking Founding Team Strategy, Environment, and Growth among US Semiconductor Ventures, 1978-1988. Administrative Science Quarterly, 35(3), 504-536.

Entrialgo, M. (2002). The Impact of the Alignment of Strategy and Managerial Characteristics on Spanish SMEs. Journal of Small Business Management, 40(3), 260-270.

Entrialgo, M., Fernandez, E., \& Vazquez, C. (2001). The Effect of the Organisational Context on SME's Entrepreneurship: Some Spanish Evidence. Small Business Economics, 16(3), 223-236.

Erickson, R. (1987). Business Climate Studies: A Critical Evaluation. Economic Development Quarterly, 1(1), 62-71.

Eriksen, B., \& Mikkelsen, J. (1996). Competitive Advantage and the Concept of Core Competence. In N. J. Foss \& C. Knudsen (Eds.), Towards a Competence Theory of the Firm. London: Routledge.

Erumban, A. A., \& de Jong, S. (2006). Cross-Country Differences in ICT Adoption: A Consequence of Culture? Journal of World Business, 41(4), 302-314.

Espiritu, S., \& Hunt, C. (1964). Social Foundations of Community Development: Readings on the Philippines. Manila: R. M. Garcia Publishing House.

Esser, K., Hillebrand, W., Messner, D., \& Meyer-Stamer, J. (1995). Systemic Competitiveness. London: Frank Cass, German Development Institute. 
Fabrigar, L., Wegener, D., McCallum, R., and Strahan, E. (1999). Evaluating the use of exploratory factor analysis in psychological research. Psychological Methods, 4(3), 272-299.

Falbe, C., Dandridge, T., \& Kumar, A. (1998). The Effect of Organisational Context on Entrepreneurial Strategies in Franchising. Journal of Business Venturing, 14(1), 125-140.

Falshaw, J. R., Glaister, K., \& Tatoglu, E. (2006). Evidence on Formal Strategic Planning and Company Performance. Management Decision, 44(1), 9-30.

Fazio, R. H. (1986). How Do Attitudes Guide Behaviour? . In R. Sorrentino \& E. T. Higgins (Eds.), Handbook of Motivation and Cognition: Foundations of Social Behaviour (pp. 203-243). New York: Guilford.

Felipe, J. (1998). The Role of the Manufacturing Sector in Southeast Asian Development: A Test of Kaldor's First Law. Journal of Post Keynesian Economics, 20(3), 463-485.

Fergusson, L. (2006). Institutions for Financial Development: What Are They and Where Do They Come From? Journal of Economic Surveys, 20(1), 27-43.

Field, A. (2005). Discovering Statistics using SPSS (2nd ed.). London: Sage Publications.

Fielden, S., \& Dawe, A. (2004). Entrepreneurship and Social Inclusion. Women in Management Review, 19(3), 139-142.

Filion, F. L. (1976). Exploring and Correcting for Non-Response bias using FollowUps of Nonrespondents Pacific Sociological Review, 19(3), 401-408.

Fiori, S. (2002). Alternative Visions of Change in Douglass North's New Institutionalism. Journal of Economic Issues, 36(4), 1025-1043.

Fisher, P. (2005). Grading Places: What Do the Business Climate Rankings Really Tell Us. Washington: Economic Policy Institute.

Fitsimmons, J., Douglas, E., Antoncik, B., \& Hisrich, R. (2004). Intrapreneurship in Australian Firms. Paper presented at the AGSE-Babson Entrepreneurial Research Conference, Melbourne.

Fogel, G. (2001). An Analysis of Entrepreneurial Environment and Enterprise Development in Hungary. Journal of Small Business Management, 39(1), 103-109.

Fogel, G., \& Zapalska, A. (2001). Small and Medium-Size Enterprise Development in Central and Eastern Europe: A Comparative Study. Comparative Economic Studies 43(3), 35-68.

Fogel, K., Hawk, A., Morck, R., \& Yeung, B. (2006). Institutional Obstacles to Entrepreneurship In M. Casson, B. Yeung, A. Basu \& N. Wadeson (Eds.), Oxford Handbook of Entrepreneurship Oxford University Press.

Fornell, C., \& Larcker, F. D. (1981). Evaluating Structural Equation Models with Unobservable Variables and Measurement Error. Journal of Marketing Research, 18(1), 39-50.

Freel, M. (2005). The Characteristics of Innovation-Intensive Small Firms: Evidence from Northern Britain. International Journal of Innovation Management, 9(4), 401-429.

Frisbie, D., \& Brandenburg, D. (1979). Equivalence of Questionnaire Items in Varying Response Formats. Journal of Educational Measurement, 16(1), 4348.

Frishammar, J. (2006). Organisational Environment Revisited: A Conceptual Review and Integration. International Studies of Management and Organisation, 36(3), 22-49. 
Fry, L., \& Smith, D. (1987). Congruence, Contingency, and Theory Building. Academy of Management Review, 12(1), 117-132.

Frye, T., \& Zhuravskaya, E. (2000). Rackets, Regulation and the Rule of Law. Journal of Law Economics \& Organisation, 16(2), 478-502.

Gambarotto, F., \& Solari, S. (2005). How Do Local Institutions Contribute to Fostering Competitiveness of Industrial Clusters? The Upgrading Process in the Italian Eyewear System. In E. Guiliani, R. Rabelloti \& M. P. van Dijk (Eds.), Clusters Facing Competition: The Importance of External Linkages. Aldershot: Ashgate.

Gartner, W., \& Bhat, S. (2000). Environmental and Ownership Characteristics of Small Businesses and their Impact on Development. Journal of Small Business Management, 38(3), 19-26.

Gatignon, H., \& Xuereb, J. (1997). Strategic Orientation of the Firm and New Product Performance. Journal of Marketing Research, 34(1), 77-90.

GBCCPA. (2007). Philippines: Country Profile. Retrieved 20 April 2007, 2007, from http://www.rowbotham.com/knowledgenet/countryprofiles/phprofil.pdf

Geiger, S., \& Hoffman, J. (1998). The Impact of the Regulatory and Corporate level Diversification on Firm Performance. Journal of Managerial Issues, 10(4), 439-453.

Gelfand, M. J., Bhawuk, D. P. S., Nishii, L. H., \& Bechtold, D. (2004). Individualism and Collectivism. In R. House, P. Hanges, M. Javidan, P. Dorfman \& V. Gupta (Eds.), Culture, Leadership, and Organisations: The GLOBE Study of 62 Societies. Thousand Oaks: Sage Publications.

Gharavi, H., \& Sor, R. (2006). Population Ecology, Institutionalism and the Internet: Travel Agencies Evolving into Middlemen. Journal of Organisational Change Management, 19(2), 104-118.

Gibbons, P. T., \& O'Connor, T. (2005). Influences on Strategic Planning Process among Irish SMEs. Journal of Small Business Management, 43(2), 170-186.

Gibbons, S. (2004). The Costs of Urban Property Crime. The Economic Journal 114(November), 441-463.

Gibson, J., Ivancevich, J., \& Donnelly, J. J. (1994). Organisations: Behaviour, Structure and Processes (8th ed.). Burr Ridge, Illinois: Irwin.

Giddens, A. (1997). Sociology. London: Polity Press.

Gilley, K. M., Walters, B., \& Olson, B. (2002). Top Management Team Risk Taking Propensities and Firm Performance: Direct and Moderating Effects. Journal of Business Strategies, 19(2), 95-114.

Gimeno, J., Folta, T., Cooper, A., \& Woo, C. (1997). Survival of the Fittest? Entrepreneurial Human Capital and the Persistence of Underperforming Firms. Administrative Science Quarterly, 42(4), 750-783.

Glaeser, E., Kallal, H., Scheinkman, J., \& Shleifer, A. (1992). Growth in Cities. Journal of Political Economy, 100(6), 1126-1152.

Glaeser, E., La Porta, R., Silanes, F. L. D., \& Shleifer, A. (2004). Do Institutions Cause Growth? Journal of Economic Growth, 9(3), 271-303.

Gleason, K., Mathur, L. K., \& Mathur, I. (2000). The Interrelationship Between Culture, Capital Structure and Performance: Evidence from European Retailers Journal of Business Research, 50(2), 185-191.

Gnyawali, D., \& Fogel, D. (1994). Environments for Entrepreneurship Development: Key Dimensions and Research Implications. Entrepreneurship Theory and Practice, 18(4), 43-62. 
Goetz, S., \& Freshwater, D. (2001). State-Level Determinants of Entrepreneurship and a Preliminary Measure of Entrepreneurial Climate. Economic Development Quarterly, 15(1), 58-70.

Goll, I., \& Rasheed, A. (2005). The Relationships Between Top Management Demographic Characteristics, Rational Decision-Making, Environmental Munificence, and Firm Performance. Organisation Studies, 26(7), 999-1023.

Gomes, C., Yasin, M., \& Lisboa, J. (2006). Performance Measurement Practices in Manufacturing Firms: An Empirical Investigation. Journal of Manufacturing Technology Management, 17(1/2), 144-167.

Gong, W., Li, Z., \& Stump, R. (2007). Global Internet Use and Access: Cultural Considerations. Asia Pacific Journal of Marketing and Logistics, 19(1), 5774.

Gonvindarajan, V. (1989). Implementing Competitive Strategies at the Business Unit Level: Implications of Matching Managers to Strategies. Strategic Management Journal, 10(3), 251-269.

Gonzalez-Benito, O., \& Gonzales-Benito, J. (2005). Cultural vs. Operational Market Orientation and Objective vs. Subjective Performance: Perspective of Production and Operations. Industrial Marketing Management, 34(8), 797829.

Goodman, L. A. (1960). On the Exact Variance of Products. Journal of the American Statistical Association, 55(292), 708-713.

Goodwin, M., Jones, M., \& Jones, R. (2005). Devolution, Constitutional Change and Economic Development: Explaining and Understanding the New Institutional Geographies of the British State. Regional Studies, 39(4), 421-436.

Grant, R. M. (2002). Contemporary Strategy Analysis: Concepts, Techniques, Applications (4th ed. ed.). Oxford: Blackwell Publishing.

Greenwood, P. E., \& Nikulin, M. S. (1996). A Guide to Chi-squared Testing. New York: Wiley.

Greenwood, R., Oliver, C., Sahlin, K., \& Suddaby, R. (2008). Introduction In R. Greenwood, C. Oliver, K. Sahlin \& R. Suddaby (Eds.), The SAGE Handbook of Organisational Institutionalism. London: Sage Publications.

Grewal, R., \& Tansuhaj, P. (2001). Building Organisational Capabilities for Managing Economic Crisis: The Role of Market Orientation and Strategic Flexibility. Journal of Marketing, 65(4), 67-80.

Griffith, D., Noble, S., \& Chen, Q. (2006). The Performance Implications of Entrepreneurial Proclivity: A Dynamic Capabilities Approach. Journal of Retailing, 82(1), 51-62.

Grimm, C., \& Smith, K. (1991). Management and Organisational Change: A Note on the Railroad Industry. Strategic Management Journal, 12(7), 557-562.

Grinyer, P., \& Yasai-Ardekani, M. (1981). Strategy, Structure, Size and Bureaucracy. Academy of Management Journal 24(3), 471-486.

Groenewegen, J., Kerstholt, F., \& Nagelkerke, A. (1995). On Integrating New and Old Institutionalism Douglass North Building Bridges. Journal of Economic Issues, 29(2), 467-475.

Grondin, D., \& Schaefer, N. (1995). Differences in the Export Activities of Female and Male Owned Small and Medium-Sized Enterprises. Women in Management Review, 10(8), 4-11.

Groves, R. (2006). Nonresponse Rates and Nonresponse Bias in Household Surveys. Public Opinion Quarterly, 70(5), 646-675. 
Groves, R., Fowler, F. J., Couper, M., Lepkowski, J., Singer, E., \& Tourangeau, R. (2004). Survey Methodology. In R. Groves, G. Kalton, J. N. K. Rao, N. Schwarz \& C. Skinner (Eds.), Wiley Series in Survey Methodology. New Jersey: John Wiley \& Sons.

Groves, R., \& Magilavy, L. (1986). Measuring and Explaining Interviewer Effects in Centralised Telephone Survey. Public Opinion Quarterly, 50(2), 251-266.

Gupta, A. (1984). Contingency Linkages Between Strategy and General Manager Characteristics: A Conceptual Examination. Academy of Management Review, 9(3), 399-412.

Gupta, A., \& Govindarajan, V. (1984). Business Unit Strategy, Managerial Characteristics, and Business Unit Effectiveness at Strategy Implementation. Academy of Management Journal, 27(1), 25-41.

Gwartney, J., Lawson, R., \& Clark, J. R. (2005). Economic Freedom of the World, 2002. The Independent Review, 9(4), 573-593.

Haber, S., \& Reichel, A. (2005). Identifying Performance Measures of Small Ventures- The Case of the Tourism Industry. Journal of Small Business Management, 43(3), 257-286.

Hadjimanolis, A. (2000). A Resource-based View of Innovativeness in Small Firms. Technology Analysis \& Strategic Management, 12(2), 263-281.

Hadjimanolis, A. (2000). An Investigation of Innovation Antecedents in Small Firms in the Context of a Small Developing Country. $R \& D$ Management, 30(3), 234-245.

Hair, J., Black, W., Babin, B., Anderson, R., \& Tatham, R. (2006). Multivariate Data Analysis (6th ed.). New York: Prentice Hall.

Hallward-Driemer, M., Wallsten, S., \& Xu, L. C. (2006). Ownership, Investment Climate and Firm Performance. Economics of Transition, 14(4), 629-647.

Hambrick, D. C., \& Mason, P. A. (1984). Upper Echelons: The Organisation as a Reflection of its Top Managers. Academy of Management Review, 9(1), 193206.

Hamilton, L. (1991). How Robust is Robust Regression? Stata Technical Bulletin, http://stata-press.com/journals/stbcontents/stb2.pdf, 22-26.

Hamilton, L. (2006). Statistics with Stata. Belmont, CA: Thomson Higher Education.

Han, J., Kim, N., \& Srivastava, R. (1998). Marketing Orientation and Organisational Performance: Is Innovation a Missing Link. Journal of Marketing, 62(4), 3045.

Hannan, M., \& Freeman, J. (1977). The Population Ecology of Organisations. American Journal of Organisations, 82(5), 929-964.

Hansemark, O. C. (1998). The Effects of an Entrepreneurship Programme on Need for Achievement and Locus of Control of Reinforcement. International Journal of Entrepreneurial Behaviour \& Research, 4(1), 28-50.

Hanson, B. (2001). Competency Models: Are Self Perceptions Accurate Enough? Journal of European Industrial Training, 29(9), 428-441.

Harding, A. (2005). Governance and Socio-Economic Change in Cities. In N. Buck, I. Gordon, A. Harding \& I. Turok (Eds.), Changing Cities: Rethinking Urban Competitiveness, Cohesion and Governance. New York: Palgrave Macmillan.

Harding, A., Wilks-Heeg, S., \& Hutchins, M. (2000). Business, Government and the Business of Urban Governance. Urban Studies, 37(1), 975-994.

Harman, H. H. (1976). Modern Factor Analysis. Chicago IL: University of Chicago. 
Harvie, C., \& Lee, B.-C. (2002). The Study of Small and Medium Sized Enterprises in East Asia. In C. Harvie \& B.-C. Lee (Eds.), Globalisation and SMEs in East Asia: Studies of Small and Medium Sized Enterprises in East Asia. Cheltenham: Edward Elgar.

Hasan, R., Mitra, D., \& Ulubasoglu, M. (2007). Institutions and Policies for Growth and Poverty Reduction: The Role of Private Sector Development. Asian Development Review, 24(1), 69-116.

Hawanini, G., Subramanian, V., \& Verdin, P. (2003). Is Performance Driven by Industry or Firm Specific Factors? A New Look at the Evidence. Strategic Management Journal, 24(1), 1-16.

Hayton, J., George, G., \& Zahra, S. (2002). National Culture and Entrepreneurship. Entrepreneurship Theory and Practice, 26(4), 33-52.

Heck, R. (1998). Factor Analysis: Exploratory and Confirmatory Approaches. In G. Marcoulides (Ed.), Modern Methods for Business Research London: Lawrence Erlbaum Associates.

Heitger, B. (2004). Property Rights and the Wealth of Nations: A Cross-Country Study Cato Journal, 23(3), 381-402.

Helen, S., \& Lioukas, S. (2003). Radical Product Innovations in SMEs: The Dominance of Entrepreneurial Orientation. Journal of Creativity and Innovation Management, 12(2), 94-108.

Hellman, J., Jones, G., Kaufmann, D., \& Schankerman, M. (2000). Measuring Governance and State Capture: The Role of Bureaucrats and Firms in Shaping the Business Environment. European Bank for Reconstruction and Development.

Helmke, G., \& Levitsky, S. (2004). Informal Institutions and Comparative Politics: A Research Agenda. Perspectives on Politics, 2(4), 725-740.

Helmsing, B. (2000). Decentralisation, Enablement and Local Governance in Low Income Countries Paper presented at the Inaugural Address as Professor of Local and Regional Planning, Faculty of Geographical Sciences, University of Utrecht.

Helmsing, B. (2003). Local Economic Development: New Generations of Actors, Policies and Instruments for Africa. Public Administration and Development, 23(1), 67-76.

Henisz, W., \& Swaminathan, A. (2008). Institutions and International Business. Journal of International Business Studies, 39(4), 537-539.

Herrschel, T., \& Newman, P. (2000). New Regions in England and Germany: An Examination of the Interaction of Constitutional Structures, Gormal Regions, and Informal Institutions. Urban Studies, 37(7), 1185-1202.

Hewitt-Dundas, N. (2006). Resource and Capability Constraints to Innovation in Small and Large Plants. Small Business Economics, 26(3), 257-277.

Hill, C. (1995). National Institutional Structures, Transaction Cost Economizing and Competitive Advantages: The Case of Japan. Organisation Science, 6(1), 119-131.

Hinkin, T. (1995). A Review of Scale Development Process in the Study of Organisations. Journal of Management, 21(5), 967-988.

Hitt, M., \& Tyler, B. (1991). Strategic Decision Models: Integrating Different Perspectives. Strategic Management Journal, 12(5), 327-351.

Hitt, M. A., Ireland, R. D., \& Hoskisson, R. E. (2007). Strategic Management: Competitiveness and Globalization (Concepts and Cases) (7th ed.). Mason, Ohio: Thomson South-Western. 
Hockberg, Y., \& Tamhane, A. (1987). Multiple Comparison Procedures. Chichester: John Wiley \& Sons

Hodgson, G. M. (1988). Economics and Institutions: A Manifesto for a Modern Institutional Economics. Cambridge: Polity Press.

Hodgson, G. M. (1993). Economic and Evolution: Bringing Life Back into Economics. Cambridge: Polity Press.

Hodgson, G. M. (1998). The Approach of Institutional Economics. Journal of Economic Literature, 36(1), 166-192.

Hodgson, G. M. (2006). What are Institutions? Journal of Economic Issues, 40(1), 125.

Hofer, C. (1975). Towards a Contingency Theory of Business Strategy. Academy of Management Journal, 18(4), 784-810.

Hofstede, G. (1980). Culture's Consequences: International Differences in Workrelated Values. Beverly Hills, CA: Sage Publications.

Hofstede, G. (1983). The Cultural Relativity of Organisational Practices and Theories. Journal of International Business Studies, 14(2), 75-89.

Hollingsworth, J. R. (2002). On Institutional Embeddedness. In J. R. Hollingsworth, K. Muller \& E. Hollingsworth (Eds.), Advancing Socio-Economics: An Institutionalist Perspective. Oxford: Rowman \& Littlefield Publishers, Inc.

Hooley, G., Greenly, G., Cadogan, J., \& Fahy, J. (2005). The Performance Impact of Marketing Resources. Journal of Business Research, 58(1), 18-27.

Hopkins, M. (2002). Crime Against Businesses: The Way Forward for Future Research. British Journal of Criminology, 42(4), 782-797.

Hoskisson, R., Eden, L., Lau, C. M., \& Wright, M. (2000). Strategy in Emerging Economies. The Academy of Management Journal, 43(3), 249-267.

House, R., Hanges, P., Javidan, M., Dorfman, P., \& Gupta, V. (2004). Culture, Leadership, and Organisations: The GLOBE Study of 62 Societies. Thousand Oaks: Sage Publications.

Hoyle, R. H. (1995). The Structural Equation Modelling Approach: Basic Concepts and Fundamental Issues In R. H. Hoyle (Ed.), Structural Equation Modelling: Concepts, Issues, and Applications Thousand Oaks: Sage Publications.

Hrebiniak, L., \& Joyce, W. (1985). Organisational Adaptation: Strategic Choice and Environmental Determinism. Administrative Science Quarterly, 30(3), 336349.

Hsueh, L.-M., \& Tu, Y.-y. (2002). Innovation and the Operational Performance of Newly Established Small and Medium Enterprises in Taiwan. Small Business Economics, 23(1), 99-113.

Hu, L. T., Bentler, P. M., \& Kano, Y. (1992). Can Test Statistics in Covariance Structure Analysis be Trusted? Psychological Bulletin, 112(2), 351-362.

Huergo, E., \& Jaumandreu, J. (2004). How Does Probability of Innovation Change with Firm Age? Small Business Economics, 22(3/4), 193-207.

Hughes, J. T. (1991). Evaluation of Local Economic Development: A Challenge for Policy Research. Urban Studies, 28(6), 909-918.

Hughes, M., \& Morgan, R. (2007). Deconstructing the Relationship Between Entrepreneurial Orientation and Business Performance at the Embryonic Stage of Firm Growth. Industrial Marketing Management, 36(5), 651-661.

Hult, G. T., Hurley, R., \& Knight, G. (2004). Innovativeness: Its Antecedents and Impact on Business Performance. Industrial Marketing Management, 33(5), 429-438. 
Huselid, M., Jackson, S., \& Schuller, R. (1997). Technical and Strategic Human Resource Management Effectiveness as Determinants of Firm Performance. Academy of Management Journal, 40(1), 171-188.

IFC. (2007). Enterprise Survey. Retrieved 1 March, 2007, from http://www.enterprisesurveys.org/Default.aspx

IMD. (2006). The World Competitiveness Yearbook. Lausanne: International Institute for International Development.

Inma, C., \& Debowski, S. (2006). Analysis of Franchise Performance through Use of a Typology: An Australian Investigation. Singapore Management Review, 28(2), 1-29.

Jackson, P. (1999). New Roles of Government in Supporting Manufacturing: The Capabilities of Support Agencies in Ghana and Zimbabwe. Public Administration and Development, 19(3), 281-298.

Jackson, P. (2002). Business Development in Asia and Africa: The Role of Government Agencies. Hampshire: Palgrave.

Jacobson, R. (1987). The Validity of ROI as a Measure of Business Performance. American Economic Review, 77(3), 470-478.

Jantunen, A., Puumalainen, K., Saarenketo, S., \& Kylaheiko, K. (2005). Entrepreneurial Orientation, Dynamic Capabilities and International Performance. Journal of International Entrepreneurship, 3(3), 223-243.

Jarvis, C., Mackenzie, S., \& Podsakoff, P. (2003). A Critical Review of Construct Indicators and Measurement Model Misspecification in Marketing and Consumer Research. Journal of Consumer Research, 30(2), 199-218.

Javidan, M. (2004). Performance Orientation. In R. House, P. Hanges, M. Javidan, P. Dorfman \& V. Gupta (Eds.), Culture, Leadership, and Organisations: The GLOBE Study of 62 Societies. Thousand Oaks: Sage Publications.

Javidan, M., House, R., Dorfman, P., Hanges, P., \& de Luque, M. (2006). Conceptualising and Measuring Cultures and their Consequences: A Comparative Review of GLOBE's and Hofstede's Approaches. Journal of International Business Studies, 37(6), 897-914.

Jessor, R., \& Jessor, S. (1973). The Perceived Environment in Behavioural Science: Some Conceptual Issues and Some Illustrative Data. The American Behavioural Scientist, 16(6), 801-828.

Jogaratnam, G. (2002). Entrepreneurial Orientation and Environmental Hostility: An Assessment of Small, Independent Restaurant Businesses. Journal of Hospitality and Tourism Research, 26(3), 258-277.

Jogaratnam, G., Tse, E., \& Olsen, M. (1999). Strategic Posture, Environmental Munificence, and Performance: An Empirical Study of Independent Restaurants. Journal of Hospitality and Tourism Research, 23(2), 118-138.

Judge, W. Q., \& Zeithaml, C. (1992). Institutional and Strategic Choice Perspectives on Board Involvement in the Strategic Decision Process. The Academy of Management Journal, 35(4), 766-794.

Jusoh, R., Ibrahim, D. N., \& Zainuddin, Y. (2006). Assessing the Alignment between Business Strategy and Use of Multiple Performance Measures Using Interaction Approach. The Business Review, 5(1), 51-60.

Kabasakal, H., \& Bodur, M. (2004). Humane Orientation in Societies, Organisations, and Leader Attributes. In R. House, P. Hanges, M. Javidan, P. Dorfman \& V. Gupta (Eds.), Culture, Leadership, and Organisations: The GLOBE Study of 62 Societies. Thousand Oaks: Sage Publications. 
Kahn, J. (2006). The Search for the Rule of Law in Russia. Georgetown Journal of International Law 37(2), 353-409.

Kaiser, H. F. (1960). The Application of Electronic Computers to Factor Analysis. Educational and Psychological Measurement, 20(1), 141-151.

Kaiser, H. F. (1970). A Second-generation Little Jiffy. Psychometrika, 35(4), 401416.

Kaiser, H. F. (1974). An Index of Factorial Simplicity. Psychometrika, 39(1), 31-36.

Kam, W. P., Kiese, M., Singh, A., \& Wong, F. (2003). The Pattern of Innovation in Singapore's Manufacturing Sector. Singapore Management Review, 25(1), 134.

Karami, A., Analoui, F., \& Kakabadse, N. (2006). The CEOs' Characteristics and their Strategy Development in the UK SME Sector. Journal of Management Development 25(4), 316-324.

Kathuria, R., \& Porth, S. (2003). Strategy-Managerial Characteristics Alignment and Performance. International Journal of Operations \& Production Management, 23(3/4), 255-275.

Kaufmann, D., Kraay, A., \& Mastruzzi, M. (2006). Governance Matters V: Aggregate and Individual Governance Indicators for 1996-2005, Policy Research Working Paper 4012. Washington DC: The World Bank.

Kauser, S., \& Shaw, V. (2004). The Influence of Behavioural and Organisational Characteristics on the Success of International Strategic Alliances. International Marketing Review, 21(1), 17-52.

Kaynak, H. (2003). The Relationship Between Total Quality Management Practices and Their Effects on Firm Performance. Journal of Operations Management, 21(4), 405-435.

Kazem, A., \& van der Heijden, B. (2006). Exporting Firm's Strategic Choices: The Case of Egyptian SMEs in the Food Industry. S.A.M. Advanced Management Journal 71(3), 21-33.

Keefer, P., \& Knack, S. (1997). Why Don't Poor Countries Catch Up? A CrossNational Test of an Institutional Explanation. Economic Inquiry, 35(3), 590602.

Keeley, R., \& Roure, J. (1990). Management, Strategy, and Industry Structure as Influences on the Success of New Firms: A Structural Model. Management Science, 36(10), 1256-1267.

Keh, H., Nguyen, T., \& Ng, H. (2006). The Effects of Entrepreneurial Orientation and Marketing Information on the Performance of SMEs. Journal of Business Venturing, 22(4), 592-611.

Kelley, L., Whatley, A., \& Worthley, R. (1987). Assessing the Effects of Culture on Managerial Attitudes: A Three-Culture Test. Journal of International Business Studies 18(2), 17-31.

Kemelgor, B. (2002). A Comparative Analysis of Corporate Entrepreneurial Orientation Between Selected Firms in the Netherlands and the USA. Entrepreneurship \& Regional Development, 14(1), 67-87.

Ketchen, D., Thomas, J., \& Snow, C. (1993). Organisational Configurations and Performance: A Comparison of Theoretical Approaches. Academy of Management Journal, 36(6), 1278-1313.

Khandwalla, P. (1977). The Design of Organisations. New York: Harcourt Brace Jovanovich Inc

Kim, J., \& Mueller, C. (1978). Factor Analysis: Statistical Methods and Practical Issues. Thousand Oaks, CA: Sage Publications. 
Kirby, D., \& Watson, A. (2003). Small Firms and Economic Development in Developed and Transition Economies: A Reader. Aldershot: Ashgate.

Kirkman, B., \& Shapiro, D. (2001). The Impact of Cultural Values on Job Satisfaction and Organisational Commitment in Self-Managing Work Teams: The Mediating Role of Employee Resistance. Academy of Management Journal, 44(3), 557-569.

Kitchell, S. (1997). CEO Characteristics and Technological Innovativeness: A Canadian Perspective. Canadian Journal of Administrative Sciences, 14(2), 111-125.

Kitson, M., \& Michie, J. (1997). Does Manufacturing Matter? Management Research News, 4(1), 71-95.

Kline, R. (2005). Principles and Practice of Structural Equation Modelling (2nd ed.). New York: The Guilford Press.

Kline, R. B. (1998). Software Review: Software Programs for Structural Equation Modelling: Amos, EQS, and LISREL. Journal of Psychological Assessment, 16(1), 343-364.

Kline, T., Sulsky, L. M., \& Rever-Moriyama, S. (2000). Common Method Variance and Specification Error: A Practical Approach to Detection. The Journal of Psychology, 134(4), 401-421.

Knight, G. (1997). Cross-Cultural Reliability and Validity of a Scale to Measure Firm Entrepreneurial Orientation. Journal of Business Venturing, 12(3), 213225.

Knight, G. (2000). Entrepreneurship and Marketing Strategy: The SME Under Globalization. Journal of International Marketing, 8(2), 12-32.

Knight, G., \& Cavusgil, S. (2004). Innovation, Organisational Capabilities, and the Born-Global Firm. Journal of International Business Studies, 35(2), 124-141.

Koberg, C., Tegarden, L., \& Wilsted, W. (1993). Environmental and Structural Influences on the Strategy-Making Process of Banks. Journal of Applied Business Research, 9(3), 58-62.

Kor, Y., \& Mahoney, J. T. (2005). How Dynamics, Management, and Governance of Resource Deployments Influence Firm-Level Performance. Strategic Management Journal, 26(5), 489-496.

Kostova, T. (1997). Country Institutional Profile: Concept and Measurement, Academy of Management Best Paper Proceedings (pp. 180-189).

Kotabe, M., \& Czinkota, M. (1991). State Government Promotion of Manufacturing Exports: A Gap Analysis Journal of International Business Studies, 23(4), 637-658.

Kotha, S., \& Nair, A. (1995). Strategy and Environment as Determinants of Performance: Evidence from the Japanese Machine Tool Industry. Strategic Management Journal, 16(1), 497-518.

Krauss, S., Frese, M., Friedrich, C., \& Unger, J. (2005). Entrepreneurial Orientation: A Psychological Model of Success Among Southern African Small Business Owners. European Journal of Work and Organisational Psychology, 14(3), 315-344.

Kreft, S., \& Sobel, R. (2005). Public Policy, Entrepreneurship, and Economic Freedom. The Cato Journal, 25(3), 595-616.

Krosnick, J. (1999). Survey Research. Annual Review of Psychology, 50(1), 537-567.

Krueger, N., Reilly, M., \& Carsrud, A. (2000). Competing Models of Entrepreneurial Intentions. Journal of Business Venturing, 15, 411-432. 
Krumholz, N. (1999). Equitable Approaches to Local Economic Development. Policy Studies Journal, 27(1), 83-95.

Kuratko, D. F., \& Hodgetts, R. M. (2004). Entrepreneurship Theory, Process, \& Practice (6th ed.). Ohio: Thomson-Western.

La Porta, R., Lopez-de-Silanes, F., Shleifer, A., \& Vishny, R. (1999). The Quality of Government. Journal of Law Economics \& Organisation, 15(1), 222-279.

Lall, S. (2000). Strengthening SMEs for International Competitiveness. Paper presented at the Workshop on What Makes Your Firm Internationally Competitive?, Cairo

Lallana, E., Pascual, P., \& Andam, Z. (2002). SMEs and e-Commerce in Three Philippine Cities, Digital Philippines Manila: Asia Foundation.

Landau, D. (2003). A Simple Theory of Economic Growth. Journal of Economic Development and Cultural Change, 52(1), 217-236.

Lankford, S. V., Buxton, B. P., Hetzler, R., \& Little, J. (1995). Response Bias and Wave Analysis of Mailed Questionnaires in Tourism Impact Assessments. Journal of Travel Research, 33(1), 8-13.

Lau, C., \& Ngo, H. Y. (2001). Organisation Development and Firm Performance: A Comparison of Multinational and Local Firms. Journal of International Business Studies, 32(1), 95-114.

Law, K., Wong, C., \& Mobley, W. (1998). Toward a Taxonomy of Multidimensional Constructs. Academy of Management Review, 23(4), 741-755.

Leach, S., Stewart, J., \& Walsh, K. (1994). The Changing Organisation and Management of Local Government. London: Macmillan.

Leaptrott, J. (2005). An Institutional Theory View of the Family Business. Family Business Review, 18(3), 215-229.

Lee, C., Lee, K., \& Pennings, J. M. (2001). Internal Capabilities, External Networks and Performance: A Study of Technology-Based Networks. Strategic Management Journal, 22(6/7), 615-640.

Lee, D. Y., \& Tsang, E. (2001). The Effects of Entrepreneurial Personality, Background and Network Activities on Venture Growth. Journal of Management Studies, 38(4), 583-600.

Lee, S. M., \& Peterson, S. J. (2000). Culture, Entrepreneurial Orientation and Global Competitiveness. Journal of World Business, 35(4), 401-416.

Lefebvre, L., Mason, R., \& Lefebvre, E. (1997). The Influence Prism in SMEs: The Power of CEO's Perceptions on Technology Policy and its Organisational Impacts. Management Science 43(6), 856.

Legaspi, P. (2000). The Enabling Role of Local Governments. In P. Tapales \& A. J. Brillantes (Eds.), Local Government in the Philippines: A Book of Readings Concepts and Practices in Decentralisation (Vol. 3). Quezon City: Centre for Local and Regional Governance and National College of Public Administration and Governance, University of the Philippines - Diliman.

Lenartowicz, T., \& Roth, K. (1999). A Framework for Culture Assessment. Journal of International Business Studies, 30(4), 781-798.

Lenartowicz, T., \& Roth, K. (2001). Does Subculture Within a Country Matter? A Cross-Cultural Study of Motivational Domains and Business Performance in Brazil. Journal of International Business Studies, 32(2), 305-325.

Lenz, R. T., \& Engledow, J. (1986). Environmental Analysis: The Applicability of Current Theory. Strategic Management Journal, 7(4), 329-346. 
Lerner, M., \& Almor, T. (2002). Relationship among Strategic Capabilities and the Performance of Women-Owned Small Ventures. Journal of Small Business Management, 40(2), 109-125.

Lewin, A., \& Minton, J. W. (1986). Determining Organisational Effectiveness: Another Look, and an Agenda for Research Management Science, 32(5), 514538.

Lewin, A., \& Volberda, H. (1999). Prolegomena on Coevolution: A Framework for Research on Strategy and New Organisational Forms. Organisation Science, 10(5), 519-534.

Li, H. (2001). How Does New Venture Strategy Matter in the EnvironmentPerformance Relationship. Journal of High Technology Management Research, 12, 183-204.

Li, H., \& Atuahene-Gima, K. (2001). Product Innovation Strategy and the Performance of New Technology Ventures in China. Academy of Management Journal, 44(6), 1123-1134.

Li, J., Lam, K., \& Qian, G. (2001). Does Culture Affect Behaviour and Performance of Firms? The Case of Joint Ventures in China. Journal of International Business Studies, 32(1), 115-131.

Liao, Y. (2006). The Effect of Fit between Organisational Life Cycle and Human Resource Management Control on Firm Performance. The Journal of American Academy of Business, Cambridge, 8(1), 192-196.

Lindell, M. L., \& Whitney, D. (2001). Accounting for Common Method Variance in Cross-sectional Research Designs. Journal of Applied Psychology, 86(1), 114-121.

Lindsay, V. (2003). Sustainable Economic Development: An Indigenous Perspective. Auckland, NZ: James Henare Maori Research Centre, University of Auckland.

Liu, S., Luo, X., \& Shi, Y. (2002). Integrating Customer Orientation, Corporate Entrepreneurship, and Learning Orientation in Organisations-in-Transition: An Empirical Study. International Journal of Research in Marketing, 19(4), 367-382.

Logan, J., \& Molotch, H. (1996). The City as a Growth Machine. In S. Fainstain \& S. Campell (Eds.), Readings in Urban Theory. Massachusetts: Blackwell Publishers.

Lopez-Claros, A., Altinger, L., Blanke, J., Drzeniek, M., \& Mia, I. (2007). The Global Competitiveness Index: Identifying the Key Elements of Sustainable Growth. In A. Lopez-Claros, M. E. Porter, X. Sala-i-Martin \& K. Scwab (Eds.), The Global Competitiveness Report 2006-2007: World Economic Forum/Palgrave Macmillan.

Lopez, S., Peon, J. M., \& Ordas, C. J. (2005). Organisational Learning as a Determining Factor in Business Performance. The Learning Organisation, 12(3), 227-245.

Lorch, J. (1975). Environment, Organisation, Individual. In A. Negandhi (Ed.), Interorganisation Theory. Kent: Kent State University.

Lumpkin, G. T., \& Dess, G. (1996). Clarifying the Entrepreneurial Orientation Construct and Linking it to Performance. Academy of Management Review, 21(1), 135-173.

Lumpkin, G. T., \& Dess, G. (2001). Linking Two Dimensions of Entrepreneurial Orientation to Firm Performance: The Moderating Role of Environment and Industry Life Cycle. Journal of Business Venturing, 16(5), 429-451. 
Lumpkin, G. T., \& Dess, G. G. (1995). Simplicity as a Strategy-making Process: The Effects of Stage of Organisational Development and Environment on Performance. The Academy of Management Journal, 38(5), 1386-1407.

Lundstrom, W., \& Lamont, L. (1976). The Development of a Scale to Measure Consumer Discontent. Journal of Marketing Research, 13(4), 373-381.

Luo, X., Sivakumar, K., \& Liu, S. (2005a). Globalisation, Marketing Resources and Performance: Evidence from China. Academy of Marketing Science Journal, 33(1), 50-65.

Luo, X., Zhuo, L., \& Liu, S. (2005b). Entrepreneurial Firms in the Context of China's Transition Economy: An Integrative Framework and Empirical Examination. Journal of Business Research, 58(3), 277-284.

Luo, Y. (1999). Environment-Strategy-Performance Relations in Small Businesses in China: A Case of Township and Village Enterprises in Southern China. Journal of Small Business Management, 37(1), 37-52.

Luo, Y. (2005). Transactional Characteristics, Institutional Environment and Joint Venture Contracts. Journal of International Business Studies, 36(2), 209-230.

Ma, X., \& Delios, A. (2007). A New Tale of Two Cities: Japanese FDIs in Shanghai and Beijing, 1979-2003. International Business Review, 16(2), 207-228.

Mabey, C., \& Gooderham, P. (2005). The Impact of Management Development on Perceptions of Organisational Performance in European Firms. European Management Review, 2(1), 131-142.

Machado, H., Gimenez, F., Gomes, V., Aligleri, L., Pelisson, C., \& Aligleri, L. (2002). Female and Male Entrepreneurs' Managerial Behaviour: A Brazilian Study. Management International, 7(1), 21-33.

MacKinnon, D., Lockwood, C., Hoffman, J., West, S., \& Sheets, V. (2002). A Comparison of Methods to Test Mediation and Other Intervening Variable Effects. Psychological Methods, 7(1), 83-104.

Madsen, E. (2007). The Significance of Sustained Entrepreneurial Orientation on Performance of Firms - A Longitudinal Analysis. Entrepreneurship \& Regional Development, 19(2), 185-204.

Madsen, E. L. (2004). Resources, Long-term Entrepreneurial Orientation, and Firm Performance. Paper presented at the 13th Nordic Conference on Small Business Research (June 1-13), Tromso.

Magdaluyo, R., Tecson, K., Batac, M. V., Geniza, A., Abasar, M., Reyes, J., et al. (2001). An Inquiry Into the Competitiveness of Emerging Philippine Cities. Manila: Philippine APEC Study Center Network, Asian Institute of Management.

Malach-Pines, A., Levy, H., Utasi, A., \& Hill, T. L. (2005). Entrepreneurs as Cultural Heroes: A Cross-Cultural, Interdisciplinary Perspective. Journal of Managerial Psychology, 20(6), 541-555.

Malhotra, N., Kim, S., \& Patil, A. (2006). Common Method Variance in IS Research: A Comparison of Alternative Approaches and a Reanalysis of Past Research. Management Science, 52(12), 1856-1883.

Manev, I., Gyoshev, B., \& Manolova, T. (2005). The Role of Human and Social Capital and Entrepreneurial Orientation for Small Business Performance in a Transitional Economy International Journal of Entrepreneurship and Innovation Management, 5(3-4), 298-318.

Manolova, T., Eunni, R., \& Gyoshev, B. (2008). Institutional Environments for Entrepreneurship: Evidence from Emerging Economies in Eastern Europe. Entrepreneurship Theory and Practice, 32(1), 203-218. 
Marino, L., Strandholm, K., Steensma, H. K., \& Weaver, K. M. (2002). The Moderating Effect of National Culture on the Relationship between Entrepreneurial Orientation and Strategic Alliance Portfolio Extensiveness. Entrepreneurship Theory and Practice, 26(4), 145-161.

Martinsons, M., \& Davison, R. (2007). Strategic Decision Making and Support Systems: Comparing American, Japanese, and Chinese Management. Decision Support Systems, 43(1), 284-300.

Maskus, K. (2000). Intellectual Property Rights and Economic Development. Case Western Reserve Journal of International Law, 32(3), 471-506.

Matsuno, K., Mentzer, J., \& Ozsomer, A. (2002). The Effects of Entrepreneurial Proclivity and Market Orientation on Business Performance. Journal of Marketing, 66(3), 18-32.

Matten, D., \& Geppert, M. (2004). Work Systems in Heavy Engineering: The Role of National Culture and National Institutions in Multinational Corporations. Journal of International Management, 10(2), 177-198.

Mauri, A., \& Michaels, M. (1998). Firm and Industry Effects Within Strategic Management: An Empirical Examination. Strategic Management Journal, 19(3), 211-219.

Mazzola, F., \& Bruni, S. (2000). The Role of Linkages in Firm Performance: Evidence from Southern Italy. Journal of Economic Behaviour \& Organisation, 43(1), 199-221.

McGrath, R. G., MacMillan, I., Yang, E., \& Tsai, W. (1992b). Does Culture Endure, or Is It Malleable? Issues for Entrepreneurial Economic Development. Journal of Business Venturing, 7(6), 441-458.

McIntyre, R. (2002). The Community as Actor in and Incubator of Economic and Social Revival: A Local-Level Economic Development Strategy Unpublished manuscript, Moscow.

McKinley, W., \& Mone, M. (2003). Micro and Macro Perspectives in Organisation Theory: A Tale of Incommensurability. In H. Tsoukas \& C. Knudsen (Eds.), The Oxford Handbook of Organisation Theory. Oxford: Oxford University Press.

Meehl, P. (1990). Why Summaries of Research on Psychological Theories are Often Uninterpretable. Psychological Reports, 66, 195-244.

Meijaard, J., Brand, M., \& Mosselman, M. (2005). Organisational Structure and Performance in Dutch Small Firms. Small Business Economics, 25(1), 83-96.

Menguc, B., \& Auh, S. (2006). Creating a Firm-Level Dynamic Capability through Capitalizing on Market Orientation and Innovativeness. Academy of Marketing Science Journal, 34(1), 63-74.

Meyer-Stamer, J. (2004). Paradoxes and Ironies of Locational Policy in the New Global Economy. In H. Schmitz (Ed.), Local Enterprises in the Global Economy: Issues of Governance and Upgrading. Cheltelham: Edward Elgar.

Meyer, K., \& Nguyen, H. V. (2005). Foreign Investment Strategies and Sub-national Institutions in Emerging Markets: Evidence from Vietnam. Journal of Management Studies, 42(1), 63-93.

Meyer, K., \& Peng, M. (2005). Probing Theoretically into Central and Eastern Europe: Transactions, Resources, and Institutions. Journal of International Business Studies, 36(6), 600-621.

Miles, M., Arnold, D., \& Thompson, D. (1993). The Interrelationship Between Environmental Hostility and Entrepreneurial Orientation. Journal of Applied Business Research, 9(4), 12-23. 
Miles, R., \& Snow, C. (1978). Organisational Strategy, Structure, and Process. New York: McGraw Hill.

Miller, D. (1987). Strategy Making and Structure: Analysis and Implications for Performance. Academy of Management Journal, 30(1), 7-32.

Miller, D. (1988). Relating Porter's Business Strategy to Environment and Structure: Analysis and Performance Implications. Academy of Management Journal, 31(2), 280-308.

Miller, D., \& Friesen, P. (1982). Innovation in Conservative and Entrepreneurial Firms: Two Models of Strategic Momentum. Strategic Management Journal, $3(1), 1-25$.

Mintu-Winsatt, A., \& Gassenheimer, J. (1995). Negotiation Differences between Two Diverse Cultures. European Journal of Marketing, 30(4), 20-39.

Mohan-Neill, S. I. (1995). The Influence of Firm's Age and Size on its Environmental Scanning Activities. Journal of Small Business Management, 33(4), 10-21.

Morgan, R., \& Strong, C. (2003). Business Performance and Dimensions of Strategic Orientation. Journal of Business Research, 56(3), 163-176.

Morris, M. H., Avila, R., \& Allen, J. W. (1993). Individualism and the Modern Corporation: Implications for Innovation and Entrepreneurship. Journal of Management, 19(3), 595-612.

Morris, M. H., Davis, D. L., \& Allen, J. W. (1994). Fostering Corporate Entrepreneurship: Cross Cultural Comparisons of the Importance of Individualism versus Collectivism Journal of International Business Studies, 25(1), 65-89.

Mosakowski, E. (1993). A Resource-Based Perspective on the Dynamic Strategy Performance Relationship - An Empirical Examination of the Focus and Differentiation Strategies in Entrepreneurial Firms. Journal of Management, 19(4), 819-839.

Mostafa, R., Wheeler, C., \& Jones, M. (2006). Entrepreneurial Orientation, Commitment to the Internet and Export Performance in Small and Medium Sized Exporting Firms. Journal of International Entrepreneurship, 3(4), 291302.

Mueller, R. O. (1996). Basic Principles of Structural Equation Modelling: An Introduction to LISREL and EQS. New York: Springer.

Munoz, J. M., Liao, J., \& Welsch, H. (2005). Success Factors Among Philippine Entrepreneurs. Paper presented at the Annual Conference of the United States Association of Small Business and Entrepreneurship, Indian Wells, California.

Murray, J., Kotabe, M., \& Wildt, A. (1995). Strategic and Financial Performance Implications of Global Sourcing Strategy: A Contingency Analysis. Journal of International Business Studies, 26(1), 181-202.

Myers, J., \& Warner, W. (1968). Semantic Properties of Selected Evaluation Adjectives. Journal of Marketing Research, 5(November), 409-412.

Nagar, V., \& Rajan, M. (2001). The Revenue Implications of Financial and Operational Measures of Product Quality. The Accounting Review, 76(4), 495-513.

Naldi, L., Nordqvist, M., Sjoberg, K., \& Wiklund, J. (2007). Entrepreneurial Orientation, Risk Taking and Performance in Family Firms. Family Business Review, 20(1), 33-48. 
Naman, J., \& Slevin, D. (1993). Entrepreneurship and the Concept of Fit: A Model and Empirical Tests. Strategic Management Journal, 14(2), 137-153.

Narain, S. (2003). Investment Promotion and Enterprise Development Bulletin for Asia and the Pacific No. 2: Economic and Social Commission for Asia and the Pacific, United Nations.

Narayanan, V., \& Fahey, L. (2005). The Relevance of the Institutional Underpinnings of Porter's Five Forces Framework to Emerging Economies: An Epistemological Analysis. Journal of Management Studies, 42(1), 207223.

Naudee, W., \& Krugell, W. F. (2003). An Inquiry into Cities and their Role in Subnational Economic Growth in South Africa. Journal of African Economies, 12(4), 476-499.

Neely, A. (1998). Measuring Business Performance. London: Profile Books Ltd.

Nelson, R. (1995). Co-evolution of Industry Structure, Technology and Supporting Institutions, and the Making of Comparative Advantage. International Journal of the Economics and Business, 2(2), 171-184.

Nerona, G. (2000). The Battle Against Software Piracy: Software Copyright Protection in the Philippines. Pacific Rim Law \& Policy Journal, 9(3), 651680.

Netemeyer, R., Bearden, W., \& Sharma, S. (2003). Scaling Procedures: Issues and Applications. Thousand Oaks, CA: Sage Publications.

Newby, R., Watson, J., \& Woodliff, D. (2003). SME Survey Methodology: Response Rates, Data Quality, and Cost Effectiveness. Entrepreneurship Theory and Practice, 28(2).

Nguyen, T., \& Bryant, S. (2004). A Study of the Formality of Human Resource Management Practices in Small and Medium-Size Enterprises in Vietnam. International Small Business Journal, 22(6), 595-618.

Niikura, R. (1999). Assertiveness Among Japanese, Malaysian, Filipino, and US White Collar Workers. Journal of Social Psychology, 139(6), 690-699.

Nkya, E. (2003). Institutional Barriers to Small-Scale Business Development: A Need for Flexibility in Tanzanian Tax and Regulatory Systems. Journal of Entrepreneurship, 12(1), 43-73.

Noble, C., Sinha, R., \& Kumar, A. (2002). Market Orientation and Alternative Strategic Orientations: A Longitudinal Assessment of Performance Indicators. Journal of Marketing, 66(4), 25-40.

Noboyuki, H. (2004). Productivity and Entrepreneurial Characteristics in New Japanese Firms. Small Business Economics, 23(4), 299-310.

North, D. (1990). Institutions, Institutional Change and Economic Performance. Cambridge: Cambridge University Press.

North, D. (1992). Institutions and Economic Theory. American Economist, 36(1), 37.

North, D. (2005). Understanding the Process of Economic Change. New Jersey: Princeton University Press.

North, D. C. (1991). Institutions. Journal of Economic Perspectives, 5(1), 97-112.

Norton, S. (1998). Poverty, Property Rights, and Human Well-being: A Crossnational Study. Cato Journal, 18(2), 233-245.

NSCB. (2007a). Income Classification for Provinces, Cities and Municipalities. Retrieved 4 June, 2008, from http://www.nscb.gov.ph/activestats/psgc/articles/con_income.asp 
NSCB. (2007b). Local Government Units. Philippine Standard Geographic Code $\begin{array}{lllll}\text { Retrieved } & 4 & \text { June, } & \text { from }\end{array}$ http://www.nscb.gov.ph/activestats/psgc/articles/con_lgu.asp

NSCB. (2007c). National Statistical Coordination Board. Retrieved 24 April, 2007, from http://www.nscb.gov.ph

NSCB. (2008). Gross National Product and Gross Domestic Product by Industrial Origin for First Quarter 2007. Retrieved 4 June 2008, from http://www.nscb.gov.ph/sna/2007/1stQ2007/2007ser1.asp

Nunnaly, J. (1978). Psychometric Theory. New York: McGraw-Hill.

O'Donnell, G. (2004). Why The Rule of Law Matters. Journal of Democracy, 15(4), 32-46.

O'Neil, M. (1979). Estimating the Nonresponse Bias Due to Refusals in Telephone Surveys. The Public Opinion Quarterly, 43(2), 218-232.

O'Regan, N. (2002). Market Share: The Conduit to Future Success? European Business Review, 14(4), 287-293.

O'Regan, N., \& Ghobadian, A. (2004a). The Importance of Capabilities for Strategic Direction and Performance. Management Decision, 42(2), 292-312.

O'Regan, N., \& Ghobadian, A. (2004b). Short- and Long-term Performance in Manufacturing SMEs - Different Targets, Different Drivers. International Journal of Productivity and Performance Management, 53(5), 405-424.

O'Regan, N., \& Ghobadian, A. (2005). Innovation in SMEs: The Impact of Strategic Orientation and Environmental Perceptions. International Journal of Productivity and Performance Management, 54(2), 81-97.

OCM. (2007). Profile of Panabo City. Retrieved 4 June 2008, from http://panabocity.gov.ph/figures.html

OCM. (2008). Profile of Tagum City. Retrieved 4 June 2008, from http://www.tagumcity.gov.ph/

OECD. (2003). Entrepreneurship and Local Economic Development: Programmes and Policy Recommendations

OECD. (2004). Evaluation of SME Policies and Programmes. Paper presented at the 2nd OECD Conference of Ministers Responsible for Small and MediumSized Enterprises - Promoting Entrepreneurship and Innovative SMEs in a Global Economy: Towards A More Responsible and Inclusive Globalisation, Istanbul, Turkey.

OECD. (2005). Entrepreneurship Centre Takes Off. The OECD Observer, November(245).

Oliver, C. (1991). Strategic Response to Institutional Processes. Academy of Management Review, 16(1), 145-179.

Oliver, C. (1997). The Influence of Institutional and Task Environment Relationships on Organisational Performance: The Canadian Construction Industry. Journal of Management Studies, 34(1), 99-123.

Ollinger, M., \& Fernandez-Cornejo, J. (1998). Sunk-Cost and Regulation in the U.S. Pesticide Industry. International Journal of Industrial Organisation, 16(2), 139-168.

Olsson, O. (1999). A Microeconomic Analysis of Institutions, Working Papers in Economics No. 25 (pp. 24). Department of Economics, Goteborg University: Goteburg University.

Ordaz, C., Alcazar, F., \& Cabrera, R. (2003). Intangible Resources and Strategic Orientation of Companies. Journal of Business Research, 56(2), 95-103. 
Orser, B., \& Hogarth-Scott, S. (2002). Opting for Growth: Gender Dimensions of Choosing Enterprise Development. Canadian Journal of Administrative Sciences, 19(3), 284-300.

Osborne, J. W., \& Waters, E. (2002). Four Assumptions of Multiple Regression that Researchers Should Always Test. Practical Assessment, Research and Evaluation, 8(2), 1-5.

Ostrom, E. (2005). Understanding Institutional Diversity. New Jersey: Princeton University Press.

Oswald, S., Mossholder, K., \& Harris, S. (1997). Relations Between Strategic Involvement and Managers' Perception of Environment and Competitive Strengths: The Effect of Vision Salience. Group and Organisational Management 22(3), 343-365.

Oxley, J., \& Yeung, B. (2001). E-Commerce Readiness: Institutional Environment and International Competitiveness. Journal of International Business Studies, 32(4), 705-724.

Oyserman, D., Coon, H. M., \& Kemmerlmeier, M. (2002). Rethinking Individualism and Collectivism: Evaluation of Theoretical Assumptions and MetaAnalyses. Psychological Bulletin, 128(1), 3-72.

Pajunen, K. (2008). Institutions and the Inflows of Foreign Direct Investment: A Fuzzy-Set Analysis. Journal of International Business Studies, 39(4), 652669.

Parboteeah, K. P., Bronson, J. W., \& Cullen, J. B. (2005). Does National Culture Affect Willingness to Justify Ethically Suspect Behaviours. International Journal of Cross Cultural Management, 5(2), 123-138.

Parboteeah, K. P., Hoegl, M., \& Cullen, J. (2008). Managers' Gender Role Attitudes: A Country Institutional Profile Approach. Journal of International Business Studies, 39(5), 795-813.

Parnell, J., Lester, D., \& Menefee, M. (2000). Strategy as a Response to Organisational Uncertainty: An Alternative Perspective on the StrategyPerformance Relationship. Management Decision, 38(8), 520-530.

Parsons, T. (1949). The Structure of Social Action: A Study in Social Theory with Special Reference to a Group of European Writers. New York: Free Press.

Parsons, T. (1951). The Social System. New York: Free Press.

Parsons, T., \& Shils, E. (1951). Toward a General Theory of Action. New York: Harper and Row.

Parto, S. (2005). Economic Activity and Institutions: Taking Stock. Journal of Economic Issues, 39(1), 21-53.

Pasadilla, G. (2005). Services: Today's Most Prolific Industry. Development Research News, 23(September-October), 1-2.

Pe-Pua, R., \& Protacio-Marcelino, E. (2000). Sikolohiyang Pilipino (Filipino Psychology): A Legacy of Virgilio G. Enriquez. Asian Journal of Social Psychology, 3(1), 49-71.

Pedhazur, E. (1982). Multiple Regression in Behavioural Research: Explanation and Prediction (2nd ed.). Forth Worth Texas: Holt, Rinehart and Winston, Inc.

Pejovich, S. (1995). Economic Analysis of Institutions and Systems (Vol. 33). Dordretch: Kluwer Academic Publishers.

Pejovich, S. (1999). The Effects of the Interaction of Formal and Informal Institutions on Social Stability and Economic Development. Journal of Markets and Morality, 2(2), 164-181. 
Pelham, A. (1999). Influence of Environment, Strategy, and Market Orientation on Performance in Small Manufacturing Firms. Journal of Business Research, 45(1), 33-46.

Pelham, A. (2000). Market Orientation and Other Potential Influences on Performance in Small and Medium-Sized Manufacturing Firms. Journal of Small Business Management, 38(1), 48-67.

Peng, M., \& Heath, P. S. (1996). The Growth of the Firm in Planned Economies in Transition: Institutions, Organisations, and Strategic Choice. Academy of Management Review, 21(2), 492-528.

Peng, M., Wang, D., \& Jiang, Y. (2008). An Institution-based View of International Business Strategy: A Focus on Emerging Economies. Journal of International Business Studies, 39(5), 920-936.

Peng, Y. (2004). Kinship Networks and Entrepreneurs in China's Traditional Economy. American Journal of Sociology, 109(5), 1045-1074.

Penrose, E. (1959). The Theory of the Growth of the Firm. New York: John Wiley.

Perry, S. (2002). A Comparison of Failed and Non-Failed Small Businesses in the United States: Do Men and Women Use Different Planning and Decision Making Strategies. Journal of Developmental Entrepreneurship, 7(4), 415423.

Peters, B. G. (1999). Institutional Theory in Political Science. London: Pinter.

Peterson, R. (1994). A Meta-Analysis of Cronbach's Coefficient Alpha. Journal of Consumer Research, 21(2), 381-391.

Pfeffer, J., \& Salancik, G. (1978). The External Control of Organisations: A Resource Dependence Perspective. New York: Harper \& Row.

Phillips, N., Lawrence, T., \& Hardy, C. (2000). Interorganisational Collaboration and the Dynamics of Institutional Fields. Journal of Management Studies, 37(1), 23-42.

Pitt, L., \& Kannemeyer, R. (2000). The Role of Adaptation in Microenterprise Development: A Marketing Perspective. Journal of Developmental Entrepreneurship, 5(2), 137-155.

Podsakoff, P., MacKenzie, S., Lee, J.-Y., \& Podsakoff, N. (2003). Common Method Biases in Behavioural Research: A Critical Review of the Literature and Recommended Remedies. Journal of Applied Psychology, 88(5), 879-903.

Pons, F., Mourali, M., \& Nyeck, S. (2006). Consumer Orientation Toward Sporting Events: Scale Development and Validation. Journal of Service Research, 8(3), 276-287.

Poon, J. M. L., Ainuddin, R. A., \& Junit, S. O. H. (2006). Effects of Self-Concept Traits and Entrepreneurial Orientation on Firm Performance. International Small Business Journal, 24(1), 61-82.

Porter, M. (1995). The Competitive Advantage of the Inner City. Harvard Business Review(May-June), 55-71.

Porter, M. E. (1980). Competitive Strategy: Techniques for Analyzing Industries and Competitors. New York: Free Press.

Prasad, B. (2003). Institutional Economics and Economic Development: The Theory of Property Rights, Economic Development, Good Governance and the Environment International Journal of Social Economics, 30(5/6), 741.

Preacher, K., Rucker, D., \& Hayes, A. F. (2007). Addressing Moderated Mediation Hypothesis: Theory, Methods and Prescriptions. Multivariate Behavioural Research, 42(1), 185-227. 
Preacher, K. J., \& Hayes, A. F. (2004). SPSS and SAS Procedures for Estimating Indirect Effects in Simple Mediation Models. Behavioural Research Methods, Instruments, \& Computers, 36(4), 717-731.

Preisendorfer, P., \& Voss, T. (1990). Organisational Mortality of Small Firms: The Effects of Entrepreneurial Age and Human Capital. Organisation Studies, 11(1), 107-129.

Presser, S., \& Blair, J. (1994). Survey Pretesting: Do Different Methods Produce Different Results? Sociological Methodology, 24, 73-104.

Price, J. (1968). Organisational Effectiveness: An Inventory of Propositions Illinois: Richard Irwin Inc.

Priem, R. (1994). Executive Judgement, Organisational Congruence, and Firm Performance. Organisation Science, 5(3), 421-437.

RA7160. (1991). Local Government Code of the Philippines. Manila: Republic of the Philippines.

Raco, M. (1999). Competition, Collaboration, and the New Industrial Districts: Examining the Institutional Turn in Local Economic Development. Urban Studies, 36(5/6), 951-968.

Rajagopalan, N. (1996). Strategic Orientations, Incentive Plan Adoption, and Firm Performance: Evidence from Electric Utility Firms. Strategic Management Journal, 18(10), 761-785.

Ramaswamy, K. (2001). Research Notes and Commentaries: Organisational Ownership, Competitive Intensity, and Firm Performance: An Empirical Study of the Indian Manufacturing Sector. Strategic Management Journal, 22(10), 989-998.

Ramaswamy, K., Thomas, A., \& Litschert, R. (1994). Organisational Performance in a Regulated Environment: The Role of Strategic Orientation. Strategic Management Journal, 15(1), 63-74.

Rammal, H., \& Zurbruegg, R. (2006). The Impact of Regulatory Quality on Intraforeign Direct Investment Flows in the ASEAN Markets. International Business Review, 15(4), 401-414.

Ramsden, M., \& Bennet, R. J. (2005). The Benefits of External Support to SMEs. Journal of Small Business and Enterprise Development, 12(2), 227-243.

Rao, P. K. (2003). The Economics of Transaction Costs: Theory, Methods and Applications. Hampshire: Palgrave Macmillan.

Redmond, W. (2005). A Framework for the Analysis of Stability and Change in Formal Institutions. Journal of Economic Issues, 39(3), 665-682.

Reed, O. L. (2001). Law, Rule of Law, and Property: A Foundation for the Private Market and Business Study. American Business Law Journal, 38(3), 441-474.

Reynolds, P., Hay, M., \& Camp, S. (1999). Global Entrepreneurship Monitor 1999 Executive Report. London: Kauffman Center for Entrepreneurial Leadership London Business School.

Richard, O. (2000). Racial Diversity, Business Strategy, and Firm Performance: A Resource-Based View. The Academy of Management Journal, 43(2), 164177.

Robson, M. (2004). Complementarity between Formal State Policy and Informal Norms: An Institutional Determinant of Success in Environmental Policy Interventions? - The Case of Deforestation in Developing Countries. Finland: Expert Group on Development Issues (EGDI) and Wold Institute for Development Economics Research (WIDER), United Nations University: 
Conference on Unlocking Human Potential: Linking the Informal and Formal Sector, 17-18 Sept 2004

Rockmore, W. B., \& Jone, F. (1996). Business Investment Strategy and Firm Performance: A Comparative Examination of Accounting and Market-Based Measures. Managerial Finance, 22(8), 44-56.

Rodrik, D. (2006). Institutions for High-Quality Growth: What They Are and How to Acquire Them. In K. Roy \& J. Sideras (Eds.), Institutions, Globalisation and Empowerment. Cheltenham: Edward Elgar.

Rodrik, D., Subramanian, A., \& Trebbi, F. (2004). Institutions Rule: The Primacy of Institutions over Geography and Integration in Economic Development. Journal of Economic Growth, 9(1), 131-165.

Rodriquez, A. C., Molina, M., Perez, A., \& Hernandez, U. (2003). Size, Age, and Activity Sector on the Growth of the Small and Medium Firm Size. Small Business Economics, 21(3), 289-308.

Rogelberg, S., \& Stanton, J. (2007). Understanding and Dealing with Organisational Survey Nonresponse. Organisational Research Methods, 10(2), 195-209.

Rogers, M. (2004). Networks, Firm Size and Innovation. Small Business Economics, 22(2), 141-154.

Rowe, W. G., \& Morrow, J. L. J. (1999). A Note on the Dimensionality of the Firm Financial Performance Construct Using Accounting, Market and Subjective Measures. Revue Canadienne des Sciences de l'Administration, 16(1), 58-70.

Ruane, M. C. (2007). Small-Scale Business Enterprises in the Philippines: Survey and Empirical Analysis. International Journal of Entrepreneurship, 11, 1-25.

Rutherford, M. (2001). Institutional Economics: Then and Now. Journal of Economic Perspectives, 15(3), 173-194.

Sadler-Smith, E., Hampson, Y., Chaston, I., \& Badger, B. (2003). Managerial Behaviour, Entrepreneurial Style, and Small Firm Performance. Journal of Small Business Management, 41(1), 47-67.

Salavou, H., Baltas, G., \& Lioukas, S. (2004). Organisational Innovation in SMEs: The Importance of Strategic Orientation and Competitive Structure European Journal of Marketing, 38(9/10), 1091.

Samie, S., \& Roth, K. (1992). The Influence of Global Marketing Standardisation on Performance. Journal of Marketing, 56(2), 1-17.

Sanchez, A., \& Perez, M. (2005). Supply Chain Flexibility and Firm Performance: A Conceptual Model and Empirical Study in the Automotive Industry. International Journal of Operations \& Production Management, 25(7/8), 681-700.

Sarder, J., Ghosh, D., \& Rosa, P. (1997). The Importance of Support Services to Small Enterprises in Bangladesh. Journal of Small Business Management, 35(2), 26-36.

Sarkar, M., Echambadi, R., \& Harrison, J. (2001). Alliance Entrepreneurship and Firm Market Performance. Strategic Management Journal, 22(1), 701-711.

Scherer, F. M. (1980). Industrial Market Structure and Economic Performance. Boston: Houghton Mifflin.

Schumacher, R., \& Lomax, R. G. (1996). A Beginner's Guide to Structural Equation Modelling. Hillsdale, New Jersey: Erlbaum.

Schumpeter, J. A. (1934). The Theory of Economic Development. Cambridge Massachusetts: Harvard University Press. 
Schwarz, N., Strack, F., Hippler, H., \& Bishop, G. (1991). The Impact of Administration Mode on Response Effects in Survey Methodology. Applied Cognitive Psychology, 5(3), 193-212.

Scott, W. R. (2001). Institutions and Organisations. Thousand Oaks: Sage Publications.

Scully, G. (1988). The Institutional Framework and Economic Development. The Journal of Political Economy, 96(3), 652-662.

Seggie, S., Kim, D., \& Cavusgil, S. T. (2006). Do Supply Chain IT Alignment and Supply Chain Interfirm System Integration Impact upon Brand Equity and Firm Performance. Journal of Business Research, 59(8), 887-895.

Shabbir, A., \& Di Gregorio, S. (1996). An Examination of the Relationship between Women's Personal Goals and Structural Factors Influencing their Decision to Start a Business: The Case of Pakistan. Journal of Business Venturing, 11(6), 507-529.

Shane, S. (1993). Cultural Influences on National Rates of Innovation. Journal of Business Venturing, 8(1), 59-73.

Shane, S. (2003). A General Theory of Entrepreneurship: The IndividualOpportunity Nexus. Massachusetts: Edwar Elgar.

Shane, S., \& Kolvereid, 1. (1995). National Environment, Strategy and New Venture Performance: A Three Country Study. Journal of Small Business Management, 33(2), 37-50.

Sharfman, M., \& Dean, J. W. (1991). Conceptualising and Measuring the Organisational Environment: A Multidimensional Approach. Journal of Management, 17(4), 681-700.

Sharma, S. (2000). Managerial Interpretations and Organisational Context as Predictors of Corporate Choice of Environmental Strategy. Academy of Management Journal, 43(4), 681-697.

Shortell, S., \& Zajac, E. (1990). Perceptual and Archival Measures of Miles and Snow's Strategic Types: A Comprehensive Assessment of Reliability and Validity. Academy of Management Journal, 33(4), 817-832.

Shrout, P., \& Bolger, N. (2002). Mediation in Experimental and Non-experimental Studies: New Procedures and Recommendations. Psychological Methods, 7(4), 422-445.

Siegel, J., Licht, A., \& Scwartz, S. (2006). Egalitarianism and International Investment, 1st Annual Conference on Empirical Legal Studies Paper, ECGI - Finance Working Paper No. 120/2006 http://ssrn.com/abstract=899082

Simon, H. (1997). Models of Bounded Rationality. Cambridge Mass: MIT Press.

Simsek, Z., Veiga, J., \& Lubatkin, M. (2007). The Impact of Managerial Environmental Perceptions on Corporate Entrepreneurship: Towards Understanding Discretionary Slack's Pivotal Role. Journal of Management Studies, 44(8), 1398-1424.

Sin, L., Tse, A., \& Yim, F. (2005). CRM: Conceptualisation and Scale Development. European Journal of Marketing, 39(11/12), 1264-1290.

Singh, K. (1997). The Impact of Technological Complexity and Interfirm Cooperation on Business Survival. Academy of Management Journal, 40(2), 339-367.

Siu, W., Lin, T., Fang, W., \& Liu, Z. (2006). An Institutional Analysis of the New Product Development Process of Small and Medium Enterprises in China, Hong Kong and Taiwan. Industrial Marketing Management, 35(1), 323-335. 
Skuras, D., Caldas, J., Meccheri, N., Psaltopoulos, D., \& Viladomiu, L. (2003). Institutional Support to Strategic Business Orientations: An Empirical Analysis of Rural Businesses in Four Countries of Southern Europe. European Business Review, 15(4), 235-245.

Skuras, D., Dimara, E., \& Vakrou, A. (2000). The Day After Grant-Aid: Business Development Schemes for Small Firms in Lagging Areas of Greece. Small Business Economics, 14(2), 125-136.

Slangen, L. H. G., van Kooten, G. C., \& Suchanek, P. (2004). Institutions, Social Capital and Agricultural Change in Central and Eastern Europe. Journal of Rural Studies, 20(2), 245-2556.

Slater, S., \& Narver, J. (2000). The Positive Effect of a Market Orientation on Business Profitability: A Balanced Replication. Journal of Business Research, 48(1), 69-73.

Smallbone, D. (2004). Institutions, Governance and SME Development in Transition Economies. Paper presented at the Expert Meeting on Good Governance for SMEs.

Sobel, M. E. (1982). Asymptotic Intervals for Indirect Effects in Structural Equations Models. In S. Leinhart (Ed.), Sociological Methodology 1982 (pp. 290-312). San Francisco: Jossey-Bass.

Sonfield, M., Lussier, R., Corman, J., \& McKinney, M. (2001). Gender Comparisons in Strategic Decision-Making: An Empirical Analysis of the Entrepreneurial Strategy Matrix. Journal of Small Business Management, 39(2), 165-173.

Spector, P. (2006). Method Variance in Organisational Research: Truth or Urban Legend. Organisational Research Methods, 9(2), 221-231.

Spicer, D., \& Sadler-Smith, E. (2005). An Examination of the General Decisionmaking Style Questionnaire in Two UK Samples. Journal of Managerial Psychology, 20(2), 137-149.

Spillan, J., \& Parnell, J. (2006). Marketing Resources and Firm Performance among SMEs. European Management Journal, 24(2/3), 236-245.

SPSS. (2005). SPSS Base 14.00 for Windows User's Guide. Chicago IL: SPSS Inc.

StataCorp. (2007). Stata User's Guide. College Station, Texas: Stata Press.

Steensma, H. K., Marino, L., Weaver, K. M., \& Dickson, P. H. (2000). The Influence of National Culture on the Formation of Technology Alliances by Entrepreneurial Firms Academy of Management Journal, 43(5), 951-973.

Stewart, W. J., Watson, W., Carland, J., \& Carland, J. (1998). A Proclivity for Entrepreneurship: A Comparison of Entrepreneurs, Small Business Owners, and Corporate Managers Journal of Business Venturing, 14(2), 189-214.

Stokes, L. (1988). Estimation of Interviewer Effects for Categorical Items in a Random Digit Dial Telephone Survey. Journal of the American Statistical Association, 83(403), 623-630.

Storey, D. J. (1982). Entrepreneurship and the New Firm. London: Croom Helm.

Storey, D. J. (1994). Understanding the Small Business Sector. London: International Thomson Business Press.

Strandholm, K., Kumar, K., \& Subramanian, R. (2004). Examining the Interrelationships among Perceived Environmental Change, Strategic Response, Managerial Characteristics and Organisational Performance. Journal of Business Research, 57(1), 58-68.

$\mathrm{Su}$, S.-H. (2006). Cultural Differences in Determining the Ethical Perception and Decision-making of Future Accounting Professionals: A Comparison 
between Accounting Students from Taiwan and the United States. Journal of American Academy of Business, Cambridge, 9(1), 147-159.

Suchman, M. C. (1995). Managing Legitimacy: Strategic and Institutional Approaches The Academy of Management Review, 20(3), 571-611.

Sudman, S. (1983). Applied Sampling. In P. H. Rossi, J. D. Wright \& A. B. Anderson (Eds.), Handbook of Survey Research. San Diego, CA: Academic Press, Inc. .

Sui, W. S., Lin, T., Fang, W., \& Liu, Z. C. (2006). An Institutional Analysis of the New Product Development Process of Small and Medium Enterprises in China, Hong Kong and Taiwan. Industrial Marketing Management 35(1), 323-335.

Sureshchandar, G. S., \& Lesiten, R. (2005). Holistic Scorecard: Strategic Performance Measurement and Management in the Software Industry. Measuring Business Excellence, 9(2), 12-29.

Swamidaas, P., \& Newell, W. (1987). Manufacturing Strategy, Environmental Uncertainty and Performance: A Path Analytic Model. Management Science, 33(4), 509-524.

Swierczek, F. W., \& Ha, T. (2003a). Entrepreneurial Orientation, Uncertainty Avoidance and Firm Entrepreneurship. International Journal of Entrepreneurship and Innovation, 4(1), 46-58.

Swierczek, F. W., \& Ha, T. (2003b). Motivation, Entrepreneurship and the Performance of SMEs in Vietnam. Journal of Enterprise Culture, 11(1), 4768.

Tabachnick, B., \& Fidell, L. (2005). Using Multivariate Statistics (4th edition ed.): Allyn \& Bacon.

Tabellini, G. (2005). Culture and Institutions: Economic Development in the regions of Europe, CESifo Working Paper No. 1492: available at Social Science Research Network Online; http://ssrn.com/abstract=754086

Tambunan, T. (2005). Promoting Small and Medium Enterprises with a Clustering Approach: A Policy Experience from Indonesia. Journal of Small Business Management, 43(2), 138-154.

Tan, J. (2001). Innovation and Risk-Taking in a Transitional Economy: A Comparative Study of Chinese Managers and Entrepreneurs. Journal of Business Venturing, 16(4), 359-376.

Tan, J. J., \& Litschert, R. (1994). Environment-Strategy Relationship and Its Performance Implications. Strategic Management Journal, 15(1), 1-20.

Taylor, N., \& Matthew, P. (2002). Financial and Psychological Costs of Crime for Small Retail Businesses. Paper presented at the Australian Institute of Criminology Trends and Issues No. 221, Canberra.

Tepper, B., \& Tepper, K. (1993). The Effects of Method Variance Within Measures. The Journal of Psychology, 127(3), 293-302.

Thomas, A., Litschert, R., \& Ramaswamy, K. (1991). The Performance Impact of Strategy-Manager Coalignment: An Empirical Examination. Strategic Management Journal, 12(7), 509-522.

Thomson, B. (2004). Exploratory and Confirmatory Factor Analysis: Understanding Concepts and Applications Washington: American Psychological Association.

Thomson, J. L. (2001). Strategic Management (4th ed.). London: ThomsonLearning. 
Thornton, J. (2007). Fiscal Decentralisation and Economic Growth Reconsidered. Journal of Urban Economics 61(1), 64-70.

Tiessen, J. (1997). Individualism, Collectivism, and Entrepreneurship: A Framework for International Comparative Research. Journal of Business Venturing 12(5), 367-384.

Triandis, H. C., \& Gelfand, M. J. (1998). Converging Measurement of Horizontal and Vertical Individualism and Collectivism. Journal of Personality and Social Psychology, 74(1), 118-128.

Tsai, M.-T., \& Shih, C.-M. (2004). The Impact of Marketing Knowledge amongst Managers on Marketing Capabilities and Business Performance. International Journal of Management, 21(4), 524-530.

Tsai, W., MacMillan, I., \& Low, M. (1991). Effects of Strategy and Environment on Corporate Venture Success in Industrial Markets. Journal of Business Venturing, 6(1), 9-28.

Tse, A., Sin, L., Yau, O., Lee, J., \& Chow, R. (2003). Market Orientation and Business Performance in a Chinese Business Environment. Journal of Business Research, 56(1), 227-239.

Tsui, A. S. (1990). A Multiple Constituency Model of Effectiveness: Empirical Examination at the Human Resource Subunit. Administrative Science Quarterly, 35(3), 458-483.

Tung, R. (1979). Dimensions of Organisational Environments : An Exploratory Study of Their Impact on Organisation Structure. Academy of Management Journal, 22(4), 672-693.

Ullman, J. B., \& Newcomb, M. D. (1998). Eager, Reluctant, and Nonresponders to a Mailed Longitudinal Survey: Attitudinal and Substance Use Characteristics Differentiate Respondents. Journal of Applied Social Psychology, 28(4), 357375.

van Heffen, O., \& Klok, P.-J. (2003). Cultural Theory Revised: Only Five Cultures or More? Contemporary Political Theory, 2(3), 289-306.

Vandenberg, P. (1999). North's Institutionalism and the Problem of Combining Theoretical Approaches University of London, Department of Economics Working Paper Series No. 87 University of London.

Vatn, A. (2005). Institutions and the Environment. Cheltenham: Edward Elgar.

Venkatraman, N. (1989). Strategic Orientation of Business Enterprises: The Construct, Dimensionality, and Measurement. Management Science, 35(8), 942-962.

Venkatraman, N., \& Prescott, J. E. (1990). Environment-Strategy Coalignment: An Empirical Test of Its Performance Implications. Strategic Management Journal, 11(1), 1-23.

Venkatraman, N., \& Ramanujam, V. (1986). Measurement of Business Performance in Strategy Research: A Comparison of Approaches. Academy of Management Review, 11(4), 801-814.

Verhees, F., \& Meulenberg, M. (2004). Market Orientation, Innovativeness, Product Innovation, and Performance in Small Firms. Journal of Small Business Management, 42(2), 134-154.

Verheul, I., \& Thurik, R. (2001). Start-Up Capital: Does Gender Matter? Small Business Economics, 16(4), 329-346.

Verheul, I., Wennekers, S., Audretsch, D., \& Thurik, R. (2002). An Eclectic Theory of Entrepreneurship: Policies, Institutions, and Culture. In D. Audretsch, R. Thurik, I. Verheul \& S. Wennekers (Eds.), Entrepreneurship: Determinants 
and Policy in a European-US Comparison. Dordrecht, The Netherlands: Kluwer Academic Publishers.

Voss, G., \& Voss, Z. (2000). Strategic Orientation and Firm Performance in an Artistic Environment. Journal of Marketing, 64(1), 67-83.

Wagner, E., \& Hansen, E. (2005). Innovation in Large Versus Small Companies: Insights from the US Wood Products Industry. Management Decision, 43(5/6), 837-851.

Walsh, J. (1988). Selectivity and Selective Perception: An Investigation of Managers' Belief Structure and Information Processing. Academy of Management Journal, 31(4), 873-896.

Walter, A., Auer, M., \& Ritter, T. (2006). The Impact of Network Capabilities and Entrepreneurial Orientation on University Spin-Off Performance. Journal of Business Venturing, 21(4), 541-567.

Wan, T., Lau, T., \& Chan, K. F. (2002). The Competitiveness of Small and Medium Enterprises: A Conceptualisation with Focus on Entrepreneurial Competencies. Journal of Business Venturing, 17(1), 123-142.

Wan, W. (2005). Country Resource Environments, Firm Capabilities, and Corporate Diversification Strategies. Journal of Management Studies, 42(1), 0022-2380.

Wan, W., \& Hoskisson, R. (2003). Home Country Environments, Corporate Diversification Strategies, and Firm Performance. Academy of Management Journal, 46(1), 27-45.

Wang, C., \& Ang, B. L. (2004). Determinants of Venture Performance in Singapore. Journal of Small Business Management, 42(4), 347-363.

Wang, J. (2004). The Rule of Law in China: A Realistic View of the Jurisprudence, the Impact of the WTO, and the Prospects for Future Development. Singapore Journal of Legal Studies, December Issue(December), 347-389.

Wang, Y. (2005). Subnational Location Strategies of Multinational Enterprises in China: Pearl River Delta vs. Yangtze River Delta. Journal of Asian Business, 21(2), 45-60.

Ward, S., \& Lewandowska, A. (2005). Shelter in Storm: Marketing Strategy as Moderated by the Hostile Environment. Marketing Intelligence \& Planning, 23(6/7), 670-687.

Watson, J. (2006). Modelling the Relationship between Networking and Firm Performance. Journal of Business Venturing, 22(6), 852-874.

Weber, E., \& Hsee, C. (2000). Culture and Individual Judgement and Decision Making. Applied Psychology: An International Review, 49(1), 32-61.

Weick, K. (1988). Enacted Sensemaking in Crisis Situations. Journal of Management Studies, 25(4), 305-317.

Weinzimmer, L., Nystrom, P., \& Freeman, S. (1998). Measuring Organisational Growth: Issues, Consequences and Guidelines. Journal of Management, 24(2), 235-262.

Welter, F., \& Smallbone, D. (2005). Entrepreneurship and Enterprise Strategies in Transition Economies: An Institutional Perspective. In F. Sjoholm \& F. Tongzon (Eds.), Institutional Change in Southeast Asia. London: Routledge Curzon.

Wernerfelt, B. (1984). A Resource-Based View of the Firm. Strategic Management Journal, 5(2), 171-180.

Westhead, P., \& Howorth, C. (2006). Ownership and management Issues Associated with Family Firm Performance and Company Objectives. Family Business Review, 19(4), 301-316. 
Whetten, D. (1989). What Constitutes a Theoretical Contribution. Academy of Management Review, 14(4), 490-495.

White, G. P. (1996). A Survey and Taxonomy of Strategy Related Performance Measures for Manufacturing International Journal of Operations and Production Management, 16(3), 42-61.

Whittington, R. (1988). Environmental Structure and Theories of Strategic Choice. Journal of Management Studies, 25(6), 521-536.

Widaman, K. F. (1993). Common Factor Analysis versus Principal Component Analysis: Differential Bias in Representing Model Parameters? Multivariate Behavioural Research, 28(3), 263-311.

Wijewardena, H., De Zoysa, A., Fonseka, T., \& Perera, B. (2004). The Impact of Planning and Control Sophistication on Performance of Small and MediumSized Enterprises: Evidence from Sri Lanka. Journal of Small Business Management, 42(2), 209-217.

Wiklund, J. (1999). The Sustainability of the Entrepreneurial OrientationPerformance Relationship. Entrepreneurship Theory and Practice, 24(1), 3748.

Wiklund, J., \& Sheperd, D. (2005). Entrepreneurial Orientation and Small Business Performance: A Configurational Approach. Journal of Business Venturing, 20(1), 71-91.

Wiklund, J., \& Shepherd, D. (2003). Knowledge-based Resources, Entrepreneurial Orientation, and the Performance of Small and Medium-sized Businesses. Strategic Management Journal, 24(13), 1307-1314.

Wilkinson, T. (2006). Entrepreneurial Climate and US State Foreign Offices as Predictors of Export Success Journal of Small Business Management, 44(1), 99-114.

Wilkinson, T., \& Brouthers, L. (2006). Trade Promotion and SME Export Performance. International Business Review, 15(3), 233-252.

Williamson, O. E. (1979). Transaction Cost Economics: The Governance of Contractual Relations. Journal of Law and Economics, 22(2), 233-261.

Williamson, O. E. (1981). The Economics of Organisation: The Transaction Cost Approach. The American Journal of Sociology, 87(3), 548-577.

Willimack, D. (2004). Evolution and Adaptation of Questionnaire Development, Evaluation, and Testing Methods for Establishment Surveys. In S. Presser, J. Rothgeb, M. Couper, J. Lessler, E. Martin, J. Martin \& E. Singer (Eds.), Methods for Testing and Evaluating Survey Questionnaire. New Jersey: John Wiley and Sons, Inc. .

Wincent, J. (2005). Does Size Matter? A Study of Firm Behaviour and Outcomes in Strategic SME Networks. Journal of Small Business and Enterprise Development, 12(3), 437-453.

Wolff, J., \& Pett, T. (2006). Small-Firm Performance: Modelling the Role of Product and Process Improvements. Journal of Small Business Management, 44(2), 268-284.

Wong, C. (2002). Developing Indicators to Inform Local Economic Development in England. Urban Studies, 39(10), 1833-1863.

Wong, T.-C. (1999). The Transition from Physical Infrastructure to Infostructure: Infrastructure as a Modernising Agent in Singapore. GeoJournal, 49(3), 279288.

Work, R. (2001). Decentralisation, Governance, and Sustainable Regional Development. In W. Stohr, J. Edralin \& D. Mani (Eds.), New Regional 
Development Paradigms: Decentralisation, Governance, and the New Planning for Local-Level Development (Vol. 3). Westport: Greenword Press. WorldBank. (2002). The Business Environment and Enterprise Performance Survey II. Retrieved 29 March 2007, 2007, from http://info.worldbank.org/governance/beeps2002/

Wright, M., Filatotchev, I., Hoskisson, R., \& Peng, M. (2005). Strategy Research in Emerging Economies: Challenging the Conventional Wisdom. Journal of Management Studies, 42(1), 1-33.

Wright, P., Kroll, M., Bevalee, P., \& Lado, A. (1995). Strategic Orientations, Competitive Advantage, and Business Performance. Journal of Business Research, 33(2), 143-151.

Wu, C., Lawler, J. J., \& Yi, X. (2008). Overt Employment Discrimination in MNC Affiliates: Home-Country Cultural and Institutional Effects. Journal of International Business Studies, 36(5), 772-794.

Wu, F., Yeniyurt, S., Kim, D., \& Cavusgil, S. (2006). The Impact of Information Technology on Supply Chain Capabilities and Firm Performance: A Resource-based View. Industrial Marketing Management, 35(1), 493-504.

Wu, W.-P., \& Leung, A. (2005). Does a Micro-macro Link Exist Between Managerial Value of Reciprocity, Social Capital, and Firm Performance? The Case of SMEs in China. Asia Pacific Journal of Management, 22(4), 445463.

Yaffee, R. (2002). Robust Regression Analysis: Some Popular Statistical Package Options [Electronic Version]. Statistics Publications, Information and Technology Services, New York University. Retrieved 16 March 2008 from http://www.nyu.edu/its/statistics/Docs/RobustReg2.pdf.

Yan, J., \& Hunt, J. (2005). A Cross-Cultural Perspective on Perceived Leadership Effectiveness. International Journal of Cross-Cultural Management, 5(1), 49-66.

Yasai-Ardekani, M. (1989). Effects of Environmental Scarcity and Munificence on the Relationship of Context to Organisational Structure Academy of Management Journal, 32(1), 131-156.

Yasuda, T. (2005). Firm Growth, Size, Age and Behaviour in Japanese Manufacturing. Small Business Economics, 24(1), 1-15.

Yaveroglu, I. S., \& Donthu, N. (2002). Cultural Influences on the Diffusion of New Products. Journal of International Consumer Marketing, 14(4), 49-63.

Yilmaz, C., Alpkan, L., \& Ergun, E. (2005). Cultural Determinants of Customer- and Learning-Oriented Value Systems and their Joint Effects on Firm Performance. Journal of Business Research, 58(10), 1340-1352.

Yin, R. (1994). Case Study Research: Design and Methods. Beverly Hills, CA: Sage Publishing.

Yoo, S. J. (2001). Entrepreneurial Orientation, Environmental Scanning, and Firm Performance in Technology-based SMEs. Paper presented at the Frontiers of Entrepreneurship Research.

Youndt, M., Snell, S., Dean, J., \& Lepak, D. (1996). Human Resource Management, Manufacturing Strategy, and Firm Performance. Academy of Management Journal, 39(4), 386-866.

Young, G., Smith, K., \& Grimm, C. (1996). "Austrian" and Industrial Organisation Perspectives on Firm-level Competitive Activity and Performance. Organisation Science, 7(3), 243-254. 
Yuchtman, E., \& Seashore, S. (1967). A System Resource Approach to Organisational Effectiveness. Administrative Science Quarterly, 32(1), 377395.

Yung-Ching, H., \& Tsui-Hsu, T. (2006). The Impact of Dynamic Capabilities with Market Orientation and Resource-Based Approaches on NPD Project Performance. Journal of American Academy of Business, Cambridge, 8(1), 215.

Yusuf, A. (2002). Environmental Uncertainty. The Entrepreneurial Orientation of Business Ventures and Performance. International Journal of Commerce and Management, 12(3/4), 83-103.

Yusuf, A., \& Saffu, K. (2005). Planning and Performance of Small and Medium Enterprise Operators in a Country in Transition. Journal of Small Business Management, 43(4), 480-497.

Zahra, S. (1993). New Product Innovation in Established Companies: Associations with Industry and Strategy Variables. Entrepreneurship Theory and Practice, 18(2), 47-70.

Zahra, S. (1996). Governance, Ownership and Corporate Entrepreneurship: The Moderating Impact of Industry Technological Opportunities. Academy of Management Journal, 39(6), 1713-1735.

Zahra, S., \& Covin, J. (1995). Contextual Influences on the Corporate Entrepreneurship-Performance Relationship: A Longitudinal Analysis. Journal of Business Venturing, 10(1), 43-58.

Zahra, S., Jennings, D., \& Kuratko, D. F. (1999). The Antecedents and Consequences of Firm-Level Entrepreneurship: The State of the Field. Entrepreneurship Theory and Practice, 24(2), 45-66.

Zairi, M. (1994). Measuring Performance for Business Results: Chapman \& Hall.

Zammuto, R. (1982). Assessing Organisational Effectiveness. Albany: State University of New York Press.

Zehir, C., Acar, A. Z., \& Tanriverdi, H. (2006). Identifying Organisational Capabilities as Predictors of Growth and Business Performance. The Business Review, 5(2).

Zehir, C., \& Eren, M. S. (2007). Field Research on Impacts of Some Organisational Factors on Corporate Entrepreneurship and Business Performance in the Turkish Automotive Industry. Journal of American Academy of Business, Cambridge, 10(2), 170-177.

Zeithaml, C., \& Zeithaml, V. (1984). Environmental Management: Revising the Marketing Perspective. Journal of Marketing, 48(2), 46-53.

Zhou, K., Gao, G., Yang, Z., \& Zhou, N. (2005). Developing Strategic Orientation in China: Antecedents and Consequences of Market and Innovation Orientation. Journal of Business Research, 58(8), 1049-1058.

Zikmund, W. (2003). Business Research Methods (7th ed.). Ohio: Thomson SouthWestern. 